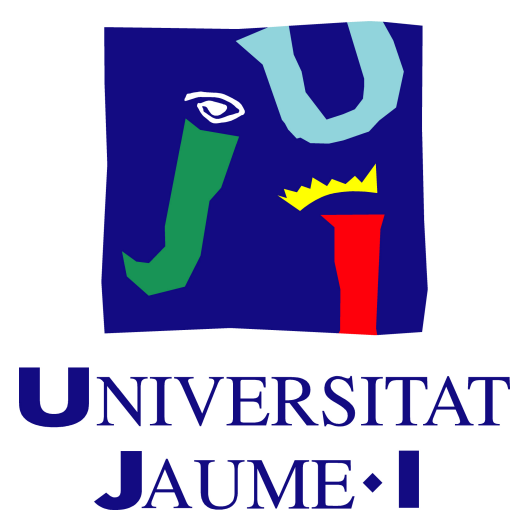

TESIS DOCTORAL

Programa de Doctorado en Derecho.

Escuela de Doctorado de la Universitat Jaume I

SEGURIDAD Y PROTECCIÓN DE DATOS EN EL SISTEMA EUROPEO

COMÚN DE ASILO: CONFLICTOS Y RETOS

Presentada por el Doctorando Jorge Agustín Viguri Cordero

Dirigida por la Prof. a Dra. María del Rosario García Mahamut

Castellón de la Plana, enero de 2020 



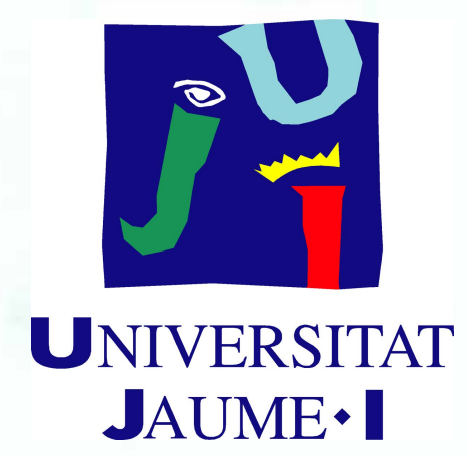

TESIS DOCTORAL

Programa de Doctorado en Derecho.

Escuela de Doctorado de la Universitat Jaume I

\section{SEGURIDAD Y PROTECCIÓN DE DATOS EN EL SISTEMA EUROPEO COMÚN DE ASILO: CONFLICTOS Y RETOS}

Memoria presentada por Jorge Agustín Viguri Cordero para optar al grado de doctor por la Universitat Jaume I

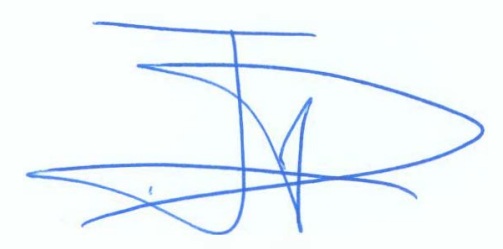

Jorge Agustín Viguri Cordero

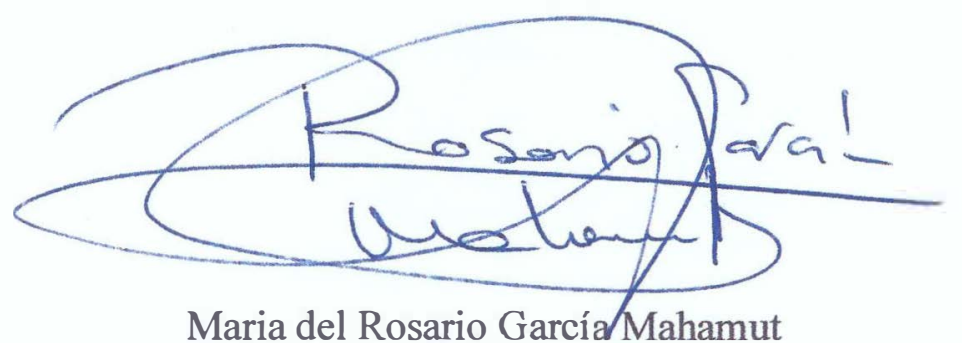

Maria del Rosario García/Mahamut 

La presente tesis doctoral ha sido realizada en el marco de la ayuda predoctoral para la formación de personal investigador de la Universitat Jaume I (UJI) (2017-2018) y de la subvención para la contratación de personal investigador de carácter predoctoral de la Generalitat Valenciana, cofinanciado por el Fondo Social Europeo (2018-2020).

Para la elaboración de la misma, ha resultado de especial importancia mi vinculación laboral durante los años 2014-2017 en el proyecto europeo CRISP "Evaluation and Certification Schemes for Security Product- Capability Projects" (ref.: SEC-2013.5.4-1). Investigador principal: Ronald Boon (Stichting Nederldnse Normalistie-Instituut), así como mi colaboración en el proyecto europeo PHAEDRA II "Improving Practical and Helpful cooperation between Data Protection Authorities" (ref.: JUST/2013/FRAC/AG/6068). Investigador principal: Professor Paul De Hert (Vrije Universiteit Brussels).

Además, también he tenido la oportunidad de realizar dos cursos de especialización relacionados con el objeto del presente estudio: a) "Armed Conflicts and International Human Rights Law", en el Instituto Internacional de Derechos del Hombre de Estrasburgo, durante la 47a Sesión Anual de Derecho Internacional de Derecho Comparado de Derechos Humanos, en julio de 2016; b) "Refugees and Migrants in International Human Rights Law", realizado en el Centro de Estudios Humanos de Poznan, Polonia, en julio de 2017.

No menos importante han sido las dos estancias de investigación que he llevado a cabo durante la elaboración de este trabajo: 1) Instituto Suizo de Derecho Comparado (ISDC), Universidad de Lausana, Suiza entre las fechas comprendidas entre el 01.07.201802.09.2018 (2 meses), bajo la supervisión de Christina Schmid, Doctora en derecho por la Universidad de Berna y Directora del ISDC; 2) Odysseus Academic Network for Legal Studies on Immigration and Asylum in Europe, Instituto adscrito a la Universidad Libre de Bruselas, Bélgica durante el periodo 01.06.2019-01.09.2019 (3 meses), bajo la supervisión de Philippe de Bruycker, Jean Monnet Chair for European Law on Immigration \& Asylum. Esta última subvencionada por la Conselleria d' Educació, Investigació, Cultura i Esport de la Generalitat Valenciana y el Fondo Social Europeo con un importe total de 5.150 euros. 

ÍNDICE

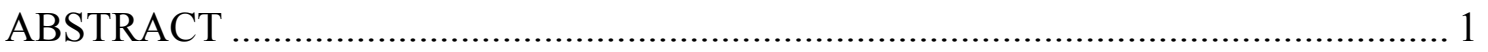

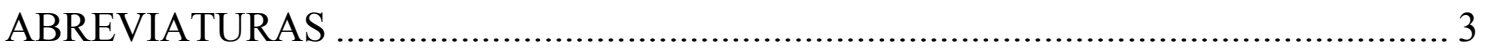

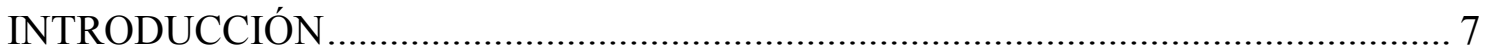

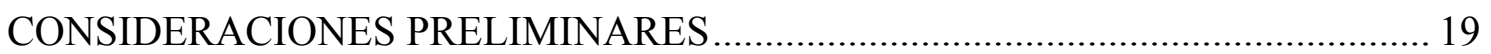

1. El derecho de asilo en Europa y la CONSTRuCción del Sistema Europeo

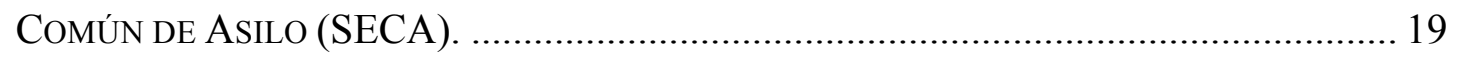

2. LAS CRISIS MIGRATORIAS Y DE REFUGIADOS. LOS PROBLEMAS RELATIVOS A LA

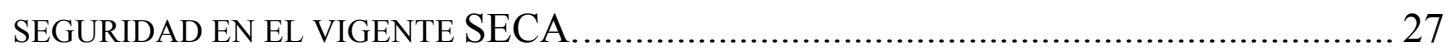

3. LA SEGURIDAD Y EL DERECHO A LA PROTECCIÓN DE DATOS EN LA (FUTURA) TERCERA

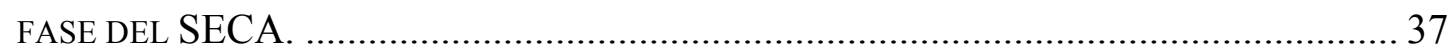

CAPITULO 1. LA SEGURIDAD NACIONAL Y SU IMPACTO EN EL SISTEMA

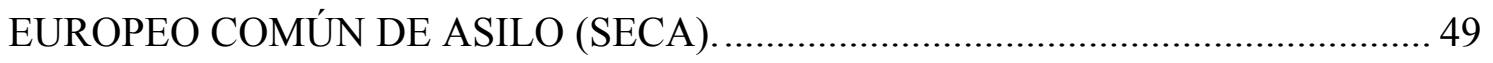

1. El CONCEPTO DE SEGURIDAd EN EL DERECHO DE ASILO: DE LA FRAGMENTACiÓN NACIONAL HACIA UN “MODELO DE INTEGRACIÓN”. .......................................................... 49

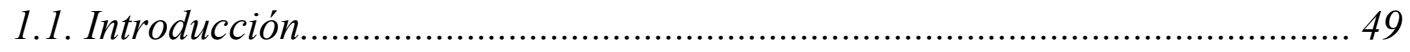

1.2. La definición del mantenimiento del orden público y de la salvaguardia de la

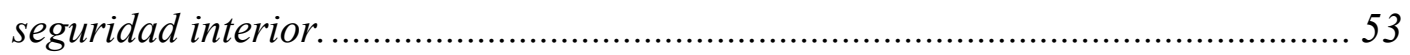

1.3. La cláusula "general" de seguridad nacional. ................................................ 66

2. IMPLiCACiones de LA SEGURIDAd COMO Límite AL DERECHO DE ASILO EN LA

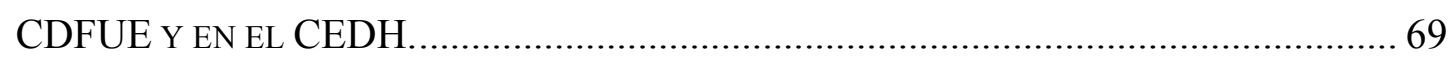

3. LA RADICALIZACIÓN COMO COMPLEJO PARÁMETRO DE EVALUACIÓN DE LA

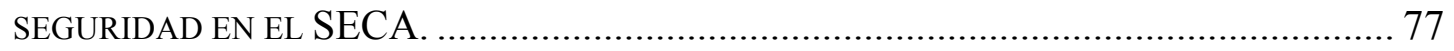

3.1. La radicalización y el reclutamiento de los solicitantes de asilo y refugiados 77

3.2. Nuevos modelos de radicalización en línea como forma de lucha contra el terrorismo.

4. LAS EXCEPCIONES DE SEGURIDAD EN LA DiRECTIVA Y PROPUESTA DE REGLAMENTO DE RECONOCIMIENTO. 89

4.1. El conflicto entre la exclusión y revocación con el principio de no devolución a la luz del CEDH.. 89 
4.2. Las cláusulas de exclusión del estatuto de protección internacional: una ponderación entre la protección de la seguridad nacional y del derecho de asilo.

4.2.1. El régimen jurídico de la exclusión: una sinóptica visión histórica. 95

4.2.2. Las cláusulas de exclusión del estatuto de refugiado por cuestiones que dependen de la seguridad nacional. Especial referencia al ordenamiento jurídico Español. 98

4.2.3. Las cláusulas de exclusión del estatuto de protección subsidiaria: el conflicto entre la seguridad nacional y los derechos de los solicitantes. 108 4.2.4. Las cláusulas de exclusión y su conflicto jurídico actual y futuro: ¿la seguridad en detrimento de la efectividad del SECA?

4.3. La revocación del estatuto de protección internacional por razones de seguridad nacional y su directa conexión con el principio de no devolución. .... 119

4.3.1. Consideraciones previas.

4.3.2. La revocación del estatuto de refugiado y protección subsidiaria en la actual Directiva de Reconocimiento. Especial referencia al ordenamiento jurídico español

4.3.3. La revocación y su trascendental avance en la propuesta de Reglamento de Reconocimiento. 131

5. REFLEXIONES CONCLUSIVAS. 135

CAPÍTULO 2. EL DERECHO A LA PROTECCIÓN DE DATOS EN EL SISTEMA EUROPEO COMÚN DE ASILO Y EN SU PROPUESTA DE REFORMA. 141

1. INTRODUCCIÓN 141

2. EL VIGENTE SECA Y LA INTERRELACIÓN ENTRE LA DIMENSIÓN DE SEGURIDAD Y EL DERECHO A LA PROTECCIÓN DE DATOS.

2.1. Antecedentes del emergente conflicto entre la seguridad nacional y el derecho a la protección de datos. 146

2.2. La protección de datos de los solicitantes de protección internacional en el actual SECA: consecuencias jurídicas de un desfasado (y todavía vigente) Reglamento de Dublín III. 151

3. EL PROCESAMIENTO E INTERCAMBIO DE DATOS E INFORMACIÓN PERSONAL EN LA PROPUESTA DE REFORMA DEL SECA. 
3.1. El estado de la cuestión en el SECA: la seguridad europea y la normativa de protección de datos.

3.2. La excepción del RGPD en las solicitudes de protección internacional. ..... 160

3.3. La aplicación de la Directiva 2016/680 de protección de datos en el ámbito penal en el SECA.

4. EL INTERCAMBIO DE INFORMACIÓN EN EL SECA: LA COOPERACIÓN ADMINISTRATIVA

4.1. El intercambio de información durante los traslados. 175

4.1.1. El intercambio de información pertinente antes de la ejecución de los traslados.

4.1.2. El intercambio de datos sanitarios antes de efectuar el traslado.

5. EL DERECHO A LA INFORMACIÓN EN EL SECA Y EN SU PROPUESTA DE REFORMA. 186 5.1. Los déficits del Sistema de Dublín y su impacto en el derecho a la información de los solicitantes de protección internacional. 186

5.2. El derecho a recibir información en la propuesta de Reglamento de Dublín $I V$ : un derecho condicionado por el deber de cooperación. 190 5.3. Los derechos de acceso, rectificación y supresión en el "Sistema de Dublín".

6. EL PROCESAMIENTO DE INFORMACIÓN Y PROTECCIÓN DE DATOS POR PARTE DE LAS AGENCIAS DE LA UE. 198

6.1. Las implicaciones para la protección de los datos en la transformación de la actual Oficina Europea de Apoyo al Asilo (EASO) en la novedosa Agencia de Asilo de la Unión Europea (AAUE).

6.1.1. De la falta de efectividad de la EASO al papel de la futura Agencia en el tratamiento de la información personal.

6.1.2. El novedoso régimen jurídico aplicable en el tratamiento de la información de la Agencia de Asilo de la UE. 203

6.2. La novedosa Guardia Europea de Fronteras y Costas: consideraciones relevantes en el derecho a la protección de la información y de los datos personales. 208

7. CONSIDERACIONES FINALES. 217

CAPÍTULO 3. SEGURIDAD Y PROTECCIÓN DE DATOS EN EL SISTEMA DE INFORMACIÓN EURODAC. 223 
1. Hacia un nuevo Reglamento del Sistema de Dactiloscopia Europea

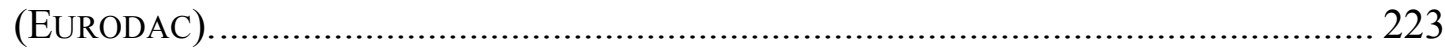

1.1. Una confluencia entre la dimensión de seguridad, eficiencia y protección de datos.

1.2. El nuevo régimen de interoperabilidad entre Eurodac y los sistemas europeos de información.

2. LA GESTIÓN COORDINACIÓN Y SUPERVISIÓN DE EURODAC Y SUS IMPLICACIONES EN LA PROTECCIÓN DE LOS DATOS PERSONALES. 236

3. LA PROPUESTA de REglamento DE EURODAC: EL INCREMENTO DE LA SEGURIDAD EUROPEA Y SU IMPACTO EN LA PROTECCIÓN DE LOS DATOS PERSONALES.

3.1. La finalidad del futuro Eurodac: de la gestión de solicitudes de protección internacional a la detección de migrantes en situación irregular. 245

3.2. La transferencia de datos a terceros países a efectos de retorno. 249

3.3. La ampliación de datos biométricos. 255

3.4. La rebaja de la edad en la toma y transmisión de datos biométricos de los 14 a los 6 años de edad. 263

3.5. El periodo de conservación de los datos. 269

4. El ACCESO A EURODAC POR PARTE DE LAS FUERZAS POLICIALES NACIONALES Y EUROPOL. 276

4.1. El acceso policial del actual Reglamento Eurodac hasta la propuesta de reforma de Eurodac: un conflicto entre seguridad y protección de datos. 276

4.1.1. Precedentes del impacto de Eurodac en el derecho a la protección de los datos.

4.1.2. El acceso policial en la propuesta de reforma de Eurodac y su impacto en la legislación de protección de datos. 281

4.2. Las modalidades de acceso con fines policiales a Eurodac........................ 287

4.2.1. El acceso a Eurodac efectuado por las autoridades nacionales. ............. 288

4.2.1.1. Acceso por parte de las autoridades designadas de los EEMM. .... 288 4.2.1.2. Autoridades verificadoras de los EEMM a los efectos de cumplimiento de la ley. 290

4.2.2. El acceso a Eurodac efectuado por la Oficina Europea de Policía (Europol).

4.3. El Reglamento 2019/818 de interoperabilidad y su impacto en el acceso a los datos de Eurodac. 
4.4. La protección de datos personales en Eurodac: la seguridad de los datos en el acceso a la información

5. CONSIDERACIONES FINALES SOBRE EL IMPACTO DE LA PROPUESTA DE REGLAMENTO DE EURODAC EN LA SEGURIDAD Y EN EL DERECHO A LA PROTECCIÓN DE DATOS........ 304

CAPÍTULO 4. EL SISTEMA EUROPEO COMÚN DE ASILO Y SUS RETOS MÁS INMEDIATOS EN EL ORDENAMIENTO JURÍDICO ESPAÑOL: ESPECIAL

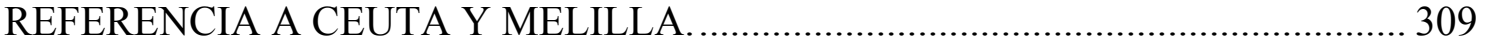

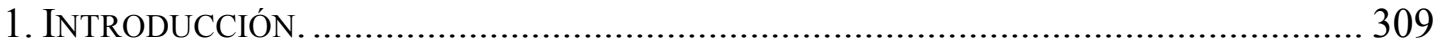

2. La Ley de Asilo y de la Protección Subsidiaria: un Balance CRÍtico 20092019.

2.1. Antecedentes....

2.2. La Ley de Asilo y de la Protección Subsidiaria a la luz del futuro SECA..... 320

2.3. La falta de reglamento de la LAPS: abordando su necesidad y pertinencia. 329 3. LuCES y SOMBras DEL PROCEDimiento Fronterizo de Ceuta y Melilla y SU IMPACTO EN EL DERECHO A LA PROTECCIÓN INTERNACIONAL.

3.1. Estado actual de la cuestión.

3.2. Régimen jurídico de las "devoluciones en caliente" y su conflicto con el derecho a la protección internacional..

3.3. La libertad de circulación de los solicitantes de protección internacional desde Ceuta y Melilla. 347

3.4. La situación de los Centros de Estancia Temporal de Inmigrantes y de los Centros de Internamiento de Extranjeros en Ceuta y Melilla. 353

4. RECAPITULACIONES FINALES 361

CONCLUSIONES FINALES 365

FINAL CONCLUSIONS. 379 


\begin{abstract}
$^{1}$
This Doctoral Thesis aims at analysing how the wide margin of appreciation with regard to all those matters that have compromised the security of Member States especially, after influxes of third-country nationals on a large scale- has conditioned the effective implementation of the current Common European Asylum System (CEAS). Thus, reactive and proactive responses will be provided in accordance with the existing legislation and the reform CEAS packages, in full accordance with a well-established CJEU and ECHR jurisprudence.
\end{abstract}

To this end, the security dimension will be examined from a three-perspective approach: on the one hand, national security limitations and exceptions to the CEAS will be scrutinised, specifically, by means of the exclusion and revocation clauses, as well as other emerging extralegal factors such as radicalisation and recruitment of asylum seekers and refugees. On the other hand, it will be undertaken a study on the right to privacy and data protection in the "Dublin System".

This discipline is placed as one of the central pillars of the System, promoting not only substantial improvements on the guarantee of the protection of the EU's external borders and the management of migratory flows, but also contributes to strengthening internal security. In this regard, one of the first attempts to determine its legal basis is conducted within various proposals of the CEAS reform, without prejudice to address those issues stemming from the recent interoperability Regulation. Ultimately, the lack of coherence of the Spanish asylum system with European regulations will be identified, focusing on the challenges that the Ceuta's and Melilla's border procedure is lately facing.

The thesis confirms the need for a balance between security imperatives and the fundamental rights and freedoms that affect applicants for international protection. Concerning to the data protection legislation in the context of the CEAS, an analysis is carried out on the effective application of the General Data Protection Regulation and the Data Protection Directive on Police Matters, evaluating their impact on the imminent reform of the European Dactyloscopy Information System. Likewise, some of the most outstanding and recent aspects of the national asylum system that should be reformed - mainly, after approval of the CEAS proposals- are highlighted for the purpose of increasing legal certainty and fostering the effective and efficient migratory management for those persons in need of international protection.

\footnotetext{
${ }^{1}$ Conforme al art. 27.1 b) de la normativa de los estudios de doctorado, regulados por el RD 99/2011, en la Universitat Jaume I (Aprobada por el Consejo de Gobierno núm. 19 de 26 de enero de 2012, modificada por el Consejo de Gobierno num. 29 de 27 de noviembre de 2012 y posterior modificación del Consejo de Gobierno núm. 37 de 25 de julio de 2013), se presenta un resumen en inglés, así como las conclusiones finales.
} 


\section{ABREVIATURAS}

ACNUR Alto Comisionado de las Naciones Unidas para los Refugiados

AIDA Asylum Information Database

AN Audiencia Nacional

Art. Artículo

AAUE Agencia de Asilo de la Unión Europea

APD Autoridad de protección de datos

BAMF Oficina Federal para la Migración y Refugio de Alemania

BIMS Biometric Identity Management System

CCBE Consejo de la Abogacía Europea

CDFUE Carta de Derechos Fundamentales de la UE

CDN Comité de los Derechos del Niño

CE Constitución Española

CEAR Comisión Española de Ayuda al Refugiado

CEDH Convenio Europeo de Derechos Humanos

CEPD Consejo Europeo de Protección de Datos

CETI Centro de Estancia Temporal de Inmigrantes

CFS Código de Fronteras Schengen

CIE Centro de Internamiento de Extranjeros

CICR Comité Internacional de la Cruz Roja

CODH Comisión de Observación de Derechos Humanos

CP Código Penal

DP Defensor del Pueblo

DIM Detector de Identidades Múltiples

Doc. Documento

DPO Delegado de Protección de Datos

DUDH Declaración Universal de los Derechos Humanos

EM Estado miembro

ELSJ Espacio de Libertad, Seguridad y Justicia

EASO Oficina Europea de Apoyo al Asilo

ECRE Consejo Europeo sobre Refugiados y Exiliados

Eu-LISA Agencia Europea para la Gestión Operativa de Sistemas Informáticos de Gran Magnitud 
EURODAC Sistema de Dactiloscopia Europea

Europol Oficina Europea de Policía

FAMI Fondo de Asilo, Migración e Integración

FCSE Fuerzas y cuerpos de seguridad del Estado

FRA Agencia de los Derechos Fundamentales de la Unión Europea

FSI Fondo de Seguridad Interior

GEFC Guardia Europea de Fronteras y Costas

GT 29 Grupo de Trabajo del Artículo 29

GTD Índice de Terrorismo Global

IRU Unidad de Referencia en Internet

ISF Fondo de Seguridad Interna

JAI Justicia y Asuntos de Interior

LAPS Ley de Asilo y de la Protección Subsidiaria

LOEx Ley Orgánica de Extranjería

LOPSC Ley Orgánica de Protección de la Seguridad Ciudadana

LIBE Libertades Civiles, Justicia y Asuntos de Interior

OAR Oficina de Asilo y Refugio

OCHA Oficina de Naciones Unidas para la Coordinación de Asuntos Humanitarios

OIM Organización Internacional para las Migraciones

ONG Organización no gubernamental

ONU Organización de las Naciones Unidas

OPI Oficina de Protección Internacional

PE Parlamento Europeo

PEB Portal Europeo de Búsqueda

PIA Evaluación de Impacto en la Privacidad

PNR Passenger Name Record

PRE Propuesta de Reglamento Eurodac

PRD Propuesta de Reglamento de Dublín

PRP Propuesta de Reglamento de Procedimiento

PRR Propuesta de Reglamento de Reconocimiento

RAE Radicalisation Awareness Network

RAN Radicalisation Awareness Network

RCDI Registro común de datos de identidad

REx Reglamento de Extranjería 
RGPD Reglamento General de Protección de Datos

SCB Servicio de Correspondencia Biométrica

SCG Grupo de Coordinación de Supervisión de Eurodac

SCG Grupo de Coordinación de Supervisión de Eurodac

SECA Sistema Europeo Común de Asilo

SEPD Supervisor Europeo de Protección de Datos

SI Sistema de Información

SIS Sistemas de Información Schengen

SIVE Sistema Integrado de Vigilancia Exterior

TEDH Tribunal Europeo de Derechos Humanos

TE-SAT Informe de Situación y Tendencias Terroristas

TFUE Tratado de Funcionamiento de la Unión Europea

TJUE Tribunal de Justicia de la Unión Europea

TL Tratado de Lisboa

TS Tribunal Supremo

TSJ Tribunal Superior de Justicia

TUE Tratado de la Unión Europea

UE Unión Europea

VIS Sistema de Información Visa 


\section{INTRODUCCIÓN}

En los últimos años, los grandes intereses de los estados han girado en torno al mantenimiento de su seguridad nacional. La vis atractiva de esta dimensión ha trascendido del ámbito fronterizo hacia un conjunto de políticas focalizadas en la prevención y contención de la inmigración irregular, la delincuencia o el terrorismo y en el que todas ellas, han tenido un impacto adverso en el derecho a la protección internacional -asilo y protección subsidiaria-. ${ }^{2}$ Pese a que el vigente Sistema Europeo Común de Asilo (SECA) proporciona un marco jurídico coherente en la protección de este derecho, su efectividad se ha visto fuertemente condicionada por un amplio margen de apreciación nacional en lo que respecta a todas aquellas cuestiones susceptibles de comprometer su propia seguridad.

Concretamente, se enardecieron políticas nacionales de "frontera cerrada" que radicaban en la aproximación entre una mayor tasa de concesión de estatuto de protección internacional al correlativo aumento de la criminalidad y de ataques terroristas. Una relación que no resulta novedosa, sino que se lleva produciendo desde los atentados de Nueva York del 11-S en el año $2001^{3}$ y que se agravó tras los acaecidos en distintos Estados miembros (EEMM) -incluida España-, ${ }^{4}$ propiciando una

\footnotetext{
${ }^{2}$ El estatuto de refugiado que tienen su razón de ser en garantizar a un nacional de tercer país que, debido a fundados temores de ser perseguido por motivos de raza, religión, nacionalidad, opiniones políticas o pertenencia a determinado grupo social, se encuentra fuera del país de su nacionalidad y, no puede o, a causa de dichos temores, no quiere acogerse a tal protección, poder obtener dicha protección. Por su parte, el de la protección subsidiaria estriba en aquellos que aún no reuniendo los requisitos para el reconocimiento del estatuto de persona refugiada, se considera que se dan motivos fundados para creer que si regresase a su país de origen o de residencia habitual se enfrentaría a un riesgo de sufrir daños graves.

${ }^{3}$ Sobre este principal precedente, remitimos a: HUYSMANS, J., BUONFINO, A., "Politics of exception and unease: immigration, asylum and terrorism in parliamentary debates in the UK", Political Studies, vol. 56, no 4, 2008, p. 767; KEPHART J. L., "Immigration and Terrorism: Moving Beyond the 9/11 Staff Report on Terrorist Travel”, Connections, vol. 5, 2006, no. 2, p. 56; KERWIN D., "How Robust Refugee Protection Policies Can Strengthen Human and National Security", Journal on Migration and Human Security, vol. 4, no 3, 2016 p. 85; BAYLIS E. A., "National Security and Political Asylum" en: D'APPOLLONIA A. C., REICH S., (Eds.), Immigration, Integration, and Security: America and Europe in Comparative Perspective, University of Pittsburgh Press, 2010, p. 164; KAUNERT, C., European internal security - towards supranational governance in the area of freedom, security and justice?, Europe in Change, Manchester University Press, Manchester, 2011, p. 72.

${ }^{4}$ Esta cuestión ha sido puesta de manifiesto, entre otros, por: GARCÍA MAHAMUT, R., "La ductilidad del derecho a la protección internacional (refugio y protección subsidiaria) ante las crisis humanitarias: un desafío para Europa y para el Sistema Común de Asilo", Teoría y Realidad Constitucional, n 38, 2016, p. 234; SERRA CRISTÓBAL, R., "Los derechos fundamentales en la encrucijada de la lucha contra el
} 
liberalización europea de las políticas de inmigración y asilo que se extienden hasta nuestros días. Ello ha ido rebajando, con otro cariz y pese a los grandes avances producidos en la materia, la coherencia del SECA, fuertemente condicionada por políticas nacionales restrictivas y conexas a la prevención exacerbada de ataques contra la seguridad de los Estados, así como por la imposibilidad de gestionar eficazmente las grandes afluencias migratorias. También en virtud de un régimen competencial que no ha tenido en cuenta la carga desproporcionada que suponía para algunos EEMM la tramitación de las solicitudes que se presentaban en sus fronteras.

Tanto es así, que las legítimas preocupaciones por la seguridad y la preservación del derecho a la protección internacional han intensificado la divergencia de posturas de los líderes europeos sobre cómo abordar esta realidad con miras a garantizar una fiel equilibrio entre la seguridad nacional y, al mismo tiempo, el derecho a la protección internacional. Recuérdese que, en mayo de 2019, la canciller Angela Merkel destacaba la urgente necesidad de cooperación con terceros estados, asistiendo a los países del Sahel frente a la amenaza de terrorismo yihadista, considerados como base nuclear de operaciones para penetrar y atacar Europa. Por el contrario, en julio de ese mismo año, el vicepresidente y ministro del Interior de Italia, Matteo Salvini, apuntaba que el terrorismo islamista era una realidad en la UE, lo cual le permitía justificar el cierre de los puertos italianos a la llegada de barcos de migrantes y refugiados mientras que, el pasado 8 de octubre, el presidente Macron reclamaba "una sociedad más vigilada" para hacer frente a la "hidra islamista" y combatir el terrorismo islámico, una amenaza continua para la sociedad francesa.

Con ello, aunque los EEMM disponen de un amplio margen de discrecionalidad para decidir sobre cuestiones que penden de su seguridad nacional, no es menos cierto que estos también tienen el deber jurídico inexcusable de cumplir con las obligaciones derivadas de los distintos instrumentos internacionales y supranacionales para la protección internacional y, muy concretamente, con la Convención de Ginebra de 1951 y el Protocolo de Nueva York de 1967, los arts. 3,5, 6 y 8 del Convenio europeo de los Derechos humanos y de las Libertades públicas (CEDH) y los arts. 18 y 19 de la Carta de Derechos fundamentals de la UE (CDFUE). ${ }^{5}$ Obligaciones sobre las que ha

terrorismo yihadista. Lo que el constitucionalismo y el derecho de la Unión Europea pueden ofrecer en común”, Teoría y Realidad Constitucional, nº 38, 2016, p. 487.

${ }^{5}$ Carta de los Derechos Fundamentales de la Unión Europea, 30 de marzo de 2010 (C-83/391). 
descansado la expansiva construcción del SECA y, por ende, la respectiva política comunitaria de asilo.

El problema de calado estriba en que las políticas de seguridad se emplazan como eje central de las políticas comunitarias, reduciendo considerablemente las garantías previstas en el SECA. En esta línea se pronunció el Servicio de Investigación del Parlamento Europeo en 2018 afirmando que la lucha contra el terrorismo había constituido una evasiva en la limitación generalizada de los derechos fundamentales ${ }^{6} \mathrm{y}$ cuyo alcance, a juicio de la Federación Internacional de Derechos Humanos ${ }^{7}$ era susceptible de provocar una regresión injustificada de los derechos humanos y las libertades fundamentales.

Transcurridas dos décadas desde los fructuosos resultados cosechados de las conclusiones de Tampere y, tras el funcionamiento del SECA durante dos generaciones -la primera entre 2004 y 2005 y la segunda entre 2011 y 2013-, no ha podido alcanzarse la tan deseada armonización de las prácticas nacionales en materia de asilo. ${ }^{8}$ A la seguridad de los EEMM, se le ha adherido la fragilidad del principio de confianza mutua, solidaridad y reparto justo de responsabilidades. El SECA ha demostrado sus limitaciones para proteger a los solicitantes de protección internacional en el contexto del creciente número de llegadas a la UE, que incrementaron exponencialmente en varios EEMM durante 2015-2016 y, años más tarde, en España. Sin embargo, fue la notoria falta de solidaridad la que evidenció un marco institucional normativo incapaz de garantizar de forma efectiva el derecho a la protección internacional.

Como respuesta a estas crisis, fueron adoptadas medidas ad hoc de diversa índole tendentes a estabilizar esta situación, incluyendo la potenciación de la cooperación con terceros países de origen y de tránsito -como la conocida declaración UE-Turquía o los acuerdos de cooperación con Libia-, los esquemas de reubicación temporal desde Italia

\footnotetext{
${ }^{6}$ Van BALLEGOOIJ W., BAKOWSKI P., The cost of non-Europe in the fight against terrorism, EPRS, European Parliament, 2018.

${ }^{7}$ Federación Internacional de Derechos Humanos (FIDH), The United Nations Counter-Terrorism Complex, Bureaucracy, Political Influence and Civil Liberties, $\mathrm{n}^{\circ}$ 700, septiembre de 2017, p. 14.

${ }^{8}$ Recordemos que uno de los principales objetivos del Consejo de Tampere fue "lograr una Unión Europea abierta y segura, plenamente comprometida con las obligaciones que emanan de la Convención de Ginebra sobre el Estatuto de los Refugiados y otros instrumentos pertinentes en materia de derechos humanos, y capaz de responder de forma solidaria a necesidades humanitarias. También debe desarrollarse un planteamiento común que garantice la integración en nuestras sociedades a los nacionales de terceros países que residen legalmente en la Unión”. Consejo Europeo de Tampere, Conclusiones de la Presidencia, 15 y 16 de octubre de 1999.
} 
y Grecia a otros EEMM -y que, desafortunadamente, no obtuvieron el apoyo de la mayor parte de estos- o los relativos al exitoso marco de reasentamiento de la UE desde terceros países. No menos importante fue la creación, a nivel institucional, de dos agencias europeas tendentes a mejorar las obligaciones del SECA: por un lado, la Agencia Europea de la Guardia de Fronteras y Costas (Frontex) en 2005, pilar en los esfuerzos de la UE para salvaguardar el espacio de libertad, seguridad y justicia renombrada como la Agencia Europea de la Guardia de Fronteras y Costas en 2016 tras la ampliación de sus competencias, ampliada nuevamente en 2019- y la Oficina Europea de Apoyo al Asilo (EASO) en 2011. Esta última facilitando una cooperación práctica en asuntos relacionados con el asilo de aquellos EEMM que se enfrentaban a graves problemas en sus sistemas nacionales de asilo, como fue el caso de Italia y Grecia - próximamente se transformará en la Agencia de Asilo de la UE (AAUE), con competencias mucho más perfeccionadas en el intercambio y análisis de la información-.

Ya en 2016, se propuso la reforma integral del SECA, ${ }^{9}$ que reflejó el importante progreso a nivel técnico en las nuevas propuestas legislativas. Sin embargo, a finales de 2019 todavía no ha sido posible un compromiso político equilibrado sobre la reforma general de este sistema. En 2018 se alcanzó un acuerdo provisional sobre la mencionada reforma que se paralizó ante las dificultades de aunar consenso en torno al conocido Reglamento de Dublín. Un instrumento que determina el régimen competencial y muestra la escasa voluntad por avanzar en un reparto más justo y proporcional de las solicitudes de protección internacional. Ahora bien, la situación de estancamiento que persiste durante más de 3 años compromete seriamente los valores fundamentales de la UE en la construcción de una legislación de asilo más coherente con las posibilidades reales nacionales.

Como resultado, el objetivo que persigue el SECA, tendente en asegurar un alto nivel de protección y uniformidad en las legislaciones nacionales de asilo, se ha visto seriamente obstaculizado ante excepciones radicadas en el mantenimiento y la preservación de la seguridad nacional. Un "punto de inflexión" que viene marcado no tanto, en virtud de que la totalidad de las Directivas y Reglamentos que conforman este

\footnotetext{
${ }^{9}$ Comisión Europea, Comunicación de la Comisión al Parlamento Europeo y al Consejo «Hacia una reforma del Sistema Europeo Común de Asilo y una mejora de las vías legales a Europa», 6 de abril de 2016. $\operatorname{COM}(2016) 197$ final.
} 
sistema incluyan disposiciones específicas de seguridad nacional, sino en su constante, dispar y, en numerosas ocasiones, arbitraria aplicación por parte de los EEMM. Un contexto que genera un marco jurídico escasamente coherente que ha limitado gravemente las garantías en la protección efectiva de los nacionales de terceros países o apátridas con intención de solicitar protección internacional en su llegada a distintos puntos fronterizos de Europa. ${ }^{10}$

El presente trabajo de investigación analiza las afluencias a gran escala de nacionales de terceros países y que propiciaron la adopción de medidas centradas en la preservación de la seguridad del EEMM afectado a fin de ofrecer medidas proactivas y reactivas coherentes y en consonancia con la normativa que desarrolla el SECA actual y su propuesta de reforma.

Desde una perspectiva metodológica, se estudiará la incidencia de la seguridad en tres ámbitos: en primer lugar, en sus correlativas limitaciones y excepciones en el actual SECA y en su propuesta de reforma con objeto de detectar las principales dificultades que han afectado al correcto ejercicio del mismo. Más concretamente, tras las graves crisis migratorias en distintos EEMM que se iniciaron en el año 2014 y que favorecieron la aplicación de políticas de excepción centradas en la protección de su seguridad. En segundo lugar, conexo a la seguridad, examinaremos cómo esta ha afectado a la determinación del régimen jurídico de protección de datos que contempla el Sistema de Dublín. De tal modo, procederemos a evaluar el impacto del procesamiento y gestión de la información de los solicitantes de protección internacional tanto en los aún vigentes Reglamento de Dublín y Eurodac como en sus propuestas de reforma, que tienden a conferir a este sistema una mayor eficiencia y eficacia, relegando a un plano secundario la protección efectiva de los datos personales. Un ámbito sobre el que ha pronunciado el Supervisor Europeo de Protección de Datos (SEPD) en multitud de ocasiones. Especialmente, a raíz de la reforma del SECA, cuando destacó la necesidad de mejorar los derechos e intereses legítimos de solicitantes de protección internacional, sujetos en situación de vulnerabilidad que se

\footnotetext{
${ }^{10}$ En la presente tesis doctoral, la referencia de nacionales de terceros países incluye también a los apátridas.
} 
ven fuertemente afectados por el tratamiento de datos personales, en particular, los solicitantes de protección internacional y los refugiados. ${ }^{11}$

Efectivamente, esta disciplina adolece en la actualidad de la seguridad jurídica que requiere el SECA, teniendo en consideración que la gestión de la información y de los datos personales objeto de tratamiento constituye uno de los ejes vertebrales del mencionado sistema. Una importancia que parte de un criterio de especialidad, pues estos datos son mayormente confidenciales y especialmente protegidos. Además, deben adoptarse todas las medidas de seguridad para que los países frente a los que se otorga protección internacional a sus nacionales no puedan acceder -ni directa ni indirectamente- a los mismos pues, en caso contrario, se estaría contraviniendo el principio sobre el que se asienta este sistema, esto es, la prohibición de no devolución que prevén la práctica totalidad de los instrumentos legales nacionales, europeos e internacionales al efecto.

Finalmente, en la última parte de este estudio analizaremos someramente algunas de las dificultades a las que se está enfrentando, desde las premisas metodológicas a las que nos hemos referido, el derecho a la protección internacional en el ordenamiento jurídico español. En concreto, nos centraremos en la gestión de los flujos migratorios y el impacto en el derecho a la protección internacional en las fronteras del sur de Ceuta y Melilla. Puntos de entrada que, por su emplazamiento en el continente africano y su zona limítrofe con Marruecos, está altamente expuesta a grandes afluencias de migrantes.

Una de las acciones sobre las que profundizaremos son las conocidas como “devoluciones en caliente", prácticas de dudosa legalidad especialmente frecuentes desde 2017 y que han dificultado la presentación de solicitudes de protección internacional. Así, relevante ha sido la primera condena por parte del TEDH actualmente a la espera de que la Gran Sala resuelva el recurso interpuesto por España-. Asimismo, analizaremos los conceptos de seguridad nacional, orden público y seguridad pública que prevé nuestra Carta Magna, y su incidencia en el derecho de asilo

\footnotetext{
${ }^{11}$ Más específicamente, el Supervisor recomendó en su Dictamen las vías principales sobre las que debía actuarse, esto es: el Reglamento de Dublín, Eurodac así como las correspondientes evaluaciones completas del impacto sobre la protección de datos y la privacidad. Supervisor Europeo de Protección de Datos (SEPD), Resumen ejecutivo del dictamen del Supervisor Europeo de Protección de Datos sobre el primer paquete de reformas del Sistema Europeo Común de Asilo (Reglamentos Eurodac, EASO y Dublín), enero de 2017 (2017/C 9/04).
} 
y protección subsidiaria. Además, se abordará la manifiesta falta de coherencia de la Ley 12/2009, de Asilo de la Protección Subsidiaria (LAPS) con la normativa comunitaria, hecho que se agrava ante la falta de desarrollo reglamentario, lo cual esboza un ordenamiento jurídico que no otorga respuestas a los problemas y situaciones actuales. Ley que, tras más de una década en vigor y, pese a resultar muy avanzada para su tiempo, no ha transpuesto las actuales directivas de procedimiento, reconocimiento y acogida, dando lugar a que la doctrina y, esencialmente, los tribunales hayan colmado estas lagunas aplicando con asiduidad las directivas del actual SECA -disposiciones que, en muchos casos, han resultado más beneficiosas que la mencionada Ley-.

En coherencia con todo lo anterior, la presente tesis doctoral se estructura en cuatro capítulos. En el capítulo primero se conceptualiza el mantenimiento del orden público, la salvaguardia de la seguridad interior y la cláusula general de seguridad nacional a la luz de la reciente jurisprudencia del TJUE y en su directa incidencia en el actual SECA. Seguidamente, procedemos a señalar los retos no previstos a los que se enfrenta este sistema a corto y medio plazo. Este es el caso de la radicalización y el reclutamiento, fenómenos de muy compleja cuantificación y evaluación que, como estudiaremos, pueden restringir seriamente la efectividad del SECA por su directa conexión con la prevención de la delincuencia y del terrorismo comunitario.

Además, se analiza la excepción de la seguridad nacional en las cláusulas de exclusión y revocación que dispone la Directiva de Reconocimiento. Cláusulas que, desde las crisis de refugiados, se han encontrado fuertemente condicionadas por la necesidad de garantizar la protección de cualquier escenario que pueda potencialmente poner en riesgo la seguridad de los Estados. Así, han sido previstos procedimientos nacionales ad hoc muy dispares en tres países (España, Alemania y Reino Unido) y que, en algunos casos, no respetan las condiciones requeridas por la jurisprudencia comunitaria y europea. A ello se agrega la búsqueda de "nuevos modelos" mediante la aplicación de las mencionadas cláusulas que permitan flexibilizar la acogida de los solicitantes de asilo, restringiendo el acceso y obtención del estatuto de protección internacional. Una denegación o retirada formal del estatuto ante una concatenación de cuestiones radicadas en la propia seguridad de los EEMM que limitará el alcance del derecho a la protección internacional para afrontar, de una forma más dúctil, los grandes retos migratorios y de asilo. 
En referencia al capítulo segundo, abordaremos la incidencia de la seguridad en el derecho a la privacidad y, en especial, a la protección de los datos de los solicitantes de protección internacional. Este derecho constituye una de las piedras angulares de la reforma del SECA para proteger las fronteras exteriores, mejorar la gestión de los flujos migratorios y contribuir a reforzar la seguridad interior. La Propuesta de Reglamento de Dublín IV incorpora directamente la vigente normativa de protección de datos, corroborando la intrínseca voluntad por fortalecer las dimensiones de eficiencia y eficacia en lo que respecta a la gestión de la información.

En este sentido, en una primera aproximación a este derecho, debe recordarse que los solicitantes de protección internacional son los titulares legítimos de sus datos y, como tal, deben conocer y comprender todos los derechos y obligaciones que les son inherentes. Si bien, la migración y asilo en la UE se enfrentan a desafíos cada vez de mayor magnitud conexos a la seguridad de los EEMM, lo cual exige crear registros e investigaciones cada vez más perfeccionados y exactos tendentes a identificar exhaustivamente al nacional de un tercer y evaluar si este merece la concesión de estatuto de protección internacional. Una compleja determinación por cuanto deberán diferenciarse, sin atisbo de duda, de otras categorías de nacionales de terceros países como migrantes económicos o incluso, posibles delincuentes o terroristas.

No obstante, las continuas limitaciones de este derecho tras su directo impacto con cuestiones que afectan directamente a la seguridad nacional poseen una serie de trascendentales connotaciones en la futura propuesta de reforma en lo que se refiere al intercambio de información previsto por este Reglamento. Se produce un conflicto de derechos fundamentales de primer orden entre el derecho a la protección internacional y el derecho a la protección de los datos personales cuando lo que se puede hallar en juego en la salvaguarda de la seguridad de Estado. El ecosistema normativo multinivel se encuentra sujeto a incertidumbres jurídicas de gran entidad en cuanto "al marco jurídico de aplicación, a las reservas competenciales y al sistema de garantías y limitaciones de los derechos en juego en diversos escenarios condicionados por los accesos y diversos controles a las fronteras exteriores de la UE". ${ }^{12}$

\footnotetext{
${ }^{12}$ GARCÍA MAHAMUT, R., VIGURI CORDERO, J., "La protección de los datos personales de los solicitantes de protección internacional en el (nuevo) Sistema Europeo Común de Asilo: grandes desafíos y graves deficiencias", Teoría y Realidad Constitucional, nº 44, 2019, p. 241.
} 
Nos enfrentamos a una enorme complejidad normativa que, desde un enfoque metodológico, exige una aproximación desde el Sistema de Dublín con objeto de delimitar el régimen jurídico aplicable, principalmente, cuando interacciona con la seguridad de los EEMM. En este aspecto, los solicitantes de protección internacional deben proporcionar su información personal y datos biométricos a un amplio conjunto de autoridades nacionales, agencias y organismos comunitarios e internacionales en multitud de contextos y situaciones. Además, estas pueden recibir información personal dimanante de otras vías seguras en su ineludible obligación de cooperación con otras autoridades nacionales, organismos o agencias europeas o internacionales.

No cabe duda de que los datos personales constituyen el eje básico sobre el que deben pivotarse todos los instrumentos y mecanismos que se activan para, en su caso, conceder o denegar esa protección internacional. Aunque ello, en sí mismo, proyecta una basta problemática desde diversas perspectivas que confluyen en el tratamiento de los datos personales y en los diversos conflictos que se originan en relación con el uso que efectúan las distintas autoridades en los distintos derechos que asisten en el ámbito de la privacidad y protección de datos.

No olvidemos que la información concerniente a los solicitantes de protección internacional, frecuentemente sensible, presenta un riesgo excesivamente elevado a que no respete la alta protección que merece. Asimismo, en el proceso intervienen un amplio conjunto de autoridades, organismos y agencias europeas e internacionales que no disponen, en la mayoría de los casos, de pautas claras y uniformes sobre utilización y tratamiento. Igualmente, estos solicitantes deben ser informados sobre la finalidad de esta recopilación y el nivel de protección requerido para promover que estos confíen en las personas y organizaciones que solicitan estos datos, entender bajo qué circunstancias se procesan así como a qué países u organismos pueden ser cedidos. Sin embargo, como tendremos oportunidad de comprobar, esta información no está siendo proporcionada en tiempo y forma, de forma que los solicitantes navegan en un entorno de generalizada incertidumbre y toman decisiones individuales que, en última instancia, pueden causarles más perjuicios en sus derechos e intereses individuales.

Este trabajo concreta la normativa que, desde el año 2018, resulta aplicable y que simplemente se mencionan de manera soslayada en los distintos instrumentos de la propuesta de reforma del SECA. Ahora bien, también destacará todo un amplio conjunto de agencias y organismos europeos e internacionales que procesan directa o 
indirectamente información personal, así como las persistentes cuestiones que giran en torno a la seguridad nacional. Factores que indudablemente, se apartan de las altas garantías del régimen jurídico ordinario y que evidencia un marco jurídico especialmente fragmentado y supeditado a un conflicto de intereses. Este parte de una imperante necesidad por "liberalizar" y flexibilizar las obligaciones nacionales y proporcionar una solución a los escasos medios materiales y humanos que disponen los estados con cierta asiduidad y que pueden llegar a comprometer su propia seguridad. Es más, todo parece pronosticar que se extenderá tras la entrada en vigor del nuevo SECA, lo que podría afectar seriamente a los principios estructurales de protección de datos si no se ofrecen soluciones a los múltiples desafíos que se derivan de la implementación de esta política comunitaria.

En la presente tesis doctoral trataremos de proyectar un haz de luz sobre todos estos déficits en el régimen jurídico vigente y que contempla la propuesta de reforma del SECA. El objetivo no es otro que intentar clarificar y sistematizar ese extenso régimen jurídico de la normativa de protección de datos de inicio a fin, es decir, desde el primer momento en el que los sujetos son interceptados e identificados, siguiendo en el proceso de determinación de la solicitud de protección internacional y tras la resolución final de la efectiva concesión de estatuto correspondiente.

Adentrándonos en el capítulo tercero, acometemos un examen exhaustivo sobre el Sistema de Información Eurodac. Desde su construcción en el año 2000, constituye una herramienta asistencial esencial para garantizar la viabilidad y continuidad del SECA en concreto, del funcionamiento del Reglamento de Dublín- que permite otorgar respuestas eficaces a los múltiples y amplios escenarios que han comprometido seriamente la seguridad europea. De tal manera, este sistema se ha ido perfeccionando en interés de los Estados, previendo potentes cautelas para aumentar su seguridad y garantizando un mejor cumplimiento de la ley y apartándose progresivamente del fiel objetivo de identificar a los solicitantes de asilo para desplazarse hacia un "mecanismo autónomo" que gestiona la información de la migración ampliamente considerada. Una transformación en un "poderoso instrumento de información" que procesa información de distintas categorías de migrantes más allá de solicitantes de protección internacional, hacia personas que han sido interceptadas con ocasión del cruce irregular de las fronteras exteriores de la UE y aquellas que se encuentran en situación ilegal en un EEMM. 
Este Sistema de Información constituye una clara muestra de ambición multidisciplinar que ha ubicado a los derechos e intereses de los solicitantes de protección internacional en un plano subsidiario y accesorio, en concreto, en lo que concierne a la protección de su información. Asimismo, a pesar de estar adscrito fundamentalmente a la gestión de la información de solicitantes de asilo, ha impulsado el incremento de su eficiencia y eficacia en detrimento de los derechos fundamentales, generando serias dudas sobre su compatibilidad con la legislación de protección de datos. Es más, ya el vigente Reglamento Eurodac marcó en el año 2015 un verdadero punto de inflexión al permitir, por primera vez, a las autoridades policiales de los EEMM y a la Europol el acceso a esta base de datos. Una medida que inició un ciclo de preocupaciones sobre el impacto en la protección de datos de los solicitantes de protección internacional que arriba hasta nuestros días.

Precisamente, son muchos y muy variados los retos que emergen en la aplicación del Reglamento de Eurodac en materia de protección de datos. Este contiene referencias derogadas del derecho supletorio en materia de protección datos. Un conflicto que pretende superarse con la aprobación de la propuesta de Reglamento de Eurodac, que otorga un trascendental avance en el régimen de garantías del derecho a la protección de datos, previendo la normativa actualmente vigente. Además, su funcionamiento pivota en torno a la dimensión de seguridad, eficiencia y eficacia, relegando a un plano subsidiario los derechos e intereses de las distintas categorías de sujetos que entran dentro de su ámbito de aplicación y que, lejos de complementar la protección de los derechos de los refugiados, interfiere negativamente en el derecho a la protección de sus datos personales.

En este capítulo examinaremos las novedades que incorpora la propuesta de Reglamento de Eurodac y su impacto en el derecho a la protección de datos. Propuesta que ampliará los datos biométricos desde las tradicionales huellas dactilares a las novedosas imágenes faciales y fijará un nuevo límite en los 6 años de edad -en lugar de los 14 actuales-. Asimismo, abordaremos otros aspectos críticos que extiende la mencionada propuesta como el periodo de conservación de los datos de 10 años y las condiciones de acceso policial a este sistema tanto por las autoridades nacionales como por la Europol. Cuestiones que no solo aproximarán -todavía más- el ámbito de la migración y el asilo a las relacionadas con la seguridad, sino que se agravarán cuando este sistema resulte plenamente interoperable entre un amplio catálogo de bases de 
datos europeas. Efectos mayormente desconocidos que incrementarán la efectividad y eficacia del sistema pero proclives a potenciales efectos adversos en la protección efectiva de los solicitantes de protección internacional. En concreto, el riesgo de que su información personal pueda llegar al conocimiento de sus países de origen o tránsito, contraviniendo indirectamente el principio de no devolución. Una prohibición de carácter absoluto que contempla la normativa internacional y europea y cuya única excepción se encuentra en la mencionada propuesta de Eurodac, la cual prevé esta modalidad de cesión de información para aquellos migrantes en situación irregular que deben ser retornados.

Por último, en el capítulo cuarto procederemos a determinar como las afluencias migratorias de grandes magnitudes que llevan produciéndose desde 2017 hasta la actualidad en España han afectado al régimen de garantías en el derecho a la protección internacional en el ordenamiento jurídico nacional. Además, acometeremos las profundas reformas que requiere la normativa española a la luz de la futura normativa europea, teniendo en consideración la elevada inseguridad jurídica que ha supuesto que España no haya transpuesto las directivas de la segunda fase del SECA y carezca de desarrollo reglamentario.

Concluiremos este estudio centrándonos en la deficitaria gestión de los flujos migratorios y de refugiados en las fronteras de Ceuta y Melilla. A la obstaculización al acceso efectivo a la solicitud de asilo o protección subsidiaria, se ha añadido la manifiesta falta de medios materiales y humanos para gestionar adecuadamente una previsible afluencia a gran escala de migrantes, abocando que estos prioricen la llegada a nuestras fronteras de forma irregular. Seguidamente, se evaluarán los diferentes impedimentos a los que se enfrentan durante la presentación y tramitación de estas solitudes en Ceuta y Melilla y las deficitarias condiciones de los centros de acogida en estos puestos fronterizos. Comprobaremos cómo la permanencia de estos individuos en estas ciudades autónomas han implicado serias limitaciones en sus derechos fundamentales, incluyendo fallas considerables en la tutela judicial efectiva, automáticas detenciones durante las ineludibles labores de identificación o las restricciones generalizadas a la libre circulación por el territorio nacional sin una base jurídica clara. Y finalizando proponiendo una serie de mejoras que requiere la gestión y tramitación de las solicitudes de protección internacional. 


\section{CONSIDERACIONES PRELIMINARES}

\section{El derecho de asilo en Europa y la construcción del Sistema Europeo Común de Asilo (SECA).}

El asilo en la Unión Europea (UE) tiene sus raíces en la Convención de 1951 sobre el Estatuto de los Refugiados firmada en Ginebra, ${ }^{13}$ un acuerdo fundado en el art. 14 de la Declaración Universal de Derechos Humanos (DUDH). ${ }^{14}$ Además, un año antes a la Convención se había creado el Alto Comisionado de las Naciones Unidas para los Refugiados (ACNUR) ${ }^{15}$ y firmado el CEDH. ${ }^{16}$

Con respecto a la primera, en 1950 se creó el ACNUR por parte de los gobiernos occidentales y redactaron la Convención de la ONU sobre el Estatuto de los refugiados "pensando en los refugiados que huían de los regímenes comunistas". Su mandato eurocéntrico persiguió en un principio la asistencia a los refugiados en Europa por su directa coincidencia con la Guerra Fría. ${ }^{17}$ Con respecto a la segunda, en el Consejo de Europa se adoptó el CEDH en 1950 con el fin de unir a los Estados de Europa tras la Segunda Guerra Mundial y promover el Estado de derecho, la democracia, los derechos humanos y el desarrollo social. En virtud del art. 19 CEDH, se estableció el Tribunal Europeo de Derechos Humanos (TEDH) -y la antigua Comisión Europea de Derechos Humanos- para garantizar el cumplimiento de las obligaciones que impone el Convenio a los Estados firmantes.

Sin embargo, la Convención, que entró en vigor el 22 de abril de 1954, únicamente se aplicaba exclusivamente a hechos ocurridos con anterioridad al 1 de enero de $1951 \mathrm{y}$ los Estados parte podían limitar dichos eventos a los acaecidos en Europa. Con la

\footnotetext{
${ }^{13}$ Convención sobre el Estatuto de los Refugiados, adoptada en Ginebra, Suiza, el 28 de julio de 1951 por la Conferencia de Plenipotenciarios sobre el Estatuto de los Refugiados y de los Apátridas (Naciones Unidas), convocada por la Asamblea General en su resolución 429 (V), del 14 de diciembre de 1950. Entrada en vigor: 22 de abril de 1954, de conformidad con el artículo 43 Serie Tratados de Naciones Unidas, $\mathrm{N}^{\circ} 2545$, Vol. 189, p. 137

${ }^{14}$ Declaración Universal de Derechos Humanos Adoptada y proclamada por la Asamblea General en su resolución 217 A (III), de 10 de diciembre de 1948.

${ }^{15}$ Fundado el 14 de diciembre de 1950.

${ }^{16}$ Inspirándose en la DUDH, el Consejo de Europa adoptó el Convenio Europeo de Derechos Humanos (CEDH), firmado el 4 de noviembre de 1950 en Roma y que entró en vigor el 3 de septiembre de 1953 para proteger los derechos humanos y las libertades fundamentales de las personas sometidas a la jurisdicción de los Estados miembros.

${ }^{17}$ ACNUR, La situación de los refugiados en el mundo. 50 años de acción humanitaria, Icaria Editorial, 2000, p. 6.
} 
adopción del Protocolo de Nueva York de 31 de enero de 1967 -en vigor desde el 4 de octubre de 1967-, la Convención alcanzó por primera vez carácter universal. Se eliminó esta limitación temporal aún persistiendo la limitación geográfica en el supuesto de aquellos Estados contratantes que hubieran optado por adoptarla cuando firmaron el Convenio original -sin perjuicio de que pudieran comunicar en cualquier momento su decisión de no volver a aplicarla-- ${ }^{18}$

En Europa, no fue hasta 1985 cuando, a raíz de la eliminación de los controles fronterizos internos de los Estados signatarios y tras la adopción del Acuerdo de Schengen, y sobre todo, del Convenio de aplicación de $1990{ }^{19}$ comenzaron a demandarse políticas de asilo más armonizadas a escala de la UE. En caso contrario, era probable un aumento generalizado de los movimientos secundarios de solicitantes de asilo. Estos podrían desplazarse entre estados con el fin de elegir su destino más oportuno, lo que requirió un refuerzo de los controles fronterizos externos y el inicio de una cooperación sin precedentes en este ámbito. Como resultado, en el Convenio de Dublín de $1990^{20}$ se fijaron los criterios para determinar cuál era el Estado responsable de examinar las solicitudes de asilo presentadas en uno de los EEMM de las Comunidades Europeas.

Con el Tratado de Maastricht en $1993,{ }^{21}$ el Consejo asoció su trabajo a la Comisión, informando al Parlamento de sus iniciativas en materia de asilo, sin que el Tribunal de Justicia de la Unión Europea tuviera competencias en estas cuestiones. Con la firma del Tratado de la Unión Europea (TUE), su art. 3.2 garantizó "la libre circulación de personas conjuntamente con medidas adecuadas en materia de control de las fronteras

\footnotetext{
${ }^{18}$ Limitación que no afecta a los Estados europeos, pues su totalidad son parte de la Convención sobre los Refugiados de 1951 y de su Protocolo de 1967. Protocolo sobre el Estatuto de los Refugiados. Del Protocolo tomaron nota con aprobación el Consejo Económico y Social en su resolución 1186 (XLI), de 18 de noviembre de 1966, y la Asamblea General en su resolución 2198 (XXI), de 16 de diciembre de 1966. En la misma resolución, la Asamblea General pidió al Secretario General que transmitiera el texto del Protocolo a los Estados mencionados en su artículo $\mathrm{V}$ a fin de que pudieran adherirse al Protocolo. Firmado en Nueva York el 31 de enero de 1967. Entrada en vigor: 4 de octubre de 1967, de conformidad con el artículo VIII. Serie Tratados de Naciones Unidas No 8791, vol. 606, p. 267

${ }^{19}$ Acervo de Schengen - Convenio de aplicación del Acuerdo de Schengen de 14 de junio de 1985 entre los Gobiernos de los Estados de la Unión Económica Benelux, de la República Federal de Alemania y de la República Francesa relativo a la supresión gradual de los controles en las fronteras comunes, 19 de junio de 1990. DO L 239 de 22.9.2000, p. 19/62.

${ }^{20}$ Convenio relativo a la determinación del Estado responsable del examen de las solicitudes de asilo presentadas en los Estados miembros de las Comunidades Europeas - Convenio de Dublín. DO C 254 de 19.8.1997, p. 1/12

${ }^{21}$ Tratado de la Unión Europea (DO C 191 de 29.7.1992, pp. 1-112).
} 
exteriores, asilo, inmigración y de prevención y lucha contra la delincuencia”.

Ya en 1999, con el Tratado de Ámsterdam, ${ }^{22}$ fueron sentadas las bases para el inicio del SECA, unificando las normas mínimas relacionadas con el asilo y dejando a los EEMM la facultad discrecional de establecer procedimientos para obtener y retirar la protección internacional. Se clarificó el fundamento jurídico de este sistema en el art. 63 del Tratado constitutivo de la Comunidad Europea, que estableció la obligación de adoptar, por parte del Consejo y en el plazo de 5 años, una serie de medidas específicas en materia de asilo, refugiados y personas desplazadas acordes con la Convención de Ginebra. Además, se armonizaron las leyes de asilo, incluyéndose los estándares más avanzados de los países del noroeste de Europa en el propio texto legal. Esto implicó que los países del sureste tuvieron que elevar sus propios estándares de protección a los refugiados y una mayor uniformidad de las legislaciones nacionales de asilo. El problema devino en que la mayor parte de los países mostraron escaso interés en convertirse en estados receptores de primera línea puesto que sus sistemas nacionales de asilo seguían siendo, en la práctica, mucho más lentos e ineficientes que los de países más avanzados.

No fue hasta las Conclusiones de Tampere de 1999 cuando, por primera vez, se introdujo la referencia a un "Sistema Europeo Común de Asilo" y como tal, comenzó la primera fase (1999-2004). ${ }^{23}$ Durante los inicios de esta fase, las instituciones supranacionales poseían un papel débil en el proceso de decisión ${ }^{24}$ y el papel del Tribunal de Justicia de la Unión Europea (TJUE) resultaba limitado en relación con las directivas de asilo. Al Convenio de Dublín de 1990 se desarrolló un proceso legislativo llevado a cabo entre 2002 y 2005, que dio lugar a la adopción del "pack legislativo europeo de asilo". Un conjunto de instrumentos jurídicos que, sin perjuicio de ulteriores reformas, se extienden hasta la actualidad. Estos están conformados por cinco

\footnotetext{
22 Tratado de Ámsterdam por el que se modifican el Tratado de la Unión Europea, los Tratados constitutivos de las Comunidades Europeas y determinados actos conexos - Declaraciones relativas al artículo K.7 del Tratado de la Unión Europea modificado por el Tratado de Ámsterdam. DO C 340 de 10.11.1997, p. 308/308

${ }^{23}$ Consejo Europeo de Tampere. Conclusiones de la Presidencia, 15 y 16 de octubre de 1999.

${ }^{24}$ No cabe pasar por alto que el Parlamento Europeo no poseía funciones de colegislador, el Consejo decidía por unanimidad y la Comisión Europea compartía su facultad de iniciar propuestas legislativas junto con los EEMM.
} 
instrumentos principales: tres Directivas Cualificación o Reconocimiento, Acogida y de Procedimiento) ${ }^{25}$ y dos reglamentos (Reglamento Dublín y Eurodac). ${ }^{26}$

La Directiva de Reconocimiento constituye el eje vertebral del SECA, estableciendo ya no solo las normas del reconocimiento de los refugiados y las personas en necesidad de asilo, sino también el contenido de la protección otorgada. Esta primera fase constituyó el eje central de protección del derecho al asilo, ${ }^{27}$ cuyo objetivo no era otro que la armonización de la legislación nacional sobre las "normas mínimas" establecidas por los instrumentos legislativos adoptados (art. 63 del Tratado constitutivo de la Comunidad Europea). Desde entonces, los EEMM están obligados a aplicar estas normas en sus ordenamientos jurídicos nacionales con una matización; no se les impidió adoptar condiciones nacionales más favorables para el beneficiario de la legislación comunitaria, en concreto, si resulta necesario para el cumplimiento de otras

\footnotetext{
${ }^{25}$ Directiva 2011/95/UE del Parlamento Europeo y del Consejo, de 13 de diciembre de 2011, por la que se establecen normas relativas a los requisitos para el reconocimiento de nacionales de terceros países o apátridas como beneficiarios de protección internacional, a un estatuto uniforme para los refugiados o para las personas con derecho a protección subsidiaria y al contenido de la protección concedida. DO L 337, 20.12.2011, p. 9-26; Directiva 2013/33/UE del Parlamento Europeo y del Consejo, de 26 de junio de 2013, por la que se aprueban normas para la acogida de los solicitantes de protección internacional. DO L 180 de 29.6.2013, p. 96/116; Directiva 2013/32/UE del Parlamento Europeo y del Consejo, de 26 de junio de 2013, sobre procedimientos comunes para la concesión o la retirada de la protección internacional, DO L 180, 29.6.2013, p. 60-95.

${ }^{26}$ Reglamento (UE) n ${ }^{\circ}$ 604/2013 del Parlamento Europeo y del Consejo, de 26 de junio de 2013, por el que se establecen los criterios y mecanismos de determinación del Estado miembro responsable del examen de una solicitud de protección internacional presentada en uno de los Estados miembros por un nacional de un tercer país o un apátrida, DO L 180, 29.6.2013, p. 31-59; Reglamento (UE) nº 603/2013 del Parlamento Europeo y del Consejo, de 26 de junio de 2013, relativo a la creación del sistema «Eurodac» para la comparación de las impresiones dactilares para la aplicación efectiva del Reglamento (UE) $n{ }^{\circ} 604 / 2013$, por el que se establecen los criterios y mecanismos de determinación del Estado miembro responsable del examen de una solicitud de protección internacional presentada en uno de los Estados miembros por un nacional de un tercer país o un apátrida, y a las solicitudes de comparación con los datos de Eurodac presentadas por los servicios de seguridad de los Estados miembros y Europol a efectos de cumplimiento de la ley, y por el que se modifica el Reglamento (UE) $n{ }^{\circ} 1077 / 2011$, por el que se crea una Agencia europea para la gestión operativa de sistemas informáticos de gran magnitud en el espacio de libertad, seguridad y justicia, DO L 180, 29.6.2013, p. 1-30.

${ }^{27}$ Al margen de este "pack legislativo europeo de asilo", la primera fase del SECA fue realmente innovadora al prever posibles crisis en los sistemas nacionales de asilo mediante la Directiva de «protección temporal», dictada principalmente para hacer frente a la llegada a gran escala de personas. Véase Directiva 2001/55/CE del Consejo, de 20 de julio de 2001, relativa a las normas mínimas para la concesión de protección temporal en caso de afluencia masiva de personas desplazadas y a medidas de fomento de un esfuerzo equitativo entre los Estados miembros para acoger a dichas personas y asumir las consecuencias de su acogida. DO L 212 de 7.8.2001, p. 12/23. Entró en vigor desde el 7 de agosto de 2001 y antes del 31 de diciembre de 2002, los EEMM debían incorporarla a su Derecho nacional aunque todavía no se ha puesto en funcionamiento.
} 
obligaciones en virtud del derecho internacional. ${ }^{28}$ El Consejo Europeo decidió que la aplicación del SECA debía llevarse a cabo en dos fases: la primera, centrada en la armonización de la legislación interna sobre normas mínimas comunes y la segunda, basada en el examen de la eficacia de los instrumentos jurídicos acordados.

Los cinco instrumentos anteriormente citados y adoptados entre 2002 y 2005 fueron sometidos a una amplia evaluación y modificación con el Programa de La Haya de noviembre de 2004. ${ }^{29}$ Este Programa exigió la aprobación - antes de finales de 2010- de los instrumentos y las medidas de la segunda fase, quedando así de relieve el deseo de la UE de superar las normas mínimas e instaurar un procedimiento de asilo único que implicara garantías comunes y un estatuto uniforme para las personas a las que se concediera protección. El diseño de la primera fase del SECA evidenciaba la necesidad de desarrollo en una segunda fase de desarrollo, con un cambio de énfasis de las normas mínimas a un procedimiento de asilo común sobre la base de un estado de protección uniforme. Esta vino motivada por las disparidades significativas entre los EEMM en la acogida o recepción de los solicitantes, los procedimientos y la evaluación del reconocimiento para la protección internacional. Es decir, incluyendo ya no solo a refugiados sino a individuos que podían necesitar de protección subsidiaria. Aquellos que, conforme a la Directiva 2004/83/CE de Reconocimiento ${ }^{30}$ no reunían la condición de refugiado pero sobre los que podían darse motivos fundados para creer que su regreso a su país de origen o de residencia habitual podría dar lugar a un riesgo de sufrir daños graves.

En consecuencia, esta normativa europea fue objeto de una "reevaluación holística" por parte de la Comisión en 2006 con objeto de llevar a cabo una refundición de los instrumentos legislativos mencionados a la luz del Programa de La Haya. En junio de

\footnotetext{
${ }^{28}$ De hecho, todas las Directivas dictadas en el seno del SECA (reconocimiento, procedimiento y acogida) establecen una considerable flexibilidad para los EEMM, que puedan adoptar o mantener normas más favorables que las previstas siempre que sean compatibles con la presente Directiva. Un margen de apreciación nacional amplio que puso en serio peligro la eficacia de la armonización y el respeto de las obligaciones internacionales.

${ }^{29}$ Comisión Europea, Comunicación de la Comisión al Consejo y al Parlamento Europeo, de 10 de mayo de 2005, «Programa de La Haya: Diez prioridades para los próximos 5 años. Una asociación para la renovación europea en el ámbito de la libertad, la seguridad y la justicia» [COM (2005) 184 final - Diario Oficial C 236 de 24.9.2005].

${ }^{30}$ Directiva 2004/83/CE del Consejo de 29 de abril de 2004 por la que se establecen normas mínimas relativas a los requisitos para el reconocimiento y el estatuto de nacionales de terceros países o apátridas como refugiados o personas que necesitan otro tipo de protección internacional y al contenido de la protección concedida
} 
2007, la Comisión publicó el Libro Verde, en el que se puso de manifiesto las principales debilidades del SECA y se sentaron las bases para redactar su segunda fase. ${ }^{31}$ Como reconoció la Comisión en $2008,{ }^{32}$ las normas mínimas de la primera fase no eran aptas para asegurar el grado deseado de armonización entre los EEMM. Consideró necesario complementar una mayor armonización jurídica con una cooperación práctica efectiva entre las administraciones nacionales de asilo para mejorar la convergencia en la toma de decisiones de asilo por parte de los EEMM. Igualmente, acordó la adopción de medidas para aumentar la solidaridad y la responsabilidad entre EEMM -incluso entre estos con terceros estados-.

Con el Pacto Europeo de Asilo en el seno de la Comisión Europea en septiembre de 2008, esta nueva fase entró en vigor, plazo que requirió su extensión hasta 2012. ${ }^{33}$ Posteriormente, el Programa de Estocolmo de 2009 previó un área común y de solidaridad que sentó las bases para esta nueva fase del SECA. Este Programa supuso una de las innovaciones más destacadas en este ámbito, pasando del mero establecimiento de normas mínimas de la fase anterior hacia "un espacio común de protección y solidaridad basado en un procedimiento común de asilo y en un estatuto uniforme para las personas a las que se concede protección internacional» sobre la base de unas "normas de protección de alto nivel". 34

Ahora bien, la principal innovación hasta la actualidad vino acompasada del Tratado de Lisboa (TL), ${ }^{35}$ que entró en vigor el 1 de diciembre de 2009. Las medidas en materia de asilo pasaron del establecimiento de normas mínimas a la creación de un verdadero

\footnotetext{
${ }^{31}$ El Libro Verde, basado en el Plan de Acción del Programa de La Haya de 2005, destaca por primera vez en uno de los capítulos la ineficacia en el sistema de reparto y solidaridad entre los Estados miembros y establece que "el objetivo de esta segunda fase es conseguir un mayor nivel común de protección y una mayor igualdad en la protección en toda la UE y garantizar un mayor grado de solidaridad entre los Estados miembros de la UE". La Comisión reconoció la necesidad de mejorar todos los aspectos del proceso de asilo, desde el momento en que el individuo busca o solicita formal o materialmente protección en la UE hasta que se encuentra una solución duradera, tratando de colmar todas las lagunas que se daban en la práctica y buscando una mayor armonización mediante la implementación de normas más estrictas (Comisión Europea, Libro Verde sobre el futuro sistema europeo común de asilo, COM (2007) 301 final, 6 junio 2007).

${ }^{32}$ Comisión Europea, Comunicación de la Comisión al Parlamento Europeo, al Consejo, al Comité Económico y Social Europeo y al Comité de las Regiones plan de política de asilo un planteamiento integrado de la protección en toda la UE, 17 de junio de 2008, $\operatorname{COM(2008)~} 360$ final, p. 3.

${ }^{33}$ Consejo de la Unión Europea, Pacto europeo sobre inmigración y asilo, 24 de septiembre de 2008.

${ }^{34}$ Programa de Estocolmo - Una Europa abierta y segura que sirva y proteja al ciudadano [Diario Oficial $\mathrm{n}^{\circ} \mathrm{C} 115$ de 4/5/2010].

${ }^{35}$ Tratado de Lisboa por el que se modifican el Tratado de la Unión Europea y el Tratado constitutivo de la Comunidad Europea (DO C 306 de 17.12.2007)
} 
sistema común con estatutos y procedimientos uniformes. También entró en vigor el Tratado de Funcionamiento de la Unión Europea (TFUE), ${ }^{36}$ que concretó la finalidad y el contenido de la segunda fase. No menos relevante fue que, tras la adopción del TL, la CDFUE (art. 6.1 TUE), se convirtió en una fuente vinculante de Derecho primario. Esto se tradujo en que todos los EEMM deben garantizar el derecho de asilo del art. 18 dentro del respeto de la Convención de Ginebra y a su Protocolo de Nueva York.

El art. 78 TFUE exigió la adopción de "medidas para un sistema europeo común de asilo", en el que se incluye un estatuto uniforme de asilo válido en cada EM, así como procedimientos comunes para las solicitudes de protección internacional recibidas de nacionales de terceros países. Los arts. 67.2 y 80 TFUE también dispusieron directamente el principio de solidaridad o el reparto equitativo de la responsabilidad entre EEMM. ${ }^{37}$

Recordemos, por ejemplo, que a finales de ese mismo año, entró en vigor en el ordenamiento jurídico español la Ley 12/2009 de asilo y Protección Subsidiaria (LAPS), de 30 de octubre, reguladora del derecho de asilo y de la protección subsidiaria. ${ }^{38}$ Esta incluyó estándares más elevados que los previstos en el SECA de la primera fase vigente en aquel momento, tal y como puso de manifiesto García Mahamut. ${ }^{39}$ Muestra de ello lo constituyó, entre otras, la equiparación de la condición de refugiado y de protección subsidiaria, una disposición que se encontraba presente en la propuesta de Directiva de Reconocimiento - de la segunda fase del SECA-. Por su

\footnotetext{
${ }^{36}$ Tratado de Funcionamiento de la Unión Europea (30 de marzo de 2010 (C 83/47).

${ }^{37}$ Se introdujeron mayores facultades en el control judicial del TJUE. El art. 267 TJUE permitió a los órganos jurisdiccionales nacionales la presentación de una cuestión prejudicial con independencia de un recurso judicial de Derecho interno, lo que motivó el desarrollo jurisprudencial más relevante del TJUE en materia de asilo, como iremos abordando en el presente estudio.

${ }^{38}$ Ley $12 / 2009$, de 30 de octubre, reguladora del derecho de asilo y de la protección subsidiaria. «BOE» núm. 263, de 31/10/2009.

${ }^{39}$ De acuerdo con García Mahamut, la LAPS se articuló en cuatro grandes ámbitos: "1. Las que se vinculan al concepto jurídico de protección internacional y a las condiciones para conceder o denegar el derecho de asilo o, en su caso, la protección subsidiaria. 2. Las que podemos vincular a la sustanciación de los procedimientos y que, amén de redundar en una mayor seguridad jurídica, profundizan en el sistema de garantías y dotan de mayor eficacia al procedimiento. 3. Las que inciden en el ámbito de los derechos que se anudan al solicitante de la protección internacional y al beneficiario de la misma. 4. Las que se pueden vincular a la calidad de un sistema de protección internacional comprometido con los derechos fundamentales. GARCÍA MAHAMUT R., "El nuevo régimen jurídico del derecho de asilo y de la protección subsidiaria en España a la luz de la Ley 12/2009, de 30 de octubre: principales novedades y desafíos", en GARCÍA MAHAMUT, R., GALPARSORO, J., VIDAL FUEYO, M., Régimen Jurídico del derecho de asilo en la Ley 12/2009, $1^{\text {a }}$ edición, Centro de Estudios Políticos y Constitucionales, Madrid, 2010, p. 41.
} 
parte, destacable fue la concreción del concepto de grupo social determinado, que comprendió la persecución por una cuestión de género y orientación o identidad sexual, incorporado a los motivos de persecución que pueden determinar la concesión de algún tipo de protección a las personas que albergan temores a sufrir persecución por este motivo.

Seguidamente, el 10 de diciembre de 2009 fue aprobado el Programa de Estocolmo para el periodo 2010-2014, que reafirmó el “objetivo de establecer un espacio común de protección y solidaridad que se base en un procedimiento común de asilo y un estatuto uniforme para las personas a las que se concede protección internacional". Este promovió una verdadera solidaridad con los EEMM sometidos a presiones específicas e hizo especial mención del papel que debía desempeñar la Oficina Europea de Apoyo al Asilo (EASO) - una de las primeras medidas de la Comisión del año 2009 en su intento por crear una organización de carácter permanente para apoyar la cooperación práctica entre los EEMM en el ámbito del asilo- que regula su Reglamento 2010/439. ${ }^{40}$

No obstante, las negociaciones sobre las propuestas del SECA progresaron muy lentamente. Pese a que el Programa de Estocolmo fijaba un plazo inicial hasta 2010 para la conclusión del SECA, no se llevó a cabo y se aplazó hasta 2012. Es más, incluso con esta prórroga, solo la Directiva de Reconocimiento refundida fue aprobada en este año. Las Directivas refundidas sobre Procedimiento y Recepción fueron finalmente adoptadas el 26 de junio de 2013, junto con el Reglamento Dublín III, a pesar de que la segunda versión de las propuestas mencionadas de la Comisión se había remitido al Parlamento Europeo y al Consejo en 2011 en el caso de las dos Directivas y en 2008 en el caso del Reglamento. Por ello, esta segunda fase se caracterizó por la ineficiencia en la refundición de las mencionadas directivas y reglamentos, pues se esperaban concluir inicialmente en 2010 pero que finalmente concluyeron en junio de 2013.

Particularmente, esta reforma superó una serie de destacadas mejoras a luz de la Convención de Ginebra y el Protocolo de Nueva York, estas son:

- la equiparación del estatuto de refugiado y protección subsidiaria;

- la naturaleza no temporal de protección internacional;

\footnotetext{
${ }^{40}$ Reglamento (UE) n 439/2010 del Parlamento Europeo y del Consejo, de 19 de mayo de 2010, por el que se crea una Oficina Europea de Apoyo al Asilo. DO L 132 de 29.5.2010, p. 11/28.
} 
- la inclusión de mejoradas cautelas y salvaguardas en el procedimiento y en las condiciones de acogida -en especial, para solicitantes de protección internacional especialmente vulnerables -;

- así como la reducción de los plazos legales en situaciones de urgencia.

Sin embargo, esta reforma resultó insuficiente para alcanzar los estándares internacionales de los derechos humanos. Como analizaremos más adelante, no todos los EEMM han transpuesto las Directivas de acogida, reconocimiento y procedimiento. Esto ha provocado divergencias en las tasas de Reconocimiento muy pronunciadas, en especial, en los supuestos de exclusión o revocación del estatuto de protección internacional que analizaremos en el próximo capítulo, sin perjuicio de que estas divergencias se hayan extendido a los procedimientos o en las condiciones de acogida.

Por lo tanto, las deficiencias sistemáticas contrarias al propio SECA han seguido acaeciendo. La carencia de instrumentos jurídicos vinculantes motivó un amplio margen de discrecionalidad nacional. Recordemos que son los EEMM los que, en última instancia, toman las decisiones cruciales para garantizar la protección de las personas en necesidad de protección internacional. Estos han adoptado posturas manifiestamente insolidarias que han originado un ineficiente y desigual reparto de responsabilidades. Tampoco han resultado aisladas las deficiencias del Reglamento de Dublín, provocando un aumento de movimientos secundarios. Todas estas consecuencias se agravaron tras las pasadas crisis migratorias y de asilo, donde la aplicación de políticas de seguridad para hacer frente a un problema de incapacidad de ciertos EEMM afectados por grandes afluencias de migrantes y refugiados ha requerido, con urgencia, una profunda reforma de este SECA para garantizar el cumplimiento integral a la luz de las obligaciones internacionales.

\section{Las crisis migratorias y de refugiados. Los problemas relativos a la seguridad en el vigente SECA.}

Uno de los hechos que afectaron a la correcta aplicación del SECA fue la grave crisis migratoria y de refugiados acaecida entre 2014 a 2017, la cual se cobró la vida de miles de nacionales de terceros países en el Mediterráneo tratando de llegar a Europa. Una crisis que fue catalogada como una de las más desalentadoras desde la Segunda Guerra 
Mundial $^{41}$ y que marcó un antes y un después en la Política Europea de Migración y Asilo y en los distintos instrumentos normativos que se activaron para solventar las lagunas y deficiencias del SECA.

Así lo recoge García Mahamut al afirmar que este espacio teóricamente común de protección y solidaridad hizo "aguas cuando las avalanchas migratorias se concentran en determinados Estados no pudiendo responder el sistema nacional a la exigencia ineludible del objetivo que persigue precisamente el SECA". ${ }^{42}$ De manera que comenzó a excepcionarse o legislarse en función de tales situaciones en defecto de normativa europea expresa que respondiese con efectividad y eficiencia a tales circunstancias.

A pesar de la reforma en el 2013 del Sistema de Dublín -compuesta por el Reglamento de Dublín y Eurodac-, este mostró un alto grado de ineficiencia para hacer frente a situaciones en las que los sistemas nacionales de asilo se enfrentaban a una presión desproporcionada. La emergencia humanitaria que experimentaron principalmente, Italia y Grecia implicó que estos asumieran una llegada desproporcional de nacionales de terceros países en sus sistemas nacionales de asilo. Precisamente, la situación de guerra de países como Siria, Irak, Afganistán o Pakistán motivó que millones de personas con manifiesta necesidad de protección internacional (refugio o protección subsidiaria) salieran de sus países de origen con destino a prósperos países de Europa. En su camino, muchos de ellos fueron identificados por traficantes sin escrúpulos capaces de proporcionar la asistencia y medios necesarios para llegar a estos países. $^{43}$

Inevitablemente, las entradas descontroladas y a gran escala de nacionales de terceros países a territorio de un EM con fronteras exteriores comprometió las garantías del SECA. Su ineficiencia e ineficacia en su aplicación derivó, con demasiada

\footnotetext{
${ }^{41}$ Esta magnitud inédita de las crisis de refugiados ha sido analizada, entre otros, por: GONZÁLEZ VEGA, J., Mitos y mistificaciones: la Unión Europea y la protección internacional (a propósito de la crisis de los refugiados). Revista de Derecho Comunitario Europeo, $\mathrm{n}^{\circ}$ 56, 2017, pp. 27-75; PUIG DE LA BELlACASA, R., “Europa ante sí misma”, Claves de Razón Práctica, nº 244, 2016, pp. 9-19.

${ }^{42}$ GARCÍA MAHAMUT, R., "La ductilidad del derecho a la protección internacional... ob. cit., p. 233.

${ }^{43}$ La identificación de estas organizaciones y de las víctimas de trata está siendo una de las apuestas más destacadas a nivel nacional y comunitario y cuyos esfuerzos se están centrando en distintos ámbitos, incluyendo tanto los "puntos calientes" de las fronteras exteriores de la UE, su llegada a territorio nacional e, incluso, en terceros países. Sobre el particular, remitimos a: Parlamento Europeo, Detecting and protecting victims of trafficking in hotspots. Ex-post evaluation, julio de 2019 (PE 631.757); Identification of TRafficked Asylum seeKers' Special Needs (TRACKS), Identification and response to the needs of Trafficked Asylum Seekers. A Comparative Report for the Republic of Cyprus, France, Ireland, Italy, Spain, The Uk and Switzerland, enero de 2018 (HOME/2014/AMIF/AG/ASYL/7849).
} 
frecuencia, en un problema para la seguridad de los Estados. A la incapacidad de asumir altísimos números de solicitudes de protección internacional en puntos fronterizos concretos, se le adicionó la imposibilidad de actuar con celeridad para diferenciar exhaustivamente entre quienes se encontraban en necesidad de protección internacional frente a diferentes categorías de nacionales de terceros países que podían constituir una amenaza para la seguridad nacional. Y aún siendo conscientes de que, efectivamente, se han producido situaciones en las que la seguridad de los Estados se ha visto altamente comprometida, esta "incapacidad" ha ido en serio detrimento del objeto principal de esta segunda fase del SECA. ${ }^{44}$ Además, ha cuestionado los valores intrínsecos de la identidad europea previstos en el art. 2 TUE, generando una intolerable aparente situación de normalidad a la falta de apoyo uniforme por parte de los EEMM. Las generalizadas políticas de seguridad que fueron aplicadas en sede nacional aproximaron la relación entre asilo y terrorismo, las cuales no resultaron en modo alguno novedosas. Como recoge el famoso estudio elaborado por Zaun, ${ }^{45}$ estas preocupaciones llevan abordándose desde hace más de dos décadas y se extienden hasta nuestros días.

El incumplimiento por parte de algunos EEMM de la normativa comunitaria fue manifiesto. Por un lado, estos no actuaron con la suficiente responsabilidad, diligencia y celeridad en la reubicación y reasentamiento a las personas en necesidad de protección internacional en el número correspondiente y en el plazo establecido por las distintas Decisiones jurídicamente vinculantes adoptadas en la UE. Por otro, los procedimientos se volvieron laxos, lo cual se agravó hasta su máximo exponente con el cierre de sus fronteras interiores que analizamos en el siguiente capítulo. Esto evidenció que la competencia nacional en materia de defensa de la seguridad nacional fuera esgrimida por muchos de los estados "como la clave de bóveda para eludir el incumplimiento de la normativa comunitaria en materia del SECA". 46 Normativa que, salvo el Reglamento de Dublín, ha sido provista de diversas excepciones a su "uniforme" aplicación por cuestiones radicadas en su seguridad y, sobre las cuales, conviene detenernos.

En este sentido, debe destacarse que, en relación con el funcionamiento del Sistema de Dactiloscopia Europea (Eurodac), esta vertiente se ha previsto desde un enfoque

\footnotetext{
${ }^{44}$ Este ha consistido en el cumplimiento de las garantías del ejercicio de los derechos que lleva aparejada la solicitud y, en su caso, el posterior reconocimiento a la protección internacional en la UE.

${ }^{45}$ ZAUN, N., "States as Gatekeepers in EU Asylum Politics: Explaining the Non-adoption of a Refugee Quota System", Journal of Common Market Studies, vol. 56, nº 1, 2018, pp. 44-62.

${ }^{46}$ GARCÍA MAHAMUT, R., VIGURI CORDERO, J., "La protección de los datos personales de los solicitantes..., ob. cit., p. 238.
} 
meramente técnico, esto es, abordando la seguridad de los datos (considerandos 27, 43 o art. 4.1) mientras que la totalidad de las directivas que conforman el SECA han dispuesto de diversas excepciones radicadas en seguridad con objeto de garantizar la salvaguardia de la seguridad de los estados. Asimismo, la Directiva de Reconocimiento 2011/95/UE dispone en el Considerando 37 la aplicación del concepto de seguridad nacional y de orden público a nacionales de terceros país pertenecientes a una asociación que apoya o respalda el terrorismo internacional. Además, esta Directiva articula un conjunto de excepciones por este motivo en diversos ámbitos como el régimen de exclusión (arts. 12 y 17.1 d), la revocación del estatuto (art. 14.4 a)), la expulsión (art. 21.2 a)) incluso estableciendo excepciones -de dudosa legalidad- en el ámbito del mantenimiento de la unidad familiar (art. 23.4), en la expedición de permisos de residencia (art. 24) o documentos de viaje (art. 25).

A tal efecto, conviene poner de manifiesto que en los derechos establecidos en la Carta Social Europea (revisada), resultan aplicables a las personas refugiadas de conformidad con el segundo párrafo de su Anexo. ${ }^{47}$ El apartado g) prevé únicamente restricciones a los derechos y principios enunciados en la Parte I "para proteger el orden público, la seguridad nacional, la salud pública (...)”, por lo que dispone de un principio de trato más favorable que el previsto en el art. 23.4 de la Directiva de Reconocimiento, la cual contempla la denegación -también la reducción o retirada- de las prestaciones relacionadas con el mantenimiento de la unidad familiar por tales motivos. Además, este "principio de trato más favorable posible" reconocido en el Anexo resulta aplicable a los refugiados y a los solicitantes de protección internacional que se encuentren en territorio europeo pues, como apunta Jimena Quesada, el Comité Europeo de Derechos Sociales (CEDS) entiende aplicable las disposiciones de la Carta Social Europea. Y teniendo en cuenta que, estos sujetos pueden sufrir una doble o triple vulnerabilidad

\footnotetext{
${ }^{47}$ El párrafo $2^{\circ}$ del Anexo de la Carta Social Europea. (Revisada). Firmada en Estrasburgo el 3 de mayo de 1996 dispone que: "cada Parte concederá a los refugiados que respondan a la definición de la Convención de Ginebra, de 28 de julio de 1951, relativa al Estatuto de los Refugiados, y que residan legalmente en su territorio, el trato más favorable posible y, en cualquier caso, no menos favorable que el que dicha Parte se haya obligado a aplicar en virtud de la Convención de 1951 y de cualesquiera otros acuerdos internacionales vigentes aplicables a esos refugiados". Por lo que respecta a España, aunque todavía no la ha ratificado, el 1 de febrero de 2019, el Consejo de Ministros aprobó un Acuerdo por el que se disponía la remisión a las Cortes Generales de la Carta Social Europea revisada y se autorizaba la manifestación del consentimiento de España para obligarse por dicha carta. https://www.lamoncloa.gob.es/consejodeministros/Paginas/enlaces/010219-enlacecartasocial.aspx [Consulta: 30 de junio de 2019]
} 
como es el caso de los menores o mujeres embarazadas, ${ }^{48}$ supuesto que Díaz Lafuente extiende por analogía, a toda clase de refugiados como aquellos perseguidos por motivos de orientación sexual e identidad de género. ${ }^{49}$

También la Directiva de Acogida 2013/33/UE regula un régimen de excepcionalidad por cuestiones que afectan a la seguridad de los EEMM - este es el caso del internamiento (art. 8.3 e)), las limitaciones de acceso de familiares, los asesores jurídicos o consejeros o las personas representantes de organizaciones no gubernamentales competentes (art. 10.4)- finalizando con la Directiva de procedimiento 2013/32/UE, que supedita la aplicación al mantenimiento del orden público y salvaguardia de la seguridad interior (Considerando 51). Inexcusablemente, dispone de la adopción del procedimiento acelerado en caso de que el sujeto pueda considerarse un potencial delincuente o terrorista (Considerando 20 y art. 31.8 j)) así como limitaciones de acceso a la información y asesoramiento en centros de internamiento y en puestos fronterizos (art. 8.2), excepciones en el registro de los solicitantes (art. $13.2 \mathrm{~d}$ )) o en el alcance de la asistencia jurídica y de la representación legal (art. 23.1).

En este punto, lo que debe criticarse con contundencia no es la previsión de medidas de seguridad en el SECA, las cuales pueden llegar a obstaculizar el objetivo de garantizar su armonización y coherencia, sino la asiduidad con la que algunos EEMM han contemplado este régimen de excepción. Este parece haber emplazado la dimensión de la seguridad - orden público, seguridad interior y nacional- hacia cuestiones centrales que nada tienen que ver con su aplicación restringida que dispone el art. 4.2 TUE. De esta manera, la normativa del SECA ha concedido excesiva flexibilidad a los EEMM para abordar aspectos que penden directamente de su soberanía, careciendo de respuestas eficaces en la necesaria ponderación entre la protección del derecho de asilo y protección subsidiaria y las cuestiones ligadas a la seguridad. Ello, pese a que Serra Cristóbal haya argumentado que la seguridad no crea una cláusula de reserva

\footnotetext{
${ }^{48}$ JIMENA QUESADA, L., "The Protection of Forcibly Displaced Persons under the European Social Charter", in Joint UNHCR/Council of Europe Colloquium on the Role of the Regional Human Rights Courts in Interpreteing and Enforcing Legal Standards for the Protection of Forcibly Displaced Persons. Conference Report, Strasbourg, Council of Europe, 2011, p. 116.

${ }^{49}$ DÍAZ LAFUENTE, J., Asilo y refugio por motivos de orientación sexual e identidad de género, Madrid, Congreso de los Diputados, 2016, p. 218.
} 
competencial exclusiva para los EEMM aunque, en última instancia, concierne a cada estado la responsabilidad de asegurarla. ${ }^{50}$

La supremacía de las actuaciones estatales por garantizar su propia seguridad nacional ha provocado una excesiva flexibilización de las disposiciones que regula el SECA, generando un elevado riesgo de vulnerar la protección que merecen sujetos como los refugiados. Es más, la doctrina española no se ha mantido al margen de este conflicto.

Como apunta De Vergottini, la predisposición y el papel dominante de la seguridad tiende a ser protegido de un modo riguroso en detrimento de la libertad. ${ }^{51} \mathrm{Su}$ reflejo, hoy día, puede apreciarse en las diferentes legislaciones nacionales de asilo. Estas parecen diseñarse bajo un prisma restrictivo; abordando los factores que ponen en serio riesgo su seguridad; sorteando y evitando la tramitación de solicitudes de protección internacional y por ende, reduciendo el despliegue de medios administrativos y económicos comúnmente limitados en sede nacional. Ello, aunque el SECA persiga precisamente una "plena convergencia entre los sistemas nacionales de asilo" y el establecimiento de un sistema cada vez más perfeccionado que permita disminuir los movimientos secundarios, la lucha contra los abusos, así como brindar una mayor asistencia a aquellos EEMM afectados por la presión migratoria.

De este modo, resulta indudable que el actual SECA reconoce el derecho de los distintos estados a administrar de manera responsable los flujos migratorios y de asilo dentro de sus fronteras -mediante el diseño de salvaguardas contra el abuso de esta institución y la protección de cualquier hecho que ponga en riesgo su propia seguridad-. Este se ha visto supeditado a todo un marco jurídico nacional que, a juicio de un sector de la doctrina, ha obstaculizado y dificultado gravemente la consecución de los objetivos del SECA. ${ }^{52}$ De esta manera, las competencias de la UE en materia de control de fronteras, asilo e inmigración se encuentran sumamente "mediatizadas" por la finalidad de salvaguardar la seguridad, tal y como apunta Porras Ramírez ${ }^{53}$, cuya

\footnotetext{
${ }^{50}$ SERRA CRISTÓBAL R., "El control de datos de circulación de personas en la UE como mecanismo de salvaguarda de la seguridad nacional", Revista de derecho politico, $\mathrm{n}^{\circ} .102,2018, \mathrm{p} .311$.

${ }^{51}$ De VERGOTTINI G., "La difícil convivencia entre libertad y seguridad. Respuestas de las democracias al terrorismo", Revista de Derecho Político, n 61, 2004, p. 35.

${ }^{52}$ GARCÍA MAHAMUT, R., "La ductilidad del derecho a la protección internacional..., ob. cit., p. 234.

${ }^{53}$ PORRAS RAMÍREZ, J. M., "El sistema europeo común de asilo y la crisis de los refugiados. Un nuevo desafío de la globalización", Revista de Estudios Políticos, nº 175, 2017, p. 211.
} 
traslación en el SECA resulta manifiesta, ante las reiteradas actuaciones nacionales opuestas a sus fines y objetivos.

Entre otras consecuencias, se hizo patente abordar aquellos aspectos que dificultaban la eficiencia y eficacia del SECA en situaciones ordinarias y extraordinarios y que aproximaban las cuestiones de seguridad en este ámbito. En abril de 2015, la Agenda Europea de Seguridad instó al establecimiento de estrictas normas comunes de gestión de las fronteras como instrumentos fundamentales para prevenir la delincuencia y el terrorismo transfronterizo. ${ }^{54}$ Un año más tarde, en abril de 2016, la Comisión propuso la reforma integral del actual SECA. ${ }^{55} \mathrm{Su}$ hoja de ruta para la renovación de las bases legales del SECA se efectuó en dos fases. En mayo de 2016, presentó un primer "paquete" de propuestas para reformar tres de los componentes de SECA -Dublín, Eurodac y la EASO- y, en julio de ese mismo año, un segundo tendente a transformar las directivas de Reconocimiento y Procedimientos en reglamentos, así como una revisión integral de la Directiva de Acogida.

Una propuesta que pretendió proporcionar luces y solventar los tan desventajosos efectos que resultaban contrarios a la propia Convención de Ginebra y que se agravaron ante dos hechos claves: las restricciones en las fronteras de diversos estados y el repunte de los ataques terroristas que afectaron a diversos EEMM como Francia, Alemania o España. Escenarios que fomentaron que las cuestiones de lucha contra el terrorismo encabezaran la agenda política tanto a nivel nacional como comunitario. Además, en junio de 2016, con la Estrategia Global para la Política Exterior y de Seguridad de la UE en el Consejo Europeo, ${ }^{56}$ se reforzó la gestión integrada de fronteras en la lucha contra

\footnotetext{
${ }^{54}$ Comisión Europea, Comunicación al Parlamento Europeo, al Consejo, al Comité Económico y Social Europeo y al Comité de las Regiones, Agenda Europea de Seguridad. 28 de abril de 2015. COM(2015) 185 final.

${ }^{55}$ Comisión Europea, Comunicación de la Comisión al Parlamento Europeo y al Consejo «Hacia una reforma del Sistema Europeo Común de Asilo y una mejora de las vías legales a Europa», 6 de abril de 2016. COM(2016) 197 final. Para un análisis sobre esta propuesta remitimos a: JAKULEVIČIENĖ L., "The Common European Asylum System", en: DE BRUYCKER P., DE SOMER M., DE BROUWER J. (eds.), From Tampere 20 to Tampere 2.0: Towards a new European consensus on migration, European Policy Centre, diciembre de 2019, p. 87-103. MARTÍNEZ ALARCÓN M.L., La politica Europea de Protección Internacional. Sistema Europeo Común de Asilo, Thomson Reuters Aranzadi, $1^{\mathrm{a}}$ edición, 2018, p. 231 y ss.

${ }^{56}$ La mencionada Estrategia, sustituyó a la primera Estrategia Europea de Seguridad (EES) del año 2003, que se ocupó de la dimensión exterior de la seguridad de Europa. (Estrategia Europea de Seguridad, Una Europa Segura en un mundo mejor, Bruselas, 12 de diciembre de 2003, p. 8). Esta Estrategia fue completada con la adopción de la Estrategia de Seguridad Interior en febrero de 2010, aprobada por el Consejo Europeo de los días 25 y 26 de marzo de ese año, que tipificaba la seguridad, libertad y justicia
} 
el terrorismo y la protección de los solicitantes de protección internacional. Esta carecía no únicamente de concreción en el difuso y amplio concepto de solidaridad, sino que tampoco facilitaba medidas claras en la determinación de los parámetros de seguridad en el ámbito de la protección internacional.

Ahora bien, el alcance de la mencionada propuesta de reforma del SECA no implicó -al menos teóricamente- un nexo directo entre seguridad y asilo. Pretendía focalizarse en la gestión integrada de fronteras, mecanismo nuclear para el mantenimiento de la seguridad en la UE. Pese a todo, no fue hasta 2017 cuando se produjeron acentuados progresos en la disolución entre esta vinculación. Primeramente, el grupo de seguridad interno en el Consejo Europeo subrayó que la llegada de migrantes ilegales constituía el principal problema para garantizar la seguridad de la UE. ${ }^{57}$

Seguidamente, la Agenda Europea de Migración, adoptada el 27 de septiembre de ese mismo año, ${ }^{58}$ hizo un primer balance de los principales logros y déficits en su aplicación. En ella se alejaron los problemas de seguridad de las cuestiones que afectaban a la tramitación y concesión de estatuto de protección internacional, salvo las acciones pertinentes sobre las que debían otorgarse preeminencia para lograr una política europea de asilo y migración más eficiente, justa y estable.

Esta iniciativa política se construyó en torno a cuatro pilares transversales:

a) la reducción de los incentivos de la migración irregular;

b) gestión de las fronteras;

c) una mayor armonización del SECA y,

d) una nueva política de migración legal.

De todos modos, pese a la adopción de todas estas iniciativas, las garantías del SECA se ven en la actualidad reducidas por cuestiones de seguridad en las que la apreciación

como políticas que se reforzaban mutuamente, respetando los derechos fundamentales, la protección internacional, el Estado de derecho y la intimidad. (Consejo Europeo, Estrategia de Seguridad Interior de la Unión Europea. Hacia un modelo europeo de seguridad, Doc. 5842/2/2010, marzo de 2010, p. 19).

Sobre esta última Estrategia, véase: Servicio Europeo de Acción Exterior, Una visión común, una actuación conjunta: una Europa más fuerte, Estrategia global para la política exterior y de seguridad de la Unión Europea, 28 y 29 de junio de 2016.

${ }^{57}$ EUObserver, "El contrabando de migrantes encabeza las prioridades delictivas de la UE", 10 de octubre de 2017.

${ }^{58}$ Comisión Europea, Comunicación de la Comisión al Parlamento Europeo, al Consejo, al Comité Económico y Social europeo y al Comité de las Regiones «relativa al cumplimiento de la Agenda Europea de Migración», COM(2017) 558 final, de 27 de septiembre de 2017. 
nacional que vincula la concesión de este estatuto a una mayor tasa de criminalidad. Un supuesto que ha generado un profundo factor desestabilizador ${ }^{59}$ en los EEMM y que ha aproximado -aun más, si cabe- la relación entre asilo y terrorismo. Y a pesar de que el último informe de Europol (2019) constate que no hay evidencia alguna de que en los últimos tiempos, los terroristas usen sistemáticamente los flujos de refugiados para ingresar en Europa sin ser detectados. ${ }^{60}$

Tanto es así, que las excepciones nacionales continúan desvirtuando el "mínimo denominador común" del SECA, prologando efectos devastadores en un marco jurídico considerablemente fragmentado que cuestiona seriamente su coherencia con las obligaciones europeas e internacionales. Más concretamente, las estrategias de seguridad y defensa nacional reflejan una patente falta de consenso entre los EEMM y un fuerte intergubernamentalismo sobre los asuntos de seguridad, uno de los campos clave donde los EEMM conservan su soberanía y donde tienden a la imposición de sus propios estándares de protección interna en detrimento de las garantías previstas por la normativa europea. Una acción que gradualmente ha sido óbice para el desarrollo coherente de una estrategia europea común eficaz para afrontar las distintas situaciones convulsas que comprometen una dimensión de seguridad nacional cada vez más europeizada. Muestra de ello puede observarse en los documentos nacionales de defensa de los distintos EEMM, los cuales han abordado los problemas relativos a migración y asilo desde distintas perspectivas.

A modo de ejemplo, Bélgica ${ }^{61}$ hace referencia a la inexorable necesidad de cooperación con los países del sur del Mediterráneo e, incluso, con terceros países en la búsqueda de soluciones a la migración irregular y a los flujos exacerbados de

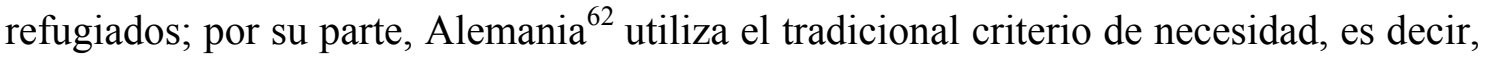

\footnotetext{
${ }^{59}$ Término acuñado por Huysmans en: HUYSMANS, J., The Politics of Insecurity: Fear, Migration and Asylum in the EU (New International Relations Series, Routledge), 2006, p. 83.

${ }^{60}$ Este Informe rectifica el estudio que fue efectuado por este organismo europeo en el año 2016 y que apuntaba a que algunos terroristas habían ingresado en la UE haciéndose pasar por refugiados, como puedo apreciarse en los ataques de París del 2015. Europol, European Union Terrorism Situation and Trend Report (TE-SAT), La Haya, 2019, p. 77; Europol, Changes in modus operandi of Islamic State (IS) revisited, 2016, p. 9.

${ }^{61}$ Ministerio de Defensa, La vision stratégique pour la Défense, 26 de junio de 2016, Bélgica. Disponible en: https://www.mil.be/sites/mil.be/files/pdf/strategic-vision-belgian-defense-fr.pdf [Consulta: 23 de junio de 2019].

${ }^{62}$ Ministerio de Alemania, Libro Blanco sobre la política de seguridad alemana y el futuro de la Bundeswehr, 19 de septiembre de 2016. Disponible en: http://www.gmfus.org/publications/white-papergerman-security-policy-and-future-bundeswehr [Consulta: 6 de mayo de 2019]
} 
destaca la relevancia de una inmigración de personas cualificadas para solventar el envejecimiento demográfico de este país, situando la migración irregular en un módulo autónomo de los retos para la política de seguridad alemana. Por el contrario, Italia ${ }^{63}$ aborda las repercusiones de los flujos masivos de migrantes en sus fronteras disponiendo la necesidad de reforzar la cooperación con la UE para asegurar la seguridad de la región euromediterránea, una de las rutas por antonomasia que ha empleado la inmigración ilegal proveniente del Cuerno de África y del Sahel.

De igual forma, la Estrategia de España del año $2013^{64}$ definía los flujos migratorios irregulares "como uno de los principales riesgos y amenazas que afectan a la seguridad nacional”, apuntando a la necesidad de una regulación de prevención, control y gestión eficaz de los flujos migratorios a través de las fronteras exteriores de la UE para garantizar una gestión eficiente de los flujos migratorios. En cambio, la sucesora Estrategia del año 2017 alude a "la mejora de los canales de migración legal, la protección de los migrantes, la lucha contra la explotación y el tráfico de personas y la cooperación en materia de retorno y readmisión (...) así como la protección asistencial a los refugiados y solicitantes de asilo". ${ }^{65}$ De todas formas, Grecia, ${ }^{66}$ por su posición extremadamente expuesta a las olas intensas de inmigrantes y refugiados, articuló una postura concluyente. Contemplaba la migración y el asilo como uno los problemas básicos que afectaban a su seguridad, declarando que su especial posición geográfica la hacía especialmente vulnerable al terrorismo internacional, al crimen organizado y a una notoria incapacidad de gestionar los flujos de migrantes ilegales o solicitantes de asilo. Unas circunstancias que, junto a las distorsiones provocadas por la política de inmigración de la UE, plantearon un gran desafío para la seguridad nacional y europea.

En definitiva, la crisis y emergencia humanitaria que experimentó la UE requirió tomar acciones inmediatas -incluidas la normativa de urgencia de carácter provisional en su respuesta tardía a la crisis por parte de la UE-, la revisión de las políticas públicas

\footnotetext{
${ }^{63}$ Ministerio de Defensa de Italia, Libro Blanco para la Seguridad Internacional y la Defensa, 30 de abril de 2015. Disponible en: https://www.difesa.it/Content/Pagine/Libro_Bianco.aspx [Consulta: 9 de mayo de 2019]

${ }^{64}$ Ministerio de Defensa de España, Estrategia de Seguridad Nacional, 31 de mayo de 2013. Disponible en:https://www.lamoncloa.gob.es/consejodeministros/Paginas/enlaces/310513Enlace\%20\%20seguridad.a spx [Consulta: 9 de mayo de 2019]

${ }^{65}$ Presidencia de Gobierno, Estrategia de Seguridad Nacional, 2017, p. 26. Disponible en: https://www.dsn.gob.es/es/estrategias-publicaciones/estrategias/estrategia-seguridad-nacional-2017

${ }^{66}$ Ministerio de Defensa Nacional de Grecia. Libro Blanco sobre Defensa, 2014. Disponible en: http://www.mod.mil.gr/mod/en/content/show/0/A70728 [Consulta: 5 de febrero de 2019]
} 
(incluidas las de seguridad) y toda una agenda de modificaciones legislativas. Por tal razón, la futura tercera fase del SECA no supondrá un mero desarrollo o perfeccionamiento de la actual, sino que reconceptualizará todos y cada uno de sus instrumentos normativos, dotándolos de la capacidad suficiente para su aplicación eficaz en multitud de escenarios críticos.

En este punto, la presente tesis doctoral parte de estas crisis de colosales dimensiones en la que fueron adoptadas medidas nacionales de excepción centradas en la protección de su seguridad nacional. Máxime cuando estas condicionaron la entrada de nacionales de terceros países y tuvo un impacto adverso en la protección efectiva de refugiados que pretendían entrar en territorio de la UE desde sus fronteras exteriores. Como examinaremos a continuación, la prevención de las crisis en los sistemas nacionales de asilo supone uno de los aspectos claves que requerirá de oportunas mejoras en el futuro SECA. Para tal fin, como abordaremos en el siguiente capítulo, la convergencia en la toma de decisiones, la gestión y disponibilidad de la información, la asistencia y cooperación de organismos y agencias europeas y la financiación a EM afectados por constituyen elementos esenciales para evitar o reducir estas dificultades en sede nacional.

\section{La seguridad y el derecho a la protección de datos en la (futura) tercera fase del SECA.}

Como se ha visto anteriormente, la falta de estándares uniformes en el actual SECA y la falta de una coordinación eficaz entre los EEMM han evidenciado enfoques divergentes tanto en su dimensión subjetiva como en su conexión con diversos aspectos de la seguridad del estado que han obstaculizado la efectividad del SECA. Esto motivó que en el 2016, la Comisión propusiera una propuesta de reforma integral. Sin embargo, esta contravino sus planes, que preveían un acuerdo político sobre la reforma general del SECA en junio de 2018, cuyo plazo resultó ambicioso y poco realista, en especial, en lo que atañe al Reglamento Dublín III, objeto de numerosos debates entre los EEMM. De hecho, el último informe de progreso del Consejo sobre los siete instrumentos legislativos que conforman la propuesta muestra escasos avances en este ámbito. ${ }^{67}$

\footnotetext{
${ }^{67}$ En relación con la propuesta de Reglamento de Procedimientos, el Consejo debe todavía negociarla con el Parlamento Europeo. Por lo que respecta a la reforma del Reglamento de Dublín, el Consejo aún no ha
} 
Esta propuesta tampoco parece restringir el margen de apreciación nacional, previendo idénticas excepciones que en las actuales Directivas. ${ }^{68}$ Por un lado, pretende ampliar el propio concepto de seguridad nacional y de orden público, en plena sintonía con las Resoluciones de Naciones Unidas. Y, más concretamente, en dos supuestos que regula la propuesta de Reglamento de Reconocimiento:

- en el caso de que un nacional de un tercer país pertenezca a una asociación que meramente "apoya" o "respalda" el terrorismo internacional (Considerando 45) y,

- en relación con la exclusión del estatuto de protección internacional, incluye la comisión de actos terroristas, focalizados por su violencia hacia la población civil, incluso si se persigue un supuesto objetivo político (art. $12.5 \mathrm{~b}$ )).

Asimismo, a pesar de que esta propuesta de reforma del SECA ha sido criticada por no incorporar mayores aspectos de seguridad que recoge el presente SECA, ${ }^{69}$ reviste un innegable valor jurídico para acometer, al menos teóricamente, las cuestiones relacionadas con la seguridad de los EEMM. Insta a respetar plenamente el derecho interno, europeo e internacional en diversos ámbitos, incluyendo respuestas contundentes en la gestión de la migración y el asilo y la lucha contra el terrorismo, elevando sustancialmente sus garantías hacia una genuina seguridad europea común.

aprobado un mandato de negociación con el Parlamento Europeo, pese a que este último, ya ha adoptado su posición. Consejo de la UE, Reforma del Sistema Europeo Común de Asilo y Reasentamiento. Informe de progreso 6600/19, 26 de febrero 2019. http://data.consilium.europa.eu/doc/document/ST6600-2019-INIT/ES/pdf

${ }^{68}$ La propuesta de Directiva de Acogida prevé limitaciones en el internamiento (art. 8.3f)), la propuesta de Reglamento de procedimiento establece la restricción de acceso a la información (art. 16.2), el examen mediante procedimiento acelerado (art. $40.1 \mathrm{f}$ ) y 40.5 b)) y el procedimiento fronterizo (art. 41.5 b)), ambos por razones de seguridad nacional. Por lo que respecta a la propuesta de Reglamento de Reconocimiento, no solo se mantienen las idénticas excepciones en el ámbito de la seguridad nacional sobre las cuestiones del mantenimiento de la unidad familiar (art. 25.4), permisos de residencia (art. 26.2 c)) o documentos de viaje (art. 27.3).

Véase: Comisión Europea, Propuesta de Directiva del Parlamento Europeo y del Consejo por la que se aprueban normas para la acogida de los solicitantes de protección internacional (texto refundido), $\operatorname{COM}(2016) 465$ final; Propuesta de Reglamento (...) por el que se establecen normas relativas a los requisitos para el reconocimiento de nacionales de terceros países o apátridas como beneficiarios de protección internacional, a un estatuto uniforme para los refugiados o para las personas con derecho a protección subsidiaria y al contenido de la protección concedida y por el que se modifica la Directiva 2003/109/CE del Consejo, de 25 de noviembre de 2003, relativa al estatuto de los nacionales de terceros países residentes de larga duración, $\operatorname{COM}(2016) 466$ final; Propuesta de Reglamento (...) por el que se establece un procedimiento común en materia de protección internacional en la Unión y se deroga la Directiva 2013/32/UE.

${ }^{69}$ LÉONARD, S., KAUNERT, C., "The development of the Common European Asylum System (CEAS). The absence of securituzation in the EU asylum policy venue", en: Refugees, Security and the European Union, Roudledge, UACES Contemporary European Studies, 2019, p. 95 
Esta propuesta del SECA tomará buen ejemplo de las estructurales carencias que posee la legislación actual, trasladando los problemas competenciales relativos a la seguridad y orden público desde el seno de los EEMM hacia la UE. Las cuestiones relativas a seguridad prevén abordarse "por defecto" mediante un gradual incremento de la efectividad de estas disposiciones y una mayor armonización. Esta reforma perfeccionará la actuación de los organismos asistenciales en fronteras exteriores sin restringir en exceso el margen de apreciación nacional. Ahora bien, pese a estas rotundas mejoras, como examinamos en los sucesivos capítulos, renacen toda una amalgama de desafíos que podrían en un futuro a corto o medio plazo comprometer la eficacia y eficiencia del SECA. Concretamente, se transparentan dos que, en el ámbito del derecho a la protección internacional, comenzaron a demandar hace ya algún tiempo atención por parte de la doctrina y son, precisamente, los que afectan a la incidencia de la seguridad nacional en este marco europeo y al tratamiento de los datos personales.

$\mathrm{Y}$ en un intento por destacar cuales son las principales novedades que incluye la propuesta de reforma del SECA, podemos aducir que esta pretende pivotarse sobre tres aspectos fundamentales que merecen detallarse:

1. La transformación jurídica de las Directivas de procedimiento y reconocimiento exceptuando de la propuesta de Directiva de Acogida- en reglamentos comunitarios. Esta modificación pretende reducir las graves y persistentes deficiencias en la armonización de los procedimientos de asilo, así como de las condiciones de Reconocimiento con sustanciales beneficios para este Sistema.

Por un lado, el mayor compromiso político por la convergencia en la toma de decisiones soslayará las grandes diferencias en las tasas de reconocimiento y el tratamiento de los solicitantes de asilo durante la evaluación de su solicitud. Recordemos que estas disparidades nacionales motivaron el incremento de los movimientos secundarios y el asylum shopping. Un fenómeno por el que, con cierta asiduidad, los nacionales de terceros países han buscado solicitar protección internacional en aquellos estados prósperos, con tasas más altas de reconocimiento y con mejores condiciones de acogida, en comparación con aquellos estados frecuentemente sobrecargados "de entrada" como Italia o Grecia. ${ }^{70}$

\footnotetext{
${ }^{70}$ ANGELONI, S., SPANO, F.M., Asylum Seekers in Europe: Issues and Solutions, Journal of International Migration and Integration, vol. 19, $\mathrm{n}^{\mathrm{o}}$ 2, mayo de 2018, p. 478; KAUNERT, C., LÉONARD, S., "The development of the EU asylum policy: venue-shopping in perspective", Journal of
} 
Por otro lado, aumentará considerablemente la eficiencia en la identificación y prevención de brechas en la seguridad de los estados mediante el diseño de un novedoso "esquema complementario" entre las necesidades europeas/nacionales y las de los propios solicitantes. ${ }^{71}$ Esto permitirá una interrelación optimizada entre ambos extremos, propiciando la emergencia de un marco jurídico integrado en el que se adecuarán las preocupaciones de seguridad nacional al efectivo cumplimiento de las disposiciones de la normativa reguladora del SECA.

Y en relación con estos instrumentos del SECA, en el próximo Capítulo nos centraremos en el exámen las cláusulas de exclusión y revocación que regula la actual Directiva de Reconocimiento y su propuesta de Reglamento. Dos causas que entran en directo conflicto con la seguridad de los EEMM con sustanciales direrencias no solo entre el estatuto de refugiado y de protección subsidiaria, sino también entre estados. Estas serán concretadas en diferentes ordenamientos jurídicos nacionales, concretamente en España, Alemania y Reino Unido ${ }^{72}$-este último de gran interés por cuanto únicamente se encuentra vinculado por la normativa de la primera fase del SECA y ante la incertidumbre sobre si este permanecerá o no dentro del ámbito de esta normativa europea-.

2. El Reglamento Dublín III no ha ofrecido una contundente respuesta a las situaciones de presión desproporcionada sobre los sistemas nacionales de asilo. En periodos concretos de afluencias masivas de nacionales de terceros países, este imponía implícitamente una distribución de solicitudes inasumible en estados que disponían de fronteras exteriores de la UE estimulando un flagrante incumplimiento en su efectiva tramitación en virtud del cierre de sus fronteras.

European Public Policy, vol. 19, nº 9, 2012, pp. 1396-1413; ARENAS HIDALGO, N., Derecho Internacional y Europeo de las Personas Refugiadas, en: MARIÑO MENÉNDEZ F.M., PÉREZ GONZÁLEZ C., CEBADA ROMERO A., (Coords.). Instrumentos y Regímenes de Cooperación Internacional, TROTTA, 2017, p. 194.

${ }^{71}$ JONES, W., TEYTELBOYM, A., "The International Refugee Match: A System that Respects Refugees' Preferences and the Priorities of States", Refugee Survey Quarterly, vol. 36, n 2, 2017, p. 89; OWEN, D., "Refugees, EU Citizenship and the Common European Asylum System A Normative Dilemma for EU Integration”, Ethical Theory and Moral Practice, Springer, 2019, p. 10.

${ }^{72}$ En virtud del Tratado de Amsterdam, este país decidió participar en todas las medidas del SECA adoptadas durante la primera fase. HM Government, Review of the Balance of Competences between the United Kingdom and the European Union: Asylum \& non-EU Migration, febrero de 2014, p. 18. Disponible

en: https://assets.publishing.service.gov.uk/government/uploads/system/uploads/attachment_data/file/279096 /BoC_AsylumImmigration.pdf 
En aras de solventar este conflicto, la propuesta del Reglamento Dublín IV (PRD IV $)^{73}$ regula un novedoso mecanismo de acción correctora. Un sistema competencial más eficiente, proporcional y justo con las necesidades nacionales que no limita el margen de apreciación nacional en la determinación de aquellas conductas susceptibles de comprometer la seguridad nacional u orden público. Este reparto equitativo de responsabilidades entre los EEMM que regula el Capítulo VII (arts. 34 y ss.), pondera permanentemente la tasa de solicitudes de las que cada EM haya sido declarado responsable e inmediatamente la compara con el porcentaje de referencia basado en una clave que tiene en cuenta la población y el PIB total de un EM. Su aplicación resultará automática cuando el número de solicitudes supere el $150 \%$ de la cifra indicada en la clave de referencia. Una solución a la sobrecarga e incapacidad de los flujos migratorios a gran escala que pretende evitar, o al menos reducir, que determinados EEMM afectados continúen imponiendo obstáculos generalizados en sus sistemas de asilo.

Más allá de estas cuestiones, debe traerse a colación el gran volumen de datos e información personal objeto de tratamiento antes, durante y posteriormente al procedimiento de determinación del estatuto de protección internacional correspondiente. La importancia de esta información durante el acceso, la tramitación, la derivación de los procedimientos, la determinación del EM responsable para conocer del asilo o los diversos procedimientos de reparto de la carga entre estados, la aplicación de mecanismos de reubicación o el reasentamiento, entre otros, da buena cuenta de la ineludible tarea de profundizar sobre el tratamiento de los datos personales de los solicitantes de protección internacional.

A tal efecto, en el Capítulo II examinaremos la protección de la información susceptible de tratamiento en el SECA. Un régimen jurídico en el que, fruto de la aplicación de políticas de seguridad nacionales, ha visto reducidas sus garantías, generando numerosos conflictos en el derecho a la privacidad y protección de datos; consecuencias que continuarán condicionando las políticas y la acción legislativa de la misma y la de los EEMM.

Así fue constatado por la Comisión a finales de 2018 cuando instó a garantizar un fiel equilibrio de las nuevas leyes de seguridad así como de la protección de datos en el

\footnotetext{
${ }^{73}$ Comisión Europea, Propuesta de Reglamento del Parlamento Europeo y del Consejo por el que se establecen los criterios y mecanismos de determinación del Estado miembro responsable del examen de una solicitud de protección internacional presentada en uno de los Estados miembros por un nacional de un tercer país o un apátrida (texto refundido), $\operatorname{COM(2016)~} 270$ final.
} 
ámbito del asilo ${ }^{74}$ y que la PRD IV traduce en su conjunción con las limitaciones y garantías que proporcionan otros instrumentos como el Reglamento General de Protección de Datos (RGPD) ${ }^{75}$-directamente aplicable en todos los Estados de la UE desde mayo de 2018- y la Directiva (UE) 2016/680 de protección de datos en el ámbito policial y de justicia. ${ }^{76}$

Una complejidad que se agrava, en buena medida, por la aplicación de amplios y difusos instrumentos normativos y por la multitud de organismos y agencias que operan directa o indirectamente en el tratamiento de las solicitudes de protección internacional. Esto incluye a las autoridades nacionales encargadas de la tramitación y de la gestión de las solicitudes de protección internacional, así como a la Guardia Europea de Fronteras y Costas (GEFC) o la futura Agencia de Asilo de la UE (AAUE) -que sustituirá a la Oficina Europea de Apoyo al Asilo-, ${ }^{77}$ regidos por el Reglamento (UE) 2018/1725 relativo a la protección de las personas físicas en lo que respecta al tratamiento de datos personales por las instituciones, órganos y organismos de la Unión, y a la libre circulación de esos datos ${ }^{.78}$ Todo ello sin perjuicio de la gran diversidad de organismos y agencias humanitarias, de seguridad y espionaje que operan en el día a día en fronteras y cuyas actuaciones únicamente se encuentran regidas por sus propios

\footnotetext{
${ }^{74}$ Comisión Europea, Una Europa que protege: la Comisión pide un mayor esfuerzo para garantizar la adopción de las propuestas sobre seguridad, 11 de diciembre de 2018.

${ }^{75}$ Reglamento (UE) 2016/679 del Parlamento Europeo y del Consejo, de 27 de abril de 2016, relativo a la protección de las personas físicas en lo que respecta al tratamiento de datos personales y a la libre circulación de estos datos y por el que se deroga la Directiva 95/46/CE (Reglamento general de protección de datos) (DO L 119 de 4.5.2016, pp. 1-88).

${ }^{76}$ Directiva (UE) 2016/680 del Parlamento Europeo y del Consejo, de 27 de abril de 2016, relativa a la protección de las personas físicas en lo que respecta al tratamiento de datos personales por parte de las autoridades competentes para fines de prevención, investigación, detección o enjuiciamiento de infracciones penales o de ejecución de sanciones penales, y a la libre circulación de dichos datos y por la que se deroga la Decisión Marco 2008/977/JAI del Consejo (DO L 119 de 4.5.2016, pp. 89-131).

${ }^{77}$ Comisión Europea, Propuesta enmendada de Reglamento relativo a la Agencia de Asilo de la Unión Europea y por el que se deroga el Reglamento (UE) n. ${ }^{\circ}$ 439/2010, Bruselas, 12 de septiembre de 2018 COM (2018) 633 final 2016/0131 (COD). A fecha de elaboración del presente trabajo, la situación sobre la propuesta es la siguiente: el 23 de enero de 2019, la Presidencia del Consejo presentó la propuesta modificada al Coreper en el que se subrayó que las propuestas de la Presidencia no contaban con el apoyo suficiente. El 4 de febrero, la Presidencia convocó una reunión de los Consejeros JAI, en la que fue examinado el nuevo texto. Sin embargo, puesto que no hubo cambios significativos en la posición de los Estados miembros con respecto a la reunión anterior, la Presidencia concluyó que se habían agotado todas las posibilidades a nivel técnico.

${ }^{78}$ Reglamento (UE) 2018/1725 del Parlamento Europeo y del Consejo de 23 de octubre de 2018 relativo a la protección de las personas físicas en lo que respecta al tratamiento de datos personales por las instituciones, órganos y organismos de la Unión, y a la libre circulación de esos datos, y por el que se derogan el Reglamento (CE) n. ${ }^{\circ}$ 45/2001 y la Decisión n. ${ }^{\circ}$ 1247/2002/CE (DOUE de 21 de noviembre de 2018).
} 
reglamentos de funcionamiento -véase el ACNUR, Europol, etc.--.

3. El Sistema de Información Eurodac fue creado en el año 2000 para la organización y registro de las impresiones dactilares de los solicitantes de protección internacional y de varias categorías de migrantes en situación irregular. A través de este sistema se obtienen, tratan, almacenan e intercambian datos personales altamente sensibles puestos al servicio de un amplio conjunto de autoridades nacionales y europeas para fines de diversa índole que exceden de la mera finalidad de determinar el EM responsable de tramitar una solicitud de protección internacional conforme al Reglamento de Dublín transformándose en una base de datos para objetivos más generales relacionados con la inmigración como el retorno o la lucha contra la migración irregular-. Su propuesta de reforma, ${ }^{79}$ aún respondiendo a criterios de accesibilidad de Dublín, incorporará novedades de profundo calado objeto de análisis en el Capítulo III. Pretende ampliarse el ámbito de actuación por medio de la inclusión y almacenamiento de datos de nacionales de terceros Estados que residan de forma irregular en la UE. También pretenden adicionarse mayores categorías de datos de carácter personal lo que desvirtúa su especialidad hacia una potente herramienta de gestión de la migración.

Por su parte, contemplará un régimen de intercambio de información más eficaz entre distintas autoridades nacionales y comunitarias. Y con independencia del potencial conflicto de la seguridad con el derecho fundamental a la intimidad, privacidad y protección de datos de los solicitantes de protección internacional y refugiados, existe una tendencia a que cualquier dificultad relativa a su funcionamiento y operatividad sea abordada desde un enfoque coordinado supranacional.

Es más, como tendremos oportunidad de comprobar, la Agencia Europea para la Gestión Operativa de Sistemas Informáticos de Gran Magnitud en el ELSJ (eu-LISA) tiene atribuida la responsabilidad de proporcionar un marco técnico y operativo a este Sistema de Información -al igual que el Sistema de Información de Visados (VIS) y Schengen (SIS II)-. También, se garantiza la máxima efectividad de este sistema por

\footnotetext{
${ }^{79}$ Comisión Europea, Propuesta de Reglamento del Parlamento Europeo y del Consejo relativo a la creación del sistema «Eurodac» para la comparación de las impresiones dactilares para la aplicación efectiva del [Reglamento (UE) n. ${ }^{\circ}$ 604/2013, por el que se establecen los criterios y mecanismos de determinación del Estado miembro responsable del examen de una solicitud de protección internacional presentada en uno de los Estados miembros por un nacional de un tercer país o un apátrida] y de la identificación de un nacional de un tercer país o un apátrida en situación ilegal, y a las solicitudes de comparación con los datos de Eurodac presentadas por los servicios de seguridad de los Estados miembros y Europol a efectos de aplicación de la ley (refundición), COM(2016) 272 final.
} 
medio del intercambio de información con organismos especializados en gestión de fronteras como la Europol o la EASO o, el organismo que sustituirá a esta, la futura AAUE. ${ }^{80}$

Asimismo, la GEFC igualmente interviene sobre el terreno, una agencia que fue objeto de reciente modificación a raíz del Reglamento 2019/1896, de 13 de noviembre de 2019, sustituyendo a la anterior "Frontex"- ${ }^{81}$ Su transformación pretende dotar de una mayor efectividad al funcionamiento del SECA, asegurando la convergencia en la evaluación de las solicitudes de protección internacional en la UE, realizar seguimientos operativos y técnicos de la aplicación del Derecho de la Unión y asistir a los EEMM en la formación de las autoridades nacionales.

Lejos de quedarse ahí, el despliegue de los novedosos "equipos conjuntos de gestión de la migración de la UE" están integrados por estos dos organismos así como miembros de Europol y autoridades del EM afectado. ${ }^{82}$ Estos últimos pretenden aunar esfuerzos para llevar a cabo actuaciones eficaces en los conocidos como puntos críticos fronterizos o hotspots nacionales, siempre y cuando lo solicite previamente el EM afectado. ${ }^{83}$ Igualmente serán esenciales para abordar uno de los mayores retos que se producen en el presente, esto es, el tratamiento criminalizado de amplias categorías de sujetos sin pautas diferenciadoras claras entre personas en necesidad de protección internacional de simples migrantes irregulares $y$, sobre el que tempranamente apuntara

\footnotetext{
${ }^{80}$ Comisión Europea, Propuesta modificada de Reglamento del Parlamento Europeo y del Consejo relativo a la Agencia de Asilo de la Unión Europea y por el que se deroga el Reglamento (UE) n. ${ }^{\circ}$ 439/2010, 12 de septiembre de 2018 COM(2018) 633 final 2016/0131 (COD).

${ }^{81}$ Reglamento (UE) 2019/1896 del Parlamento Europeo y del Consejo de 13 de noviembre de 2019 sobre la Guardia Europea de Fronteras y Costas y por el que se derogan los Reglamentos (UE) n. ${ }^{\circ}$ 1052/2013 y (UE) 2016/1624 (DOUE de 14 de noviembre de 2019).

${ }^{82}$ Este nuevo órgano aparece contemplado en la Propuesta -y su propuesta modificada- de Reglamento del Parlamento Europeo y del Consejo relativo a la Agencia de Asilo de la Unión Europea. Véase Comisión Europea, Propuesta de Reglamento relativo a la Agencia de Asilo de la Unión Europea y por el que se deroga el Reglamento (UE) n. ${ }^{\circ}$ 439/2010 COM/2016/0271 final; Contribución de la Comisión Europea a la reunión de dirigentes celebrada en Salzburgo los días 19 y 20 de septiembre de 2018. $\operatorname{COM}(2018) 633$ final 2016/0131 (COD), Bruselas, de 12 de septiembre de 2018.

${ }^{83}$ Sobre el concepto de los hotspots, remitimos a: KOURACHANIS, N., "Asylum Seekers, Hotspot Approach and Anti-Social Policy Responses in Greece (2015-2017)", Journal of International Migration and Integration, vol. 19, n 4, 2018, pp. 1153-1167; FERNÁNDEZ ROJO, D., "Los hotspots: expansión de las tareas operativas y cooperación multilateral de las agencias europeas Frontex, Easo y Europol", Revista de Derecho Comunitario Europeo, no. 61, 2018, pp. 1038-1043; BALDWIN-EDWARDS M., K. BLITZ B. et. CRAWLEY H., "The politics of evidence-based policy in Europe's 'migration crisis", Journal of Ethnic and Migration Studies”, vol. 45, n 12, 2019, pp. 2139-2155; ORSINI, G., ROOS, C., "EU hotspots, relocation and absconded migrants in Italy. How to save Schengen within a failing Dublin system?”, EL-CSID Policy Brief, Issue 2017/03, octubre de 2017.
} 
Bonfliglio $^{84}$-incluso de otras que pueden comprometer la seguridad de los EEMM-. Su despliegue se efectuará a petición del EM considerado "de acogida" y bajo la coordinación de la $\mathrm{CE}$, que faculta a las distintas agencias y organismos de la UE su actuación “de apoyo". Además, se otorgará un acceso al procedimiento de protección internacional coherente y adaptado a las necesidades nacionales en virtud de un renovado Reglamento de Dublín y las fases procedimentales y el reconocimiento resultarán armonizadas gracias a la aplicación de los nuevos reglamentos comunitarios.

Todo ello se aderezará por otra de las nuevas realidades que afecta al funcionamiento de Eurodac, el actual marco relativo al establecimiento de un marco para la interoperabilidad de los sistemas de información de la UE (cooperación policial y judicial, asilo y migración) que regulan los Reglamentos 2019/817 y 2019/818 -este último aplicable a los SSII en el ámbito de la cooperación policial y judicial, el asilo y la migración-- ${ }^{85}$ Una nueva funcionalidad que parte de la Resolución de 6 de julio de 2016 sobre las prioridades estratégicas para el programa de trabajo de la Comisión para $2017^{86}$ y en la que el PE "pidió que se presentaran propuestas para mejorar y desarrollar los sistemas de información de la UE existentes, colmar las lagunas de información y avanzar hacia su interoperabilidad, asi como sus propuestas sobre la obligación de intercambiar información a nivel de la UE, junto con las salvaguardias necesarias en materia de protección de datos".

Sin perjuicio de ulterior análisis en el Capítulo III, este Reglamento proporcionará a los agentes sobre el terreno -en concreto, a la guardia de fronteras, la policía, los funcionarios de inmigración, autoridades administrativas y judiciales, entre otros- el

\footnotetext{
${ }^{84}$ BONFIGLIO S.,"The Right not to be criminalised", Democrazia e Sicurezza, Democracy Security Review, anno III, n. 3, 2013, p. 3.

${ }^{85}$ Reglamento (UE) 2019/817 del Parlamento Europeo y del Consejo de 20 de mayo relativo al establecimiento de un marco para la interoperabilidad de los sistemas de información de la UE en el ámbito de las fronteras y los visados y por el que se modifican los Reglamentos (CE) $n^{\circ} 767 / 2008$, (UE) 2016/399, (UE) 2017/2226, (UE) 2018/1240, (UE) 2018/1726 y (UE) 2018/1861 del Parlamento Europeo y del Consejo, y las Decisiones 2004/512/CE y 2008/633/JAI del Consejo y el Reglamento (UE) 2019/818 del Parlamento Europeo y del Consejo de 20 de mayo relativo al establecimiento de un marco para la interoperabilidad entre los sistemas de información de la UE en el ámbito de la cooperación policial y judicial, el asilo y la migración y por el que se modifican los Reglamentos (UE) 2018/1726, (UE) 2018/1862 y (UE) 2019/816.

${ }^{86}$ Parlamento Europeo, Preparación del Programa de trabajo de la Comisión para 2017. Resolución del Parlamento Europeo, de 6 de julio de 2016, sobre las prioridades estratégicas para el programa de trabajo de la Comisión para 2017 (2016/2773(RSP)). DO C 101 de 16.3.2018, p. 116. El Acta de este período parcial de sesiones se publicó en el DO C 289 de 31.8.2017.
} 
acceso rápido, eficiente, sistemático y controlado de los sistemas de información (SSII). Se alza como una prioridad en la gestión e intercambio de la información tendente en la optimización de la tramitación de las solicitudes en frontera, la gestión de los flujos migratorios y el refuerzo de la seguridad interior. Un sistema interoperable que como ya se ha señalado en otro trabajo, "tiene por objeto evitar la duplicidad de datos reduciendo los solapamientos y poniendo de manifiesto la discrepancia en los datos- e identificar a las personas de forma más fiables -incluidas las personas con múltiples identidades- reduciendo la usurpación de identidad, mejorar y armonizar los requisitos de calidad de los datos de los respectivos sistemas de información de la UE, facilitar la aplicación técnica y operativa por los Estados miembros de los sistemas de información de la UE existentes y futuros, reforzar y simplificar las garantías de seguridad de los datos y de protección de datos que rigen en los respectivos sistemas de información de la UE". 87

De ahí que el Considerando 9 de este Reglamento establezca la interoperabilidad de los siguientes sistemas de la UE: "Sistema de Entradas y Salidas (SES), el Sistema de Información de Visados (VIS), el Sistema Europeo de Información y Autorización de Viajes (SEIAV), Eurodac, el Sistema de Información de Schengen (SIS), y el Sistema Europeo de Información de Antecedentes Penales de nacionales de terceros países (ECRIS-TCN), para que estos sistemas de información y sus datos se complementen mutuamente, respetando al mismo tiempo los derechos fundamentales de los individuos, especialmente el derecho a la protección de los datos personales". Una interconectividad que exigirá la creación de los conocidos como "componentes de interoperabilidad", es decir, "un portal europeo de búsqueda (PEB), un servicio de correspondencia biométrica compartido (SCB compartido), un registro común de datos de identidad (RCDI) y un detector de identidades múltiples (DIM)”.

La interoperabilidad supondrá un trascendental avance en el modo en el que se dispondrá de la información entre todos estos sistemas de la UE. Sin embargo, estos han sido diseñados desde un enfoque técnico. Y obsérvese que el Considerando 37 precisa que la eficacia en el cumplimiento de los objetivos de cada uno de los SSII requiere "la identificación exacta de las personas cuyos datos personales almacenan”. Por ello, este

\footnotetext{
${ }^{87}$ GARCÍA MAHAMUT, R., VIGURI CORDERO, J., "La protección de los datos personales de los solicitantes... ob. cit., p. 239.
} 
modelo nuevo de información para la gestión de la seguridad, las fronteras y la migración no podrá menoscabar los derechos fundamentales y por tanto, en el SECA. 


\section{CAPITULO 1.}

\section{LA SEGURIDAD NACIONAL Y SU IMPACTO EN EL SISTEMA EUROPEO COMÚN DE ASILO (SECA).}

\section{El concepto de seguridad en el derecho de asilo: de la fragmentación nacional hacia un "modelo de integración".}

\subsection{Introducción.}

Aunque las políticas de asilo han dependido fundamentalmente de los sistemas nacionales, la UE ha ido desempeñando un papel progresivamente más importante tras el Acuerdo de Schengen (1985) y el Tratado de Ámsterdam (1997), que otorgaron nuevas competencias a la UE en materia de control de fronteras y legislación en materia de asilo por medio de un mecanismo institucional especial. Si bien, fue en el Programa de Tampere (1999-2004) donde se creó un marco jurídico común centrado en una política referente de asilo. El Consejo Europeo acordó el desarrollo del SECA así como la elaboración de un plan quinquenal para el período 2000-2005 que finalizó con el Programa de la Haya (2005-2009), el cual previó expresamente el establecimiento de un procedimiento común de asilo a la par que fue forjándose progresivamente la creación de un marco europeo de protección de datos. Del mismo modo, fue en este programa donde se dispuso la necesidad de encontrar, por primera vez, un equilibrio entre la protección de la vida privada y la seguridad a la hora de compartir información por parte de las fuerzas de seguridad nacionales en la lucha contra el terrorismo, así como una mayor cooperación entre estas.

Partiendo de los logros conseguidos en estos dos programas anteriores, en materia de asilo, el TL del año 2007 (en vigor desde diciembre de 2009) transformó jurídicamente el establecimiento de normas mínimas hacia la creación de un sistema común que incluye estatutos y procedimientos uniformes, previendo igualmente la aplicación del principio de solidaridad y de reparto equitativo de la responsabilidad entre los EEMM, reafirmado por el Programa de Estocolmo (2010-2014). En este momento, los esfuerzos comenzaron a centrarse, no solo en el establecimiento de una nueva y segunda fase del SECA para 2012 -finalmente adoptada a finales de 2013-, sino también en el refuerzo del Espacio de Libertad, Seguridad y Justicia (ELSJ) mediante la implementación de 
medidas centradas en los intereses y las necesidades de los ciudadanos y desarrollando una estrategia de seguridad interior para la UE dirigida a luchar contra la delincuencia organizada y el terrorismo transfronterizo.

La seguridad interior fue vinculada a la adopción de una estrategia de seguridad exterior de la UE y a un mayor fortalecimiento de la cooperación con terceros países. Y lo cierto es que cada uno de estos programas originaron un ciclo de reflexiones sobre la conexión entre asilo e inmigración, terrorismo, delincuencia internacional y control de fronteras, ${ }^{88}$ los cuales fueron especialmente avivados tras los distintos escenarios que comprometieron la seguridad nacional. Esto desvirtuó la ponderación entre los intereses nacionales y comunitarios hacia una intolerable situación en la que algunos EEMM priorizaron la protección de los problemas relacionados con su seguridad en detrimento de los derechos de los refugiados. ${ }^{89}$

En consecuencia, pese a los progresos realizados desde el primer programa plurianual de Justicia y Asuntos de Interior (JAI) que tuvo lugar entre 2010-2014 o la revisión intermedia de estas orientaciones en el año $2017,{ }^{90}$ indudablemente, las políticas de asilo de la UE presentan una especial complejidad para la consecución de acuerdos a largo plazo entre los EEMM y la UE. Ello se debe, en buena medida, a uno de los principales desafíos abordados por el ELSJ en los últimos tiempos, centrado en la crisis migratoria y de refugiados que ha afectado a distintos países del Mediterráneo, unido a las cuestiones relacionadas con la seguridad nacional como la lucha contra la radicalización, el terrorismo o la delincuencia organizada transnacional.

\footnotetext{
${ }^{88}$ HUYSMANS J., "Migrants as a security problem: Dangers of 'securitizing' societal issues", en: MILES R., THRANHARDT D, (eds.). Migration and European integration: The dynamics of inclusion and exclusion. London: Pinter Publishers, 1995, p. 53; ANDERSSON, R., "Hardwiring the Frontier? The Politics of Security Technology in Europe's 'Fight against Illegal Migration'”, Security Dialogue, vol. 47, $\mathrm{n}^{\circ} 1,2016$, pp. 22-39; BIGO, D., "The (in)securitization practices of the three universes of EU border control: Military/Navy-borderguards/police-database analysts”, Security Dialogue, vol. 45, no 3, 2014 , pp. 209-225.

${ }^{89}$ VÖLKEL J., "When Interior Ministers play diplomats. Fatal ambiguities in Europe's securitised migration policy”, en: JÜNEMANN A, FROMM N., SCHERER N, (eds.), Fortress Europe? Challenges and Failures of Migration and Asylum Policies, Wiesbaden: Springer VS; 2017, p. 84; COLLETT, E., Future EU policy development on immigration and asylum: Understanding the challenge, MPI policy brief series, $\mathrm{n}^{\circ}$ 4, 2014, p. 2. Accesible en: from http://www.migrationpolicy.org/research/future-eupolicy-development-immigration-and-asylum-understanding-challenge [Consulta: 28 de mayo de 2019]

${ }^{90}$ Consejo de la UE, Revisión intermedia de las directrices estratégicas de JAI - Información de la Presidencia, 1 de diciembre de 2017, (15224/1/17 REV 1). Accesible en: http://data.consilium.europa.eu/doc/document/ST-15224-2017-REV-1/en/pdf
} 
Este Espacio se prevé en el art. 3.2 TUE como un objetivo de la UE y establece expresamente que "la Unión ofrecerá a sus ciudadanos un espacio de libertad, seguridad y justicia sin fronteras interiores, en el que esté garantizada la libre circulación de personas juntamente con medidas adecuadas en materia de control de las fronteras exteriores, asilo, inmigración y de prevención y lucha contra la delincuencia”. Por su parte, el Título V de la Parte III del TFUE (arts. 67 a 89) abarca cuatro grandes ejes de competencias: las políticas sobre control fronterizo, asilo e inmigración (Cap. II); cooperación judicial en materia civil (Cap. III); cooperación judicial en materia penal (Cap. IV), y cooperación policial (Cap. V). ${ }^{91}$

En el tema que nos ocupa, aunque los flujos de migrantes y refugiados a gran escala han reflejado una gran diversidad de enfoques nacionales para el asilo y los problemas de cooperación en el marco jurídico del SECA, los distintos conflictos que han impactado en la seguridad nacional y europea y la falta de centralización y liderazgo de la UE en la gestión de los asuntos de asilo han propiciado cierta escasez armonizadora. Esta ha radicado, precisamente, en el uso extensivo de políticas nacionales de seguridad. Por ende, ha contrariado el objetivo esencial del SECA dirigido a impulsar altos estándares comunes y una cooperación más estrecha que garantice que los individuos reciban un tratamiento similar en cualquier punto donde soliciten asilo. Fruto de ello, se ha fomentado una concepción paulatinamente orientada a dar respuesta a los múltiples obstáculos y conflictos que afectan a la seguridad tanto en su dimensión interior como exterior. Una dualidad conceptual complementaria en el ámbito del asilo.

Pese a que el SECA pretende garantizar la seguridad jurídica, aplicando reglas comunes a todos los solicitantes de asilo, a juicio de Léonard y Kaunert, la razón principal no parece analizarse bajo el prisma del principio de igualdad, sino desde una percepción de seguridad conectada con la reducción de los movimientos secundarios entre EEMM. ${ }^{92}$

Con respecto a la seguridad interior, a pesar de que las autoridades nacionales deben garantizar el mayor grado de seguridad dentro de sus fronteras, las distintas vicisitudes acaecidas en esta sede trascienden al ámbito comunitario. Los EEMM ostentan la

\footnotetext{
${ }^{91}$ Es más, en materia de asilo, el art. 67 TFUE dispone que este Espacio "Garantizará la ausencia de controles de las personas en las fronteras interiores y desarrollará una política común de asilo, inmigración y control de las fronteras exteriores que esté basada en la solidaridad entre Estados miembros y sea equitativa respecto de los nacionales de terceros países".

${ }^{92}$ LÉONARD, S., KAUNERT, C., "The development of the Common European..., ob. cit., p. 89.
} 
competencia exclusiva para decidir acerca de su seguridad interior (art. 72 TFUE), lo cual supone un amplio poder de maniobra y discrecionalidad en la toma de decisiones. También implica lo que podemos considerar como un "arma de doble filo", pues no únicamente se anteponen los intereses nacionales sino que, correlativamente, tiende a eludirse la aplicación efectiva y coherente del SECA. Una situación especialmente crítica que esboza un convulso contexto en lo que a los sistemas nacionales de asilo se refiere, donde estas actividades operan fuera del alcance de la legislación de la UE. Correlativamente, esta seguridad interior cede -cada vez más- hacia su dimensión exterior, una competencia compartida entre la UE y los EEMM (art. 4 TFUE), la cual se contempla dentro del ELSJ con gran amplitud pues se limita a la gestión de las fronteras exteriores, asilo e inmigración (arts. 77 y ss. TFUE del Capítulo II del Título V TFUE), incluyendo una política común de visados (arts. 77.2 a) y 79.2 a) TFUE), la cooperación judicial penal (arts. 82 a 86 ) y policial (arts. 87 a 89 ).

$\mathrm{Y}$ en relación con ambas vertientes de seguridad, su convergencia se refleja en las libertades fundamentales, las cuales están sujetas a exigencias de "política pública o seguridad pública", ${ }^{93}$ concepto que debía aplicarse a ambas dimensiones de seguridad con objeto de proteger el monopolio de la fuerza de un estado contra cualquier tipo de amenaza. ${ }^{94}$ A pesar de ello, el Tribunal de Justicia de la Unión Europea (TJUE) concretó en el año 97 que "los Estados miembros, que siguen siendo los únicos competentes para el mantenimiento del orden público y la protección de la seguridad interior, gozan de margen de apreciación para determinar cuáles son, ante una situación dada, las medidas más idóneas para eliminar (...) cualquier perturbación susceptible de comprometerla", siempre y cuando estas medidas sean proporcionales y no constituyan "un medio de discriminación arbitraria". ${ }^{95}$ Frente a esta clásica interpretación jurisprudencial, no resulta baladí enfatizar que el TFUE prevé estas excepciones a lo

\footnotetext{
${ }^{93}$ La seguridad pública fue definido en el año 1984 el TJUE de forma muy concreta abordándose desde el prisma del mercado interior (Sentencia del Tribunal de Justicia Campus Oil Limited y otros c. Minister for Industry and Energy y otros, de 10 de julio de 1984 (Asunto 72/83), párr. 34).

${ }^{94}$ STJUE Angela Maria Sirdar c. The Army Board y Secretary of State for Defence, de 26 de octubre de 1999 (Asunto C-273/97), párr. 34; Tanja Kreil y Bundesrepublik Deutschland, de 11 de enero de 2000 (Asunto C-285/98), párr. 17, Alfredo Albore, de 13 de julio de 2000 (Asunto C-423/98), párr. 18, Petición de decisión prejudicial planteada por la Cour de cassation de Luxemburgo contra Aimé Richardt y Les Accessoires Scientifiques SNC, de 4 de octubre de 1991 (Asunto C-367/89), párr. 22.

${ }^{95}$ Sentencia del Tribunal de Justicia Comisión c. República Francesa, de 9 de diciembre de 1997 (Asunto C-265/95), párr. 33.
} 
largo de múltiples derechos. ${ }^{96} \mathrm{Y}$ pese a que estas se formulan de forma análoga en cada una de ellos, ha tenido un distinto alcance, incluso, en lo que atañe a la migración y el asilo.

En este ámbito, el título V del TFUE antes mencionado regula las condiciones aplicables a los nacionales de terceros países (art. 67 y ss. TFUE). Las políticas de la UE en este espacio se caracterizan por una distribución de poderes que asigna competencias legislativas a la UE, pero reserva poderes ejecutivos a los EEMM. Así lo reconoce el art. 67.1 TFUE, que establece que este título opera dentro del respeto de los derechos fundamentales y de los distintos sistemas y tradiciones jurídicas nacionales, aunque pugna directamente con la excepción de seguridad nacional que reconoce el art. 72 TFUE y el art. 4.2 TUE y que pasamos a analizar a continuación.

1.2. La definición del mantenimiento del orden público y de la salvaguardia de la seguridad interior.

Mientras que el art. 72 TFUE dispone que el Título V TFUE sobre el ELSJ no afectará al "ejercicio de las responsabilidades que incumben a los Estados miembros en cuanto al mantenimiento del orden público y la salvaguardia de la seguridad interior", el art. 73 establece que "Los Estados miembros estarán abiertos a organizar entre ellos y bajo su responsabilidad las formas de cooperación y coordinación que consideren apropiadas entre los departamentos competentes de sus administraciones responsables de salvaguardar la seguridad nacional”. Además, el art. 276 TFUE excluye el pronunciamiento del TJUE para "comprobar la validez o proporcionalidad de operaciones efectuadas por la policía u otros servicios con funciones coercitivas de un Estado miembro, ni para pronunciarse sobre el ejercicio de las responsabilidades que incumben a los Estados miembros respecto del mantenimiento del orden público y de la salvaguardia de la seguridad interior".

Esta reserva nacional, sin embargo, no es absoluta. La UE goza de competencia en este ámbito. El art. 4.2 j) TFUE establece la competencia compartida entre la UE y los EEMM en el Espacio de Libertad, Seguridad y Justicia que complementa el art. 67.3 TFUE al contemplar que "la UE se esforzará por garantizar un alto nivel de seguridad" a través de medidas tanto para prevenir y combatir la delincuencia como de

\footnotetext{
${ }^{96}$ Véanse los arts. 36, 45.3, 52 o 62 TFUE.
} 
coordinación y cooperación entre autoridades policiales, judiciales y otras autoridades competentes. Es por este motivo por el que la seguridad interior de la UE está regulada en un capítulo distinto al que se ocupa de las políticas sobre fronteras, migración y asilo.

La seguridad "exterior" de la UE tiene un régimen muy específico que lo hace autónomo de las “políticas ordinarias" de la UE y viceversa. Dos dimensiones que, en el ámbito del asilo, están cada vez más interrelacionadas y requieren un papel cada vez mayor de las agencias de la UE como la Oficina Europea de Policía (Europol), Frontex $^{97}$ o la EASO. Aun con todo, el alcance de las competencias nacionales y europeas en este contexto no resulta especialmente claro incluso 10 años después de la entrada en vigor del TL, que transformó la cooperación policial y judicial en materia penal en "políticas ordinarias".

Indudablemente, ensamblar jurídicamente la protección de las fronteras, los flujos migratorios y la protección del derecho de asilo exige un "modelo político comunitario supranacional" en el que los aspectos de seguridad, económicos y sociopolíticos deben abordarse de manera coherente para dar solución a problemas cada vez más imprevisibles, complejos e interdependientes entre los EEMM. Ello requerirá de grandes avances técnicos y procedimentales que se adecúen a estas nuevas situaciones a la par de una legislación coherente con las necesidades nacionales, sin perjuicio de la necesidad de reformar el Sistema de Dublín hacia un régimen competencial más proporcional a las posibilidades efectivas de los EEMM y con reglas más próximas a los principios de solidaridad y reparto equitativo de las responsabilidades entre ellos (art. 80 TFUE). Se requiere un cambio de paradigma que reoriente las técnicas y procedimientos de vigilancia por parte de los operadores jurídicos, fundamentalmente, las distintas autoridades policiales y administrativas nacionales hacia el "objetivo común" de proporcionar protección internacional a aquellos sujetos que se hayen en necesidad y excluir a otros que, o bien no entran dentro de tal definición o bien, pueden llegar a comprometer la seguridad nacional.

Sin embargo, como hemos ya destacado, la reforma del SECA a través de una tercera fase de armonización del acervo de la UE en materia de asilo, presentada por la Comisión en 2016, resultó ser demasiado ambiciosa para concluir en el período parlamentario 2014-2019. Su bloqueo se produjo, en esencia, por la falta de consenso

\footnotetext{
${ }^{97}$ Aunque a esta agencia se la conoce por Frontex, en el presente estudio diferenciamos entre Frontex y la nueva GEFC.
} 
entre el Consejo y el PE y, entre otros aspectos, el que respecta a la solidaridad entre los EEMM. Pese a todo, estos deberían implantar una perspectiva común, coherente y armonizada para afrontar las amenazas que afectan a su seguridad desde el ámbito comunitario o global. Para tal fin, resulta crucial superar la percepción generalizada de que la migración -ampliamente considerada- constituye una amenaza para la seguridad de los EEMM hacia un modelo que afronte esta situación desde un prisma de intereses mutuos y coherentes en la UE. Así, los vínculos entre los problemas relativos al terrorismo, la migración irregular y las legislaciones de asilo deberán acometerse de un modo diferenciado, adoptando mecanismos de prevención y procedimientos cada vez más eficientes y garantes con la protección de los derechos humanos.

En este punto, en aras de analizar el impacto del art. 72 TFUE en este ámbito, la concreción de la dimensión de "mantenimiento del orden público" se encuentra en la jurisprudencia del TJUE, que trata la excepción de "política pública" a las libertades fundamentales del mercado interior ya abordadas anteriormente. De manera similar, la "seguridad interior" puede equipararse al concepto de "seguridad pública", otro de los motivos que justifican las excepciones a la normativa comunitaria.

Ahora bien, las políticas nacionales que aplican la excepción de seguridad tienen su origen en el art. 72 TFUE, que persigue preservar los poderes ejecutivos nacionales. La legislación de la UE debe respetar la jurisdicción estatal con respecto al orden público y la seguridad interior, máxime porque la UE no tiene competencias propias en la lucha contra el terrorismo -más allá de las relativas a su financiación (art. 75 TFUE), normas mínimas sobre la definición de delitos con una dimensión transfronteriza (art. 83.1 TFUE), la cooperación entre las distintas autoridades nacionales (art. 89 TFUE) y el régimen de asistencia mutua en caso de ataques terroristas (art. 222 TFUE)-. Por ende, en términos generales, la estructura interna de las fuerzas de seguridad y las autoridades policiales corresponde a los EEMM, que ostentan "la posibilidad de organizar entre ellos y, bajo su responsabilidad, normas de cooperación y coordinación en la medida en que lo estimen apropiado, entre los servicios competentes de sus administraciones responsables de velar por la seguridad nacional" (art. 73 TFUE). Al margen de que el TJUE haya reconocido que "si bien, en principio, la legislación penal y las normas de 
procedimiento penal son competencia de los Estados miembros, esta rama del Derecho puede, no obstante, verse afectada por el Derecho de la Unión". ${ }^{98}$

Sobre este carácter general del art. 72 TFUE, no es menos cierto que el TFUE prevé que el derecho de la UE resulte aplicable a tres cuestiones nucleares para garantizar la plena efectividad del SECA:

1) En materia de protección internacional y temporal, la conocida como "cláusula de emergencia" del art. 78.3 TFUE fue adoptada, precisamente, para hacer frente a la gran afluencia de nacionales de terceros países. El Consejo adoptó la Decisión vinculante por la que se previó la reubicación de 120.000 solicitantes de protección internacional que debía llevarse a cabo hasta el 25 de septiembre de $2017 .{ }^{99}$ Esta fue objeto de manifiesta oposición por parte de Hungría por atentar directamente contra su seguridad nacional y que, fruto de su negativa en la adopción de este mecanismo así como de su obligación de acogida, recibió la condena del TJUE por la violación del art. 78.3 TFUE. La STJUE Eslovaquia y Hungría c. Consejo de la Unión Europea, de 6 de septiembre de 2017 conceptualizó el límite de la seguridad de estado, estableciendo que "Los Estados miembros solo podrán ejercer el derecho a rehusar la reubicación de un solicitante en su territorio cuando existan motivos razonables para considerar que dicha persona constituye un peligro para la seguridad nacional o el orden público". ${ }^{100}$ Además, el 25 de julio de 2019, la Comisión llevó a Hungría ante el TJUE tras identificar que su legislación nacional criminalizaba a los solicitantes de asilo, penalizando la formalización de estas solicitudes y restringiendo el acceso a este derecho. ${ }^{101}$

Es más, la proliferación de prácticas meramente nacionales pone de relieve un débil grado de cooperación marcadas por políticas de securitización cada vez más interdependientes entre sí. A modo de ejemplo, la experiencia en los últimos años muestra como los países del Grupo de Visegrado -conformado por Polonia, Eslovaquia,

\footnotetext{
${ }^{98}$ STJUE Alexandre Achughbabian y Préfet du Val-de-Marne, de 6 de diciembre de 2011 (Asunto C329/11), párr. 33; Minh Khoa Vo, de 10 de abril de 2012 (Asunto C-83/12), párr. 37.

${ }^{99}$ Decisión (UE) 2015/1601 del Consejo de 22 de septiembre de 2015 por la que se establecen medidas provisionales en el ámbito de la protección internacional en beneficio de Italia y Grecia, 24 de septiembre de 2015 (L 248/80).

${ }^{100}$ STJUE Hungría y Eslovaquia c. Consejo de la UE, de 6 de septiembre de 2017 (Asuntos acumulados C-643/15 y C-647/15), párr. 22.7.

${ }^{101}$ Comisión Europea, La Comisión lleva a Hungría ante el Tribunal por criminalizar las actividades en apoyo de los solicitantes de asilo y abre una nueva infracción por la no provisión de alimentos en las zonas de tránsito, comunicado de prensa, 25 de julio de 2019. La traducción es nuestra. Disponible en: https://ec.europa.eu/commission/presscorner/detail/EN/IP_19_4260
} 
Hungría y la República Checa- han tratado de eludir las obligaciones en materia de reasentamiento alegando un conflicto de intereses que contraría su propia política de garantizar su seguridad nacional. Tanto es así que López Aguilar apuntaba que el gobierno polaco del PiS "se ha situado prácticamente extramuros de Decisiones europeas adoptadas en Consejo y de normas europeas vigentes, resistiendo la lectura evolutiva (por más que hoy consolidada) del principio fundacional del Derecho europeo que garantiza la supremacía de la Constitución sobre ningún otro poder constituido en el Estado (art.2 TUE)". ${ }^{102}$ Unas declaraciones que constatan la manifiesta carencia de solidaridad de este Grupo (art. 80 TFUE), teniendo presente que estos habían reconocido que no se habían detectado conflictos destacados de personas que pusieran en peligro su seguridad interior. Más bien, "potenciales problemas de radicalización durante la "crisis de refugiados" que devenían en actos extremos de varios grupos militantes así como un fundamentalismo Islámico que promovía el terrorismo global". ${ }^{103}$ En consecuencia, fruto de la manifiesta oposición de este grupo de las cuotas obligatorias de acogida de refugiados, la UE instó a sancionar a este grupo de países. Sanciones que todavía no han sido impuestas pese a que este Grupo impide cualquier avance humanitario en la crisis de los refugiados tal y como ha analizado pormenorizadamente López Aguilar. ${ }^{104}$

A pesar de que las competencias comunitarias en este ámbito (art. 3.2 TUE) se encuentran compartidas con los EEMM (art. 4.2 j) TFUE), la débil coordinación entre las políticas estatales y supranacionales así como una sistemática contravención de los

\footnotetext{
${ }^{102}$ LOPEZ AGUILAR J. F., "De nuevo (y todavia) Polonia: Rule of Law y art.7 TUE en el Parlamento Europeo y el Tribunal de Justicia", Teoría y Realidad Constitucional, no 44, 2019, p. 145; Ídem: "El caso de Polonia en la UE: retrocesos democráticos y del estado de derecho y «dilema de Copenague»", Teoría y Realidad Constitucional, $\mathrm{n}^{\mathrm{0}} 38,2016$, pp. 105-113.

${ }^{103}$ Budapest Centre For Mass Atrocities Prevention, Capabilities of the Visegrad Group in preventing extremism, p. V, 2017. Por su parte, Francia y Alemania desearon encontrar una solución multilateral a las crisis de refugiados y su impacto en las fronteras interiores precisamente tras el rechazo por el Grupo Visegrado de la aceptación de cuotas obligatorias para la reasentamiento en el área Schengen (Traynor, I and HARDING, L., Merkel calls on EU to share burden of migrant crisis, The Guardian, 25 de agosto, 2015, p. 13).

${ }^{104}$ Así se recoge en LOPEZ AGUILAR J. F., "De nuevo (y todavia) Polonia: Rule of Law... ob. cit., p. 158. En este sentido, conviene recordar que el exministro del Interior de Polonia afirmó que aceptar inmigrantes habría resultado más perjudicial para la seguridad de este país que enfrentarse a la potestad sancionadora de la UE. En la actualidad, el primer ministro propuso en 2018 implementar programas de ayuda dirigidos a entidades radicadas en el Líbano y Jordania, en vista de la admisión de un gran número de refugiados procedentes de Siria. Euractiv, Commission readies sanctions against the Visegrad Four, 7 de junio de 2017. Disponible en: https://www.euractiv.com/section/central-europe/news/commissionreadies-sanctions-against-the-visegrad-four/ [Consulta: 15 de febrero de 2019]
} 
principios de solidaridad y el reparto equitativo de la responsabilidad entre los EEMM permite hablar de una notoria falta de armonización y coherencia contraria al objetivo vital del SECA.

2) Por lo que respecta a la regulación de la cooperación entre las autoridades nacionales y las instituciones o agencias europeas especializadas en la gestión de la migración, asilo y fronteras sobre las que posteriormente nos detendremos, el art. 79.5 TFUE prevé el respeto al derecho de los EEMM en la determinación del volumen de admisión de nacionales de terceros países. Una disposición que exige acometer, de un modo proactivo o preventivo, la incapacidad o sobrecarga de ciertos EEMM a la tramitación y acogida de grandes afluencias de migrantes y solicitantes de protección internacional por medio de un alto nivel de coordinación en el intercambio de información entre las autoridades nacionales y las agencias u organismos comunitarios al efecto. Asimismo, teniendo en consideración que la UE no tiene poderes de ejecución stricto sensu (art. 88.3 TFUE), esta disposición pretende reducir o, al menos, solventar los problemas de seguridad a los que se han enfrentado los EEMM.

Sin embargo, en los últimos años, ha sido empleado como "pretexto" para eludir el compromiso internacional con la llegada de refugiados a gran escala aunque como tal, no pueda emplearse como argumento que justifique per se la aplicación de excepciones radicadas en seguridad nacional. La determinación de las bases legales para restringir los derechos fundamentales en interés público sigue siendo, en última instancia, responsabilidad de los EEMM.

3) En el alcance del dominio nacional de los poderes operativos en el mantenimiento de la política pública y la seguridad, también se incluye el área relativa a las fronteras interiores nacionales. ${ }^{105}$ Un desafío que tiene por objeto frenar el terrorismo yihadista o la inmigración irregular y que ha propiciado que, en los últimos años, hayan sido aplicadas medidas extraordinarias por medio del establecimiento de controles dentro del

\footnotetext{
${ }^{105}$ En el año 2012, el TJUE estableció que la eliminación del control en las fronteras interiores no debía afectar "al ejercicio de las competencias de policía de las autoridades competentes de los Estados miembros en virtud de su Derecho interno, en la medida en que el ejercicio de tales competencias no tenga un efecto equivalente a las inspecciones fronterizas, y que ello también es aplicable a las zonas fronterizas". (STJUE Atiqullah Adil y Minister voor Immigratie, Integratie en Asiel, de 19 de julio de 2012 (Asunto C-278/12)). Para ello, adoptó un criterio flexible separando la relación entre los controles de identidad llevados a cabo por la policía en áreas cercanas a la frontera del control fronterizo sistemático, pues sería incompatible con la definición del mercado interior sin fronteras interiores del art. 26.2 TFUE. (STJUE Staatsanwaltschaft Offenburg, de 21 de junio de 2017 (Asunto C-9/16)).
} 
espacio Schengen. ${ }^{106}$ Esta situación hizo peligrar seriamente la libertad de circulación en el área Schengen que regula el art. 21.1 en su relación con los arts. 67 y 72 TFUE. ${ }^{107}$ De hecho, numerosos estudios han apuntado la necesidad de potenciar una política exterior europea que desarrolle una política adecuada de asilo que "compense" la libre circulación y asegure una gestión más eficiente de los flujos migratorios. ${ }^{108}$ En especial, como alude Lopez Aguilar, "el equilibrio adecuado entre la libertad de circulación y movimiento de personas y la eficacia en la lucha contra el crimen y contra sus amenazas, ha de ser observado de manera permanente y de acuerdo con los principios de proporcionalidad y de necesidad de acuerdo con los arts. 49 y 51 a 54 CDFUE". 109 En la actualidad, en su condición de presidente de la Comisión LIBE reclamó durante su participación en el Consejo informal JAI su grado más alto de coordinación hacia una "gestión común de las fronteras de la UE" que persiga intereses comunes para "desmantelar el negocio de los traficantes de personas". ${ }^{110}$

Acometiendo un análisis sobre esta situación, conviene recordar que determinados

\footnotetext{
${ }^{106}$ Sobre esta cuestión, remitimos a los estudios de: SPIKERBOER, T., "The human costs of burden control", European Journal of Migration and Law, 9 (1), 2007, pp. 147-161; CORNELISSE, G., "What's wrong with Schengen? Border Disputes and the Nature of Integration in the Area without Internal Borders", Common Market Law Review, no 51, 2014, pp. 741-770; ADLER, E. BARNETT M., "Security Communities in Theoretical Perspective", en Security Communities, 1998, pp. 29-65, Cambridge University Press; BREMBERG, N., "The European Union as Security Community-Building Institution: Venues, Networks and Co-operative Security Practices", Journal of Common Market Studies, vol. 53, $\mathrm{n}^{\circ}$ 3, 2015, pp. 674-692.

${ }^{107}$ La cuestión prejudicial planteada ante el TJUE en el asunto Gena Ivanova Cholakova/Osmo rayonno, de 10 de enero de 2013 determinó que estas disposiciones debían interpretarse de forma no excluyente con una disposición nacional de un EEMM, siempre y cuando representase una amenaza a su orden público o seguridad interior. TJUE, Petición de decisión prejudicial planteada por el Administrativen sad Sofia-grad (Bulgaria) presentada el 10 de enero de 2013 - Gena Ivanova Cholakova/ Osmo rayonno upravlenie pri Stolichna direktsiya na vatreshnite raboti (Asunto C-14/13). Sobre el particular, remitimos a: VON DANWICH, T., "The Rule of Law in the Recent Jurisprudence of the ECJ", en: Strengthening the Rule of Law in Europe. From a Common Concept to Mechanisms of Implementation, SCHROEDER W. (ed.), Hart Publishing, Modern Studies in European Law, 2016, p. 166.

${ }^{108}$ OLESTI RAYO, A., "Las políticas de la Unión Europea relativas al control de las fronteras, asilo e inmigración", Revista de Derecho Constitucional Europeo, $\mathrm{n}^{\circ}$ 10, 2008, pp. 13-48; GOIG MARTÍNEZ, J.M., "Inmigración, asilo y refugio ante los retos actuales de la política exterior europea", Revista de Derecho UNED, no 18, 2016, p. 66; DEL VALLE GÁLVEZ A., "Unión Europea, crisis de refugiados y limes imperii", Revista General de Derecho Europeo, n. 38, 2016, pp. 1-13. DONAIRE VILLA, F. J. "¿De qué hablamos cuando hablamos de coordinación en el ámbito de la Unión Europea y, por tanto, del ELSJ?", en F. J. DONAIRE VILLA, A. OLESTI RAYO (dirs.). Técnicas y ámbitos de coordinación en el Espacio de Libertad, Seguridad y Justicia, Marcial Pons, Madrid, 2015, p. 32.

${ }^{109}$ LOPEZ AGUILAR J.F., "El legislador europeo en materia de seguridad y justicia tras el Tratado de Lisboa: avances hacia la cooperación judicial penal en la UE", Teoría y Realidad Constitucional, $\mathrm{n}^{\circ}$. 32 , 2013, p. 202.

${ }^{110}$ Consejo Europeo, Reunión informal de ministros de Justicia y Asuntos de Interior, 18 y 19 de julio de 2019.
} 
estados, en virtud de su margen de apreciación nacional, emplearon la excepción temporal que regula el art. 25 y ss. del Reglamento 2016/399 o, comúnmente denominado Código de Fronteras Schengen (CFS), modificado parcialmente por el Reglamento 2017/458 de 15 de marzo de 2017. ${ }^{111}$ Este último pretendió reforzar los controles mediante la comprobación en las bases de datos pertinentes en las fronteras exteriores $^{112}$ y concluyó el 8 de junio de 2017. El Consejo de la UE adoptó una serie de conclusiones en relación con el establecimiento de controles de seguridad de la migración irregular, destacando la importancia de establecer mejores prácticas en términos de controles de seguridad. ${ }^{113}$ Máxime teniendo en cuenta los precedentes de los controles fronterizos excepcionales o de emergencia intra-Schengen que fueron impuestos en virtud del art. 25 CFS tras la crisis migratoria a gran escala del año 2015 y que limitaron muy seriamente la libertad de circulación en el área Schengen.

Por un lado, Alemania, Austria, Eslovenia, Suecia, Dinamarca y Noruega ${ }^{114}$ alegaron que la afluencia masiva migratoria de 2015 constituía una amenaza para su seguridad interior, estableciendo controles internos temporales con objeto de favorecer una acción correctora de los déficits en materia de seguridad. ${ }^{115}$ Tal fue el alcance de esta

${ }^{111}$ Reglamentos 2016/399 del Parlamento Europeo y del Consejo, de 9 de marzo de 2016, por el que se establece un Código de normas de la Unión para el cruce de personas por las fronteras y 2017/458 del Parlamento Europeo y del Consejo, de 15 de marzo de 2017, por el que se modifica el Reglamento (UE) 2016/399 en lo relativo al refuerzo de los controles mediante la comprobación en las bases de datos pertinentes en las fronteras exteriores.

${ }^{112}$ Este Reglamento comunitario previó una mejorada identificación de los conocidos "combatientes terroristas extranjeros", sentando las bases sobre una primera interoperabilidad de los datos contenidos en distintas bases de datos. Esta modificación prevé adaptarse más eficientemente a la realización de inspecciones en las fronteras exteriores y evitar cualquier tipo de amenaza para la seguridad interior, esto es, permitiendo una identificación más detallada de los individuos que tengan la intención de ocultar su identidad o que sean objeto de alertas importantes por motivos de seguridad o de arresto (Considerando 1 y 10) sin perjuicio de rebajar estas comprobaciones si su impacto fuera desproporcionado salvo en caso de dudas sobre la autenticidad del documento de viaje o cuando existan indicios de que una persona puede constituir una amenaza para el orden público o la seguridad interior. En este último caso, la guardia de fronteras debe consultar todas las bases de datos pertinentes (Considerando 11). Una mayor inspección ordinaria donde la comprobación exhaustiva en las distintas bases de datos no se considera una amenaza para el orden público, la seguridad interior (art. $1.2 \mathrm{~b}$ ).

${ }^{113}$ Consejo de la Unión Europea, Conclusiones del Consejo en las que se recomienda realizar controles de seguridad en caso de migración irregular, 8 de junio de 2017 (10152/17). Disponible en: http://data.consilium.europa.eu/doc/document/ST-10152-2017-INIT/es/pdf

${ }^{114}$ Este último, a pesar de que no es un Estado miembro de la UE, si forma parte o está asociado al espacio "Schengen"

${ }^{115}$ Consejo de la Unión Europea, "Nota de la Delegación Alemana al Grupo de Trabajo en Fronteras", 14 de septiembre de 2015. http://data.consilium.europa.eu/doc/document/ST-11986-2015-INIT/en/pdf; "Nota de la Delegación Austríaca al Grupo de Trabajo en Fronteras, 17 de septiembre de 2015. http://data.consilium.europa.eu/doc/document/ST-12110-2015-INIT/en/pdf; "Nota de la Delegación 
habilitación, que Eslovenia la amplió en una ocasión mientras que Suecia la extendió hasta el 18 de diciembre, modificándola ulteriormente por los controles especificados en el art. 23 CFS. Por otro lado, a raíz de los ataques terroristas perpetrados en París el 13 de noviembre de 2015, el 7 de diciembre de 2015, Francia notificó la reintroducción de controles fronterizos desde el 14 de diciembre de 2015 hasta el 26 de febrero de 2016 y que extendió hasta el 27 de marzo 2016. Este considerable lapso de tiempo respondía ya no solo a criterios basados en su seguridad nacional, sino en una cuestión basada en terrorismo de conformidad con el art. 23 CFS. ${ }^{116}$ Igualmente, tras la Cumbre de La Valeta sobre migración de noviembre de 2015, también Malta alegó amenaza terrorista global para imponer límites fronterizos.

La experiencia de estas crisis evidenció una perceptible escasez de detalles sobre los motivos para la reintroducción de controles fronterizos por parte de estados como Alemania o Austria, que alegaron que la falta estructural de fuerzas policiales constituía una amenaza contra su seguridad interior y orden público. Noruega, por su parte, articuló su estrategia de defensa y amenaza contra su seguridad sobre el carácter impredecible de estas llegadas. ${ }^{117}$ Y particularmente relevante fue que la restricción en

Permanente de Dinamarca al Secretario General del Consejo de la Unión Europea", 19 de octubre de 2015. http://data.consilium.europa.eu/doc/document/ST-13214-2015-INIT/en/pdf; "Nota de la Delegación de Eslovenia al Grupo de Trabajo en Fronteras", 20 de octubre de 2015. http://data.consilium.europa.eu/doc/document/ST-13170-2015-INIT/en/pdf; "Nota de la Delegación de Suecia al Grupo de Trabajo en Fronteras", 12 de noviembre de 2015. http://data.consilium.europa.eu/doc/document/ST-14047-2015-INIT/en/pdf; "Nota de la Delegación de Noruega al Grupo de Trabajo en Fronteras", 25 de noviembre de 2015. http://www.statewatch.org/news/2015/nov/eu-council-norway-schengen-closing-borders-11-15.pdf.

[Consultas: 15 de febrero de 2019]

La Comisión publicó la evaluación sobre la aplicación de las limitaciones entre fronteras que llevaron a cabo en Alemania, Austria y Eslovenia al amparo del art. 25 CFS el 23 de octubre de 2015 e hizo público el octavo informe bianual sobre el funcionamiento del área Schengen, para el período entre el 1 de mayo y el 10 de diciembre de 2015. Véase Comisión Europea, Opinión sobre la necesidad y proporcionalidad de los controles y las fronteras interiores reintroducidas por Alemania y Austria, Bruselas, 23 de octubre de 2015, 7100 final; Comisión Europea, Comunicación de la Comisión al Parlamento Europeo y al Consejo, Octavo informe bianual sobre el funcionamiento del espacio Schengen. Del 1 de mayo al 10 de diciembre de 2015, de 15 de diciembre de 2015 (COM(2015) 675 final).

${ }^{116}$ Consejo de la Unión Europea, "Nota de la Delegación de Francia al Grupo de Trabajo en Fronteras", 11 de febrero de 2016. http://data.consilium.europa.eu/doc/document/ST-5981-2016-INIT/en/pdf [Consulta: 17 de febrero de 2019]

${ }^{117}$ Sobre un análisis exhaustivo sobre esta cuestión, véase: DINGOTT ALKOPHER, T., BLANC, E., "Schengen Area shaken: the impact of immigration-related threat perceptions on the European security community", Journal of International Relations and Development, vol. 20, $\mathrm{n}^{\circ}$ 3, 2017, p. 521, GUILD, E., "Seguridad, Terrorismo y Asilo en el Schengen Area", Anuario CIDOB de la Inmigración, 20152016, pp. 58-78; Parlamento Europeo, The Cost of Non-Schengen: Civil Liberties, Justice and Home Affairs aspects Cost of Non-Europe Report, Septiembre de 2016, p. 18; FIJNAUT, C., "The Refugee 
las fronteras interiores de verdaderos EEMM afectados por los flujos migratorios a gran escala como Grecia o Italia, que no reintrodujeron controles en este ámbito.

La mayor parte de los EEMM justificaron el restablecimiento de los controles fronterizos dentro del espacio Schengen, basándose deficiencias en sus fronteras exteriores incompatibles con su seguridad u orden público. Supuestos contrarios al Considerando $26 \mathrm{y}$ al art. $25 \mathrm{CFS}$, que exigen que el restablecimiento de controles fronterizos para hacer frente a amenazas no pueda efectuarse sin proceder previamente a otro tipo de medidas menos restrictivas y generales -pese a que la Comisión justifica su aplicación en supuestos no solo de terrorismo transfronterizo, sino también a movimientos secundarios irregulares- ${ }^{118}$

Los EEMM quedan obligados a tramitar tanto las solicitudes de protección internacional que se les plantean -aun cuando se generen movimientos secundarios y el sujeto en cuestión entre en un EM que hubiera reintroducido controles en su frontera nacional- como a los migrantes en situación irregular -en cuyo caso deberán aplicarse las fases del procedimiento previsto en la Directiva de retorno con arreglo al CFS- ${ }^{119}$ Sin embargo, la imprecisa o amplia justificación de los supuestos susceptibles de atentar directamente contra la seguridad y el orden público ante la llegada de solicitantes de protección internacional constituyen supuestos contrarios a la normativa internacional, al SECA y que no permiten la reintroducción de controles en fronteras interiores de acuerdo con el CFS. Esta flexibilidad puede ser, incluso, más restrictiva si la Comisión y los EEMM adoptan el "procedimiento inmediato" para restablecer los controles temporales de fronteras interiores en virtud de los arts. 28 y 29 CFS.

En este caso, la activación del procedimiento específico previsto en el art. 29 CFS por el que se procedió a una evaluación sin previo aviso en Grecia durante la afluencia masiva de emigrantes en 2015 constituyó una de las medidas que la Comisión previó

Crisis - The End of Schengen", European Journal of Crime, Criminal Law and Criminal Justice, vol. 23, $\mathrm{n}^{\mathrm{o}} 4,2015$, p. 317.

${ }^{118}$ Comisión Europea, Factsheets Compilation, 2017-2018, p. 131.

${ }^{119}$ Un Estado miembro debe aplicar las fases del procedimiento de retorno establecidas en la «Directiva retorno» a la situación de un nacional de un tercer país detenido o interceptado con ocasión del cruce irregular de una frontera interior en la que se han restablecido los controles fronterizos con arreglo a las disposiciones del Código de fronteras Schengen. De acuerdo con las Conclusiones del Abogado General en el asunto C-444/17, 17 de octubre de 2018. Accesible en: https://curia.europa.eu/jcms/upload/docs/application/pdf/2018-10/cp180156es.pdf 
para fomentar la vuelta al funcionamiento normal. ${ }^{120} \mathrm{Y}$ a pesar de la reintroducción parcial de controles fronterizos por parte de lo 5 estados más afectados sobre tramos concretos de sus fronteras interiores y de forma conexa en rutas con Grecia, país sumamente deficiente en este ámbito ${ }^{121}$ y a sus continuas prórrogas (un total de 3 ) sobre el establecimiento de controles fronterizos motivadas por una serie de formalidades y condiciones previstas en el CFS, esto es, la justificación de generación de movimientos secundarios, la obligación de presentar a la Comisión los informes sobre los controles con objeto de supervisar su pertinencia y necesidad y la aplicación extraordinaria de esta medida, previendo alternativas menos invasivas en el área Schengen.

Es importante destacar que, una vez finalizados los controles fronterizos el $11 \mathrm{de}$ noviembre de 2017, los movimientos secundarios se redujeron drásticamente. ${ }^{122}$ Desde este año, las políticas de fronteras centradas en la seguridad pugnan directamente con las inspecciones mínimas que regula el Reglamento 2017/458, cuyo régimen jurídico está centrado en una verificación rápida de la validez del documento de viaje para cruzar la frontera que persigue mantener la libre circulación de personas en el área Schengen (Considerando $2^{\circ} \mathrm{CFS}$ ). Unas inspecciones que deben respetar, en todo caso, los derechos fundamentales (art. 4 CFS), lo que requiere una obligación activa para los EEMM en el despliegue del personal adecuado y los medios suficientes para garantizarlas y así evitar o reducir un tiempo de espera desproporcionado, uno de los factores que obstaculizan el flujo del tráfico ordinario en las fronteras exteriores.

De hecho, las comprobaciones sistemáticas en las distintas bases de datos en las fronteras se articulan en el Considerando 11 de forma accesoria, de modo que los EEMM no deberán realizarlas “(...) cuando, sobre la base de una evaluación de riesgo, se determine que esa relajación no va a poner en peligro la seguridad”. Esto se traduce en que el restablecimiento de controles fronterizos por los motivos del art. 25 CFS exige

\footnotetext{
${ }^{120}$ Comisión Europea, Comunicación de la Comisión al Parlamento Europeo, al Consejo Europeo y al Consejo «Restablecer Schengen - Hoja de ruta», de 4 de marzo de 2016, COM(2016) 120 final.

${ }^{121}$ Decisión de Ejecución 2017/818 del Consejo de 11 de mayo de 2017 por la que se establece una Recomendación para prorrogar la realización de controles temporales en las fronteras interiores en circunstancias excepcionales que pongan en peligro el funcionamiento global del espacio Schengen. Véanse las Recomendaciones 2016/1989 del Consejo, de 11 de noviembre de 2016, y (UE) 2017/246 del Consejo, de 7 de febrero de 2017, para prorrogar la realización de controles temporales en las fronteras interiores en circunstancias excepcionales que pongan en peligro el funcionamiento global del espacio Schengen.

${ }^{122}$ Comisión Europea, Comunicación de la Comisión al Parlamento Europeo, al Consejo Europeo y al Consejo «sobre la protección y refuerzo Schengen», $\operatorname{COM}(2017) 570$ final, de 27 de septiembre de 2017, p. 4.
} 
no solo justificar la amenaza grave para el orden público y la seguridad interior, sino su aplicación extraordinaria o como último recurso. Igualmente, deberán cumplirse las formalidades del art. 26 CFS -tanto la evaluación de la amenaza y el principio de proporcionalidad como un análisis de la repercusión del restablecimiento de la fronterade acuerdo con el procedimiento ordinario que regula el art. 27 -salvo que se requiera una actuación inminente contra la amenaza a la seguridad interior u orden público, en cuyo caso se seguirá el procedimiento del art. 28 CFS-.

Además, su comprobación no puede ser óbice para la tramitación de las solicitudes de protección internacional. La Directiva de Acogida 2013/33/UE prohíbe la detención e internamiento si no resulta de aplicación uno de los supuestos tasados del art. 7.3, cuya letra e) plantea un amplio margen de discrecionalidad puesto que establece “cuando así lo exija la protección de la seguridad nacional y el orden público”. Y la reintroducción de controles en las fronteras interiores -a diferencia de las exteriores cuyo fin último es garantizar el control de toda la UE- no debe perseguir un exclusivo interés jurídico nacional radicado en la amenaza contra su seguridad, sino que deben ponderarse la necesidad de la medida teniendo en cuenta los distintos intereses en juego.

La naturaleza del espacio Schengen se basa en el "transgubernamentalismo intensivo, ${ }^{123}$ término acuñado por Ziotti por el que redistribuye las responsabilidades entre la UE y los gobiernos nacionales. Sin embargo, cada Estado aborda la gestión de sus fronteras interiores de forma distinta, imponiendo restricciones radicadas en su propia seguridad que vacían de protección no únicamente las garantías del CFS sino, indirectamente, la implementación de otras políticas europeas y concretadas a nivel nacional como es el caso de las que conciernen al SECA. En este caso, la gestión del asilo se contempla como una cuestión que pende directamente de la libertad fronteriza, como factor que puede desestabilizarla. ${ }^{124}$ Estos solicitantes, salvo que se encuentren excepcionalmente detenidos, pueden trasladarse sin mayores controles a otros estados pertenecientes al área Schengen -salvo que se hubieran aplicado restricciones temporales-. Una tendencia al alza tras las llegadas "masivas" de refugiados en puntos fronterizos concretos donde una patente falta de cooperación agonizó la libertad de

${ }^{123}$ ZIOTTI R., Cultures of Border Control: Schengen and the Evolution of Europe's Frontiers, Chicago II, University of Chicago Press, 2008, p. 4.

${ }^{124}$ GROENENDIJK K., "New Borders Behind Old Ones: Post-Schengen Controls Behind internals Borders and Inside The Netherlands and Germany", en: GROENENDIJK K., GUILD E., MINDERHOUD P., (eds.), In Search of Europe's Borders, Kluwer Law International, La Haya, 2003, p. 58. 
circulación de las fronteras interiores. En este sentido, la medida extraordinaria de restablecer controles fronterizos interiores debería superarse no solo mediante el diseño de las políticas migratorias y de asilo orientadas hacia un reparto más justo de las responsabilidades y una mayor solidaridad (art. 80 TFUE), sino también adoptando rotundas medidas de refuerzo de las fronteras exteriores y controles policiales nacionales proporcionales y eficaces, tendentes a paralizar o reducir el "efecto dominó" que, por desgracia, acaeció cuando los estados antes mencionados restablecieron controles en sus fronteras interiores. ${ }^{125}$

Finalmente, independientemente de estos tres contextos determinados con anterioridad, aunque el TJUE pueda determinar un mayor o menor alcance del ámbito de aplicación del art. 72 TFUE, no tiene jurisdicción alguna para revisar la legalidad de las medidas concretadas por los EEMM (art. 276 TFUE). ${ }^{126}$ Por consiguiente, los tribunales nacionales no pueden remitir la cuestión prejudicial ante el TJUE (art. 267 TFUE) a pesar de su conflicto con los derechos fundamentales garantizados por la CDFUE, de tal manera que si la medida de seguridad se basa exclusivamente en su legislación nacional, los EEMM únicamente se encontrarán vinculados por tales disposiciones cuando apliquen el Derecho de la UE (art. 51.1 CDFUE). Ahora bien, en la medida que la ley comunitaria regula este ámbito -en este supuesto, la reintroducción temporal de controles en las fronteras internas dentro de la UE-, el TJUE puede entrar a conocer sobre este asunto puesto que afecta a la esencia del derecho comunitario. ${ }^{127}$ Por analogía, también lo serían las reiteradas excepciones de la legislación nacional al SECA sobre las que nos detendremos más adelante o, incluso, las condiciones que se regulan para la concesión del visado humanitario para los solicitantes de asilo, ${ }^{128}$ al

\footnotetext{
${ }^{125}$ Recordemos que la Comisión en su recomendación de 2017 instó a la aplicación de parámetros de proporcionalidad y eficacia por parte de la legislación de cada Estado. Recomendación de la Comisión, de 12 de mayo de 2017, sobre los controles policiales proporcionados y la cooperación policial en el espacio Schengen, C(2017) 3349 final. Ahora bien, los Estados alegaron que estos controles no sustituían, sino que podían completar los controles en las fronteras interiores, especialmente en un corto plazo de tiempo. Comité Permanente de Cooperación Operativa en materia de Seguridad Interior (COSI) del Consejo celebró un debate orientativo el 20 de junio de 2017 y un debate complementario el 10 de julio de 2017.

${ }^{126}$ El art. 276 TFUE dispone específicamente que este Tribunal "no será competente para comprobar la validez o proporcionalidad de operaciones efectuadas por la policía u otros servicios con funciones coercitivas de un Estado miembro, ni para pronunciarse sobre el ejercicio de las responsabilidades que incumben a los Estados miembros respecto del mantenimiento del orden público y de la salvaguardia de la seguridad interior".

${ }^{127}$ STJUE Melki y Abdeli, de 22 de junio de 2010 (Asuntos acumulados C-188/10 y C189/10).

${ }^{128}$ Sobre este nuevo visado humanitario que afecta a los solicitantes de asilo, véase: Parlamento Europeo, Humanitarias Visas, European Added Value. Assessment accompanying the European Parliament's
} 
tratarse de legislación eminentemente comunitaria que limita con el mantenimiento del orden público y la salvaguardia de la seguridad interior de los EEMM.

\subsection{La cláusula "general" de seguridad nacional.}

Por lo que respecta al art. 4.2 TUE, este alude a un criterio más amplio como es la seguridad nacional, disponiendo que la UE respetará en el plano nacional “(...) sus identidades nacionales, inherentes a sus estructuras fundamentales, políticas y constitucionales, que incluyen el autogobierno regional y local. Deberá volver a respetar sus funciones esenciales del Estado, incluida la garantía de la integridad territorial del Estado, el mantenimiento de la ley y el orden y la protección de la seguridad nacional. En particular, la seguridad nacional sigue siendo responsabilidad exclusiva de cada Estado miembro".

El mencionado artículo incorpora una triple obligación en el derecho de la UE, la cual se concreta tanto en el respeto a las identidades nacionales; su integridad territorial y mantenimiento de la ley y el orden; como por la cláusula de seguridad nacional, que refuerza todo este régimen de garantías. ${ }^{129}$ Una disposición que también recoge el Considerando $3^{\circ}$ del preámbulo de la CDFUE y que diverge de la vertiente de "seguridad" del TFUE, que se limita a la interior, es decir, a los asuntos de justicia y de interior que reconoce el Título V TFUE.

Mientras que la identidad fue una extensión de la conocida como "cláusula de identidad" circunscrita, por primera vez, al derecho primario por el Tratado de

legislative own-initiative report (Rapporteur: Juan Fernando López Aguilar), Study European Parliamentary Research Service, octubre de 2018. Disponible en http://www.europarl.europa.eu/RegData/etudes/STUD/2018/621823/EPRS_STU\%282018\%29621823_E N.pdf [Consulta: 29 de junio de 2019]

${ }^{129}$ El alcance de la identidad nacional resulta especialmente amplio. Tanto es así, que el TJUE no ha concretado su alcance, más allá de reconocer como tal los elementos estructurales de los EEMM. Y tanto si se trata de Estados republicanos o monárquicos (STJUE Sayn-Wittgenstein, de 22 de diciembre de 2010. Asunto C-208/09), como si están o no federados (Conclusiones del Abogado General, Comisión Europea c. España, de 30 de mayo de 2013. Asunto C-151/12) Ahora bien, esta primera labor de especificación plantea dudas sobre si las identidades nacionales se limitan únicamente a las estructuras orgánicas de los Estados. El TJUE concreta este concepto de forma general aunque, hasta hoy, son los EEMM los que ostentan la capacidad de adaptación y concreción a sus identidades nacionales individuales. Sobre las identidades nacionales, véase GROUSSOT, X., "Constitutional Dialogues, Pluralism and Conflicting Identities” en: AVBELJ M., KOMÀREK J., (eds.), Constitutional Pluralism in the European Union and Beyond, Oxford: Hart Publishing, 2012, pp. 319-341. 
Maastricht de $1992,{ }^{130}$ su segundo y tercer párrafo relativos a la propia seguridad de estado fueron adoptados tras las negociaciones del TL con el propósito de evitar amplias políticas que cuestionasen, con independencia de la excepción de seguridad del art. 72 TFUE, la efectividad del ELSJ del art. 67 TFUE. Aun así, ha revestido un alto grado de ambigüedad, previéndose su aplicación para una gran amalgama de escenarios, inclusive, en las competencias nacionales y comunitarias en el ámbito del asilo. ${ }^{131}$

Por lo que respecta al "mantenimiento de la ley y el orden", aunque coincide con el concepto de "seguridad pública u orden público" que regula el TFUE en gran parte de su articulado, ${ }^{132}$ difiere del concepto de "seguridad interior" (art. 72), "seguridad nacional” (art. 73), “intereses esenciales de seguridad” (art. 346.1 a) y b)), la dimensión de seguridad exterior (arts. 220 y ss.) o seguridad internacional (art. 347). No obstante, el "mantenimiento de la ley y el orden" y "seguridad nacional" convergen de la disposición general del art. 4.2 TUE, que abarca posibles políticas relacionadas con las amenazas contra la seguridad pública, las cuales han sido reconocidas por la jurisprudencia del TJUE como motivos que justifican las excepciones a la legislación de la UE desde un doble extremo:

La primera de ellas impone una obligación legal a la UE de respetar todos aquellos elementos relacionados con la identidad nacional -es más, la doctrina se muestra favorable a emplear esta materia como medio de impugnación directa de la validez del derecho de la UE, el ejercicio incorrecto de sus competencias y el incumplimiento del principio de subsidiariedad-. ${ }^{133}$ Una exigencia que no equivale a la inherente excepción generalizada de excluir de facto todas aquellas medidas de alcance comunitario por

${ }^{130}$ Sobre un análisis de la identidad nacional, véase: VON BOGDANDY A., SCHILL, S., "Overcoming Absolute Primacy: Respect for National Identity under the Lisbon Treaty", Common market law review, vol, 48, $\mathrm{n}^{\circ}$ 5, 2011, p. 1441; BESSELINK, L.F.M., "National and constitutional identity before and after Lisbon", Utrecht Law Review, vol. 6, n 3, 2010, p. 41; MARTÍNEZ LOPEZ-SAEZ M., "A la búsqueda de la identidad constitucional: una aproximación al caso español y europeo en clave de pluralismo constitucional y diálogo judicial", Revista de Derecho Político, nº 105, 2019, pp. 236 y ss.

${ }^{131}$ PEERS S., "Legislative Update, EU Inmigration and Asylum Competence and Decision Marking in the Treaty of Lisbon", European Journal of Migration and Law, vol. 10, n 2, 2008, pp. 219-247.

${ }^{132}$ Véanse los arts. 36, 45 (3), 52, 65.1 b) TFUE

${ }^{133}$ BURGORGUE-LARSEN, L., "A Huron at the Kirchberg Plateau or a Few Naïve Thoughts on Constitutional Identity in the Case-Law of the Judge of the European Union" en ARNAIZ A., LLIVINA C., (eds.), National Constitutional Identity and European Integration, Cambridge, Intersentia, 2013; DOBBS M., "Sovereignty, Article 4(2) TEU and the Respect of National Identities: Swinging the Balance of Power in Favour of the Member States?", Yearbook of European Law, vol. 33, nº 1, 2014, pp. 298-334; Ídem., "The Shifting Battleground of Article 4(2) TEU: Evolving National Identities and the corresponding need for EU management?", European Journal of Current Legal Issues, vol. 21, $\mathrm{n}^{\circ} 2$, 2015. 
cuestiones radicadas en la seguridad pública. ${ }^{134}$ De esta manera, pese a que corresponde al EM tomar las medidas apropiadas para asegurar su seguridad interna y externa, la amplia jurisprudencia del TJUE recuerda que el mero hecho de una decisión relativa a seguridad de Estado no puede resultar en la no aplicación del derecho de la UE. ${ }^{135}$

En cambio, la dimensión de "seguridad nacional" congrega el monopolio del poder de un Estado en lo que respecta tanto a la seguridad interior y exterior, pese a que nada se establece sobre si existe un límite absoluto o relativo. De acuerdo con esto, todo parece indicar que se trata de esta última, por cuanto la obligación de "respetar" en sede nacional el derecho de la UE exige equilibrar de manera proporcional ambos intereses en juego. Es más, Claes y Klambert consideran que el art. 4.2 TUE no crea una obligación de la UE de otorgar prioridad a los intereses nacionales en detrimento de los comunitarios ni tampoco impone una obligación derivada del principio de lealtad. ${ }^{136}$ Tampoco el TJUE ofrece un criterio concreto, sino que apuesta por un enfoque mixto, es decir, en algunos casos, ha tenido en cuenta la estructura organizativa de los EEMM como límite estricto a la legislación de la UE, reservándose la prerrogativa para limitar su alcance ${ }^{137} \mathrm{y}$, en otros supuestos -mayoritarios desde el año 96-, se aplica una regla estricta de proporcionalidad, ponderando los intereses en conflicto y los medios menos

\footnotetext{
${ }^{134}$ La STJUE Comisión c. Portugal, de 4 de marzo de 2010 determinó que un EM no podía tender a evitar la aplicación del derecho de la UE invocando intereses de seguridad nacional como justificación para no aplicar sus obligaciones consuetudinarias. Asimismo, recordó que los arts. 36, 45, 52, 65, 72, 346 y 347 del TFUE prevén expresamente derogaciones aplicables en casos concretos que puedan afectar la seguridad pública. Véase párr. 62 de la STJUE Comisión c. Portugal, de 4 de marzo de 2010 (Asunto C38/06) y párr. 31 STJUE Alexander Dory c. Bundesrepublik Deutschland, de 11 de marzo de 2003 (Asunto C186-01).

${ }^{135} \mathrm{La}$ Gran Sala del TJUE respondió a la cuestión prejudicial planteada por la Corte Apelación de Reino Unido en la STJUE ZZ/Secretary of State for the Home Department, de 4 de junio de 2013, (Asunto C300/11), párr. 38 o STJUE (Gran Sala) Comisión Europea c. República Italiana, de 15 de diciembre de 2009 (Asunto C-387/05), párr. 45. Véase igualmente De WITTE B., "Exclusive Member State Competences - Is There Such a Thing?", en: GARBEN, S., GOVAERE I., (eds.), The Division of Competences Between the EU and the Member States: Reflections on the Past, the Present, and the Future, Portland, OR: Hart Publishing, 2017, pp. 71-72.

${ }^{136}$ CLAES M., "Negociating Constitutional Identity or Whose Identity is it Anyway?, en Constitutional Conversations in Europe: Actors, Topics and Procedures, Intersentia, 2012, pp. 205-207; KLAMBERT M., "Article 4" en: Commentary on the EU: Treaties and the Charter of Fundamental Rights, KLAMERT, M., KELLERBAUER, M., TOMKIN J. (eds.), Oxford, 2019, p. 45.

${ }^{137}$ STJUE Digibet and Albers, de 12 de junio de 2014 (Asunto C-156/13); Remondis, de 21 de diciembre de 2016 (Asunto C-51/15); Izsák and Dabis, de 10 de mayo de 2016 (Asunto T-529/13).
} 
intrusivos que permitan determinar si las desviaciones nacionales de la legislación de la UE resultan o no justificados. ${ }^{138}$

Como veremos en sucesivos epígrafes, esta cláusula de identidad y reconocimiento de la propia seguridad de los EEMM se ha previsto en cada uno de los instrumentos jurídicos del SECA, disponiendo de continuas excepciones sobre este asunto. Ello con independencia de que ofrezca una regulación "común" - e incluso más coherente en la propuesta de reforma- sin dejar de lado el considerable y necesario grado de apreciación nacional para garantizar sus intereses de seguridad. ${ }^{139}$ Esta cláusula requiere una interpretación de la normativa comunitaria que, en todo caso, resulte coherente con la identidad y las funciones esenciales de los EEMM, por lo que las excepciones que contempla la normativa reguladora del SECA -y el resto de legislación comunitaria específica- no limitará las acciones nacionales que exceptúen su aplicación por cuestiones basadas en la seguridad y la defensa nacional, sin perjuicio de que se efectúe su cumplimiento con el criterio de proporcionalidad antes mencionado y, en todo caso, respetando los derechos fundamentales de la UE.

\section{Implicaciones de la seguridad como límite al derecho de asilo en la CDFUE y en el CEDH.}

Una de las cuestiones centrales que deben traese a colación es que tanto el TJUE como el TEDH ostentan jurisdicción en lo referente a la entrada y permanencia de inmigrantes en los EEMM y, en concreto, al régimen jurídico de las solicitudes de asilo, a la vista de los derechos reconocidos en el CEDH y en la CDFUE. De tal forma que, como apunta López Guerra, "se ha hecho evidente en varios casos referentes a la aplicación de las llamadas Reglas de Dublín, (en sus sucesivas versiones) sobre las obligaciones de los Estados que las suscriben relativas al envío, para una decisión sobre esa solicitud, del demandante de asilo al país en que hubiera efectuado su primera

\footnotetext{
${ }^{138}$ STJUE Comisión c. Gran Ducado de Luxemburgo, de 2 de Julio de 1996 (Asunto C-473/93); Comisión c. Gran Ducado de Luxemburgo, de 24 de mayo de 2011 (Asunto C-51/08), Runevič-Vardyn and Wardyn, de 12 de mayo de 2011 (Asunto C-391/09), Anton Las c. PSA Antwerp NV, de 16 de abril de 2013 (Asunto C-202/11), Nabiel Peter Bogendorff von Wolffersdorff c. Standesamt der Stadt Karlsruhe $y$ Zentraler Juristischer Dienst der Stadt Karlsruhe, de 2 de junio de 2016 (Asunto C-438/14).

${ }^{139}$ Así, recuérdese que las medidas adoptadas por la UE incompatible con el art. 4.2 TUE fueron de facto consideradas ilegales en la STJUE Torresi, de 17 de julio de 2014 (Asunto C-58/13).
} 
entrada en el ámbito territorial de la Unión Europea". ${ }^{140}$ Esto ha propiciado que se produzca un diálogo judicial especialmente intenso en el ámbito del derecho de asilo entre el Tribunal de Luxembugo y Estrasburgo, aspecto sobre el que se ha adentrado la doctrina constitucionalista ${ }^{141}$ y que profundizaremos más adelante.

Dicho esto, no debe obviarse que, al amparo del art. 6.1 TUE, la CDFUE se aplica en todos los asuntos que entran dentro del ámbito de aplicación de la legislación de la UE. Esta se sitúa en un rango semejante a los Tratados de la UE y resulta vinculante para los EEMM cuando "están aplicando la legislación de la Unión" (art. 51 CDFUE). Y, en lo referente al derecho a la protección internacional, tal y como estipula el art. 288 TFUE, los EEMM han implementado el conocido como "pack legislativo de asilo", ya sea por medio de la transposición de las "tradicionales" directivas al efecto -reconocimiento, procedimiento o acogida- como por la aplicación directa de los reglamentos comunitarios - esto es, del conocido como Sistema de Dublín.

Ahora bien, las distintas cláusulas de seguridad que con posteridad se abordarán han exceptuado en reiteradas ocasiones la aplicación coherente y uniforme del SECA. Una exclusión que no faculta a que los EEMM eludan el cumplimiento de las obligaciones de la CDFUE, puesto que esta tiene efectos vinculantes en sede nacional. ${ }^{142}$ Esta cuestión conduce a la afirmación de que los EEMM deben garantizar el derecho de asilo (art. 18 CDFUE) y la legislación relativa a la libre circulación de personas (art. 45.2 CDFUE), tanto si los sujetos son ciudadanos de la UE - es decir, ya disponen de estatuto

\footnotetext{
${ }^{140}$ LOPEZ GUERRA L., "E1 Tribunal Europeo de Derechos Humanos, el Tribunal de Justicia de la UE y «le mouvement nécessaire des choses»", Teoría y Realidad Constitucional, nº 39, 2017, p. 181.

${ }^{141}$ En relación con el diálogo judicial entre el TJUE, el TEDH y los tribunales constitucionales nacionales, véase entre otros: LOPEZ GUERRA L., "El diálogo entre el Tribunal Europeo de Derechos Humanos y los tribunales españoles. Coincidencias y divergencias", Teoría y Realidad Constitucional, $\mathrm{n}^{\circ}$ 32, 2013, pp. 139-158; De VERGOTTINI, G., "El diálogo entre tribunales", Teoría y Realidad Constitucional, $\mathrm{n}^{\circ}$ 28, 2011, pp. 335-352; ROCA TRÍAS, E., GARCÍA COUSO S., “¿Es real el diálogo entre tribunales? Cuestión prejudicial y control de constitucionalidad por vulneración de derechos y libertades fundamentales", Teoría y Realidad Constitucional, no 39, 2017, pp. 529-548; GARCÍA ROCA J., "El diálogo entre el Tribunal Europeo de Derechos Humanos y los Tribunales Constitucionales en la construcción de un orden público europeo", Teoría y Realidad Constitucional, n 30, 2012, pp. 183-224.

${ }^{142} \mathrm{Al}$ respecto el TJUE determinó que, tras una decisión de denegación de un visado, nada obstaba a que la CDFUE no fuera igualmente aplicable. STJUE Soufiane El Hassani y Minister Spraw Zagranicznych, de 13 de diciembre de 2017 (Asunto C-403/16). Así, pretende solventarse el conflicto jurídico entre la no aplicación del derecho primario de la UE (la CDFUE) y el sometimiento a las fuentes de Derecho secundario (en este caso, la normativa reguladora del SECA). Sobre estas cuestiones, remitimos a: JIMENA QUESADA L., "La consagración de los derechos fundamentales: de principios generales a texto fundacional de la Unión Europea", Cuadernos europeos de Deusto, nº 50, 2014, p. 183.
} 
formal de refugiado o protección subsidiaria- o nacionales de terceros países solicitantes sobre los cuales se determinará si tienen derecho o no a recibir protección internacional-. De tal manera, la CDFUE deberá aplicarse con independencia de la invocación de razones de política pública o de seguridad pública, teniendo presente que la omisión del derecho de la UE no obsta a que se respeten los derechos fundamentales reconocidos en la Carta.

Además, todas las restricciones en los derechos fundamentales por cuestiones que penden del propio concepto de seguridad deben cumplir con estrictos criterios de necesidad, proporcionalidad y una consecución del interés general (art. 53 CDFUE). Limitaciones que, en el ámbito del SECA, resultan especialmente frecuentes en el derecho a la seguridad personal y la libertad (art. 6), el respeto de la vida privada y familiar (art. 7), la protección de datos personales (art. 8) o la detención, expulsión o extradición (art. 19). Esta afirmación refuta la teoría de un importante sector doctrinal, que reconocían que en virtud del proceso de integración de la UE, las normas de protección internacional en varios EEMM eran, a grandes rasgos, muy garantistas y se situaban en un plano superior en lo que respecta a la protección de los derechos e intereses de este colectivo, en comparación con terceros estados. ${ }^{143}$ Sin embargo, como analizan empíricamente Léonard y Kaunert, las políticas de asilo en la UE se encuentran "securitizadas" desde hace más de dos décadas, ${ }^{144}$ dando lugar a la aplicación de generalizadas limitaciones al amparo del art. 53 CDFUE.

También el CEDH dispone de cláusulas de limitación -en este caso, formuladas de forma distinta-. Por ejemplo, en relación con el derecho al respeto a la vida privada y familiar, el art. 8 CEDH tipifica directamente que esta "deberá estar prevista por la ley y constituya una medida que, en una sociedad democrática, sea necesaria para la seguridad nacional, la seguridad pública (...)". Una diferencia que solventa el TEDH, que tiende a adoptar normas uniformes a todas estas disposiciones con objeto de paliar las divergencias entre las respectivas cláusulas. Así lo reconoce Grabenwarter cuando afirma que, el Tribunal de Estrasburgo otorga especial preeminencia a los principios de proporcionalidad y necesidad en una sociedad democrática como elemento central que

\footnotetext{
${ }^{143}$ ZAUN N., EU Asylum Policies: The Power of Strong Regulating States. Basing-stoke, Palgrave Macmillan, 2017, p. 58; EL-ENANY N., THIELEMANN E., "The Impact of EU Asylum Policy on National Asylum Regimen”, en: WOLFF S., GOUDAPPEL F., De ZWAAN J. (eds.), Freedom Security and Justice after Lisbon and Stockholm, The Hague, TMC Asser, 2011, p. 97.

${ }^{144}$ LÉONARD, S., KAUNERT, C., Refugees, Security and the European... ob. cit, p. 166.
} 
justifica tal vulneración de derechos. ${ }^{145}$ De tal forma que, la correspondencia entre los derechos garantizados por la CDFUE y CEDH resulta muy próxima.

Efectivamente, el apartado $3^{\circ}$ del art. 52 CDFUE así parece reflejarlo al regular expresamente que "En la medida en que la presente Carta contenga derechos que correspondan a derechos garantizados por el Convenio Europeo para la Protección de los Derechos Humanos y de las Libertades Fundamentales, su sentido y alcance serán iguales a los que les confiere dicho Convenio. Esta disposición no impide que el Derecho de la Unión conceda una protección más extensa". Por ende, las limitaciones de derechos en la CDFUE y el CEDH son, cuantos menos, análogas o semejantes. ${ }^{146}$

Igualmente, el art. 52 CDFUE también asegura que las cláusulas de limitación generales se mantengan, incluso, para las garantías del Convenio donde existen restricciones más concretas, como el derecho a la libertad y a la seguridad cuando alude a los múltiples supuestos que limitan este derecho (art. $5 \mathrm{CEDH}) .{ }^{147}$ De hecho, el segundo párrafo del apartado $3^{\circ}$ del art. 52 CDFUE declara que el derecho de la UE puede ir más allá del alcance de las garantías del CEDH, como ocurre en el ámbito del derecho de asilo a través de toda la normativa reguladora del SECA. Del mismo modo, esta cláusula insta implícitamente a que el TJUE desarrolle un estándar más favorable que el Convenio, el cual reconoce una amplia jurisprudencia en lo que respecta a los intereses de seguridad nacionales y, más concretamente, en su relación con el derecho a

\footnotetext{
${ }^{145}$ Véase el análisis doctrinal y jurisprudencial del art. 8 que recoge Grabenwarter en su obra y que no detallamos por no guardar relación directa con el ámbito del asilo. GRABENWARTER, C., European Convention on Human Rights. Commentary, Munich, CH Beck, Hart, Nomos, 2014.

${ }^{146}$ Conviene apuntar que, para Borowsky, el art. 52 CDFUE resulta plenamente coherente con el CEDH la cual se extiende, incluso, a las limitaciones de los derechos de la Carta. BOROWSKY M, "Artikel 52" en: MEYER J., (ed.), Charta der Grundrechte der Europäischen Union, Baden-Baden 4 a edición Nomos, 2014.

${ }^{147}$ De acuerdo con el art. 5 CEDH, estos supuestos son los siguientes: "a) Si ha sido privado de libertad legalmente en virtud de una sentencia dictada por un tribunal competente; b) Si ha sido detenido o privado de libertad, conforme a derecho, por desobediencia a una orden judicial o para asegurar el cumplimiento de una obligación establecida por la ley; c) Si ha sido detenido y privado de libertad, conforme a derecho, para hacerle comparecer ante la autoridad judicial competente, cuando existan indicios racionales de que ha cometido una infracción o cuando se estime necesario para impedirle que cometa una infracción o que huya después de haberla cometido ; d) Si se trata de la privación de libertad de un menor en virtud de una orden legalmente acordada con el fin de vigilar su educación o de su detención, conforme a derecho, con el fin de hacerle comparecer ante la autoridad competente ; e) Si se trata de la privación de libertad, conforme a derecho, de una persona susceptible de propagar una enfermedad contagiosa, de en enajenado, de un alcohólico, de un toxicómano o de un vagabundo; f) Si se trata de la detención o de la privación de libertad, conforme a derecho, de una persona para impedir su entrada ilegal en el territorio o contra la cual esté en curso un procedimiento de expulsión o extradición".
} 
la protección de datos, objeto de análisis en el capítulo $2^{\circ}$ y $3^{\circ}$ en su relación con el Sistema de Dublín. ${ }^{148}$

Sobre esta vinculación puede deducirse que, para las limitaciones de los derechos fundamentales afectados por legislaciones nacionales, en la medida en que sea aplicable tanto la CDFUE como las garantías del CEDH, las normas establecidas en esta última y desarrolladas por el TEDH deberán servir como "fuente de interpretación". ${ }^{149}$ Si bien, a efectos prácticos, el TJUE desarrolla una regla "estandarizada" de proporcionalidad la cual resulta, en gran medida, equivalente a la que contempla la jurisprudencia del TEDH. Y sin perjuicio de que se haya determinado un mayor nivel de protección en ciertos contextos, como por ejemplo, en la protección de datos de carácter personal.

Por lo tanto, en la mayoría de los casos, será la prueba de la proporcionalidad la que justifique la adopción de limitaciones en un derecho. Una cuestión que, en el ámbito del asilo, como podrá observarse a lo largo de este capítulo, operará bajo parámetros vinculantes como la prohibición general de devolución -incluso en su directa conexión con las cláusulas de exclusión o revocación del estatuto de protección internacional por cuestiones de seguridad nacional-. Se trata de un límite quasi absoluto que protege a un nacional de un tercer país frente a su expulsión si esta hipotética decisión pudiera comprometer su vida o integridad física, tal y como reconoce una amplia jurisprudencia del TJUE y TEDH a la que haremos referencia expresa.

Al margen de estas garantías, conviene tener presente que el art. $15 \mathrm{CEDH}$ prevé la posibilidad de derogar determinados derechos fundamentales cuando se constate la existencia de "un peligro público que amenace la vida de la nación". ${ }^{150}$ Una disposición

\footnotetext{
${ }^{148}$ STJUE Tele2 Sverige AB c. Post- och telestyrelsen y Secretary of State for the Home Department c. Tom Watson y otros, de 21 de diciembre de 2016 (Asunto C-203/15), párr. 129; J. N. y Staatssecretaris van Veiligheid en Justitie, de 15 de febrero de 2016 (Asunto C-601/15), párr. 46.

${ }^{149}$ Sobre un análisis sobre esta cuestión, remitimos al documento del TEDH, División de Investigación. Seguridad nacional y jurisprudencia europea, 2013. Disponible en: https://rm.coe.int/16806ae199 (únicamente en versión francesa). Para un análisis doctrinal al respecto, véase: PEERS S., PRECHAL, S, en: PEERS S., HERVEY, T., KENNER, J., WARD A. (eds.), The EU Charter of Fundamental Rights - A Commentary, Oxford (Hart), 2014, párr. 52.100 y ss.; LENAERTS, K., "Exploring the Limits of the EU Charter of Fundamental Rights", European Constitutional Law Review, vol. 8, nº 3, 2012, pp. 375-403; Ídem. "Limits on Limitations: The Essence of Fundamental Rights in the EU", German Law Journal, vol. 20, n 6, 2019, pp. 779-793; FRANTZIOU, E., "Constitutional Reasoning in the European Union and the Charter of Fundamental Rights: In Search of Public Justification”, European Public Law, vol. 25, $\mathrm{n}^{\circ} 2$, 2019, pp. 183-203.

${ }^{150}$ TEDH, Guía sobre el art. 15 del Convenio Europeo de los Derechos Humanos, abril de 2017. Disponible en: http://www.echr.coe.int/Documents/Guide_Art_15_ENG.pdf Human Rights Press Unit,
} 
que no se encuentra explícitamente regulada en la CDFUE y exige su aplicación en supuestos extraordinarios, ${ }^{151}$ sin contrariar las restantes obligaciones que dimanan del derecho internacional, incluyendo, consecuentemente, el derecho de asilo conforme a la Convención de Ginebra y Protocolo de Nueva York. Esta medida de carácter excepcional deriva del art. 4.1 TUE y arts. 72 y 347 TFUE, que disponen su adopción a nivel nacional por cuanto afecta a las áreas de defensa nacional. Este fue el caso de países como Francia y Ucrania y Turquía ${ }^{152}$ que comunicaron la derogación de disposiciones del Convenio por causas no relacionadas -al menos, directamente- con las crisis migratorias y de asilo, sino ante situaciones realmente graves que afectaron a su defensa nacional. Supuestos que varían desde intervención militar de las fuerzas rusas dentro del territorio ucraniano hasta los ataques terroristas de Francia -ambos en 2015- o el golpe de estado en Turquía en 2016 y sobre el que el TEDH se pronunció condenando (sentencia Alparslan Altan c. Turquía, de 16 de abril de 2019). ${ }^{153}$

Por lo tanto, la extraordinariedad de tal precepto únicamente permite la derogación de los derechos fundamentales cuando un estado se ve obligado a tomar medidas para

Factsheet - derogation in time of emergency, noviembre de 2017. Disponible en: www.echr.coe.int/Docu-ments/FS_Derogation_ENG.pdf [Consultas: 27 de junio de 2019]

${ }^{151}$ Recuerda Buzan que la extraordinaridad implica "elevar los problemas por encima de la política". BUZAN B., "Security Analysis: Conceptual Apparatus", en: BUZAN B., WAEVER O., WILDE de JAAP (eds), Security. A New Framework for Analysis, Boulder, CO, London, Lynne Rienner, 1998, p. 25. ${ }^{152}$ El 21 de mayo de 2015, el Parlamento de Ucrania adoptó la Resolución N ${ }^{\circ} 462$-VIII, que declaró una excepción al Convenio Europeo de Derechos Humanos (Convenio) por la intervención militar de las fuerzas rusas dentro del territorio ucraniano. Esto constituyó para este país una emergencia pública que amenazaba la vida de la nación. El 13 de noviembre de 2015, después de los ataques terroristas que ocurrieron en París, Francia presentó su propia excepción a sus obligaciones bajo la Convención, que fue invocado, entre otros motivos, para proceder a la detención generalizada de presuntos narcotraficantes y para interrogar a los migrantes irregulares. El 21 de julio de 2016, Turquía tomó una decisión similar y comunicó la derogación de la $\mathrm{CEDH}$ ante el Secretario general del Consejo de Europa, tras el golpe militar fallido. Según las autoridades turcas, planteaba peligros significativos para la seguridad pública y constituía una amenaza para la vida de la nación. Consejo de Europa, Reservations for the Protection of Human Rights and Fundamental Freedoms. Disponible en: https:/www.coe.int/en/web/conventions/fulllist/-/conventions/treaty/005/declarations. [Consulta: 20 de mayo de 2019]

${ }^{153}$ STEDH Alparslan Altan c. Turquía, de 16 de abril de 2019. Demanda no 12778/17. Esta sentencia del Tribunal de Estrasburgo constituye una de las decisiones más relevantes hasta el momento sobre la cláusula de derogación del art. $15 \mathrm{CEDH}$, condenando a Turquía por violaciones contrarias al art. 5 CEDH tras el intento de golpe de Estado el 15 de julio de 2016. El Tribunal anuló la cláusula de emergencia de este país ante la utilización errónea de esta cláusula por la que aprovechaba este marco jurídico excepcional para fines contrarios a su finalidad, haciendo uso de una interpretación extensiva de un delito flagrante basado meramente en una mera sospecha de pertenencia a una organización criminal. El TEDH enfatizó que las dificultades a las que se ha enfrentado Turquía posteriormente al golpe de Estado no pueden proporcionar una "carta blanca" para no aplicar y vulnerar el derecho a la libertad y a la seguridad del art. $5 \mathrm{CEDH}$, procediendo a la detención de individuos sin prueba alguna que demuestre su pertenencia a una organización criminal. 
enfrentar graves disturbios nacionales que alteren su orden público, en caso de guerra o de conflicto internacional de gran magnitud, los cuales están sujetos a una serie de condiciones tasadas por el TEDH. Desde un punto de vista formal, la situación de emergencia exige la notificación al Secretario General del Consejo de Europa además de su declaración a efectos de publicidad en sede nacional (apartado $3^{\circ}$ del art. 15 $\mathrm{CEDH}),{ }^{154}$ mientras que, su vertiente material requiere que la finalidad de dicha declaración sea "una situación excepcional de crisis o emergencia que afecte a toda la población y constituya una amenaza para la vida de la comunidad del estado". ${ }^{155}$

Asimismo, el apartado $2^{\circ}$ del mencionado artículo excluye expresamente la derogación del derecho a la vida (art. 2), la prohibición de la tortura (art. 3), el sometimiento a esclavitud o servidumbre (art. 4.1) o las violaciones al principio de legalidad (art. 7). En este caso, la obligación de respetar estos derechos fundamentales considerados "inderogables" debe aplicarse a todos aquellos escenarios que pueden poner en serio riesgo la eficacia del derecho a la protección internacional. Por esta razón, las crisis migratorias y de asilo -como las que se produjeron a gran escala durante los años 2015 y 2016- no pueden justificarse como causas que comprometan el peligro público de países afectados de acuerdo con el art. $15 \mathrm{CEDH}$, no tanto por la magnitud de estas circunstancias para la seguridad de un determinado estado, sino por los efectos tan adversos que puede acarrear para los derechos humanos de los refugiados.

La prohibición de entrada generalizada de estos sujetos supondría una violación indirecta de los arts. 2 y $3 \mathrm{CEDH}$ en una diversidad de contextos sobre los que lleva pronunciándose el TEDH. ${ }^{156}$ Ya desde la pasada década, prohibió el rechazo genérico a la entrada de sujetos en situación de riesgo en las fronteras de un EM, tanto sus fronteras terrestres como marítimas (STEDH Gebremedhin c. Francia, de 26 de julio de 2007). También ha obligado a evaluar el nivel de riesgo en el país de origen o tránsito para garantizar la protección que brinda el art. 3 CEDH (STEDH Saadi c. Italia de 28 de febrero de 2008).

\footnotetext{
${ }^{154}$ STEDH Brannigan and Mcbride c. Reino Unido, de 26 de mayo de 1993. Demanda $\mathrm{n}^{\circ}$ 14553/89.

${ }^{155}$ STEDH Lawless c. Irlanda, de 1 de julio de 1961. Demanda n ${ }^{\circ} 332 / 57$.

${ }^{156}$ Véase las sentencias del TEDH Soering c. Reino Unido, de 7 de julio de 1989 (demanda no 14038/88); Chahal c. Reino Unido, de 15 de noviembre de 1996 (demanda no 22414/93); Ahmed c. Austria, de 17 de diciembre de 1996 (demanda $n^{\circ}$ 25964/94); Hilal c. el Reino Unido, de 6 de marzo de 2001 (demanda ${ }^{\circ}$ 45276/99).
} 
Ahora bien, estas garantías produjeron una clara restricción de la actuación de los estados contratantes a la hora de adoptar aquellas medidas de expulsión tendentes en garantizar el mantenimiento de su seguridad. La Gran Sala del TEDH en la sentencia M.S.S. c. Bélgica y Grecia, de 21 de enero de $2011^{157}$ restringió las condiciones de expulsión incluso entre EEMM y reconoció que no cabía la expulsión de un solicitante de asilo desde Bélgica a Grecia si el procedimiento de asilo en este país, sumamente deficitario en lo que a condiciones de acogida se refería, no ofrecía garantías eficaces contra la devolución arbitraria. Consecuentemente, como recoge López Guerra, “el Tribunal ordenó al Gobierno griego que se abstuviera de deportar al recurrente en tanto se tramitaba su petición de asilo. ${ }^{158}$ A su vez, recordemos que, en el asunto Hirsi Jamaa $y$ otros c. Italia, de 23 de febrero 2012, ${ }^{159}$ la expulsión sumaria de migrantes ampliamente considerados interceptados en el mar por parte de las autoridades de Italia constituyó una actuación contraria al art. $3 \mathrm{CEDH}$ pues estos sujetos deberían haber podido acceder al procedimiento de asilo en este país.

Frente a estas estrictas condiciones en el régimen de devolución y expulsión, la STEDH Othman (Abu Qatada) c. Reino Unido, de 17 de enero de $2012^{160}$ supuso una de las más llamativas excepciones en este ámbito, autorizando la devolución de un nacional jordano que había obtenido el estatuto de refugiado en el Reino Unido en virtud de la ley de 2005 relativa a la prevención del terrorismo. El TEDH analizó el Memorándum de Entendimiento entre ambos países y consideró que su regreso al país de origen no expondría al sujeto a un riesgo real de tortura. Un importante pronunciamiento que vislumbró la crucial e imperiosa necesidad de cooperación entre estados no únicamente contratantes del CEDH sino con terceros Estados y que, aun con todo, no resulta ajeno a un potencial conflicto de gran entidad con el derecho de asilo. La falta de certeza absoluta sobre el respeto a los derechos inderogables cede ante una peligrosa cooperación que puede traspasar los límites en materia de protección internacional, dotando al procedimiento de devolución y expulsión de una mayor flexibilidad de las garantías previstas en el CEDH.

\footnotetext{
${ }^{157}$ STEDH M.S.S. c. Bélgica y Grecia, de 21 de enero de 2011. Demanda no 30696/09.

${ }^{158}$ LOPEZ GUERRA L., "La evolución del Sistema Europeo de Protección de Derechos Humanos, Teoría y Realidad Constitucional, n 42, 2018, p. 123.

${ }^{159}$ STEDH Hirsi Jamaa y otros c. Italia, de 23 de febrero 2012. Demanda $n^{\circ}$ 27765/09

${ }^{160}$ STEDH Othman (Abu Qatada) c. Reino Unido, de 17 de enero de 2012. Demanda n 8139/09.
} 
Una medida "a largo plazo" que en marzo de 2019 fue calificada por el Parlamento Europeo (PE) como "eje de la dimensión externa de la política de migración de la UE"161 y que ha entablado un diálogo político y estableciendo alianzas con terceros países susteptible de ser concretada a nivel nacional. ${ }^{162}$ Estas actuaciones articulan novedosos y eficaces procedimientos de gestión migratoria y devolución de migrantes a terceros países seguros. Si bien, son susceptibles de impactar negativamente en las garantías del derecho de asilo, aumentando el riesgo de vulnerar el principio de no devolución. No olvidemos que, con independencia de que las relaciones sean fructíferas y permitan constatar una "apariencia de respeto" del $\mathrm{CEDH},{ }^{163}$ se trata de estados "colaboradores" que sufren una alta inestabilidad política, económica, social, etc., lo que puede propiciar consecuencias desventajosas para este colectivo migrante.

\section{La radicalización como complejo parámetro de evaluación de la seguridad en el SECA.}

3.1. La radicalización y el reclutamiento de los solicitantes de asilo y refugiados.

La gran tipología de escenarios terroristas y la adhesión de distintos grupos de sujetos desplazados como los refugiados a los objetivos perseguidos por grupos extremistas violentos ha ampliado la tipificación de conductas susceptibles de consideración radical, incluyendo como perfiles terroristas a "difusas" categorías de

${ }^{161}$ Parlamento Europeo, The migration issue, Briefing. EU policies - Delivering for citizens, 2019, p. 2.

${ }^{162} \mathrm{La}$ asistencia humanitaria hacia migrantes y refugiados comenzó en el año 2011 a los países en conflicto como Siria o Irak y se extendió a la cooperación con otros países claves en la gestión de la crisis de los refugiados como Turquía, uno de los principales países de acogida. Tanto es así, que los EEMM acordaron otorgar de forma adicional 3.000 millones de euros para contribuir al Mecanismo de la UE para los refugiados en Turquía. Comisión Europea, Primer informe anual sobre el mecanismo de la UE para los refugiados en Turquía, marzo de 2017, $\operatorname{COM(2017)~} 130$ final.

Asimismo, la cooperación también se externaliza hacia los países de los Balcanes Occidentales -no pertenecientes a la UE- como Serbia incluso a países de África. Parlamento Europeo, EU asylum, borders and external cooperation on migration Recent developments, mayo de 2018. Accesible en: https://www.europarl.europa.eu/RegData/etudes/IDAN/2018/621878/EPRS_IDA(2018)621878_EN.pdf [Consulta: 26 de julio de 2019]

${ }^{163}$ Sobre esta cuestión, Jimena Quesada acuñó el término de "operaciones indirectas de inseguridad" cuando se refería al controvertido y actualmente suspendido Acuerdo entre la UE y Turquía de 18 de marzo de 2016. JIMENA QUESADA, L., "El asilo en los instrumentos europeos de derechos humanos: sinergias y optimización protectora ante la crisis humanitaria", en la obra colectiva Europa, ¿Tierra de asilo? Desafios y respuestas, Ararteko, Colección "Jornadas sobre derechos humanos", Vitoria-Gasteiz, 2016, $\quad$ p. $\quad 34$ (consulta online http://www.ararteko.eus/RecursosWeb/DOCUMENTOS/1/0_4086_3.pdf). [Consulta: 26 de julio de 2019] 
nacionales de terceros países como inmigrantes legales e ilegales, personas con derecho a protección subsidiaria, refugiados, etc. $-{ }^{164}$ Indudablemente, la radicalización y el extremismo violento constituyen trascendentales desafíos para el mantenimiento de la seguridad europea.

Pese a que no puede constatarse una correlación directa entre la concesión del estatuto de protección internacional con el incremento de ataques terroristas, la emergencia de recientes fenómenos como el reclutamiento y la radicalización plantean, en la actualidad, una seria dificultad cuando afecta al ámbito del SECA. Esto ha sido objeto de estudios doctrinales que han subrayado que la radicalización de sujetos que ostentan el estatuto de refugiado constituye un riesgo de primer calado pues la probabilidad de que puedan convertirse en delincuentes, y lo que es peor, terroristas, aumenta exponencialmente en comparación con otras categorías de sujetos. ${ }^{165}$ A esta situación se le adiciona la proximidad física y social de los solicitantes de protección internacional con los militantes islamistas radicales, organizaciones terroristas o dedicadas a la trata de seres humanos, en especial, en puntos fronterizos exteriores de la UE.

Incuestionablemente, la falta de medios materiales y humanos en sede nacional para afrontar la radicalización enardecieron políticas nacionales de seguridad excesivamente restrictivas lo que dificultó el acceso al procedimiento. Tanto es así, que han sido aplicadas generalizadas cláusulas de exclusión sin una óptica de ejecución clara (véase apartado $4^{\circ}$ ) con una clara tendencia a reforzar sus fronteras nacionales -las cuales lindan con las exteriores de la UE-, impidiendo la entrada de las categorías de sujetos antes mencionadas. Asimismo, la amplitud de las posibles causas o comportamientos atípicos, violentos, no confiables, etc. tanto a priori como a posteriori a la concesión del estatuto de protección internacional ha lastrado la efectividad de este derecho. Estos pueden atribuirse a un conjunto de factores psicológicos que se producen tras la huida, el "shock cultural" o la falta de inserción social en el Estado de acogida y se extiende

\footnotetext{
${ }^{164}$ NESSER, P., "Jihadism in Europe after the Invasion of Iraq: Tracing Motivational Influences from the Iraq War on Jihadism in Western Europe", Studies in Conflict and Terrorism, vol. 29, n. 4, 2006, p. 327; KOSER, K., CUNNINGHAM A., "Migration, Violent Extremism and Terrorism: Myths and Realities" en: Global Terrorism Index 2015: Measuring and Understanding the Impact of Terrorism Institute for Economics and Peace, 2015.

165 SCHMID, A., P., "Radicalisation, De-Radicalisation, Counter-Radicalisation: A Conceptual Discussion and Literature Review", The International Centre for Counter-Terrorism - The Hague 4, $\mathrm{n}^{\circ}$. 2, 2013, p. 35.
} 
hasta el generalizado aumento de ataques xenófobos o la formulación de políticas nacionales fuertemente descompasadas con las necesidades específicas de este colectivo, especialmente, en aquellos países receptores que se encuentran afectados por flujos migratorios a gran escala.

De hecho, los Países Bajos llevan desarrollando desde 2007 diversos estudios que reflejan que las cuestiones que comprometen la seguridad nacional se han alejado de la concesión de estatuto de asilo hacia otros asuntos que emanan del propio Estado de acogida desde donde se inicia el proceso de radicalización. ${ }^{166}$ Ello evidenciaba la alta probabilidad de reclutamiento de refugiados por parte de grupos extremistas, fundamentalmente, de aquellos que poseían estrechos vínculos sociales, religiosos o de identidad social con estas redes yihadistas. Un impacto en este país que atrajo el interés de la Comisión en 2014 al abordar la radicalización de este colectivo en situación de vulnerabilidad y que inició un conjunto de proyectos por parte de la Radicalisation Awareness Network (RAN). ${ }^{167}$

La práctica 2.5.8 titulada "Capacitar a los miembros del personal de los centros de acogida sobre prevención y denuncia del radicalismo"168 se focalizaba, precisamente, en la determinación de actuaciones sospechosas y susceptibles de radicalización, las cuales tenían comienzo en centros de acogida con manifiesta escasez de personal e insuficientes medios materiales para llevar a cabo su actividad de un modo apropiado. Las deficitarias condiciones de estos centros propiciaron una alarmante oleada propensa a la radicalización.

Un año más tarde, Europol alertó acerca del especial riesgo de radicalización de una parte de refugiados sirios, los musulmanes suníes que, tras su llegada al continente Europa, constituían el principal objetivo de los reclutadores islamistas extremistas. ${ }^{169}$

\footnotetext{
${ }^{166}$ OOSTEROM-STAPLES, H., "Using National Security and Public Policy to Combat Terrorism: The Case of the Netherlands", European Journal of Migration and Law, vol. 10, nº 1, 2008, p. 53; De BIE, J. L., De POOT, C. J., VAN DER LEUN, J. P., "Jihadi networks and the involvement of vulnerable immigrants: reconsidering the ideological and pragmatic value", Global Crime, vol. 15, no 3-4), 2014, p. 282.

${ }^{167}$ Comisión Europea, Comunicación de la Comisión al Parlamento Europeo, al Consejo, al Comité Económico y Social Europeo y al Comité de las Regiones, «prevenir la radicalización hacia el terrorismo y el extremismo violento: una respuesta más firme de la UE», COM (2013) 941 final, Bruselas, de 15 de enero de 2014, p. 2.

${ }^{168}$ Radicalisation Awareness Network (RAN) Collection, Preventing Radicalisation to Terrorism and Violent Extremism. Approaches and Practices, 2018.

${ }^{169}$ Europol, European Union Terrorism Situation and Trend Report (TE-SAT), La Haya, 2016, p. 7.
} 
Igualmente, la Estrategia Global sobre Política Exterior y de Seguridad de la UE de $2016^{170}$ subrayó la lucha contra el extremismo violento y la radicalización como nudo gordiano de su política, pese a que únicamente aludía a la necesidad de adoptar medidas efectivas para evitar la difusión de cualquier tipo de conducta o acción susceptible de proliferación de acuerdo con los valores intrínsecos de la UE, sin concretar otro tipo de acciones preventivas.

Con todo ello, la predisposición de que los refugiados desplazados pudieran sumarse a los objetivos de los extremistas violentos exige la adopción de un nuevo modelo jurídico que adecue e integre estas cuestiones esenciales en el mantenimiento de la seguridad europea y nacional en la protección efectiva de las personas desplazadas. Si bien, no es menos relevante destacar que en la actualidad, la radicalización y el extremismo carecen de estudios sobre su correlativo impacto en el $\mathrm{SECA}^{171}$ pese a que, en los últimos tiempos, se hayan implementado políticas nacionales que persigan la finalidad de prevenir la radicalización de solicitantes de protección internacional y refugiados. Las primeras respuestas fueron proporcionadas a través de distintos programas en el Reino Unido, los Países Bajos, Dinamarca y Noruega, que consideraron que resultaban más efectivas si tenían un objetivo específico sobre personas vulnerables o en situación de vulnerabilidad que las meras iniciativas proactivas o preventivas. ${ }^{172}$

Sin embargo, la complejidad en la determinación de las conductas susceptibles de comprometer la seguridad nacional y europea en un ámbito tan sensible como el asilo requiere la adopción de nuevos mecanismos de coordinación sostenibles a largo plazo de forma que, como destaca la $\mathrm{CE}$, reúnan a distintos actores desde un plano multinivel -local, regional, nacional y comunitario- para proceder a una exhaustiva identificación

\footnotetext{
${ }^{170}$ Consejo de la Unión Europea, Conclusiones del Consejo relativas a la Estrategia Global sobre Política Exterior y de Seguridad de la Unión Europea-Conclusiones del Consejo (13202/16), 17 de octubre de 2016.

${ }^{171}$ Sobre estos parámetros, véase: ELEFTHERIADOU, M., "Refugee Radicalization/militarization in the age of the European refugee crisis: A Composite model", Terrorism and Political Violence Journal, 2018, pp. 1-22; ANDRE V., F. MANSOURI, LOBO M., "A Fragmented Discourse of Religious Leadership in France: Muslim Youth between Citizenship and Radicalization," Journal of Muslim Minority Affairs, vol. 35, no. 2, 2015, pp. 89-117; HALL J., "Are Migrants More Extreme than Locals after War? Evidence from a Simultaneous Survey of Migrants in Sweden and Locals in Bosnia" Journal of Conflict Resolution, $\mathrm{n}^{\circ}$ 60(1), 2016, pp. 89-117; NEUMANN P. R., "Radicalized: New Jihadists and the Threat to the West", Democracy and Security, vol. 13, no 4, London: IB Tauris, 2016, pp. 395-396.

${ }^{172}$ VIDINO, L., BRANDON J., Countering Radicalization in Europe, The International Centre for the Study of Radicalisation and Political Violence (ICSR), London, 2012, p. 70. Disponible en: http://icsr.info/wp-content/uploads/2012/12/ICSR-Report-Countering- Radicalization-in-Europe.pdf.
} 
de conductas y patrones de comportamiento susceptibles de contrariar la seguridad nacional o europea. ${ }^{173}$ Igualmente, debería adoptarse una sinergia de estrategias comunes y eficientes encaminadas a la determinación temprana de organizaciones o grupos terroristas especializados en el reclutamiento de sujetos en situación de vulnerabilidad a través de los distintos SSII nacionales y europeos al efecto.

Sobre el particular, el próximo SECA potenciará las acciones de detección, prevención y supresión de actuaciones susceptibles de poner en riesgo la seguridad de los EEMM por medio de una pionera interoperabilidad de los SSII aplicables a la protección internacional (véase capítulo $3^{\circ}$ ). No obstante, como veremos a continuación, esta interconectividad sin precedentes permanece ajena a la emergencia de desconocidos desafíos en Internet, lo que requiere una categórica apuesta de la UE por la adopción de un marco proactivo que permita abordar potenciales acciones terroristas o de delitos de especial gravedad.

3.2. Nuevos modelos de radicalización en línea como forma de lucha contra el terrorismo.

La prevención de la radicalización en Internet tuvo sus comienzos recientes en el año 2015, cuando la Comisión organizó el "Foro de Internet de la UE", reuniendo a los gobiernos, Europol y a las mayores empresas de tecnología y redes sociales para analizar esta situación crítica emergente. Una acción que resultó ser todo un éxito pues los stakeholders o partes interesadas llegaron al consenso de que debía garantizarse que el contenido ilegal fuera eliminado con la mayor brevedad posible. ${ }^{174}$ Por su parte, el 23 de abril de 2015, el Consejo Europeo llevó a cabo una reunión extraordinaria sobre la lucha de la radicalización. En ella se evaluaron las situaciones de emergencia que afectaban a los flujos de migrantes en el mar Mediterráneo, como parte de la orientación política otorgada a las agencias de la UE y fue destacada la imperante necesidad de prevenir el reclutamiento por medio de soportes informáticos.

Por primera vez, el Consejo solicitó a Europol la ampliación de sus actividades de vigilancia en Internet para contrarrestar la radicalización y el reclutamiento de terroristas que operaban frecuentemente en Internet, que culminó el siguiente año con la

\footnotetext{
${ }^{173}$ Comisión Europea, A Europe that protects: EU cities against radicalisation, 26 de febrero de 2019.

${ }^{174}$ Comisión Europea, EU Internet Forum: Bringing together governments, Europol and technology companies to counter terrorist content and hate speech online, Press release, 3 de diciembre de 2015.
} 
creación de la Unidad de Referencia en Internet (IRU - UE). Esta Unidad especializada, a pesar de que comenzó a funcionar sin una regulación en esta materia, contribuyó a la interrupción de las redes de tráfico ilícito de inmigrantes y para la consecución de este objetivo, determinó que debía eliminarse cualquier contenido ilícito utilizado por los traficantes para atraer inmigrantes y refugiados sin establecer medidas concretas para la consecución de este fin. ${ }^{175}$

Fue en 2017 cuando esta falta de seguridad jurídica se solventó con la aprobación de la Directiva 2017/541 de lucha contra el terrorismo, ${ }^{176}$ que otorga respuestas jurídicas a la detección y eliminación de la radicalización por medio de la coordinación y el intercambio de información y experiencias sobre políticas nacionales de prevención y el apoyo a los profesionales que entran en contacto con personas vulnerables a la radicalización (considerandos 32 y 33). Esta Directiva exige a los EEMM el conocimiento de los delitos de terrorismo independientemente del lugar en el que se encuentre el grupo u organización terrorista (art. 19.5) y obliga a adoptar acciones preventivas a largo plazo sobre todo tipo de conductas de radicalización, combinando eficaces medidas en materia de justicia penal con políticas de educación, inclusión social e integración. Pero quizá, los dos aspectos más relevantes fueron la tipificación del delito de provocación de conductas de gravedad que, sin llegar a participar directamente en la comisión de ataques terroristas, pueden generar un elevado riesgo o propiciar la consecución de actos de terrorismo (art. 5). También cabe destacar el conocido como "autoradicalismo", que penaliza la fabricación o el uso de explosivos, armas de fuego u otras armas o sustancias (art. 8).

Sin embargo, esta Directiva no regula cuestiones trascendentales relacionadas con la radicalización en Internet, considerada una de las plataformas por excelencia que emplean las mafias organizadas que trafican con nacionales de terceros países. Únicamente dispone que los EEMM deben identificar y eliminar cualquier tipo de provocación pública a la comisión de un delito de terrorismo en su territorio, adoptando

\footnotetext{
${ }^{175}$ La IRU - UE se inició en el contexto del creciente número de ataques y amenazas en Europa, donde se hizo patente que los recursos disponibles para investigar las comunicaciones basadas en Internet resultaban limitados por parte de los EEMM. Esta ampliación responde a una mejor coordinación y apoyo a las investigaciones nacionales. Europol, EU Internet Referral Unit, Year One Report Highlights, European Police Office, 2016.

${ }^{176}$ Directiva (UE) 2017/541 del Parlamento y del Consejo de 15 de marzo de 2017 relativa a la lucha contra el terrorismo y por la que se sustituye la Decisión marco 2002/475/JAI del Consejo y se modifica la Decisión 2005/671/JAI del Consejo, DO L 88, de 31.3.2017, p. 6/21.
} 
medidas para bloquear el acceso a dicho contenido por parte de los usuarios de Internet (art. 21.2) sin llegar a determinar el procedimiento específico o los mecanismos de coordinación entre los EEMM para frenar la propagación de contenido radical.

Paralelamente, y amén del alcance de esta Directiva en materia de prevención de la radicalización, la Comisión no solo ha potenciado algunos mecanismos para eliminar el contenido terrorista online en junio de 2017, sino que también ha reforzado la coordinación entre estados, un contexto que ha estado muy fragmentado y escasamente uniforme. ${ }^{177}$ Aun así, no se han acometido algunos de los grandes desafíos que sigue planteando Internet. Las actuaciones nacionales continúan siendo escasamente coordinadas e incoherentes en la prevención, identificación y eliminación de contenido radical y extremista. De hecho, la Comisión informó que se habían difundido casi 700 nuevas piezas de propaganda oficial de Da'esh solo en enero de 2018 y la conocida Base de datos de Hashes, implementada por compañías del Foro de Internet de la UE, registraba más de 80.000 hashes de videos o imágenes terroristas solo durante $2016 .{ }^{178}$

Las autoridades nacionales y prestadores de servicios en la red no disponen de herramientas eficaces para identificar comportamientos susceptibles de consideración radical. Es necesaria una mejorada actuación conjunta a nivel comunitario, la cual parece que vendrá solventada con la novedosa propuesta de Reglamento sobre la prevención de la difusión de contenido terrorista en línea, ${ }^{179}$ que perfeccionará la Directiva de lucha contra el terrorismo por medio de la regulación de las oportunas acciones nacionales que eviten contenido extremista terrorista en la red ante el uso indebido de los servicios de alojamiento de datos. Su contenido pretende reducir drásticamente no solo la entrada de potenciales terroristas como solicitantes de protección internacional sino la radicalización de los residentes comunitarios.

\footnotetext{
${ }^{177}$ Comisión Europea, $8 .^{\circ}$ Informe de avance hacia una Unión de la Seguridad genuina y efectiva. $\operatorname{COM(2017)} 354$ final, junio de 2017. Entre las relaciones entre Estados, el Plan de acción anglo-francés publicado en 2017 incluía varias propuestas de acceso a contenido cifrado de información, así como la eliminación de material extremista entre ambos países. French-British Action Plan, 13 de junio de 2017.

${ }^{178}$ Comisión Europea, Security Union, A Europe that protects: Fighting Terrorism Online: Public-private sector cooperation as important as ever at the fourth EU Internet Forum. 5 de diciembre 2018.

${ }^{179}$ Consejo de la Unión Europea, Propuesta de Reglamento del Parlamento Europeo y del Consejo sobre la prevención de la difusión de contenidos terroristas en línea (15336/18), de 6 de diciembre de 2018. El PE ya lo ha aprobado en primera lectura mediante en procedimiento legislativo ordinario. Véase Resolución legislativa del Parlamento Europeo, de 17 de abril de 2019, sobre la propuesta de Reglamento del Parlamento Europeo y del Consejo para la prevención de la difusión de contenidos terroristas en línea (COM(2018)0640 - C8-0405/2018 - 2018/0331(COD)), 17 de abril de 2019.
} 
En este sentido, su Considerando $2^{\circ}$ menciona la necesidad de atajar la utilización de los servicios de alojamiento de datos por parte de grupos terroristas y sus seguidores, acción que ha permitido la difusión de contenidos terroristas en línea, la propagación de mensajes de radicalización y el reclutamiento de personas, así como la facilitación y dirección de actividades terroristas. Si bien, sus disposiciones siguen resultando excesivamente amplias y propicias a la consecución de conflictos de diversa índole. Por ejemplo, el Considerando 9 equipara el contenido terrorista con la mera expresión de puntos de vista radicales, polémicos o controvertidos en el debate público sobre cuestiones políticas sensibles. Una amplia consideración resulta desproporcionada con la libertad de expresión e información tal y como defiende el Comité Meijers ${ }^{180}$ y que pretende solventarse en virtud de estrictos criterios de proporcionalidad entre el riesgo y el nivel de exposición a contenidos terroristas con el respeto de los derechos fundamentales de los usuarios y la libertad de expresión y de información en una sociedad abierta y democrática recogidos en el art. 6.

En definitiva, esta propuesta regula todo un conjunto de acciones preventivas tendentes a compensar la propagación instantánea que genera este tipo de actuaciones radicales por toda la red, las cuales tienen un impacto adverso y de difícil ponderación en la salvaguardia de la seguridad nacional. El art. 3 en conexión con el art. 1 b) requiere una mayor responsabilidad de los prestadores de servicios, que deberán evaluar, con carácter prioritario, los requerimientos de las autoridades competentes y eliminar información radical extremista. No menos relevante es la propuesta de la Comisión de eliminar el contenido en Internet en un tiempo récord, tan solo 1 hora, ${ }^{181}$ una previsión que tipifica directamente el art. 4.2 de la mencionada propuesta y que fue aprobado por el PE en primera lectura en abril de 2019, respaldado de nuevo por la Comisión de Libertades Civiles, Justicia y Asuntos de Interior LIBE el 24 de septiembre por el que fue aprobado el mandato para comenzar las discusiones con los ministros de la UE.

\footnotetext{
${ }^{180}$ Meijers Committee, Standing Committee of Experts on International Immigration, Refugee and Criminal Law, Comments on the proposal for a Regulation on preventing the dissemination of terrorist content online, CM1904. (COM (2018) 640 final).

${ }^{181}$ Comisión Europea, A Europe that protects: Countering terrorist content online. 12 de septiembre de 2018.
} 
Ahora bien, en el derecho a la protección internacional, estas actuaciones no permanecen ajenas a distintos riesgos que impactan directamente en dos ámbitos manifiestamente diversos:

a) La radicalización genera numerosos beneficios a mafias organizadas que trafican ilícitamente con nacionales de terceros países. Estas poseen un gran conocimiento sobre puntos fronterizos críticos o hotspots y son capaces de atraer a un gran número de personas, las cuales toman peligrosas rutas hacia países que garanticen condiciones de vida dignas. Sin embargo, aprovechándose de su necesidad imperiosa de llegar a Europa, han sido fácilmente interceptados por traficantes expertos en la detección de cualquier falla que permita penetrar con relativa facilidad en territorio comunitario. Además, sacan provecho de la escasez de personal y de condiciones materiales que, con asiduidad, disponen los campamentos de refugiados, diseñados y predispuestos a convertirse en "campos de cultivo" al arbitrio de los intereses de traficantes como así manifiestan Loescher y Milner. ${ }^{182}$ Por su parte, Hathaway alerta que las políticas nacionales hacia refugiados fomentan un "purgatorio en campamentos y barrios marginales urbanos". 183

Sobre este asunto, la Recomendación del Consejo de 22 de mayo de 2018 aborda parcialmente esta situación crítica, promoviendo políticas de inclusión como elemento disuasorio a la radicalización. ${ }^{184}$ Asimismo, la Red de Concienciación sobre Radicalización conocida como la RAN está llevando a cabo en la actualidad numerosos esfuerzos en este ámbito, reuniendo a profesionales de todos los EEMM para desarrollar mejores prácticas que proporcionen las habilidades requeridas de forma que pueda afrontarse el extremismo violento procedentes de refugiados y migrantes. ${ }^{185}$ Este

\footnotetext{
${ }^{182}$ LOESCHER, G., MILNER, J., "Protracted Refugee Situations and State and Regional Insecurity." Conflict, Security, and Development, vol. 4, $\mathrm{n}^{\circ}$. 1, 2014, p. 7. Accesible en: http://dx.doi. org/10.1080/1467880042000206831.

${ }^{183}$ HATHAWAY J. C., "The Global Cop-Out on Refugees", International Journal of Refugee Law, 2019, p. 11.

${ }^{184}$ Recomendación del Consejo de 22 de mayo de 2018 relativa a la promoción de los valores comunes, la educación inclusiva y la dimensión europea de la enseñanza.

${ }^{185}$ En 2016, este organismo destacó en un evento temático titulado "La crisis de refugiados y migrantes: nuevos desafíos apremiantes para contrarrestar la política del Grupo de Trabajo contra el Extremismo Violento" que se estaba produciendo una radicalización y el reclutamiento en los centros de refugiados y destacó que un pequeño número de terroristas entre la gran cantidad de refugiados y migrantes se encontraban en estos centros. Ello constató que la crisis de los refugiados exacerbaba las tensiones y la polarización de la sociedad, produciendo efectos desventajosos como una mayor radicalización de los refugiados por parte del terrorismo yihadista extremista. Es más, el documento señalaba que los extremistas y terroristas intentaron polarizar deliberadamente la relación entre refugiados y Estados de
} 
organismo incluyó una visita puntera en Suecia, en la que fueron aplicadas novedosas acciones de prevención de acciones extremistas en el ámbito del asilo. ${ }^{186}$ El mencionado estudio llegó a la conclusión sobre la escasa interrelación entre ambas políticas y, pese a que admitió que los refugiados poseían un mayor riesgo de ser radicalizados y/o explotados por reclutadores extremistas. Igualmente, recalcó que existía una mayor probabilidad a la estigmatización de este colectivo en situación de vulnerabilidad, pudiendo ser considerados como potenciales terroristas.

Y con independencia de Suecia, no se han producido destacados avances en el resto de EEMM. La falta de mecanismos de prevención de estas conductas y las lagunas está dificultando gravemente los procedimientos nacionales de determinación del estatuto de protección internacional. Por tal razón, las autoridades deben elevar las cautelas y controles en el seno del procedimiento, exigiendo una compleja tarea de evaluación que establezca, con rigor, el grado de peligrosidad y si un solicitante puede ser merecedor del estatuto de protección internacional. Un conjunto de actuaciones que pueden resultar cruciales para la propia seguridad de los sujetos si la valoración de los comportamientos radicales reviste notoria entidad -en este aspecto, recuérdese que, en caso de serio riesgo la seguridad del EM de acogida, podría incluso aplicarse la cláusula de exclusión que regula la Directiva de Reconocimiento y la propuesta de Reglamento de Reconocimiento como analizamos posteriormente-.

En la consecución de estos objetivos, Eurodac podría compensar esta excesiva rigidez a pesar de que únicamente incluye información y datos de carácter personal y excluye la descripción de conductas o comportamientos susceptibles de consideración radical (véase capítulo $3^{\circ}$ ). Una limitación funcional que viene compensada gracias a la interoperabilidad de este sistema con el resto de SSII europeos al efecto y a la acción de Europol que, a través de la UE-IRU, identifica contenido terrorista online en coordinación con los EEMM. Desde el año 2007, viene recogiendo anualmente en el

acogida. El estudio refleja cómo el Daesh recoge en su revista online Dabiq la voluntad de "destruir la zona gris". De hecho, el Daesh ha producido docenas de videos sobre las crisis de refugiados y cuya temática comprende: 1. Occidente no se preocupa por los refugiados. 2. Se considera que cualquier refugiado que huye a un área no musulmana ha cometido un gran pecado. 3. Debido a su pecado, cualquier musulmán que muera en el camino a Occidente será castigado por Dios. 4. Cualquiera que huya del capiphat se convertirá en un objetivo de Daesh. Véase Radicalisation Awareness Network (RAN), Centro de Excelencia, Ex Post Paper, The refugee and migrant crisis: new pressing challenges for CVE policies, 8 de mayo de 2016, p. 4.

${ }^{186}$ La Red de Concienciación sobre Radicalización (RAN), Study visit on "PVE and CVE in and around asylum centres and within refugee communities", 13 y 14 de septiembre de 2018, pp. 2-3. 
Informe de Situación y Tendencias Terroristas (TE-SAT) toda una serie de conductas europeas directa o indirectamente vinculadas con el terrorismo en Internet. El Informe de Europol de 2018 destacaba que, aunque ya parecía que Internet desempeñaba un papel importante en la radicalización, la amenaza había aumentado de forma exponencial durante este último año. ${ }^{187}$ Un hecho que recalca el último Informe del año 2019, el cual pone de manifiesto el incremento de movimientos xenófobos contra colectivos muy concretos, como los persistentes ataques a las infraestructuras de los solicitantes de protección internacional - centros de alojamiento, acogida o campos de refugiados-. Una situación que, en países como Italia, ha sido alimentado por un discurso político contrario a la entrada de migrantes ampliamente considerados. ${ }^{188}$

Por tanto, las políticas actuales tienden a desarrollar la tipificación de nuevas conductas sospechosas de radicalización en Internet en virtud de un cruce de información sin precedentes. Una novedosa práctica sobre las que no existe parámetro de evaluación alguno y que pretende identificar exhaustivamente a las distintas categorías de nacionales de terceros países que pretenden entrar a través de fronteras exteriores de la UE, principalmente, aquellos sobre los que existe cualquier tipo de información al respecto y que permite revelar su potencial conflicto con la seguridad nacional u orden público. ${ }^{189}$ Esta intensa labor de prevención y detección deberá respetar las más altas garantías en la protección de los solicitantes de protección internacional, por lo que, salvo que concurran elementos que evidencien una manifiesta incompatibilidad con la seguridad del estado competente, la mera apreciación de comportamientos radicales no deberá excluir per se la concesión de estatuto de protección internacional sino que cualquier restricción o denegación requerirá de necesaria extraordinariedad, es decir, deberán haberse adoptado previamente todas las medidas eficaces y apropiadas de seguridad, económicas o sociales que permitan revertir estas acciones radicales.

De igual manera, cabe subrayar que la dificultad en la identificación de patrones de comportamiento susceptibles de radicalización excede de la evaluación efectuada en el seno del procedimiento protección internacional hacia cuestiones más complejas y

\footnotetext{
${ }^{187}$ Europol, European Union Terrorism Situation and Trend Report (TE-SAT), La Haya, 2018, p. 4.

${ }^{188}$ Europol, European Union Terrorism, ob. cit., 2019, pp. 23 y 61.

${ }^{189}$ Advierte la Comisión que, ningún sujeto cruzará las fronteras de la UE de forma inadvertida pues todas las bases de datos relevantes en material de seguridad se encuentran ya cruzadas. Comisión Europea, Security Union, A Europe that protects: 15 out of 22 Security Union legislative initiatives agreed so far, 20 de marzo de 2019.
} 
vinculadas directamente con los residentes europeos. Debe recordarse que, durante 2017, la mayor parte de los ataques en la UE fueron principalmente cometidos por nacionales o residentes radicalizados en su país de residencia sin haber viajado al extranjero para unirse a un grupo terrorista. ${ }^{190}$ En marzo de 2018, también la Comisión constató que la mayoría de los sospechosos de terrorismo involucrados en ataques recientes en Europa nacieron y/o se criaron en diferentes estados y se radicalizaron, precisamente, en estos países de residencia. ${ }^{191}$

Por todo ello, estos datos no dejan de demostrar que la prevención de la radicalización requiere de contundentes esfuerzos coordinados por parte de las instituciones nacionales y comunitarias que se extiende más allá del procedimiento de determinación del estatuto de protección internacional hacia una serie de políticas coherentes no únicamente orientadas hacia la detección de conductas radicales sino de otras que favorezcan la inclusión social de grupos con mayores tasas de radicalización, entre los que indudablemente se encuentran los sujetos con estatuto de refugiado o protección subsidiaria. El Fondo de Seguridad Interna (ISF) deberá corregir la falta de seguridad jurídica y la excesiva rigidez del procedimiento, asistiendo a los EEMM de una manera más flexible y eficaz, a fin de que aborden de un modo contundente aquellas cuestiones relativas a la lucha contra el terrorismo y la radicalización. Todo ello, fomentando un intercambio de información garante con la protección de los derechos humanos entre las autoridades administrativas y/o policiales de la UE e intensificando las operaciones conjuntas transfronterizas en plena sintonía con los recursos disponibles en el Fondo de Asilo y Migración. ${ }^{192}$

Por su parte, la detección temprana y anticipada de estas conductas deberá asumirse por todo un conjunto de actores que intervienen directa o indirectamente en todo el proceso de integración de los refugiados, exigiendo una labor de cooperación en la identificación de cualquier anomalía sensible a la radicalización desde su origen, tal y

\footnotetext{
${ }^{190}$ Este informe destacaba la amenaza emergente de las conductas de radicalización cuya visión general desde 2006 reflejaba notorias transformaciones, por medio de soportes cibernéticos y ante la preferencia de llevar a cabo actos terroristas mediante artefactos explosivos improvisados. Sobre esta cuestión, subrayaba que los ataques yihadistas eran cometidos principalmente por terroristas locales, radicalizados en su país de residencia sin haber viajado para unirse a un grupo terrorista en el extranjero y que, frecuentemente, no tienen directos enlaces con el Estado Islámico o cualquier otra organización yihadista. Europol (2016), EU Terrorism Situation.., ob. cit., p. 19.

${ }^{191}$ Comisión Europea, A Europe that protects: EU Mayors' Conference: "Building Urban Defences Against Terrorism", 8 de marzo de 2018.

${ }^{192}$ Comisión Europea, EU Budget for the Future, 13 de junio de 2018.
} 
como ha llevado a cabo de forma pionera Dinamarca, que ha adoptado acciones que previenen y combaten el extremismo violento y la radicalización gracias a la amplia colaboración entre varios actores de servicios sociales, los sistemas educativos y de salud, las autoridades policiales y los servicios de inteligencia y seguridad. ${ }^{193}$

\section{Las excepciones de seguridad en la Directiva y propuesta de Reglamento de}

\section{Reconocimiento.}

4.1. El conflicto entre la exclusión y revocación con el principio de no devolución a la luz del CEDH.

El principio de no devolución se erige como una de las piedras angulares del derecho internacional de los refugiados. Refleja el compromiso de la comunidad internacional de garantizar a todas las personas el disfrute de los derechos humanos, incluidos los derechos a la vida, a no ser sometidos a tortura ni a tratos crueles, inhumanos o degradantes y a preservar su libertad y seguridad. La protección contra la devolución surge del art. 33.1 de la Convención de Ginebra y se aplica a aquellos que cumplen con los requisitos de la definición de refugiado contenida en su art. 1. ${ }^{\circ}$ y no entran dentro del ámbito de aplicación del art. 1F.

Por lo que respecta al CEDH, el art. 3 establece la prohibición de que un individuo pueda ser sometido a tortura o a penas y tratos inhumanos o degradantes. De tal forma que, en los casos de devolución, incluyendo los supuestos de deportación y expulsión, el Estado será responsable de tales actos, en especial, "donde se han demostrado fundamentos sustanciales para creer que la persona en cuestión, si es deportada, correría un riesgo real de ser sometida a un tratamiento contrario al artículo 3 en el país de destino". ${ }^{194}$ Por lo tanto, la evaluación de este tratamiento contrario al CEDH debe efectuarse por el Tribunal a la luz de la situación general en el país receptor y las circunstancias personales del solicitante.

\footnotetext{
${ }^{193}$ Sobre esta cuestión, véase: Danish Institute for International Studies, An Introduction to the Danish approach to countering and preventing extremism and radicalization, 2015; RAN Policy Paper, Developing a local prevent framework and guiding principles - Part 2, noviembre 2018.

${ }^{194}$ STEDH, F.G. c. Suecia, de 23 de marzo de 2016 (Demanda n ${ }^{\circ} 43611 / 11$ ) y J.K. y Otros c. Suecia, de 23 de agosto de 2016 (Demanda $n^{\circ}$ 59166/12).
} 
Como analizaremos a continuación, este principio ha sido objeto de estudio por parte de un amplio sector doctrinal ${ }^{195} \mathrm{y}$ dispone de una extensa jurisprudencia por parte TEDH en los últimos años, y más concretamente, tras las crisis migratorias acaecidas desde 2014. Estas incidieron seriamente en el derecho a la protección internacional pues no han sido aislados los distintos contextos que han comprometido seriamente la efectividad de este derecho y que distan desde la falta efectiva de acceso al procedimiento, por motivos que comprometen la seguridad de ese Estado o porque este no es competente bajo los criterios competenciales del Sistema de Dublín.

Un magnífico botón de muestra lo constituyen los amplios pronunciamientos del Tribunal de Estrasburgo ante la devolución directa o indirecta de individuos ante situaciones que claramente exceden de las tipificadas en la normativa reguladora del SECA, esto es, tras una decisión individualmente considerada con todas las garantías que aplique la correspondiente cláusula de exclusión o revocación. Como punto de partida, la STEDH Khlaifia y otros c. Italia, de 1 de septiembre de 2015, parcialmente revocada por la Gran Sala TEDH el 15 de diciembre de 2016 estableció un dudoso precedente en la devolución de "migrantes" ampliamente considerados puesto que no entró a valorar su perfil del solicitante ni tampoco fue decretado efecto suspensivo a la expulsión efectuada por las autoridades nacionales. La Gran Sala analizó si las condiciones de detención de los migrantes proporcionadas por Italia incurrían en una violación de los arts. 3 y 5 CEDH en relación con el art. 4 del Protocolo $n^{\circ} 4,{ }^{196}$ que prohíbe la expulsión colectiva de extranjeros. Un aspecto muy debatido por la criterio divergente entre la Sala y Gran Sala, a lo que se adiciona el voto particular emitido por uno de los magistrados. ${ }^{197}$

\footnotetext{
${ }^{195}$ BÜRLI, N., The Principle of Non-Refoulement under the ECHR and the UN Convention against Torture and Other Cruel, Inhuman or Degrading Treatment or Punishment Eman, Hamdan Brill/Nijhoff, 2016, pp. 1-404.

${ }^{196}$ Protocolo número 4 al Convenio para la Protección de los Derechos Humanos y de las Libertades Fundamentales reconociendo ciertos derechos y libertades además de los que ya figuran en el Convenio y en el Protocolo Adicional al Convenio. Estrasburgo, 16 de septiembre de 1963.

${ }^{197}$ En la STEDH Khlaifia y otros c. Italia, de 1 de septiembre de 2015 (Demanda no 16483/12), tres Tunecinos fueron devueltos a su país de origen sin la posibilidad de ser entrevistados individualmente para examinar si consideraban interponer las correspondientes solicitudes de protección internacional. Las autoridades italianas alegaron que durante las dos semanas de estancia en los respectivos centros, los demandantes podían haber contado con la asistencia de intérpretes que les hubiera permitido formalizar en su caso la solicitud. Sin embargo, la Gran Sala, a diferencia de la Sala, consideró revelador que 72 migrantes en similares condiciones, hubieran interpuesto solicitudes de protección internacional, logrando suspender su expulsión y falló aludiendo a que los denunciantes pudieron contar con la oportunidad de notificar a las autoridades cualquier razón que hubiera justificado su permanencia en Italia y su no expulsión, a pesar de que no pudo determinarse si los denunciantes conocían o no sus derechos y si
} 
En este caso, no fueron investigadas las razones por las cuales los migrantes deseaban permanecer en el país italiano. En su defecto, consideraron a estos como migrantes en lugar de otorgarles la posibilidad efectiva de presentar solicitudes de protección internacional. Una falta de examen individualizado que se justificó por la "indirecta facultad" que disponían los migrantes para interponer un recurso contra su expulsión y que no efectuaron. Esto pone en evidencia la falta de estrictas y eficaces cautelas en referencia a la no devolución que prevé la Convención de Ginebra y la normativa reguladora del SECA.

Es más, debe recordarse que un año antes, la STEDH A.C. c. España, de 24 de abril de $2014^{198}$ exigía el examen por parte de un tribunal nacional de todas las circunstancias concretas del individuo y sus posibles efectos adversos, prohibiendo la devolución ante la falta de un examen de fondo de la solicitud de asilo o por no agotar las vías de recursos internos como exige el art. 35.1 CEDH. Incluso, ante las desfavorables condiciones de acogida en países afectados por la afluencia masiva de migrantes como Italia y Grecia, que imposibilitaba el regreso de solicitantes a estos países (SSTEDH M.S.S. c. Bélgica y Grecia, de 21 de enero de 2011, Tarakhel c. Suiza, de 4 de noviembre de 2014 Nasr et Ghali c. Italia, de 23 de febrero de 2016). ${ }^{199}$ A ello se exceptuaba el "genérico traslado" otros Estados por imposibilidad manifiesta, ante problemas de salud físicos o psicológicos de los solicitantes. Y es que, salvo que fuera acreditado con base en un supuesto muy concreto, no justificaba la excepcionalidad requerida para permanecer en este nuevo Estado (A.S. c. Suiza, de 30 de junio de 2015 o Ilias y Ahmed c. Hungría, de 14 de marzo de 2017). ${ }^{200}$

Además, han podido detectarse notables dificultades para proceder a la efectividad de esta decisión de retorno en los supuestos en los que el EM no proporcionó el estatuto

podían haber presentado su solicitud motu propio. Por ello, desestimó la permanencia de estos tres sujetos en territorio italiano si bien, el magistrado disidente fue especialmente crítico con el fallo al considerar, afortunadamente, que la Gran Sala no debió basarse en meras presunciones y remarcando que el Gobierno debía haber presentado pruebas concluyentes que constataran los denunciantes fueron informados de su derecho a solicitar asilo y que igualmente, habían procedido a su expulsión tras ser entrevistados de forma individual (párr. 11 a 18), situación poco probable teniendo en cuenta las circunstancias excepcionales de la llegada masiva de migrantes y el incendio en uno de los centros de detención.

${ }^{198}$ STEDH A.C. c. España, de 24 de abril de 2014. Demanda n ${ }^{\circ}$ 6528/11. Para un análisis sobre la misma, remitimos a: MARIA PORTILLA F. J., "Examen de las Sentencias del Tribunal de Estrasburgo que afectan al Reino de España", Teoría y Realidad Constitucional, no 42, 2018, pp. 273-310.

${ }^{199}$ SSTEDH M.S.S. c. Bélgica y Grecia...ob. cit; Tarakhel c. Suiza, de 4 de noviembre de 2014 (demanda $\mathrm{n}^{\circ}$ 29217/12); Nasr et Ghali c. Italia, de 23 de febrero de 2016 (demanda no 6528/11).

${ }^{200}$ SSTEDH A.S. c. Suiza, de 30 de junio de 2015 (demanda ${ }^{\circ}$ 39350/13) o Ilias y Ahmed c. Hungría, de 14 de marzo de 2017 (demanda no 47287/15). 
de refugiado o protección subsidiaria pero en el que se encuentra residiendo el sujeto, enardeciendo así un potencial conflicto para su seguridad nacional. Por ejemplo, en el asunto Ahmed Ahmed Tchatayev, de 14 de enero de $2010,{ }^{201}$ se solicitó a las autoridades ucranianas la no devolución de un individuo a Rusia. Esto permite corroborar una de las frecuentes manifestaciones que transgreden el principio de no devolución que ponen en serio riesgo la seguridad europea. Y aunque la solución a priori puede basarse en una devolución "inicial” al Estado que concedió en estatuto de protección internacional para que decida sobre la revocación y, si procede a la luz del art. $3 \mathrm{CEDH}$, su ulterior devolución por parte del EM responsable, se plantean serias dudas sobre su efectividad en el marco de la libertad de circulación dentro del área Schengen.

Ahora bien, en relación con la rigidez en la expulsión, no han sido escasos los conflictos de enorme calado entre la seguridad nacional y la devolución objeto de interpretación por parte del TEDH, ya sea por el incumplimiento de medidas cautelares que exigían la permanencia del sujeto hasta el examen de la demanda ${ }^{202}$ o por medio de

${ }^{201}$ Pese a que Austria concedió el estatuto de refugiado político, en 2010, fue arrestado en Ucrania. Sus archivos móviles contenían instrucciones técnicas de demolición y fotos de personas muertas en una explosión. Rusia, que ya había solicitado su extradición tras ser considerado culpable de asesinato en masa, vio la negativa del TEDH a esta devolución por temor a que pudiera enfrentarse a "un juicio injusto y sufriere el riesgo de sufrir tortura y tratos inhumanos o degradantes". En esta misma línea se posicionó Amnistía Internacional así como la Interpol, esta última negando incluirlo en su lista de vigilancia terrorista motivando la escasa probabilidad de comisión de ataques terroristas en Europa. Véase Amnistía Internacional, Acción Urgente, Ucrania obligada a paralizar extradición, (UA 07/10). https://heavy.com/news/2016/07/akhmed-chatayev-ahmed-asylum-austria-chataev-istanbul-airport-

bombing-terror-attack-isis-russia/

Previamente en 2008, había sido detenido junto a otros ciudadanos procedentes de Chechenia en Suecia cuando la policía encontró rifles de asalto, explosivos y municiones Kalashnikov en su automóvil, donde fue condenado a más de 1 año en una prisión sueca. En mayo del 2011 fue nuevamente detenido, en el control fronterizo de Bulgaria y Turquía ante la orden de extradición Rusa, de nuevo denegada en virtud de su estatuto del refugiado. En septiembre del 2012, fue otra vez detenido en Georgia al portar dos granadas por lo que fue acusado de posesión ilegal de explosivos, y en virtud de su estatuto de refugiado, consiguió no ser extraditado por su estatuto concedido por Austria en 2003. Finalmente, Ahmed Tchatayev pudo cometer un atentado en el aeropuerto de Estambul de 2016 que se cobró la vida de 44 personas y dejó más de 230 heridos y que este ciudadano ruso de origen checheno, se unió al Estado Islámico en 2015 luchando en la actualidad en Siria, tal y como así señala un informe policial turco se une a una serie de supuestos que evidencian la incompatibilidad del sujeto con la seguridad europea e internacional.

${ }^{202}$ La STEDH Labsi c. Eslovaquia, de 24 de septiembre de 2012 (demanda n ${ }^{\circ}$ 33809/08) versó sobre la deportación de un ciudadano argelino de territorio eslovaco tras verse rechazada su solicitud de asilo, por haber sido declarado culpable de participación en la preparación de un acto terrorista en Francia. El solicitante fue deportado a Argelia en abril de 2010 a pesar de que en el año 2008, el TEDH comunicó al Gobierno eslovaco una medida cautelar por la cual, el solicitante no debía ser extraditado a Argelia hasta que el Tribunal Constitucional de este país acordara el resultado final de su procedimiento de asilo en virtud del art. 39 Reglamento TEDH. Pese a ello, se procedió a la devolución y el TEDH consideró que se 
las conocidas como " transferencias extrajudiciales o entregas extraordinarias". Prácticas secretas que vienen amparadas por el principio legítimo de "secreto de Estado" y suponen una flagrante violación de los derechos humanos, atentando directamente contra la propia institución de la protección internacional. ${ }^{203}$ En este último caso, la STEDH Nasr et Ghali c. Italia anteriormente citada analizó el secuestro del imán egipcio Abu Omar por parte de agentes de la CIA junto con el apoyo de funcionarios italianos y su traslado a Egipto, donde estuvo recluido y torturado en secreto durante más de 12 meses. El TEDH terminó concluyendo por unanimidad que habían sido violado los arts. 3, 5, 8, $13 \mathrm{CEDH}$ por parte del gobierno italiano. Un supuesto que, necesariamente, obliga a contextualizar las transferencias extrajudiciales o entregas extraordinarias, prácticas secretas que, en este caso, el ejecutivo italiano había permitido y que, en virtud al principio legítimo de "secreto de Estado", logró no solo preservar la impunidad de los responsables de estas actuaciones, sino que atentó contundentemente contra la propia institución de la protección internacional.

Y en esta misma línea, merece traer a colación el fallo del Tribunal Supremo griego, de 26 de enero de 2017 que consideró no extraditar a 8 soldados turcos que participaron activamente en un intento de golpe de Estado en Turquía. Esta negativa a la extradición vino motivada por la alta posibilidad de que estos se enfrentasen a una restricción de sus derechos humanos fundamentales. Una decisión que terminó agravando las relaciones diplomáticas con Turquía, país clave en la gestión de las crisis migratorias y de refugiados, que acusó directamente al gobierno griego de proporcionar refugio y

\footnotetext{
habían violado los arts. 3, 13 y $34 \mathrm{CEDH}$ señalando que, en el momento de los hechos, las personas condenadas por actos terroristas fueron expuestos a graves riesgos de malos tratos en Argelia, y aun así se procedió a la deportación, contraviniendo la medida cautelar solicitada por el TEDH que impidió el examen debido de la demanda.

${ }^{203}$ Las "entregas extraordinarias" pueden definirse como detenciones y arrestos secretos de sujetos considerados terroristas que provienen de países en conflicto. Constituyen prácticas ocultas entre Estados para interceptar acciones terroristas que se producen posteriormente a los ataques del 11-S. Estas entregas, catalogadas como desapariciones forzadas, vulneran derechos fundamentales (detención, tortura o tratos inhumanos o degradantes, incluso poniendo en serio riesgo la vida, etc.) durante los interrogatorios y contravienen el derecho internacional de los refugiados, violando sistemáticamente la Convención de Ginebra. En la actualidad, cabe destacar otras dos condenas por parte del TEDH en relación con estas prácticas secretas: STEDH El-Masri c. Macedonia, de 13 de diciembre de 2012 (demanda $\mathrm{n}^{\circ}$ 39630/09), Abd Al Rahim Hussayn Muhammad Al Nashiri c. Polonia, de 6 de mayo de 2011 (demanda $\mathrm{n}^{\circ}$ 28761/11), Husayn (Abu Zubaydah) c. Polonia, de 24 de julio de $2014{\text { (demanda }{ }^{\circ}}^{\circ}$ 7511/13). Igualmente, véase: Consejo de Europa, Asamblea Parlamentaria sobre Asuntos Jurídicos y Derechos Humanos, Presuntas detenciones secretas y traslados ilegales entre estados que implican a Estados miembros del Consejo de Europa, Documento n ${ }^{\circ}$ 10957, pp. 12 y 15-24, 2 de junio de 2006.
} 
protección a golpistas. ${ }^{204}$ No olvidemos que, el 22 de julio de 2019, el Gobierno turco declaró la suspensión del acuerdo UE-Turquía del año 2016 tras las sanciones dictadas por la UE contra este país por sus exploraciones de gas en aguas Chipriotas. ${ }^{205}$

Finalmente, la STEDH X c. Países Bajos, de 10 de julio de 2018 estableció que no cabía alegar persecución en el país de origen por el simple hecho de que estas autoridades fueran conocedoras de la comisión de delitos graves o, incluso, por la mera presentación de una solicitud de asilo. En su defecto, debía concretarse individualmente si el tercer país era capaz de ofrecer protección legal efectiva contra la devolución al Estado de origen. ${ }^{206}$ Un criterio que había adoptado con anterioridad un Tribunal Administrativo Federal suizo el 8 de febrero de $2018 .^{207}$

Por el contrario, la STEDH $X$ c. Suecia, de 9 de enero de 2018 apreció que el intercambio de información entre los Servicios de seguridad suecos y las autoridades marroquíes era de tal magnitud, que su devolución aumentaba exponencialmente la probabilidad en la adopción de prácticas en el país de destino contrarias al art. 3 CEDH. Por tal motivo, decretó su permanencia en territorio sueco a pesar de comprometer

\footnotetext{
${ }^{204}$ Comunicado emitido por la Asociación de Jueces y Fiscales Griegos. Accesible en: http://ende.gr/wpcontent/uploads/2017/02/merged_document.pdf

${ }^{205}$ Consejo de la UE, Declaración UE-Turquía, Comunicado de prensa, 144/16, 18 de marzo de 2016. Un estudio sobre el estado de derecho en Turquía y un balance sobre el acuerdo, remitimos a: ALLUÉ BUIZA A., "Los derechos fundamentales en Turquía, un claro retroceso", Teoría y Realidad Constitucional, $\mathrm{n}^{\circ}$ 38, 2016, pp. 471-485.

${ }^{206}$ La STEDH X c. Paises Bajos, de 10 de julio de 2018 (demanda n. 14319/17) se refirió a la devolución de un ciudadano marroquí de los Países Bajos a su país de origen. El demandante, cuya solicitud de asilo había sido rechazada, fue arrestado en 2015 por cargos relacionados con el terrorismo y condenado a doce meses de prisión. Solicitó protección ante el TEDH sobre la base de que su traslado a Marruecos lo pondría en riesgo de ser sometido a un tratamiento contrario al art. 3 del $\mathrm{CEDH}$, dado que las autoridades marroquíes estarían al tanto de su condena por delitos relacionados con el terrorismo en los Países Bajos, su vinculación con una célula militante marroquí desmantelada y su solicitud de asilo. El TEDH se basó en la información disponible sobre el país de origen en Marruecos, como en los informes del Grupo de Trabajo de la ONU sobre Detenciones Arbitrarias y las observaciones del Comité de Derechos Humanos de la ONU y afirmó que podían darse malos tratos y la tortura por parte de la policía y las fuerzas de seguridad marroquíes, especialmente, en el supuesto de personas sospechosas de terrorismo o de poner en peligro la seguridad nacional. Sin embargo, el Tribunal no consideró que existiera una práctica general y sistemática de tortura y malos tratos, la cual debía determinarse en función del sujeto afectado. En el caso del solicitante, si bien debió suponerse que las autoridades marroquíes eran conscientes de la naturaleza de la condena del solicitante en los Países Bajos, nada indicaba que las autoridades marroquíes hubiesen tomado alguna medida que demostrara que las autoridades judiciales marroquíes no respetarían el principio de ne bis in idem al procesar al demandante en Marruecos como terrorista por su condena en los Países Bajos. Por lo tanto, el Tribunal consideró que la evaluación realizada por las autoridades nacionales era adecuada y estaba suficientemente respaldada, por lo que el traslado del solicitante a Marruecos no daría lugar a una violación del art. $3 \mathrm{CEDH}$.

${ }^{207}$ Tribunal Administrativo Federal Suizo, de 8 de febrero de 2018. Demanda n ${ }^{\circ}$ D-635/2018.
} 
seriamente su seguridad nacional. ${ }^{208}$ En esta misma línea, la STEDH M.A. c. Francia, de 1 de febrero de 2018 entendió que Francia había violado el art. 3 CEDH ante la elevada probabilidad de que Argelia, país de origen del solicitante, procediera a su detención, maltrato y/o tortura. ${ }^{209}$ En ambos casos, el TEDH se basó en los informes del Comité de las Naciones Unidas (ONU) contra la Tortura y de distintas ONGs, los cuales fueron concluyentes para determinar su incompatibilidad con el CEDH.

4.2. Las cláusulas de exclusión del estatuto de protección internacional: una ponderación entre la protección de la seguridad nacional y del derecho de asilo.

\subsubsection{El régimen jurídico de la exclusión: una sinóptica visión histórica.}

Tras la II Guerra Mundial, tanto la Constitución de la Organización Internacional de Refugiados de Nueva York de 1956 como la DUDH de 1948 fueron los primeros instrumentos internacionales que previeron disposiciones relativas a la exclusión del estatuto de protección de los refugiados. Respecto de la primera, la Parte II del Anexo II contenía una enumeración relativa a todas aquellas personas que no debían recibir asistencia por parte de la Organización mientras que, la Declaración disponía en el art. 14.2 que las personas que habían cometido delitos no políticos o actos contrarios a los propósitos y principios de las Naciones Unidas no podían invocar el derecho de asilo.

${ }^{208}$ STEDH X c. Suecia, de 9 de enero de 2018 (demanda ${ }^{\circ}$ 36417/16). En marzo de 2016, el Servicio de Seguridad Sueco solicitó a la Agencia Sueca de Migración la expulsión del solicitante. Mientras las autoridades revisaban la solicitud de expulsión, el sujeto presentó una solicitud de asilo argumentando que si fuera expulsado a Marruecos correría un riesgo real y personal de ser sometido a torturas u otros tratos inhumanos al considerarse una amenaza para la seguridad nacional Sueca por los delitos graves cometidos y puesto que esa información había sido transmitida a las autoridades marroquíes.

${ }^{209}$ STEDH M.A. c. Francia, de 1 de febrero de 2018 (demanda n ${ }^{\circ}$ 9373/15). Este caso se refería a un ciudadano argelino que fue condenado a siete años de prisión y fue objeto de una orden de exclusión permanente del territorio francés por participar en una conspiración en la preparación de actos terroristas. En diciembre de 2014, el solicitante presentó una solicitud de asilo, que fue rechazada por la Oficina Francesa para la Protección de los Refugiados y los Apátridas (OFPRA). El 20 de febrero de 2015, se informó al abogado de la demandante de que el solicitante estaba siendo expulsado y presentó una nueva solicitud de medidas provisionales ante el TEDH, exigiendo al Gobierno francés que no devolviera al solicitante. Sin embargo, el solicitante fue trasladado a Argelia bajo custodia policial. El solicitante sostuvo que su traslado a Argelia lo expuso a un grave riesgo de trato contrario al art. $3 \mathrm{CEDH}$, que el Gobierno francés había incumplido sus obligaciones en virtud del art. $34 \mathrm{CEDH}$ al no cumplir con la medida provisional. Con respecto a su queja en virtud del artículo 3 del CEDH, el Tribunal reafirmó como así se pronunció en la STEDH Daoudi c. Francia, de 3 de diciembre de 2009 (demanda ${ }^{\circ}$ 19576/08) o H.R. c. Francia, de 22 septiembre de 2011 (demanda no 64780/09)- que era legítimo que los Estados contratantes tomaran una posición muy firme contra aquellos que contribuían a actos terroristas. Sin embargo, varios informes del Comité de la ONU contra la Tortura y de ONGs describieron que los sospechosos de terrorismo en Argelia a menudo fueron detenidos, maltratados o torturados. Por lo tanto, Francia fue condenada por violación del art. 3 del CEDH por la devolución del solicitante a Argelia. 
Sin embargo, ambos documentos tenían una serie de limitaciones legales. La Constitución de la Organización Internacional de Refugiados constituyó una organización internacional que fue creada con un fin específico, esto es, responder a las atrocidades acaecidas tras la II Guerra Mundial y a las graves consecuencias que produjo para los sujetos refugiados y los desplazados internos, previendo su aplicación a las distintas categorías de personas afectadas por el gran conflicto bélico. Si bien, no contemplaba cláusulas de exclusión expresamente reconocidas. En cambio, la DUDH no era un instrumento legalmente vinculante, tenía un carácter más general o universal, promoviendo el pleno respeto de los derechos humanos. En este caso, no preveía ni directa ni indirectamente la institución del derecho de asilo ni mucho menos, definiciones de sujetos excluidos de recibir tal protección.

Fue en 1952 cuando el ACNUR finalmente asumió el trabajo de la Organización Internacional de Refugiados, cuyo Estatuto todavía no regulaba ninguna cláusula de exclusión. Esta se adicionó en la Convención sobre Refugiados adoptada en Ginebra un año antes, el 28 de julio de 1951, pero que no entró en vigor hasta el 22 de abril de 1954 en virtud de su art. 43. Por tanto, en la Convención de Ginebra se incluyó tanto definición general del refugiado como aquellos supuestos en las que no debía aplicarse, previendo formalmente el régimen jurídico de exclusión del estatuto de refugiado. Un instrumento jurídico en vigor en la actualidad y cuyo art. 1F describe los distintos supuestos en los que no deben aplicarse la protección conferida por esta, es decir, a aquellos sujetos sobre los que existan motivos fundados para considerar: "a) que ha cometido un delito contra la paz, un delito de guerra o un delito contra la humanidad, de los definidos en los instrumentos internacionales elaborados para adoptar disposiciones respecto de tales delitos; b) que ha cometido un grave delito común, fuera del país de refugio, antes de ser admitida en él como refugiada; c) que se ha hecho culpable de actos contrarios a las finalidades y a los principios de las Naciones Unidas". 210

El objetivo de estas cláusulas de exclusión son dos; proporcionar estatuto de refugiado a sujetos que actúan de buena fe y requieren tal protección, excluyendo a aquellos no merecedores de tal estatuto y permitir eludir el reconocimiento de este derecho a sujetos que han cometido o incitado actos delictivos de gran entidad, lo cual

\footnotetext{
${ }^{210}$ La Convención también regula otras cláusulas de exclusión en los arts. 1D y 1E, las cuales se aplican a los sujetos que ya reciben asistencia de Naciones Unidas así como las personas que no se necesitan protección internacional pues pueden recibir protección en su Estado de origen o residencia.
} 
refleja que sus autores no sean dignos de recibirla. Esta dualidad funcional pretende asegurar la seguridad de los estados de acogida, denegando que un sujeto pueda residir libremente en su territorio nacional, precisamente, por ser culpable de atrocidades y delitos comunes graves.

Esta exclusión se sitúa al inicio del procedimiento de determinación del estatuto de protección internacional que corresponda, dando comienzo a la evaluación de todas las circunstancias personales. De tal manera, como veremos a continuación, la aplicación de las cláusulas de exclusión impedirá a los estados conceder la condición de refugiado o protección subsidiaria a un sujeto; aunque ello no implicará que el estado competente no deba otorgar al sujeto excluido su derecho a permanecer en su territorio por otras razones -sin perjuicio de que las obligaciones internacionales requieran su extradición o sea juzgado penalmente-. Por tanto, estas cláusulas facultan a que el solicitante no reciba el estatuto de protección internacional, operando independientemente a las órdenes de expulsión y no devolución de los arts. 32 y 33.2 de la Convención de Ginebra.

En el presente estudio acometemos un análisis jurídico sobre los problemas jurídicos existentes que están planteando estas cláusulas en la normativa europea tras los distintos escenarios que han comprometido la seguridad de los EEMM, desde las conocidas crisis migratorias, a los atentados terroristas o delitos graves cometidos directa o indirectamente por solicitantes de protección internacional previamente a la formalización de su estatuto correspondiente. Ello de conformidad con el art. 1F de la Convención de Ginebra, la Directiva de Reconocimiento en los arts. 12 y 17 y, dada la especial trascendencia que la interpretación jurisprudencial (nacional, internacional y comunitaria) del art. 1F de la Convención de Ginebra y la tansposición de los arts 12 y 17 de la Directiva de Reconocimiento han tenido en el ordenamiento español, dedicaremos una especial atención al análisis de los arts. 8 y 11 de la LAPS.

Analizaremos detenidamente las principales novedades que incorpora la propuesta de Reglamento de Reconocimiento (PRR) y que, con todo pronóstico, exigirá modificaciones de enorme calado en los ordenamientos jurídicos nacionales. La pertinencia de este análisis sobre las cláusulas de exclusión radica en un empleo frecuente de las mismas en contextos sumamente críticos que no siempre reúnen las garantías requeridas. De ahí, la exigencia metodológica de concretar el alcance efectivo de tales cláusulas a traves de la jurisprudencia, básicamente, del TJUE y del TEDH, sin 
soslayar la colisión que se produce entre las cláuslas de exclusión y la expulsión en relación con la prohibición de la tortura del art. $3 \mathrm{CEDH}$.

\subsubsection{Las cláusulas de exclusión del estatuto de refugiado por cuestiones que} dependen de la seguridad nacional. Especial referencia al ordenamiento jurídico Español.

En la normativa reguladora del SECA, el art. 12 de la Directiva de Reconocimiento reproduce los motivos de exclusión que regula el art. 1F, diferenciando entre aquellos sujetos que no requieren protección (apartado $1^{\circ}$ ) y aquellos que comprometen seriamente la seguridad del Estado de acogida, objeto de examen en el presente estudio (apartado $2^{\circ}$ ). ${ }^{211}$ La aplicación de estas exclusiones exige una interpretación de acuerdo con su finalidad general, respetando el núcleo esencial de la Convención de Ginebra y el resto de tratados en la materia (art. 78 TJUE) tal y como recuerda la jurisprudencia del TJUE. ${ }^{212}$ De esta manera, en el caso de producirse alguno de estos supuestos mencionados, el Estado de acogida competente en la tramitación de la solicitud estará facultado a no proporcionar protección internacional e, incluso, a inaplicar la prohibición del principio de no devolución si el sujeto debe ser efectivamente juzgado por los hechos delictivos cometidos. ${ }^{213}$

Ahora bien, estas cláusulas están sujetas a una limitación de carácter temporal. El hecho de que una persona haya sido objeto en el pasado de una decisión de exclusión de la condición de refugiado por incompatibilidad con la seguridad de este Estado no debe presumir per se que su mera presencia en el territorio del EM de acogida constituye un riesgo real, presente y suficientemente grave. Es más, con carácter general, como

\footnotetext{
${ }^{211}$ Dispone este apartado lo siguiente: "Los nacionales de terceros países o los apátridas quedarán excluidos de ser refugiados en caso de que existan motivos fundados para considerar que: a) han cometido un delito contra la paz, un delito de guerra o un delito contra la humanidad, de los definidos en los instrumentos internacionales elaborados para adoptar disposiciones respecto de tales delitos; b) han cometido un grave delito común fuera del país de refugio antes de ser admitidos como refugiados; es decir, antes de la expedición de un permiso de residencia basado en la concesión del estatuto de refugiado; los actos especialmente crueles, incluso si su comisión persigue un supuesto objetivo político, podrán catalogarse como delitos comunes graves; c) se han hecho culpables de actos contrarios a las finalidades y a los principios de las Naciones Unidas establecidos en el Preámbulo y en los artículos 1 y 2 de la Carta de las Naciones Unidas."

${ }^{212}$ STJUE Karem El Kott, de 19 de diciembre 2012 (Asunto c-364/11), STJUE Andre Lawrence Shepherd contra Bundesrepublik Deutschland, de 26 de febrero de 2015 (Asunto c-472/13).

${ }^{213}$ Sobre esta cuestión, véase ACNUR, Documento del ACNUR sobre la aplicación de las cláusulas de exclusión: el artículo $1 F$ de la Convención de 1951 sobre el Estatuto de los Refugiados, septiembre de 2003, apartado 3.
} 
examina la STJUE (Gran Sala) H.F de 2 de mayo de $2018,{ }^{214}$ es necesaria una evaluación individual previa a la adopción de una medida restrictiva o excluyente de seguridad nacional y orden público que aprecie la amenaza contra la protección de los derechos de los ciudadanos de la UE y sus familiares, esto es, el grado de peligrosidad real de un sujeto en un periodo de tiempo concreto. Indudablemente, la comisión de estos actos de notoria entidad implicará una "alta probabilidad" de exclusión -supuesto que, recordemos, se extiende a los casos de incitación (apartado $3^{\circ}$ del art. 12 de la Directiva)-. ${ }^{215}$ Si bien, puede vislumbrarse como el grado de peligrosidad de un sujeto y su incompatibilidad con la seguridad nacional y orden público tiende a priorizar el espacio de tiempo al hecho delictivo, por lo que la acogida en un periodo de tiempo concreto deberá comportar, inexorablemente, un peligro real y próximo para la seguridad del Estado competente.

La aplicación de las cláusulas de exclusión, tal y como se regula en la actual Directiva de Reconocimiento, a nuestro juicio, ha mermado la protección efectiva del derecho a obtener, en su caso, la protección internacional de quienes pudieran hallarse en necesidad de obtenerla. Debe constatarse la complejidad jurídica que reviste en el seno del procedimiento la aplicación de las mismas, siendo objeto de profundas críticas doctrinales que han alertado cómo estas resultan extensibles a supuestos donde no acaece una amenaza real e inminente, pero resulta "conveniente" para el interés del Estado competente. ${ }^{216}$ Un factor que se ha agravado por la patente falta de coherencia y

\footnotetext{
${ }^{214}$ STJUE (Gran Sala), H.F, de 2 de mayo de 2018. Asuntos acumulados C-331/16 K y C-366/16.

${ }^{215}$ En el plano internacional, la incitación ha venido contemplándose en las Resoluciones de Naciones Unidas tras los atentados terroristas de Nueva York del 11-S del año 2001. Véase, Resolución 1373 (2001). Aprobada por el Consejo de Seguridad en su 4385 sesión, celebrada el 28 de septiembre de 2001 (S/RES/1373 (2001), Resolución 1624 (2005). Aprobada por el Consejo de Seguridad en su 5261a sesión, celebrada el 14 de septiembre de 2005 S/RES/1624 (2005). Resolución 2322 (2016). Aprobada por el Consejo de Seguridad en su $7831^{\text {a }}$ sesión, celebrada el 12 de diciembre de 2016 (S/RES/2322). Resolución 2396 (2017) Aprobada por el Consejo de Seguridad en su 8148 a sesión, celebrada el 21 de diciembre de 2017.

${ }^{216}$ SCOTT, M., "Refugee from Climate Change-Related Harm. Evaluating the Scope of International Protection within the Common European Asylum System", en: BAULOZ C., INELI-CYGER M., SINGER S., STOYANOVA V. (eds.), Seeking Asylum in the European Union. Selected Protection Issues Raised by the Second Phase of the Common European Asylum System, Leiden: Brill/Nijhoff, 2015, p. 215; GILBERT, S., "Exclusion under Article 1F since 2001: Two steps backwards, one step forward", en: CHETAIL V., BAULOZ C. (eds.) Research Handbook on International Law and Migration. Research Handbooks in International Law (Cheltenham: Edward Elgar Publishing), 2014, p. 523; SINGER, S., "Exclusion Clauses of the Refugee Convention in Relation to National Immigration Legislations, European Policy and Human Rights Instruments: Article $1 \mathrm{~F}$ versus the NonRefoulement Principle", International Journal of Refugee Law, vol. 29, $\mathrm{n}^{\circ}$ 1, marzo de 2017, pp. 198200.
} 
uniformidad en la evaluación de tales amenazas, dependientes fundamentalmente de los conceptos relacionados con la seguridad nacional que reproducen los EEMM, en especial, del grave delito común que disponen los arts. 1F b) de la Convención de Ginebra y 12.2 b) de la Directiva de Reconocimiento.

$\mathrm{Y}$ en lo que atañe a su concreción en los ordenamientos jurídicos nacionales, por ejemplo, en España, el art. 8.2 $2^{\circ}$ b) LAPS excluye de protección a personas extranjeras sobre las que existan motivos fundados para considerar que "han cometido fuera del país de refugio antes de ser admitidas como refugiadas, es decir, antes de la expedición de una autorización de residencia basada en el reconocimiento de la condición de refugiado un delito grave". Y, entiende como tal, "los que lo sean conforme al Código Penal español y que afecten a la vida, la libertad, la indemnidad o la libertad sexual, la integridad de las personas o el patrimonio, siempre que fuesen realizados con fuerza en las cosas, o violencia o intimidación en las personas, así como en los casos de la delincuencia organizada, debiendo entenderse incluida, en todo caso, en el término delincuencia organizada la recogida en el apartado cuarto del artículo 282 bis de la Ley de Enjuiciamiento Criminal, en relación con los delitos enumerados". 217

En Alemania, la Sección $89^{\mathrm{a}}$ de su Código Penal regula la perpetración de un delito grave y violento que ponga en peligro al estado con una pena de prisión que comprende entre los 6 meses a 10 años, con lo cual una pena entre ambos intervalos podría ser susceptible de exclusión. ${ }^{218}$ Mientras que, en Reino Unido, la Sección 72 de la Ley de Nacionalidad, Inmigración y Asilo de 2002 define como delito grave aquellos que sean condenados a una pena de al menos, 2 años de prisión. Ahora bien, frente a esta generalización, el parágrafo $6^{\circ}$ otorga potestad al condenado y operadores sociales para

\footnotetext{
${ }^{217}$ Sobre el alcance de esta cláusula, véanse las SSAN de 30 de enero de 2017 (recurso n 253/2015), de 21 de diciembre de 2015 (recurso ${ }^{\circ}$ 281/2014) y de 25 de enero de 2013 (recurso no 937/2011)

${ }^{218}$ El Código Penal Alemán regula como delito grave aquel que ponga en peligro al Estado, esto es, un delito contra la vida en virtud de las secciones 211 o 212 o contra la libertad personal en virtud de las secciones 239a o 239b, con intención de perjudicar la existencia o la seguridad de un Estado o de una organización internacional, o para abolir, despojar de efecto legal o socavar los principios constitucionales de la República Federal de Alemania. Código Penal en la versión promulgada el 13 de noviembre de 1998, Boletín Oficial Federal [Bundesgesetzblatt] I p. 3322, modificado por el artículo 1 de la Ley de 24 de septiembre de 2013, Boletín Oficial Federal I p. 3671 y con el texto del artículo 6 (18) de la Ley de 10 de octubre de 2013, Boletín Oficial Federal I p. 3799.
} 
que refuten su compatibilidad con el estatuto de refugiado en un contexto individualizado. $^{219}$

Aunque son los Estados los que definen sus conceptos de delito grave, ha sido el TJUE el que ha establecido ciertas garantías en la aplicación de estas cláusulas con una clara finalidad de incrementar la seguridad jurídica en este ámbito. En el año 2018, instauró un nuevo precedente desmarcándose de las prácticas nacionales que venían produciéndose hasta la fecha, en las que la simple apreciación de la gravedad de estos actos habilitaba a una aplicación automática de estas cláusulas carente de evaluación de proporcionalidad y necesidad alguna. Una valoración de todas y cada una de las circunstancias que permite, en última instancia, aplicar esta cláusula, elevando las garantías de este derecho pero imponiendo también una "considerable obstaculización" para los intereses nacionales, que deberán, en todo caso, otorgar acceso al procedimiento para cumplir con la obligación de proceder a una evaluación individualmente considerada. ${ }^{220}$

Por lo tanto, esta previsión aumenta sustancialmente las garantías del SECA, dotando de una mayor eficacia al procedimiento y cuyo régimen jurídico debe "compensarse" mediante el criterio de eficiencia y disponibilidad de fuentes de información relevantes que desarrolló la EASO en el año 2017. Este adiciona a los tradicionales indicadores, otras acciones cotidianas frecuentes a nivel nacional como el rastreo de fuentes abiertas y redes sociales. ${ }^{221}$ De hecho, el modo de recopilación de información de solicitantes de protección internacional u otras categorías de nacionales de terceros países a través de estas redes muestra, en palabras de Rallo Lombarte, "la vertiginosa evolución tecnológica y la globalización (...) permite intercambiar fácilmente información sobre

\footnotetext{
${ }^{219}$ Reino Unido. Home Office, Asylum policy instruction Revocation of refugee status Version 4.0, 16 de enero de 2016, p. $30 . \quad$ Accesible en: https://assets.publishing.service.gov.uk/government/uploads/system/uploads/attachment_data/file/493918 /revocation_of_refugee_status_v4_0_EXT.pdf

${ }^{220}$ La propuesta de reglamento para la creación un procedimiento común armonizará los procedimientos de asilo a través de procedimientos específicos más breves que permitan determinar si un sujeto compromete o no la seguridad de ese Estado de acogida. Regula el procedimiento acelerado aplicable en este supuesto para el tratamiento de las solicitudes inadmisibles (art. 40.2 en relación con el art. 34.1 de la mencionada propuesta).

${ }^{221}$ Define no exhaustivamente como identificadores, la identidad y documentos de viaje, información del país de origen, la solicitud de extradición, sentencia condenatoria, antecedentes penales y órdenes de arresto, información de bases de datos oficiales, declaraciones del solicitante (incluidas en la solicitud inicial y en las entrevistas) o de terceros. EASO, Guía Práctica de la EASO. Exclusión, enero de 2017, p. 20. Disponible en: https://easo.europa.eu/sites/default/files/EASO-Practical-Guide-Exclusion-ES.PDF
} 
sus comportamientos y sus preferencias, y hacerla pública a nivel mundial a una escala sin precedentes".222

Por lo tanto, ello deberá implicar tanto la obligación positiva de informar al solicitante sobre estas pruebas con objeto de brindarle la posibilidad efectiva de alegar o refutar aquello que considere oportuno como negativa, es decir, absteniéndose a requerir información privada -no accesible libremente- en contra del consentimiento del solicitante. Además, puede seguirse el procedimiento acelerado del art. $31.8 \mathrm{~g}$ ) de la Directiva de Reconocimiento -que, en el caso de España, seguirá la tramitación de urgencia que dispone el art. $25.1 \mathrm{f})$ LAPS-.

Por lo que se refiere a la propuesta de Reglamento de Reconocimiento, pese a que esta cláusula permanece invariable en este ámbito, especifica y detalla el concepto de comisión de delitos graves con miras a promover una mayor uniformidad en las prácticas nacionales. A tal efecto, el novedoso apartado $5^{\circ}$ define delito común grave en los siguientes términos:

“actos especialmente crueles y desproporcionados (letra a) así como los actos de notoria entidad, como supuestos de terrorismo o los que emplean violencia hacia la población civil (letra b)" -en ambos casos, añade incluso si tienen un objetivo político--

Una regulación muy trascendental que exigirá que las legislaciones nacionales concreten su concepto de delito grave como motivo de exclusión, solventando así la divergente interpretación de un delito político dentro de la consideración de delito común grave. Además, el Considerando 45 de la propuesta también alude a aquellos supuestos en los que el nacional pertenece a una asociación que apoya el terrorismo internacional o lo respalda. Un hecho sobre el que se advirtió por parte de la Sala de Inmigración y Asilo del Tribunal Superior de Reino Unido en el año 2013, al establecer lo siguiente: “(...) la misma conducta puede ser considerada un delito en un país, mientras que en otros ni siquiera se considera una falta leve, un enfoque razonable sería aplicar las normas internacionales (....). ${ }^{223}$

\footnotetext{
${ }^{222}$ RALLO LOMBARTE A., "Del derecho a la protección de datos a la garantía de nuevos derechos digitales" en: Tratado de Protección de Datos, Valencia, Tirant lo Blanch, 2019, p. 24. Véase también RALlO LOMBARTE, A., MARTÍNEZ, R. (Eds.): Derecho y Redes Sociales, $2^{\mathrm{a}}$ edición, CivitasThomson Reuters, 2013, Pamplona.

${ }^{223}$ Sala de Inmigración y Asilo del Tribunal Superior (Reino Unido), sentencia de 25 de julio de 2013, AH (Article 1F b)). Traducción no oficial.
} 
Por lo que respecta al ordenamiento jurídico español, la LAPS contempla entre su definición los delitos contra el patrimonio, "siempre que fuesen realizados con fuerza en las cosas, o violencia o intimidación en las personas" sin perjuicio de la regulación de los delitos que regula el CP como graves (art. 13). Una definición que excede de la que proporcionará el futuro Reglamento de Reconocimiento.

El mencionado artículo faculta a proceder a la exclusión por la comisión de un robo del art. $237 \mathrm{CP}$, un delito que ni constituye un acto cruel y desproporcionado, ni de notoria entidad como los casos de terrorismo y cuya violencia hacia la población civil no tiene, a los efectos de la definición de la propuesta, entidad suficiente para excluir del derecho a la protección internacional. ${ }^{224}$ Por consiguiente, en aras de reducir esta generalizada falta de seguridad jurídica dentro del ámbito de aplicación de esta Directiva, las legislaciones nacionales únicamente deberán prever delitos de especial gravedad, absteniéndose a prever tipos penales -aun de gravedad- pero que resultan excesivamente generalizados y amplios, como ocurre en el caso español con los delitos contra el patrimonio con violencia o intimidación.

Asimismo, las autoridades nacionales del país de acogida deberían aplicar su derecho nacional, considerando otros factores como la gravedad del delito en el plano internacional y el país de procedencia del solicitante. Una influencia procedente del derecho anglosajón que pretende promover un alto nivel de coherencia y protección de los solicitantes de asilo de acuerdo con el criterio que adopta ACNUR, que insta a que estas autoridades aprecien de forma conjunta o aislada la naturaleza del acto, la sanción, el daño efectivo y la forma del procedimiento utilizado para enjuiciar el delito. ${ }^{225}$

Se trata de una exigencia que trasciende de la propuesta, que no alude -ni siquiera mínimamente- a la ponderación entre la naturaleza del delito y el umbral de persecución. A nuestro entender, esta valoración, como causa de exclusión, convendría adaptarla al grado de persecución sufrida, debiendo conferir a las autoridades decisorias la potestad de determinar la naturaleza del delito así como las circunstancias atenuantes

\footnotetext{
${ }^{224}$ Un argumento que respalda el Tribunal Constitucional Austriaco, que consideró que los delitos cometidos por el solicitante de protección subsidiaria, robo y malversación menor, no cumplían con el criterio de gravedad del delito exigido en el art. 17 de la anterior Directiva de Reconocimiento. Solo los «delitos graves» daban lugar a la retirada de la protección subsidiaria, excluyendo "varios delitos menores". Sentencia del Tribunal Constitucional (Austria), de 13 de diciembre de 2011, U 1907/10, 15.

${ }^{225}$ ACNUR, Directrices sobre protección internacional no. 5: La aplicación de las cláusulas de exclusión: El artículo 1F de la Convención de 1951 sobre el Estatuto de los Refugiados, 4 de septiembre 2003, HCR/GIP/03/05, apartado 14 .
} 
o agravantes oportunas. Igualmente, como regla general, la carga de la prueba corresponderá al Estado competente, quien deberá acreditar el cumplimiento de los criterios de exclusión, aunque se le imponga al solicitante un "deber de cooperación activo" en la determinación de los hechos y circunstancias relevantes para su solicitud. ${ }^{226} \mathrm{Y}$ sin perjuicio del "régimen compensatorio" que requiere el rígido sistema de exclusión, el cual exige únicamente determinar razones serias, en lugar del alcance "más allá de toda duda razonable" que contempla, como regla general, el derecho penal nacional. ${ }^{227}$ Por tanto, la interpretación de estas cláusulas de exclusión deberá realizarse de forma restrictiva, en vista de las graves consecuencias que puede conllevar para el solicitante afectado.

No menos importante es la incorporación en la propuesta de un nuevo apartado $6^{\circ}$, que exige que se proceda a la exclusión del estatuto de refugiado por los motivos tasados en este artículo, imposibilitando que, en el marco del procedimiento de determinación de su estatuto correspondiente, las autoridades procedan a una evaluación de proporcionalidad adicional. Esta disposición pretende no solo reducir los supuestos de exclusión del estatuto de refugiado, sino también dar cumplimiento al principio de tipicidad. De esta manera, los solicitantes verán excluido su estatuto de refugiado exclusivamente tras la apreciación de las causas legales establecidas con anterioridad, redundando sustancialmente en el incremento de la seguridad jurídica.

Sin embargo, pese a que la propuesta de Reglamento logra adaptar las cláusulas de exclusión del estatuto de refugiado a la normativa internacional, no aborda uno de los más críticos desafíos que, a nuestro juicio, se presentan, esto es, la controvertida equiparación entre la comisión de delitos de especial gravedad y la mera incitación, extremos que deberían entenderse desde un doble extremo:

1. La incitación exigirá un comportamiento manifiestamente radical y grave que resulte incompatible con la concesión del estatuto de refugiado;

2. Los EEMM de acogida deberían contemplar una cláusula de subsidiariedad, esto es, la adopción de políticas menos restrictivas y, en última instancia, aplicarla a la

\footnotetext{
${ }^{226}$ La EASO determina la inversión de la carga de la prueba ante dos supuestos concretos: si el solicitante está acusado por un tribunal penal internacional sobre delitos graves o se ha acreditado que el solicitante ha sido o ha continuado siendo voluntariamente miembro y ha ocupado un puesto destacado en un gobierno represor o una organización que comete actos excluibles. EASO, Guía Práctica, ob. cit., enero de 2017, pp. 9-10.

${ }^{227}$ EASO, Guía Práctica..., ob. cit., enero de 2017, p. 9
} 
incitación a la realización de actuaciones incompatibles con la concesión de estatuto de protección internacional. La EASO interpretó este criterio tras la evaluación de los criterios de asistencia e inducción en el marco de una empresa delictiva conjunta o un propósito común. ${ }^{228}$ En consecuencia, la incitación requerirá la asistencia práctica intencionada tendente a facilitar la comisión de esos delitos, así como mediante potenciales efectos sobre su perpetración aun sin necesidad de una conexión causal directa entre la conducta y la comisión del delito. Además, como examina Bahtiyar, los sujetos en cuestión deberán poder ejercer su derecho de defensa con todas las garantías jurídicas. $^{229}$

Por su parte, con independencia del conflicto al que hemos hecho referencia, conviene reflejar que el vínculo entre beneficiario y terrorismo carece de una falta de concreción en el art. 1F de la Convención de Ginebra y en el propio art. 12 de la Directiva de Reconocimiento y propuesta de Reglamento. Una disposición que exige una interpretación que garantice un correcto equilibrio entre la no obstaculización de la lucha contra el terrorismo y la protección efectiva de los solicitantes de protección internacional. Sobre esta cuestión, recuérdese que el TJUE adoptó una interpretación extensiva de estas cláusulas en la STJUE Lounani, de 31 de enero de $2017^{230}$ en la que apreció que esta no podía limitarse exclusivamente a la comisión de actos terroristas, puesto que "la participación en las actividades de un grupo terrorista podía abarcar un amplio catálogo de comportamientos de gravedad variable” (párr. 71), y entre otros, “el reclutamiento, organización, transporte o equipamiento de sujetos que viajan de un

\footnotetext{
${ }^{228}$ EASO, Exclusión: Artículos 12 y 17 de la Directiva de Reconocimiento (2011/95/UE). Análisis Judicial, enero de 2016, pp. 42-43

${ }^{229}$ Sobre el derecho de defensa de los solicitantes de protección internacional, remitimos a BAHTIYAR, Z., Exclusion clauses of the Refugee Convention in relation to national immigration legislations, European policy and human rights instruments: Article $1 F$ versus the non-refoulement principle, Oisterwijk: Wolf Legal Publishers (WLP), 2016, pp. 104 y ss.

${ }^{230}$ STJUE Lounani, de 31 de Enero de 2017. Asunto C-573/16. Asimismo, con anterioridad, la STJUE, Bundesrespublik Deutschland c. B y D, (Gran Sala) de 9 de noviembre de 2010 (Asuntos acumulados C57/09 y C-101/09), estableció la aplicación individualizada de las cláusulas de exclusión y la necesidad de evaluación de los hechos concretos para determinar los hechos o actos concretos cometidos por el interesado (parágrafo 87). Además, el mero hecho de que la persona hubiera pertenecido a una organización terrorista no podía llevar aparejada su exclusión automática del estatuto de refugiado (parágrafo 88 y 89). Del mismo modo, la STJUE, A, B y C de 2 diciembre de 2014 (Asuntos acumulados C-148/13, C-149/13 y C-150/13) exigía que las disposiciones de la Directiva 2004/83 debían efectuarse a la luz de su estructura general y de su finalidad, con plena observancia de la Convención de Ginebra y de los demás tratados, respetando asimismo los derechos reconocidos por la Carta (párrafo 46).
} 
estado distinto al de su residencia o nacionalidad para cometer, planificar o preparar actos terroristas" (párr. 69).

Y aunque una interpretación extensiva puede facultar a la exclusión de los solicitantes de protección internacional con base en una mera conexión indirecta y ampliamente considerada con un acto terrorista, la equiparación de las distintas actividades que motivan la aplicación de estas cláusulas requiere un examen de "todas las circunstancias individuales de los hechos concretos de los que tenga conocimiento para determinar si hay motivos fundados para creer que los actos cometidos por la persona afectada entran dentro de este caso de exclusión” (párr. 72). En este caso, la STJUE determinó que las actividades podían justificar la exclusión del estatuto de refugiado y que la condena firme por los tribunales del EM competente revestía entidad suficiente para equipararse a los actos contrarios a los fines de Naciones Unidas. Remarcó que, el mero hecho de que el sujeto fuera un miembro destacado de una organización sin demostrar el intento, amenaza o comisión de un acto terrorista podía constituir justificación suficiente para proceder a la exclusión.

Este pronunciamiento marcó un precedente al contrariar, precisamente, la doctrina jurisprudencial de este Tribunal en la STJUE Bundesrepublik Deutschland c. B and D, de 9 de noviembre de 2010 antes mencionada, que afirmaba que la adopción automática de la cláusula de exclusión por mera pertenencia a una organización terrorista se encontraba supeditada a factores "de especial emergencia" en ámbito nacional. Por lo que el inminente peligro para el EM de acogida, justificaba la ausencia de gravámenes como la exigencia de una evaluación de proporcionalidad. Una sentencia muy criticada no tanto por propiciar un margen excesivamente flexible en sede nacional, sino por promover actuaciones con tendencia hacia la arbitrariedad. ${ }^{231}$

De igual manera, la vinculación de un sujeto con un perfil potencialmente terrorista parece flexibilizar la aplicación de las cláusulas de exclusión a los supuestos de mera incitación y $\sin$ perjuicio de que la STJUE (Gran Sala) A y otros/Minister van Buitenlandse Zaken de 14 de marzo $2017^{232}$ se pronunciase de nuevo adoptando un criterio restrictivo en relación con la consideración de "conflictos armados" en el

\footnotetext{
${ }^{231}$ PEERS S., "Foreign fighters' helpers excluded from refugee status: the ECJ clarifies the law", Blogspot EU Law Analysis, 31 de enero de 2017. Accesible en: http://eulawanalysis.blogspot.com/2017/01/foreign-fighters-helpers-excluded-from.html

${ }^{232}$ STJUE (Gran Sala) A y otros/Minister van Buitenlandse Zaken de 14 de marzo 2017. Asunto C158/14.
} 
derecho internacional, la cual no impedía su clasificación como "actos terroristas" en el derecho de la UE, teniendo en cuenta la complejidad en la determinación de estas acciones en un conflicto armado y su finalidad claramente "contraria a los propósitos y principios de las Naciones Unidas".

Para terminar, la propuesta debería haber incluido expresamente la distinción entre la exclusión del estatuto de refugiado y su independencia con una ulterior expulsión. En este sentido, el próximo pronunciamiento del TEDH en el asunto M.A. c. Estonia ${ }^{233}$ deberá abordar esta situación. Recordemos que este asunto versa sobre la deportación de un ciudadano que entró en Estonia de forma irregular desde Rusia y solicitó directamente asilo. Las autoridades nacionales rechazaron su petición y el Tribunal Supremo de este país sostuvo que el solicitante no podía ser considerado como un refugiado, aunque se habían dado motivos sustanciales para creer que, si regresaba a su país de origen, correría un riesgo real de sufrir un daño grave. A pesar de ello, la solicitud de protección subsidiaria fue rechazada de plano, al constituir una amenaza para la seguridad nacional y el orden público de este país, aun alegando el solicitante que la deportación de Estonia a Rusia violaría el art. $3 \mathrm{CEDH}$, pues Rusia lo devolviera a Uzbekistán. Tal y como analizamos en las cláusulas de revocación, convendría que el TEDH se pronunciase en esta línea, diferenciando entre un sujeto con estatuto formal de refugiado y un mero sujeto que, aunque no tiene derecho a gozar de los beneficios derivados de su reconocimiento como refugiado, tampoco puede ser devuelto. En caso contrario, contravendría el art. 33.1 de la Convención de Ginebra y el art. 3 CEDH. ${ }^{234}$

En definitiva, las cláusulas de exclusión del estatuto de refugiado resultan aplicables no solo a sujetos sobre los que "existan motivos fundados para considerar" que han cometido los delitos anteriormente señalados, sino que se extiende a difusas conductas de "mera incitación". Esta mayor amplitud pretende elevar las garantías de los EEMM,

\footnotetext{
${ }^{233}$ STEDH M.A. c. Estonia, de 2 de octubre de 2018 (demanda n ${ }^{\circ}$ 46173/18).

${ }^{234}$ En esta línea, remitimos a la Decisión de la Junta de Apelaciones de Refugiados de Dinamarca, de 6 de febrero de 2017. En este caso, un solicitante había formado parte del ejército sirio, que abandonó el territorio previamente a la presentación de una solicitud de asilo en Dinamarca. Se constató que existían razones fundadas para suponer que el solicitante había cometido un crimen de guerra y lesa humanidad durante su servicio militar, le fue denegado el estatuto de refugiado al amparo del art. 10.1 de la Ley de Extranjería de Dinamarca y del art. $1 \mathrm{~F}$ a) de la Convención. Sin embargo, esta Junta prohibió su expulsión, pues apreció un elevado riesgo de persecución en país de origen. La información se encuentra disponible en la web oficial de Asylum Law Database. Accesible en: https://www.asylumlawdatabase.eu/en/case-law/denmark-refugee-appeals-board\%E2\%80\%99s-decision6-february-2017 [Consulta: 4 de agosto de 2019]
} 
facultados a excluir actuaciones que pueden comportar un serio peligro para su propia seguridad nacional. Sin embargo, exige mayores garantías en el procedimiento, por cuanto deberán constatarse todas y cada una de las actuaciones que justifiquen tal decisión, con independencia de su expulsión. La aplicación de las mencionadas cláusulas no podrá vulnerar directa ni indirectamente la prohibición de la tortura y de las penas o los tratos inhumanos o degradantes de los arts. 4 CDFUE o $3 \mathrm{CEDH}^{235}$

En consecuencia, tras la decisión de exclusión de estatuto de protección internacional, los Estados de acogida deben prever respuestas contundentes contra la devolución de un sujeto a un país que podría violar sus derechos fundamentales. Es más, el apartado $6^{\circ}$ del art. 12 de la mencionada propuesta únicamente facultará a la exclusión en las condiciones establecidas en los anteriores apartados sin sujeción, en modo alguno, a una evaluación de proporcionalidad adicional con respecto al caso en cuestión. Sin embargo, como abordaremos a continuación, la definición de grave delito común de la propuesta generará un conflicto de competencias entre EEMM y la UE que, con toda certeza, no restringirá las armas profundamente discrecionales nacionales, lo cual puede desvirtuar este régimen de garantías.

\subsubsection{Las cláusulas de exclusión del estatuto de protección subsidiaria: el conflicto} entre la seguridad nacional y los derechos de los solicitantes.

La Directiva de Reconocimiento ya establecía desde el año 2004 una significativa diferenciación entre las cláusulas de exclusión del estatuto de refugiado y de la protección subsidiaria. De tal modo, tanto art. 17 de la vigente Directiva como el art. 18 de su propuesta de Reglamento excluyen de protección a aquellos nacionales de terceros países sobre los que existan motivos fundados para considerar la comisión de los mismos supuestos que refugiado, esto es: "a) un delito contra la paz, un delito de guerra o un delito contra la humanidad; b) un delito grave; c) sean culpables de actos contrarios a las finalidades y a los principios de las Naciones Unidas establecidos en el Preámbulo y en los artículos 1 y 2 de la Carta de las Naciones Unidas; d) constituyen un peligro para la comunidad o para la seguridad del Estado miembro en el que se encuentran".

Este último apartado supone la clara diferencia de la exclusión del estatuto de refugiado. Este estatuto adiciona esta última letra como causa de exclusión, la cual se

\footnotetext{
${ }^{235}$ Para un análisis sobre el particular, remitimos a: KOSIŃSKA, A.M., "The Problem of Exclusion from Refugee Status on the Grounds of Being Guilty of Terrorist Acts in the CJEU Case-law: Commentary on the Lounani Case", European Journal of Migration and Law, vol. 19, nº 4, 2017, p. 446.
} 
aplica en aquellos casos en los que el sujeto constituye un peligro para la comunidad o para la seguridad del EM en el que se encuentran.

Esta excede de las cláusulas a la luz del art. 1F de la Convención y tiene su razón de ser en la excepción a la prohibición de devolución del art. 33.2, ${ }^{236}$ regulando de un concepto jurídico que corresponde desarrollar a los EEMM. En España, el art. 11.1 d) LAPS concretó esta seguridad tanto en su dimensión interior y exterior como para el orden público-.

Igualmente, estos supuestos se extienden no solo a la comisión de tales actos, sino a su incitación o participación (apartado $2^{\circ}$ ), contemplando la exclusión si "antes de su admisión en el Estado miembro de que se trate, hubiesen cometido uno o varios delitos (...) sancionables con una pena privativa de libertad de haberse cometido en tal Estado miembro y si hubiesen dejado su país de origen únicamente para evitar las sanciones derivadas de tales delitos" (apartado $3^{\circ}$ de la Directiva -letra e) de la mencionada propuesta). Por ende, a diferencia de la exclusión para la condición de refugiado, en el caso de los sujetos que pueden entrar dentro de la definición de la protección subsidiaria, estas cláusulas constituyen herramientas más flexibles para garantizar la seguridad nacional $\mathrm{u}$ orden público de los estados. Esto ha generado una teórica "equiparación" en la protección de ambos estatutos que dista mucho de ser real y efectiva y que va en serio detrimento de las garantías del propio derecho a la protección internacional, máxime si no se categoriza exhaustivamente a estos solicitantes.

Este estatuto puede crear un potencial y crítico conflicto de intereses en sede nacional, en especial, en aquellos contextos donde el conflicto constitucional "protección internacional versus seguridad nacional" requiere rebajar sustancialmente las garantías en el derecho a la protección internacional, provocando los siguientes déficits estructurales en este derecho:

\footnotetext{
${ }^{236} \mathrm{El}$ alcance del art. 33 de la Convención ha sido interpretado por la doctrina como una disposición extraordinaria o de último recurso de tal modo que por un lado, otorga prevalencia a los problemas de seguridad dentro del Estado de acogida sobre los riesgos potenciales que un refugiado reconocido puede enfrentar en caso de regresar a su país de origen y por otro lado, las autoridades de asilo permiten aplicar una gran discrecionalidad "con respecto a los asuntos policiales y de seguridad, lejos de su verdadera misión". BOGGIA COSADIA, F., "Protection subsidiare et menace à l'ordre public: l'application de la clause d'exclusion de l'article 17(1)(d) de la directive 2004/83/CE du Conseil de l'Union européenne en France", en: CHETAIL V., LALY-CHEVALIER C., (eds.), Asile et extradition: Théorie et pratique de l'exclusion du statut de réfugié, Bruylant, 2014, p. 134; GUILD, E., GARLICK, M., "Refugee protection, counter-terrorism and exclusion in the European Union”, Refugee Studies Quarterly, vol. 29, nº 4, 2010, p. 63.
} 
1. Con independencia de las cláusulas de exclusión equivalentes que se prevén en ambos estatutos, lo cierto es que, el art. 17 apartado b) ${ }^{237}$ no solo carece de limitación temporal o territorial alguna, sino que abarca delitos tanto comunes como políticos. Por ello, se habilita al EM de acogida a excluir de estatuto de protección subsidiaria a aquellos sujetos que han cometido un delito muy grave no únicamente con anterioridad a la expedición del permiso de residencia -que se amplían a supuestos de incitación y participación-. También con independencia del lugar en que se hubieran cometido y de la tipología del delito, esto es, abarcando no solo conductas dentro del EM de acogida, sino en cualquier otro Estado de tránsito u origen. Incluso extendiéndose a los delitos de origen exclusivamente político (apartado 1 letra b).

Esta disposición resulta excesivamente amplia para los fines que se persiguen, pudiendo menoscabar, en su caso, el contenido del derecho a la protección subsidiaria. Las únicas dos garantías que prevén este instrumento del SECA son la necesidad de que el delito sea desproporcional para los fines perseguidos y su calificación en la mayoría de las jurisdicciones como muy grave. Por lo tanto, no se considerará como tal la acumulación de delitos menos graves que pueda resultar en una pena de considerable $\operatorname{gravedad}^{238}$ pues requerirá, en todo caso, un examen individual de todos y cada uno de los delitos cometidos, su autoría y todas las circunstancias, de modo que permitan dilucidar la proporcionalidad en la aplicación de la cláusula de exclusión.

2. En relación con la letra d) art. 17 de la Directiva de Reconocimiento ${ }^{239}$ constituye $^{2}$ el instrumento más flexible que ostentan los estados para proceder a la exclusión de protección a un determinado sujeto, pues habilita a implementar la mencionada cláusula en el supuesto de que este "constituya un peligro para la comunidad o para la seguridad del Estado miembro en el que se encuentran”. Esta disposición ha diferido desde sus orígenes en el art. 1F de la Convención sobre los refugiados y su régimen de excepción otorga un arma discrecional al Estado de acogida, que puede determinar si la actuación de un sujeto puede entrar en directa colisión con su propia seguridad. De acuerdo con la EASO, este precepto prioriza la seguridad de los Estados a los posibles

\footnotetext{
${ }^{237}$ Y en similares términos, la art. 18 b) de la propuesta de Reglamento de Reconocimiento.

${ }^{238}$ Sentencia del Tribunal Constitucional (Austria), de 13 de diciembre de 2011, ob. cit, 17.

${ }^{239}$ E, igualmente, el art. 18 d) de propuesta de Reglamento de Reconocimiento.
} 
riesgos a los que se puede enfrentar un refugiado reconocido en caso de ser devuelto a su país de origen. ${ }^{240}$

Por lo tanto, a falta de pronunciamiento del TJUE que dilucide este extremo, el peligro para la comunidad o para la seguridad del EM debería respetar ciertos parámetros coherentes y de seguridad jurídica. Ello, en buena medida, mediante la potenciación de un intercambio de información entre las autoridades nacionales y organismos europeos en Eurodac y con la interoperabilidad con los restantes SSII europeos (véase Capítulo III). Con ello, pese a que la determinación de las conductas que pueden suponer un peligro para la seguridad constituye una valoración eminentemente nacional, la exclusión por este motivo requerirá de ciertos criterios homogéneos a nivel comunitario, de modo que el "mínimo denominador común" sea ponderado mediante la coexistencia de información específica en los mencionados SSII, advertencias entre las autoridades policiales nacionales, Europol o agencias europeas especializadas como la AAUE y, esencialmente, la recientemente creada GEFC. Esta última, como analiza Moreno Lax, efectuará evaluaciones vinculantes sobre la vulnerabilidad de la gestión de las fronteras de los EEMM afectados por contextos que pueden comprometer su seguridad. ${ }^{241}$ Una actuación conjunta y coordinada entre estos organismos que permitiría obtener la información necesaria para determinar el potencial perfil del sujeto contrario a la seguridad europea y nacional.

Al efecto, como trataremos en el Capítulo III, esta mayor accesibilidad a la información se encauzará a través de la interoperabilidad entre los SSII europeos, lo cual no resultará ajena a riesgos de enorme calado, por ejemplo, la posibilidad de que incremente la aplicación de estas cláusulas de exclusión, por cuanto se facilita la detección de cualquier conducta sospechosa de poner en riesgo la seguridad del EM en el que se encuentran. Un riesgo que fue abordado en España, donde la Sala de lo Contencioso de la Sección II de la Audiencia Nacional (AN) en la Sentencia 5689/2013, de 26 de diciembre de 2013 determinó que la mera existencia de información que pudiera involucrar al sujeto en la participación, directa o indirecta, de un delito contra la humanidad sin una condena previa no facultaba a la aplicación de esta causa de

\footnotetext{
${ }^{240}$ EASO, Exclusión: Artículos 12 y 17 de la Directiva de Reconocimiento ob. cit., p. 53.

${ }^{241}$ MORENO LAX V., Assessing Asylum in Europe - Extraterritorial Border Controls and Refugee Rights under EU Law, Oxford, Oxford University Press, 2017, p. 164.
} 
exclusión. ${ }^{242}$ De tal modo, a falta de parámetros claros que aborden esta nueva mayor disponibilidad de la información, su trascendencia en las cláusulas de exclusión exigirá un acto jurídico como una condena o, al menos, una alerta contrastada entre distintos SSII que desvirtúe la presunción de inocencia.

3. Finalmente, el apartado $3^{\circ}$ del art. $17^{243}$ amplía las cláusulas de exclusión a un solicitante de protección subsidiaria que, antes de su admisión, hubiese cometido uno o varios delitos distintos al previsto en el apartado $1^{\circ}$, si este o estos "fueran sancionables en este país con una pena privativa de libertad y si hubiesen dejado su país de origen únicamente para evitar las sanciones derivadas de tales delitos". La EASO considera que esta exclusión debe aplicarse a los conocidos "fugitivos de la justicia", aquellos que se aprovechan del procedimiento de protección subsidiaria para huir de la justicia de su país de origen y evitar así, la imposición de las sanciones penales correspondientes. ${ }^{244}$ Si bien, el elemento conflictivo estriba, en esencia, en la falta de especificación de la pena de privación de libertad.

\section{Recordemos que la STJUE Shajin Ahmed contra Bevándorlási és Menekültügyi} Hivatal, de 13 de septiembre de $2018^{245}$ condenó a Hungría sobre la interpretación que hizo sobre esta cláusula de exclusión. Concretamente, su ley nacional disponía que cualquier sentencia condenatoria de privación de libertad a 5 años o superior tenía automáticamente la consideración de delito grave y, por tanto, el solicitante quedaba excluido de protección subsidiaria. Y, si bien, una condena de este calibre puede resultar, a priori, proporcional para los fines de exclusión, el TJUE exige -al igual que en la aplicación del resto de cláusulas- que, dentro del alcance de esta exclusión, la consideración de "delito grave" incompatible con este estatuto deba ser considerado individualmente, concretando la "gravedad" específica mediante una evaluación completa de todas y cada una de las circunstancias.

\footnotetext{
${ }^{242} \mathrm{La}$ AN revocó la resolución de subsecretaría del Ministerio del Interior por la que se denegaba el derecho de asilo, ante la existencia de motivos fundados para considerar que el recurrente había cometido delitos contra la humanidad. La AN determinó que esta exclusión debía aplicarse tras una condena previa por delitos de lesa humanidad impuesta en un juicio celebrado con todas las garantías. Sentencia de la Audiencia Nacional, de 26 de diciembre de 2013 (recurso n ${ }^{\circ}$ 327/2012). Para un comentario de la misma, remitimos a: ALMQVIST J.M., "El derecho de asilo y los límites a su aplicación por delito de lesa humanidad", Revista Española de Derecho Internacional, Madrid, enero-junio, 2014, pp. 229- 232.

${ }^{243} \mathrm{Al}$ igual que el art. $18.1 \mathrm{e}$ ) de la propuesta de Reglamento de Reconocimiento.

${ }^{244}$ EASO, Exclusión: Artículos 12 y 17 de la Directiva de Reconocimiento, ob. cit., p. 55.

${ }^{245}$ STJUE Shajin Ahmed contra Bevándorlási és Menekültügyi Hivatal de 13 de septiembre de 2018. Asunto C-369/17.
} 
En definitiva, la determinación de un sujeto como posible beneficiario de la protección subsidiaria otorga a las autoridades nacionales una flexibilidad sin precedentes para excluir de protección a un sujeto ante la comisión de cualquier delito que esté tipificado con una pena privativa de libertad, independientemente de su gravedad o del momento en el que fue llevado a cabo. Únicamente se exige que la comisión del acto penado sea razón principal por la cual solicita protección subsidiaria, esto es, que el solicitante hubiera pretendido sortear las sanciones derivadas de los delitos cometidos en el país de origen. Por ello, esta discrecionalidad se encuentra limitada, de tal forma que los EEMM no pueden abstenerse de aplicar la cláusula de exclusión a un sujeto que ha cometido uno de los hechos tipificados como tal. ${ }^{246}$ Una vinculación de los EEMM que persigue la finalidad de salvaguardar la integridad de la institución de asilo, la confianza en las decisiones nacionales de otros EEMM y la seguridad de la UE en su conjunto.

\subsubsection{Las cláusulas de exclusión y su conflicto jurídico actual y futuro: ¿la} seguridad en detrimento de la efectividad del SECA?

El análisis detenido sobre estas cuestiones nos lleva a estudiar la predisposición a catalogar a los solicitantes como potenciales sujetos con derecho a protección subsidiaria, en lugar de refugiado pese a que estos dos estatutos sean jurídicamente distintos. $^{247}$ Si bien, el empleo de las cláusulas de exclusión aplicables a los solicitantes de protección subsidiaria es ciertamente más amplio que en el caso de refugiado, situación que permite constatar serios obstáculos en la efectividad de este derecho por los siguientes dos motivos:

\footnotetext{
${ }^{246}$ EASO, Guía Práctica, ob. cit, p. 40; EASO, Exclusión: Artículos 12 y 17 de la Directiva de Reconocimiento, ob. cit., p. 55.

${ }^{247} \mathrm{La}$ diferencia entre ambos estatutos es clara. Por lo que respecta a la figura de refugiado, se trata de "un nacional de un tercer país que, debido a fundados temores a ser perseguido por motivos de raza, religión, nacionalidad, opiniones políticas o pertenencia ha determinado grupo social, se encuentra fuera del país de su nacionalidad y no puede o, a causa de dichos temores, no quiere acogerse a la protección de tal país, o un apátrida que, hallándose fuera del país donde antes tuviera su residencia habitual por los mismos motivos que los mencionados, no puede o, a causa de dichos temores, no quiera regresar a él, y al que no se aplica el artículo 12". Por lo que se refiere a la protección subsidiaria, el sujeto en cuestión no cumple con los requisitos para ser un refugiado. Ahora bien, se entiende que pueden darse "motivos fundados para creer que, si regresase a su país de origen o, en el caso de un apátrida, al país de su anterior residencia habitual, se enfrentaría a un riesgo real de sufrir alguno de los daños graves definidos en el art. 15 y que no puede o, a causa de dicho riesgo, no quiere acogerse a la protección de tal país”. Véase art. 2 apartados d) y f) de la Directiva de Reconocimiento.
} 
1. Al margen del análisis concreto de cada caso, durante la crisis migratoria del año 2014 a 2016, pudo evidenciarse cómo la gran mayoría de los nacionales sirios, recibieron estatutos distintos. Por una parte, Alemania, Austria, Grecia, Bulgaria o Noruega, entre otros, otorgaron casi, exclusivamente, estatuto de refugiado. Mientras que por otra, Suecia, España, Chipre y Malta otorgaron mayormente protección subsidiaria. $^{248}$

Además, un año más tarde, de acuerdo con la encuesta de la Oficina Federal para la Migración y Refugio de Alemania (BAMF) ${ }^{249}$ y la EASO, Alemania cambió radicalmente de criterio, aplicando estrictamente la Directiva de Reconocimiento y concediendo a los solicitantes de protección internacional provenientes de Siria el estatuto de protección subsidiaria. ${ }^{250}$ Con ello, no pretendemos examinar de forma exhaustiva -en este último caso- el discordante criterio entre ambas cláusulas sino reflejar cómo algunos EEMM han utilizado ambos estatutos de forma escasamente exhaustiva, en especial, durante periodos de grandes afluencias de solicitantes de protección internacional en puntos fronterizos nacionales.

2. El segundo de ellos versa sobre las serias reticencias de algunos EEMM a la hora de aportar información acerca de las subcategorías de solicitantes de protección internacional. Esta escasa transparencia ha sido suscitada, fundamentalmente, en países que han afrontado flujos exacerbados en frontera ${ }^{251} \mathrm{y}$ cuya situación de opacidad tuvo uno de sus precedentes en Suiza. Desde sus orígenes, la Oficina Federal Suiza para los Refugiados, en el presente denominada Oficina Federal de Migración, advertía que no hacían públicas las razones por las que concedía el estatuto de refugiado o protección

\footnotetext{
${ }^{248}$ Eurostat, Resoluciones en primera instancia sobre solicitudes de protección internacional, 2015. La tasa de concesión de protección subsidiaria de nacionales Sirios fue del 97.8\% en Chipre, 92.7\% en Malta, 90.1\% en España y $87.5 \%$ en Suecia.

${ }^{249}$ Del alemán, Bundesamt für Migration und Flüchtlinge (BAMF).

${ }^{250}$ Hasta agosto de 2016, alrededor de 225.000 ciudadanos sirios solicitaron estatuto de refugiado. Alrededor de 51,000 de ellos recibieron protección subsidiaria mientras que, durante todo el período de 2015, tan solo 61 de estos solicitantes fueron reconocidos como beneficiarios de protección subsidiaria. Una diferencia porcentual del 0,06\% a 4,2\%. Véase Bundesamt für Migration und Flüchtlinge (BAMF), Estadística de asilo entre 2015 y agosto de 2016. Igualmente, para un enfoque más amplio sobre estos datos remitimos a: EASO, Annual Report, julio de 2015, pp. 24-28.

${ }^{251}$ Revelador resulta que, entre 2013-2015, Italia no informara ni proporcionara datos sobre decisiones de protección de refugiados, humanitarios o subsidiarias de países de origen de la UE. De igual modo, tampoco Francia informó datos para estas subcategorías para países de origen de la UE.

Véase Eurostat, "First instance decisions on applications by citizenship, age and sex. Annual aggregated data", marzo de 2018, http://appsso.eurostat.ec.europa.eu/nui/show.do?dataset=migr_asydcfsta\&lang=en.
} 
subsidiaria. ${ }^{252}$ Una serie de indicios que permiten constatar una tramitación de solicitudes de protección internacional de forma imprecisa, ya sea porque el solicitante no logra probar las razones de su persecución para su consideración como refugiado, no resulten convincentes para las autoridades o estas tiendan, en un mayor grado, a clasificar a los solicitantes dentro de la categoría de protección subsidiaria.

Tanto es así que, a nuestro modo de ver, esta catalogación ha reflejado una aparente "inoperatividad práctica" en la diferenciación conceptual entre los dos estatutos. Una circunstancia que agrava efectos de la conocida como "asylum lottery", concepto que fue acuñado en 2011 por el Consejo Europeo sobre Refugiados y Exiliados (ECRE) en el seno del SECA para referirse a las diferencias sustanciales que se producían a la hora de solicitar asilo en los distintos EEMM ${ }^{253}$ y que, hasta la actualidad, ha sido objeto de estudio por un amplio sector doctrinal. ${ }^{254}$

En este sentido, pese a que el alcance del principio de no devolución se aplicará indistintamente en ambos estatutos, lo cierto es que, como ha podido analizarse con anterioridad, las garantías distarán mucho de ser similares o equivalentes, en especial, en aquellos supuestos en los que un sujeto puede directa o indirectamente revestir un riesgo para la seguridad nacional. Es por ello por lo que las cláusulas de exclusión no deberían transformarse automáticamente en instrumentos de lucha contra la delincuencia y el terrorismo. Únicamente debería procederse a la expulsión del solicitante tras la adopción de una decisión de exclusión en el que hayan sido evaluadas, con carácter previo y de forma individual, todas y cada una de las particularidades que permitan justificar la aplicación de la mencionada cláusula. Ello con independencia de

\footnotetext{
${ }^{252}$ Sobre esta advertencia, merece especial lectura: NADIG, A., "Human Smuggling, National Security", and Refugee Protection, Journal of Refugee Studies", vol. 15, 1, 1 de marzo de 2002, p. 7.

${ }^{253}$ Consejo Europeo para los Refugiados y los Exiliados, Lotería de asilo en la UE en 2010 (basado en los datos de las tendencias globales del ACNUR), 2011.

${ }^{254}$ EULE T.G., BORRELLI L.M., LINDBERG A., WYSS A., "Decision-Making and the Role of Law" en: Migrants Before the Law, Palgrave Macmillan, Cham, 2019; SCHNEIDER, G., RIEDEL, L., The Asylum Lottery: Recognition Rates Vary Strongly within Germany, EU Immigration and Asylum Law and Policy: Droit et Politique de l'Immigration et de l'Asile de l'UE, 2017; BECKER, U., HAGN, J, Reform of the European AsylumSystem: Why Common Social Standards are Imperative, CESifo DICE Report, fo Institut - Leibniz-Institut für Wirtschaftsforschung an der Universität München, vol. 14, nº 4, 2016, p. 21; PARUSEL B., SCHNEIDER J., Reforming the Common European Asylum System: Responsibilitysharing and the harmonisation of asylum outcomes, Report 2017:9, Delmi, 2017, p. 17; TRAUNER, F., "Asylum policy: the EU's 'crises' and the looming policy regime failure", Journal of European Integration, vol. 38, $\mathrm{n}^{\circ} 3,2016$, p. 313.
} 
que, indudablemente, la consideración de un sujeto como potencial beneficiario de este estatuto rebaje sus garantías de protección en comparación con el de refugiado.

En este contexto, la exigencia en la determinación individualizada de todas y cada una de las circunstancias en el seno de un procedimiento ha evidenciado una serie de conflictos en sede nacional. Por ejemplo, en Francia, el Consejo de Estado falló el 11 de abril de 2018 que un acto de naturaleza terrorista cometido por una organización considerada como tal en la UE había carecido de evaluación suficiente por parte del Tribunal Nacional de Asilo acerca de la gravedad del acto del solicitante a la luz del art. 1F (b y c) de la Convención de Ginebra ${ }^{255}$. Del mismo modo, en Reino Unido, la Corte de Apelación ya había declarado en el año 2015 que rechazaba de plano los mecanismos técnicos de evaluación a los que aducía el Tribunal de instancia a la hora de examinar no únicamente la gravedad del acto cometido, sino también hechos subjetivos posteriores como el "perdón formal” para determinar la procedencia de la exclusión. ${ }^{256}$ Asimismo, el 4 de septiembre de 2018, el Tribunal Administrativo Supremo de Bulgaria se pronunció sobre la exclusión por razones de "seguridad nacional" de un solicitante de protección subsidiaria procedente de Siria. En la consideración de esta amenaza, el Tribunal dictaminó que la Agencia Estatal para los Refugiados debió presentar pruebas concretas que probaran su incompatibilidad con la seguridad de este Estado, afirmando que el solicitante también debía ostentar el derecho a conocer esta información. Consecuentemente, este Tribunal falló que la Agencia Estatal para los Refugiados no probó suficientemente que el solicitante representara una amenaza para la seguridad de Bulgaria, revocando la resolución de la Agencia Estatal para los Refugiados y ordenando una reconsideración de su estatuto. ${ }^{257}$

Por lo que respecta a España, la Sección Quinta de la Sala de lo Contencioso del Tribunal Supremo (TS) ha abordado, en el último año, dos cuestiones conflictivas sobre la aplicación de las cláusulas de exclusión. Por un lado, en la STS 212/2019, de 29 de enero de 2019 se pronunció sobre la vinculación de un procedimiento de extradición y

\footnotetext{
${ }^{255}$ Consejo de Estado Francés, de 11 de abril de 2018 ( $\mathrm{n}^{\circ}$ 402242). Esta decisión se encuentra actualmente recurrida ( $\left.\mathrm{n}^{\circ} 402242\right)$.

${ }^{256}$ Corte de Apelación de Reino Unido, Sentencia AH (Argelia) c. Secretario de Estado del Ministerio de Interior, de 14 de octubre de 2015 (C1/2013/712).

${ }^{257}$ European Database of Asylum Law, Bulgaria: Judgment on threat to national security of Syrian asylum applicant, 4 de septiembre de 2018. Accesible en: https://www.asylumlawdatabase.eu/en/content/bulgaria-judgment-threat-national-security-syrian-asylumapplicant [Consulta: 4 de agosto de 2019]
} 
el derecho de asilo, reconociendo que, al instarse la entrega en la extradición podía debilitarse "de manera contundente la veracidad de sus alegaciones de persecución y parece responder a una estrategia para evitar la extradición en curso del interesado". Ahora bien, la Sala destacó que cuando hubiera sido acordada la entrega de una persona a un Estado que la reclama en un procedimiento de extradición, cuya sentencia hubiera adquirido firmeza, no era posible acceder al derecho de asilo por los mismos hechos que fueron tomados en consideración en aquel primer procedimiento, salvo hechos $a$ posteriori que permitieran esclarecer la concurrencia de las circunstancias para la concesión de asilo. ${ }^{258}$

Por otro lado, con respecto al derecho a permanecer en territorio nacional -aun excluyéndose el estatuto de protección internacional-, la STS 1884/2019, de 10 de junio de 2019, ${ }^{259}$ impidió la concesión de una autorización de permanencia por razones humanitarias por los mismos motivos que la solicitud de protección internacional (arts. 37. b) y 46.3 LAPS). El TS concluyó que la apreciación de la causa de exclusión por actos contrarios a las finalidades y a los principios de las Naciones Unidas no imposibilitaba la concesión de una autorización de permanencia por razones humanitarias que disponen los arts. 37.b) de la Directiva de Reconocimiento y 46.3 LAPS, siempre que concurrieran circunstancias para ello. Sin embargo, advirtió que el recurrente no había solicitado -ni en el escrito presentado en vía administrativa ni en la demanda- la petición de residencia por motivos humanitarios, exclusivamente "en el suplico del escrito de interposición insta ex novo con el carácter subsidiario a una hipotética desestimación de su pretensión principal”, esto es, el reconocimiento del estatuto de refugiado y, en defecto de esta, protección subsidiaria. Además, las razones alegadas para la autorización de residencia por motivos humanitarios no diferían de las esgrimidas para la solicitud de asilo y de protección subsidiaria.

\footnotetext{
${ }^{258}$ STS 212/2019, de 29 de enero de 2019 (recurso no 4835/2017). Un nacional de Omán fue condenado en este país por un delito de fraude a una pena de prisión de tres meses a dos años, tras ser interceptado en Dinamarca, fue devuelto a España en virtud del régimen competencial del Reglamento de Dublín. Tras el procedimiento de extradición que ya había adquirido firmeza, presentó una solicitud de asilo basándose en los mismos hechos, si bien, aludiendo a que su devolución colisionaba directamente con el temor fundado de ser sometido a torturas, tratos inhumanos o degradantes. Un argumento que contrariaba el procedimiento de extradición, que consideró que no había riesgo a la vulneración de este derecho ante los mismos hechos alegados en el otro procedimiento. Por ello, confirma la resolución del Ministerio del Interior de 12 de abril de 2016, por la que se denegaba el derecho de asilo y protección subsidiaria y revoca la estimación previa por la Audiencia Nacional.

${ }^{259}$ STS 1884/2019, de 10 de junio de 2019 (recurso no ${ }^{\circ}$ 5805/2017).
} 
Por último, y al margen de los últimos pronunciamientos judiciales, la EASO se ha encargado de proporcionar eficientes medios de información para solventar la excesiva rigidez de los procedimientos nacionales de exclusión. La creación de una "Red de Puntos de Contacto Nacionales de Exclusión" 260 en febrero de 2017 marcó un antes y un después en el intercambio de información. Con esta Red comenzó toda una serie de puntos de contacto entre la EASO con los EEMM sobre cuestiones relacionadas con las exclusiones de protección internacional. Esta apoya a países sobre la decisión de exclusión de un sujeto, fundamentalmente, si las distintas agencias y organismos que operan en fronteras disponen de información al efecto.

Además de esta iniciativa, el Reglamento 2019/818, de 20 de mayo de 2019 relativo al establecimiento de un marco para la interoperabilidad entre los SSII de la UE -sobre el que nos detendremos en el Capítulo III- ya propicia un intercambio de información entre multitud de bases de datos comunitarias, incluyendo Eurodac. Aunque la interoperabilidad de este sistema no comenzará a llevarse a cabo hasta que se apruebe el Reglamento de reforma de Eurodac, la mayor accesibilidad a la información personal que, en el ámbito del asilo, podría generar situaciones sumamente desventajosas como la aplicación indiscriminada de estas cláusulas y la falta de acceso efectivo al procedimiento de protección internacional, contrariando lo dispuesto en el art. 5 del mencionado Reglamento.

La tendencia hacia la sistemática exclusión por el simple hecho de conocer información localizada en un SI que no ha sido puesta a disposición del solicitante puede desembocar en una toma de decisiones basada en información parcial, incompleta, incluso inexacta. Sus consecuencias pueden ser devastadoras en la efectividad de este derecho, aumentando los contextos en los que puede excluirse a un solicitante de protección internacional y contrariando tanto la jurisprudencia del TJUE sobre el particular, así como las mejoras que preverá el futuro Reglamento de Reconocimiento.

Por todo ello, debería fomentarse un intercambio de información preciso, oportuno y, en mayor medida, contrastado que permita dilucidar la incompatibilidad de un sujeto con el estatuto correspondiente pues de lo contrario, puede dar lugar a prácticas nacionales contrarias al propio derecho de protección internacional. ${ }^{261}$ Para tal fin, la

\footnotetext{
${ }^{260}$ Sobre esta Red, véase: https://www.easo.europa.eu/easo-exclusion-network-0

${ }^{261}$ Recuérdese que Kapferer ya apuntaba en el año 2000 que las violaciones de los derechos humanos
} 
información utilizada para justificar la exclusión correspondiente deberá revestir entidad suficiente en la consecución del arduo equilibrio entre los derechos e intereses de los solicitantes y la seguridad de los EEMM. ${ }^{262}$

4.3. La revocación del estatuto de protección internacional por razones de seguridad nacional y su directa conexión con el principio de no devolución.

\subsubsection{Consideraciones previas.}

A diferencia de la exclusión, la revocación no viene como tal regulada en la Convención sobre los Refugiados de 1951 ni el Protocolo de 1967 sobre el estatuto de los refugiados sino que deriva de manera implícita de las causas de cesación del art. 1C, que establece las circunstancias en las cuales la Convención de Refugiados dejará de aplicarse porque un individuo ya no necesita protección. Además, únicamente tras la revocación formal del estatuto de protección internacional -al igual que tras la exclusión formalmente decretada- podrá procederse a su expulsión de acuerdo con el art. 33.2, desvirtuando así la prohibición de devolución o refoulement que regula el art. 33.

La revocación del estatuto de protección internacional se encuentra estrechamente vinculado al contenido esencial de la exclusión del art. $1 \mathrm{~F}$ de la Convención de Ginebra. ${ }^{263}$ Permite al Estado de acogida invalidar el estatuto de refugiado o protección subsidiaria a sujetos que, una vez reconocidos como tal, no debieron haberse acogido al mismo, ya no deben ostentarlo o, simplemente, no puede aplicarse una cláusula de exclusión por cuanto no se dan las condiciones previstas en la propia definición de sujeto con derecho a estatuto de refugiado -art. 1A de la Convención de Ginebra o arts. 2 d) y 9 de la Directiva de Reconocimiento- o protección subsidiaria -arts. 2 f) y 15-.

constituyen uno de los supuestos por excelencia de aplicación de las cláusulas exclusión por parte de tribunales nacionales sobre información inexacta o errónea. KAPFERER, S., 'Exclusion Clauses in Europe - A Comparative Overview of State Practice in France, Belgium and the United Kingdom', International Journal of Refugee Law, vol. 12, 2000, p. 206.

${ }^{262}$ La obra de Tazreiter es realmente crítica con este equilibrio, aludiendo a una relación que excede de estos parámetros hacia otros relacionados con las necesidades e intereses nacionales TAZREITER C., Asylum Seekers and the State. The Politics of Protection in a Security-Conscious World, London Routledge, 2017, pp. 272.

${ }^{263}$ ACNUR, Cancelación del Estatuto de Refugiado, NU Doc. PPLA/2003/02, marzo de 2003, Ginebra: ACNUR, 2003, p. 38. 
Por ello, los Estados no deben cumplir con la obligación de proporcionar tal estatuto, conforme a los arts. 13 y 18 de la mencionada Directiva. Y, a diferencia de la exclusión, esta tiene lugar posteriormente al procedimiento de determinación del estatuto de protección internacional, tras nuevos acontecimientos o hechos que evidencien que el sujeto en cuestión ya no cumple con la definición de refugiado o protección subsidiaria y por tanto, estatuto que le fue conferido.

El objeto del presente epígrafe se centrará en las causas concretas que regula la Directiva de Reconocimiento sobre el régimen jurídico de la revocación del estatuto de refugiado y protección subsidiaria (arts. 14 y 19), procediendo a examinar su concreción en el ordenamiento jurídico español y las diferencias existentes en Alemania y Reino Unido. Estados en los que se han previsto particularidades muy sustanciales en la aplicación de estas cláusulas que deberían contemplarse en el futuro Reglamento de Reconocimiento.

A tal efecto, se abordarán cuestiones conflictivas en sede nacional que facultan a las autoridades a anular el estatuto previamente concedido por cuestiones que afectan a su seguridad nacional. Además, se analizarán las novedades que introducen estas cláusulas en la propuesta de reforma de Reglamento de Reconocimiento, las cuales incrementarán sustancialmente la seguridad jurídica si bien, requerirán modificaciones de gran calado en las legislaciones nacionales que no resultarán ajenas a un potencial conflicto con su seguridad.

\subsubsection{La revocación del estatuto de refugiado y protección subsidiaria en la actual} Directiva de Reconocimiento. Especial referencia al ordenamiento jurídico español.

A diferencia de la normativa internacional, en lo relativo a la normativa reguladora del SECA, la Directiva de Reconocimiento regula expresamente la revocación del estatuto de protección internacional en los arts. 14.1 como 19.1. Como tal, lo hace de una forma cuanto menos amplia, facultando a dictar una resolución al efecto por parte de una autoridad judicial o cuasi judicial o de un organismo gubernamental o administrativo en el supuesto de que haya dejarlo de serlo conforme a los arts. $11 \mathrm{y}$ 16. ${ }^{264}$ Las autoridades decisorias pueden revocar ambos estatutos en los supuestos en los

\footnotetext{
${ }^{264}$ Disponen expresamente ambos arts. lo siguiente: "Por lo que respecta a las solicitudes de protección internacional presentadas después de la entrada en vigor de la Directiva 2004/83/CE, los Estados miembros revocarán el estatuto de refugiado o protección subsidiaria concedido a los nacionales de terceros países o apátridas por un organismo gubernamental, administrativo, judicial o cuasi judicial, o
} 
que sea necesario que cese la protección o que surjan motivos de exclusión posteriormente a la concesión de la protección internacional (apartados $2^{\circ}$ ) y los cuales vienen concretados por los apartados $3^{\circ}$, que tipifican esta posibilidad en dos supuestos:

a) si el sujeto en cuestión debía haber sido excluido de la condición de refugiado conforme al art. $12 \mathrm{o}$;

b) ante la tergiversación u omisión de hechos o información falsa y que fue decisiva para su concesión.

Sobre estos requisitos en la aplicación de la revocación del estatuto, la cuestión prejudicial Mohammed Bilali y Bundesamt für Fremdenwesen und Asyl, de 23 de mayo de $2019^{265}$ interpretó el alcance en el art. 19 en relación con la protección subsidiaria. La Oficina Federal de Inmigración y Asilo de Austria preguntó al TJUE si podía o no revocarse el estatuto de protección subsidiaria ante el conocimiento de hechos relativos al interesado que no se conocían con anterioridad a la concesión de este estatuto. Cambios relativos a las circunstancias fácticas que ni eran relevantes ni tampoco podía acusarse de engaño al solicitante; simplemente dejaba de cumplirse la definición de protección subsidiaria.

El TJUE determinó que cuando el Estado en cuestión tiene nueva información que contraría la que fue previamente analizada en su evaluación inicial y permita determinar que esa persona no se enfrenta a un daño grave del art. 15 , nada impide la revocación de este estatuto, puesto que tales nuevos hechos subyacentes a la concesión ya no justifican la protección que fue conferida en su día. En consecuencia, pese a que el error no sea atribuible al solicitante, este hecho no altera la revocación del estatuto de protección subsidiaria -lo cual, no necesariamente implicará la pérdida de su derecho de residencia, pues el sujeto puede solicitar otro tipo de protección fuera del alcance de esta Directiva-.

Siguiendo con la disposición, el apartado $4^{\circ}$ del art. 14 de la Directiva habilita a las autoridades nacionales a revocar el estatuto de refugiado por cuestiones relacionadas con la seguridad del Estado de acogida, ante la apreciación de causas de exclusión que

dispondrán la finalización de dicho estatuto o se negarán a renovarlo, en caso de que dichas personas hayan dejado de ser refugiados de conformidad con el artículo 11 o 16 ".

${ }^{265}$ STJUE Mohammed Bilali y Bundesamt für Fremdenwesen und Asyl, de 23 de mayo de 2019 (asunto C-720/17). 
no fueron identificadas o completamente determinadas durante el proceso de concesión, es decir:

a) que existan motivos razonables para apreciar que este sujeto "constituye un peligro para la seguridad del Estado miembro en el que se encuentra" o;

b) por haber sido "condenado por sentencia firme por un delito de especial gravedad, constituye un peligro para la comunidad de dicho Estado miembro".

Estos motivos de revocación no se contemplan para el estatuto de protección subsidiaria pues, en ese caso, los EEMM ya disponen de una mayor flexibilidad para excluir directamente de protección si estos constituyen un peligro para la comunidad o para la seguridad del EM en el que se encuentran. Por ende, la apreciación de las causas de este apartado $4^{\circ}$ implicará que el EM podrá devolver al refugiado en cuestión (art. $\left.21.2^{\circ}\right)$

De acuerdo con lo manifestado, las preocupaciones relativas a la seguridad de los EEMM fueron incluidas de forma expresa en esta Directiva. Precisamente, por ampararse en presunciones fundadas en lugar de pruebas contundentes que demuestren la inequívoca necesidad de revocar el estatuto de protección internacional correspondiente, Larsaeus exigió la tipificación de alternativas que fueran respetuosas con los derechos de los individuos durante la eliminación de este estatuto. En efecto, por representar una amenaza para la seguridad, en concreto, garantías como las que ofrece el derecho penal internacional, a través del enjuiciamiento o la extradición. ${ }^{266}$

Además, la expresión de que "existan motivos razonables" o la condena en un tercer país puede no respetar el alto nivel de protección para el sujeto, especialmente, si tenemos en cuenta la mayor probabilidad de ulterior devolución y su conflicto con los arts. 3 CEDH y 4 CDFUE. Y máxime teniendo presente que este instrumento del SECA introdujo una cláusula más amplia que la dispuesta en el art. 33.2 de la Convención, que cuestionaba seriamente su plena coherencia con el derecho internacional de los refugiados y los derechos humanos. ${ }^{267}$ Debate que fue recientemente abordado en la

\footnotetext{
${ }^{266}$ LARSAEUS, N., "The Relationship between Safeguarding Internal Security and Complying with International Obligations of Protection. The Unresolved Issue of Excluded Asylum Seekers", $\mathrm{n}^{\circ} 73$ Nordic Journal of International Law, 2004, pp. 69-97.

${ }^{267}$ LAUTERPACHT E., BETHLEHEM, D., "The scope and content of the principle of non-refoulement: Opinion”, en: FELLER, E., TÜRK V., NICHOLSON F., (eds.), Refugee Protection in International Law Cambridge, CUP, 2003, pp. 87-177.
} 
STJUE $M y$ otros contra Ministerstvo vnitra y X. y X. C. Commissaire général aux réfugiés et aux apatrides, de 14 de mayo de $2019 .{ }^{268}$

En este pronunciamiento, el Tribunal de Luxemburgo examinó la compatibilidad del art. 14.4 de la Directiva de Reconocimiento a la luz del Convenio de Ginebra y del art. 18 CDFUE, un respeto a la normativa internacional que parte de la aplicación del art. 78.1 TFUE. El TJUE reconoció que los nacionales de un tercer país o los apátridas, con independencia de la concesión formal o no del estatuto jurídico de refugiado y, siempre que tuvieran temores reales y fundados de ser perseguidos en su país de origen o de residencia, debían poder ostentar el derecho a permanencer en el territorio del EM mediante una autorización de carácter administrativo que estuviera dispuesta en otra ley distinta de la del asilo.

Así, recordó la mayor amplitud del derecho comunitario con respecto a la prevista por la Convención, ${ }^{269}$ afirmando que el concepto de "refugiado" ${ }^{270}$ constituye un acto meramente declarativo e independiente de su reconocimiento formal a través de la concesión del "estatuto de refugiado". ${ }^{271}$ Dicho lo cual, la revocación del art. 14.4 no faculta a que la persona, con temores fundados de ser perseguida en su país de origen o residencia -valga la redundancia-pierda la condición de refugiado, sino únicamente la revocación formal de su estatuto. La revocación por este motivo del apartado $4^{\mathrm{o}} \mathrm{o}$, incluso, del $5^{\circ}$-que permite a los EEMM denegar el estatuto de refugiado si la decisión todavía no ha sido tomada-, resultan independientes de la autorización a permanecer legalmente en el territorio del EM en cuestión.

Por consiguiente, las cláusulas de revocación se sitúan un paso por delante de las que dispone la Convención. Mientras esta última contempla la posibilidad de la devolución

\footnotetext{
${ }^{268}$ STJUE $M$ y otros contra Ministerstvo vnitra y X. y X. C. Commissaire général aux réfugiés et aux apatrides, de 14 de mayo de 2019 (Asuntos acumulados C-391/16, C-77/17 y C-78/17). El primer caso, M (C-391/16), se refería a un individuo de origen checheno cuyo derecho de asilo fue revocado debido a que fue condenado por un delito grave, constituyendo amenaza para la seguridad nacional. El segundo, $X$ (C-77/17), se refiere a un ciudadano de Costa de Marfil que solicitó asilo tras ser condenado por delitos graves, y cuya solicitud fue rechazada. Y en el tercero, X (C-78/17), el solicitante era un refugiado reconocido cuyo Estado fue revocado y se ordenó su expulsión del Estado debido a la gravedad de los delitos que había cometido.

${ }^{269}$ Mientras que la Directiva contempla la posibilidad de que se revoque o deniegue la concesión del estatuto de refugiado con la finalidad de garantizar la protección de la seguridad y de la comunidad del EM de acogida mientras que la Convención de Ginebra permite, por los mismos motivos, la inaplicabilidad del principio de prohibición de la devolución de un refugiado a un Estado donde peligre su vida o su libertad.

${ }^{270}$ Véase arts. 2 d) de la Directiva y $1 \mathrm{~A}$ de la Convención.

${ }^{271}$ Regulado en los arts. 2 e) en relación con el 13 de la Directiva.
} 
en los contextos del art. 33.2 del Convenio, su concreción en el art. 21.2 de la Directiva de Reconocimiento debe interpretarse en línea con los arts. 4, 19.2 CDFUE o art. 3 $\mathrm{CEDH}$, que prohíben la exposición a la tortura y los tratos y penas inhumanos o degradantes así como la devolución, expulsión y extradición. De tal modo, en los supuestos en los que se proceda a la revocación formal del estatuto de refugiado, el sujeto podrá continuar ostentando la prerrogativa de no devolución, siempre que pueda implicar un serio riesgo de contravenir sus derechos fundamentales. ${ }^{272}$

Además, nada obsta al sujeto al que le ha sido revocado su estatuto de refugiado poder o que pueda continuar disfrutando de los derechos contemplados en la Convención (art. 14.6). ${ }^{273}$ Una necesaria delimitación de los efectos de la revocación formal de la Directiva de Reconocimiento que asegura su plena sintonía conceptual con la Convención. A su vez, respalda el incesante análisis doctrinal que lleva produciéndose en las dos últimas décadas, ${ }^{274}$ que ha reconocido la protección de los refugiados cuyo estatuto había sido revocado y a pesar de ello, seguía operando el

\footnotetext{
${ }^{272}$ En esta particularidad radica la principal diferencia entre la revocación de la cesación de los arts. 11 y 16 de la mencionada Directiva. En este último caso, recuérdese que el Estado de acogida retira el estatuto de protección internacional conferido al dejar de existir o cambiar sustancialmente las condiciones que llevaron a la concesión del mismo de tal forma que esta protección ya no es necesaria. La STJUE Abdulla y Otros c. Bundesrepublik Deutschland, de 2 de marzo de 2010 anteriormente citada determinó que la cesación debía aplicarse ante un cambio de circunstancias significativo, no temporal y cuando ya no existe un temor fundado u otra razón de persecución. Y concreta que, en la evaluación de los cambios en las circunstancias, los Estados deben verificar no únicamente que los actores hayan tomado medidas razonables para evitar la persecución, sino también que la persona tenga acceso efectivo a esa protección. Una evaluación que, al igual que en la devolución que puede derivarse de la exclusión, debe reunir el mismo estándar de probabilidad que fue empleado cuando se otorgó la condición de refugiado. Véase también ACNUR, Public statement in relation to Salahadin Abdulla and Others v. Bundesrepublik Deutschland pending before the Court of Justice of the European Union, C-175/08; C-176/08; C-178/08 \& C-179/08 (Geneva: UNHCR, August 2008). Accesible en: http://www.refworld.org/docid/48a2f0782.html. [Consulta: 9 de enero de 2019]

${ }^{273}$ Expresamente, los derechos reconocidos en los arts. 3, 4, 13, 16, 20, 22, 25, 27, 29 y 31 a 33 de la Convención de Ginebra.

${ }^{274}$ Sobre el respeto de altas garantías en la protección de estos sujetos contra la inaplicación del principio de no devolución, remitimos a: CLAYTON G., Removal en: Textbook on Immigration and Asylum Law, Oxford University Press, 2016, 7th edition, pp. 580-581; MORGADES GIL, S., "La protección de los demandantes de asilo por razón de su vulnerabilidad especial en la jurisprudencia del Tribunal Europeo de Derechos Humanos", Revista de Derecho Comunitario Europeo, n 37, 2010, pp. 801-842; GIL BAZO M., "Refugee Status, Subsidiary Protection, and the Right to Be Granted Asylum Under Ec Law", UNHCR, New Issues in Refugee, Research Paper, $\mathrm{n}^{\circ}$ 136, 5 de enero de 2007; VALDEZ ARROYO, F., Ampliación del concepto de refugiado en el derecho internacional contemporáneo, Fondo Editorial PUCP, 2004, p. 221; CRAGE S., "The More Things Change ... Developments in German Practices towards Asylum Seekers and Recognised Refugees”, Journal German Politics, vol. 25, nº 3, 2016, pp. 344-365.
} 
principio de no devolución. Inclusive, cuando su mera presencia pudiera comprometer seriamente la seguridad del Estado de acogida o del resto de EEMM.

Por lo que respecta al alcance de estas cláusulas de la mencionada Directiva en los ordenamientos jurídicos de España o Alemania, estos son indudablemente más claros y concretos. Por lo que respecta a España, el art. 44 LAPS regula la revocación de ambos estatutos por los mismos motivos que contempla la mencionada Directiva, disponiendo lo siguiente:

“1. Procederá la revocación del estatuto de refugiado o del estatuto de protección subsidiaria cuando: a) concurra alguno de los supuestos de exclusión previstos en los artículos 8, 9, 11 y 12 de esta Ley; b) la persona beneficiaria haya tergiversado u omitido hechos, incluido el uso de documentos falsos, que fueron decisivos para la concesión del estatuto de refugiado o de protección subsidiaria; c) la persona beneficiaria constituya, por razones fundadas, un peligro para la seguridad de España, o que, habiendo sido condenada por sentencia firme por delito grave, constituya una amenaza para la comunidad."

Pese a que se trata de una ley que entró en vigor hace más de una década, ya incluía expresamente la contundente separación entre la revocación y expulsión, prohibiendo esta última si puede conllevar un "peligro para su vida o su libertad o en el que estén expuestos a tortura o a tratos y penas inhumanos o degradantes o, en su caso, en el que carezca de protección efectiva contra la devolución al país perseguidor o de riesgo".

La revocación del estatuto de refugiado de un ciudadano por representar un riesgo para la seguridad nacional, en su máxima categoría de amenaza, viene regulado en el apartado $1^{\circ} \mathrm{c}$ ) LAPS del mencionado artículo. ${ }^{275}$ Como tal, no requiere probar de forma concluyente que un sujeto pertenece a una organización terrorista, sino la concurrencia de "razones fundadas" por las que constituyen un peligro para la seguridad nacional. No obstante, esta peligrosidad debe vincularse con la seguridad del país donde se encuentre el refugiado, de forma que no debe concurrir un riesgo potencial y abstracto. En su

\footnotetext{
${ }^{275}$ Esta letra c) dispone concretamente lo siguiente: "constituya, por razones fundadas, un peligro para la seguridad de España, o que, habiendo sido condenada por sentencia firme por delito grave, constituya una amenaza para la comunidad"
} 
defecto, requiere de un peligro determinado derivado de la presencia del titular del derecho de asilo al cual se le revoca este estatuto en territorio nacional. ${ }^{276}$

Y en directa conexión con esta causa de revocación, la Sección Tercera de la Sala de lo Contencioso del TS, en su Sentencia 2021/2014, de 30 de mayo de $2014^{277}$ también consideró que existían razones fundadas para estimar que un sujeto beneficiario del derecho de asilo constituía una amenaza real y grave para la seguridad de España, "por cuanto su comportamiento que incita al odio interreligioso revela una peligrosidad que resulta incompatible con la seguridad y confianza que debe proporcionar un Estado democrático a sus ciudadanos". Un fallo importante también por el voto particular de dos del Magistrado Sánchez Bordona, al que se adhirió la Magistrada Perelló Doménech, que vieron necesario formular dos cuestiones prejudiciales ante el TJUE.

La primera de ellas giró en torno al significado de la cláusula de seguridad del Estado del art. 44.1 c) LAPS. Pretendía dilucidarse si era conforme a la Directiva que una persona en posesión del estatuto de refugiado fuera privado de él, por constituir un peligro para la seguridad del Estado, cuando no se le atribuyera ninguna actuación propia que, en términos objetivos, amenace, afecte o ponga en riesgo dicha seguridad. Más bien, si sus actos y manifestaciones, por su contenido, pudieran dar lugar a reacciones violentas e injustificables de terceras personas que, estas sí, pudieran perjudicar la seguridad interior o exterior del Estado. ${ }^{278}$

\footnotetext{
${ }^{276}$ STS, de 2 de octubre de 2008 (recurso $n^{\circ}$ 66/2006), STS 818/2009, de 17 de diciembre de 2009 (recurso $\mathrm{n}^{\circ}$ 4858/2006) y SAN, de 3 de octubre de 2013 (recurso $\mathrm{n}^{\circ}$ 4001/2013). Sobre esta última, remitimos a: ARRUFAT CÁRDAVA A., "Revocación de la condición de refugiado por riesgo para la seguridad nacional", Revista Española de Derecho Internacional, Madrid, enero-junio, 2014, pp. 226229.

${ }^{277}$ STS 2021/2014, de 30 de mayo de 2014 (recurso no 3511/2013). Para un análisis detallado sobre esta, remitimos a: CARRERA HERNÁNDEZ F. J., "Jurisprudencia española en materia de Derecho internacional público - Comentarios de sentencias - Revocación del estatuto de refugiado por motivos de seguridad nacional", Revista Española de Derecho Internacional, Madrid, enero-junio, 2014, pp. 201205.

${ }^{278}$ La STS 583/2008, de 27 de marzo de 2008 (recurso ${ }^{\circ}$ 192/2006) extendió esta falta de imputación incluso a la falta de informes que apunten concretamente a la revocación por la existencia de "motivos fundados para considerar que se ha hecho culpable de actos contrarios a las finalidades y a los principios de las Naciones Unidas" (art. 1F c) de la Convención). Por un lado, los dos informes jurídicos emitidos tanto por el Abogado del Estado-Jefe del Ministerio del Interior como por la Asesoría Jurídica Internacional del Ministerio de Asuntos Exteriores y Cooperación no realizaban referencia alguna a esta argumentación jurídica. Por otro, únicamente el Centro Nacional de Inteligencia hacía mención del precepto convencional 33.2 para proceder a la revocación de la condición de refugiado del recurrente, la cual no fue acogida por este Tribunal porque el propio informe del CNI no reflejaba la necesaria y fundada situación de peligro para España como consecuencia de las actividades que se relatan del
} 
En este aspecto, conviene recordar que el art. 1F de la Convención prevé que esta no sea aplicable a sujetos sobre los que existen motivos fundados para considerar que han cometido delitos muy graves. De tal modo, esta revocación resulta mucho menos restrictiva, permitiendo retirar el estatuto a sujetos que "constituyen, por razones fundadas, un peligro para la seguridad de España, o que, habiendo sido condenada en sentencia firme por delito grave, constituya una amenaza para la comunidad" (art. 14.4 Directiva y 44.1. c) LAPS). ${ }^{279}$ Trae a colación el criterio no vinculante del ACNUR, el apuntó que esta modalidad de revocación desborda el ámbito de aplicación de los arts. 1F a) y c) de la Convención, pretendiendo remitir una cuestión prejudicial en este sentido. ${ }^{280}$ El criterio de Sánchez Bordona sobre esta cuestión resulta plenamente coherente, pues una circunstancia es que el sujeto deba excluirse por incompatibilidad directa con el derecho a la protección internacional (o como alude el ACNUR, que sean indignos de recibirla) ${ }^{281} \mathrm{y}$, otra muy distinta, que no sea merecedor de continuar disfrutando de los derechos inherentes que proporciona el mismo.

La segunda cuestión radica en el mayor o menor nexo causal que puede establecerse entre la conducta del refugiado y las acciones de terceros, a los efectos de considerar a aquel como un peligro o amenaza para la seguridad del Estado. En especial, la prudencia con la que deben manejarse los términos de incitación, provocación o inducción a comportamientos violentos contra la seguridad del Estado. ${ }^{282}$ Así, el

recurrente y porque las afirmaciones a las que aludía el Informe versaban sobre "situaciones de crisis y de deterioro de relaciones hispano- guineanas" o "de riesgo para sus intereses y ciudadanos" (FJ 50).

279 Aun así, la jurisprudencia del TS sobre esta cuestión ha reconocido que la ponderación y compaginación de intereses constitucionales, esto es, entre la seguridad de España y la protección de los refugiados "se revelan como de difícil conciliación" aunque otorgando preeminencia a la tutela judicial efectiva del recurrente (STS de 2 de octubre de 1987, STC de 15 de marzo de 1990, STS de 4 de abril de 1997, STS 583/2008).

${ }^{280}$ El voto particular segundo apuntó a las tres posibles formas de tratar esta cuestión y cito textualmente: "La primera es decir que existe aquella falta de ajuste y que la Directiva prima sobre la Convención. La segunda es decir que existe la falta de ajuste y que la Convención prima sobre la Directiva y sobre las normas nacionales en materia de inmigración. La tercera es decir que el status revocado sobre la base de las disposiciones [de la Directiva y de las normas nacionales] es diferente del status de refugiado que contempla la Convención y que, por ello, no haya aquella falta de ajuste. Esta última solución es la correcta a nuestro juicio". La diversidad de enfoques mantenidos por órganos jurisdiccionales de diferentes Estados miembros hace tanto más necesaria la respuesta unificadora del Tribunal de Justicia de la Unión Europea sobre esta cuestión".

${ }^{281}$ ACNUR, La aplicación de las cláusulas de exclusión: El artículo 1F de la Convención de 1951 sobre el Estatuto de los Refugiados, 4 de septiembre de 2003 (HCR/GIP/03/05).

${ }^{282}$ Dispone el voto particular tercero lo siguiente: "cuando se trata de la expresión de opiniones o juicios en los que no se hace ningún llamamiento a tales comportamientos, pero cuyo contenido puede ser 
magistrado mostró su incertidumbre sobre si la falta de respuesta penal incriminatoria era suficiente para la aplicación de la revocación del estatuto de refugiado. Además, el examen de la amenaza para la seguridad nacional a efectos de revocación determinada por el Ministerio del Interior, corresponde a la jurisdicción contencioso administrativa y no penal. Ahora bien, a juicio de este magistrado, "ello no implica que se pueda calificar de irrelevante la respuesta jurisdiccional del Estado, en sede penal, frente a los mismos hechos que están en la base de la revocación”.

El estándar de determinación de la revocación nada tiene que ver con el empleado en el Derecho penal de probar esta incompatibilidad "más allá de toda duda razonable", garantizando una mayor flexibilidad a las autoridades nacionales de proceder a la revocación ante hechos que presuman la amenaza para la seguridad del Estado español.

Asimismo, el alcance de la seguridad de España del art. 44.1 c) debe reunir las siguientes garantías procedimentales del art. 45.2 LAPS:

“a) que sea informada por escrito de que se está reconsiderando su derecho de asilo o de protección subsidiaria, así como de los motivos de dicha reconsideración;

b) que le sea otorgado trámite de audiencia para la formulación de alegaciones.

c) que la autoridad competente pueda obtener información precisa y actualizada de diversas fuentes, como por ejemplo, cuando proceda, del Alto Comisionado de las Naciones Unidas para los Refugiados (ACNUR), sobre la situación general existente en los países de origen de las personas afectadas, y

d) que cuando se recopile información sobre el caso concreto con objeto de reconsiderar el estatuto de refugiado, dicha información no se obtenga de los responsables de la persecución de tal modo que dé lugar a que dichos responsables sean informados directamente de que la persona interesada es un refugiado cuyo estatuto está siendo reconsiderado, ni se ponga en peligro la integridad física de la persona interesada y de las personas a su cargo, ni la libertad y la seguridad de sus familiares que aún vivan en el país de origen."

Igualmente, el apartado $3^{\circ}$ contempla la posibilidad de que la Oficina de Asilo y Refugio (OAR) pueda archivar el expediente por causas no suficientemente fundadas, recogiendo toda una serie de garantías que exceden del contenido esencial de la violenta contra el Estado en el que reside su autor". 
Directiva. En el caso de que concurran los supuestos para la revocación, esta ley resulta muy garantista, pues el expediente se traslada de esta Oficina a la Comisión Interministerial de Asilo y Refugio, que valora individualmente si concurren o no las causas de revocación conforme a los apartados $4^{\circ}$ y $5^{\circ}$.

Por lo tanto, aunque el TJUE haya concretado el alcance de los arts. 14.1 y 19.1 de la Directiva de Reconocimiento, lo cierto es que la LAPS lleva efectuando una inequívoca distinción entre la revocación y la expulsión desde 2009. Regula un coherente, eficaz y garantisa procesamiento de información que fomenta la imparcialidad en la toma de estas decisiones, puesto que la Oficina encargada de detectar la procedencia de las causas de revocación eleva a la Comisión Interministerial de Asilo y Refugio este asunto, este último entrando a valorar individualmente su concurrencia.

En relación con Alemania, la Sección 73 de la Ley de Asilo de este país ${ }^{283}$ regula la revocación del estatuto de refugiado -también aplicable al estatuto de protección subsidiaria- y contiene dos disposiciones para los procedimientos de revocación: el apartado $1^{\mathrm{o}}$ reproduce las mismas cláusulas de revocación que las previstas en la Directiva de Reconocimiento. Si bien, lo más relevante es el apartado $2^{\circ}$ es la "revisión rutinaria" del estatuto otorgado tras 3 años posteriores a su concesión. Un procedimiento que se inicia de oficio y que, a diferencia de otros EEMM -como el caso de España-, adopta un criterio muy eficiente de "reconsideración inicial" de la solicitud, evaluando, tras este periodo considerable de tiempo, si ha habido un cambio de circunstancias que permita la aplicación de la mencionada cláusula.

La BAMF, responsable de llevar a cabo el procedimiento de revocación, tiene la intención de revocar el estatuto de refugiado, informa previamente de ello al sujeto por escrito, motivando las causas por las que pretende revocar o retirarlo. Además, tras la entrada en vigor de la nueva legislación al efecto en diciembre de 2018, se autorizó a la Oficina alemana a imponer obligaciones muy similares a las que se aplican durante el procedimiento de asilo. Los sujetos con estatuto de protección internacional deben cooperar en todo momento con estas autoridades en el marco de los procedimientos de

\footnotetext{
${ }^{283}$ Ley de Asilo de Alemania en la versión promulgada el 2 de septiembre de 2008. Boletín Oficial del Estado I, p. 1798), última enmienda del art. 2 por la Ley de 11 de marzo de 2016 (Boletín Oficial del Estado I, p. 394). Accesible (traducción oficial al inglés) en el siguiente enlace: https://www.gesetze-iminternet.de/englisch_asylvfg/ [Consulta: 9 de febrero de 2019]
} 
revocación. ${ }^{284}$ La ley alemana establece expresamente que estas medidas deben respetar los principios de necesidad y proporcionalidad, atribuyendo garantías procesales a los interesados. Por lo tanto, si la BAMF decide revocar o retirar el estado, el refugiado tiene dos semanas para apelar la decisión en un tribunal administrativo con efectos suspensivos hasta su resolución firme.

Finalmente, en Reino Unido, el párrafo 339AC de las normas de inmigración regula las cláusulas de revocación por los mismos motivos que prevé la normativa internacional y europea. Concretamente, dispone que cuando un refugiado no pueda ser expulsado dado el riesgo para la vulneración del art. $3 \mathrm{CEDH}$, deberán considerarse extremos como la duración o las condiciones de los distintos tipos de autorización de residencia. Asimismo, pese a que la competencia para proceder a la revocación del estatuto de refugiado se lleva a cabo de forma ordinaria por la Unidad de Revisión de Estado, en aquellos supuestos que pongan en peligro la seguridad de este Estado, será atribuida a la Unidad de casos especiales o penales. ${ }^{285}$

En definitiva, mientras que la legislación de España y Reino Unido aluden de forma expresa a la diferenciación entre la decisión de revocación y la expulsión, Alemania entiende implícitamente este criterio en coherencia con el respeto a la CDFUE y al CEDH. Sin perjuicio de las novedades que a continuación abordaremos y que pretenden incorporarse en el futuro Reglamento de Reconocimiento, tanto en Alemania como Reino Unido pueden encontrarse especificidades que convendría incluir en el futuro reglamento de la LAPS. Este es el caso de la necesidad de revisar los estatutos otorgados en un periodo de tiempo oportuno -por ejemplo, cada 2 o 3 años-, disponer expresamente la obligación de colaboración de los refugiados o sujetos con estatuto de protección subsidiaria durante todo el procedimiento de revocación o, incluso, creando un órgano ad hoc especializado y encargado de conocer de los hechos relacionados con estos sujetos y que puedan comprometer la seguridad de España.

\footnotetext{
${ }^{284}$ Como desarrolló recientemente Kalkmann, estas obligaciones se resumen en la obligación de asistir a una entrevista personal, cooperar con las autoridades para la aclaración de las identidades si fuera necesario, someterse a cualquier medida de identificación proporcional y necesaria o la obligación de aceptar el almacenamiento de datos personales por parte de las autoridades alemanas y/o aceptar la transferencia de datos a otras autoridades dentro y fuera del país. KALKMANN, M., "Das Gesetz zur Einführung der Mitwirkungspflicht in Widerrufsverfahren”, Asylmagazin 1-2/2019, p. 6.

${ }^{285}$ Reino Unido, Home Office, Asylum policy instruction Revocation of refugee status, ob. cit., p. 12.
} 
4.3.3. La revocación y su trascendental avance en la propuesta de Reglamento de Reconocimiento.

Las cláusulas de revocación se han diseñado como eficientes herramientas para garantizar el control post-hoc de la inmigración y el asilo si bien, estas pueden impactar negativamente en la protección efectiva de los sujetos con estatuto de refugiado o protección subsidiaria. Estas propician una noción de temporalidad que puede poner en riesgo la seguridad jurídica de aquellos que ostentan el estatuto de protección internacional.

A juicio de Neylon, la gran amplitud de estas cláusulas en la presente Directiva parte de la noción de "eficiencia administrativa", la cual ha limitado el procedimiento de revocación del estatuto de refugiado y protección subsidiaria y ha arribado a la propia esencia del SECA, flexibilizando las excepciones previstas en el principio de no devolución. ${ }^{286}$ De hecho, la toma de decisiones relacionadas con la finalización de la protección internacional corresponde a una autoridad judicial o cuasi judicial, un órgano gubernamental o administrativo, aún con todo esbozando un régimen jurídico divergente en sede nacional susceptible de rebajar las garantías del SECA.

En este sentido, cabe subrayar que, durante 2019, se ha identificado cómo individuos procedentes de Siria y con estatuto de refugiado en Alemania, han viajado de nuevo a este país durante las vacaciones. Una situación sobre la que se hizo eco el diario alemán Deutsche Welle (DW) que, en una entrevista al Ministro del Interior alemán, Horst Seehofer, esgrimió la opinión del ejecutivo sobre lo que cataloga como una evidencia de que "los refugiados no han sido perseguidos en sus paises de procedencia". No dudó en declarar que en cuanto estas situaciones llegasen a conocimiento de las autoridades alemanas, "procederían a una investigación sobre la revocabilidad o no del estatuto de refugiado". ${ }^{287}$ Ese mismo año, la Junta de Apelaciones de Refugiados en Dinamarca invalidó las decisiones emitidas por su Servicio de Inmigración, que habían retirado los permisos de residencia a 6 ciudadanos sirios tras la revocación formal de su estatuto de protección internacional. Durante la evaluación de la situación actual en Siria, llegaron a la conclusión de que continuaba siendo volátil y que se procedían a abusos graves

\footnotetext{
${ }^{286}$ NEYLON A., "Producing Precariousness: 'Safety Elsewhere' and the Removal of International Protection Status under EU Law", European Journal of Migration and Law, vol. 21, n 1, 2019, p. 25.

${ }^{287}$ Germany's Seehofer warns refugees who take Syria vacations, 18 de agosto de 2019. Accesible en: https://www.dw.com/en/germanys-seehofer-warns-refugees-who-take-syria-vacations/a-50069317 [Consulta: 20 de agosto de 2019].
} 
contra los derechos humanos, contrariando el art. $3 \mathrm{CEDH}$, lo que motivó acertadamente la revocación de las decisiones del Servicio de Inmigración y la concesión de permisos de residencia a todos los solicitantes en virtud de su ley nacional. $^{288}$

Por fortuna, la reforma de la Directiva de Reconocimiento por un reglamento comunitario solventará parcialmente estas diferencias a nivel nacional. Este dispondrá una legislación directamente aplicable en la regulación del procedimiento de revocación para ambos estatutos (arts. 14 y 20) la cual permanece, en buena medida, invariable. Con ello, ambos contemplan en los arts. 14.1 f) y 20.1 d) la posibilidad de la devolución por las dos cuestiones antes mencionadas y relacionadas con la seguridad nacional (art. 23.2). Si bien, no se prevén disposiciones específicas que eviten un excesivo empleo de las cláusulas de revocación, en concreto, en aquellos casos sumamente complejos como el retorno por motivos desconocidos de refugiados a sus países de origen. Y pese a las "escasas" modificaciones en esta propuesta de reforma, pueden apreciarse ciertas mejoras que incrementarán la eficiencia y eficacia en la aplicación de las cláusulas de exclusión, entre las que conviene destacar las siguientes:

1. Por un lado, "perfeccionará" las garantías procesales de los solicitantes, otorgándoles la oportunidad de presentar información por medios de documentación escrita así como mediante las declaraciones que se lleven a cabo durante la entrevista personal (art. 4.2 de la propuesta).

2. Por otro lado, reforzará las normas sobre el examen de ambos estatutos a fin de verificar si continúan cumpliéndose los criterios de elegibilidad. Serán articuladas distintas excepciones sobre este extremo, por ejemplo; no emitiendo, retirando o no renovando el permiso de residencia a un miembro de la familia en el supuesto de unidad familiar (art. 25.4), cualquier permiso de residencia (art. $26.2 \mathrm{c}$ ) o documentos de viaje (art. 27.3).

3. Además, en aras de elevar la eficacia de este régimen jurídico, los arts. 15 y 21 introducen un nuevo modelo de revisiones sistemáticas y periódicas tal y como ya ha adoptado el modelo alemán. Este pretende garantizar la regularidad en el control de

\footnotetext{
${ }^{288}$ Denmark: Refugee Appeals Board finds returns to Syria would violate fundamental rights in six trial cases, 24 de junio de 2019. Accesible en: https://www.asylumlawdatabase.eu/en/content/denmarkrefugee-appeals-board-finds-returns-syria-would-violate-fundamental-rights-six-trial [Consulta: 29 de junio de 2019]
} 
nuevas condiciones, instando a las autoridades decisorias a la realización de un examen a posteriori cuando se produzcan modificaciones significativas relevantes en el país de origen que se contemplen en documentos a nivel comunitario.

Se trata de una disposición que dotará de una mayor garantía del contenido esencial del derecho en el SECA y que redundará en su mayor efectividad al futuro SECA ante pontenciales situaciones que, por su excepcionalidad, puedan suponer un serio riesgo para los sistemas nacionales de asilo. Para este fin, la AAUE se erigirá como "centro neurálgico" de conocimientos especializados, implementando un novedoso análisis común de acuerdo con su propia capacidad de gestión de información y datos relativos a la situación del asilo en la UE y en terceros países, tal y como dispone la propuesta de su Reglamento de funcionamiento en su art. 2.1 f). ${ }^{289}$ Además, estos análisis serían remitidos a los EEMM para que conozcan, de primera mano, la situación presente en los distintos países de origen, así como otros factores relacionados con la migración a la UE y asilo en puntos fronterizos concretos. Un grado de cooperación que, en sintonía con la interoperabilidad de los SSII comunitarios, articularán un modelo de intercambio de información sin precedentes.

Y sobre esta cuestión, el Reglamento 2019/818 de interoperabilidad en el ámbito de la cooperación policial y judicial, el asilo y la migración supone un avance trascendental en la consecución de estos objetivos. Las autoridades nacionales son capaces de acceder a una amplia tipología de información personal en un amplio periodo de tiempo, esto es, desde que el sujeto arriba a territorio nacional hasta fases posteriores al procedimiento y concesión del estatuto oportuno. Sin lugar a dudas, al igual que hemos mencionado con respecto a las causas de exclusión, este novedoso régimen jurídico aumentará la tasa de revocación gracias al conocimiento especializado y mejorado que ya disponen las autoridades nacionales ante la recepción sistemática de datos. Paralelamente, también permitirá contrastar y corroborar de una manera más eficiente si el sujeto es merecedor o no de seguir ostentando el estatuto que le fue otorgado. Todo ello, mediante una comprobación sistemática de aquellos hechos que han podido ser contradictorios o discordantes con los proporcionados por el -aquel entonces- solicitante.

\footnotetext{
${ }^{289}$ Véase también los Considerandos 11,14 y arts. 4, 8.2 a), 10, 13.2, 31.1 e) y 32.2 g). Comisión Europea, Propuesta de Reglamento relativo a la Agencia de Asilo de la Unión Europea y por el que se deroga el Reglamento (UE) n. ${ }^{\circ}$ 439/2010. $\operatorname{COM(2016)~} 271$ final.
} 
La interoperabilidad y su conexión causal con una mayor tasa de revocación tiene serias implicaciones en los derechos humanos, en concreto, en el derecho al respeto de la vida privada y familiar de los arts. 7 CDFUE y 8 CEDH. La incorporación de un constante flujo de información y la falta de una regulación que prevea estrictamente el modo por el cual debe garantizarse el derecho a la información del interesado o la rectificación aquella que sea imprecisa, errónea u obsoleta puede provocar decisiones arbitrarias que menoscaben la protección efectiva del derecho al asilo.

4. Sin obviar la dimensión de eficiencia, esta propuesta también dispone que la determinación de cualquier factor que pueda justificar la revocación del estatuto conferido deberá efectuarse durante la renovación de los permisos de residencia -por primera vez para los refugiados y segunda para los beneficiarios de protección subsidiaria tal y como regulan los arts. 15.1 a) y 21.1 b) - y, en casos extraordinarios, cuando se informe de cambios significativos en la situación de un país de origen concreto. ${ }^{290}$ Una previsión enormemente favorable para los intereses nacionales que permitirá no solo una mayor armonización y control, sino que, además, no impone cargas administrativas adicionales a los EEMM.

5. Además, se incluye un "periodo de gracia" de tres meses en ambos estatutos (art. 14.5 y 20.3). Esto favorecerá que, en aquellos casos en los que se haya revocado el estatuto por cambios en las circunstancias personales o ajenas al individuo, pueda modificarse su estatuto por otros motivos justificables -reunificación familiar, trabajo, estudios, humanitarios, etc.- y que permitan su residencia legal.

Ahora bien, pese a estos notorios avances, la mencionada propuesta continuará otorgando una amplia flexibilidad a los EEMM en la aplicación de medidas encaminadas a la revocación del estatuto de protección internacional por su incompatibilidad con la seguridad nacional. El aumento de la eficiencia y eficacia del nuevo SECA puede evidenciar una mayor probabilidad de revocación, en concreto, en aquellos escenarios que comprometen la seguridad de los Estados. Especialmente, si a ello se adicionan las nuevas técnicas y procedimientos de intercambio de información entre la AAUE y las autoridades nacionales -que no parece restringirse a una mera colaboración entre ellos, sino también con otros organismos y agencias europeas e

${ }^{290}$ Véase Propuesta de Reglamento de Reconocimiento, Exposición de motivos, p. 11. 
internacionales como la GEFC, Europol o el ACNUR, entre otros- o el nuevo modelo de interoperabilidad entre los distintos SSII de la UE.

Sin perjuicio de las consideraciones relativas al intercambio de esta información, objeto de análisis en el siguiente capítulo, la firme apuesta por nuevas técnicas de cooperación en la recopilación e intercambio de datos relativos a los distintos sujetos que entran o pretenden arribar a territorio de la UE supondrá un incremento de la disponibilidad de la información en la toma de decisiones de las autoridades nacionales. Con ello, este nuevo -y todavía desconocido- alcance de la información unido a la falta de criterios tasados y más claros sobre cómo evaluar y procesar toda esa información puede crear divergencias muy sustanciales en las decisiones de revocación, lo cual iría en serio detrimento de los derechos e intereses de los refugiados o sujetos con estatuto de protección subsidiaria.

\section{Reflexiones conclusivas}

El actual SECA se ha encontrado supeditado a toda una serie de reiteradas y persistentes actuaciones nacionales tendentes a mantener y garantizar su seguridad y orden público, una competencia exclusiva de los EEMM (art. 72 TFUE) que ha generado que el Sistema Europeo Común de Asilo vea obstaculizado su objeto principal y resulte muy fragmentado y escasamente uniforme. El uso dispar a nivel nacional de los conceptos de política pública, seguridad pública o seguridad nacional exceptúan la aplicación coherente del SECA pese a que, como recoge el TJUE en una extensa jurisprudencia, la legislación de asilo de la UE debe interpretarse de forma favorable, como así se efectúa en la legislación sobre la libre circulación en la UE. Si bien, este sistema de garantías se ha rebajado hasta el punto que las persistentes excepciones radicadas en la seguridad nacional han resultado, con frecuencia, incompatibles con las obligaciones previstas en el derecho internacional que conforma la Convención de Ginebra y Protocolo de Nueva York, lo que requiere un mayor grado de apertura hacia la dimensión de seguridad exterior, competencia que comparte la UE y los EEMM en virtud del art. 4 TFUE y que desarrolla, en toda su extensión, el ELSJ en su Título V.

Los primeros avances pueden apreciarse en la propuesta del SECA, iniciada en 2016 y que pretende acometer la gestión de las solicitudes de protección internacional de una forma más eficaz y eficiente -incluso ante circunstancias extraordinarias que ponen en serio riesgo la viabilidad de un EM- mediante la "transformación” jurídica de la actual 
Directiva de Reconocimiento y procedimiento en reglamentos comunitarios, un renovado y "mejorado" Reglamento Dublín “de cuarta generación” y el despliegue de novedosos y "perfeccionados" organismos europeos especializados en la gestión fronteriza como la GEFC o la futura AAUE. Sin embargo, pese a que esta propuesta tiende a trasladar la toma de decisiones desde el seno de los EEMM hacia el ámbito comunitario con miras a facilitar una "reconceptualización" de la seguridad progresivamente más integrada, complementaria y yuxtapuesta al propio derecho a la protección internacional, todo parece indicar que no logrará resolver todas estas cuestiones sensibles a nivel nacional.

Recordemos que producen desafíos emergentes en el SECA sobre los que nada aborda la mencionada propuesta. Parámetros no cuantificados en la actualidad como la radicalización pueden propiciar una peligrosa y automática vinculación de estos sujetos con problemas relativos a la seguridad nacional y europea. Asimismo, al margen de la propuesta de reforma del SECA, la Directiva 2017/541 de lucha contra el terrorismo prevé perfeccionarse con el futuro Reglamento sobre la prevención de la difusión de contenidos terroristas en línea con el objetivo de proporcionar medidas más contundentes en la disociación entre los problemas relacionados con la seguridad y el derecho de asilo. Es más, esta última apuesta decididamente por acometer profundas y eficaces medidas sin precedentes para abordar los conflictos más graves de seguridad, procediendo al cierre quasi automático de vínculos extremistas en Internet, es decir, en un plazo máximo de 1 hora. Un hecho que, sin ningún género de duda, incrementará la seguridad online pero que también puede provocar verdaderos retrocesos no solo en la libertad de expresión e información, sino en la propia efectividad del derecho a la protección internacional. En concreto, cabe constatar una cierta tendencia a ampliar la inclusión de acciones susceptibles de radicalización, lo que generaría una flagrante discriminación de un colectivo en situación de vulnerabilidad y un arma excesivamente discrecional en la aplicación de cláusulas de exclusión o revocación si estos patrones de conducta no se individualizan y se examinan con suma cautela y nitidad certeza jurídica.

Seguidamente, deben analizarse jurídicamente los dos procedimientos por antonomasia que supeditan tanto la concesión del estatuto de protección internacional como su continuidad una vez ya ha sido formalmente otorgado. 
- Por lo que respecta a las cláusulas de exclusión, tanto el art. 1F de la Convención de Ginebra como los arts. 12 y 17 de la Directiva de Reconocimiento establecen supuestos tasados para excluir del estatuto de refugiado y de la protección subsidiaria a sujetos que contrarían la propia seguridad nacional, los cuales se han volcado directamente en las legislaciones de los EEMM. Ahora bien, al margen de la comisión e incitación de delitos contra la paz, delitos de guerra o contra la humanidad (letra a)) y la culpabilidad de actos contrarios a las finalidades y a los principios de las Naciones Unidas (letra c)), el supuesto más problemático radica en la definición de grave delito común previsto en la letra $b$ ). Un precepto que ha producido una enorme disparidad en las legislaciones nacionales, menoscabando la función homogeneizadora del SECA, el principio de seguridad jurídica y, lo que es peor, de la protección efectiva de este derecho. Y sin perjuicio de los enormes esfuerzos del Tribunal de Luxemburgo, que ha interpretado restrictivamente el alcance de estas cláusulas, recordando por un lado, la exigencia de constatar la especial gravedad de tales delitos en el país de origen, prescindiendo de fórmulas automáticas de exclusión (STJUE Shajin Ahmed contra Bevándorlási és Menekültügyi Hivatal, de 13 de septiembre de 2018) y por otro, subrayando la obligación de proceder a una evaluación individual previa a la adopción de la exclusión correspondiente por razones de seguridad nacional y orden público (Gran Sala TJUE H.F, de 2 de mayo de 2018). De tal modo, desvirtúa la presunción que facultaba a los EEMM a excluir directamente de protección a un sujeto tras la comisión de los delitos tipificados en tales preceptos.

En aras de solventar este marco jurídico fragmentado, la propuesta de Reglamento de Reconocimiento incorpora un novedoso apartado $5^{\circ}$ que define delito común grave refiriéndose a "actos especialmente crueles y desproporcionados (letra a) así como los actos de notoria entidad, como supuestos de terrorismo o los que emplean violencia hacia la población civil (letra b)", los cuales también se aplican ante un objetivo político e, incluso, a aquellos que pertenecen a una asociación que apoya el terrorismo internacional o lo respalda (Considerando 45).

La normativa del SECA incluye una definición de este calibre, lo que confirma la progresiva cesión competencial de la seguridad interior desde los EEMM (art. 72 TFUE), hacia su dimensión exterior (arts. 77 y ss. TFUE). Por consiguiente, esta requerirá modificaciones de gran calado en las legislaciones nacionales como ocurrirá en el ordenamiento jurídico español donde el art. $8.2^{\circ}$ LAPS abarca dentro de delito 
grave a efectos de exclusión no solo los relativos a la vida, la libertad, la indemnidad, la libertad sexual o la delincuencia organizada, sino también "la integridad de las personas o el patrimonio, siempre que fuesen realizados con fuerza en las cosas, o violencia o intimidación en las personas". Y que duda cabe que el delito de robo, pese a tener la consideración de delito grave en el CP, no será coherente con la definición que tipificará el futuro Reglamento de Reconocimiento, por lo que esta definición en la LAPS deberá restringirse a aquellos delitos graves que sean manifiestamente incompatibles con la seguridad de España.

Además, para el caso de la exclusión del derecho a la protección subsidiaria, el art. 17 d) de la Directiva de Reconocimiento $-y$, en similares términos, el art. 18 d) de propuesta de Reglamento-, facultan a excluir a un sujeto ante conductas que "constituyan un peligro para la comunidad o para la seguridad del Estado miembro en el que se encuentran". Este precepto otorga una flexibilidad sin precedentes en la determinación de la exclusión correspondiente.

La escasa información que han dispuesto las autoridades nacionales de los solicitantes de protección internacional y sus efectos perjudiciales pretenden resolverse a través de una mejor y más perfeccionada gestión de la información. Desde el año 2017, la EASO lleva instando al empleo de fuentes de información personal relevantes para arrojar respuestas concluyentes sobre la concesión o exclusión del estatuto de protección internacional individualmente considerado, agregando, por primera vez, prácticas nacionales frecuentes como el rastreo de fuentes abiertas y redes sociales. Estas técnicas de recopilación de información sufren un trascendental avance tras la creación de una novedosa estructura jurídica tendente a recopilar y compartir gran tipología de datos personales a través de eficientes SSII. Este es el caso del Reglamento de Interoperabilidad 2019/818, un novedoso régimen jurídico por el que las autoridades pueden acceder a diversas bases de datos comunitarias para detectar cualquier dato y patrón de comportamiento susceptible de comprometer la seguridad nacional, seguridad pública u orden público.

B. En cuanto al régimen jurídico relativo a la revocación, los arts. 14 y 17 de la Directiva de Reconocimiento carecen de una falta de concreción sobre las condiciones y límites estrictos y específicos para proceder a este tipo de cancelación, como reconoce una extensa jurisprudencia tanto del TJUE -en aplicación de esta Directiva y del art. 4 CDFUE-, como del TEDH -por su directa incidencia en el art. 3 CEDH- la cual ha 
exigido dos condiciones: 1) la evaluación individualizada de todas las circunstancias personales con carácter previo a la adopción de una decisión final de revocación y 2) una clara distinción entre la revocación y las acciones posteriores restrictivas de derechos como la expulsión que, necesariamente, deberá llevarse a cabo tras una decisión firme que constate de forma fehaciente que la devolución al país de origen no vulnerará la prohibición a la tortura, los tratos y penas inhumanos o degradantes -tal y como regula expresamente el ordenamiento jurídico español o alemán, entre otros-. Cabe adicionar a estos conocidos requisitos la reciente STJUE Mohammed Bilali y Bundesamt für Fremdenwesen und Asyl, de 23 de mayo de 2019, que determinó que estas cláusulas resultaban aplicables con independencia de si la decisión fue o no causada por hechos atribuibles al interesado, puesto que no siguen cumpliendo con la definición del estatuto de refugiado o protección subsidiaria.

Por ende, todos estos extremos vinculantes deberían incorporarse directamente en el futuro Reglamento de Reconocimiento con objeto de aumentar la seguridad jurídica, teniendo en cuenta que la revocación no adiciona cuestiones relevantes al régimen previsto en la actual Directiva. Ello con independencia de que este Reglamento uniformizará e incrementará las garantías durante los procedimientos de revocación facultando que el afectado pueda presentar información pertinente que desvirtúe la supresión del estatuto anteriormente otorgado- además de introducir un nuevo modelo de revisiones sistemáticas y periódicas que afectará a la identificación de posibles causas de revocabilidad, tal y como ya desarrolla el modelo alemán y cuyas consecuencias son, actualmente, desconocidas. 


\section{CAPÍtULLO 2.}

\section{EL DERECHO A LA PROTECCIÓN DE DATOS EN EL SISTEMA EUROPEO COMÚN DE ASILO Y EN SU PROPUESTA DE REFORMA.}

\section{Introducción}

Los innumerables conflictos que han aproximado la seguridad nacional a la protección efectiva de los solicitantes de asilo y refugiados han afectado directamente en el derecho a la privacidad y protección de datos de este colectivo. A pesar de este impacto, uno de los problemas de mayor calado que presenta el actual SECA está relacionado con la ausencia de estudios que aborden el derecho a la protección de datos personales. $^{291}$

El déficit de estudios doctrinales en la materia ha influido es un hecho, a nuestro juicio, de la mayor relevancia: las autoridades nacionales y europeas especializadas en la gestión de solicitudes de protección internacional carecen de una comprensión práctica sobre cuándo y cómo recopilar, procesar, almacenar, analizar, emplear y compartir información personal de manera responsable y respetuosa con la legislación de protección de datos vigente, principalmente, en un contexto marcado por el potencial valor de esta información para prevenir futuros desafíos de seguridad, así como otorgar respuestas eficientes a estas situaciones.

La protección de datos de carácter personal en el ámbito del asilo constituye un campo emergente que debe abordar los incesantes retos que afectan desde distintas perspectivas -especialmente políticas y jurídicas- a la seguridad europea. Sin embargo, carece de una "arquitectura jurídica sólida" que afronte los problemas de seguridad y protección internacional y que asegure la protección efectiva de la información y datos personales de estos nacionales de terceros estados. Ya en 2014, el por aquel entonces candidato para la presidencia de la Comisión Europea, Jean-Claude Juncker, destacó la necesidad de combatir el crimen y el terrorismo transfronterizo como responsabilidad común europea y erradicar, igualmente, la delincuencia organizada, la trata de personas,

\footnotetext{
${ }^{291}$ En este punto, Costello hace especial referencia a la debilidad práctica de la protección de datos en el control de la migración y su incidencia directa en el derecho de los refugiados. Esta autora abre el camino hacia la investigación sobre la interacción progresiva y regresiva de la protección de datos en su directa conexión con la migración y refugio. COSTELLO C., The Human Rights of Migrants and Refugees in European Law, Oxford, Oxford University Press, 2016, pp. 138 y ss.
} 
el contrabando o los delitos cibernéticos. Una lucha efectiva contra los problemas relacionados con el terrorismo que, al mismo tiempo, tenía en consideración los derechos y valores fundamentales, incluidos los derechos procesales y la protección de datos personales. ${ }^{292} \mathrm{Y}$ pese a que estas declaraciones constituyeron el precedente moderno por excelencia entre la necesidad de combatir aquellos aspectos que comprometen seriamente la seguridad europea y la firme apuesta por el desarrollo de una nueva legislación de protección de datos, lo cierto es que, en el presente, este conflicto no ha proporcionado respuestas contundentes a los retos emergentes en el derecho a la protección internacional.

Fue dos años más tarde cuando el Supervisor Europeo de Protección de Datos (SEPD), apuntó que la gestión de fronteras y el ámbito policial constituían objetivos distintos. Estos debían distinguirse de una forma más contundente, en concreto, las distintas categorías de sujetos como refugiados, los solicitantes de asilo, los inmigrantes en situación irregular y los viajeros ordinarios. Y aunque afirmaba que resultaba concluyente garantizar la seguridad de los EEMM en el diseño de nuevas fórmulas de cooperación e intercambio de datos, no lo era menos el pleno respeto de la libertad y los derechos fundamentales y libertades. ${ }^{293}$ Con ello, el derecho a la protección de datos en el ámbito de la protección internacional ha estado fuertemente ligado a cuestiones que penden de la seguridad de los EEMM. Además, las distintas fases del SECA han contemplado este régimen jurídico como una disciplina meramente "accesoria y subsidiaria".

No resulta baladí aducir que las potenciales violaciones que se podrían producir, por ejemplo, por una posible divulgación involuntaria o la pérdida de un listado de solicitantes de asilo, puede poner en serio riesgo su vida o la de sus familiares si, por algún casual, llega a conocimiento del país de origen. Sobre el particular, recuérdese que en noviembre de 2017, un servicio de almacenamiento en la nube que era empleado por varias agencias de la Naciones Unidas y distintas organizaciones no gubernamentales $(\mathrm{ONG})$ fue pirateado y la información sobre los refugiados se vio seriamente comprometida. ${ }^{294}$

\footnotetext{
292 Directrices políticas para la próxima Comisión Europea, 15 de julio de 2014.

${ }^{293}$ SEPD, Migration, security and fundamental rights: A critical challenge for the EU, 22 de septiembre de 2016. Accesible en: https://edps.europa.eu/sites/edp/files/edpsweb_press_releases/edps-2016-14smartborders_en.pdf

${ }^{294}$ PARKER, B., "Security lapses at aid agency leave beneficiary data at risk", The New Humanitarian,
} 
Por lo tanto, no cabe soslayar la relevancia por la exigencia de implementar nuevos modelos de gestión de la información en el ámbito del SECA que incluyan, por defecto, sendas previsiones a la protección efectiva de los datos susceptibles de tratamiento. En este sentido, Hathaway fue uno de los primeros académicos en reconocer el derecho a la privacidad en el derecho del asilo. Determinó la vulneración de este derecho no solo en situaciones en las que existía un sustancial riesgo de proceder a un registro o vigilancia ilícita, sino que lo extendió a todos aquellos escenarios en los que la autonomía personal de los individuos, incluyendo su libertad de expresión, resultaba seriamente amenazada. $^{295}$

Igualmente, la STJUE Y.S c. Minister voor Immigratie, Integratie en Asiel Minister voor Immigratie, Integratie en Asiel c. M.S., de 17 de julio de $2014^{296}$ constituye una de las escasas resoluciones que analiza el impacto de la anterior legislación de protección de datos sobre un solicitante de asilo que solicitó un permiso de residencia temporal. En este caso, el TJUE clarificó el alcance de los datos personales de acuerdo con la Directiva 95/46/CE y proporcionó pautas más claras sobre el procedimiento de acceso a los datos personales. Particularmente, atribuyó la mera obligación para las autoridades de dar traslado al solicitante de un resumen completo en el que constasen los datos personales de forma inteligible. El TJUE alegó que no era necesario proporcionar tales datos "en la forma material en que existía o se había registrado inicialmente", una interpretación que permitió a las autoridades nacionales un mayor margen de discrecionalidad en aras de proteger sus derechos y, al mismo tiempo, cumplir con el deber de información así como de acceso, rectificación o supresión de los datos.

En consecuencia, el TJUE, basándose en las conclusiones del Abogado General, señaló que los solicitantes tenían un interés legítimo en acceder a la información, puesto que esta información podía haber cambiado o incluso constar de forma incompleta, condicionando seriamente una decisión futura. Igualmente, clasificó los datos de carácter personal en tres tipos:

- aquellos meramente abstractos;

noviembre de 2017. Accesible en: www.thenewhumanitarian.org/investigations/2017/11/27/securitylapsesaid-agency-leave-beneficiary-data-risk. [Consulta: 27 de abril de 2019]

${ }^{295}$ HATHAWAY, J., FOSTER, M., "Serious harm" en The Law of Refugee Status. Cambridge: Cambridge University Press, 2014, p. 287.

${ }^{296}$ STJUE Y.S c. Minister voor Immigratie, Integratie en Asiel Minister voor Immigratie, Integratie en Asiel c. M.S., de 17 de julio de 2014. Asuntos acumulados C-141/12 y C-372/12. 
- hechos ilustrativos no relacionados con una persona identificable y;

- la clasificación legal de los hechos relacionados con una persona identificada o identificable y su evaluación en el contexto de la ley aplicable; siendo este último la única tipología de datos que entraba dentro de la aplicación de la Directiva.

Esta primera sentencia fue tan relevante que Peers apuntó a la especial utilidad de esta información para que los solicitantes de asilo pudieran hacer valer, por diferentes medios, el derecho a una buena administración frente a las tradicionales decisiones arbitrarias, infundadas y contrarias al propio objetivo del SECA. ${ }^{297}$

Sin embargo, en este punto, con carácter general, no ha sido abordado el alcance del derecho a la protección de datos en el ámbito del SECA. Por ende, la primera cuestión que conviene examinar estriba muy probablemente en el hecho de que esta disciplina jurídica se circunscribe en un régimen jurídico separado por un criterio de especialidad. Su naturaleza específica resulta apreciable ante connotaciones persistentes de seguridad y los diferentes y amplios organismos y agencias humanitarias, de seguridad y espionaje que operan en fronteras. Estos no se han adherido a los principios generalmente aceptados en materia de protección de datos. Sus actuaciones únicamente se encuentran regidas por sus reglamentos de desarrollo. Además, conviene tener presente la convergencia de diversas bases de datos y sistemas de información especializados, en concreto, Eurodac. Este sistema especializado en la gestión del asilo ha previsto desde sus orígenes el procesamiento de datos personales de acuerdo con su propio Reglamento de desarrollo, incluyendo la actual interoperabilidad con un amplio conjunto de sistemas de información y bases de datos.

Como resultado, el nivel de protección de los datos personales de los solicitantes de protección internacional se encuentra significativamente limitado y difuso. El gran despliegue de organismos permite constatar la gran dificultad en la determinación de un régimen jurídico común y coherente en el derecho a la protección internacional. Un riesgo que vaticinó Boehm al principio de la pasada década, aludiendo a que las prácticas a la hora de procesar, gestionar, compartir y eliminar sus datos personales en el ámbito de la migración y asilo han sido frecuentemente intrusivas. ${ }^{298}$

\footnotetext{
${ }^{297}$ PEERS, S., "Data protection rights and administrative proceedings", Blogspot EU Law Analysis, de 17 de julio de 2014. Accesible en: http://eulawanalysis.blogspot.com/2014/07/data-protection-rightsand.html

${ }^{298}$ Para una primera aproximación acerca de este conflicto, véase: BOEHM, F., "Data Protection
} 
A raíz de la propuesta de reforma del SECA que anunció la Comisión en abril de $2016,{ }^{299}$ el SEPD reconoció la necesidad de reforzar la efectividad de las vías de entrada de la migración y el asilo en la UE. Si bien, al mismo tiempo, destacó que estas mejoras debían acompañarse de un incremento de los derechos e intereses legítimos de las personas que podían verse afectadas por el tratamiento de datos personales, en particular, las relativas a grupos en situación de vulnerabilidad, los cuales requerían de una protección específica $y$, entre los que se incluían, a los solicitantes de protección internacional y refugiados. En su Dictamen, recomendó las vías principales sobre las que debía actuarse - a través del Reglamento de Dublín, Eurodac así como la necesidad de llevar a cabo evaluaciones completas del impacto sobre la protección de datos y la privacidad. $-{ }^{300}$

Dicho esto, esta primera aproximación por parte del SEPD no ha obstado para que, hoy en día, la recopilación e intercambio de información y datos entre autoridades administrativas y policiales haya rebajado las garantías de protección del derecho a la protección de datos. Una interrelación seguridad y protección internacional que ha afectado seriamente a los derechos de los solicitantes de protección internacional y de los refugiados, reduciendo generalizadamente el régimen de garantías de este derecho ante las persistentes cuestiones radicadas en la seguridad de los EEMM.

Constituye, por tanto, un deber garantizar la protección efectiva por parte de aquellos sujetos sobre los que se recopila información personal, especialmente, en momentos convulsos en los que la incidencia de la seguridad nacional ha flexibilizado, en exceso, el derecho a la protección de datos en este ámbito. En el presente capítulo se abordará un análisis pormenorizado del complejo, difuso, incluso y seriamente desfasado marco normativo vigente con intención de concretar y actualizar un ámbito desactualizado y superado tras la efectiva aplicación del actual régimen jurídico de protección de datos en Europa, compuesto principalmente por el RGPD y la Directiva 2016/680 de protección de datos en el ámbito penal.

\footnotetext{
Standard in the AFSJ", Information sharing and data protection in the Area of Freedom, Security and Justice - Towards harmonised data protection principles for information exchange at EU-level, Springer, 2011 , p. 28.

${ }^{299}$ Comisión Europea, «Hacia una reforma del Sistema... ob. cit., 2016.

${ }^{300}$ Supervisor Europeo de Protección de Datos (SEPD). Opinión 07/2016 sobre la reforma del primer paquete Sistema Europeo Común de Asilo de 21 de septiembre de 2016. Accesible en: https://edps.europa.eu/sites/edp/files/publication/16-09-21_ceas_opinion_en.pdf y Resumen ejecutivo del dictamen del SEPD sobre el primer paquete...ob. cit.
} 


\section{El vigente SECA y la interrelación entre la dimensión de seguridad y el derecho a la protección de datos.}

2.1. Antecedentes del emergente conflicto entre la seguridad nacional y el derecho a la protección de datos.

En 1974 el Consejo de Europa acometió, por primera vez, el conflicto entre seguridad y protección de datos. ${ }^{301}$ Estableció en el art. 3 (c) que el art. 9.2 (a) del Convenio $\mathrm{n}^{\mathrm{o}} 108$ de $1981^{302}$ permitía excepciones en la protección de datos, siempre y cuando estuviera previsto en la legislación nacional y fuera una medida necesaria en una sociedad democrática para proteger la seguridad del Estado, entre otras causas.

Seguidamente, tanto la DUDH (art. 12) como en el Pacto Internacional de Derechos Civiles y Políticos (art. 17.1) garantizaron el derecho a la protección contra cualquier injerencia arbitraria en su privacidad. ${ }^{303}$ Asimismo, los arts. 8 CDFUE y 16 TFUE regulan el derecho de toda persona a la protección de los datos personales, este último exceptuando su efectiva aplicación por las razones de seguridad anteriormente analizadas en los arts. 72 y 73 TFUE. En similares términos se contempla en el CEDH, que reconoce expresamente en el art. 8 el derecho al respeto a la vida privada y familiar (apartado $1^{\circ}$ ), aunque prevé la limitación de este derecho siempre que la injerencia esté prevista por ley y constituya una medida que, en una sociedad democrática, sea necesaria para la seguridad nacional, entre otros (apartado $2^{\circ}$ ).

Esta excepción tuvo su precedente directo en los atentados de Nueva York de septiembre de $2001 .^{304}$ La especial preeminencia de la dimensión de seguridad nacional en detrimento de la protección de los datos personales se intensificó hasta el punto de

\footnotetext{
${ }^{301}$ Resolución 74/29, del Comité de Ministros del Consejo de Europa en materia jurídica, relativa a la protección de la vida privada de las personas físicas respecto de los bancos de datos electrónicos en el sector público. (Adoptada por el Comité de Ministros el 20 de septiembre de 1974, durante la $236^{\mathrm{a}}$ reunión de los Delegados de los Ministros).

${ }^{302}$ Consejo de Europa, Convenio para la protección de las personas con respecto al tratamiento automatizado de datos de carácter personal, hecho en Estrasburgo el 28 de enero de 1981.

${ }^{303}$ ACNUR, CCPR General Comment No. 16: Article 17 (Right to Privacy), The Right to Respect of Privacy, Family, Home and Correspondence, and Protection of Honour and Reputation, 8 de abril de 1988.

${ }^{304}$ De VRIES, G., "The European Union's Role in the Fight against Terrorism", Irish Studies in International Affairs, vol. 16, 2005, p. 4; ARCHICK, K., "US-EU Cooperation against Terrorism", Congressional Research Service, diciembre 2014, p. 1; QUIRINE E., "Digital Security Governance and Accountability in Europe: Ethical Dilemmas in Terrorism Risk Management", Journal of Politics and Law, vol. 6, no 4,2013 , p. 36.
} 
excluir la normativa básica sobre la materia a las autoridades administrativas y policiales, así como agencias de seguridad e inteligencia que operaban directa o indirectamente sobre migrantes "ampliamente considerados". Este supuesto alertó al Grupo de Trabajo del Artículo 29 (GT29), cuyo Dictamen 10/2001 ${ }^{305}$ se hizo eco de la necesidad de garantizar un enfoque equilibrado entre la lucha contra el terrorismo y el compromiso de respetar, en mayor medida, los derechos fundamentales en las sociedades democráticas. Además, tras las revelaciones de Edward Snowden sobre la recopilación masiva de datos y las operaciones de vigilancia masiva por parte de la Agencia de Seguridad Nacional de EEUU en junio de $2013,{ }^{306}$ el GT29 publicó una Opinión en la que reconocía que los programas de vigilancia administrados por los EEMM con fines de seguridad nacional, no se encontraban vinculados por la legislación de la UE. ${ }^{307}$

Como ya señalamos, tras el TL, el Espacio de libertad, Seguridad y de Justicia (ELSJ) pasó a ser una política comunitaria sujeta al procedimiento legislativo común. Esto llevó a "una nueva política, genuinamente europea, que trasciende por lo tanto su preliminar estadio de cooperación reforzada intergubernamental en el marco del anterior III Pilar", como destaca López Aguilar. ${ }^{308}$ Con ello, pese a que la seguridad excluya las altas garantías previstas en la normativa de protección de datos, no cabe duda de que, tras la entrada del Programa de Estocolmo, aplicado por el Plan de Acción que se adoptó en junio de $2010,{ }^{309}$ se apostó decididamente por fortalecer la seguridad interior

\footnotetext{
${ }^{305}$ El Grupo de Trabajo del Artículo 29 destacó en el Dictamen 10/2001 el carácter generalmente intrusivo de un conjunto de medidas concernientes a la vigilancia en tiempo real, el acceso generalizado a sistemas de información y el intercambio de datos entre distintas autoridades públicas. Grupo de Trabajo del Artículo 29, Dictamen 10/2001 del Artículo 29 sobre la necesidad de un enfoque equilibrado en la lucha contra el terrorismo, 14 de diciembre de 2001.

${ }^{306}$ «Edward Snowden comes forward as source of NSA leaks», The Washington Post, 9 de junio de 2013. Disponible en: https://www.washingtonpost.com/politics/intelligence-leaders-push-back-on-leakers-media/2013/06/09/fff80160-d122-11e2-a73e-826d299ff459_story.html?utm_term=. bd468dbb4341 [Consulta: 23 de abril de 2019].

307 Article 29 Data Protection Working Party, "Opinion 04/2014 on surveillance of electronic communications for intelligence and national security purposes", 819/14/EN, WP 215, 10 de abril de 2014.

${ }^{308}$ LOPEZ AGUILAR, J.F., "La protección de datos en la UE: el punto de vista del Parlamento Europeo" en: GARCÍA MAHAMUT R., TOMÁS MALLÉN, B. (eds.), El Reglamento General de Protección de Datos. Un enfoque nacional y comparado. Especial referencia a la LO 3/2018 de protección de datos y garantía de los derechos digitales, Valencia, Editorial Tirant lo Blanch, 2019, p. 41.

${ }^{309}$ Consejo de la UE, Programa de Estocolmo: Una Europa abierta y segura que sirva y proteja al ciudadano [Diario Oficial ${ }^{\circ}$ C 115 de 4/5/2010]. Comunicación de la Comisión al Parlamento Europeo, al Consejo, al Comité Económico y Social Europeo y al Comité de las Regiones, de 20 de abril de 2010 -
} 
y exterior y la cooperación entre autoridades judiciales y con terceros países. En este punto, comenzó a emerger el tratamiento de datos automatizados de los migrantes como un instrumento más del acceso efectivo y controlado a la UE.

Este Programa subrayó la importancia de garantizar la seguridad de los propios ciudadanos europeos, contar con controles fronterizos reforzados para impedir la inmigración ilegal y la delincuencia transfronteriza al mismo tiempo que se debía garantizar el acceso a las personas en clara necesidad de solicitar protección internacional. Igualmente, instó a que los países de la UE hicieran uso de la justicia en red, es decir, las tecnologías de la información y la comunicación aplicadas al ámbito de la justicia como método para robustecer la confianza mutua y la coherencia respecto al ordenamiento jurídico internacional a fin de crear un entorno jurídico seguro que permitiera interactuar con los países que no pertenecen a ella, previendo no solo el refuerzo del papel de la nueva agencia de Frontex, sino también la operatividad de las bases de datos sobre migración y asilo (en especial Eurodac, VIS y Schengen) para responder de manera más eficaz a los múltiples desafíos que presentaba una fragmentada normativa de protección de datos en el ámbito del SECA.

Sin embargo, el trascendental avance del Programa en la protección efectiva de la información relativa a los solicitantes de asilo y refugiados resultó, a todas luces, insuficiente. La regulación de protección de datos de los solicitantes de asilo no seguía formalmente el régimen general de la Directiva 95/46/CE de protección de datos, a pesar de su expresa inclusión en el vigente y desactualizado RD III. Del mismo modo, a causa de las continuas excepciones por razones de seguridad, tampoco fue aplicable, en toda su extensión, el régimen jurídico contemplado en la Decisión marco de $2008 .^{310}$ Frente a este régimen general, la normativa especializada ha venido apartándose de la aplicación uniforme de este marco jurídico, en especial, los distintos SSII y bases de

Garantizar el espacio de libertad, seguridad y justicia para los ciudadanos europeos - Plan de acción por el que se aplica el Programa de Estocolmo [COM(2010) 171 final - no publicada en el Diario Oficial].

${ }^{310}$ La Decisión Marco 2008/977/JAI establecía en el artículo 1 que el fin era garantizar un alto nivel de protección de los derechos y libertades fundamentales de las personas físicas y en particular su derecho a la intimidad en lo que atañe al tratamiento de datos personales en el marco de la cooperación policial y judicial en materia pena (apartado $1^{\circ}$ ) y era susceptible de aplicación tanto al tratamiento automatizado como no automatizado, total o parcial (apartado $3^{\circ}$ ). Ahora bien, se excluía expresamente de aplicación aquellas cuestiones que afectaban directamente a los intereses esenciales de seguridad del Estado y a las actividades específicas de inteligencia en el sector de la seguridad del Estado (apartado $4^{\circ}$ ), lo que evidencia la exclusión, cuanto menos parcial, del tratamiento de datos en el ámbito de la inmigración y asilo. 
datos (en especial, Eurodac), el tratamiento de datos por parte de las instituciones y organismos comunitarios, así como agencias comunitarias especializadas en seguridad, migración y asilo (GEFC, AAUE o Europol). De hecho, estas han seguido expresamente la regulación del Reglamento 2001/45 sobre tratamiento de datos personales por las instituciones y los organismos comunitarios y a la libre circulación de estos datos. $^{311}$

La falta de respuestas coherentes a la protección de datos en el derecho de asilo fue especialmente compensada por los organismos especializados en asilo. Especialmente, el ACNUR viene exigiendo la imperante necesidad de elevar la seguridad jurídica en este ámbito desde el año 2008. Este reconoció, por primera vez, que debía implementarse un sistema reforzado de protección de datos aplicable a los refugiados en un contexto en el que se producían fuertes disparidades entre organismos y agencias especializadas. $^{312}$

Fruto de ello, estas comenzaron a analizar sus procedimientos en relación con el procesamiento de los datos personales. En el año 2010, la Organización Internacional para las Migraciones (OIM) llevó a cabo una reestructuración interna para reforzar la protección de datos en el ámbito de la migración y asilo, ${ }^{313}$ procedimiento que se encontró con el escaso interés del Comité Internacional de la Cruz Roja (CICR). En 2013, revisó sus normas profesionales para mejorar los sistemas de gestión de la información confidencial, aunque no llevaron a cabo cambios reales y efectivos. ${ }^{314}$ Ello, a pesar de que, tal y como recogían los informes de noviembre de 2013, fueron identificadas brechas de seguridad de considerable entidad en Red Rose, un sistema online para gestionar la distribución de ayuda utilizada por el CICR y que lo hacía

\footnotetext{
${ }^{311}$ Reglamento (CE) n ${ }^{\circ} 45 / 2001$ de 18 de diciembre de 2000 relativo a la protección de las personas físicas en lo que respecta al tratamiento de datos personales por las instituciones y los organismos comunitarios y a la libre circulación de estos datos. DO L 8, 12.1.2001, p. 1-22.

${ }^{312}$ ACNUR, Comentarios del ACNUR sobre la Propuesta de la Comisión Europea para la reforma del Reglamento del Parlamento Europeo y del Consejo por el que se establecen los criterios y mecanismos para la determinación del EM responsable del examen de una solicitud de protección internacional presentada en uno de los EEMM por un nacional de un tercer país o por un apátrida ("Dublín II") (COM(2008) 820, de 3 de diciembre de 2008).

${ }^{313}$ Organización Internacional para las Migraciones (OIM), Manual de Protección de Datos, 2010. http://publications.iom.int/system/files/pdf/iomdataprotection_web.pdf.

${ }^{314}$ Comité Internacional de la Cruz Roja, "normativa profesional relativa a la labor de protección llevada a cabo por los agentes humanitarios y los defensores de los derechos humanos en los conflictos armados y otras situaciones de violencia", 2013. https://www.icrc.org/spa/assets/files/2011/p0999spa.pdf. [Consulta: 3 de abril de 2019]
} 
especialmente vulnerable a los piratas informáticos. ${ }^{315}$ Este incidente reflejó las profundadas debilidades en el procesamiento de datos personales, en concreto, en un contexto en el que las agencias humanitarias han recurrido a la ayuda de sistemas de procesamiento de datos digitales como técnicas eficientes de asistencia y cooperación. En efecto, el propio CICR subrayó en su manual de protección de datos y acción humanitaria que se desencadenaban importantes motivos de interés público en la recopilación de datos personales, en concreto, cuando la actividad en cuestión se conecta con un mandato humanitario establecido en virtud del derecho internacional. ${ }^{316}$

Por lo que concierne al estatuto del ACNUR, prevé la recopilación de información personal sobre una base legítima reformado en resoluciones posteriores de la Asamblea General de la ONU. ${ }^{317}$ En mayo de 2015, adoptó su política sobre la protección de los datos personales ${ }^{318}$ e implementó, por un lado, una Evaluación de Impacto en la Privacidad (PIA) sobre las intervenciones basadas en dinero en efectivo en el año $2015^{319}$ y por otro, la herramienta de proyección demográfica DPTOOL a finales de 2017. Este potente Sistema de Información registraba información de los sujetos que

\footnotetext{
${ }^{315}$ Mautinoa Technologies identificó varios problemas de seguridad en una plataforma de software utilizada por las agencias de ayuda para almacenar los datos de las personas vulnerables, exponiéndolos a "riesgos muy significativos". Red Rose lo negó en todo momento. Sin embargo, se constató que el proveedor de sistemas y tecnologías de pago Mautinoa, ingresó en un servidor de la ONG en la nube, Catholic Relief Services, y accedió a nombres, fotografías, detalles familiares, números PIN y coordenadas del mapa para más de 8.000 familias que recibían asistencia de la ONG en África Occidental. En respuesta, Oxfam, uno de los varios clientes de la plataforma, comunicó la suspensión temporal de nuevos datos en los sistemas Red Rose, como medida de prevención. La información puede encontrarse en: https://www.irinnews.org/investigations/2017/11/27/security-lapses-aid-agency-leavebeneficiary-data-risk. [Consulta: 18 de mayo de 2018].

${ }^{316}$ CICR, Handbook on Data Protection in Humanitarian Action, KUNER C., MARELLICA M. (eds.), 2017, parágrafo 3.4 , p. 49.

${ }^{317}$ Véase ACNUR, Note on the Mandate of the High Commissioner for Refugees and his Office, octubre de 2013, disponible en: http://www.unhcr.org/uk/526a22cb6.pdf [Consulta: 25 de abril de 2018].

${ }^{318}$ Este estudio exige que el personal del ACNUR aplique toda un conjunto de principios en el procesamiento de datos personales: (a) Procesamiento legítimo y justo, (b) Especificación de la finalidad, (c) Necesidad y proporcionalidad, (d) Precisión, (e) Respeto de los derechos del interesado, (f), Confidencialidad, (g) Seguridad y (h) Responsabilidad y supervisión. ACNUR, Politica sobre la Protección de Datos Personales de las Personas del Interés del ACNUR, mayo 2015. http://www.refworld.org/cgi-bin/texis/vtx/rwmain/opendocpdf.pdf?reldoc=y\&docid=58aadc2b4.

[Consulta: 30 de abril de 2018].

${ }^{319}$ Este PIA ha tenido como objetivo la identificación de los riesgos de privacidad que planteaba su programa y buscar mejorar las salvaguardas que pueden mitigar esos riesgos, abordando el desafío de garantizar que los datos de refugiados no fueran utilizados para fines distintos a los especificados inicialmente. ACNUR, Privacy Impact Assessment of UNHCR Cash Based Interventions, diciembre de 2015. Accesible en: http://www.globalprotectioncluster.org/_assets/files/tools_and_guidance/cash-basedinterventions/erc-privacy-impact-assessment-of-unher-cbi_en.pdf [Consulta: 1 de mayo de 2018].
} 
requerían asistencia, procesando y compartiendo información personal de forma anonimizada con las distintas operaciones del ACNUR. Este sistema supuso un serio precedente en la incremento de las garantías de protección de datos, privacidad y seguridad de este colectivo a la par que aumentó la eficiencia del procedimiento de protección internacional. ${ }^{320}$ Además, ese mismo año, una auditoria desarrollada en el Programa Mundial de Alimentos de las Naciones Unidas volvió a detectar graves anomalías en la seguridad en la protección de datos. ${ }^{321}$ Tanto es así que, en marzo de 2019, la Oficina de la ONU para la Coordinación de Asuntos Humanitarios (OCHA) también publicó de forma provisional unas guías de responsabilidad de los datos ${ }^{322}$ con objeto de analizar estos incidentes en sus acciones humanitarias.

2.2. La protección de datos de los solicitantes de protección internacional en el actual SECA: consecuencias jurídicas de un desfasado (y todavía vigente) Reglamento de Dublín III.

En un intento por concretar cuáles son las garantías del derecho a la protección de datos en el actual SECA, debemos destacar que si algo ha caracterizado al-desfasado pero "todavía en vigor"- RD III ha sido la incapacidad para hacer frente a problemas estructurales en materia de gestión de crisis en materia de protección internacional. El Preámbulo ha constituido una parte esencial del texto para solventar las profundas lagunas e incongruencias jurídicas. Su enfoque está orientado hacia la protección de la

\footnotetext{
${ }^{320}$ El sistema, a priori garantista con la privacidad y la seguridad de los sujetos, no aportó conclusiones exactas, sino que estimó el número futuro de personas desplazadas o solicitantes de asilo. Para ello, cruzó distintos datos ya recogidos (concretamente, el número de nacimientos, muertes así como la magnitud de la migración forzada o personas desplazadas en un determinado territorio) para predecir, a corto plazo, los posibles movimientos ordinarios. Ahora bien, el sistema únicamente funcionaba ante contextos muy concretos que excedían de circunstancias extraordinarias que, en buena medida, fueron las causantes de los desplazamientos de personas a gran escala. Más información acerca del proyecto: http://demographicprojection.unher.org/ o http://www.unhcr.org/statistics/unhcrstats/59bbeb384/unherstatistics-technical-series.html [Consulta: 5 de mayo de 2018].

${ }^{321} \mathrm{La}$ citada auditoría exigió la necesidad de definir y clarificar las funciones y responsabilidades de los socios, la implementación efectiva de los compromisos políticos con la seguridad y la privacidad de los datos de los beneficiarios y fortalecer los procesos de gestión de identidad e información de los beneficiarios. Naciones Unidas, Programa de Alimentos Mundial, Internal Audit of Beneficiary Management Office of the Inspector General Internal Audit Report, noviembre de 2017 (AR/17/17). https://docs.wfp.org/api/documents/WFP0000040084/download/?_ga=2.43869413.1326768420.1516256388-1682848339.1511261484

${ }^{322}$ Centre for Humanitarian Data. OCHA. Data Responsibility Guidelines: Working Draft. March. The Hague, The Netherlands, 2019. Accesible en: https://centre.humdata.org/wpcontent/uploads/2019/03/OCHA-DR-Guidelines-working-draft-032019.pdf.
} 
seguridad europea y el profundo respeto de los derechos humanos. Un equilibrio que se ha visto truncado por los intereses nacionales y, más concretamente, por las cuestiones que radican en la seguridad de los EEMM, que no solo han propiciado la adopción de generalizadas excepciones a la efectiva aplicación de los instrumentos de protección de datos en el ámbito del asilo, sino que su régimen jurídico aplicable se encuentra desactualizado y resulta manifiestamente difuso.

El mencionado Reglamento no resulta ajeno a generar una elevada inseguridad jurídica, pese a que haya sido coronado como la "herramienta jurídica esencial" a la hora de interpretar el resto de la legislación aplicable dentro del ámbito del SECA. En este sentido, el Considerando 26 RDIII atribuye a la anterior Directiva 95/46/CE, carácter esencial en la aplicación al tratamiento de datos personales por los EEMM con arreglo al presente Reglamento. Del mismo modo, el Considerando 27 previó que, en el supuesto de intercambio de datos personales en el seno de un traslado -incluidos datos sensibles-, debía garantizar una asistencia adecuada por parte de autoridades para así asegurar la continuidad de la protección de los derechos reconocidos, instando a la adopción de disposiciones especiales para garantizar la protección de los datos relativos a los solicitantes que se encuentren en esa situación. Al margen de los mencionados considerandos, su art. 34.9 regula una contundente aplicación de esta Directiva en los supuestos de derecho a la información, especialmente, en caso de trasgresión de este derecho "por razón, por ejemplo, de su carácter incompleto o inexacto, tendrá derecho a su rectificación o supresión" y que culmina con las medidas necesarias para garantizar la seguridad en el ámbito de protección de los datos del art. 38.

Qué duda cabe de que el mencionado Reglamento, atendiendo a un criterio de especialidad, concretó la regulación específica en materia de protección de datos aplicable a los solicitantes de protección internacional siguiendo el régimen previsto en la mencionada Directiva, actualmente derogada. Además, surgen toda una serie de conflictos en el plano nacional en relación con las obligaciones activas dirigidas a las autoridades que desempeñan un papel fundamental en la consecución de los objetivos establecidos en el Reglamento. Una falta de respuestas en el SECA que parece confirmar los profundos riesgos que han ido rebajando las garantías de los interesados en el ámbito de la protección internacional y que, a nuestro juicio, son básicamente los que siguen: 
1. Los responsables en la toma de decisiones no cuentan con la suficiente formación en la recopilación, procesamiento, almacenamiento, análisis y posterior intercambio compartir información personal. Una particularidad en el SECA sobre la que se hizo eco un estudio y que resultaba propensa a poner en serio peligro la seguridad de los interesados. ${ }^{323} \mathrm{La}$ responsabilidad de proteger no solamente comprende aquellos contextos en los que se ve comprometida la seguridad nacional, sino también la información y datos personales de los solicitantes de protección internacional. Un elemento clave para garantizar su seguridad personal y que, inevitablemente, requiere la ponderación de estos dos intereses en conflicto. El problema deviene en que este campo emergente centra sus esfuerzos en las preocupaciones vinculadas con la seguridad de los EEMM y sitúa en un plano secundario los aspectos básicos de privacidad y protección de datos.

Esta situación es susceptible de contrariar el Reglamento de Dublín, que fue pionero en destacar la necesidad de formación en el ámbito de la protección de datos de las autoridades, así como de generar un alto nivel de conocimiento de las autoridades competentes en materia de asilo. Al efecto, hizo especial mención de la capacidad y formación óptima para reunir las condiciones necesarias capaces de garantizar la prestación de una asistencia adecuada y la protección de los derechos. El RD III alude en los mencionados considerandos, a un criterio de especialidad en el tratamiento de estos datos para garantizar, entre otros, la protección de los datos personales de los solicitantes de protección internacional -en particular, datos especialmente sensibles como los relacionados con la salud-, de conformidad con la Directiva 95/46/CE de protección de datos.

2. Estos nacionales de terceros países también se enfrentan a un potencial acceso por parte de un amplio conjunto de autoridades tanto nacionales como organismos y agencias europeas especializadas -como Frontex, la EASO o la Europol-. Además, se adiciona el acceso y comunicación de este tipo de información por parte de otros organismos y agencias comunitarias e internacionales, en especial, el ACNUR. Por ende, el procesamiento, gestión y comunicación de la información personal supone un desafío de primer orden a la luz de la normativa de protección de datos por cuanto

\footnotetext{
${ }^{323}$ SCARNECCHIA D.P., RAYMOND N.A., GREENWOOD F., HOWARTH C, POOLE D.N., "A Rights-based Approach to Information in Humanitarian Assistance", PLOS Currents Disasters, ed. 1, 20 de septiembre de 2017, p. 4.
} 
impacta directamente en las garantías del SECA, y más concretamente, en el Sistema de Dublín y Eurodac.

3. En relación con los datos de carácter personal concernientes a los solicitantes de protección internacional y refugiados, conviene apuntar que, en su mayor parte, corresponden a datos especialmente sensibles. Estos abarcan aquellos biométricos y se extienden a toda aquella información relativa a las causas de persecución que motivarán y sustentarán la solicitud de protección internacional.

El propio procedimiento de protección internacional tiende a recopilar una gran tipología de datos e información personal. Este comprende tanto aquellos identificadores -nombres, nacionalidades, lugar de procedencia y fecha de nacimiento-, como los extensos datos sensibles. Sobre estos últimos, desde una perspectiva meramente formal, se trata de datos que, por su tipología, deben catalogarse como sensibles y engloban desde las actuales huellas dactilares hasta las imágenes faciales que prevé la nueva propuesta de Reglamento Eurodac (PRE). En cambio, desde un enfoque material, la información pertinente que justifica la persecución que han sufrido en el país de origen, es decir, uno de los ejes vertebrales que sustenta la solicitud de protección internacional, resultará susceptible de esta misma clasificación.

En consecuencia, en el actual SECA emerge un conflicto constitucional de primer orden. Por un lado, el vigente RD III deriva a una derogada Directiva de protección de datos y por otro, concurre una generalizada escasa formación de las autoridades nacionales en la protección de la información personal que se agrava en virtud del potencial acceso y procesamiento por parte de autoridades nacionales y europeas. Una situación que acarrea una serie de consecuencias jurídicas que, afectando a la protección efectiva de la información de quienes se hallan en necesidad de protección internacional, obstaculizan la protección efectiva -si bien matizada- de la protección de sus datos personales.

Se trata de un escenario fuertemente complejo en el que conviene prestar especial atención a estos parámetros, de forma que se permita el desarrollo futuro de un marco jurídico coherente y garantista con la protección efectiva de los solicitantes de protección internacional. Ello en vista de que los datos personales susceptibles de procesamiento resultan -en mayor medida- sensibles. A ello se adiciona la situación de persecución que sufren este colectivo por parte de un número indeterminado de actores tanto en estados de origen, tránsito o incluso mafias organizadas expertas en interceptar 
a estos colectivos de personas. Además, estos sujetos no disponen, en numerosas ocasiones, de identificación alguna o incluso recurren a identificaciones falsas tras una incesante labor por parte de mafias organizadas en fronteras exteriores de la UE. ${ }^{324} \mathrm{Con}$ ello, a la dificultad en la obtención de datos personales, se adhiere la exigencia de que estos resulten exactos, fehacientes e incluso contrastados para proceder así a la correcta verificación de las causas que llevan a solicitar protección internacional. Sin embargo, esta situación ha generado un marco jurídico actual en el que coexisten generalizadas limitaciones en la efectividad de este derecho y sobre las que, como abordaremos a continuación, no se ofrecen soluciones coherentes y efectivas en la futura reforma del SECA.

\section{El procesamiento e intercambio de datos e información personal en la} propuesta de reforma del SECA.

3.1. El estado de la cuestión en el SECA: la seguridad europea y la normativa de protección de datos.

Nos encontramos en un periodo de tiempo en el que las necesidades nacionales de seguridad y la lucha contra el terrorismo están llevando a que muchos estados implementen legislaciones que restringen los derechos fundamentales de los ciudadanos de la UE y de terceros países. Por ejemplo, Francia aprobó el 30 de octubre de 2017 su Ley contra el terrorismo, en un contexto fuertemente marcado por el auge de ataques terroristas que experimentó este país. ${ }^{325}$ De hecho, recuérdese que, ese mismo año se pronunció el TEDH en la sentencia Ayçaguer c. Francia, de 22 de junio de 2017, que recordó el indispensable respeto a la vida privada y a la protección de datos personales,

\footnotetext{
${ }^{324}$ EMN Ad-Hoc Query on Impact of false/forged documents in the immigration and asylum procedures, 16 de junio de 2017. Accesible en: https://ec.europa.eu/homeaffairs/sites/homeaffairs/files/2017.1204_lu_impact_of_falseforged_documents.pdf

Para un studio sobre la cuestión, veáse HOLLINS K. "Comparative international approaches to establishing identity in undocumented asylum seekers", Lowy Institute's Migration and Border Policy Project, $\mathrm{n}^{\circ} 8,11$ de abril de 2018. Accesible en: https://www.lowyinstitute.org/publications/comparativeinternational-approaches-establishing-identity-undocumented-asylum-seekers [Consulta: 17 de abril de 2018].

${ }^{325}$ Ello generó una seria preocupación por parte de un sector doctrinal que ha apelado, como no puede ser de otra manera, a la necesaria ponderación entre la seguridad y la libertad tras la declaración del Estado de emergencia. Véase, por todos: TAMBOU O., "The New French Antiterrorism Law: Towards a Balance between Security and Liberty after the State of Emergency?", European Data Protection Law Review, vol. 3, no 4, 2017, pp. 518-523.
} 
derechos fundamentales que deben equilibrarse con las exigencias de la seguridad pública. ${ }^{326}$

Dicho esto y centrándonos en el ámbito del SECA, cabe establecer que, como ya hemos apuntado, las continuas implicaciones de la migración y el asilo con la seguridad de los EEMM exige una labor de crear registros e investigaciones cada vez más completos y exactos. La determinación fehaciente de los sujetos merecedores del pleno derecho a protección internacional exige identificar exhaustivamente el perfil del solicitante, principalmente, con objeto de diferenciarlo, sin ningún género de duda, de otras categorías de sujetos como pueden ser los migrantes irregulares e incluso potenciales delincuentes o terroristas. Una pretensión que ha favorecido la creación de nuevas iniciativas tendentes a asegurar que las autoridades nacionales conozcan en detalle quién pretende cruzar las fronteras exteriores comunes de la UE.

A finales de 2018, la Comisión Europea destacó la exigencia de garantizar el respeto de las nuevas leyes de seguridad, así como de la protección de datos en el ámbito del asilo. ${ }^{327}$ Un equilibrio entre ambos extremos que ha abogado por la aplicación de medidas que, incluso, exceden de los objetivos del SECA. Este es el caso del establecimiento de SSII interoperables o la gestión exhaustiva de las fronteras interiores o exteriores. Estos constituyen buenos ejemplos sobre los que pretende pivotarse el futuro aumento de seguridad europea. No osbtante, esta dimensión ha afectado seriamente a la normativa reguladora del asilo en Europa y, en especial, a las garantías que prevé la legislación de protección de datos en este ámbito.

Conviene apuntar que si garantizar la seguridad en las fronteras exteriores e interiores de la UE constituye un aspecto crucial, no lo es menos asegurar que las propuestas respeten la privacidad y protección de datos de los interesados, así como el resto de derechos fundamentales. Para la consecución de estos fines, se requiere una actuación conjunta y coordinada en el plano comunitario, de forma que los EEMM

\footnotetext{
${ }^{326}$ STEDH Ayçaguer c. Francia, de 22 de junio de 2017. Demanda no 8806/12. En la mencionada sentencia, el TEDH consideró que el régimen jurídico relativo a la conservación de perfiles de ADN en un fichero no ofrecía, en cuanto a su duración y posibilidad de eliminación, una protección suficiente al interesado así como carecía de equilibrio justo entre los intereses públicos y privados. Por lo tanto, concluyó que Francia se había excedido en su margen de apreciación nacional condenando en ámbito penal al demandante por el simple hecho de imposibilitar el registro de su perfil genético. Una condena que interfería con el principio de proporcionalidad y necesidad en una sociedad democrática del art. 8 CEDH.

${ }^{327}$ Comisión Europea, Una Europa que protege...ob. cit., p. 3.
} 
desarrollen nuevas vías de reconocimiento de protección internacional más eficientes, eficaces a la par que respetuosas con los derechos humanos.

Una de las primeras cuestiones que merece especial análisis se centra en determinar el complejo régimen aplicable al procesamiento y protección de la información y datos personales concernientes a los solicitantes de protección internacional.

Así pues, de conformidad con los arts. 16.2 a) y 82.1 TFUE, el legislador europeo aprobó el RGPD y la Directiva (UE) 2016/680 de protección de datos en el ámbito policial y de justicia, dos instrumentos comunitarios cuyos ámbitos de aplicación resultan especialmente difusos en lo que respecta a la aplicación a los sujetos de protección internacional.

En primer lugar, conviene precisar que el RGPD no recoge explícitamente los derechos de la recopilación de datos en el contexto migratorio, ni mucho menos lo hace en relación con el derecho a la protección internacional. La corrección de errores del RGPD modificó el ámbito de aplicación del art. 3.2 en el tratamiento de datos personales de interesados de aquellos residentes en la UE por aquellos que simplemente se encuentren en la UE. ${ }^{328}$ Esta radical transformación, se encuentra en plena en sintonía con el Considerando 14 RGPD, que establece que la protección otorgada por el mismo debe aplicarse a las personas físicas independientemente de su nacionalidad o de su lugar de residencia.

De hecho, tal y como destacó el Consejo Europeo de Protección de Datos (CEPD) en las Directrices $3 / 2018,{ }^{329}$ los controladores o procesadores no establecidos en la UE, pero que llevan a cabo actividades de procesamiento comprendidas en el art. 3.2, están obligados a designar un representante en la UE y cumplir con el RGPD. Aun así, reconoce que surgen muy diversos escenarios en función del tipo de actividades de procesamiento, la entidad que lleve a cabo estas actividades de procesamiento o la ubicación de dichas entidades.

\footnotetext{
${ }^{328}$ Corrección de errores del Reglamento (UE) 2016/679 del Parlamento Europeo y del Consejo, de 27 de abril de 2016, relativo a la protección de las personas físicas en lo que respecta al tratamiento de datos personales y a la libre circulación de estos datos y por el que se deroga la Directiva 95/46/CE (Reglamento general de protección de datos). L 127/3, 23 de mayo de 2018.

${ }^{329}$ Consejo Europeo de Protección de Datos, Directrices 3/2018 sobre el alcance territorial del RGPD (Artículo 3) - Versión para consulta pública. Adoptado el 16 de noviembre de 2018. Disponible en: https://edpb.europa.eu/our-work-tools/public-consultations/2018/guidelines-32018-territorial-scope-gdprarticle-3_es
} 
Uno de estos supuestos estriba en que las organizaciones internacionales disponen de inmunidad en la aplicación del RGPD aunque actúen en territorio europeo. ${ }^{330}$ Estas no han resultado ajenas a la adopción de altas garantías en el respeto de la protección de los datos obtenidos bajo su mandado u operación. Si bien, como se refleja anteriormente, supeditado a sus propias reglas internas de protección de datos. Por lo tanto, resulta esencial que los controladores y procesadores -en especial, aquellos que operan a nivel internacional- realicen una cuidadosa evaluación de sus actividades de procesamiento, a fin de determinar si el procesamiento de datos personales queda dentro del alcance del RGPD.

Ahora bien, en lo relativo al régimen jurídico de la propuesta del SECA, la aplicación del RGPD se extiende a los solicitantes de protección internacional. Por un lado, tanto la PRD IV en su Considerando 38 como la Propuesta de Reglamento de Procedimiento (PRP) ${ }^{331}$ en su Considerando 68, establecen la obligación de que las autoridades nacionales apliquen las altas garantías previstas en el RGPD para el procesamiento de datos personales. Como regla general, estas incluirán las altas medidas de seguridad en el tratamiento de los datos personales, así como la prevención del acceso a los datos por parte de terceros, la divulgación de información personal ilícita o no autorizada, incluso la alteración o la pérdida de los datos personales procesados de acuerdo con los arts. 38 RD III y 50 PRD IV.

Por otro lado, no son escasas sus referencias en la PRE. El Preámbulo y varias disposiciones de la propuesta hacen explícita alusión al RGPD. Entre ellas, se encuentra la prohibición de transferencia de datos a los terceros países, salvo que estos apliquen las garantías del RGPD o en virtud de lo que establezcan las normas nacionales adoptadas con arreglo a la Directiva de protección de datos en el ámbito penal, en cuyo caso parece facultarse la transferencia con la finalidad de cooperación entre ambos países (Considerando 50). También regula los derechos de acceso, rectificación y supresión conforme al capítulo III del RGPD [art. 31(1)], la supervisión por parte de las

\footnotetext{
${ }^{330}$ Sobre la tensión en las organizaciones internacionales entre "privilegios e inmunidades" y RGPD, merece especial lectura: KUNER C., "International Organizations and the EU General Data Protection Regulation Exploring the Interaction between EU Law and International Law", International Organizations Law Review, vol. 16, n 1, 2019, pp. 158-191.

${ }^{331}$ Comisión Europea, Propuesta de Reglamento del Parlamento Europeo y del Consejo por el que se establece un procedimiento común en materia de protección internacional en la Unión y se deroga la Directiva 2013/32/UE, COM(2016) 467 final 2016/0224 (COD)
} 
autoridades nacionales de control del art 46.1 RGPD [art. 32.(1)] o la transferencia de datos a terceros países a efectos de retorno [art. 38 (1)].

Además, el alcance del RGPD ha excedido del propio SECA hacia las acciones que llevan a cabo el ACNUR sobre la materia. Este organismo posee una guía sobre protección de datos del año 2018 en el que reconoce las altas garantías en este ámbito. ${ }^{332}$ Igualmente, dispone de una plantilla sobre el intercambio de datos entre este con un gobierno nacional ${ }^{333}$ para proteger la privacidad y confidencialidad de los datos individuales por defecto y promoviendo, al mismo tiempo, mejoras en la prestación de servicios para los refugiados. Como regla general, no incluye datos sensibles, su extraordinaria incorporación responde a estrictos criterios de necesidad y limitación de la finalidad.

De este modo, relevantes son no solo las continuas referencias al RGPD, así como al actualizado Convenio $108+$ de $2018,{ }^{334}$ sino la articulación de toda una serie de excepciones en su aplicación, precisamente, en virtud del interés superior de estos sujetos como es el caso del consentimiento. ${ }^{335}$ Además, contempla la figura del Delegado de Protección de Datos (DPO), encargado de la revisión de todos los acuerdos

\footnotetext{
332 ACNUR, Guidance on the Protection of Personal Data of Persons of Concern to UNHCR, 23 de agosto de 2018, p. 15. Disponible en: https://www.refworld.org/docid/5b360f4d4.html [Consulta: 30 de noviembre de 2018]

${ }^{333}$ ACNUR, Modelo de acuerdo sobre el intercambio de datos personales con los gobiernos en el contexto de la entrega del proceso de determinación de la condición de refugiado, Ginebra: ACNUR. Disponible en: https://www.unhcr.org/50a646f79.pdf [Consulta: 30 de noviembre de 2018].

${ }^{334}$ Consejo de Europa, Convenio para la protección de las personas con respecto al tratamiento automatizado de datos de carácter Personal, Comité de Ministros, Elsinore, 18 de mayo de 2018.

${ }^{335}$ Por ejemplo, como regla general, el procesamiento de datos personales por parte del ACNUR para una solución distinta a la inicial no comunicada previamente al interesado requiere, como regla general, del nuevo consentimiento de acuerdo con el art. 5 (b) RGPD. Sin embargo, las distintas actuaciones necesarias para paliar las brechas que ponen en serio riesgo la seguridad nacional facultan a que el ACNUR y el resto de organizaciones y agencias puedan apartarse de esta limitación con objeto de llevar a cabo todas las actuaciones necesarias para asegurarla siempre y cuando se lleven a cabo de forma proporcional e individual y ateniendo a "imperantes motivos de interés público" [art. 6.1 (e) RGPD]. Y pese a que su mandato no permite proporcionar asistencia a sujetos que pueden comprometer la seguridad de los Estados, reconoce que lo cierto es que, frecuentemente, no resulta viable la obtención del consentimiento de todos los sujetos interesados. Asimismo, incorpora la adecuación de múltiples disposiciones del RGPD como la implementación de todas las medidas razonables para garantizar que los datos personales inexactos se eliminen o corrijan sin demora indebida, y no conservándose más tiempo del necesario para los fines para los que fueron recopilados [art. 5.1 (d) RGPD], el fiel respeto a los principios de necesidad, proporcionalidad y limitación de almacenamiento [art. 5.1 (e) RGPD y art. 5.4 (e) del Convenio 108+].

Véase sobre el particular: ACNUR, Guidance on the Protection of Personal Data... ob. cit, 2018, p. 65; FRA y Consejo de Europa, Handbook on European data protection law, sección 3.5, 2018, p. 129.
} 
de transferencia de datos personales a una autoridad nacional policial o judicial y del asesoramiento, en consulta con las excepciones que se exijan por parte de la Sección de Protección y Seguridad Nacional de la División de Protección Internacional.

En definitiva, no cabe duda de que el RGPD resulta aplicable. Su previsión se encuentra en la propuesta de reforma del SECA, principalmente, en lo relativo a la aplicación de las medidas técnicas y organizativas adecuadas para garantizar la seguridad de los datos. En concreto, la prevención del acceso a los datos por parte de terceros, la divulgación de información personal ilícita o no autorizada o, incluso, la alteración o la pérdida de los datos personales. Situaciones que, como hemos señalado, en caso de producirse, pondrían en serio peligro la seguridad del solicitante, expuesto a su interceptación y persecución por parte de países de origen o terceros países de residencia.

Ahora bien, como veremos a continuación, el RGPD se encuentra excluido directamente de este ámbito, propiciando un régimen jurídico muy complejo que puede rebajar los estándares que prevé la propuesta de reforma del SECA en materia de protección de datos.

3.2. La excepción del RGPD en las solicitudes de protección internacional.

En el derecho de protección de datos de los solicitantes de protección internacional, las autoridades nacionales requieren de un marco jurídico más flexible que el previsto en el RGPD para la tramitación de las solicitudes de protección internacional. Sus altas garantías reconocidas pueden limitar seriamente las actuaciones de autoridades nacionales que gestionan solicitudes de asilo lastrando el procedimiento de asilo, el cual exige identificar y discernir las distintas categorías de sujetos así como proporcionar las condiciones de acogida necesarias durante la tramitación de una forma eficiente. En estos casos, parece optarse por seguir extendiendo un difuso marco jurídico en la protección de los derechos de los solicitantes que se aparta de las garantías tipificadas en el RGPD, previendo un conjunto de limitaciones con objeto de salvaguardar los intereses nacionales y la seguridad de los EEMM.

El Considerando 16 RGPD excluye de su aplicación las "actividades relativas a la seguridad nacional y (...) al tratamiento de datos de carácter personal por los EEMM en el ejercicio de las actividades relacionadas con la política exterior y de seguridad 
común de la Unión". En similares términos, el art. 2(2)(b) RGPD excluye el procesamiento de datos personales por parte de los EEMM cuando realizan actividades relacionadas con el asilo, el control de fronteras y la inmigración. Y sobre esta exclusión, algunos países como el Reino Unido o Alemania han restringido los derechos de los migrantes y solicitantes de protección internacional, por ejemplo, el derecho de acceso a información o el consentimiento. ${ }^{336}$

Pese a estas exclusiones, el art. 23.1 de este Reglamento contempla limitaciones en el ejercicio de este derecho para salvaguardar la seguridad del estado, la defensa o la seguridad pública -entre otros-. Estas deben ser proporcionales y necesarias pues, de lo contrario, podría impedirse o dificultarse de facto la investigación que requiere determinar los motivos y existencia de la persecución sufrida.

Unas restricciones que se encuentran igualmente previstas en la Directiva 2002/58/CE sobre la privacidad y las comunicaciones electrónicas ${ }^{337}$ donde el art. 15 en relación con la anterior directiva de protección de datos las preveía siempre y cuando resultaran necesarias, apropiadas y proporcionadas en una sociedad democrática para fines específicos de orden público, como proteger la seguridad de los estados. Limitaciones, actualmente, necesarias y especialmente aplicables durante los

\footnotetext{
${ }^{336}$ En el Reino Unido, la Ley de Protección de datos de 2018 contiene una cláusula en materia de protección de datos (Data Protection Bill Clause). Concretamente, la Sección 15, exceptúa a la inmigración de la aplicación del RGPD en su parágrafo $4^{\circ}$, que se ampara en el interés público general del art. 23.1 e) RGPD. Esta excepción se encuentra actualmente pendiente de revisión judicial

En este mismo sentido, Alemania aprobó la ley destinada a fortalecer la seguridad fronteriza a expensas de la privacidad de los solicitantes de asilo. Un proyecto de ley anunciado por el Ministerio del Interior en febrero de 2017 permitiría a las autoridades alemanas tomar datos de teléfonos inteligentes, portátiles y demás dispositivos de solicitantes de asilo en el país, con el fin de determinar sus identidades y nacionalidades (anteriormente, los funcionarios solo podían tomar datos personales con el consentimiento de los solicitantes de asilo). La Oficina Federal de Migración y Refugiados (BAMF) estableció que la medida está dirigida a los solicitantes de asilo que llegan a Alemania sin pasaporte o con documentos falsificados, una ley a todas luces desproporcionada con el derecho a la privacidad. Sobre el particular, véase: TANGERMANN J., "Documenting and Establishing Identity in the Migration Process Challenges and Practices in the German Context Focussed study by the German National Contact Point for the European Migration Network", European Union Working Paper, $\mathrm{n}^{\circ}$ 76, 27 de septiembre de 2017.

${ }^{337}$ Directiva 2002/58/CE del Parlamento Europeo y del Consejo, de 12 de julio de 2002, relativa al tratamiento de los datos personales y a la protección de la intimidad en el sector de las comunicaciones electrónicas (Directiva sobre la privacidad y las comunicaciones electrónicas), «DOCE» $\mathrm{n}^{\circ} 201$, de 31 de julio de 2002. DO L 201, 31.7.2002, pp. 37-47. Esta Directiva está en proceso de reforma por el conocido como e-Privacy. Véase: Propuesta de Reglamento sobre el respeto de la vida privada y la protección de los datos personales en el sector de las comunicaciones electrónicas y por el que se deroga la Directiva 2002/58/CE (Reglamento sobre la privacidad y las comunicaciones electrónicas). COM/2017/010 final 2017/03 (COD).
} 
procedimientos para la gestión eficiente de las fronteras exteriores, considerado uno de los elementos centrales del sistema de control de fronteras.

Paralelamente, la intervención directa e indirecta de un amplio conjunto de actores en la gestión de la información y datos personales de los solicitantes de protección internacional ha propiciado la creación de un extenso marco jurídico especializado. Por un lado, el Reglamento (UE) 2018/1725 resultará aplicable a las agencias especializadas en gestión del asilo como la GEFC, ${ }^{338}$ la futura AAUE, así como el tratamiento de datos personales por parte de instituciones, órganos y organismos de la UE. Por otro lado, las autoridades policiales nacionales o la Europol o incluso servicios de inteligencia o espionaje nacionales disponen de un elevado margen de actuación, apartándose generalizadamente de las garantías que prevé el mencionado RGPD. Una amplia flexibilidad de las autoridades policiales en el cumplimiento de la legislación protección de datos fue objeto de debate en la STEDH Catt c. Reino Unido, de 24 de enero de $2019^{339}$ que limitó las facultades de la policía en relación con la recopilación y retención de los datos personales al determinar que este país había vulnerado el derecho a la privacidad del Sr. Catt, un activista por la paz cuyos datos se encontraban en una base de datos de carácter extremista pese a carecer de antecedentes penales. A raíz de la mencionada Sentencia, el TEDH exige el examen del cumplimiento del principio de necesidad del art. $8 \mathrm{CEDH}$ esencialmente, cuando las facultades otorgadas a los estados resultan confusas. Estos contextos propician un elevado riesgo de arbitrariedad en virtud del incesante desarrollo tecnológico de los SSII que emplean las distintas autoridades policiales y agencias de seguridad.

Por lo tanto, este régimen jurídico excesivamente amplio y divergente se encuentra, en buena medida, justificado por la exigencia de una intensiva actuación nacional, en cooperación con un amplio espectro de organismos europeos, que determinen previamente al examen la solicitud de protección internacional- los siguientes extremos:

\footnotetext{
${ }^{338}$ El 12 de septiembre de 2018, la Comisión propuso la actualización del Reglamento de la Guardia Europea de Fronteras y Costas con el objetivo de mejorar el control de las fronteras exteriores de la UE y que culminó el pasado 13 de noviembre con el Reglamento 2019/1896 sobre la Guardia Europea de Fronteras y Costas.

${ }^{339}$ STEDH Catt c. Reino Unido, de 24 de enero de 2019. Demanda no. 43514/15.
} 
a) La identificación de los nacionales de terceros países y una investigación consistente en la valoración de conductas personales susceptibles de impactar negativamente en la seguridad nacional.

b) La determinación del EM responsable para conocer la solicitud de protección internacional de acuerdo con el "Sistema de Dublín" así como la reubicación o reasentamiento en otro EM o incluso país tercero.

c) El mantenimiento de la supervisión y el control de los flujos migratorios, los cuales indudablemente afectarán -en mayor o menor medida- al propio procedimiento de protección internacional en lo que respecta al deber de proporcionar información, el establecimiento de las condiciones de acceso, rectificación o supresión de los datos de los sujetos interesados.

d) Por último, la optimización de la capacidad de los sistemas nacionales de asilo en un periodo de tiempo concreto. Esta situación requerirá una sinergia eficiente de recursos materiales, humanos, financieros y de infraestructuras basadas en los flujos migratorios precisos. Un contexto especialmente complejo sobre todo, en aquellos EEMM que han resultado afectados por las crisis migratorias y de asilo que se produjeron en el 2015, los cuales soportaron una carga desproporcionada de solicitudes.

3.3. La aplicación de la Directiva 2016/680 de protección de datos en el ámbito penal en el SECA.

Como se ha puesto de manifiesto, las solicitudes de protección internacional se han vinculado, con asiduidad, a escenarios que, en la pasada década y, muy especialmente, en el último lustro con las crisis migratorias y de refugiados, han puesto en riesgo el mantenimiento de la seguridad de los EEMM. Una situación que evidenció una estructural falta de seguridad jurídica en el tratamiento de la información y datos personales en el ámbito del SECA. En consecuencia, el SEPD se hizo eco de las crecientes preocupaciones de la UE en la lucha contra el terrorismo y exigió la búsqueda de un equilibrio entre la seguridad y la privacidad en el procesamiento de datos personales, especialmente, las gestionadas por parte de las autoridades policiales. Este organismo reconoció la necesidad de introducir mejoras importantes sobre acciones vulnerables de este colectivo para proceder a una evaluación mejorada de los 
derechos e intereses legítimos de las personas que puedan verse afectadas por el tratamiento de datos personales. ${ }^{340}$

Pese a esta "voluntad teórica" por incrementar las garantías en la protección de la información, la propuesta de reforma del SECA no arroja respuestas contundentes en este sentido. Esto puede agravar la falta de concreción del régimen jurídico, cuyas persistentes limitaciones se equiparan no tanto a las dispuestas en el RGPD sino, más bien, a la Directiva 2016/680 de protección de datos en el ámbito penal. De hecho, la propuesta de reforma del SECA alude a ambas normas sin especificar cuando se aplica una en defecto de la otra.

A modo de ejemplo, el art. 3 apartado 2 y 4 PRE equiparan los términos previstos en la Directiva de protección de datos de ámbito penal a los definidos en el RGPD. Del mismo modo, el art. 36.2 (h) prevé adecuarse al RGPD o Directiva a la hora de crear perfiles que describan las funciones y responsabilidades de las personas autorizadas al acceso, registro, actualización, supresión y búsqueda de datos de Eurodac. Un supuesto de "alternancia" entre las dos normativas de protección de datos que repite el art. 37.4 a la hora de levantar las prohibiciones de transferencia de datos.

Ahora bien, la plasmación del RGPD en la PRE recibió críticas por el Consejo Europeo de Refugiados y Exiliados (ECRE) que aconsejaba eliminar estas referencias, ${ }^{341}$ no tanto por una potencial confusión con la aplicación de la Directiva de protección de datos en el ámbito penal, sino por el carácter eminentemente policial de la misma. El amplio despliegue de autoridades policiales y servicios de seguridad en la gestión de la información que contempla Eurodac exige un marco jurídico que "flexibilice" el margen de maniobra de las autoridades nacionales -aunque ello implique una limitación en los derechos de los solicitantes de asilo-. Para ello, el art. 35 de la mencionada propuesta prevé la sujeción a la nueva Directiva relativa a la protección de datos en el ámbito penal.

\footnotetext{
${ }^{340}$ Supervisor Europeo de Protección de Datos (SEPD), Dictamen del Supervisor Europeo de Protección de Datos sobre el segundo paquete de fronteras inteligentes de la UE, 13 diciembre de 2016 (C 463/11). Véase también Supervisor Europeo de Protección de Datos, Protección de Datos y Privacidad en 2018: Más allá del RGPD, 20 Marzo 2018. https://edps.europa.eu/press-publications/press-news/pressreleases/2018/data-protection-and-privacy-2018-going-beyond-gdpr_en

${ }^{341}$ Consejo Europeo de Refugiados y Exiliados (ECRE). Comentarios sobre la Propuesta de refundición del Reglamento Eurodac, $\operatorname{COM}(2016)$ 272, Julio de 2016, p. 6
} 
Esta se encuentra en plena sintonía con la Directiva 2017/541 relativa a la lucha contra el terrorismo, ${ }^{342}$ ambas enmarcadas dentro del Plan de Acción presentado por la Comisión para intensificar la lucha contra la financiación del terrorismo. ${ }^{343}$ De hecho, esta última Directiva constituye un buen ejemplo de integración pues incluye una cláusula explícita - la primera de este tipo- sobre derechos fundamentales, y, al mismo tiempo, tiene en cuenta parámetros necesarios en este aspecto como los principios de necesidad y proporcionalidad de las interferencias con los derechos de libertad de circulación, protección de datos y libertad de expresión que reconocen los arts. 8 y 11 CDFUE. No obstante, la seguridad de los ciudadanos de la UE se erige como una de las prioridades legislativas de la UE tal y como así parece reflejar la Declaración conjunta sobre las prioridades legislativas de la UE para 2018-2019, de 14 de diciembre de $2017^{344}$

El vínculo entre ambos instrumentos jurídicos resulta especialmente notorio. Por un lado, la Directiva de protección de datos 2016/680 regula la libre circulación de datos personales entre las autoridades competentes para fines de prevención, investigación, detección o enjuiciamiento de infracciones penales o de ejecución de sanciones penales. Esta incluye la protección y la prevención frente a las amenazas para la seguridad pública en el seno de la UE y la transferencia de estos datos personales a terceros países y organizaciones internacionales, al mismo tiempo que garantiza un alto nivel de protección de los datos personales. Además, los Considerandos 7, 11 y 14 también prevé la adopción de normas específicas relativas a la protección de las personas físicas en lo que concierne al tratamiento de datos personales, excluyendo el tratamiento de datos personales en el marco las actividades relacionadas con la seguridad nacional. En todo caso, el art. 15 dispone que las autoridades nacionales podrán restringir los

\footnotetext{
${ }^{342}$ Directiva (UE) 2017/541 del Parlamento Europeo y del Consejo de 15 de marzo de 2017 relativa a la lucha contra el terrorismo y por la que se sustituye la Decisión marco 2002/475/JAI del Consejo y se modifica la Decisión 2005/671/JAI del Consejo.

${ }^{343}$ Comisión Europea, Comunicación de la Comisión al Parlamento Europeo y al Consejo, Plan de acción para intensificar la lucha contra la financiación del terrorismo, COM/2016/050 final, 2 de febrero de 2016 (http://europa.eu/rapid/press-release_IP-16-202_es.htm). Además, tal fue el impacto del terrorismo, que la Comisión en abril 2016, la elaboró las primeras estrategias para allanar el camino hacia una Unión de la Seguridad genuina y efectiva (http://europa.eu/rapid/press-release_IP-16-1445_es.htm) que se extiende hasta nuestros días.

${ }^{344}$ Esta Declaración pretende tomar medidas encaminadas a garantizar que las autoridades de los EEMM identifiquen los sujetos que cruzan la frontera exterior común de la UE, establecer sistemas de información interoperables en la UE para la gestión de la seguridad, las fronteras y la migración, y a reforzar los instrumentos de lucha contra el terrorismo. Declaración conjunta sobre las prioridades legislativas de la UE para 2018-2019. OJ C 446, 29 de diciembre de 2017, p. 1-3.
} 
derechos de los interesados única y exclusivamente si estos comprometen su propia seguridad.

Por otro lado, la Directiva de lucha contra el terrorismo concreta las mencionadas disposiciones no solo ponderando la seguridad y protección de datos bajo el paraguas de criterios de eficacia, necesidad y proporcionalidad, sino aludiendo al respeto de las normas de la UE sobre protección de datos en lo que respecta al intercambio de información en la lucha contra el terrorismo. Además, como señalan los Considerandos 21, 25 y 35 también deberán respetarse los principios establecidos en el art. 2 TUE, los derechos y libertades fundamentales y los principios consagrados en la CDFUE, en particular, la prohibición de discriminación, el respeto a la vida privada y familiar y a la protección de datos de carácter personal.

Con ello, salvo la tramitación y gestión de la información por parte de autoridades policiales, las correspondientes limitaciones de derechos en la protección de datos en relación con el ámbito de asilo deberán responder a inexorables razones de seguridad nacional que no permitan -en modo alguno- ampliar y equiparar los derechos de acuerdo con las disposiciones del RGPD. Estas restricciones deberán efectuarse de forma individual, sobre una solicitud en concreto y sin causar indefensión al interesado. Máxime, habida cuenta de la posición delicada del solicitante y de la importancia que revisten sus datos personales en todo el proceso de determinación del estatuto de refugiado o protección subsidiaria.

No obstante, la aplicación de la Directiva parece justificarse por el amplio despliegue de autoridades policiales en la gestión de este tipo de información y por la exigencia que radica en la imperante necesidad de investigar la identidad, el perfil del solicitante y las causas que motivan su persecución. En la consecución de estas acciones, las autoridades administrativas y policiales nacionales requieren de una mayor flexibilidad en sus actuaciones, en concreto, en contextos de grandes flujos migratorios donde un amplio número de sujetos solicitan protección internacional. Las formalidades del RGPD merecen por tanto rebajarse para proteger, de un modo eficiente, a los sujetos de protección internacional. Ello pese a que la nueva PRD IV regule referencias expresas a la protección de los datos personales en materia de acceso, rectificación o supresión de los datos [art. 6. 1h)] a todas las categorías de datos personales [art. $6.1 \mathrm{~g}$ )]. 
Ahora bien, la aplicación generalizada de este marco jurídico supondría, a todas luces, una criminalización de los solicitantes, cuyos escenarios podrían generar dos consecuencias desventajosas:

1) La diferencia de trato entre los ciudadanos de la UE y los solicitantes de protección internacional puede generar potenciales efectos discriminatorios a este último ante la equiparación de este colectivo a otras categorías de sujetos como potenciales delincuentes o terroristas. Teniendo en consideración que, estas limitaciones no son aplicables a otras categorías de sujetos como los turistas que llegan a los distintos países de la UE. ${ }^{345}$

2) Por su parte, estas limitaciones también pueden dificultar excesivamente el acceso de los solicitantes al procedimiento de protección internacional e impedir que estos puedan comprobar la información que consta en su expediente y los datos personales que figuran en la solicitud, pudiéndose conculcar el contenido de este derecho.

3.4. La seguridad y protección de datos en el Reglamento de Dublín y su propuesta de reforma.

Como ya hemos dicho anteriormente, el régimen jurídico de "seguridad y protección de datos" constituye uno los aspectos más relevantes para garantizar el control efectivo de los datos relativos a los solicitantes de protección internacional y que prevé tanto el actual Sistema de Dublín (art. 38) como la futura reforma (art. 50) en el Capítulo IX. Esta disposición ha resultado aplicable desde la entrada en vigor del actual Reglamento de Dublín y supone una las principales disposiciones que permite establecer un "punto de unión entre el Sistema de Dublín y la legislación de protección de datos”. Sin embargo, su alcance no ha sido todavía interpretado en el plano comunitario. ${ }^{346}$

El mencionado artículo habilita a los EEMM a adoptar "todas aquellas medidas técnicas y organizativas apropiadas" para asegurar la seguridad de los datos personales transmitidos y evitar el acceso o la divulgación ilícitos o no autorizados, la alteración o la pérdida de los datos personales tratados. Para tal fin, las autoridades nacionales deben

\footnotetext{
${ }^{345}$ Situación que se revertirá cuando entre en pleno funcionamiento la interoperabilidad de todos los SSII europeos. En concreto, tras la reforma de los mencionados sistemas. Para un análisis sobre el particular, remitimos al Capítulo III del presente trabajo.

${ }^{346}$ Especialmente relevante resulta que organismos como el ECRE o el ACNUR no hayan abordado el impacto de la seguridad y protección de datos en el mencionado sistema. ECRE, Comentarios sobre la Propuesta de Dublín IV... ob. cit.; ACNUR, Left in limbo, Study on the implementation of the Dublin III Regulation, agosto de 2017.
} 
llevar a cabo un exhaustivo análisis de riesgos que permita establecer adecuadas medidas de seguridad y de control que respeten los derechos y libertades de los solicitantes. En caso contrario, cualquier brecha de seguridad podría evidenciar un grave peligro para la seguridad e integridad física del solicitante y para la viabilidad y credibilidad del sistema en su conjunto.

Por consiguiente, el criterio de adecuación que dispone el Sistema de Dublín debería exigir el desarrollo e implementación de las más altas medidas de seguridad en la protección de la información de acuerdo lo dispuesto en el art. 32 RGPD. No cabe obviar que el riesgo en caso de que este tipo de datos fueran destruidos, perdidos, alterados, transmitidos o incluso comunicados con sus países de origen $-\mathrm{o}$ incluso terceros estados de tránsito- podría causar un serio perjuicio al sujeto en situación de vulnerabilidad en cuestión, incluso irreparable, pudiendo atentar contra su propia vida o la de personas relacionadas con este. Además, este riesgo de acceso no autorizado que regula el art. 32.2 RGPD aumenta exponencialmente si se tiene en cuenta el amplio acceso por parte de autoridades administrativas y policiales y la gran disponibilidad de la información personal en virtud de la interoperabilidad de Eurodac con otros SSII. Razón de más para adoptar las medidas de seguridad más elevadas de acuerdo con el apartado $1^{\circ}$ del mencionado artículo. ${ }^{347}$

A colación de este precepto, el Reglamento de Dublín exige implícitamente proteger de un modo eficaz la información de este grupo en situación de vulnerabilidad por lo que las autoridades nacionales de control deben llevar a cabo un férreo control de la legalidad del tratamiento de datos personales. Por ello, en el marco del Sistema de Dublín, los EEMM deberían definir claramente las medidas de control y seguridad de acuerdo con el RGPD que prevé el actual RD III.

Sentando esto, la nueva Propuesta no alude a su adecuación al RGPD aunque desde otra perspectiva, prevé directamente la implementación de tres tipos de autoridades (segundo apartado, art. 50):

a) Tanto el art. 35 RD III como el art. 47 PRD IV exigen la presencia de autoridades encargadas del cumplimiento de las obligaciones derivadas del Sistema de Dublín. Estas autoridades tienen por objeto el cumplimiento de las obligaciones del mencionado

\footnotetext{
${ }^{347}$ El art 32.1 RGPD exige que las medidas de seguridad que se adopten se elijan en función de parámetros como "El riesgo calculado y la probabilidad de que ocurra."
} 
sistema. La futura PRD IV pretende que sus actuaciones revistan carácter instrumental aunque, lo cierto es que atribuye paralelamente mayores obligaciones en relación con el mecanismo de asignación. En efecto, estas autoridades deberán encargarse no solo de responder a las peticiones de información y toma de cargo, sino también a las notificaciones de readmisión y todas aquellas necesarias para dar cumplimiento al mencionado mecanismo.

b) Asimismo, la PRD IV prevé la adopción dos novedosas autoridades:

- Primero, en virtud de la creación de un sistema automatizado de comunicación entre el sistema central y las infraestructuras nacionales, insta a la creación de autoridades nacionales encargadas de registrar y controlar la cuota de solicitudes de protección internacional y la aplicación del novedoso mecanismo de asignación (art. 44.1 PRD IV).

- Segundo, las autoridades verificadoras para detectar y compartir información de sujetos que pueden constituir una amenaza para la seguridad nacional o el orden público (art. 40 PRD IV). Esta última, dentro del mecanismo de asignación correctora, se corona como una de las novedades que prevé Dublín IV para elevar las garantías de la protección de la información tras incidentes que pueden comprometen la seguridad de los EEMM. Ello en vista de que el art. 40 PRD IV faculta a que el EM beneficiario transmita al de asignación, de forma especialmente sumaria, los datos biométricos de los solicitantes que pueden comprometer la seguridad nacional o el orden público. Incluso, el apartado $2^{\circ}$ permite compartir, tras la alerta, toda la información disponible del solicitante en cuestión con los servicios de seguridad del EM beneficiario sin exigencia de comunicarse a través de los necesarios canales de comunicación electrónicos del art. 47.4 PRD IV. Una excepción que rebaja sustancialmente la protección de la información transmitida y que deberá, en todo caso, llevarse a cabo de forma individualizada y en función del tipo de alerta concreta.

Con ello, las novedosas autoridades de la propuesta otorgarán una mayor efectividad y eficacia a las actuaciones nacionales por medio de la articulación de todo un sistema de detección e intercambio de información entre autoridades nacionales y europeas. Ahora bien, en el caso de que el solicitante pueda ser considerado sospechoso de constituir un peligro para la seguridad nacional u orden publico, se contemplan extensas exclusiones para garantizar la mayor flexibilidad necesaria por parte de las autoridades nacionales. 
Y, sobre esta cuestión, el art. 40 PRD IV regula toda una serie de parámetros excepcionales en relación con la gestión de la información de sujetos que pueden comprometer la misma. El apartado $2^{\circ}$ prevé un novedoso deber de información entre el EM de asignación y de acogida. Se exige al primero informar al segundo sobre la existencia de dicha alerta, especificando los servicios de seguridad del EM de solicitud que hayan sido plenamente informadas, debiendo dejarse constancia de la existencia de la alerta en el sistema automatizado, con arreglo al art. 23.2 d) PRD IV. Todo ello en un plazo muy breve, de tan solo una semana a contar desde la recepción de las impresiones dactilares.

Por su parte, el apartado $3^{\circ}$ art. 40 PRD IV prevé el sometimiento al procedimiento acelerado en los supuestos en los que el resultado de la verificación de seguridad confirme que, por razones fundadas, puede considerarse al solicitante un peligro para la seguridad nacional o el orden público. De este modo, el EM beneficiario de solicitud será el EM responsable y examinará la solicitud mediante este procedimiento ad hoc, de acuerdo con el art. 31.8 de la Directiva 2013/32/UE. Relevante fue la enmienda 197 que presentó el PE sobre el particular, que incluye igualmente que en el caso de riesgo de fuga, pueda llevarse a cabo el internamiento de acuerdo con el art. 29 PRD IV. ${ }^{348}$

En relación con la legislación de protección de datos, la PRD IV únicamente dispone en el Considerando 33 que deben establecerse "normas apropiadas para aquellos casos en que haya motivos fundados para considerar que un solicitante constituye un peligro para la seguridad nacional o el orden público”. Concretamente, normas relativas al intercambio de información entre las autoridades competentes responsables en materia de asilo de los EEMM. En este apartado, debe advertirse que resultan ciertamente escasas a la luz del régimen de protección de datos en lo relativo a la necesidad de individualizar la amenaza para la seguridad nacional u orden público.

El principio de limitación de la finalidad resulta el único "tímido límite" previsto en el apartado $4^{\circ}$, al establecer que únicamente se procederá al intercambio de esta tipología de información para los fines de evaluación de un solicitante y su potencial amenaza con la seguridad nacional u orden publico. Ello, sin perjuicio del régimen

\footnotetext{
${ }^{348}$ Parlamento Europeo, Comisión de Libertades Civiles, Justicia y Asuntos de Interior, Informe sobre la propuesta de Reglamento del Parlamento Europeo y del Consejo por el que se establecen los criterios y mecanismos de determinación del Estado miembro responsable del examen de una solicitud de protección internacional presentada en uno de los Estados miembros por un nacional de un tercer país o un apátrida (texto refundido) $(\mathrm{COM}(2016) 0270$ - C8-0173/2016 - 2016/0133(COD)), 6.11.2017.
} 
sancionador del artículo 40 del Reglamento Dublín III (artículo 50 PRD IV), que deja en manos de los EEMM, la adopción de las medidas necesarias para garantizar que toda utilización indebida de los datos tratados de conformidad con el presente Reglamento sea objeto de una sanción efectiva, proporcionada y disuasoria, incluidas las de carácter administrativo y penales previstas en el Derecho nacional.

\section{El intercambio de información en el SECA: la cooperación administrativa.}

El intercambio de información en el Sistema de Dublín se ha vinculado tradicionalmente con la necesidad de prevenir, detectar e investigar de un modo satisfactorio cualquier actividad relativa al ámbito penal. Su estrecha relación con materias sensibles y vinculadas con la seguridad ha propiciado que, en el plano internacional, este intercambio se haya acotado a ámbitos eminentemente confidenciales, ajenos a control público y escasamente regulados. Esta ha sido la postura que ha tomado el Relator Especial de las Naciones Unidas para la Lucha contra el Terrorismo. En 2014 declaraba que "la ausencia de leyes para regular los acuerdos de intercambio de información entre los Estados había dejado el camino abierto para que las agencias de inteligencia entablaran acuerdos bilaterales y multilaterales clasificados que exceden de la supervisión de cualquier autoridad independiente". 349

Sin embargo, el intercambio de información en Europa constituye un elemento esencial para la gestión de la migración y el asilo, principalmente, a través de los SSII, sobre los cuales, como veremos más adelante, se han ido perfeccionando hasta su inminente interoperabilidad. Un avance que, no solo impacta de lleno al SECA en su conjunto, sino que no se ha acompasado de un eficiente intercambio de información a la luz del Sistema de Dublín. Las actuaciones nacionales han resultado escasamente coherentes y coordinadas, afectando tanto al propio procedimiento de protección internacional como a la seguridad y confianza mutua entre los EEMM. Tanto es así, que Boehm reconoció la imperante necesidad de implementar reglas de protección de datos que solventen estos potenciales conflictos en un marco jurídico en el que las amplias

\footnotetext{
${ }^{349}$ Naciones Unidas, Informe del Relator Especial de las Naciones Unidas sobre la promoción y la protección de los derechos humanos y las libertades fundamentales en la lucha contra el terrorismo, de 23 de septiembre de 2014 (A/69/397), párr. 44
} 
autoridades de inmigración y asilo no han sido capaces de proporcionar protección suficiente a los solicitantes de protección internacional. ${ }^{350}$

Este "desfase" temporal y material exige replantear este sistema con miras a intensificar un intercambio efectivo de información coherente, común y plenamente respetuoso con la privacidad y protección de datos por medio de nuevas vías de reconocimiento más eficientes con el derecho a la protección internacional. Este marco debe ser capaz de identificar y diferenciar a genuinos sujetos merecedores de tal concesión de migrantes u otras categorías de sujetos que pueden llegar a comprometer la seguridad europea. Y en relación con el actual Reglamento de Dublín, el intercambio de información no ha propiciado marcos de cooperación y coordinación apropiados entre EEMM en lo que concierne al procedimiento de protección internacional. Las sustanciales diferencias entre los procesos nacionales de asilo, la falta de confianza mutua y los intereses nacionales han reflejado escasos avances en el intercambio de información tal y como constata el informe de AIDA de $2018 .{ }^{351}$

Al margen de la implementación del Sistema de Información Eurodac, el intercambio a la luz de este sistema y efectuado entre EEMM y los organismos y agencias de la UE especializadas en control fronterizo ha excedido del fin principal de determinar el EM responsable para conocer $\mathrm{y}$, posteriormente, tramitar las solicitudes de protección internacional -así como los fines del mencionado Reglamento o la ejecución de los traslados- hacia cuestiones directamente vinculadas con la dimensión de la seguridad, eficiencia y eficacia del SECA.

Fruto de esta necesidad de potenciación, la cooperación transfronteriza ha permitido un exacerbado aumento de las técnicas de recopilación de información y datos personales. Estas responden a los múltiples conflictos que se han producido en fronteras, reduciendo los plazos en la tramitación de las solicitudes y perfeccionando, al mismo tiempo, la identidad de los sujetos. Ahora bien, las excesivas consideraciones de seguridad nacional en el procesamiento de información personal ha rebajado las garantías requeridas en el intercambio de información personal, dotando a las autoridades nacionales de una amplia flexibilidad en la toma de decisiones. También ha

\footnotetext{
${ }^{350}$ BOEHM F., "AFSJ Actors in the Light of the European Data Protection Standard", en: Information Sharing and Data Protection in the Area of Freedom..., ob. cit, , pp. 310-311.

${ }^{351}$ Asylum Information Database (AIDA), The Dublin system in 2017. Overview of developments from selected European countries, marzo de 2018., p. 5-10. Accesible en: http://www.asylumineurope.org/sites/default/files/aida_2017update_dublin.pdf
} 
propiciado la emergencia de consecuencias sumamente desventajosas en los derechos de los solicitantes. Tanto es así, que la doctrina especializada en asilo ha considerado que el Sistema de Dublín se erige como "un instrumento de coerción con un coste humano masivo y con una escasa finalidad pública". 352

No cabe soslayar que el actual SECA prevé destacadas mejoras en relación con la protección de datos y de la información. El art. 48 de la Directiva de procedimiento obliga a las autoridades administrativas a cumplir de forma exhaustiva con el principio de confidencialidad, definido en el Derecho nacional, en relación con la información que obtengan en el curso de su trabajo.

Igualmente, para garantizar la protección de la información, el art. 49 impone unos requisitos vinculantes en las actuaciones de coordinación entre EEMM, entre los que caben destacar los siguientes:

1. El deber de designar un punto de contacto nacional, debiendo adoptar todas las medidas oportunas para fomentar una comunicación directa y un intercambio de información entre las autoridades competentes.

2. La exigencia de comunicación entre las autoridades nacionales y la Comisión - del inicio al final- de todas aquellas causas excepcionales, en concreto, ante la presentación de solicitudes de protección internacional de un gran número de nacionales de terceros países o apátridas.

Estos requisitos también se encuentran contemplados en el art. 6 de la propuesta de Reglamento de Procedimiento Común (PRP), que regula el principio de confidencialidad y el art. 40 PRR, el punto de contacto nacional. Por otro lado, art. 57.2 PRP contempla el deber de comunicación directa entre las autoridades nacionales y la Comisión Europea.

Asimismo, relevante resulta la PRD IV, que no permanece ajena a la dimensión de seguridad y articula toda una serie de novedosas medidas para asegurarla. Por ejemplo, alude a la imperante necesidad de articular normas y procedimientos de intercambio de información apropiados y pertinentes para hacer frente a una amenaza terrorista o cualquier otro aspecto que pueda constituir un peligro para la seguridad nacional y

\footnotetext{
${ }^{352}$ GUILD, E., COSTEllO, C., GARLICK, M., MORENO-LAX, V., MOUZOURAKIS, M., "New approaches, alternative avenues and means of access to asylum procedures for persons seeking international protection”. Study for the LIBE Committee. European Parliament, nº 20, 2014, p. 15.
} 
orden público de los EEMM (Considerando 33 PRD IV). Y sobre esta cuestión, tal y como destaca en su exposición de motivos, prevé -por primera vez- ampliar el intercambio de información con terceros países como muestra de una mayor cooperación para la gestión de la migración y asilo. Ello teniendo presente las persistentes deficiencias fundamentales en el SECA.

Además, esta propuesta regula el intercambio de información pertinente a efectos de las verificaciones de seguridad. Exige al EM donde se encuentre el solicitante, independientemente de que sea o no competente para examinar su solicitud, que tome las huellas dactilares -sin perjuicio de su extensión a otros identificadores biométricos tal y como así prevé la Propuesta de Eurodac- a fin llevar a cabo un perfil básico del solicitante que evalúe si resulta, a priori, una amenaza para la seguridad nacional o el orden público. Un control que no pretende establecer cargas adicionales a EEMM no competentes en la tramitación de una solicitud, sino un "nuevo modelo de cooperación" en labores de identificación y prevención de sujetos que pueden comprometer la seguridad europea, determinando aquellas consideraciones preliminares de considerable relevancia que pueden evidenciar este potencial conflicto.

En la mejora de esta cooperación práctica y el intercambio de información sobre los asuntos relacionados con la aplicación del SECA, la propuesta de reforma del Sistema de Dublín prevé dos innovaciones:

- En primer lugar, las reglas competenciales que tipifica el vigente RD III parecen trasladarse a un segundo plano en la nueva Propuesta. El sistema de alerta rápida que preveía el art. 33 RD III y que fue catalogado como una "traslación de la versión inicial del principio de solidaridad hacia un término legal análogo", 353 no ha sido aplicado hasta la fecha.

Este sistema ha estado basado en la recopilación y el análisis de datos continuos, en particular, por parte de la EASO, la cual debía proporcionar a la Comisión un flujo de información permanente y fiable. ${ }^{354} \mathrm{Su}$ transformación en un verdadero "mecanismo de asignación correctora” previsto en el Capítulo VII PRD IV (arts. 34 y ss.), constituirá

\footnotetext{
${ }^{353}$ MITSILEGAS V., "Solidarity and Trust in the Common European Asylum System", Comparative Migration Studies, vol. 2, nº 2, 2014, p. 197.

${ }^{354}$ MAIANI F., "The Dublin III Regulation: A New Legal Framework for More Humane System?" en: Reforming the Common European Asylum System: The New European Refugee Law; CHETAIL, V., De BRUYCKER, P., MAIANI, F. (eds), Immigration and Asylum Law and Policy in Europe, Brill, 2016, p. 139.
} 
una parte esencial en el futuro intercambio de información. No resultarán escasos los supuestos en los que se exija realizar ajustes en la asignación de los solicitantes a través de distintas claves de referencia con miras a garantizar un sistema adecuado de reparto de la responsabilidad entre EEMM.

- En segundo lugar, el art. 49 PRD IV regula la implementación de una red de unidades de Dublín que cuenta con la colaboración de la AAUE de acuerdo con el art. 47.1. Esta red se inició en febrero de 2016 por medio de la integración de unidades de 31 países UE+ con el objetivo de facilitar la implementación del Reglamento de Dublín. Además, incluye el innovador desarrollo de herramientas prácticas y la orientación para la transmisión de información ${ }^{355}$ en vista de los múltiples conflictos y de la generalizada descoordinación que se produce en la actualidad.

Por todo ello, el tema que aquí nos ocupa estriba en determinar las trascendentales transformaciones que sufre el intercambio de información entre autoridades nacionales en la PRD IV previamente al inicio del procedimiento de protección internacional. Un notorio progreso que pretende garantizar una aplicación coherente, eficaz y plenamente respetuoso con los derechos e intereses de los solicitantes de protección internacional. No obstante, no resultará ajena a toda una multitud de desafíos que puede comprometer y desvirtuar esta tipología de información objeto de intercambio.

\subsection{El intercambio de información durante los traslados.}

\subsubsection{El intercambio de información pertinente antes de la ejecución de los} traslados.

La protección de la información personal durante el momento previo a efectuar el traslado de un solicitante desde el Estado en el que se encuentra hasta el que resulta competente para la tramitación de su solicitud de asilo puede resultar muy crítico, en concreto, si se tiene en cuenta que el almacenamiento, intercambio y eliminación de

\footnotetext{
${ }^{355}$ Hasta la fecha, de acuerdo con los datos proporcionados por la EASO, únicamente se han desarrollado diversas jornadas en las que, con la participación de profesionales sobre la materia, fueron abordados los desafíos que emergían del funcionamiento de DubliNet, la plataforma de comunicación segura del Sistema de Dublín que se encuentra bajo coordinación y responsabilidad de Eu-LISA. Concretamente, se puso de manifiesto la escasa coherencia a la hora de llevar a cabo acciones nacionales de transferencias a la luz del Sistema de Dublín pese a que el Reglamento europeo, como veremos más adelante, deja escaso margen de maniobra en este sentido. Sobre el particular, el 8 de junio de 2018 tuvo lugar la primera de las jornadas que analiza el impacto de la base de datos DubliNet. Accesible en: https://www.easo.europa.eu/dublin-network-steering-group-mt
} 
estos datos se incoan previamente a la apertura del procedimiento de determinación del EM responsable de conocer y tramitar la solicitud de protección internacional.

Este intercambio, que tiene por finalidad la preparación de los traslados, se contempla en los arts. 31 y 32 RD III (arts. 32 y 33 PRD IV). Pretende asegurar que las autoridades nacionales estén en posición de proporcionar al solicitante que va a ser trasladado, la asistencia adecuada, el cuidado de su salud física y psíquica, así como la protección y los derechos reconocidos en este Reglamento y en la Directiva de Acogida. Para la consecución de los mencionados objetivos, el art. 32 PRD IV exige el intercambio de todos aquellos datos que "resulten adecuados, pertinentes y limitados a lo necesario para los fines exclusivos de garantizar que las autoridades competentes con arreglo al Derecho nacional del EM responsable puedan prestar una asistencia adecuada a la persona interesada".

La mencionada propuesta incorpora tácitamente la minimización de los datos que expresamente prevé el art. 5.1 c) RGPD. Por lo tanto, el tratamiento deberá efectuarse únicamente de aquellos datos que sean necesarios para el objeto del traslado, adoptando todas las medidas razonables para garantizar la rectificación o supresión de los mismos en caso de inexactitud. Asimismo, en todo caso, estos datos deberán tratarse de una forma compatible con su seguridad y confidencialidad, es decir, impidiendo el acceso o uso no autorizados de dichos datos y del equipo utilizado en el tratamiento.

Por primera vez, la PRD IV introduce los criterios de adecuación y necesidad. Esto viene a reflejar una estricta aplicación de la legislación de protección de datos de acuerdo con el RGPD, superando el excesivo margen de maniobra que otorgaba el RD III aludiendo a criterios de mera utilidad y no excesividad y que, actualmente, contempla la Directiva de protección de datos en el ámbito penal en el art. 4.1 c).

Además, esta reforma toma buen ejemplo de la Opinión 07/2016 del SEPD, ${ }^{356}$ que recomendaba en el parágrafo 9 que la información personal y, más concretamente, que los identificadores no fueran empleados, en modo alguno, para finalidades que excedían del objeto principal del Sistema de Dublín de conformidad con los arts. 5.1 b) RGPD, 4.1 b) de la Directiva de protección de datos en el ámbito penal y el art. 8.2 CDFUE. Precisamente, la transmisión de información deberá emplearse de forma exclusiva en aras de garantizar que las autoridades competentes de recibir el traslado estén en

${ }^{356}$ Supervisor Europeo de Protección de Datos (SEPD). Opinión 07/2016 sobre la reforma..., ob. cit, 21 de septiembre de 2016. 
condiciones no solamente de prestar una asistencia adecuada durante el traslado, sino de asegurar la continuidad del procedimiento del mencionado sistema. Así, insta a reforzar las relaciones entre EEMM a fin de evitar dobles recopilaciones de datos idénticos, - sin perjuicio de la comprobación que se efectúe sobre la exactitud de los mismos-. Y, como tal, no se refiere en concreto al intercambio de datos biométricos, los cuales se encuentran almacenados directamente en Eurodac, sino más bien, al intercambio de cualquier tipo de información personal que permita establecer un perfil -cuanto menosexacto del solicitante en cuestión. En consecuencia, esta cooperación incrementará aumentando la eficiencia del procedimiento en el EM receptor a través de criterios adecuados, pertinentes y limitados a la finalidad que se espera obtener de ellos, esto es, la mera identificación de un sujeto como solicitante de protección internacional y las particularidades específicas que pudiera requerir durante su traslado.

Por lo tanto, este sistema acomete mejoras sustanciales para evitar que la autoridad competente del EM responsable no deba retrotraerse al inicio de sus actuaciones, más bien, partiendo de los datos obtenidos por la autoridad del otro EM, dar traslado al solicitante acerca de los mismos y ampliar a aquellos la información concerniente al sujeto en cuestión. Los fines de tratamiento deberán ser recopilados con fines determinados, explícitos y legítimos, esto es, cumpliendo tanto con el art. 8 del CEDH y art. 7 en relación con los arts. 1, 3.1 y 52.1 CDFUE, como salvaguardando los principios de limitación de la finalidad y minimización de datos del art. 5.1 b) y c) RGPD.

La adopción de tales principios no solo supondrá la adecuación de los altos estándares tipificados en el RGPD, sino que redundará positivamente en la eficiencia y eficacia de este intercambio de datos, esto es, mejorando de manera sustancial la comunicación y reduciendo considerablemente los plazos de conformidad con el Considerando 28 RD III (art. 40 PRD IV).

Por lo que concierne al apartado $2^{\circ}$ del mencionado artículo, faculta a que el EM que ejecute el traslado transmita al EM responsable toda información esencial para la protección de los derechos y las necesidades inmediatas especiales, incluyendo:

a) cualquier medida inmediata que el EM responsable tenga que adoptar para garantizar que se atienden adecuadamente las necesidades especiales;

b) datos de contacto de miembros de la familia; 
c) en el caso de menores de edad, información sobre su educación; y

d) una estimación de la edad del solicitante.

Además, el apartado $3^{\circ}$ prohíbe un tratamiento posterior a los previstos en un inicio, teniendo en consideración la gran tipología de datos susceptibles de registro y traslado. Para tal fin, este apartado exige que este intercambio de información tenga lugar, exclusivamente, entre las autoridades comunicadas a la Comisión a través de la red de comunicaciones electrónicas al efecto, «DubliNet» tal y como regula el art. 35 RD III (art. 47 PRD IV). Un precepto que resulta esencial para salvaguardar los derechos e intereses de los solicitantes. En la práctica actual, esta formalidad no parece encontrarse supeditada a excepciones nacionales, puesto que tal y como aduce la PRD IV, todos los EEMM han comunicado que utilizan de manera frecuente esta red electrónica segura de intercambio de información. Únicamente recurren a canales de información informales en circunstancias excepcionales de escasa relevancia - no constando en los informes que envían a la Comisión Europea-.

Finalmente, el apartado $4^{\circ}$ del art. 31 RD III (art. 32.4 PRD IV) insta a elaborar un formulario normalizado para la transmisión de estos datos requeridos (apartado $4^{\circ}$ ), debiendo aplicarse, en todo caso, las normas establecidas en el art. 46.8. Además, establece que, con objeto de facilitar el intercambio de información entre los EEMM, la Comisión deberá elaborar el citado formulario para la transmisión de los datos requeridos por el presente artículo mediante actos de ejecución, adoptándose de conformidad con el procedimiento de examen a que se refiere el art. 44.2. Debe apuntarse que, en la actualidad, todavía no se han establecido propuestas sobre este extremo.

Desde una perspectiva material, esta firme apuesta por el empleo de mecanismos “estandarizados" en el intercambio de información aumentará la eficiencia del procedimiento de comunicación de datos. Se trata de elementos del todo pertinentes y necesarios para fomentar un intercambio de información y datos coherentes entre las distintas autoridades, donde no cabe duda de su importancia a la hora de fomentar una actuación rápida y eficiente en el intercambio de información y datos personales como elemento básico para garantizar la protección efectiva de los solicitantes de protección internacional. Además, estos instrumentos pueden fomentar el cumplimiento del principio delimitación de la finalidad y minimización de los datos, incluyendo "por 
diseño y defecto" aquellas consideraciones oportunas para tal fin (casillas pertinentes, espacio limitado, información básica, etc.).

Ahora bien, no cabe obviar que, desde un enfoque estrictamente formal, estos documentos pueden propiciar un contexto de intercambio de información y datos personales que no reúna las altas garantías necesarias para la consecución de su estricta finalidad, aumentando el riesgo de que la información sea transmitida violando las garantías del art. 5.1 c) RGPD. Por tanto, la trasmisión de la información, en todo caso, deberá llevarse a cabo para garantizar el cumplimiento concreto de algunos de los fines del Sistema de Dublín.

En definitiva, la firme apuesta de la PRD IV por fomentar el intercambio de información antes de la ejecución de los traslados apuesta decididamente por un modelo de inclusión de información adecuada y de necesidad en detrimento de criterios de utilidad y no excesividad, vislumbrando aquella información estrictamente útil para la consecución de los fines que se persiguen. Estos límites no deben obstaculizar la labor de las autoridades nacionales, sino más bien, un sistema "perfeccionado" capaz de respetar las garantías de protección de datos del RGPD y responder tanto a las necesidades de los solicitantes de protección internacional como a las reglas competenciales del mencionado sistema.

\subsubsection{El intercambio de datos sanitarios antes de efectuar el traslado.}

La alta probabilidad de que los solicitantes de protección internacional sufran problemas de salud físicos y psicológicos de naturaleza variada no es una afirmación novedosa. ${ }^{357} \mathrm{El}$ punto conflictivo radica en que estos sujetos se enfrentan a serias dificultades para acceder a la atención médica adecuada una vez solicitan asilo en alguno de los EEMM - con independencia de que estos resulten competentes o no para tramitar esta solicitud y que incluso se extiende al país de acogida-. Las autoridades nacionales deben proveer atención sanitaria como una de las condiciones básicas de acogida, adaptando esta a las particularidades del solicitante y procediendo a realizar un reconocimiento médico. ${ }^{358}$

\footnotetext{
${ }^{357}$ Para un estudio interesante sobre la alta posibilidad de tienen los solicitantes de asilo de sufrir problemas de salud, remitimos a: NORREDAM, M., MYGIND, A., KRASNIK, A., "Access to health care for asylum seekers in the European Union-a comparative study of country policies", European Journal of Public Health, vol. 16, $\mathrm{n}^{\circ}$ 3, June 2006, p. 285.

${ }^{358}$ Véanse el Considerando 31 y los arts. 11 y 13 de la Propuesta de Directiva de Acogida.
} 
Sin embargo, un sector doctrinal del Reino Unido reconoce explícitamente la existencia de deficiencias en el reconocimiento de la protección internacional por cuestiones radicadas en la salud de este colectivo, ${ }^{359}$ principalmente, por problemas relacionados con la falta de entendimiento. Una barrera idiomática en sus relaciones con el personal sanitario que no se solventa cuando estos son reasentados. ${ }^{360}$

En el ámbito del SECA, el intercambio de información de datos sanitarios se encuentra regulado en el art. 32 RD III (art. 33 PRD IV). Un régimen jurídico que pretende abordar estos déficits mediante el tratamiento de esta tipología de datos sensibles por parte del Estado trasladante.

Este se erige, junto a los datos biométricos previstos para los fines de identificación de Eurodac, como una de las principales excepciones a la recopilación de datos sensibles durante una fase anterior al inicio del procedimiento de protección internacional. De tal modo que, esta recopilación no necesariamente resultará exigible como sustento de la propia solicitud de protección internacional, sino de asegurar el cumplimiento de la exigencia de proporcionar asistencia médica adaptada a una situación de riesgo concreta.

Recordemos que la Comisión detalló que los datos relacionados con la salud durante la entrada de los solicitantes en la UE debían manejarse con "suma cautela", 361 evitando decisiones arbitrarias contra el origen étnico, religión, género, etc. y salvaguardando rigurosamente la dignidad, el bienestar, la autonomía, la seguridad y de su seguridad personal como la de sus familiares. Por este motivo, este procesamiento deberá respetar la más alta protección jurídica a la luz del Sistema de Dublín y de la normativa de protección de datos, ateniendo a la necesidad y proporcionalidad de esta información para la consecución de los fines que les son inherentes tal y como regulan los arts. 9 RGPD y 10 de la Directiva de protección de datos en el ámbito penal.

Así, esta disposición favorece al EM competente la prestación de atención básica a los solicitantes con problemas relacionados con su salud, por lo que resultará aplicable a

\footnotetext{
${ }^{359}$ ALLOTEY P., The health of refugees: public health perspectives from crisis to settlement, Oxford: Oxford University Press, 2003; STRONG J, VARADY C, CHAHDA N., "Health status and health needs of older refugees from Syria in Lebanon", Conflict and Health, 2015, vol. 9, $\mathrm{n}^{\circ}$ 1, 2015, p.12.

${ }^{360}$ CHENG I.H., DRILLICH A., SCHATTNER P., "Refugee experiences of general practice in countries of resettlement: a literature review", British Journal of General Practice, $n^{\circ}$ 65, 2015, p. 171.

${ }^{361}$ Comisión Europea, Guidance note - Research on refugees, asylum seekers \& migrants.

Disponible en: http://ec.europa.eu/research/participants/data/ref/h2020/other/hi/guide_research-refugeesmigrants_en.pdf
} 
sujetos especialmente vulnerables -con independencia de su extensión a otras categorías de solicitantes-. Así lo contempla el apartado $1^{\circ}$ al englobar en esta categoría a personas discapacitadas, a personas mayores, mujeres embarazadas, menores y personas que han sido víctimas de torturas, violación u otras formas graves de violencia sexual, física y psicológica. Faculta al EM que proceda al traslado a transmitir al responsable, de conformidad con su derecho nacional, información sobre las necesidades especiales de la persona que deba ser trasladada a través de un certificado médico común junto con los documentos necesarios al efecto. ${ }^{362}$

En vista de la sensibilidad de estos datos, el apartado $2^{\circ}$ regula su intercambio a condición de que el solicitante afectado o la persona que le representa otorgue su consentimiento expreso. Una regla que dispone de dos excepciones:

1) La no voluntad de otorgarlo no impide el efectivo traslado del solicitante, precisamente, para evitar el abuso de derecho en la cesión de estos datos sensibles. Esta cesión únicamente pretende efectuarse a favor de los derechos e intereses de los solicitantes de protección internacional.

2) Las cuestiones que pueden comprometer la salud y seguridad pública en el intercambio de estos datos también resultan ajenos a la exigencia de recabar el consentimiento, precisamente, al tratarse de factores plenamente vinculados a la propia seguridad de los Estados. En este último supuesto, deberá equilibrarse cuidadosamente el propósito o finalidad de la cesión sin el consentimiento con los intereses de protección de los solicitantes y sus implicaciones en la seguridad de los Estados. Precisamente, ante la falta de una definición común en el ámbito del SECA y teniendo en consideración que puede implicar situaciones delicadas, complejas y dispares entre EEMM que resulten incluso contrarias a los intereses propios de los solicitantes de protección internacional.

Para finalizar, este procesamiento está sujeto a las siguientes formalidades:

- Por un lado, se incluye la exigencia de que se lleve a cabo por profesionales de la salud vinculados por la obligación de secreto profesional (apartado $3^{\circ}$ ).

- Por otro, el intercambio deberá preverse únicamente mediante estos sujetos para

\footnotetext{
${ }^{362}$ Asimismo, en la imperiosa necesidad de fomentar esta cesión de información, al igual que el resto de información previa al traslado, podría extenderse la implementación de técnicas eficientes y estandarizadas para el tratamiento de los datos antes del traslado, concretamente la posibilidad de introducir formularios normalizados tal y como dispone el Considerando 34 RD III o el art. 47 PRD VI.
} 
fines exclusivos de proporcionar asistencia sanitaria necesaria (apartado $4^{\mathrm{o}}$ ). Un precepto que tipifica el principio de limitación de la finalidad.

- Finalmente, se atribuye a la Comisión la potestad de dictar actos de ejecución con objeto de adoptar condiciones uniformes y modalidades prácticas para el intercambio de la información (apartado $5^{\circ}$ ).

4.2. El intercambio de información: la cooperación administrativa.

El intercambio de información se encuentra tipificado en toda su extensión en el Capítulo VII (Capítulo VIII PRD IV), que regula su aplicación en el ámbito de la cooperación administrativa. Concretamente, el art. 34 RD III (art. 46 PRD IV) establece que, como regla general, los EEMM deberán comunicar y transmitir los datos personales relativos a un solicitante.

Ahora bien, el primer apartado acota este criterio general por los principios de suficiencia, pertinencia y necesidad. Un supuesto que sufrirá una "transformación esencial" con el PRD IV al adicionar, a los criterios antes mencionados, el principio de minimización de datos del art. 5.1 c) RGPD. Ello implica que la recopilación de datos personales deberá orientarse hacia la consecución de los siguientes tres supuestos:

a) la determinación del EM responsable;

b) el examen de la solicitud de protección internacional;

c) el cumplimiento de cualquiera de las obligaciones derivadas del presente Reglamento (apartados 1 y 7 del art. 34 RD III).

$\mathrm{Su}$ aplicación restringe la actuación de los EEMM, que únicamente deben intercambiar información para los fines anteriormente mencionados, contemplándose diversas limitaciones tendentes a garantizar la protección del solicitante de potenciales efectos negativos. Por ejemplo, retirar una solicitud infundada en el país de origen previo al traslado, contrastar la información para estudiar la viabilidad de la solicitud o determinar un posible abuso de derecho ante información falsa o contradictoria, entre otras. Igualmente, esta protección se extiende a la información que ya ha sido intercambiada, "blindando" y extendiendo la misma al control de los datos susceptibles de intercambio, y de los que ya se encuentran a disposición del EM requirente (apartado $\left.7^{\mathrm{o}}\right)$

El apartado $2^{\circ}$ del mencionado artículo -tanto en la versión del actual RD III como 
PRD IV- exige recopilar la mayor parte de los datos personales del solicitante para el cumplimiento de los objetivos del Sistema de Dublín, esto es, los nombres y apellidos, fecha y lugar de nacimiento, los documentos de identidad y de viaje, datos biométricos previstos en Eurodac, lugares de residencia y los itinerarios de viaje, documentos de residencia o visados expedidos por un EM, lugar donde se presentó la solicitud, fecha de presentación de una eventual solicitud de protección internacional anterior, la fecha de presentación de la solicitud actual, así como la fase alcanzada del procedimiento y, en su caso, la decisión que se haya adoptado. Con ello, el intercambio de datos sensibles concernientes a los motivos invocados por el propio solicitante así como cualquier decisión efectuada al respecto solo podrá requerirse en virtud del principio de necesidad y en favor de los intereses del solicitante (apartado $3^{\circ}$ RD III y PRD IV) siendo vinculantes en dos supuestos:

a) el EM requerido podrá negarse a dar curso a una petición presentada si considera que puede perjudicar los intereses esenciales o poner en peligro la protección de los derechos y libertades de la persona afectada o de cualquier otra persona;

b) la comunicación de los motivos de persecución exige elevar el estándar de protección por lo que quizá en este extremo, debería reforzarse el papel de las autoridades a los efectos de transmisión de información, teniendo en cuenta la necesidad implícita de recabar el consentimiento del interesado.

Sobre esta cuestión, la Decisión $B S$ y RS c. Tribunal de Apelaciones de Refugiados y Ministro de Justicia e Igualdad de Irlanda el 14 de junio de $2017,{ }^{363}$ proporciona una de las escasas y valiosas líneas interpretativas sobre el alcance de este precepto. En este caso, fueron examinadas dos importantes cuestiones en relación con la aplicación del art. 34 RD III. Este Tribunal interpretó que el mencionado artículo no confería un

\footnotetext{
${ }^{363}$ Este caso muestra un ejemplo de eficaz intercambio de información entre este país y el Reino Unido en el marco del régimen de intercambio de información del art. 34 RD III. Concretamente, dos ciudadanos albaneses que vivían en Kosovo y que solicitaron asilo en Irlanda a finales de 2014. Tras llegar a Irlanda, estos solicitantes no proporcionaron datos relativos a su procedencia previa, por lo que la Oficina competente presentó una solicitud de información a las autoridades de Reino Unido en virtud del art. 34 RD III mediante la transmisión de las huellas dactilares de los solicitantes. Las autoridades del Reino Unido indicaron que los solicitantes habían obtenido una visa turista habiendo empleado distintas identificaciones, por lo que se esclareció que este país resultaba competente para conocer sobre la solicitud de asilo. Los solicitantes apelaron esta decisión ante el Tribunal de Apelaciones de Refugiados y posteriormente ante el Tribunal de Apelación, en ambos casos desestimadas. Corte de Apelaciones de Irlanda, Sentencia BS \& RS c. The Refugee Appeals Tribunal \& ors (IECA 179), 14 de junio de 2017. Accesible en: http://www.bailii.org/cgi-bin/format.cgi?doc=/ie/cases/IECA/2017/CA179.html
} 
derecho al solicitante de asilo, sino que únicamente pretendía facilitar el intercambio de información entre los EEMM. Por tanto, el derecho a la tutela judicial efectiva -y más bien, el derecho a un recurso efectivo del art. 27 RD III- no se exponía a ser vulnerado, puesto que, de lo contrario, "un solicitante que no proporcionara toda la información relevante a las autoridades nacionales, podría argumentar posteriormente que el formulario utilizado por las autoridades para buscar información adicional carece de pruebas suficientes al amparo del art. 34 RD III, obstaculizando la transferencia (...), lo que iría en contra de los objetivos del RD III". ${ }^{364}$ Además, este Tribunal rechazó el recurso sobre la vulneración de la protección de datos, ya que la toma de las huellas dactilares y posterior intercambio de esta información con el Reino Unido tenía un interés legítimo, se obtuvo legalmente y fue empleado para los fines que establece el RD III.

Esta Decisión sienta las bases de lo que consideramos que debería ser el criterio que debe regir el futuro Sistema de Dublín, dado que refleja un régimen jurídico que excede del propio interés individual del solicitante de acceder, modificar o suprimir los datos que constan en su expediente hacia otros bienes constitucionales en juego.

El art. 34 RD III (art. 46 PRD IV) impone una serie de límites para la protección efectiva de los solicitantes en relación con el intercambio de información entre autoridades de los distintos EEMM y únicamente permite que la petición de información se envíe de forma individualizada en el contexto de una solicitud de protección internacional (apartado $4^{\circ} \mathrm{RD}$ III o PRD IV). Esto implica una prohibición tácita de comunicación de datos de forma masiva o sobre un grupo de sujetos en concreto, en vista de que han sido llevados a cabo con objeto de aumentar exponencialmente la eficiencia del procedimiento, por ejemplo, por razón de nacionalidad $-\mathrm{y}$, en concreto, tras los flujos exacerbados de migrantes y solicitantes de protección internacional en fronteras exteriores de la UE-. ${ }^{365}$

Además, cuando la petición de información tenga por finalidad la comprobación de la existencia de un criterio que pudiera implicar la responsabilidad del EM requerido, deberán señalarse las pruebas e información pertinente sobre las que se funda, debiendo proceder de fuentes fiables -e independientemente de la determinación de la

\footnotetext{
${ }^{364}$ Véase parágrafos 55 y 56 de la mencionada Sentencia. (La traducción es nuestra).

${ }^{365}$ BAIRD, T., "Functional Actorness? Border Security in the EU and Turkey", International Journal of Public Administration, vol. 38, $\mathrm{n}^{\circ}$ 12, 2015, p. 851.
} 
responsabilidad y la competencia de un EM según el presente Reglamento-.

Frente a esto, no conviene obviar que, el apartado $5^{\circ}$ del PRD IV reduce el plazo del EM requerido para responder de cinco a dos semanas, plazo que podrá exceder mediante causa justificada y con independencia de la obligación de responder aun incumpliendo los plazos señalados. Asimismo, el apartado $6^{\circ}$ recuerda la necesidad de que el intercambio de información a petición de un EM se efectúe solo entre las autoridades que han sido comunicadas a la luz del art. 47, cumpliendo con el principio de limitación de la finalidad y minimización de datos del apartado $7^{\circ}$.

Por lo tanto, el Sistema de Dublín exigirá que la recopilación se realice de forma determinada, explícita y legítima para la consecución de sus objetivos, esto es, la determinación del EM responsable; el examen de la solicitud de protección internacional; y el cumplimiento de cualquiera de las obligaciones derivadas del presente Reglamento. Sin perjuicio de que ulteriormente, esta información no sea tratada de manera incompatible con dichos fines.

Pese a estas garantías en el intercambio de información administrativa, la nueva PR IV no contempla los derechos de los solicitantes de una forma exhaustiva, adoleciendo de los que a continuación se mencionan:

- En primer lugar, no contempla en toda su extensión el respeto al principio de minimización de los datos -ambos sistemas tipifican el criterio de suficiencia en lugar de prever la adecuación de los datos-. Además, el apartado $8^{\circ}$ del art. 34 RD III por el cual establecía la obligación de que el EM que transmitiese los datos cumpliera con criterios de exactitud, se suprime en la PRD IV. Tal es la importancia de este precepto, que su aplicación permite que estos informen a los EM destinatarios, en cualquier momento, para que procedan a su corrección o eliminación, manteniendo los datos actualizados en todo momento.

- En segundo lugar, la PRD IV tampoco dispone que el solicitante tenga derecho a que se le comunique, a petición suya, la información que se haya tratado. Este ostenta el derecho a su rectificación o supresión si se constata que dicha información ha sido tratada infringiendo las disposiciones del presente Reglamento. Se suprime igualmente la posibilidad de que el solicitante ejerza su derecho al recurso ante las autoridades competentes o judiciales del EM que deniegue el derecho de acceso o de rectificación o supresión de los datos que le conciernan (apartado $9^{\circ} \mathrm{RD}$ III). 
- Y para finalizar, el apartado $8^{\circ}$ establece que debe dejarse constancia de la transmisión y la recepción de la información intercambiada en cada uno de los EEMM afectados, en el expediente individual de la persona de que se trate, en un registro o en ambos. Elimina tanto el principio de limitación del plazo de conservación del art. 5.1 e) RGPD que contempla actualmente el apartado $11^{\circ} \mathrm{RD}$ III relativo al periodo de conservación de tales datos, como la adopción de medidas oportunas para garantizar el cumplimiento de la legislación de protección de los datos a través de medios de control efectivos -especialmente, si los datos no se tratan de forma automática, o no figuran ni están destinados a figurar en un expediente- (párrafo $12^{\circ}$ ).

Las carencias en el régimen de cooperación administrativa pretenden "compensar" la imposición de ciertas obligaciones para las autoridades nacionales que contempla la nueva Propuesta. En este sentido, recuérdese, como hemos señalado anteriormente, que el Considerando 17 PRD IV alude a la exigencia de que el primer Estado, pese a no ser competente para el conocimiento de fondo de la solicitud, verifique la admisibilidad de la pretensión con respecto al primer país de asilo y al tercer país seguro. Además, por un lado, insta a que se examinen las solicitudes inadmisibles o que, probablemente, no necesiten protección internacional y por otro, mediante procedimiento acelerado, aquellas que provengan de países de origen seguros indicados en la lista de la UE, así como por solicitantes que puedan colisionar de una forma directa con la seguridad europea. El problema devendrá en que este primer país no esté soportando una carga desproporcional de solicitudes de protección internacional-factor que se prevé solventar con la citada Propuesta- pues, en caso contrario, podría presumirse un conflicto de intereses que obligue a una reevaluación completa de la solicitud por parte del Estado competente.

\section{El derecho a la información en el seca y en su propuesta de reforma.}

5.1. Los déficits del Sistema de Dublín y su impacto en el derecho a la información de los solicitantes de protección internacional.

El control de los datos determina la capacidad de evaluar el riesgo de los distintos sujetos que pretenden entrar a territorio de la UE. En lo que concierne a los solicitantes de protección internacional, estos tienen no solo la obligación de proporcionar diversa tipología de información personal, sino que ostentan su derecho a ser informados 
plenamente de sus derechos, de la finalidad de la información y de las consecuencias. No obstante, como veremos a continuación, este último extremo no se ha proporcionado en multitud de contextos y escenarios, provocando un intercambio de información ineficiente y propicio a que los solicitantes no cooperen en su identificación.

Aún con todo, el art. 4 RD III así como el art. 8 de la Directiva de procedimiento y el art. 29 del Reglamento Eurodac regulan el derecho a la información. Estas disposiciones dotan al procedimiento de protección internacional de una mayor transparencia y confianza por parte de los solicitantes, que deben conocer la información de la que se dispone cuando así fuera posible. El art. 4 RD III y art. 29 del Reglamento de Eurodac (art. 30 PRE) concretan este derecho con el fin de que el solicitante en cuestión conozca la información relativa a su derecho a solicitar protección internacional, los propósitos de tal recopilación además de otorgarle cierta potestad para garantizar el control de sus datos personales. Una información que debe proporcionarse de manera eficiente, lo más completa posible, adaptada a un lenguaje que pudiera razonablemente entender y a la comunicación a cuestiones personales (género, edad, estado físico y mental, nivel educativo, etc.).

Igualmente, debe cumplir con las condiciones de acogida, suministrando la información en el "idioma que entiendan o que sea razonable suponer que entienden", proporcionando un intérprete si resultase necesario (Considerando 25 y art. 8.2 de la PRP). ${ }^{366}$ Es más, como exigió la STJUE Heinz Huber c. Bundesrepublik Deutchland, de 16 de diciembre de 2008, esta prestación debe realizarse tanto de forma oral como escrita. $^{367}$

De este modo, como concreta la EASO, debe asegurarse de que "las personas que quieren solicitar protección internacional sean capaces de hacerlo". ${ }^{368}$ Ahora bien, pese a que el ACNUR constata que la mencionada propuesta mejora la "imparcialidad en el procedimiento", 369 considera que la inclusión de que los solicitantes estén informados en un idioma que realmente entiendan -en lugar de uno que deban entender- presupone

\footnotetext{
${ }^{366}$ De acuerdo con los Considerandos 13, 18, 25, 64 y arts. 8.2 y 3, 12.8, 24.4 y 35.1 de la Propuesta de Reglamento de procedimiento.

${ }^{367}$ TJUE Heinz Huber c. Bundesrepublik Deutchland, de 16 de diciembre de 2008 (Asunto ${ }^{\circ}$ C-524/06)

${ }^{368}$ EASO y FRONTEX, Access to the Asylum. Procedure. What you need to know. Publications Office of the European Union, 2016, p. 17.

${ }^{369}$ ACNUR, Comentarios sobre la Propuesta de la Comisión Europea para un Reglamento de Procedimientos de Asilo, abril de 2019, COM (2016) 467, p. 10. Disponible en: https://www.refworld.org/docid/5cb597a27.html
} 
que un solicitante habla o entiende el idioma oficial de su país de origen, un supuesto no exacto susceptible resultar incorrecto. ${ }^{370}$

Sin esta certeza en el verdadero entendimiento por parte del solicitante de todo aquello que se le comunica, se desvirtúan todos y cada uno de los extremos que deben proporcionarse a los solicitantes de acuerdo con el actual art. 4 RD III y art. 29 Reglamento Eurodac (art. 30 PRE). Por lo que atañe al Reglamento de Dublín, recoge la obligación de reflejar los objetivos del presente Reglamento y las consecuencias de la presentación de otra solicitud en un EM diferente, así como sus posibles consecuencias; los criterios para determinar el Estado miembro responsable, la jerarquía de esos criterios en las diferentes etapas del procedimiento y su duración; la entrevista personal; la posibilidad de impugnar una decisión de traslado; la posibilidad de las autoridades de intercambiar datos sobre la persona con la única finalidad de cumplir sus obligaciones derivadas del presente Reglamento o el ejercicio de los derechos de acceso, rectificación o supresión de los datos. En relación con Eurodac, prevé la identidad del responsable del tratamiento, los fines de tratamiento de sus datos en Eurodac, los destinatarios de los datos o la obligatoriedad de la toma de las impresiones dactilares.

Además, el Sistema de Dublín pretende elevar las garantías en el derecho a prestar información a los solicitantes de asilo, ateniendo a que este colectivo ha sido comúnmente reacio a proporcionar datos personales ante unas condiciones que podemos considerar como "poco propicias". Tanto el art. 4.3 RD III como el. 29.3 de Reglamento Eurodac previeron un folleto común y coherente a nivel europeo que incluyera la información básica a la que hace referencia la mencionada normativa y fuera lo suficientemente flexible para adaptarse a las particularidades de los EEMM, permitiendo a estos adicionar y completar información.

Al margen de este avance, este derecho se ha supeditado a todo un conjunto de actuaciones nacionales que han limitado su efectividad. Ya en el año 2010, un estudio realizado por la Agencia de Derechos Fundamentales (FRA) ${ }^{371}$ advertía de las graves

\footnotetext{
${ }^{370}$ ACNUR, Comentarios sobre la propuesta modificada de la Comisión Europea de Directiva del Parlamento Europeo y del Consejo sobre procedimientos comunes para otorgar y retirar el Estado de protección internacional (refundición) COM (2011) 319 final, enero de 2012,p. 13. Disponible en: https://www.refworld.org/docid/4f3281762.html

${ }^{371}$ European Union Agency for Fundamental Rights, The duty to inform applicants about asylum procedures: the asylum-seeker perspective, 2010.

Accesible en: http://fra.europa.eu/en/publication/2010/duty-inform-applicants-about-asylum-proceduresasylum-seeker-perspective
} 
carencias en el derecho a la información que, paralelamente, comportaba una obstaculización grave al acceso del derecho a la protección internacional. Además, las excepciones en lo que respecta a la divulgación de información o fuentes por motivos de seguridad que disponen el Considerando 12 RD III y el art. 23 de la Directiva de procedimiento, han excluido la obligación por parte de las autoridades nacionales de garantizar el derecho a la información a los solicitantes. Esta falta de efectividad no ha permanecido ajena en la propuesta de reforma del SECA. La exposición de motivos de la PRD IV refleja que la información proporcionada a los solicitantes sobre el procedimiento de Dublín difería considerablemente en función del Estado donde se tramitaba la solicitud, destacando que, frecuentemente, las autoridades nacionales, o bien no proporcionaban la información suficiente, esta resultaba obsoleta o, no era facilitada en tiempo y forma al interesado.

Tras su promulgación, estos déficits fueron constatados por el Comité Económico y Social Europeo, el cual señaló en la Opinión sobre la reforma del SECA, que los Estados debían ser responsables en ofrecer a los solicitantes información detallada y actualizada relativa a los procedimientos del Sistema de Dublín. ${ }^{372}$ Posteriormente, en abril de 2018, tal y como publicó el Informe final denominado INFORM financiado por el Fondo de Asilo, Migración e Integración, se puso de manifiesto que la información continuaba resultando, en mayor parte, compleja para la mayor parte de solicitantes de protección internacional. ${ }^{373}$ Sobre esta advertencia, la EASO publicó ese mismo año un documento informativo que subrayaba, nuevamente, profundos desafíos holísticos en relación con este derecho. Destacó, entre otras, la dificultad para llegar a un colectivo amplio y con grandes disparidades nacionales, lo que exigía destinar mayores esfuerzos nacionales en perfilar y acotar el deber de información. ${ }^{374}$

Sin embargo, la responsabilidad esencial de suministrar información recae en las autoridades de los EEMM, las cuales deben apostar por proporcionar toda la

\footnotetext{
${ }^{372}$ Comité Económico y Social Europeo, Dictamen sobre la Propuesta de Reglamento del Parlamento Europeo y del Consejo por el que se establecen los criterios y mecanismos de determinación del EM responsable del examen de una solicitud de protección internacional presentada en uno de los EEMM por un nacional de un tercer país o un apátrida (texto refundido) [COM(2016) 270 final - 2016/0133(COD)], SOC/543, 19 de octubre de 2016.

${ }^{373}$ The People for Change Foundation, Legal and Procedural Information for Asylum Seekers in Europe: Comparative Report, abril de 2018. Disponible en: https://www.informasylum.eu/uploads/1/2/1/7/12176018/midj6040_middlesex-uni-asylum-comparative-report-web_1_.pdf ${ }^{374}$ Oficina Europea de Apoyo al Asilo (EASO), Briefing Paper. Access to Information in the Context of Asylum: Exploring Existing Resources, Good Practices and Ways Forward, 2018, p. 21.
} 
información necesaria y pertinente a los solicitantes de asilo previamente al acceso al procedimiento. Los nacionales de terceros países deben estar informados sobre todos aquellos aspectos relevantes que afectan a sus datos personales y, en todo caso, deberían procesarse de manera transparente, inteligible y de forma fácilmente comprensible tal y como prevé el art. 12 RGPD. Lo manifestado con anterioridad exigirá la adopción de todo un conjunto de acciones que, como veremos a continuación, pretenden elevar los estándares del derecho a la información con miras a superar este generalizado desconocimiento de la información y que, en los últimos años, han abordado tanto el ICF como los Informes de AIDA. ${ }^{375}$ Ello en vista de que la propuesta prevé escasos avances en este sentido pues no resultará ajena a potenciales conflictos jurídicos en su conexión con el derecho a la protección de datos de los interesados.

5.2. El derecho a recibir información en la propuesta de Reglamento de Dublín IV: un derecho condicionado por el deber de cooperación.

El derecho a recibir información en el ámbito de la protección internacional puede catalogarse como una de las disciplinas más afectadas tras las grandes afluencias de sujetos en fronteras exteriores que se produjeron entre los años 2014 a 2016. Estas circunstancias obstaculizaron el ejercicio efectivo de este derecho, articulándose como un límite a la imperante necesidad de gestionar eficientemente las solicitudes de protección internacional. Y pese a que la propuesta de reforma del SECA dispone de excepciones radicadas en seguridad en relación con el intercambio de información en el Considerando 33 PRD IV y art. 16.2 PRR, ${ }^{376}$ las dificultades burocráticas y logísticas

\footnotetext{
${ }^{375}$ Estos informes advirtieron la estructural carencia de comprensión de la información sobre el procedimiento de Dublín en la mayor parte de los EEMM. En el contexto de la evaluación del RD III, los comentarios de los expertos nacionales de Alemania, Grecia o Italia señalaron que era probable que los solicitantes no comprendieran correctamente la información proporcionada, teniendo en cuenta la complejidad del procedimiento de Dublín. Information and Cooperation Forum (ICF), Evaluation of the implementation of the Dublin III Regulation, March 2016, p. 11.). Por lo que concierne a los Informes nacionales de AIDA, también alertaban que la información proporcionada a los solicitantes resultaba incompleta en países como Francia, Hungría o Reino Unido. Para mayor información acerca de los Informes, véase: Asylum Information Database (AIDA) Country Report France: Fourth Update, December 2015, p. 54; Country Report Hungary: Fourth Update, November 2015, p. 35 o Country Report UK: Fourth Update, November 2015, p. 46.

${ }^{376}$ En estos casos, el Considerando 33 PRD IV dispone la necesidad de "establecer normas apropiadas" en relación con el intercambio de información en aquellos supuestos en los que existe razones fundados para considerar que un solicitante constituye un peligro para la seguridad nacional o el orden público. Asimismo, el art. 16.2 PRR deniega el acceso a la información del solicitante en los supuestos en que la divulgación de información o de fuentes comprometa la seguridad nacional.
} 
inherentes a la exigencia de proporcionar información por parte de las autoridades nacionales pretenden supeditarse a la inexcusable obligación de cooperación de los solicitantes de protección internacional. Ello, tras destacarse por parte de un sector doctrinal que, este colectivo, no era proclive a participar y colaborar durante este proceso de información, propiciando "deficiencias sistemáticas" tendentes a la desafección y al auge de los movimientos secundarios. ${ }^{377}$

Estas parecen que fueron las razones que llevaron a que la reforma del Sistema de Dublín contemple la información como un derecho del solicitante (art. 6 PRD IV), subordinado a la obligación recíproca de cooperación. De esta forma, los solicitantes deben proporcionar todos los datos, elementos e información a su alcance (art. 4 PRD IV), irrumpiendo la exigencia de un esquema de "cooperación mutua" entre las autoridades competentes de los EEMM y los solicitantes de protección internacional (art. 4.2 PRD IV).

No obstante, esta novedosa disposición no resulta ajena a diversos conflictos jurídicos. La excesiva amplitud de esta disposición puede restringir, de una forma excesiva, la libertad del solicitante al requerir, precisamente, que se presente "tan pronto como sea posible" y, a más tardar, durante la entrevista personal, todos y cada uno de los elementos y la información pertinente para la determinación del EM responsable. Y sobre esta cuestión, se advierte que, en caso contrario, podrían aplicarse las consecuencias del incumplimiento previstas en el art 5 PRD IV, esto es, el sometimiento al procedimiento acelerado. En este sentido, se requiere tanto que el sujeto actúe de buena fe, cooperando y proporcionando toda la información en su haber y con la máxima diligencia debida, atribuyendo a las obligaciones del solicitante un carácter coercitivo.

Estos plazos considerablemente breves y estrictos mostraron la preocupación del Consejo de la Abogacía Europea (CCBE), que recomendó la inclusión de garantías procesales más sólidas y favorables que permitieran establecer un plazo razonable para

\footnotetext{
${ }^{377}$ Estas deficiencias sistemáticas fueron abordadas por parte de un amplio sector doctrinal en relación con la nueva propuesta de reformal del SECA. Véase: DEN HEIJER, M., RIJPMA, J., SPIJKERBOER, T., "Coercion, Prohibition, and Great Expectations: The Continuing Failure of the Common European Asylum System", Common Market Law Review, $\mathrm{n}^{\circ}$ 53, 2016, p. 627; VEDSTED-HANSEN, J., "Reception conditions as human rights: pan-European standard or systemic deficiencies?" en CHETAIL, V., DE BRUYCKER P., MAIANI F. (eds.), Reforming the Common European Asylum System..., ob. cit, pp. 319-324.
} 
la presentación de pruebas. ${ }^{378}$ Además, esta disposición adolece de una falta de concreción, pues no alude específicamente al tipo de información omitida ni tiene en cuenta cuestiones personales que podrían justificar un posible incumplimiento de estas obligaciones. Ello puede comprometer seriamente la propia viabilidad de la solicitud de protección internacional y contrariar los “estándares de protección mejorados” de la propuesta del SECA. Tanto es así, que el ECRE recomendaba proporcionar una definición detallada acerca de los "elementos" e "información" que se esperan obtener del solicitante durante la entrevista. ${ }^{379}$

Por ello, una posible omisión de información a estos efectos debería resultar grave y de considerable entidad, de forma que desvirtúe la protección del Estado de acogida o incluso comprometa su propia seguridad, ponderándose igualmente en relación con las circunstancias concretas del sujeto (problemas psicológicos como consecuencia de la persecución sufrida, la edad del solicitante, su posible falta de confianza, etc.).

En esta misma línea, el art. 6 a) PRD IV establece la necesidad de que se dé a conocer al solicitante la irrelevancia de su elección del EM para que conozca del examen de la solicitud de protección internacional. Y muestra del similar carácter restrictivo, el apartado b) adiciona que, en el supuesto de que el solicitante abandonara el EM competente, no tendrá derecho a las condiciones de acogida en otro distinto. ${ }^{380}$ De nuevo, esta disposición, que excluye la asistencia sanitaria de emergencia, persigue disuadir y reducir drásticamente los movimientos secundarios, sin tener en cuenta otros parámetros que justifiquen la no aplicación de los derechos de acogida.

Finalmente, la nueva PRD IV mantiene el derecho a la información, que se extiende a los criterios y procedimientos en cada una de las fases (apartado c). En todo caso, deberá constar su duración y el progresivo mantenimiento, así como una entrevista personal (apartado d), donde los solicitantes tendrán la obligación de presentar y probar la información sobre la presencia de miembros de la familia en el EM -el carácter

\footnotetext{
${ }^{378}$ Consejo de la Abogacía Europea (CCBE), Comentarios sobre la propuesta de la Comisión de Reglamento por el que se establecen los criterios y mecanismos para determinar el Estado miembro responsable del examen de una solicitud de protección internacional presentada en uno de los Estados miembros por un nacional de un tercer país o un apátrida (versión refundida) - COM (2016) 270, p. 8.

${ }^{379}$ ECRE, Comentarios sobre la propuesta de la Comisión sobre el Reglamento Dublín IV COM(2016) 270, octubre de 2016, p. 21. Disponible en: https://www.ecre.org/wp-content/uploads/2016/10/ECREComments-Dublin-IV.pdf

${ }^{380} \mathrm{La}$ sustitución, reducción o retirada de las condiciones materiales de acogida se contemplan en el art. 19 de la Directiva de Acogida y art. 20 de su propuesta de reforma.
} 
potestativo requerido hasta ahora se excluye en la nueva propuesta-. También, prevé la posibilidad de impugnar una decisión de traslado (letra e) PRD IV bajo supuestos muy concretos como las violaciones de derechos humanos o el riesgo de sufrir tratos inhumanos o degradantes.

Por su parte, el enfoque manifiestamente restrictivo de la vigente Directiva también pretende "compensarse" por medio de la ampliación de los derechos de información que prevé el art. 30.2 PRE, esto es: proporcionar datos de contacto del responsable de la protección de datos, las categorías de destinatarios de datos, período durante el que se conservarán los datos o el derecho a solicitar del responsable del tratamiento que se completen los datos personales incompletos -incluyendo la identidad del responsable de la protección de datos en el folleto básico comentado anteriormente-.

Por todo ello, la mencionada propuesta parece supeditar el deber de información de las autoridades a la cooperación activa de los solicitantes de asilo. Sin embargo, deberían ser las autoridades las que cumplan con su deber de información desde el inicio, esto es, inmediatamente después de que se haya presentado la solicitud de asilo. La lectura de los derechos a los solicitantes en este momento resultará fundamental para aumentar la generalizada desconfianza y trasparencia en el procedimiento de protección internacional. Por lo tanto, este cumplimiento de forma proactiva debería llevarse a cabo sin supeditar las actuaciones nacionales a conductas personales reprochables sobre las cuales, el solicitante no es plenamente consciente de sus efectos en el marco del procedimiento.

5.3. Los derechos de acceso, rectificación y supresión en el "Sistema de Dublín”.

El Sistema de Dublín prevé todo un conjunto de acciones destinadas a proteger los datos personales de los solicitantes de protección internacional. En similares términos que disponía el intercambio de información antes de la ejecución previamente a una decisión de traslado o en la cooperación administrativa, el art. 4 e) RD III reitera, de un modo explícito, la limitación de tratamiento datos personales, uno de los principios más básicos y estructurales de la legislación de protección de datos.

En este sentido, las autoridades competentes de los EEMM deben intercambiar información relativa a los solicitantes con la única finalidad de cumplir con las obligaciones derivadas del presente Reglamento. Un sometimiento que la nueva PRD 
IV adhiere, de igual manera, a la nueva AAUE (letra f), el organismo gestor de información en el ámbito del asilo. Y pese a que nada establece el Sistema de Dublín, esta limitación en el tratamiento de los datos deberá transmitirse a los interesados en coherencia con el art. 31.1 PRE, el cual remite a las disposiciones del RGPD y exige este deber de comunicación de los datos personales registrados en el Sistema Central.

Por lo tanto, las autoridades deberán dar traslado de los datos que consten en sus expedientes nacionales -de acuerdo con Dublín-, como a nivel central -por parte del Sistema de Información Eurodac-, respetando, en todo caso, el contenido del art. 18 RGPD, que exige la aplicación de este principio en los siguientes supuestos.

- En primer lugar, el responsable del tratamiento deberá comunicar al solicitante la limitación del tratamiento en una gran diversidad de supuestos y que incluyen: que este haya solicitado la impugnación de la exactitud de los datos personales;

- En segundo lugar, cuando se oponga a la supresión de los datos personales y solicite la limitación de su uso sobre un tratamiento ilícito;

- En tercer lugar, cuando los datos no resulten ya necesarios pero el solicitante los necesite para la formulación, el ejercicio o la defensa de acciones en el ámbito del SECA;

- Finalmente, cuando el interesado hubiera ejercitado su oposición al tratamiento de sus datos, durante el lapso de tiempo que se verifica si la concurrencia de motivos legítimos del responsable prevalecen sobre los del sujeto en cuestión.

En este sentido, para garantizar esta limitación de tratamiento será necesario potenciar la escasa e ineficiente cooperación y comunicación entre las autoridades con los solicitantes de protección internacional, de forma que se incremente la escasa seguridad jurídica del procesamiento a la luz del actual SECA. Tal ha sido su relevancia que, en la Opinión del SEPD sobre la reforma del SECA en relación con el Sistema de Dublín, ${ }^{381}$ deberían ser incorporados mayores referencias al ámbito de la protección de datos en el texto final del Reglamento.

Este principio se extiende al derecho a la información que recoge el art. 4 RD III (art. 6 PRD), disponiendo también un conjunto de acciones nacionales destinadas a

${ }^{381}$ SEPD, "Opinion on the First reform package on the Common European... ob. cit, 21 de septiembre de 2016. 
garantizar los derechos para los interesados, concretamente, la previsión de los derechos de acceso, rectificación o supresión (letra f del RD III y art. 31 PRE), así como la adopción de procedimientos para el ejercicio de tales derechos, incluidos los datos de contacto de las autoridades encargadas del cumplimiento de las obligaciones derivadas del presente Reglamento, las autoridades nacionales de protección de datos y, tal y como añade la PRD IV en el art. 6.1 letra h), los datos de contacto del responsable de protección de datos.

Se conforma un Sistema de Dublín que debe proporcionar estos derechos -con la única excepción general de oposición- además de exigir a los EEMM la adopción de procedimientos específicos que publiciten los datos de contacto del responsable de protección de datos, así como las autoridades nacionales de protección de datos. Una disposición que persigue atender las reclamaciones relativas a la protección de datos personales (art. $6.1 \mathrm{~h}$ PRD IV). El problema radica en que este sistema únicamente prevé estos derechos, sin que sean desarrollados en toda su extensión en los distintos instrumentos normativos del SECA. Por tanto, resulta ineludible acometer un análisis jurídico del contenido de estos derechos a la luz de la normativa de protección de datos.

Por lo que concierne al ejercicio del derecho de acceso, el responsable debe otorgarlo al interesado para conocer no solo sobre el tratamiento de sus datos, sino su derecho de acceso a los datos personales sobre distintos extremos como: “a) los fines del tratamiento; b) las categorías de datos personales de que se trate; c) los destinatarios o las categorías de destinatarios a los que se comunicaron o serán comunicados los datos personales, en particular destinatarios en terceros $\mathrm{u}$ organizaciones internacionales; (...); e) la existencia del derecho a solicitar del responsable la rectificación o supresión de datos personales o la limitación del tratamiento de datos personales relativos al interesado" (art. 15 RGPD).

Además, este derecho presenta unas particulares de necesaria adopción en lo que a los solicitantes de protección internacional se refiere. Por un lado, la letra g) RGPD dispone que, si los datos personales no se han obtenido directamente del interesado, deberá proporcionarse información disponible sobre su origen. Este extremo no deberá facultar, bajo ninguna circunstancia, a solicitar información sobre los países de origen. En caso contrario, supondría lo que consideramos una violación del "principio de devolución virtual o telemático", con los derivados riesgos para el solicitante o las personas relacionadas con este o esta. Por esta razón, deberá aplicarse de forma 
restringida, entendiendo por origen aquellos datos almacenados en la base de datos Eurodac y que permitan constatar los "primeros" datos del solicitante que fueron procesados, es decir, aquellos que se originaron el momento en el que el sujeto entró en territorio de alguno de los EEMM.

Por otro lado, también exige facilitar una copia de los datos personales objeto de tratamiento que deberá adaptarse, en todo caso, al lenguaje que conozca o entienda el interesado, siendo igualmente un servicio proporcionado de manera gratuita tal y como prevé el art. 15.2 y 3 RGPD en relación con el art. 6.2 PRD IV. Estos constituyen imperiosos elementos intrínsecos que facultan a la preparación de la entrevista personal o, incluso, la capacidad para apelar contra cualquier decisión desestimatoria o restrictiva de derechos. Deberán, por tanto, suministrarse en tiempo y forma para garantizar ejercicio eficaz del derecho de acceso a la información. Una situación que ha resultado aparentemente compleja en países como Bélgica, donde las autoridades se han mostrado reticentes a emitir una copia del cuestionario a los solicitantes, atribuyéndoles una intolerable "presunción de mala fe" basada en la posible utilización de estas copias para corregir las incongruencias en sus historias no contrastadas e incluso inventadas. ${ }^{382}$

Pero lo cierto es que todas estas condiciones necesarias para garantizar el acceso a la información personal se erigen como facultades intrínsecas para ejercer igualmente el derecho a la rectificación de aquellos datos que resulten incompletos o inexactos (art. 16 RGPD) e incluso la supresión de los mismos (art. 17 RGPD). Unas causas que el Sistema de Dublín amplía a lo supuestos de tratamiento ilegal de los datos (art. 4.1 f) RD III o 6.1 h) PRD IV).

Estos derechos permiten contrastar tanto la información que consta en el expediente como aquella facilitada por el solicitante y, en su caso, proceder a la corrección o eliminación de aquellos datos inexactos o incorrectos tanto de oficio como a instancia del sujeto interesado. Igualmente, deberá procederse sin demora, permitiendo ejercer dicho derecho con facilidad y a intervalos razonables, con el fin de conocer y verificar la licitud del tratamiento, ${ }^{383}$ garantizando el cumplimiento del principio de exactitud y limitación de la finalidad, aspectos esenciales en el Sistema de Dublín en materia de protección de datos.

\footnotetext{
${ }^{382}$ Rapport intérimaire de la Commission chargée de l'évaluation de la politique du retour volontaire et de l'éloignement forcé d'étrangers présenté au Ministre de l'Asile et de Migration le 22 février 2019, p. 53. Accesible en: https://bit.ly/2TKdcwP (únicamente en francés).

${ }^{383} \mathrm{Tal}$ y como así disponen los Considerandos 59 y 63 RGPD.
} 
Además de Dublín, la PRE también prevé que los derechos de rectificación y oposición puedan ejercerse en un EM distinto al que transmitió los datos; el art. 31.2 exige que las autoridades nacionales se pongan en contacto con las del EM que haya transmitido los datos para que se compruebe la exactitud y la legalidad de su transmisión y registro en el Sistema Central. Y, en el que caso de que se constate que los datos registrados en el Sistema Central son inexactos o fueron registrados ilícitamente, el EM que los haya transmitido los rectificará o suprimirá, debiendo informar por escrito al sujeto de los datos para rectificar, completar, suprimir, o restringir el tratamiento de los datos personales que guarden relación con él conforme al art. 31.3.

En el supuesto de que el EM que transmitió tales datos no acepte su inexactitud o ilicitud, deberá motivarlo tanto al EM requirente como al solicitante (art. 31.4), sin perjuicio de todas las formalidades que prevé el mencionado artículo como la exigencia de proporcionar la información necesaria para identificar al sujeto de los datos (31.5), el deber de colaboración entre autoridades nacionales para que puedan ejercerse tales derechos de una forma eficiente y ágil (31.6), la consignación de acceso en un registro que documente por escrito que dicha solicitud se ha presentado y de qué manera se ha tratado (31.7). Por último, la APD que haya transmitido los datos y la del EM en que esté presente el solicitante, facilitará esta información para proceder al ejercicio del derecho, rectificación, oposición o restricción del tratamiento de datos personales que le conciernan, de acuerdo con las reglas de cooperación del Capítulo VII RGPD (art. $31.8)$.

Por lo tanto, el futuro Sistema de Dublín únicamente deberá excluir la oposición a los datos si, en el momento que se solicita protección internacional, concurren diversos motivos legítimos que habilitan al responsable nacional al tratamiento de su información, prevaleciendo esta a los derechos e intereses personales del sujeto en cuestión. Además, el ejercicio de los derechos de acceso, rectificación o supresión no resultarán, en modo alguno, absolutos. El Considerando 73 y art. 23 RGPD prevén limitaciones basadas en "objetivos importantes de interés público general de la Unión o de un EM, en particular un importante interés económico o financiero (...)” como la salvaguarda de la seguridad del Estado o su defensa. Limitaciones que, en todo caso, deberán aplicarse de forma excepcional, siempre y cuando constituya una medida adoptada bajo los principios de necesidad y proporcionalidad. 
Asimismo, en su relación con la Directiva de protección de datos en el ámbito penal, esta prevé limitaciones en el derecho de acceso (art. 15.1 d)) y en la rectificación o supresión (art. 16.4 d)) por cuestiones radicadas en seguridad nacional. Ello, sin perjuicio de que el Considerando 40 prevea la restricción en el ejercicio de estos derechos, si las solicitudes son manifiestamente infundadas o excesivas, como cuando el interesado solicita información de forma "poco razonable y repetitiva o abusa de su derecho a recibir información”. Además, si este proporciona información falsa o engañosa al presentar la solicitud, el responsable del tratamiento podrá negarse a dar curso a la solicitud.

Al margen de estos derechos, la PRD IV incluye - por primera vez- el derecho que ostentan los solicitantes a conocer las categorías de sus datos personales (letra g) y, cuando resulte necesario, el procedimiento de asignación familiar (letra i). No obstante, quizá dentro de este alcance, hubiera resultado más apropiado la inclusión de la ampliación al conocimiento de los fines para los que se tratan, el plazo de tratamiento, así como los destinatarios concretos. También, en el hipotético supuesto que esa información se base en la elaboración de perfiles, deberían establecerse las consecuencias de dicho tratamiento, un supuesto carente en el Sistema de Dublín y sobre el que deben establecerse pautas al respecto. ${ }^{384}$

Pese a todo, estas novedosas disposiciones aumentarán la transparencia en el seno del procedimiento, otorgando a los interesados un haz de facultades sobre el conocimiento y control de las distintas categorías de datos almacenados y superando la generalizada falta de confianza de los solicitantes en el procedimiento en el que las autoridades procesan la información. Ello teniendo en cuenta tanto la especial sensibilidad como la posición vulnerable de una parte de los interesados.

\section{El procesamiento de información y protección de datos por parte de las} agencias de la UE.

\footnotetext{
${ }^{384}$ Sobre el particular, remitimos a: JANS J., Profiling of asylum seekers, The Office of the Commissioner-general for Refugees and Stateless persons, 2010. Accesible en: https://www.unhcr.org/50aa05599.pdf y DIAZ LAFUENTE J., "Los desafíos de la sociedad global digitalizada y la protección de datos personales. Análisis de la elaboración de perfiles en el Reglamento General de Protección de Datos de la Unión Europea”, en GARCÍA MAHAMUT R., TOMÁS MALlÉN, B. (eds.), El Reglamento General de Protección de Datos... ob. cit, pp. 287-309.
} 
6.1. Las implicaciones para la protección de los datos en la transformación de la actual Oficina Europea de Apoyo al Asilo (EASO) en la novedosa Agencia de Asilo de la Unión Europea (AAUE).

6.1.1. De la falta de efectividad de la EASO al papel de la futura Agencia en el tratamiento de la información personal.

La Oficina Europea de Apoyo al Asilo (EASO), regulado por el vigente Reglamento $2010 / 439,{ }^{385}$ ha constituido uno de los organismos asistenciales por excelencia de los EEMM. Desde su creación, ha "institucionalizado" la cooperación práctica en el ámbito del asilo. ${ }^{386}$ No obstante, a esta Agencia se le han atribuido una serie de funciones de carácter operacional y no ejecutivas, contemplando la gestión e intercambio de información especializada en asilo como uno de sus ejes vertebrales de su funcionamiento. ${ }^{387}$ Unas actuaciones excesivamente amplias que fueron catalogadas de "heterogéneas" 388 y que han abarcado desde facultades de gestión, procesamiento e intercambio de datos relevantes sobre los países de origen, así como la difusión del conocimiento sobre la ley de asilo de la UE. Asimismo, comprendiendo el apoyo a los EEMM que se han enfrentado a serias dificultades en sus sistemas nacionales de asilo incluso a través del despliegue de equipos de apoyo de emergencia-.

Tal fue el papel de la EASO en la intensificación de la cooperación práctica que, en la Agenda Europea de Migración del año 2015 -la primera anteriormente a la de 2017-, la Comisión reconoció su importancia como un verdadero "centro de información sobre los países de origen para fomentar la toma de decisiones más uniformes, adoptar medidas fundamentales en materia de formación y crear redes especializadas de autoridades nacionales para mejorar la cooperación operativa en materia de asilo". 389

\footnotetext{
${ }^{385}$ Reglamento (UE) n ${ }^{\circ}$ 2010/439 del Parlamento Europeo y del Consejo, de 19 de mayo de 2010, por el que se crea una Oficina Europea de Apoyo al Asilo. DO L 132, 29.5.2010, p. 11-28.

${ }^{386}$ TSOURDI, L., "Bottom-up Salvation? From Practical Cooperation Towards Joint Implementation Through the European Asylum Support Office", European Papers: a Journal on Law and Integration, vol. $1, \mathrm{n}^{\mathrm{o}} 3,2016$, pp. 998.

${ }^{387}$ Una carencia en la toma de decisiones en la que se apunta a razones políticas, presupuestarias y de mera eficiencia. COMTE, F., "A New Agency Is Born in the European Union: The European Asylum Support Office", European Journal of Migration and Law, vol. 12, n 4, 2010, p. 381.

${ }^{388}$ CRAIG, P., EU Administrative Law, Oxford: Oxford University Press, 2012, p. 149.; GRILLER, S., ORATOR, A., "Everything Under Control? The "Way Forward" for European Agencies in the Footsteps of the Meroni Doctrine", European Law Review, 2010, p. 1

${ }^{389}$ Comisión Europea, Comunicación de la Comisión al Parlamento Europeo, al Consejo, al Comité Económico y Social Europeo y al Comité de las Regiones una Agenda Europea de Migración, $\operatorname{COM}(2015) 240$ final, 13 de mayo de 2015.
} 
Un año más tarde, el Consejo abogaba por la necesidad de implementar un proceso de producción de información sobre los países de origen de la EASO más estructurado, racionalizado y común a los principales países de origen e instaba a reforzar los recursos disponibles para la producción de información sobre los países de origen. ${ }^{390}$

Sin embargo, el funcionamiento de la EASO no ha resultado ajeno a críticas de enorme calado. Esta oficina se ha visto condicionada por la realización de actuaciones que, con asiduidad, han vulnerado la normativa de protección de datos que regula su propio Reglamento, el cual prevé en el Considerando 28 y art. 42.4 la "obviedad" de que el tratamiento de datos personales debe efectuarse con arreglo al derogado Reglamento 2001/45. Además, especial advertencia merece que la protección de datos no ha sido abordada en ninguno de los informes anuales de la EASO $^{391}$ evidenciando el escaso interés por el pleno respeto de la normativa de protección de datos. Actualmente, está abierta una investigación por parte del Defensor del Pueblo Europeo por una presunta participación de la EASO en el procedimiento acelerado de frontera por vía rápida así como un seguimiento de las denuncias de los funcionarios de la EASO que toman decisiones contrarias a su propio Reglamento de funcionamiento. ${ }^{392}$

Ahora bien, estos enormes déficits pretenden solventarse "parcialmente" gracias al despliegue de la futura Agencia de Asilo de la Unión Europea (AAUE). A finales de 2018, fue publicada su propuesta de Reglamento, ${ }^{393}$ la cual, no implica una mera modificación de la actual EASO, sino toda una "verdadera transformación" de esta Agencia en un centro puntero de conocimientos propios e independientes de la información técnica que disponen los EEMM. Esta gozará de facultades autónomas que, si bien facilitarán un mejorado funcionamiento del SECA, también resultarán susceptibles de generar una serie de potenciales riesgos en relación con la protección de la información personal.

\footnotetext{
${ }^{390}$ Consejo de la Unión Europea, Conclusiones del Consejo sobre la convergencia en las prácticas de asilo, 21 de abril de 2016, 8210/16 (ASIM 58).

${ }^{391}$ En especial, ni siquiera el ultimo informe alude a los graves problemas de cumplimiento de esta agencia de las normas básicas de protección de datos. EASO, Annual Report 2018, 24 de junio de 2019.

${ }^{392}$ Federación Europea de Sindicatos de Servicios Públicos (EPSU), European Court of Auditors finds irregularities in EASO and FRONTEX spending, 16 de octubre de 2018. Disponible en: https://www.epsu.org/article/european-court-auditors-finds-irregularities-easo-and-frontex-spending

${ }^{393}$ Propuesta de Reglamento relativo a la Agencia de Asilo de la Unión Europea..., ob. cit., $\mathrm{COM} / 2016 / 0271$ final.
} 
En esta línea, la exposición de motivos de la propuesta del Sistema de Dublín, ${ }^{394}$ ya preveía una reforma integral de este organismo, fundamentalmente, ateniendo al "modesto papel" que ha desempeñado la EASO y la falta de unas pautas claras sobre cómo gestionar y procesar la información que obtiene y recibe. Una reforma que pivota sobre la necesidad de "descentralizar" el intercambio de información entre las autoridades nacionales, convirtiendo a esta Agencia en el centro neurálgico de conocimiento y análisis del fenómeno migratorio vinculado al asilo.

Además, las referencias en la propuesta de Reglamento de la AAUE sobre la necesidad de mejorar y reforzar la cooperación práctica y el intercambio de información constituirá uno de los aspectos más relevantes cuando efectivamente entre en funcionamiento. En la consecución de estos objetivos, la AAUE se erigirá como piedra angular en la cooperación práctica y labor de apoyo entre EEMM, tal y como disponen los arts. 2.1 a) y 3. Se llevará a cabo una producción más estructurada y racional y una agrupación de la información sobre la situación en los países de origen mediante las redes europeas específicas al efecto que evite la duplicación de esfuerzos con los EEMM y garantice una "pionera convergencia" en la evaluación de las solicitudes de protección internacional (Considerando 11).

En este sentido, la Agencia incorpora como núcleo duro de su funcionamiento el procesamiento de una gran tipología de información para garantizar la asistencia operativa y técnica (Considerando 15), así como el despliegue de expertos propios para ayudar a las autoridades nacionales a recibir, registrar, examinar las solicitudes de protección internacional y facilitar la información actualizada sobre terceros países incluidos los países de origen-.

Además, sus actuaciones resultarán cruciales para las autoridades decisorias. Estas emplearán, en buena medida, toda la información relevante, precisa y actualizada proporcionada sobre la situación que impera en el país de origen del solicitante (Considerando 30) como sustento de la propia solicitud de protección internacional. Para la consecución de estos objetivos, alude al tratamiento de datos personales para desempeñar sus tareas de asistencia técnicas y operativas a los EEMM con la intención de propiciar un contexto que fomente el eficaz intercambio de información con los EEMM (Considerando 35 y 39).

\footnotetext{
${ }^{394}$ Propuesta de Reglamento por el que se establecen los criterios y mecanismos... ob. cit., p. 3. 2016/0133 (COD).
} 
El papel de la AAUE revestirá consecuencias de considerable entidad en el tratamiento e intercambio de información de personal, cuyo impacto en la protección de los solicitantes de protección internacional vendrá afectado, trasversalmente, sobre los siguientes extremos:

1. En relación con el procesamiento de información, esta Agencia ostentará un papel ejecutor del nuevo Sistema de Dublín IV. La AAUE deberá colaborar no solo en la red de unidades de Dublín para mejorar la cooperación práctica y el intercambio de información sobre todos los asuntos relacionados con la aplicación de este sistema (art. 49 PRD IV), sino que asumirá el actual mecanismo de alerta rápida y capacidad de respuesta o el establecimiento de la clave de referencia (art. 35 PRD IV) y su acceso al sistema automatizado (art. 45 PRD IV). Además, exigirá que la Comisión adopte actos de ejecución para garantizar canales de transmisión electrónica seguros entre las autoridades nacionales con la Agencia para transmitir información y datos dactiloscópicos obtenidos con arreglo a Eurodac (art. 47.4 PRD IV).

2. Sobre la evaluación y catalogación de terceros países como "seguros", la Agencia proporcionará sus opiniones a la Comisión sobre este punto. Tal y como prevé el art. 11 de la propuesta, la Agencia ayudará a la Comisión a revisar de forma periódica la situación en terceros países contemplados en la lista común de la UE como países de origen seguros. Incluso, cuando la Comisión considere incluir otro tercer país a la lista, podrá recabar información procedente de la Agencia sobre el tercer país en cuestión. En definitiva, la propuesta del SECA pretende que la Agencia se convierta en un verdadero organismo de "conocimiento especializado", como así parece reflejarlo el Considerando 12.

3. La Agencia proporcionará asistencia operativa y técnica a petición de los EEMM o por iniciativa propia. Y pese a que la decisión final corresponderá, en última instancia, a los EEMM, los datos facilitados por la AAUE abarcarán desde la identificación y registro de solicitantes de asilo, asistencia o realización de entrevistas tanto de admisibilidad como de fondo, la preparación de decisiones administrativas sobre solicitudes de protección internacional, el apoyo logístico o servicios de interpretación y traducción o el despliegue de equipos de apoyo de asilo (art. 16 y 16 bis de la propuesta de Reglamento de la Agencia).

Con ello, las autoridades nacionales basarán el sustento de sus decisiones, en buena medida, en la información proporcionada por la Agencia, incluso coexiste una 
progresiva cesión de la soberanía de los EEMM que incluso, a largo plazo, podría apartar a las autoridades nacionales y adoptar por ellas mismas la función principal de tomar decisiones en primera instancia sobre las solicitudes de asilo, aunque la Comisión reconoce de manera realista que esta perspectiva se encuentra en un horizonte lejano. ${ }^{395}$

6.1.2. El novedoso régimen jurídico aplicable en el tratamiento de la información de la Agencia de Asilo de la UE.

Por lo que respecta al régimen jurídico aplicable en el tratamiento de la información y datos personales de esta Agencia, ni la Comisión ni la doctrina comunitaria se ha adentrado en proporcionar pautas claras sobre el alcance de las actividades de la actual EASO en el derecho a la protección de datos de carácter personal -mucho menos, de la futura AAUE-.

Sobre esta cuestión, la actual EASO dispone de una nota informativa acerca del tratamiento de los datos de los usuarios la cual establece que únicamente recaban datos "de mera información" y otorga al interesado el derecho de acceso, rectificación o supresión de los datos en su poder. ${ }^{396} \mathrm{Sin}$ embargo, como hemos señalado con anterioridad, su propio Reglamento no ha contemplado disposiciones específicas sobre la necesidad de proteger los datos personales que obtiene en el transcurso de sus operaciones, remitiendo únicamente a criterios de subsidiariedad del Reglamento $2001 / 45$

Las novedosas incorporaciones que la nueva Agencia pretende adoptar en materia de protección de los datos personales superará la generalizada falta de respuestas de la EASO en un ámbito que ha provocado serias deficiencias en su funcionamiento. De este modo, la disposiciones de su propuesta de Reglamento se encuadran como eje vertebral en su funcionamiento, sujeto a la aplicación del Reglamento 2018/1725 (art. 30.1). Ello, sin perjuicio de su extensión al RGPD en lo relativo a la supervisión de los datos y la salvaguarda de los derechos de los interesados, tal y como dispone el Considerando 38 de la mencionada propuesta.

Para ello, la Agencia deberá designar un responsable de la protección de datos (art. 30.2), encargado, entre otras funciones, de controlar la legalidad de los actos de

\footnotetext{
${ }^{395}$ Comisión Europea, Propuesta enmendada de Reglamento relativo a la Agencia de Asilo..., ob. cit., 633 final 2016/0131 (COD).

${ }^{396}$ EASO, Privacy Statement Concerning the Processing of Personal Data Related to the Distribution of EASO, 1 de febrero de 2019 (EASO/CSU/2019/013).
} 
procesamiento de información. Un supuesto que, hoy día, contempla la EASO y que publicita en su página web.

Asimismo, el futuro Reglamento le impondrá la facultad de tratamiento de los datos, aparte de la finalidad específica que veremos a continuación, a efectos administrativos (art. 30.3), supeditando la transferencia de información única y exclusivamente a las autoridades de los EEMM con un interés legítimo en la información -por ejemplo, para tramitar una solicitud de protección internacional, ofrecer condiciones de acogida especificas, etc.-. Es más, el art. 30.4 de la propuesta impondrá una prohibición expresa de transferencia a las autoridades de terceros países o a terceras partes, incluidas las organizaciones internacionales, de todos aquellos datos e información personal que son tratados por la Agencia en el marco del presente Reglamento.

Por lo que respecta a los fines del tratamiento de datos personales (art. 31), una de las novedades en este ámbito radicará en la inclusión de los principios de limitación de la finalidad y minimización de los datos que contempla el Considerando $35 \mathrm{y}$ el art. 31.3 de la propuesta. En este sentido, se prohibirá el tratamiento ulterior de datos personales conservados con fines distintos de los establecidos en el presente Reglamento, limitando la actuación de la futura AAUE al cumplimiento de los fines concretos del art. 31.1, esto es, las funciones de prestación de asistencia técnica y operativa, la realización de estudios de casos, la tramitación de las solicitudes de protección internacional de menores o personas vulnerables, la facilitación del intercambio de información con los EEMM, con la Agencia Europea para la Gestión de la Cooperación Operativa en las Fronteras Exteriores de los EEMM, así como con Europol o Eurojust o el análisis de información sobre la situación del asilo. Una limitación de la finalidad que, el art. 31.3 extenderá, incluso, a cualquier tipología de transferencia de datos que ya haya sido efectuada. Estos principios, incluso tipificados en la PRD IV (Considerando 39 y art. 50.3), no solo someterá el procesamiento de datos personales de la Agencia al control del SEPD, sino que exigirá que sus actuaciones que lleven a cabo respetando tales principios, al amparo del art. 6.1 f) PRD IV.

Resulta indudable que la Agencia recopilará información personal para llevar a cabo labores de apoyo operativo y técnico a los EEMM, especialmente, en las fronteras exteriores en colaboración con Frontex. Estas garantías pueden verse afectadas por la emergencia de crisis migratorias y de asilo no previstas en un primer momento y que 
excedan, incluso, de la capacidad inicial de la Agencia para hacer frente a la misma, en cooperación con las autoridades nacionales del país afectado.

Con independencia de los graves déficits nacionales para acometer de forma eficaz los grandes movimientos en frontera, el papel de la Agencia resulta esencial como “factor de compensación". Sin embargo, pese a que esta se encuentra vinculada por el Reglamento 2018/1725, no resulta desdeñable mencionar que este organismo asistencial podría recopilar información sin las garantías debidas si, finalmente, su personal no es capaz de adaptarse a las situaciones concretas que podrían requerir los muy diversos y complejos escenarios en la práctica.

En consecuencia, una de las contingencias a las que se enfrenta la protección de información de la AAUE es que su Reglamento facultará a la recopilación de información en un amplio conjunto de escenarios y de distintas categorías de sujetos migrantes, solicitantes de protección internacional o delincuentes- en situaciones tan distintas como la gestión de las crisis migratorias, la identificación de solicitantes de protección internacional o la prevención de la delincuencia transfronteriza, entre otras. Estas constituirán prioridades de actuación para la AAUE y como tal, su propuesta de Reglamento permitirá procesar datos personales de distintas personas. Se incluye a aquellas sospechosas de estar involucradas en actividades delictivas, como el tráfico de migrantes, el terrorismo o la trata de personas. Una información que pretende compartirse con las autoridades de los EEMM e, incluso, con Europol o Eurojust, con el propósito de llevar a cabo investigaciones relevantes para multitud de fines y para lo que requerirá un tratamiento de datos distinto y especificado.

Así, el Capítulo VII (arts. 29 y ss.) de la mencionada propuesta establece las disposiciones sobre la protección de los datos personales, otorgando a la AAUE un claro y esencial mandato en el tratamiento de los datos personales que excederá del fin principal de gestionar y procesar información exclusivamente concerniente a solicitantes de asilo. Esta situación puede contrariar los principios de protección de datos antes mencionados si no se prevén respuestas diferenciadas y adaptadas a cada uno de los fines. Y, en relación con el intercambio de información, el ejercicio de la actividad de la Agencia requerirá de mecanismos eficientes de cooperación entre la AAUE y los EEMM, cumpliendo con los criterios de oportunidad y precisión (Considerando 7), así como el respeto de los principios de necesidad y proporcionalidad (Considerandos 35, 39 y art. 31.2). 
Estos principios generales de la legislación de la UE deberán delimitar claramente los amplios poderes de la Agencia en relación con la exigencia de lograr un equilibrio entre los medios de información que pretenden recabarse y el objetivo concreto que pretende lograrse. Así, la recogida e intercambio de información de solicitantes de protección internacional deberá realizarse con miras a proporcionar un mejor acceso al procedimiento en sede nacional, mientras que la recogida de datos de migrantes irregulares o potenciales delincuentes deberá radicar en identificar y prevenir cualquier entrada no controlada de estos sujetos. Para la consecución de estos fines, los datos personales susceptibles de tratamiento deberán especificarse en todo momento para determinar la responsabilidad. Además, la eficiencia en la transmisión de la información exige que los EEMM u otras Agencias de la UE apliquen no solo restricciones de acceso o utilización de determinados datos -incluso si estos fueron ya trasmitidos a la Agencia anteriormente (art. 31.4)-, sino la supresión de todos aquellos datos tratados por la Agencia en un plazo de 30 días, salvo aquellos tratados con fines administrativos de acuerdo con el Considerando 40 y art. 32.3.

Finalmente, la propuesta de Reglamento de la AAUE tipifica en el art. 32 el tratamiento de los datos personales recopilados con la única finalidad de prestar asistencia técnica y operativa. En este sentido, el apartado $1^{\circ}$ exige que la utilización por la Agencia de los datos personales recopilados por esta, o comunicados a la Agencia por los EEMM cuando preste asistencia técnica y operativa a los EEMM, se limitará al nombre, fecha de nacimiento, sexo, nacionalidad, profesión o educación, impresiones dactilares y fotografía digitalizada de los nacionales de terceros países.

Este tenor respeta la plena coherencia con el intercambio de información en el Sistema de Dublín (arts. 34 PRD III o 46 PR IV) pese a que excluye, curiosamente, la recopilación de elementos físicos de identificación, es decir, documento de identidad o de viaje. Con ello, parece que esta disposición prevea la "mera asistencia" de la Agencia a los EEMM en la recopilación de información, pues no termina de clarificar la función ejecutiva de esta en la toma de decisiones en relación con el procesamiento de la información personal. Consecuentemente, plantea numerosos interrogantes como por ejemplo, si el procesamiento de datos sensibles -huellas dactilares o imágenes facialesresponderán a la estricta finalidad de determinación del EM responsable/competente de tramitar la solicitud o si por el contrario, únicamente se efectúa con fines de identificación. 
De hecho, el art. 32.2 faculta a que la AAUE trate todos estos datos para llevar a cabo no solo la clásica función básica de identificación y registro -recordemos que, hasta ahora, esta facultad ha venido realizándose por parte de la EASO-, sino que ahora también prevé una función de "perfeccionamiento asistencial" a través de la facilitación del examen de las solicitudes de protección internacional, la prestación de asistencia a las autoridades nacionales competentes responsables del examen de las solicitudes de protección internacional o en la ejecución de decisiones de reubicación. Además, amplía los motivos de procesamiento a la necesidad de transmisión de esta información a una multitud de organismos -Agencia Europea para la Gestión de la Cooperación Operativa en las Fronteras Exteriores de los EEMM, a Europol o a Eurojust, las autoridades de los EEMM o los servicios de inmigración y asilo- así como para el análisis de la información.

Finalmente, el art. 32.3 prevé que los datos personales se supriman en el plazo más breve posible desde la efectiva transmisión de la información a los organismos o fines antes mencionados cuyo plazo de almacenamiento no podrá exceder de 30 días desde la recopilación o recepción de dichos datos.

En definitiva, la AAUE estará facultada a procesar e intercambiar "prácticamente" toda la información relativa a solicitantes de protección internacional para fines concretos de identificación, asistencia o cooperación con las autoridades nacionales. Sin embargo, quizá la propuesta debería mejorarse con la previsión del establecimiento de un numerus clausus de datos e información personal bajo su mandato, un supuesto realmente complejo en vista de que su intervención se amplía a múltiples escenarios.

Asimismo, a nuestro juicio, la propuesta debería concretar cuál es la función de intercambio con el resto de organismos europeos, puesto que exceden de propósito principal de gestión de la información relativa a la protección internacional hacia cuestiones más amplias relativas a migración -ampliamente considerada-, como así contempla el Considerando 20 de la mencionada propuesta. Por lo tanto, este alcance debería abordarse por parte del SEPD, por cuanto los principios de protección de datos nucleares de minimización y limitación de la finalidad que contempla el art. 4.1 c) y d) del Reglamento 2018/1725 pueden verse seriamente comprometidos.

Pese a todo, el funcionamiento de la Agencia en lo que atañe al tratamiento de los datos personales deberá seguir su propio Reglamento además del relativo al tratamiento de datos personales por las instituciones, órganos y organismos de la Unión. Ello con 
independencia de su extensión al RGPD en lo relativo a la supervisión de los datos y la salvaguarda de los derechos de los interesados de conformidad con el Considerando 38 de la propuesta de Reglamento AAUE.

6.2. La novedosa Guardia Europea de Fronteras y Costas: consideraciones relevantes en el derecho a la protección de la información y de los datos personales.

Desde sus orígenes el 1 de mayo de 2005, Frontex ha constituido una de las agencias de la UE de más rápido crecimiento en cuanto a presupuesto y personal, concretamente, en comparación con la EASO. Su crecimiento en la última década puede considerarse, a todas luces, sorprendente. Tras las crisis migratorias durante el año 2015, Frontex comenzó a obtener mayores recursos y competencias adicionales en relación con la ejecución de órdenes de retorno de la UE de migrantes en situación irregular, así como mayores atribuciones de responsabilidades contra el crimen organizado y el contrabando de seres humanos. ${ }^{397}$ De este modo, en virtud del Reglamento 2016/1624, de 14 de septiembre de 2016 y que entró en vigor en octubre de $2016,{ }^{398}$ fue transformado en la Agencia Europea de la Guardia de Fronteras y Costas (AEGFC), conocida como "Frontex +", reforzando sus funciones tal y como ha profundizado doctrina especializada sobre el funcionamiento de esta Agencia. ${ }^{399}$ Frontex comenzó a recopilar datos específicos como el sexo o la edad de los migrantes irregulares en 2018.400

\footnotetext{
${ }^{397}$ A pesar de su rápido crecimiento, la eficiencia de Frontex en la consecución de sus operaciones depende de las contribuciones voluntarias de los EEMM. De acuerdo con su Informe Anual de 2017, esta agencia contrató a más de 1.700 oficiales de los EEMM para sus operaciones. (Secretaría General del Consejo de la UE, "Frontex Annual Activity Report 2017", 27 de junio de 2018, FRONT 199, COMIX 352). Además, contó con 1500 agentes del contingente de reacción rápida, junto con barcos, aviones y equipos adicionales. Su personal creció en un tercio, a 488, solo en 2017, con el objetivo de duplicarlo en 2018. (FRONTEX, A year in review. First 12 months of the European Border and Coast Guard Agency, Varsovia, 2017, p. 3).

${ }^{398}$ Con excepción de los arts. 20.5 y 6 , y art. 39.7 que fueron aplicables a partir del 7 de diciembre de 2016 así como de los arts. 29, 30, 31 y 32, aplicables a partir del 7 de enero de 2017.

${ }^{399}$ Para un estudio acerca de las nuevas funciones de esta agencia, véase: RIJPMA, J., "Frontex and the European System of Border Guards: The Future of European Border Management", en FLETCHER, M., HERLIN-KARNELL E., MATTERA C., (eds.). The European Union as an Area of Freedom, Security and Justice, 2016, London: Routlegde, pp. 217-246; FERNÁNDEZ ROJO, D., "Reglamento 2016/1624: de Frontex a la Guardia Europea de Fronteras y Costas", Revista General de Derecho Europeo, no 41, 2017, pp. 223-251.

${ }^{400}$ FRONTEX, Risk Analysis for 2019, p. 6 .
} 
Su mandato original ha ido ostentando facultades cada vez más centradas en la coordinación de las operaciones de control de fronteras, la preparación de evaluaciones de riesgos y la asistencia a los EEMM en las misiones de capacitación y retorno.

Dicho lo anterior, y dada la especial trascendencia en el tema que nos ocupa, procederemos a analizar pormenorizadamente la legislación de protección de datos que la GEFC deberá garantizar a la luz de su reciente Reglamento 2019/1896, de 13 de noviembre, que entró en vigor el 4 de diciembre de 2019.

Tras el Discurso sobre el Estado de la Unión (SOTEU) en septiembre de 2018, pese a que no fueron materializadas las propuestas más ambiciosas de reforma del SECA, se previó reforzar los controles fronterizos exteriores, situando a la reforma del Reglamento de este organismo en una de las prioridades por antonomasia para la consecución de este objetivo. El proyecto de reforma durante el mencionado discurso se centró en un "un cuerpo permanente de 10.000 funcionarios de operaciones de la UE con poder ejecutivo y su propio equipo" para permitir que la UE "intervenga donde y cuando sea necesario". ${ }^{401}$ El Consejo dio luz verde el 28 de marzo de 2019 a esta medida, como elemento nuclear del refuerzo de esta Agencia, culminando con la adopción del actual Reglamento 2019/1896.

Sobre este incremento sustancial del número de funcionarios, los primeros estudios ya aludieron a que un grupo tan elevado de guardas fronterizos plantearía una serie de interrogantes, en concreto, sobre cual será la formación que reciban en materia de protección de datos. ${ }^{402} \mathrm{Si}$ bien, merece llevar a cabo un análisis pormenorizado que evalúe el impacto del nuevo Reglamento de la GEFC en el cumplimiento de la legislación de protección de datos.

En un primer plano, en términos de responsabilidad, la GEFC opera en estos momentos con grandes intereses en juego relacionados con los derechos humanos y, más concretamente, con la protección de los datos personales que gestiona para la consecución de su cometido, esto es, "contribuir a un nivel eficiente, de elevada calidad y uniforme de control fronterizo y de retorno" para una amplísima variedad de

\footnotetext{
${ }^{401}$ Comisión Europea, State of the Union 2018. A fully equipped European Border and Coast Guard Questions and Answers. Strasbourg, 12 de septiembre de 2018.

${ }^{402}$ Una primera aproximación sobre la necesidad de una mejorada formación de los organismos y agencias de la UE, puede consultarse: KUNER, C., DAN JERKER B., SVANTESSON, C., LYNSKEY, O., MILLARD, C., "Data protection and humanitarian emergencies", International Data Privacy Law, vol. $7, \mathrm{n}^{\circ} 3,1$ de agosto de 2017, p. 147.
} 
funciones. ${ }^{403}$ Ahora bien, la transferencia de poderes nacionales a esta Agencia de la UE no es la solución a los problemas relacionados con las grandes presiones migratorias si ello no viene acompasado de una reforma estructural del Sistema de Dublín y de un apoyo proactivo o preventivo hacia los EEMM que sufren presiones migratorias desproporcionadas con sus propios medios. Es más, estas funciones ampliadas plantean serias preocupaciones sobre la protección efectiva en el derecho a la protección internacional.

Debe hacerse mención de que los sistemas nacionales de retorno deberán estar plenamente interconectados a un sistema central operado por la Guardia, lo cual implicará una cesión mecánica de información con la clara finalidad de dotar de una mayor eficiencia tanto de los procedimientos de asilo como de retorno. En este caso, si la información confidencial relacionada con el expediente de asilo es empleada para facilitar los procedimientos de retorno, esto supondría una vulneración del principio de limitación de la finalidad que tipifica el art. 4.1 b) del Reglamento 2018/1725.

\footnotetext{
${ }^{403}$ Estas vienen desarrolladas en el art. 10 del Reglamento, entre las que cabe destacar unas funciones básicas como: a) supervisar los flujos migratorios y realizar análisis de riesgos que abarquen todos los aspectos de la gestión integrada de las fronteras; b) supervisar las necesidades operativas de los Estados miembros en relación con la aplicación de los retornos, incluida la recopilación de datos operativos; c) realizar evaluaciones de la vulnerabilidad (...) d) supervisar la gestión de las fronteras exteriores mediante funcionarios de enlace de la Agencia en los Estados miembros; e) supervisar el respeto de los derechos fundamentales en todas sus actividades en las fronteras exteriores y en las operaciones de retorno; f) apoyar el desarrollo y el funcionamiento de EUROSUR; g) asistir a los Estados miembros en circunstancias que requieran un aumento de la asistencia técnica y operativa en las fronteras exteriores mediante la coordinación y organización de operaciones conjuntas, teniendo en cuenta que algunas situaciones pueden implicar emergencias humanitarias y salvamento marítimo de conformidad con el Derecho de la Unión y con el Derecho internacional.

Por su parte, también otras de carácter específico como: j) desplegar el cuerpo permanente en el marco de los equipos de gestión de fronteras, los equipos de apoyo a la gestión de la migración y los equipos de retorno (en lo sucesivo, denominados colectivamente «equipos») durante las operaciones conjuntas, las intervenciones fronterizas rápidas, las operaciones de retorno y las intervenciones de retorno; $\mathrm{k}$ ) crear un contingente de equipamiento técnico, incluido un contingente de equipamiento de reacción rápida, que se desplegará en operaciones conjuntas, en intervenciones fronterizas rápidas y en el marco de los equipos de apoyo a la gestión de la migración, así como en operaciones e intervenciones de retorno; 1) desarrollar y gestionar, con el apoyo de un mecanismo interno de control de calidad, sus propias capacidades técnicas y humanas para contribuir al cuerpo permanente, incluida la contratación y la formación de los miembros de su personal que actúan como miembros de los equipos, y al contingente de equipamiento técnico; $\mathrm{m}$ ) en el marco de los equipos de apoyo a la gestión de la migración en los puntos críticos (...) p) desplegar equipos de retorno durante las intervenciones de retorno; q) en el marco de los respectivos mandatos de las agencias en cuestión, cooperar con Europol y Eurojust y prestar ayuda a los Estados miembros en circunstancias que requieran una mayor asistencia técnica y operativa en las fronteras exteriores en la lucha contra la delincuencia transfronteriza y el terrorismo.
} 
Comparto con De Bruycker su afirmación de que "existe una relación inversamente proporcional entre responsabilidad y solidaridad: cuanto más responsabilidad se le asigna a la UE, menor es la necesidad de solidaridad entre los EEMM y cuanto menos responsabilidad ostenta la UE, más necesidad hay de solidaridad entre los EEMM". ${ }^{404}$ En consecuencia, si la UE quiere recuperar la credibilidad en el campo de la migración y asilo, deberá adoptar una sinergia de estrategias que combine fronteras sólidas, mejoradas y unas funciones más fortalecidas de esta Agencia para la consecución de los objetivos que tiene encomendados. Ahora bien, todas estas medidas no deberán resultar ajenas al pleno respeto de los derechos humanos, en especial, en la protección de los datos personales.

Adentrándonos en el nuevo Reglamento 2019/1896 que regula el funcionamiento de la GEFC, este contempla diversas disposiciones de protección de datos. Por una parte, el Considerando 26 insta a que los EEMM garanticen la exactitud de los datos, su actualización constante y su obtención lícita, debiéndose aplicar plenamente "el Derecho de la Unión en materia de protección de datos", esto es, el RGPD y la Directiva de Protección de datos en el ámbito penal.

Por otra parte, contiene referencias directas al régimen de protección de datos de la UE, disponiendo que cualquier sistema o aplicación que emplee la red de comunicación deberá cumplir con "la totalidad del Derecho de la Unión en materia de protección de datos durante todo su ciclo de vida" (párrafo $2^{\circ}$ del art. 14). También requiere que los planes operativos para las operaciones conjuntas describan no solo las funciones que le son propias de acuerdo con sus competencias ejecutivas sino los requisitos sobre protección de datos (art. $38.3^{\circ}$ d)). Asimismo, el régimen de cooperación de esta Agencia con instituciones, órganos y organismos de la UE y con organizaciones internacionales exige el cumplimiento de los requisitos de protección de datos (art. 68.5), por lo que deberá cumplirse con las reglas del Capítulo V del Reglamento 2018/1725 - en similares parámetros que la futura AAUE-. Y en el caso de que se realicen acuerdos de trabajo que prevean transferencia de datos personales a terceros países, esta Agencia deberá solicitar la autorización previa del SEPD (art. 73.4).

Lejos de quedarse ahí, el Capítulo IV (Disposiciones generales) regula en la Sección 2 (arts. 86 a 92) el tratamiento de datos personales por la GEFC en un considerable

\footnotetext{
${ }^{404}$ DE BRUYCKER, P., "The European Border and Coast Guard: A new Model Built in an old logic", European Papers: A Journal on Law and Integration, $\mathrm{n}^{\circ}$ 1, 2016, p. 566.
} 
esfuerzo por superar la vinculación de la protección de datos al exclusivo intercambio de información -sin perjuicio de los escasos cambios en esta materia, más allá de las modificaciones en el régimen de garantías aplicables al intercambio de información a efectos de retorno sobre las que abordamos en el siguiente capítulo-.

El art. 86 constituye el eje vertebral de la protección de datos de esta Agencia, el cual remite al Reglamento 2018/1725 aplicable para el tratamiento de datos personales. Además, suprime cualquier tipo de referencia al respeto de la normativa nacional y de la Unión en materia de seguridad y de protección de datos a los funcionarios de enlace de la Agencia en los EEMM que preveía la propuesta en el art. 32.5. En su defecto, regula normas de seguridad sobre la protección de la información clasificada y de la información sensible no clasificada en el art. 92.

Siguiendo este criterio, el apartado $2^{\circ}$ tomó en consideración la enmienda $n^{\circ} 403$ del $\mathrm{PE},{ }^{405}$ que clarificó esta disposición exigiendo que las restricciones que se apliquen en este ámbito respeten la protección de los datos personales, así como los criterios de necesidad y proporcionalidad en relación con el objetivo que se persigue, ateniendo a los riesgos para los derechos del interesado.

Al margen de estos dos conflictos, el mencionado artículo ya no dispone de la "prohibición general" de transferencia de datos personales a terceros países. En su defecto, reconoce en el apartado $3^{\circ}$ la posibilidad de que la Agencia transfiera datos personales a un tercer país u organización internacional "de conformidad con las disposiciones del capítulo V del Reglamento (UE) 2018/1725 en la medida en que dicha transmisión sea necesaria para la ejecución de las tareas de la Agencia”, esto es, para cualquier tipo de operaciones o intervención de retorno.

De esta manera, solventa el conflicto anterior que prohibía esta transferencia y por la que regulaba toda una serie de excepciones a esta "regla general". En cambio, este Reglamento es más conciso, previendo expresamente que esta transferencia no podrá menoscabar "los derechos de los solicitantes de protección internacional y de los beneficiarios de protección internacional, en particular por lo que se refiere al principio de no devolución" (apartado $4^{\circ}$ ) al igual que, con independencia de que la información

\footnotetext{
${ }^{405}$ Parlamento Europeo, Comisión de Libertades Civiles, Justicia y Asuntos de Interior, Informe sobre la propuesta de Reglamento del Parlamento Europeo y del Consejo sobre la Guardia Europea de Fronteras y Costas y por el que se derogan la Acción Común n. ${ }^{\circ}$ 98/700/JAI del Consejo, el Reglamento (UE) n. ${ }^{\circ}$ 1052/2013 del Parlamento Europeo y del Consejo y el Reglamento (UE) 2016/1624 del Parlamento Europeo y del Consejo, (COM(2018)0631 - C8-0406/2018 - 2018/0330(COD)), 12 de febrero de 2019.
} 
haya sido cedida a terceros países, esta no pueda transmitirse a otros terceros países o terceras partes (apartado $5^{\circ}$ ). De gran relevancia fueron las enmiendas $n^{\circ} 404$ y $405 \mathrm{PE}$, que especificaron la prohibición absoluta de intercambio de información de la Agencia a un tercer país si esta transmisión pudiera emplearse para identificar a personas o grupos de personas cuyas solicitudes de acceso a protección internacional estén siendo o hayan sido examinadas.

Una excepcional transmisión que, incluso, habilita que esta Agencia pueda aprobar normas internas para restringir la aplicación de los derechos de notificación, rectificación, supresión o bloqueo, así como el derecho de oposición del interesado y que exige, en todo caso, que los datos no se almacenen en la plataforma y se supriman inmediatamente después de la confirmación de recepción y "tan pronto como concluya la operación" (art. 49.1).

Y pese a que esta cesión de información a terceros países deberá efectuarse de forma individualizada, también requerirá que todas las actuaciones se encaminen a garantizar el pleno respeto de los derechos fundamentales de los migrantes y refugiados, su derecho a ser informados de aquellos actos que les afecten de forma "objetiva, pormenorizada, global, fiable y fácilmente comprensible" (art. 114.2). Una mejora sustancial en el derecho a la información si tenemos en cuenta que en su propuesta se preveía este derecho en un idioma "que pudieran comprender", y que fue objeto de especial preocupación por el Comité Meijers, principalmente, por la potencial injerencia excesiva en este derecho. ${ }^{406}$ De tal modo, apuntó que la exigencia de un retorno rápido podía aumentar el riesgo de que los derechos de protección de datos se supeditaran a esta intrínseca finalidad. Un riesgo que parece superarse en virtud del nuevo art. 87.1 que enumera finalidades concretas y tasadas para el tratamiento de estos datos personales ${ }^{407}$ y que, en consecuencia, exige al EM u organismo de la UE que facilite

\footnotetext{
${ }^{406}$ Meijers Committee Standing Committee of Experts on International Immigration, Refugee and Criminal law, CM1817 Comments on the draft for a new Regulation on a European Border and Coast Guard, (COM (2018) 631 final) and the amended proposal for a Regulation on a European Union Asylum Agency $(\operatorname{COM}(2018) 633$ final $), 27$ de noviembre de 2018. Accesible en: https://www.eerstekamer.nl/eu/documenteu/cm1817_notitie_van_de_commissie/f=/vku0ofm4fpqh.pdf

${ }^{407}$ Las finalidades que dispone el mencionado artículo son las siguientes: "a) llevar a cabo sus funciones de organización y coordinación de operaciones conjuntas, proyectos piloto, intervenciones fronterizas rápidas y en el marco de los equipos de apoyo a la gestión de la migración previstas en los artículos 37 a 40; b) llevar a cabo sus funciones de apoyo a los Estados miembros y a terceros países en las actividades previas al retorno y de retorno, y gestionar los sistemas de gestión del retorno, así como coordinar u organizar operaciones de retorno y prestar asistencia técnica y operativa a los Estados miembros y a
} 
datos personales a la GEFC, quien deberá fijar el fin o fines concretos, de modo que la Agencia únicamente podrá desmarcarse si lo autoriza el proveedor mediante un registro escrito de las evaluaciones de la compatibilidad caso por caso (apartado $2^{\circ}$ ). Ello con independencia de que puedan imponerse limitaciones "de acceso o uso" general o específico, "también en lo relativo a la transferencia, al borrado o a la destrucción." (apartado $3^{\circ}$ ). Inclusive, la Agencia también estará vinculada si la necesidad de limitación de tratamiento surge tras la transferencia de los datos personales.

Por todo ello, la GEFC desempeñará en los sucesivos años una misión de enorme complejidad focalizada en el intercambio de información pertinente, necesaria $\mathrm{y}$ proporcional para los fines de retorno. Ello sin obviar, como es lógico, el cumplimiento de ciertos parámetros como la eficiencia y la protección de datos. Cuestiones aparentemente contrarias entre sí, por la atribución en el análisis individualizado de la categoría de los sujetos, la tipología de información y los parámetros de necesidad y proporcionalidad en la trasmisión de información. Además, el principio de limitación de la finalidad en el tratamiento de los datos personales supedita la actuación de esta Agencia a los exclusivos fines que tiene encomendados.

Para la consecución de sus objetivos, el art. 88.1 exige que previamente a cada operación conjunta, operación de retorno o cualquier intervención que lleve a cabo la Agencia, esta determinará con cada EEMM "las responsabilidades en el cumplimiento de las obligaciones en materia de protección de datos", clarificando la tipología de datos personales susceptibles de recogida durante las operaciones conjuntas, proyectos piloto e intervenciones rápidas: "a) datos personales de individuos que crucen las fronteras exteriores sin autorización; b) necesarios para confirmar la identidad y la nacionalidad de los nacionales de terceros países en el marco de las actividades de retorno, incluidas las listas de pasajeros; c) números de matrícula de vehículos, números de identificación de vehículos, números de teléfono o números de identificación de barcos y de aeronaves relacionados con las personas a que se refiere la letra a) y que sean necesarios para analizar las rutas y los métodos utilizados para la inmigración ilegal”.

terceros países de conformidad con el artículo 48; c) facilitar el intercambio de información con los Estados miembros, la Comisión, el SEAE, los órganos y organismos de la Unión y las organizaciones internacionales (...); d) facilitar el intercambio de información con las autoridades con funciones policiales de los Estados miembros, Europol o Eurojust, de conformidad con el artículo 90; e) realizar análisis de riesgos por la Agencia (...)" 
Indudablemente, la Agencia procesará en estos años una multitud de datos personales procedentes de distintas categorías relacionadas con el control fronterizo, migración, asilo o retorno, entre las que se incluyen los sujetos relacionados en actividades delictivas transfronterizas, la inmigración ilegal, la trata de personas e incluso, el terrorismo. Por este motivo, el Reglamento incorpora un nuevo apartado $2^{\circ}$ del art. 88 por el que permite el tratamiento de datos por parte de la Agencia solo en tres supuestos: "a) cuando la transmisión de estos datos a las autoridades de los Estados miembros pertinentes responsables en materia de control fronterizo, migración, asilo o retorno o a los órganos y organismos de la Unión competentes resulte necesaria para que esas autoridades o esos órganos $\mathrm{y}$ organismos cumplan sus funciones de conformidad con el Derecho de la Unión y nacional; b) cuando la transmisión de estos datos a las autoridades de los Estados miembros pertinentes, órganos y organismos de la Unión competentes, terceros países de retorno u organizaciones internacionales resulte necesaria a efectos de la identificación de nacionales de terceros países, la obtención de documentos de viaje y la facilitación o el apoyo del retorno; c) cuando resulten necesarios para realizar análisis de riesgos".

Sin embargo, nada dispone esta Sección especializada en la protección de los datos sobre las cautelas específicas que deben tomarse en consideración. Y ello pese a que su funcionamiento se centra no solo en la prevención de sujetos que pueden comprometer la seguridad europea y de los EEMM -tráfico ilícito de migrantes, la trata de seres humanos o el terrorismo-, sino también en el control de la migración no controlada y que, indiscutiblemente, su mandato incluye la recopilación de datos de solicitantes de protección internacional.

Por lo tanto, serán los análisis de riesgo que lleve a cabo la Agencia con las otras partes -ya sean EEMM, AAUE, Europol, Eurojust, entre otros- los que diferencien de una manera más clara entre los distintos sujetos y los fines del procesamiento en cuestión con objeto de cumplir exhaustivamente con las normas de protección de datos, cuyo marco jurídico variará de un modo sustancial. De hecho, coincido parcialmente con Rijpma y Santos $\operatorname{Vara}^{408}$ cuando aluden a que, en el caso de que recopile

\footnotetext{
${ }^{408}$ RIJPMA, J., The proposal for a European Border and Coast Guard: evolution or revolution in external border management?, Study for the LIBE Committee of the European Parliament, 2016, p. 22; SANTOS VARA, J., "La transformación de Frontex en la Agencia Europea de la Guardia de Fronteras y Costas: ¿hacia una centralización en la gestión de las fronteras?", Revista de Derecho Comunitario Europeo, n $^{\circ} 59,2018$, p.166.
} 
información sobre la gestión de datos relativos a inmigrantes, se aplicará el RGPD y, para el resto de tipos penales, la Directiva 2016/680. En efecto, el RGPD no solo excluye las actividades relativas a la seguridad nacional, sino también las relativas a la política exterior y de seguridad común de la Unión. ${ }^{409} \mathrm{Si}$ bien, tal y como hemos sostenido con anterioridad, pese a que el RGPD debería aplicarse al procesamiento e intercambio de información del asilo por su directa inclusión en la propuesta reforma del Sistema de Dublín, concurren una multitud de supuestos susceptibles de exclusión.

Esta reforma también recibió advertencias por parte del SEPD. En su Dictamen 02/2016 de 18 de marzo de 2016 sobre la entonces propuesta de Reglamento de GEFC, ${ }^{410}$ determinó que la carencia de contundentes reformas en disposiciones de protección de datos así como la falta de precisión entre las funciones de la Agencia en ámbitos tan distintos como la gestión de la migración y las fronteras y las acciones relacionadas con la delincuencia transfronteriza podía implicar violaciones sistemáticas en la protección de datos, básicamente, en la protección de los solicitantes de protección internacional. De hecho, como se ha señalado en el art. 88.2 a) se faculta a que la Agencia pueda tratar datos de diversa índole - control fronterizo, migración, asilo, etc.-

En definitiva, la Agencia tratará datos personales de una gran tipología de nacionales de terceros países, englobando desde delincuentes, terroristas a migrantes irregulares, solicitantes de protección internacional por lo que debe cooperar activamente con las autoridades de los EEMM e incluso terceros países competentes para la consecución de los ámbitos regulados por su Reglamento de funcionamiento. Con independencia de que se prohíba este intercambio de información, esta pluralidad de objetivos constituye un aspecto enormemente conflictivo que, como ya hemos señalado, puede poner en riesgo las altas garantías que exige la tramitación de la información personal en el ámbito de la protección internacional. Específicamente, que esta información pueda llegar a disposición de las autoridades de los terceros países que han perseguido a un determinado individuo que presente solicitar protección internacional, y que constituiría una flagrante violación del "principio de devolución virtual". Y en buena medida, trayendo a colación el criterio del SEPD en el año 2016, por el que debería delimitarse de un modo más claro las responsabilidades entre la nueva Agencia y los EEMM para

\footnotetext{
${ }^{409}$ Véase Considerando 16 RGPD.

${ }^{410}$ SEPD, Opinion 02/2016, Recomendaciones del Supervisor Europeo de Protección de Datos relativas a la propuesta de Reglamento Europeo sobre la Guardia Europea de Fronteras y Costas, 18 de marzo de 2016.
} 
evitar una confusión en la responsabilidad de las obligaciones de protección de datos de cada controlador. ${ }^{411}$ Una sugerencia que no ha reflejado el Reglamento de esta Agencia.

Así, esta transferencia debe supeditarse a los requisitos previstos en el RGPD y Directiva de protección de datos en el ámbito penal en sintonía con el tratamiento de los datos personales en el marco de EUROSUR (art. 89). De esta forma, únicamente se deberá proceder a transferir, excepcionalmente y para fines concretos de retorno, los datos sobre una decisión de adecuación que asegure que un tercer país se adhiere a altos estándares similares a los previstos en la normativa de protección de datos de la UE. En su defecto, la Agencia únicamente debe transferir información personal si existen salvaguardas apropiadas establecidas en un acuerdo vinculante entre autoridades públicas de acuerdo con los arts. 47 y 48 del Reglamento 2018/1725.

Una discusión sobre las garantías en el seno de la cooperación operativa conjunta entre un EM con un tercer país que fue iniciada por Rijpma, que apostaba por permitir, exclusivamente, el intercambio de datos únicamente a los Estados que son parte en el CEDH, así como a la Convención de Ginebra sobre Refugiados y al Protocolo adicional. ${ }^{412}$ En todo caso, supone una presunción de que la cooperación con terceros países, pese a que se efectúa en exclusiva a efectos de retorno, vacía de protección las normas de la UE sobre la gestión de las fronteras, la migración y asilo.

Finalmente, la eliminación en estos supuestos se procederá una vez transmitido a las autoridades competentes de los EEMM, a otros órganos y organismos de la Unión, en especial a la EASO, una vez que se hayan utilizado para la elaboración de los análisis de riesgos, sin resultar superior a 90 días desde la fecha de recogida de dichos datos, límite que impone el art. 91.1 del Reglamento. Consecuentemente, convendría que este precepto fuera interpretado en líneas similares a la excepcionalidad de la transferencia de datos personales por parte de la futura AAUE, es decir, deberían asimismo basarse en una evaluación de la adecuación del tercer país o en el uso de salvaguardas adecuadas al efecto.

\section{Consideraciones finales.}

En este capítulo hemos abordado un estudio detallado del derecho a la protección de

\footnotetext{
${ }^{411}$ EDPS, Opinion 02/2016... ob. cit, p. 15.

${ }^{412}$ RIJPMA, J., The proposal for a European Border and Coast Guard... ob. cit., 2016, p. 23.
} 
datos en el ámbito del SECA, una disciplina escasamente abordada por la doctrina y la jurisprudencia en un ámbito de enorme relevancia como lo es, la garantía del derecho a la protección internacional.

Por todo ello, este estudio descansa sobre tres ejes fundamentales: la determinación del complejo régimen jurídico aplicable; el intercambio de información en el Sistema de Dublín y finalmente, las implicaciones de la legislación de protección de datos en la propuesta de reforma de la AAUE y en la recientemente reformada GEFC.

Dicho esto, se reflejan las siguientes conclusiones al respecto:

1. Por lo que respecta al régimen jurídico aplicable, el actual RD III contempla la adopción de una Directiva de protección de datos que, en la actualidad, está derogada en virtud del RGPD y de la Directiva 2016/680 de protección de datos en el ámbito penal. Pese a que su previsión se encuentra en la Propuesta de reforma del SECA -tanto la Propuesta de Reglamento de Dublín, Eurodac como la de Procedimiento-, la corrección de errores del RGPD extendió su ámbito de aplicación a aquellos sujetos que simplemente se encuentren en la UE, como los solicitantes de protección internacional. Pese a ello, el RGPD no solo excluye directamente de aplicación el asilo, el control de fronteras y la inmigración $-\mathrm{y}$, ni que decir tiene, la seguridad nacional-, sino que la intervención de un amplio conjunto de actores en la gestión de la información se aparta generalizadamente de estas garantías, por cuando se rigen por sus propios reglamentos.

Esta situación continuará generando una elevada inseguridad jurídica a pesar de los profundos esfuerzos de organismos internacionales como el ACNUR, que en 2018 publicó la Guía de Protección de Datos en la que adapta directamente el RGPD al tratamiento de los datos personales de los sujetos bajo su misión, exceptuándolo a actuaciones que imposibilitarían la consecución de sus objetivos. Una previsión que debería resultar extensible a todos aquellos organismos y agencias que procesan información personal de solicitantes de protección internacional en Europa.

De este modo, este procesamiento se basa en una amplia tipología de datos personales, incluyendo aquellos de carácter sensible, que deberán adoptarse altas medidas de seguridad como prevé el art. 50 PRD IV para prevenir del acceso a los datos por parte de terceros, la divulgación de información personal ilícita o no autorizada o la alteración o la pérdida de los datos personales procesados. Ahora bien, la propuesta de reforma del SECA permanece ajena a cuestiones de gran entidad en relación con la 
protección de datos:

- En primer lugar, sufre de un déficit a la hora de abordar correctamente los problemas actuales y que parten desde escasa formación de las autoridades sobre la legislación de protección de datos, el potencial acceso e intercambio de información de autoridades de los EM y de organismos europeos o la interoperabilidad entre los distintos SSII.

- En segundo lugar, el propio procedimiento de protección internacional tiende a recopilar una gran tipología de datos e información personal, incluyendo tanto aquellos identificadores entre los que se incluyen nombres, nacionalidades, lugar de procedencia y fecha de nacimiento como los extensos datos sensibles. Esta tendencia a la recopilación de todos aquellos datos al alcance del solicitante deberá acotarse a la aplicación de los principios de minimización y limitación de la finalidad.

2. El intercambio de información en el actual y futura reforma del SECA resulta un factor clave para dotar a este sistema de condiciones necesarias que garanticen su buen funcionamiento. Así, la amplia flexibilidad en la toma de decisiones a la hora de intercambiar información se encuentra supeditada a diversas formalidades vinculantes como el principio de confidencialidad (arts. 6 y 48 PRP), el deber de designar un punto de contacto nacional y la potenciación de comunicación entre los EEMM y la Comisión (arts. 49 y 57.2 PRP). Ciertamente, sin perjuicio de las consideraciones técnicas del intercambio de información de los datos contemplados directamente en Eurodac, la PRD IV otorgará verdadera naturaleza jurídica al intercambio de información por medio de la inclusión de sustanciales mejoras en relación con las medidas de seguridad.

En este sentido, se impone la obligación de cooperación en labores de identificación por parte del EM donde se encuentre el solicitante, independientemente de que resulte competente sobre el conocimiento del mismo de conformidad con el Sistema de Dublín. Y pese a que el derecho a la protección de datos parece encontrarse supeditado a la apremiante necesidad de aumentar la seguridad y la eficiencia del procedimiento, la mencionada reforma promueve una cooperación sin precedentes con miras a evitar la recogida de datos similares e investigaciones paralelas, prestando atención al respeto de la información obtenida durante todas las fases que, a continuación, se destacan:

a) Antes de la ejecución de los traslados. La PRD IV se aparta de los actuales criterios de utilidad de la información y no excesividad del art. 31 RD III actualmente 
previstos en el art. 4.1 c) de la Directiva de protección de datos en el ámbito penal, contemplando directamente el principio de minimización de datos del art. 5.1 c) RGPD. La necesidad de que estos sean adecuados, pertinentes y limitados a lo necesario elevará las garantías de protección de datos previamente a la ejecución de los traslados, previniendo decisiones arbitrarias derivadas de la escasez generalizada de información así como el desconocimiento acerca de los datos que constan en el expediente de protección internacional.

Con ello, la totalidad de los modelos de intercambio de información, incluyendo los datos sanitarios antes de efectuar el traslado que prevé la reforma del SECA, contienen remisiones al pleno respeto del principio de limitación de la finalidad del art. 5.1 b) RGPD. Inclusive la transferencia de datos a terceros países a efectos de retorno (art. 38 PRE) que se aborda en el siguiente capítulo se encuentra supeditada al cumplimiento de las reglas que regula el art. 46 RGPD. Ahora bien, en este último supuesto, las decisiones de adecuación o acuerdos de readmisión con la mayoría de países de retorno posibilita excepcionalmente la aplicación de un criterio de interés público que prevé el art. 50.1 d) del Reglamento 2018/1725, el cual se aparta de las disposiciones que prevé el RGPD. Un supuesto conflictivo que no debería estar presente en el SECA, puesto que eleva el riesgo de un posible intercambio de datos de potenciales sujetos perseguidos con terceros países. Este intercambio no solo exceptúa las altas garantías del SECA, sino que podría contrariar, en ciertos supuestos, el principio de no devolución.

b) Igualmente, la cooperación administrativa de la PRD IV pretende superar los criterios de suficiencia, pertinencia y necesidad que recoge el art. 4.1 c) de la Directiva de protección de datos en el ámbito penal hacia el respeto del principio de minimización de los datos. Ahora bien, en este régimen jurídico se lleva a cabo de forma parcial pues en lugar de prever la adecuación de los datos personales a los fines concretos, prevé la adopción de un "ambiguo" criterio de suficiencia que parece flexibilizar de estas obligaciones.

Pese a este sutil progreso, la PRD IV carece de una serie de facultades en relación con los derechos de los solicitantes. El art. 46 PRD IV omite criterios de exactitud que prevé el vigente art. $34.8^{\circ} \mathrm{RD}$ III así como el derecho a la rectificación, supresión y derecho al recurso (apartado $9^{\circ}$ ). Asimismo, elimina tanto el principio de limitación del plazo de conservación [apartado $11^{\circ}$ y art. 5.1 e) RGPD] como la exigencia de adoptar las medidas oportunas para garantizar el cumplimiento de esta protección de datos a 
través de medios de control efectivos (párrafo $12^{\circ}$ ). Un considerable retroceso en la protección efectiva del intercambio de información que pretende flexibilizar las obligaciones de estas autoridades nacionales, "compensando" las novedosas obligaciones del futuro Sistema de Dublín para llevar a cabo actuaciones independientemente de que estos sean competentes para tramitar el fondo de la solicitud de protección internacional.

c) Finalmente, el derecho a ser informado constituirá una de las piedras angulares de la reforma del SECA. La mayor disponibilidad de la información a los solicitantes de protección internacional se encontrará supeditado al deber de colaboración y cooperación con las autoridades nacionales (arts. 6 y 4 RPD IV).

3. En último término, y en relación con el procesamiento de información en el ámbito del SECA, cabe aducir la tendencia a trasladar progresivamente su gestión desde el seno de los EEMM hacia organismos europeos como la EASO (futura AAUE) o Frontex (futura GEFC). Las propuestas de reforma de reglamento de ambas agencias contemplan la aplicación del Reglamento 2018/1725 en el procesamiento de los datos personales. Si bien, la necesidad de una intervención rápida y de urgencia sobre flujos migratorios y la intervención eminentemente en fronteras de las agencias podría propiciar constantes interferencias en el derecho fundamental a la protección de datos personales, en vista de que ostentarán de amplias y perfeccionadas facultades en relación con la gestión e intercambio de datos personales. 


\section{CAPÍtULOO 3.}

\section{SEGURIDAD Y PROTECCIÓN DE DATOS EN EL SISTEMA DE INFORMACIÓN EURODAC.}

\section{Hacia un nuevo Reglamento del Sistema de Dactiloscopia Europea (Eurodac).}

1.1. Una confluencia entre la dimensión de seguridad, eficiencia y protección de datos.

Los SSII en la gestión de las fronteras llevan implementando medidas tecnológicas para la recopilación y gestión de datos personales a gran escala desde el año 2000, precisamente, con la intención de "compensar" la gran movilidad en territorio de la UE, detectar con rapidez cualquier factor que pueda comprometer la seguridad de los EEMM y prevenir la entrada de migrantes no deseados.

Por lo que se refiere al derecho de asilo, esta recopilación se ha efectuado a través del sistema Eurodac, creado por el Reglamento 2000/2725 para la aplicación efectiva del Convenio de Dublín, aplicable desde el 15 de enero de $2003 .{ }^{413}$ Este Reglamento comenzó a implementar la biometría en el ámbito del asilo como elemento que permitía a los EEMM obtener información exacta sobre la identidad del solicitante por medio de su huella dactilar y así conocer aquel Estado competente para el examen de una solicitud de asilo presentada en la UE. Y lo cierto es que, tal ha sido el precedente de la utilización de datos biométricos en Eurodac que, la doctrina especializada en este sistema ha afirmado que su uso excede del cumplimiento de las estrategias que llevaban a cabo los Estados fronterizos del área Schengen hacia su aplicación a fines concretos en materia de asilo. ${ }^{414}$

Hasta el momento, el procesamiento de esta tipología de datos biométricos había sido empleado para labores de identificación en el ámbito humanitario y, en contextos

\footnotetext{
${ }^{413}$ Reglamento n. ${ }^{\circ}$ 2000/2725 del Consejo, de 11 de diciembre de 2000, relativo a la creación del sistema «Eurodac» para la comparación de las impresiones dactilares para la aplicación efectiva del Convenio de Dublín.

${ }^{414}$ TRAUNER, F., “Asylum policy - the EU's 'crises'... ob. cit., pp. 318; BROUWER, E., Eurodac: "Its limitations and temptations", European Journal of Migration and Law, vol. 4, n 2, 2002, pp. 231-247.
} 
muy excepcionales, durante proyectos piloto efectuados por el ACNUR. ${ }^{415}$ Precisamente, la utilización ordinaria en el funcionamiento de Eurodac emergió de estas iniciativas hasta convertirse en el elemento principal e indispensable para aumentar la eficiencia del procedimiento de asilo y afrontar posibles flujos masivos de migrantes y refugiados, ${ }^{416}$ facultando a una rápida determinación del EM competente de tramitar la solicitud de protección internacional. Una herramienta que, como tendremos oportunidad de comprobar, ha ido perfeccionándose en interés de los EEMM en el cumplimiento de sus obligaciones europeas e internacionales.

Esta primera versión de Eurodac fue refundida por el actual Reglamento (UE) $\mathrm{n}^{\mathbf{o}}$ 2013/603, que se adoptó y entró en vigor el 19 de julio de 2013, aunque su efectiva aplicación se produjo el 20 de julio de 2015. Una nueva versión que se enfrentó a déficits estructurales y continuados en ciertos sistemas nacionales de asilo tal y como puso de manifiesto el análisis de riesgos de Frontex de 2016 al subrayar que, alrededor de 1 millón de personas había viajado por la UE sin los documentos de viaje adecuados durante el cénit de la crisis de refugiados en $2015,{ }^{417}$ lo cual generó una teórica incapacidad en la identificación de los migrantes por parte de las autoridades nacionales. Por ejemplo, las autoridades griegas estimaron que, a más de un tercio de las personas que llegaban a las islas griegas no se les tomaron las huellas dactilares. Una situación que no solo acaeció en países afectados por la gran afluencia de migrantes y refugiados en sus fronteras, sino que, curiosamente, fue también aducido por Estados prósperos como pretexto para eludir el compromiso de acogida de estos sujetos. Así lo enfatizaba este mismo informe al reflejar que las autoridades alemanas en la región de Baviera admitieron que tampoco eran capaces de registrar todas las huellas de los solicitantes en su territorio.

La dificultad a la que se enfrentaron determinados EEMM para hacer frente a la gran afluencia de personas llegando a territorio de la UE se hizo principalmente patente tras la frecuente oposición de los solicitantes de protección internacional a la toma de huellas dactilares. Muchos de ellos atentaron contra su propia integridad física -

\footnotetext{
${ }^{415}$ ACNUR, Handbook for registration. Procedures and Standards for Registration, Population Data Manegement and Documentation, 2003. Accesible en: https://www.refworld.org/pdfid/3f967dc14.pdf

${ }^{416}$ Al margen del Sistema de Dublín, este incremento de la eficiencia del SECA vino, igualmente acompasado de la Directiva 2001/55/CE de protección temporal en caso de flujos masivos, hoy en día en vigor.

417 FRONTEX, Risk analysis for 2016 p. 5. Disponible en: http://frontex.europa.eu/assets/Publications/Risk_Analysis/Annula_Risk_Analysis_2016.pdf
} 
automutilaciones, cortes o quemaduras en las puntas de los dedos- lo que obstaculizó o imposibilitó, en muchos casos, su identificación efectiva. ${ }^{418}$ Esta circunstancia fue propiciada como consecuencia de un Reglamento de Dublín profundamente viciado desde su origen, que ha mantenido los intereses de los solicitantes en el más absoluto olvido. De hecho, fue examinada la presión a la que se enfrentaron los solicitantes de protección internacional en frontera, donde su generalizada negativa al registro de sus huellas dactilares puso en serio peligro la efectividad del sistema. Además, como consecuencia de la aplicación del RD III, ciertos EEMM con una carga desproporcionada para tramitar solicitudes de protección internacional, tendían a evitar el registro de las huellas dactilares con objeto de minimizar sus probabilidades de ser responsables de acuerdo con Dublín, ${ }^{419}$ incluso tras los acuerdos de reubicación, reasentamiento o la potenciación de acuerdo de cooperación con terceros Estados.

Ello motivó la apremiante necesidad de una reforma integral tendente a aumentar la eficiencia de este sistema. De este modo, el 4 de mayo de 2016, como parte del primer paquete de reformas, la Comisión presentó la propuesta del Reglamento de Eurodac (PRE), la cual pretende no solo adaptarse a los cambios en la propuesta del Reglamento de Dublín, sino también reforzar su finalidad mediante una considerable ampliación de los datos personales. A su carácter asistencial del Reglamento de Dublín, este fue diseñado jurídicamente con novedosas facultades tendentes a reforzar las acciones en la lucha contra la migración irregular y facilitar su retorno.

Una propuesta que, tres años más tarde, continúa en fase de negociación, ${ }^{420}$ teniendo presente que, el 6 de marzo de 2019, la Comisión instó a los colegisladores a adoptar

\footnotetext{
${ }^{418}$ Véase Base de datos de Información de Asilo, Informe del país -Italia, segunda actualización, abril de 2014, ACNUR, Recomendaciones de aspectos importantes de la protección de los refugiados en Italia, julio de 2013.

${ }^{419}$ ECRE, Comentarios sobre el documento de trabajo de los servicios de la Comisión Europea "sobre la aplicación del Reglamento Eurodac en lo que respecta a la obligación de toma de huellas digitales", junio de 2015.

${ }^{420}$ En el año 2017, el presidente de la Comisión solicitó al PE y al Consejo que adoptaran las propuestas del SECA para finales de 2018, situación que no ha ocurrido y que retrasa considerablemente su aprobación, en especial el reglamento Eurodac. En relación con la propuesta de Reglamento de Eurodac, en el seno del PE, la propuesta fue asignada a la Comisión de Libertades Civiles, Justicia y Asuntos de Interior donde la relatora publicó un borrador de informe el 2 de febrero de 2017 en el que pretendía extender el alcance del reglamento a los apátridas además de a los nacionales de terceros países, agregando una opción para realizar consultas basadas en datos alfanuméricos y simplificando y ampliando el acceso de Europol a la base de datos y un mes más tarde, se presentó el proyecto de dictamen sobre cuestiones presupuestarias. (Parlamento Europeo, Comisión de Presupuestos, Proyecto de dictamen sobre la propuesta de Reglamento del Parlamento Europeo y del Consejo relativa a la creación
} 
esta propuesta legislativa sin demora antes de la celebración de las elecciones al PE con la finalidad de permitir la inclusión de Eurodac dentro de la futura infraestructura interoperable de los distintos SSII de la UE, la cual finalmente, no pudo llevarse a cabo.

Pese a todo, en el presente Capítulo analizaremos las sustanciales mejoras que contiene la mencionada propuesta, la identificación de amplias categorías de migrantes que, efectivamente, exceden de los solicitantes de protección internacional hacia aquellos nacionales de terceros países que se encuentran en situación ilegal y a los que han entrado en la UE de forma irregular por las fronteras exteriores para potenciar la redocumentación de un nacional de un tercer país que debe ser retornado. Lejos de quedarse aquí, la propuesta también insta a rebajar la edad de la toma de datos biométricos, ampliar el periodo de conservación de datos y extender, todavía más, el conocido acceso de las fuerzas policiales nacionales y Europol a este Sistema de Información.

Estas nuevas modalidades supondrán una verdadera metamorfosis jurídica de Eurodac, hacia un incremento de su eficiencia sin precedentes que afronte los múltiples problemas a los que se enfrenta la migración y asilo en su conjunto. Si bien,

del sistema "Eurodac", 7 de marzo de 2017). Este borrador fue aprobado por la Comisión LIBE el 30 de mayo de 2017 y recibió un mandato para las negociaciones con el Consejo. El 28 de abril de 2017, la Presidencia maltesa presentó sus sugerencias para modificar el texto del proyecto de Reglamento Eurodac y presentó un informe de progreso el 9 de junio de 2017 (Parlamento Europeo, Proyecto de resolución legislativa del Parlamento Europeo sobre el establecimiento de "Eurodac" para la comparación de huellas dactilares, 9 de junio de 2017) y fue seguido por un mandato actualizado en Coreper el 15 de junio de 2017.

El Consejo y el PE continuaron manifestando divergencias sobre la duración del período de almacenamiento de datos para los solicitantes de asilo, concretamente, el período de conservación de los datos y el derecho de información de los interesados. Si bien, estos alcanzaron un acuerdo político preliminar el 19 de junio de 2018 sobre la mayor parte de las disposiciones -almacenamiento de mayores datos biométricos, ampliación a migrantes irregulares, reducción de la edad de 14 a 6 años o el acceso de Europol a esta base de datos de una manera más eficiente, entre otros-. (Parlamento Europeo, Asilo: Acuerdo para actualizar la base de datos de huellas dactilares de la UE, Comunicado de prensa, 19 de junio de 2018).

La Presidencia austriaca continuó trabajando a nivel técnico sobre las disposiciones relacionadas con el reasentamiento en el Reglamento Eurodac y el 18 de octubre de 2018, el Consejo Europeo evaluó los avances en su reunión y pidió esfuerzos para concluir la reforma del SECA lo antes posible. De hecho, antes de la celebración del Consejo Europeo de diciembre de 2018, la Comisión destacó la importancia de adoptar las propuestas de reforma pendientes, incluido el Reglamento Eurodac. Ello con independencia de una falta de acuerdo sobre los instrumentos más conflictivos del SECA, esto es, tanto el Reglamento de Dublín como el Reglamento de Procedimientos de Asilo. Durante los días 6 y 8 de febrero de 2019, se celebró una reunión informal de ministros de justicia y asuntos de interior en el que los EEMM no dieron un mandato a la presidencia para continuar la ronda de reuniones con el PE. (Consejo Europeo, Informe de progreso de la Presidencia, 26 de febrero de 2019). http://www.europarl.europa.eu/legislativetrain/theme-towards-a-new-policy-on-migration/file-jd-recast-eurodac-regulation 
paralelamente, también poseerá un mayor impacto y, cuanto menos adverso, en la protección de los derechos e intereses de los solicitantes de protección internacional, más concretamente, en el derecho a la privacidad y a la protección de sus datos personales.

En esta línea, cabe aducir que tal fue el impacto de esta propuesta que, en ese mismo año, el ECRE ${ }^{421}$, el $\mathrm{SEPD}^{422}$ o el Comité Meijers ${ }^{423}$ acometieron distintos análisis que coincidieron en sus potenciales implicaciones - de difícil encaje constitucional- con el derecho a la protección de datos. Igualmente, la Comisión $\operatorname{LIBE}^{424}$ expresó en su Informe de 2017 sus reticencias sobre la efectividad de este derecho, centrándose en su aplicación a diversas categorías de sujetos -no siempre clasificados rigurosamente-, el acceso de Europol, la GEFC o la transferencia a terceros países a efectos de retorno, cuestiones que fueron, igualmente, objeto de análisis por parte del ACNUR. ${ }^{425}$

Sin embargo, no es una cuestión baladí subrayar que estos riesgos derivados del pleno respeto a la protección de datos han venido justificándose tras los temores asociados a las amenazas relativas a la seguridad interna de los Estados en el que las identidades de los migrantes permanecían frecuentemente indeterminadas, una situación

\footnotetext{
${ }^{421}$ ECRE, Comentarios sobre la propuesta de la Comisión sobre el Reglamento de Eurodac COM(2016) 272, julio de 2016.

${ }^{422}$ Supervisor Europeo de Protección de Datos, Opinión 07/2016 sobre el Primer paquete de reformas..., ob.cit., p. 2.

${ }^{423}$ Meijers Committee, standing committee of experts on international immigration, refugee and criminal law, Note on the proposed reforms of the Dublin Regulation (COM (2016) 197), the Eurodac recast proposal (COM (2016) 272 final), and the proposal for an EU Asylum Agency (COM(2016)271 final), CM1609.

${ }^{424}$ Parlamento Europeo, Informe sobre la propuesta de Reglamento del Parlamento Europeo y del Consejo relativo a la creación del sistema «Eurodac» para la comparación de las impresiones dactilares para la aplicación efectiva del [Reglamento (UE) n. ${ }^{\circ} 604 / 2013$, por el que se establecen los criterios y mecanismos de determinación del Estado miembro responsable del examen de una solicitud de protección internacional presentada en uno de los Estados miembros por un nacional de un tercer país o un apátrida y de la identificación de un nacional de un tercer país o un apátrida en situación ilegal, y a las solicitudes de comparación con los datos de Eurodac presentadas por los servicios de seguridad de los Estados miembros y Europol a efectos de aplicación de la ley (versión refundida) (COM(2016)0272 - C80179/2016 - 2016/0132(COD)), 8 de junio de 2017.

${ }^{425}$ ACNUR, Comentarios sobre la propuesta de la Comisión Europea del Reglamento del Parlamento Europeo y del Consejo sobre el establecimiento de "Eurodac" para la comparación de las impresiones dactilares para la aplicación efectiva del Reglamento (UE) n. ${ }^{\circ}$ 604/2013, por el que se establecen los criterios y mecanismos de determinación del Estado miembro responsable del examen de una solicitud de protección internacional presentada en uno de los Estados miembros por un nacional de un tercer país o un apátrida y de la identificación de un nacional de un tercer país o un apátrida en situación ilegal, y a las solicitudes de comparación con los datos de Eurodac presentadas por los servicios de seguridad de los Estados miembros y Europol a efectos de aplicación de la ley, mayo de 2017.
} 
que abordó el PE en una reunión informativa sobre las reformas legislativas de Eurodac. ${ }^{426}$ Asimismo, la Comisión alertó acerca de la situación de "aparente normalidad" que se produjo ante una realidad sumamente caótica para los EEMM en el que un gran número de migrantes habían entrado de forma irregular y permanecían invisibles a efectos de Eurodac y, por ende, a Europa. Un escenario de potenciales implicaciones para la seguridad europea en su conjunto y que, indiscutiblemente, elevó el riesgo de movimientos secundarios -e incluso posteriores- no autorizados, así como las estancias irregulares generalizadas en la UE. ${ }^{427}$

Ciertamente, esta propuesta de Eurodac supondrá una trascendental transformación de este sistema, adoptándose soluciones eficientes a todos estos conflictos que llevan produciéndose en los últimos tiempos. Es más, como aduce la Comisión, dispondrá de una optimada identificación de los solicitantes de asilo, unos retornos más efectivos y un preciso seguimiento de los movimientos secundarios, entre otras mejoras de menor entidad. ${ }^{428}$ Ahora bien, paralelamente a este incremento de la eficiencia del sistema, capaz de afrontar las "brechas estructurales" que se produjeron en los controles fronterizos -una de las cuestiones nucleares para garantizar el mantenimiento de la seguridad nacional y europea-, su aplicación resultará susceptible de impactar excesivamente en los derechos fundamentales. Sobre esta compleja ponderación, señala Goizueta Vértiz que, aunque el concepto de seguridad resulta elástico, debe respetar el límite del contenido esencial del derecho a la protección de datos, teniendo en cuenta los fines de la cooperación policial y el bien jurídico protegido por el derecho a la protección de datos. Si bien, reconoce la gran complejidad para lograr el correcto equilibrio entre seguridad y libertad, ${ }^{429}$ como se produce en Eurodac.

\footnotetext{
${ }^{426}$ Servicio de Estudios del Parlamento Europeo (EPRS), Recast Eurodac Regulation, 10 de marzo, 2017. Disponible

http://www.europarl.europa.eu/RegData/etudes/BRIE/2016/589808/EPRS_BRI\%282016\%29589808_EN .pdf

${ }^{427}$ Comisión Europea, Migración y Asuntos de Interior, Identificación de solicitantes (EURODAC). Accesible en: https://ec.europa.eu/home-affairs/what-we-do/policies/asylum/identification-ofapplicants_en

${ }^{428}$ Comisión Europea, Reforma del Sistema Europeo Común de Asilo: qué cambiará con las reformas y por qué las necesitamos ahora, diciembre de 2018. https://ec.europa.eu/homeaffairs/sites/homeaffairs/files/what-we-do/policies/european-agenda-migration/20181204_managingmigration-factsheet-4-eurodac-regulation_es.pdf

${ }^{429}$ GOIZUETA VÉRTIZ, J., "La cooperación policial en el seno de Europol: el principio de disponibilidad y la confidencialidad de la información”, Revista Española de Derecho Constitucional, $\mathrm{n}^{\circ}$ 110, 2017, p. 102.
} 
Por lo tanto, en este instrumento del SECA es donde se evidencia el principal conflicto constitucional entre la privacidad y protección de datos y las tareas de prevención, detección e investigación de la migración irregular, movimientos secundarios e, incluso, de delitos graves o terrorismo. Todo ello exige analizar jurídicamente su impacto en estos derechos a fin de lograr un equilibrio entre una mejor gestión eficaz de la migración y, en mayor medida, el asilo y una mejora sustancial de sus derechos legítimos e intereses particulares.

1.2. El nuevo régimen de interoperabilidad entre Eurodac y los sistemas europeos de información.

Con independencia de la PRE, la interoperabilidad entre los distintos SSII no fue incluida como parte de la reforma del SECA en el año 2016. Esta surgió como una de las principales iniciativas legislativas de urgencia de la agenda europea del año 2018 y 2019, en concreto, de la necesidad de compartir y acceder a información relevante y que se encuentra disponible en otro EEMM, organismo o agencia de la UE a través de los múltiples SSII empleados al efecto.

Se trata de un progreso fundamental para adaptar la gestión de los SSII europeos a los convulsos escenarios que impactan en la seguridad de los EEMM, otorgando soluciones más precisas en torno a la diferenciación entre los migrantes irregulares, delincuentes o potenciales terroristas de verdaderos sujetos con necesidad de recibir protección internacional, facilitando un rápido y seguro intercambio de información. Tanto es así, que el Consejo previó contar con sus numerosos beneficios para “incrementar considerablemente la seguridad en la UE, permitir controles más eficientes en las fronteras exteriores, mejorar la detección de múltiples identidades y ayudar a prevenir y combatir la migración irregular (...) al tiempo que se salvaguardan los derechos fundamentales". 430

Si bien, sobre esta interconectividad se pronunció contundentemente el GT29, advirtiendo que la falta de criterios comunes en los Reglamentos que regulan cada sistema podría dar lugar a actuaciones muy divergentes a nivel nacional, de modo que

\footnotetext{
${ }^{430}$ Consejo de la UE, Interoperabilidad de los sistemas de información de la UE: el Consejo adopta dos Reglamentos, 14 de mayo de 2019. Disponible en: https://www.consilium.europa.eu/es/press/pressreleases/2019/05/14/interoperability-between-eu-information-systems-council-adopts-regulations/
} 
los nacionales de terceros países podían verse sujetos a diferentes prácticas policiales en función del EM donde se encuentren. ${ }^{431}$

Por lo tanto, en sintonía con lo ya expuesto en el capítulo anterior, la novedosa interoperabilidad no debe priorizar únicamente en su eficiencia y en el aumento de la seguridad, sino que correlativamente deberá respetar el derecho a la vida privada, privacidad y la protección de datos. Resulta indudable que la interoperabilidad pretende "reconceptualizar" todas las bases de datos europeas centralizadas como herramientas perfeccionadas y adaptadas a escenarios cada vez más amplios y complejos. Un proceso sobre el que, en el presente, se desconocen los límites estrictos y cuyo impacto en los mencionados derechos resulta más que evidente, equiparándose a un nuevo "modelo de vigilancia masiva en la UE", el cual ha sido objeto de límites en los últimos años por parte del TJUE.

Recordemos que en el Dictamen 1/15 relativo a la transferencia de datos del Passenger Name Record (PNR) de la UE a Canadá, la Gran Sala del TJUE determinó que dicha transferencia no equivalía a un sistema ilícito de vigilancia masiva pues su alcance personal únicamente se aplicaba a aquellos viajeros de la UE a Canadá. ${ }^{432}$ Por el contrario, como veremos más adelante, en las sentencias Digital Rights Ireland y Tele $2{ }^{433}$ el mencionado Tribunal consideró que cada base de datos por sí misma no podía establecer un régimen de vigilancia masiva, generalizado e indiscriminado conforme al Dictamen 1/15, cada uno de ellos engloba a una parte o categoría de nacionales de terceros países.

En consecuencia, no parece arriesgado avanzar que el régimen de interoperabilidad tenderá a configurarse como un nuevo modelo de vigilancia masivo que pudiera contrariar el criterio del Tribunal. Y, ello porque tras este "simple" concepto se encuentra un marco legal especialmente complejo en el que convergen distintas bases de datos a nivel europeo, en el que cada una de ellas recopila una gran tipología de

\footnotetext{
${ }^{431}$ GT29, "Dictamen sobre las propuestas de la Comisión sobre el establecimiento de un marco para la interoperabilidad entre los sistemas de información de la UE en el ámbito de las fronteras y los visados, así como la cooperación policial y judicial, el asilo y la migración”, 11 de abril de 2018, WP266, p. 11.

${ }^{432}$ TJUE (Gran Sala), Dictamen 1/15, de 26 de julio de 2017.

${ }^{433}$ Como veremos más adelante, en las SSTJUE Digital Rights Ireland y Tele2, la Gran Cámara estableció que se trataba de casos de vigilancia masiva por lo que prohibió su tratamiento por abarcar "prácticamente a toda la población de la UE". Véase SSTJUE, Digital Rights Ireland y Seitlinger y otros, de 8 de abril de 2014 (Asuntos acumulados C-293/12 y C-594/12) y Tele2 Sverige AB c. Post- och telestyrelsen..., ob. cit.
} 
datos e información personal para fines concretos, específicos e, incluso, excluyentes entre sí y que identifican a una multitud de distintas categorías de nacionales de terceros países. $^{434}$

Aún con todo, en todas ellas confluyen características comunes. Por ejemplo, a excepción del Sistema Europeo de Información y Autorización de Viajes (ETIAS), tanto Eurodac, como los sistemas de información Visa (VIS), Schengen (SIS) o de Antecedentes Penales (ECRIS-TCN) procesan "categorías especiales de datos personales" de acuerdo con el art. 9 RGPD. A su vez, las autoridades policiales y Europol pueden tener acceso a los registros -tanto en condiciones específicas (VIS, Eurodac, ETIAS) como por imperativo legal (SIS II y ECRIS-TCN)- e, igualmente, en cada una de ellas, los datos son conservados durante un período de tiempo significativo.

Sin embargo, quizá lo más relevante es que el cruce de información entre todas estas bases de datos creará una interconectividad sin precedentes que ampliará la finalidad de cada sistema hacia un "multipropósito" que excede de los estrictos criterios que prevén específicamente sus reglamentos de funcionamiento. De acuerdo con Bunyan, pretende establecerse un paso decisivo hacia un teórico "sistema de información único europeo al servicio de un Gran Hermano de la $\mathrm{UE}^{, 435}$ en el que se supedita el derecho a la privacidad y protección de datos a las cuestiones intrínsecas de seguridad. La toma de

\footnotetext{
${ }^{434}$ Por ejemplo, mientras Eurodac tiene por objeto la recopilación de las huellas dactilares - ampliado a los datos de imagen facial en la PRE- de los solicitantes de protección internacional, nacionales de terceros países interceptados al cruzar las fronteras irregularmente o en situación ilegal en el territorio de un Estado miembro (arts. 15 y ss.), el VIS se aplica a los visitantes titulares de un visado para entrar en especio Schengen (art. 7 y ss. del Reglamento 767/2008 de 9 de julio de 2008 sobre el Sistema de Información de Visados (VIS) y el intercambio de datos sobre visados de corta duración entre los Estados miembros (Reglamento VIS). L 218/60). Por su parte, ETIAS -futuro SEIAV- registrará los visitantes de países exentos de la obligación de visado en caso de tránsito aeroportuario o para estancias previstas en el territorio de los Estados miembros cuya duración no exceda de 90 días en cualquier periodo de 180 días; refugiados y apátridas cuando el país tercero en el que residan y que haya expedido su documento de viaje sea uno de los terceros países que figuran en el anexo II del Reglamento (CE) n. ${ }^{\circ}$ 539/2001 y que estén exentos de la obligación de visado o nacionales de terceros países que cumplan las siguientes condiciones: sean miembros de la familia de un ciudadano de la Unión al que se aplique la Directiva 2004/38/CE o de un nacional de un tercer país beneficiario del derecho a la libre circulación con arreglo al Derecho de la Unión; y no sean titulares de la tarjeta de residencia contemplada en la Directiva 2004/38/CE. [art. 2 de la Propuesta de Reglamento por el que se crea un Sistema Europeo de Información y Autorización de Viajes (SEIAV) y por el que se modifican los Reglamentos (UE) n. ${ }^{\circ} 515 / 2014$, (UE) 2016/399, (UE) 2016/794 y (UE) 2016/1624 (COM(2016) 731 final)].

${ }^{435}$ BUNYAN T., The "point of no return" Interoperability morphs into the creation of a Big Brother centralised EU state database including all existing and future Justice and Home Affairs databases, Statewatch, mayo de 2018. Accesible en: http://www.statewatch.org/analyses/eu-interop-morphs-intocentral-database.pdf
} 
decisiones tiende a inaplicar el principio de la limitación de la finalidad, aproximándose -en exceso- a las cuestiones relacionadas con el mantenimiento de la seguridad y el orden público.

Dicho esto, debemos apuntar que la interoperabilidad fue definida por la Comisión en el año 2005 como "la capacidad de los sistemas y de los procesos empresariales que respaldan la cesión de datos y permite el intercambio de información $\mathrm{y}$ conocimiento". ${ }^{436} \mathrm{Si}$ bien, su impulso se produjo tras el repunte de los ataques terroristas que experimentaron los EEMM durante los años 2015 y 2016 que llevó a la creación de un Grupo de expertos de alto nivel sobre sistemas de información e interoperabilidad, que dio luz verde a la implementación de esta iniciativa en mayo de $2017^{437}$

Ello sin perjuicio de que se encontrara parcialmente prevista en la propuesta de refundición del Reglamento Eurodac desde al año 2016. La Exposición de Motivos y el Considerando 14 ya hacían referencia a la Comunicación de la Comisión titulada «Sistemas de información más sólidos e inteligentes para la gestión de las fronteras y la seguridad» ${ }^{438}$ como un primer paso para dotar a este sistema de los elementos necesarios hacia su interoperabilidad con otros SSII, bajo criterios de necesidad y proporcionalidad. Disponía textualmente que “(...) con el apoyo del grupo de expertos sobre sistemas de información e interoperabilidad, la Comisión evaluará la necesidad y proporcionalidad de establecer la interoperabilidad con el Sistema de Información de Schengen (SIS) y el Sistema de Información de Visados (VIS). En este contexto (...) la Comisión examinará igualmente si es necesario revisar el marco jurídico para el acceso a Eurodac a efectos de aplicación de la ley".

Y, aunque la PRE aún se encuentra en proceso de negociación, lo cierto es que el régimen jurídico de la interoperabilidad ya se encuentra previsto tanto en los ámbitos de las fronteras y los visados y de la cooperación policial y judicial, el asilo y la migración a través de los Reglamentos europeos 2019/817 y 2019/818, de 22 de mayo de 2019. La

\footnotetext{
${ }^{436}$ Comunicación de la Comisión al Consejo y al Parlamento Europeo sobre una mayor eficacia, interoperabilidad y sinergia entre las bases de datos europeas en el ámbito de la Justicia y los Asuntos de Interior, Bruselas, 24 de noviembre de 2005, COM(2005) 597 final

${ }^{437}$ Comisión Europea, High-level expert group on information systems and interoperability, Final report, 11 de mayo de 2017, (2017)2412067.

${ }^{438}$ Comisión Europea, Comunicación de la Comisión al Parlamento Europeo y al Consejo. Sistemas de información más sólidos e inteligentes para la gestión de las fronteras y la seguridad, de 6 de abril de 2016 [COM(2016) 205 final].
} 
aprobación de este último incidirá directamente en el futuro Reglamento de Eurodac, pese a que, a la actualidad, se erige como uno de los primeros precedentes legales a nivel comunitario que vincula directamente el asilo y el derecho penal, una conexión que no está exenta a riesgos de gran calado en los derechos de distintas categorías de nacionales de terceros países. A juicio del SEPD, esta decisión de hacer que los sistemas informáticos a gran escala sean interoperables entre sí "no es principalmente una elección técnica sino política" que marcará "un punto de no retorno", ${ }^{439}$ facultando al empleo de los datos para fines que no se encuentran expresamente regulados en sus Reglamentos y que, como veremos más adelante, afectará transversalmente a cada uno de los SSII, incluyendo a Eurodac.

En aras de concretar el contenido del Reglamento 2018/818 sobre la futura reforma de este último Sistema, su art. 20 concreta el inicio de este acción de comprobación. Dispone expresamente que la autoridad policial de un EEMM está autorizada a consultar los datos biométricos de una persona tomada durante un control de identidad del Repositorio de identidad común con el único propósito de identificación. Una disposición, a todas luces amplia, que distaba del mismo artículo en la propuesta anterior a su aprobación, que autorizaba a la identificación con la estricta finalidad de contribuir a prevenir y combatir la migración irregular y asegurar un alto nivel de seguridad. Un precepto sobre el que, como anticipó el SEPD, no lograba determinar si estos controles respondían al control de la inmigración o a procedimientos policiales. ${ }^{440}$

Estas verificaciones de identidad que efectúan las autoridades policiales podrían propiciar prácticas discriminatorias, ${ }^{441}$ teniendo en cuenta que pueden acceder a una gran cantidad de información de distinta tipología con fines que nada tienen que ver los

\footnotetext{
${ }^{439}$ SEPD, Dictamen 4/2018 sobre las propuestas de dos reglamentos que establecen un marco para la interoperabilidad entre los sistemas de información a gran escala de la UE, 16 de abril de 2018, p. 3. Disponible en: https://edps.europa.eu/sites/edp/files/publication/2018-0416_interoperability_opinion_en.pdf ${ }^{440}$ SEPD, Dictamen sobre las propuestas de dos reglamentos..., ob. cit., p. 7

${ }^{441}$ El Comité Meijers emitió una opinión en este sentido el 19 de febrero de 2018 afirmando lo siguiente: "La propuesta agrega otra tarea de compleja supervisión difícil y técnicamente muy complicada a la larga lista de tareas de las APDs. Igualmente, se plantean preguntas con respecto a la "necesidad y proporcionalidad" de trato diferencial entre los ciudadanos de la UE y los nacionales de terceros países, por lo que advirtió "el riesgo de discriminación de los nacionales de terceros países y de personas de raza o etnia origen". Meijers Committee, Comments on the Proposal for a Regulation of the European Parliament and of the Council on establishing a framework for interoperability between EU information systems (police and judicial cooperation, asylum and migration) 12 de diciembre de 2017, COM (2017) 794, 19 de febrero de 2018 (CM1802). Disponible en: https://www.commissiemeijers.nl/sites/all/files/cm1802_comments_on_com_2017_794.pdf
} 
unos de los otros, propiciando una indirecta elaboración de perfiles contraria al art. 11.3 de la Directiva de protección de datos en el ámbito penal. Asimismo, el procesamiento de sus datos biométricos será susceptible de comparación inmediata con cualquier otro dato disponible en diversas bases de datos europeas, acarreando posibles consecuencias desventajosas para sujetos en situación de vulnerabilidad como los solicitantes de protección internacional, que pueden enfrentarse a una llegada a territorio de la UE en condiciones sumamente precarias. En esta línea se pronunció la FRA en julio de 2017, cuando publicó un informe sobre los derechos fundamentales y la interoperabilidad de los SSII de la UE en el que destacaba el riesgo que podía suponer la elaboración de perfiles si su uso no se restringía a casos excepcionales amparados bajo el principio de necesidad por razones de interés público. ${ }^{44}$

No obstante, resulta incuestionable que esta gestión de la información en el ámbito del SECA garantizará una exhaustiva identificación de los sujetos que desean entrar en territorio de la UE, facilitando la diferenciación entre diversas categorías de sujetos migrantes irregulares, delincuentes o potenciales terroristas de verdaderos refugiados-. El problema radicará en que, paralelamente, también aumentará la elusión de los compromisos de los Estados al disponer, correlativamente, de un mayor conocimiento que faculte a las autoridades nacionales a proceder a la exclusión o revocación del estatuto de protección internacional ante circunstancias que puedan comprometer su propia seguridad. Una acción sobre la cual no se dispone de parámetros comunes y homogéneos de evaluación.

Además, la interoperabilidad exceptúa indirectamente el principio de limitación de la finalidad, uno de los principios básicos de la legislación de protección de datos que prevén los arts. 8.2 CDFUE, 5.1b) RGPD, 3.3 de la Directiva de protección de datos en el ámbito penal y 11 del Convenio $108+$ y, como alertan el SEPD o la FRA, puede incluso contravenirlo. ${ }^{443}$ En este sentido, cada una de las bases de datos posee una naturaleza compartimentada en sí misma, su funcionamiento responde a unos

\footnotetext{
${ }^{442}$ FRA, Fundamental rights and the interoperability of EU information systems: borders and security, 2017, p. 9.

${ }^{443}$ SEPD, Dictamen sobre las propuestas de dos reglamentos..., ob. cit., p. 3; FRA, Fundamental rights and the interoperability of EU..., ob. cit., p. 21.
} 
parámetros muy concretos por lo que la interoperabilidad puede desvirtuar la funcionalidad técnica específica de cada uno de los sistemas. ${ }^{444}$

En efecto, pese a que permitirá que el futuro Reglamento de Eurodac pueda emplear la información del resto de SSII para cumplir eficazmente con sus objetivos, también reconfigurará transversalmente todos estos sistemas a largo plazo, incorporando un acceso cada vez más amplio a distintos datos personales y fomentando una disponibilidad de la información sin precedentes. No obstante, la adopción final de la implementación práctica de esta interoperabilidad se encuentra supeditada a la aprobación de la propuesta del paquete de asilo. Este Reglamento de interoperabilidad no prevé disposiciones específicas para Eurodac. Su arquitectura actual no resulta, en modo alguno, adecuada para tales fines. Consecuentemente, estas disposiciones comenzarán a adoptarse respecto a Eurodac a partir de la fecha en que sea aplicable la refundición de su actual Reglamento. Un plazo que prevé extenderse en los sucesivos años y que, en línea con la previsión de la Comisión Europea, gozará de plena operatividad a finales para el año $2023 .{ }^{445}$

Por todo ello, la interoperabilidad no deberá convertirse en un fin en sí mismo, ni aplicarse como un modo de alterar la naturaleza y los propósitos y fines de Eurodac $-\mathrm{O}$ del resto de SSII-. Deberá ser capaz de asistir a las autoridades nacionales en la determinación de aquellos supuestos concretos y merezcan una labor intensa de cotejo y validación de esta información, apartándose de las garantías de la legislación de protección de datos por su especial incidencia en la seguridad europea.

A nuestro juicio, la interoperabilidad debería abordarse como una forma de superar la actual "compartimentación" estanca y los "puntos ciegos o invisibles" que han dificultado la labor de las autoridades nacionales. De esta manera, independientemente del incremento de la eficiencia y eficacia de la PRE, el futuro Sistema deberá combinar la información de que disponen los restantes sistemas, las autoridades nacionales e,

\footnotetext{
${ }^{444}$ En el año 2010, la Comisión señaló expresamente que un sistema general de información de la UE "constituiría una restricción grave e ilegítima del derecho de las personas a la privacidad y la protección de datos y plantearía enormes desafíos en términos de desarrollo y operación". Comisión Europea, Panorama general de la gestión de la información en el espacio de libertad, seguridad y justicia, $\operatorname{COM}(2010) 385$ final, 20 de julio de 2010, p. 3.

${ }^{445}$ Parlamento Europeo, Interoperabilidad entre los Sistemas de información fronteriza y de seguridad de la UE, Junio de 2019 (PE 628.267). Disponible en: https://www.europarl.europa.eu/RegData/etudes/BRIE/2018/628267/EPRS_BRI(2018)628267_EN.pdf
} 
incluso, las agencias europeas como la GEFC, la AAUE o Europol para extraer conclusiones más precisas y exactas sobre los solicitantes de protección internacional y las dos categorías de migrantes irregulares objeto de procesamiento por esta base de datos y sobre la que nos detendremos con posterioridad.

\section{La gestión coordinación y supervisión de Eurodac y sus implicaciones en la protección de los datos personales.}

Eurodac no ha procesado información personal que exceda de un gran volumen de huellas digitales, el sexo de la persona o el EM de origen. Una situación que, como veremos en sucesivos epígrafes, mutará profundamente con la PRE al extender la biometría a las imágenes faciales, incluyendo también información alfanumérica como el nombre y apellido o cualquier alias y su nacionalidad, lugar y fecha de nacimiento, etc.

A pesar de esta gran recopilación de datos personales, no es menos cierto que las huellas dactilares han sido y son, actualmente, el verdadero dato instrumental para la consecución de los objetivos de identificación de Eurodac y determinación, en su caso, del primer lugar de presentación de la solicitud de asilo. De hecho, según la última estadística anual que llevó a cabo la agencia eu-LISA en 2018, los EEMM y la Europol transmitieron con éxito un total de 879.072 grupos de huellas dactilares al Sistema Central Eurodac durante ese año sobre distintas categorías de sujetos. ${ }^{446}$

Estos datos disminuyeron un 13\% en comparación con el tráfico registrado en 2017, salvo la toma de huellas de personas detenidas ilegalmente en el territorio de un EM, que aumentaron ligeramente. ${ }^{447}$ Esto constata que la mayor parte de las huellas dactilares almacenadas en el sistema central de Eurodac corresponden a solicitantes de protección internacional -un 97\% frente a un "residual" 3\% de nacionales de terceros países o apátridas que cruzaron las fronteras exteriores de forma irregular-. Por ello,

\footnotetext{
${ }^{446}$ El Sistema Central Eurodac procesó 551.253 huellas dactilares de solicitantes de protección internacional de 14 años o más (categoría 1); 103.333 huellas dactilares de personas de 14 años o más detenidas al cruzar irregularmente la frontera exterior de un Estado miembro (categoría 2); 224.180 huellas dactilares de personas de 14 años o más, detenidas ilegalmente en el territorio de un Estado miembro (categoría 3); 306 huellas dactilares enviadas por las autoridades designadas de la ley del EM o Europol (únicamente búsquedas) para prevenir, detectar o investigar delitos terroristas u otros delitos graves (categorías 4 y 5). Véase Eu-LISA, EURODAC - 2018, Annual Statistics, Factsheet, febrero de 2019. Accesible en: https://www.eulisa.europa.eu/Publications/Reports/Eurodac\% $20 \% 20$ 2018\%20statistics\%20-\%20factsheet.pdf

${ }^{447}$ Eu-LISA, EURODAC-2018 Annual Report, junio de 2019, p. 4.
} 
resulta indiscutible que Eurodac está relacionado principalmente con el procesamiento de información en el ámbito del asilo, cuyo registro de huellas dactilares y ulterior comparación con los datos registrados en los archivos nacionales permiten una identificación con un mínimo margen de error sobre la identidad de los sujetos, reflejando la alta efectividad de este sistema en la consecución de los objetivos del SECA. Ahora bien, el tratamiento de esta información no ha resultado ajeno a contundentes críticas doctrinales, las cuales han examinado que las huellas dactilares no solo poseen riesgos desconocidos de considerable entidad, sino que también puede propiciar la inclusión de identificaciones erróneas e inexactas, ${ }^{448}$ así como un uso incorrecto, en cuyo caso, como apunta Jacobsen o Rahman, incurriría en "una creciente exposición hacia nuevas formas de intrusión e inseguridad". 449

De tal manera, este procesamiento de datos a nivel nacional no contempla disposiciones que regulen detalladamente la protección de datos a nivel comunitario, emergiendo una gran disparidad y falta de uniformidad en los distintos EEMM. Ello, pese a los ingentes esfuerzos de cooperación, por parte del Grupo de Coordinación de Supervisión de Eurodac (SCG), como de supervisión. En este último caso, la agencia eu-LISA es la encargada de la Gestión Operativa de Sistemas Informáticos de Gran Magnitud en el Espacio de Libertad, Seguridad y Justicia, tal y como regula el Reglamento de Eurodac o los reglamentos aprobados en el año 2018 de eu-LISA o el relativo al tratamiento de datos por parte de las instituciones comunitarias.

Conviene subrayar, como también han puesto de manifiesto González Fuster o Gutwirth que la falta de regulación a nivel nacional ha ocasionado situaciones en las que el nivel adecuado de protección no puede garantizarse de forma satisfactoria,

\footnotetext{
${ }^{448}$ FARRAJ, A., "Refugees and the Biometric Future: The Impact of Biometrics on Refugees and Asylum Seekers." Columbia Human Rights Law Review, no 42, 2010, p. 891. BOHLIN, A., "Protection at the cost of Privacy. A study of the biometric registration of refugees." Master's Thesis, University of Lund, 2008, p. 8.

449 JACOBSEN, K. L., "Experimentation in Humanitarian Locations: UNHCR and Biometric Registration of Afghan Refugees", Security Dialogue, vol. 46, n² 2, 2015, pp. 144-164. RAHMAN, Z., "Biometrics in the Humanitarian Sector", The Engine Room and Oxfam, marzo de 2018. Accesible en: www.theengineroom.org/wp-content/uploads/2018/03/Engine-Room-Oxfam-Biometrics-Review.pdf.

REIDY, E. "How a fingerprint can change an asylum seeker's life", The New Humanitarian, 21 de noviembre de 2017. Disponible en: www.thenewhumanitarian.org/special-report/2017/11/21/howfingerprint-can-change-asylum-seeker-s-life
} 
produciendo un grave desafío en la protección requerida de los datos personales. ${ }^{450}$ En esta línea, y ciñéndonos al Reglamento Eurodac, tanto el actual como su propuesta de reforma prevén un estricto régimen jurídico en materia de gestión, coordinación y supervisión en la información contenida el Eurodac y que resulta conveniente analizar desde dos perspectivas:

1. La gestión y coordinación de Eurodac pueden categorizarse como factores esenciales para asegurar el correcto funcionamiento del sistema y la seguridad de sus datos, en vista de "la elevada calidad técnica y la legalidad de las consultas son esenciales para garantizar el funcionamiento correcto y libre de contratiempos de Eurodac" (Considerando 43 o 53 PRE). De este modo, a nivel nacional, las Autoridades de protección de datos (APDs) son las encargadas de garantizar el pleno respeto y control de los datos personales de Eurodac (art. 30 o 32 PRE). Por su parte, el SEPD tiene encomendada la facultad de gestionar el tratamiento de datos en sus operaciones “centralizadas" que lleva a cabo eu-LISA de acuerdo con el Reglamento 2018/1725 de protección de datos aplicable a las instituciones (art. 31 o 33 PRE).

Tanto las ADPs como el SEPD se coordinan dentro de sus competencias respectivas, debiendo cooperar "activamente en el marco de sus responsabilidades y garantizarán una supervisión coordinada de Eurodac" (art. 32 o 34 PRE). Una labor que, aunque el Reglamento Eurodac no lo contempla explícitamente, en los últimos años ha sido atribuida al SCG, que publica anualmente un Informe sobre su actividad desarrollada en este ámbito. ${ }^{451}$ El último data de los años comprendidos entre 2016-2017 en el que únicamente acomete observaciones relativas al presente Reglamento. En consecuencia, en el presente no se encuentran referencias expresas sobre cuál será el papel que llevará a cabo el SCG en el futuro Reglamento Eurodac.

\footnotetext{
${ }^{450}$ GONZALEZ FUSTER G., GUTWIRTH S., "When 'digital borders' meet 'surveilled geographical borders'. Why the future of EU border management is a problema", en BURGESS E., GUTWIRTH S., (eds.), A Threat Against Europe?: Security, Migration and Integration, Vubpress, 2011, p. 179.

${ }^{451}$ El SCG únicamente ha analizado el impacto del reglamento Eurodac que entró en vigor en 2015 en las condiciones de acceso a la información por parte de las autoridades policiales (incluida Europol) a los datos de Eurodac. Precisamente, este informe reflejó las profundas preparaciones que habían llevado a cabo tanto por parte de la agencia eu-LISA como las autoridades nacionales encargadas de Eurodac y acogió con satisfacción los esfuerzos realizados por estas autoridades para garantizar la aplicación de las disposiciones de Eurodac. La falta de los dos informes posteriores se debe a la carencia de aprobación del nuevo Reglamento, por lo que los aspectos más esenciales del mismo todavía no han entrado en vigor. Véase Secretariado del Grupo de Coordinación y Supervisión de Eurodac, Informe de actividad 20162017, p. 6. Los informes se encuentran disponibles en: https://edps.europa.eu/data-protection/european-itsystems/eurodac_en
} 
2. Por su parte, eu-LISA tiene atribuida la responsabilidad de la Infraestructura de Comunicación en las funciones de supervisión, seguridad y coordinación de las relaciones entre los EEMM y el proveedor (art. 4.2 o 5.3 PRE).

Esta agencia fue creada por el Reglamento 2011/1077, que le atribuyó la responsabilidad de la gestión operativa del Sistema de Información de Schengen (SIS) y el Sistema de Información de Visas (VIS). Dos años más tarde, el Reglamento de Eurodac 2013/603 le confió la gestión operativa del sistema.

Eu-LISA ha sido responsable de garantizar la continuidad de los SSII y de los datos, su seguridad, integridad y disponibilidad. En su funcionamiento ordinario, uno de sus ejes vertebrales es el cumplimiento de la normativa de protección de datos de la UE y la capacitación de las autoridades nacionales en el cumplimiento de la misma. Por ello, esta agencia colabora activa y directamente tanto con los proveedores de sistemas nacionales como con las APDs, el SEPD y las distintas redes de oficiales de seguridad.

Tal ha sido la relevancia de la protección de datos por parte de la Agencia en los últimos años, que el Informe de eu-LISA sobre Eurodac de 2017 adoptó toda una serie de recomendaciones proporcionadas por el SEPD. Estas estribaron en la necesidad de incrementar la protección de datos aplicables a las medidas organizativas y de seguridad, aprobar su nuevo Reglamento de funcionamiento y revisar y actualizar sus controles técnicos de seguridad.

En este contexto, tanto el Delegado de Protección de datos (DPO) como la Unidad de Seguridad y el Sector de Sistema de Asilo de eu-LISA comenzaron a trabajar conjuntamente para implementar estas mejoras, que fueron abordadas durante $2018,{ }^{452}$ año en el que fue aprobado el Reglamento 2018/1726 que desarrolla el funcionamiento de esta agencia ${ }^{453}$ y que, introduce dos principales novedades al efecto:

a) Por una parte, encomendó la gestión operativa de Eurodac mediante la dirección de un Consejo de Administración y el Grupo Consultivo de Eurodac. De acuerdo con el art. 27.1 del mencionado Reglamento, este Grupo proporciona asesoramiento al Consejo de Administración sobre el funcionamiento técnico de Eurodac, especialmente, en lo

\footnotetext{
${ }^{452}$ Eu-LISA, EURODAC-2017. Annual Report, junio de 2018, p. 9.

${ }^{453}$ Reglamento (UE) 2018/1726 del Parlamento Europeo y del Consejo, de 14 de noviembre de 2018, relativo a la Agencia de la Unión Europea para la Gestión Operativa de Sistemas Informáticos de Gran Magnitud en el Espacio de Libertad, Seguridad y Justicia (eu-LISA), y por el que se modifican el Reglamento (CE) n. ${ }^{\circ}$ 2006/1987 y la Decisión 2007/533/JAI del Consejo y se deroga el Reglamento (UE) n. ${ }^{\circ}$ 2011/1077. PE/29/2018/REV/1. DO L 295, 21.11.2018, p. 99-137.
} 
relativo a la preparación del programa de trabajo anual y del informe anual de actividad, facilitando igualmente todas las actividades, cuestiones y experiencias relacionada con este Sistema.

Durante 2018, el mencionado Consejo se reunió un total de cuatro veces para discutir la disponibilidad y el rendimiento del sistema central de Eurodac, debatir y aprobar su operatividad y evaluar la formación proporcionada de acuerdo con el art. 40.1 del Reglamento Eurodac (art. 42.1 PRE). Todo ello fructificó en el Informe anual de euLISA sobre Eurodac del año 2018, ${ }^{454}$ en el que se destacaron notorios avances en las áreas de seguridad y protección de datos en relación con los distintos sujetos objeto de procesamiento por parte del sistema central de Eurodac, supervisado por el SEPD. Es más, tras su estrecha colaboración con el DPO de eu-LISA durante los años 2017 y 2018, las recomendaciones del informe de inspección del SEPD concluyeron de forma satisfactoria, cumpliendo con el calendario previsto por su DPO. ${ }^{455}$ De este modo, fue adoptada una nueva política de identificación y control de todas aquellas brechas de seguridad que habían afectado a los datos personales, procediendo a su registro a efectos de vigilancia y ulterior eliminación.

b) Por otra parte, el art. 8 del Reglamento Eu-LISA ha facultado a que esta agencia, de forma pionera, sea la responsable de la formación y gestión operativa de DubliNET, el canal separado de transmisión electrónica segura que emplean las autoridades de los EEMM. El 11 de octubre de 2018, la Red de Unidades de Dublín de la EASO reunió a expertos de 24 EEMM para abordar los desafíos y las buenas prácticas del uso de DubliNET. Esta reunión se centró en el papel clave de eu-LISA en el funcionamiento de este canal y se acordó que la EASO debía mejorar los flujos de intercambio de información y la cooperación práctica entre las autoridades nacionales y eu-LISA con objeto de superar los obstáculos prácticos relacionados con el uso del sistema. ${ }^{456}$

Además, tal es la importancia de esta Agencia para acometer los grandes retos en la gestión de la información que De Bruycker propuso que debía crear un "Funcionario de

\footnotetext{
${ }^{454}$ Eu-LISA, EURODAC-2018 Annual Report, ob. cit., p. 11.

${ }^{455}$ Sobre las acciones detalladas en este aspecto, véase: Eu-LISA, DPO Annual Work Report 2017. Data Protection Officer Ares(2018) 1040021.

${ }^{456} \mathrm{La}$ información de la reunión ha sido extraída de la web oficial de la EASO. Accesible en: https://www.easo.europa.eu/easo-dublin-network-expert-meeting-eu-lisa
} 
Derechos Fundamentales" ${ }^{457}$ con independencia de su DPO. Aún con todo, la falta de efectividad que ha podido apreciarse en los últimos años deberá superarse tras la entrada en vigor del futuro sistema Eurodac, momento en el que, como ya se ha examinado, resultará aplicable el nuevo régimen de interoperabilidad entre los SSII comunitarios, atribuyendo a eu-LISA el papel central de su desarrollo e implementación técnica.

\section{La propuesta de Reglamento de Eurodac: el incremento de la seguridad} europea y su impacto en la protección de los datos personales.

En la era digital, las nuevas tecnologías aplicables a los SSII tienden a identificar cada vez más exhaustivamente una "inequívoca verificación de la identidad de las personas" bajo su mandato operacional. Desde la implementación de los datos biométricos aplicables al control de fronteras y la gestión de la migración en la UE en el año 2003, sus beneficios se han extendido a multitud de escenarios y contextos jurídicos. Tanto es así, que en los últimos tiempos, los pasaportes biométricos constituyen una de las herramientas de control más efectivas de los nacionales en los distintos Estados. ${ }^{458}$

Precisamente, el procesamiento dactiloscópico se considera una "decisión estratégica" para una multitud de finalidades que exceden de la propia identificación de los solicitantes de asilo hacia cuestiones conexas a la asistencia humanitaria. ${ }^{459}$ Una particularidad de la que parece hacerse eco Eurodac, emplazándose como un "sistema hegemónico" que permite la verificación e identificación de la identidad más allá del ámbito del asilo desde la reforma de Eurodac en julio de 2015 y que, como veremos más adelante, marcó un serio precedente tras el reconocimiento del acceso por parte de las autoridades policiales nacionales y de la Europol. Además, Eurodac comenzó a recopilar información no únicamente de los solicitantes de asilo (art. 9), sino de otras dos categorías de personas susceptibles de ser registradas por el citado sistema: los

\footnotetext{
${ }^{457}$ DE BRUYCKER P., Towards a new European consensus on migration and asylum, en: DE BRUYCKER P., DE SOMER M., DE BROUWER J. (eds.), From Tampere 20 to Tampere 2.0 ... ob.cit., p. 157.

${ }^{458}$ TORPEY J, The Invention of the Passport. Surveillance, Citizenship, and the State, Cambridge: Cambridge University Press, 2018; SULLIVAN C., Digital identity. From emergent legal concept to new reality. Computer Law \& Security Review, no 34, 2018, p. 723; BEDUSCHI, A., "Digital identity: Contemporary challenges for data protection, privacy and non-discrimination rights", Big Data \& Society, 2019, p. 2. Accesible en: https://doi.org/10.1177/2053951719855091

${ }^{459}$ JACOBSEN, K. L., "On Humanitarian Refugee Biometrics and New Forms of Intervention”, Journal of Intervention and Statebuilding, 2017, pp. 1-23.
} 
nacionales de terceros países o apátridas que cruzan la frontera externa de forma irregular (art. 14) y los nacionales de terceros países o apátridas que se encuentran ilegalmente en un EM (art. 17), siempre y cuando estos individuos no fueran menores de 14 años.

En esta línea, estamos de acuerdo con Ferraris cuando sostiene que, de acuerdo con el Informe Anual de 2016 de Eurodac, la diferenciación de los migrantes por parte de los EEMM ha resultado arbitraria, excediendo del mandato estrictamente establecido con objeto de proporcionar una respuesta "eficiente" a los problemas de identificación de una migración cada vez más amplia, desplazándose desde "una base de datos creada originariamente con funciones administrativas a una poderosa herramienta que categoriza a las personas y define su incierto futuro". ${ }^{460}$ De hecho, esta modificación del vigente Reglamento vislumbró el carácter prioritario del procesamiento de una tipología de información cada vez más extensa en detrimento de las garantías relativas a la protección de estos datos. Un supuesto que alcanzará su cota más álgida tras la aprobación de la PRE, la cual proporcionará un cambio de paradigma para dar solución a la falta de identificación efectiva de los solicitantes de asilo de los últimos tiempos recordemos, que sus huellas resultaban asiduamente destruidas, dañadas o, simplemente, su registro no se contemplaba para los menores de 14 años-, al igual que a la frecuente indeterminación y generalizados movimientos secundarios de migrantes irregulares.

Con carácter general, estos déficits prevén superarse mediante la inclusión de novedosas disposiciones objeto de análisis detallado en los sucesivos epígrafes. Estas aumentarán vertiginosamente las dimensiones de eficiencia y eficacia de este sistema, aunque también pueden conducir a la creación de un sistema diseñado a modo de arma discriminatoria para los solicitantes de protección internacional. En especial, si correlativamente no se promueven altos estándares en materia de protección de datos. En este sentido, la mencionada propuesta remite directamente a la normativa comunitaria de protección de datos y lo hace de una forma, cuanto menos, confusa y excesivamente amplia, propiciando un contexto de fuerte inseguridad jurídica.

\footnotetext{
${ }^{460}$ FERRARIS V., "Economic Migrants and Asylum Seekers in Ten Fingers: Some Reflections on Eurodac and Border Control", Centre Border-Criminologies Blog, 2017.

Disponible en: https://www.law.ox.ac.uk/research-subject-groups/centre-criminology/centrebordercriminologies/blog/2017/05/economic-migrants
} 
Como ya abordamos en el capítulo anterior, la mencionada propuesta dispone de referencias expresas al RGPD en los Considerandos 49 y 50 RGPD, que contemplan su adecuación para la responsabilidad del tratamiento de los datos, la salvaguardia de los derechos de los sujetos de los datos y la supervisión de la protección de los datos, así como su remisión en el caso de que se proceda a transferir los datos a terceros países. Sin embargo, muchas de las incertidumbres jurídicas sobre el régimen jurídico se solventarán en el futuro Reglamento de Eurodac.

Los Considerandos 47 y 48 PRE prevén la aplicación de esta Directiva al tratamiento general de datos personales que lleven a cabo los EEMM en aplicación del presente Reglamento, excluyendo únicamente el que realicen las autoridades designadas o verificadoras competentes de los EEMM para fines de "prevención, investigación, detección o persecución de los delitos de terrorismo o de otros delitos graves, en particular la protección frente a las amenazas contra la seguridad pública y la prevención de las mismas". Por lo tanto, como ya vatininó De Hert, no hay atisbo de duda de que el procesamiento de la información se efectuará de acuerdo con las disposiciones que regula la Directiva de protección de datos en el ámbito penal. ${ }^{461}$

Por lo tanto, salvo las oportunas cuestiones de tratamiento de datos para estos fines, la mencionada Directiva será aplicable en toda su extensión en lo que respecta al tratamiento de la información de Eurodac, siempre que este se lleve a cabo por las autoridades competentes de los EEMM. Su aplicación también se contempla tanto en el art. 3.2 PRE -que equipara jurídicamente el concepto de datos a los establecidos en los apartados $2^{\circ}$ y $3^{\circ}$ del art. 3 de esta Directiva cuando el tratamiento de datos personales sea efectuado por las autoridades nacionales encargadas del examen de las solicitudes de protección internacional presentadas por un nacional de un tercer país o un apátrida-, como en el art. 35.1 PRE, -por el que dispone que las APDs de cada EM controlen la legalidad del tratamiento de los datos personales, incluida su transmisión desde y hacia Eurodac-.

Ahora bien, lo que resulta especialmente complejo en la PRE a los efectos de determinación del régimen jurídico aplicable en materia de protección de datos es la remisión conjunta tanto al RGPD como a la mencionada Directiva de protección de

\footnotetext{
${ }^{461}$ Sobre un primer análisis de esta Directiva, remitimos a: De HERT, P., PAPAKONSTANTINOU, V., "The New Police and Criminal Justice Data Protection Directive: A First Analysis", New Journal of European Criminal Law, vol. 7, $\mathrm{n}^{\circ}$ 1, 2016, pp. 7-19.
} 
datos en el ámbito penal para regular los siguientes aspectos: la seguridad de los datos (art. 36.2 h), esencialmente, en lo relativo a la supervisión de las autoridades nacionales de control, las excepciones a la prohibición de transferencia de datos a terceros países, organismos internacionales o particulares (art. 37.4) o las reclamaciones contra un EM por los perjuicios causados como consecuencia de violaciones en este sentido (art. 40.3).

Además, pese a las referencias a ambos instrumentos jurídicos, la PRE carece de una previsión expresa de los principios estructurales de protección de datos, entre los que se incluyen los relativos al tratamiento de datos personales que dispone tanto el art. 5 RGPD como el art. 4 de la Directiva de protección de datos en el ámbito penal. ${ }^{462}$ Es más, estos se contemplan expresamente en la PRD IV y, sobre las cuales, nos remitimos al Capítulo anterior.

Las autoridades nacionales y europeas deben considerar la adopción de estos requisitos como parte de una infraestructura básica, de manera que contemple un conjunto de medidas técnicas y organizativas apropiadas como así regula el art. 25 RGPD y art. 20 de la Directiva de protección de datos en el ámbito penal. Y para ello, debería implementarse todo un marco jurídico de protección de datos desde el diseño y por defecto que evite y/o reduzca las posibles violaciones en la protección de los datos gestionados por este sistema. ${ }^{463}$ Para ello, los proveedores de datos deberán operar aplicando las mejores prácticas en materia de protección de datos, adoptando toda una serie de medidas organizativas y técnicas encaminadas a favorecer el respeto de la legislación de protección de datos, garantizando un marco jurídico proactivo o preventivo eficaz. Ello, en vista del nuevo contexto jurídico marcado por la modificación "holística" de Eurodac y la potencial irreparabilidad del perjuicio causado $^{464}$ en caso de que, como consecuencia de unas brechas de considerable entidad

\footnotetext{
${ }^{462}$ Los principios son los que siguen: licitud, lealtad, limitación de la finalidad, minimización de datos, exactitud, limitación del plazo de conservación, integridad y confidencialidad o responsabilidad proactiva -esta última, requiriendo la implementación de todas aquellas medidas técnicas u organizativas que se consideren adecuadas-.

${ }^{463}$ En esta línea, véase: RACHOVITSA A., "Engineering and lawyering privacy by design: Understanding online privacy both as a technical and an international human rights issue", International Journal of Law and Information Technology 24, 2016, p. 374; SCHARTUM DW, "Making privacy by design operative", International Journal of Law and Information Technology, vol. 24, no 2, 2016, p. 151.

${ }^{464}$ Debe destacarse que, si esa información llega a disposición de las autoridades del país de origen o de residencia, las consecuencias pueden ser catastróficas para los solicitantes de protección internacional, y especialmente, para sujetos relacionados directa o indirectamente con este y sitos en ese país.
} 
en la protección de los datos de este sistema, la información que consta en el mismo pueda llegar directa o indirectamente a su país de origen. ${ }^{465}$

Por su parte, el art. 35.2 PRE dispone que el tratamiento de datos personales efectuado por Europol con arreglo al presente Reglamento se llevará a cabo de conformidad con el Reglamento (UE) 2016/794 relativo a Europol, supervisado por una autoridad independiente y externa. ${ }^{466}$ Además, la recopilación de estos datos biométricos deberá cumplir estrictamente con el principio de limitación de la finalidad (art. 35.3 PRE). Esto requiere que la obtención de los datos personales conforme a Eurodac únicamente persiga los criterios establecidos en el art. 1 c), esto es, la prevención, detección o investigación del caso específico para el que hayan sido solicitados por un EM o por la Europol. De este modo, la aplicación de este límite no solo resulta uno de los principios básicos de la protección de datos, sino que su inclusión ya fue uno de los principales argumentos que obstaculizó la reforma este sistema en la pasada década. ${ }^{467}$

Una vez destacados los rasgos generales de la mencionada propuesta, en los siguientes subepígrafes se analiza cada una de las reformas que prevé el futuro Sistema de Información Eurodac y su impacto en el derecho a la protección de los datos personales. Pretenden abordarse todos aquellos aspectos que pueden comprometer seriamente la efectividad de este derecho por su especial correlación con el incremento de la seguridad y eficiencia del sistema, lo cual exigirá elevar las garantías de la protección de la información objeto de procesamiento y ulterior tratamiento.

3.1. La finalidad del futuro Eurodac: de la gestión de solicitudes de protección internacional a la detección de migrantes en situación irregular.

En los últimos tiempos, el Reglamento Eurodac ha operado como una base de datos de protección internacional que no ha proporcionado respuestas eficaces para abordar

\footnotetext{
${ }^{465}$ Esto, recordemos, podría dar lugar a represalias contra el solicitante o cualquier persona relacionada directamente con él.

${ }^{466}$ Reglamento (UE) 2016/794 del Parlamento Europeo y del Consejo, de 11 de mayo de 2016, relativo a la Agencia de la Unión Europea para la Cooperación Policial (Europol) y por el que se sustituyen y derogan las Decisiones 2009/371/JAI, 2009/934/JAI, 2009/935/JAI, 2009/936/JAI y 2009/968/JAI del Consejo. DO L 135, 24.5.2016, p. 53-114.

${ }^{467}$ BROUWER E., "Effective Remedies in Immigration Procedures: ECHR" en: Digital Borders and Real Rights, Effective Remedies for Third-Country Nationals in the Schengen Information System, 2008, Brill | Nijhoff, p. 205.
} 
los problemas relativos a la seguridad de los EEMM, especialmente, en contextos de crisis migratorias en los que las categorías de sujetos distintas de los solicitantes de asilo -más concretamente, migrantes irregulares generalmente considerandos-, permanecieron "invisibles a la UE". ${ }^{468}$ Los EEMM no estaban facultados para almacenar los datos de huellas dactilares de nacionales de terceros países en situación irregular en Eurodac, emergiendo la imperiosa necesidad de conservar esta información a los efectos de compararla mediante el "cruce de datos" entre Eurodac y las distintas bases de datos existentes a nivel nacional.

En aras de solventar este conflicto, una de las novedades que prevé la PRE es la exigencia de adaptación de este sistema a los múltiples retos emergentes en la gestión fronteriza y migración ampliamente considerada. De tal modo, contempla la recopilación de estos datos en su art. 1, adicionando un nuevo apartado b) que amplía formalmente la prestación de asistencia a los supuestos de control de "la inmigración ilegal a la Unión y los movimientos secundarios dentro de su territorio y con la identificación de los nacionales de terceros países en situación ilegal para determinar las medidas apropiadas que han de adoptar los Estados miembros, incluidas la expulsión y la repatriación de las personas residentes sin autorización”. Y para ello, remite al art. 3.1 d) PRE para definir situación ilegal como "la presencia de un nacional de un tercer país en territorio de un EEMM que no cumpla o haya dejado de cumplir las condiciones de entrada que regula el art. 5 del Código de Fronteras Schengen (CFS) u otras condiciones de entrada, estancia o residencia en ese EM".

A los efectos de identificación, la PRE mantiene las tres categorías de sujetos ya mencionadas, esto es, los solicitantes de protección internacional (art. 10.1), nacionales de terceros países o apátridas que hayan sido interceptados por las autoridades competentes de control con ocasión del cruce irregular de fronteras terrestres, marítimas o aéreas (art. 13.1) y aquellos que se encuentren ilegalmente en su territorio (art. 14.1). Si bien, lo notoriamente relevante a nuestros efectos es la ampliación de la finalidad tradicional de Eurodac, la cual pretende comprobar si estas dos últimas categorías distintas de los solicitantes de protección internacional han presentado anteriormente una solicitud de asilo en otro EM. Por tanto, el art. 13 y 14 PRE cumplirán una "función autónoma" de identificación de migrantes en situación irregular, facilitando a las autoridades de migración y asilo el control de los individuos que tratan de ingresar o

${ }^{468}$ Véase p. 2 de la Exposición de Motivos que acompaña a la propuesta de Reglamento 
permanecer en forma irregular en la UE, detectando los movimientos secundarios y potenciando su readmisión y retorno a sus países de origen. Disposiciones que vienen a reflejar el espíritu del Considerando 11 PRE consistente en "abordar la migración y, en particular, reducir y prevenir la migración irregular".

El acceso a esta información ayudará a los EEMM a determinar en qué momento y en qué preciso lugar ha ingresado un migrante a la UE con objeto de facilitar su identificación y la redocumentación de estas personas para que puedan regresar a sus países de origen -en el supuesto de que no tengan derecho a permanecer en territorio de la UE-. Una ampliación que únicamente se contempla desde una dimensión de la eficacia y que carece de referencias expresas en relación con la protección de los datos personales. Ello, pese a que desvirtúa la finalidad tradicional y principal del sistema encaminado a facilitar la consecución del Reglamento de Dublín hacia un nuevo "sistema autónomo" de detección de sujetos ajenos o que nada tienen que ver con las causas que dan lugar a la concesión del estatuto de protección internacional.

Ahora bien, esta ampliación generará consecuencias sumamente desventajosas, pudiendo contrariar indirectamente el principio de no devolución si, correlativamente, no se prevén garantías específicas para los sujetos en clara necesidad de protección internacional. Desde este punto de vista, a diferencia de la PRD IV-, ${ }^{469}$ la PRE nada dispone acerca de garantizar el pleno respeto de la limitación de la finalidad durante la recogida. Su incorporación evitaría la criminalización de los solicitantes de protección internacional y ayudaría a reducir considerablemente el margen de discrecionalidad de las autoridades nacionales a los fines concretos que se persiguen.

Por ende, considerando que la finalidad de procesamiento de los datos responderá a objetivos muy distintos, este principio debería tipificarse en el nuevo Eurodac, estableciendo condiciones específicas sobre cada una de las categorías de sujetos. Una diferenciación que deberá ser exhaustiva, principalmente, tras su interoperabilidad con el resto de SSII, en especial, para evitar los retos a medio plazo y sobre los que declaró SEPD, apuntando que podía tener un impacto desproporcionado sobre ciertas categorías de sujetos, aumentando la posibilidad de efectuar perfiles discriminatorios. ${ }^{470}$ Una afirmación que afectaría a los solicitantes de protección internacional a los que podría aplicarse los efectos de otra categoría de sujetos que nada tiene que ver con la suya

\footnotetext{
${ }^{469}$ Véase a modo de ejemplo el art. 33.4 PRD IV.

${ }^{470}$ SEPD, Dictamen sobre las propuestas de dos reglamentos..., ob. cit., p. 17.
} 
como, por ejemplo, los migrantes en situación irregular y la cesión de datos a terceros países para fines de retorno, tal y como analizaremos en el siguiente epígrafe.

Además, nada impide que las autoridades que recopilan esta información pongan a disposición del interesado -concretamente, a los solicitantes de protección internacional- que esta se encuentra sujeta a la limitación de tratamiento para fines concretos de gestión de asilo tal y como contemplan los arts. 4.3 RGPD y 13.1 e) de la Directiva antes mencionada. Un supuesto que incrementaría la confianza y transparencia del procedimiento de toma de datos personales en los interesados sin perjuicio de que, excepcionalmente, pueda emplearse para cuestiones que afectan a seguridad nacional.

Igualmente, no debemos obviar que esta ampliación de la finalidad aumenta el riesgo de que las autoridades nacionales recopilen una mayor tipología de datos personales, excediendo de la estricta finalidad de mero registro o identificación de sujetos relacionados directa o indirectamente con la solicitud de protección internacional. En este caso, debería aplicarse igualmente el principio de minimización de los datos ${ }^{471}$ de forma que la ampliación de la información pueda efectuarse en supuestos muy tasados. Por ejemplo, en aras de agilizar el procedimiento que se trate y siempre esos datos sean requeridos en una fase posterior de la determinación del procedimiento de protección internacional -respetando, en todo caso, las garantías procesales-.

En definitiva, la reforma de Eurodac supedita el respeto a la protección de la información al aumento de todas aquellas cuestiones que pueden comprometer la seguridad de los EEMM. Tanto es así, que el principio de limitación de la finalidad se muestra carente en la mencionada propuesta, pese a su implícita y tímida inclusión en la restante normativa reguladora del SECA. Lejos de esto, también debería contemplarse la minimización de los datos a los supuestos concretos que enumera Eurodac. Ello, a pesar de que estos principios están ciertamente expuestos a su no aplicación, precisamente, ante cuestiones vinculadas con la seguridad nacional que parecen desvirtuar el régimen de garantías del derecho a la protección de datos, al requerir el empleo de estos datos para multitud de fines que exceden de las estrictas funciones de gestión de la migración y asilo. Por ello, estos principios deberían orientar las actuaciones que lleven a cabo las autoridades nacionales $-\mathrm{y}$ agencias europeas- a la

\footnotetext{
${ }^{471}$ Únicamente la propuesta de reglamento de la Agencia de Asilo de la UE contempla este principio en el Considerando $35 \mathrm{y}$ el art. 31.3.
} 
hora de procesar y transmitir datos personales concernientes a las dos categorías de migrantes en situación irregular así como a los solicitantes de asilo.

\subsection{La transferencia de datos a terceros países a efectos de retorno.}

La transferencia de datos a terceros países constituye una de las principales novedades de la PRE, la cual se aparta de la prohibición de la cesión de información relativa a los solicitantes de asilo y refugiados que dispone el art. 25 del actual Reglamento Eurodac (art. 37 PRE) y centra su foco de atención en los migrantes irregulares que deben ser retornados a sus países de origen (arts. 13 y 14 PRE). Como ya hemos puesto de manifiesto, esta novedad no afectará a los solicitantes de protección internacional -puesto que de lo contrario, contravendría los instrumentos jurídicos europeos e internacionales que protegen el derecho de asilo contra la devolución-. Ahora bien, no es menos cierto que coexistirá un alto riesgo de que la información concerniente a los solicitantes de protección internacional pueda emplearse para estos fines. $^{472}$

Al margen de este desafío, la PRE prevé su régimen jurídico en los Considerandos 50 y 51 y en el art. 38, por el que se establece la excepcionalidad de este intercambio de información, esencialmente aplicable a las relaciones de la UE con Turquía ${ }^{473}$ y que pretende aplicarse a terceros países con objeto de promover los procedimientos individuales de retorno. Aunque tiene por objeto reducir, o incluso evitar, que estas órdenes sean obstaculizadas, se dilaten excesivamente o resulten difícilmente ejecutables, constituye un aspecto sobre el que, en la actualidad, no existe parámetro de evaluación alguno, más allá del especial interés que mostró el SEPD por clarificar este precepto tras su incorporación formal en la mencionada propuesta. ${ }^{474}$

Por tanto, en una labor de interpretación, conviene apuntar que este régimen jurídico faculta a las autoridades nacionales a compartir determinada información bajo

\footnotetext{
${ }^{472}$ De hecho, en el año 2018, la Agencia de los Derechos Fundamentales de la Unión Europea (FRA) puso de manifiesto que esta prohibición no era íntegramente respetada por parte de los EEMM, al detectar errores que evidenciaban una catalogación como migrantes irregulares a genuinos solicitantes de protección internacional. FRA, Under watchful eyes - biometrics, EU IT-systems and fundamental rights, marzo de 2018, p. 77. Disponible en: https://fra.europa.eu/sites/default/files/fra_uploads/fra-2018biometrics-fundamental-rights-eu_en.pdf

${ }^{473}$ Tal y como señala la exposición de motivos de la PRD IV.

${ }^{474}$ Supervisor Europeo de Protección de Datos (SEPD). Opinión 07/2016 sobre la reforma..., ob. cit, párrafo 76.
} 
condiciones muy concretas, proscribiendo la transferencia de datos contenidos directamente en Eurodac por parte de las autoridades nacionales y, siendo igualmente extensible, a organismos internacionales y particulares que tanto contempla el art. 35 del Reglamento de Eurodac (art. 37 PRE).

Esta disposición deberá interpretarse en sintonía con la actual Directiva de procedimiento, aun teniendo presente que regula el intercambio de información concerniente exclusivamente a los solicitantes de protección internacional. A tal efecto, el art. 45.2 a) habilita únicamente a que la autoridad competente pueda obtener información actualizada y precisa de diversas fuentes como de la EASO o ACNUR sobre la situación general existente en los países de origen de las personas afectadas (apartado b). ${ }^{475}$ De este modo, esta transferencia, de acuerdo con el criterio del ACNUR, exige una imperante necesidad de "establecer garantías adecuadas para garantizar que no se compartan datos personales ni ninguna otra información relacionada las autoridades del país de origen hasta el rechazo definitivo de la solicitud de asilo". ${ }^{476}$ Por lo tanto, este intercambio limitado a fines concretos de asilo, debería extenderse al resto de categorías de sujetos con el objetivo de propiciar un contexto que promueva la obtención generalizada de información relevante a efectos de retorno procedente de vías alternativas, comunicando únicamente al tercer país interesado aquella estrictamente necesaria a estos efectos.

Pese a ello, ciñéndonos al contenido de la transferencia de datos a terceros países, esta cooperación dispone exclusivamente la posibilidad de que, en el marco de una orden de retorno, las autoridades nacionales puedan intercambiar información con terceros países que deben readmitir a sus nacionales, teniendo en consideración la importancia de expedición de documentación de viaje para la consecución de esta finalidad. A tal efecto, el Considerando 50 PRE exige la aplicación del RGPD y las normas nacionales adoptadas con arreglo a la Directiva de protección de datos en el ámbito penal a fin de asegurar que los EEMM tengan la posibilidad de cooperar activamente con dichos terceros países a efectos del presente Reglamento y sobre sujetos ajenos, en todo caso, a la concesión de protección internacional.

\footnotetext{
${ }^{475}$ Esta disposición se traslada a los Considerandos 11 y 30 de la propuesta de Reglamento de Procedimiento e igualmente se extiende al principio de confidencialidad del art. 6.2 y el art. $33.2 \mathrm{~b}$ ).

${ }^{476}$ ACNUR, Comentarios sobre la Propuesta de la Comisión Europea, ob. cit..., p. 14.
} 
De igual manera, el Considerando 51 PRE prohíbe el intercambio de información en relación con los aspectos manifestados en la solicitud de protección internacional, a pesar de que el EM haya determinado que no se trata de un sujeto con derecho a protección internacional. Una prohibición que pretende evitar posibles represalias que puedan adoptarse en el tercer país en cuestión por toda aquella información que ha sido manifestada en la propia solicitud de protección internacional.

Igualmente, el novedoso art. 38 PRE prevé un régimen de intercambio de información aplicable a los sujetos de situación irregular a efectos de retorno bajo específicas condiciones que se detallan a continuación:

1. El primer apartado del este artículo dispone que el tercer país debe cumplir con las garantías que contempla directamente en el Capítulo V del RGPD, es decir, la plena sujeción de las transferencias de datos para la identificación de sus nacionales que regula el art. 46 RGPD. Y para probar la identidad de estos nacionales a efectos de retorno, deben concurrir los siguientes requisitos:

a) que el tercer país convenga expresamente en la utilización de los datos exclusivamente con el fin para el que se haya facilitado, así como la supresión de estos cuando ya no resulte justificado su mantenimiento.

En este sentido, tipifica directamente el principio de limitación de la finalidad de los datos por el que requiere proporcionar derechos exigibles y acciones legales efectivas a los interesados. En concreto, el art. 1, apartado 1, letra b) regula explícitamente "la utilización de los datos únicamente con el fin para el que se hayan facilitado" y para lo que resulte lícito y necesario con la finalidad de "prestar asistencia en relación con el control de la inmigración ilegal a la Unión y los movimientos secundarios dentro de su territorio y con la identificación de los nacionales de terceros países en situación ilegal para determinar las medidas apropiadas que han de adoptar los EEMM, incluidas la expulsión y la repatriación de las personas residentes sin autorización". Una información que, igualmente, deberá suprimirse cuando su mantenimiento no esté justificado, es decir, que no sea necesaria en relación con los fines para los que fueron recogidos, como regula en similares términos el art. 17.1 a) RGPD.

b) Que el EM de origen que introdujo los datos en el Sistema Central de Eurodac haya prestado su consentimiento y se le haya informado al interesado de que sus datos personales podrán ser compartidos con las autoridades de un tercer país. 
Se trata de una referencia expresa al principio de publicidad del art. 35 PRE que requiere que el EM de origen que introdujo los datos en el Sistema Central haya otorgado previamente su consentimiento explícito de que los datos específicos podrían ser susceptibles de ser transmitidos a países de origen. Y con independencia de esta inclusión, en el caso de que esta información decida compartirse con las autoridades del tercer país, deberá ser comunicado al interesado. Ahora bien, no se requerirá el consentimiento del sujeto de los datos, sino una mera puesta en conocimiento con objeto de favorecer las distintas acciones de regreso.

Con ello, el tercer país objeto de retorno por parte del nacional del tercer país deberá ofrecer garantías adecuadas en la protección de los datos personales, un concepto que fue definido por el TJUE en el caso Schrems, que exigió a este tercer país garantizar, en virtud de su legislación interna o de sus compromisos internacionales, un nivel de protección de los derechos y libertades fundamentales que sea esencialmente equivalente al garantizado dentro de la UE. ${ }^{477}$

Y sobre las decisiones de adecuación que se adoptan para la consecución de estos objetivos, únicamente proceden de los siguientes países: Canadá, Argentina, Guernsey, Isla de Man, Jersey, Islas Feroe, Israel, Uruguay, Nueva Zelanda, Estados Unidos o Japón. ${ }^{478}$ En el resto de países, corresponderá a cada EEMM crear las condiciones necesarias para garantizar la transferencia de estos datos de acuerdo con el RGPD, mediante la implementación de instrumentos jurídicamente vinculantes y exigibles entre las autoridades u organismos públicos. $\mathrm{Y}$, en su defecto, de normas corporativas vinculantes, cláusulas tipo de protección de datos adoptadas tanto por la Comisión como por la autoridad de control nacional, códigos de conducta y mecanismos de

\footnotetext{
${ }^{477}$ Sobre un estudio exhaustivo sobre el particular, remitimos a: LÓPEZ AGUILAR, J.F., "La protección de datos personales en la más reciente jurisprudencia del TJUE: los derechos de la CDFUE como parámetro de validez del derecho europeo, y su impacto en la relación trasatlántica UE-EEUU”, Europa: Parlamento y Derechos. Paisaje tras la Gran Recesión, Tirant lo Blanch, 2017, p. 202.

${ }^{478}$ Canadá: Decisión 2002/2/CE de la Comisión, de 20 de diciembre de 2001, respecto de las entidades sujetas al ámbito de aplicación de la ley canadiense de protección de datos; Argentina: Decisión 2003/490/CE de la Comisión, de 3 de junio de 2003; Guernsey: Decisión 2003/821/CE de la Comisión, de 21 de noviembre de 2003; Isla de Man: Decisión 2004/411/CE de la Comisión, de 28 de abril de 2004; Jersey: Decisión 2008/393/CE de la Comisión, de 8 de mayo 2008; Islas Feroe: Decisión 2010/146/UE de la Comisión, de 5 de marzo de 2010; Israel: Decisión 2011/61/UE de la Comisión, de 31 de enero de 2011; Uruguay: Decisión 2012/484/UE, de la Comisión de 21 de agosto de 2012; Nueva Zelanda: Decisión 2013/65/UE de la Comisión, de 19 de diciembre de 2012; Estados Unidos: Decisión (UE) 2016/1250 de la Comisión, de 12 de julio de 2016 (únicamente aplicable a las entidades certificadas en el marco del Escudo de Privacidad UE-EE.UU) y Japón: Decisión de 23 de enero de 2019.
} 
certificación, junto con compromisos vinculantes y exigibles por parte del responsable o el encargado del tratamiento que aplique garantías adecuadas en el tercer país, incluyendo las relativas a los derechos de los interesados. ${ }^{479}$

Este criterio de adecuación exigirá que los EEMM revisen los acuerdos bilaterales de intercambio de datos con terceros países con objeto de evaluar, exhaustivamente, si su nivel de protección puede equiparse al dispuesto en el RGPD o Directiva de protección de datos en el ámbito penal. Una obligación que, en lo que se refiere al SECA, pretende proporcionar garantías apropiadas en la cesión de información pero que resulta vacía de protección por cuanto coexiste un régimen excepcional a la mencionada decisión de adecuación. En este sentido, el Reglamento 2018/1725 dispone en los arts. 47 y 48 que esta transferencia de datos puede llevarse a cabo por organismos asistenciales en frontera como la GEFC si existen garantías adecuadas a través de acuerdos vinculantes jurídicamente entre las autoridades públicas. A falta de estos, el art. 50.1 d) del mencionado Reglamento permite la transferencia de datos en situaciones especiales, esto es, si es necesaria por "razones importantes de interés público". Un precepto que deberá interpretarse restrictivamente pues, en caso contrario, desvirtuaría este régimen jurídico de protección de datos.

2. El apartado $2^{\circ}$ del art. 38 PRE impone una prohibición absoluta de comunicar a cualquier tercer país información relacionada directa o indirectamente con el hecho de presentación de solicitudes de protección internacional, especialmente, cuando se trate del país de origen. Además, excluye el deber de proporcionar los datos biométricos que recopila Eurodac a efectos de identificación inicial y que se fueron transmitidos al Sistema Central de acuerdo con el art. 10.1.

Pese a ello, esta disposición no clarifica si estos datos biométricos pueden llegar a compartirse con terceros países cuando fueron recogidos no con objeto de solicitar protección internacional, sino como control de identidad de los nacionales de terceros países irregulares.

Como veremos en epígrafes posteriores, la ampliación en la toma de datos

\footnotetext{
${ }^{479}$ Sobre este último requisito, véase VIGURI CORDERO, J., "Los mecanismos de certificación (códigos de conducta, sellos y marcas)", en RALLO LOMBARTE, A., GARCÍA MAHAMUT, R. (eds.), Hacia un nuevo derecho europeo de protección de datos, Editorial Tirant lo Blanch. Valencia, 2015, p. 930; VIGURI CORDERO, J., "Los mecanismos de certificación en la Ley Orgánica de Protección de Datos y Garantía de los Derechos Digitales: un nuevo paradigma a la luz del RGPD" en GARCÍA MAHAMUT R., TOMÁS MALLÉN, B. (eds.), El Reglamento General de Protección de Datos... ob. cit., pp. 367-387.
} 
biométricos a las distintas categorías de migrantes constituye una de las novedades más relevantes de la mencionada propuesta. La exposición de motivos prevé esta ampliación con la finalidad de emplear tal información para asistir a un EM en la redocumentación de un nacional de un tercer país que pretende ser retornado. Indiscutiblemente, esta recopilación de datos biométricos cuenta con grandes beneficios para las autoridades nacionales. Estas pueden disponer de un conocimiento importante sobre los desplazamientos, determinar eficazmente el país o los países de tránsito de los migrantes irregulares o prevenir medios engañosos que evitan su identificación. Sin embargo, esto no faculta a que las autoridades nacionales intercambien esta tipología de información sensible con los países de origen de forma generalizada, sino que deberá procederse si resultan esenciales para llevar a cabo las acciones de retorno, en coherencia con estrictos criterios de minimización de los datos y limitación de la finalidad que recoge el art. $5.1 \mathrm{~b}$ ) y c) RGPD.

3. Finalmente, el apartado $3^{\circ}$ del art. 38 prohíbe que los terceros países accedan "directamente" al Sistema Central para la comparación o transmisión de los datos dactiloscópicos así como cualquier otro dato personal de un nacional de un tercer país o apátrida. Tampoco puede concederse el acceso mediante el Punto de Acceso Nacional designado de un EM. Este apartado viene a confirmar tácitamente que los terceros países podrían acceder a los datos contenidos en el Sistema Central de forma indirecta, es decir, únicamente a través del intercambio de información o transferencia de datos que lleven a cabo con los EEMM a efectos exclusivos de retorno y sobre los límites anteriormente señalados.

En definitiva, esta cesión de información excepcional y ajena al ámbito del asilo exigirá las altas garantías que contempla la legislación de protección de datos anteriormente mencionada, que se encontrará supeditada a la plena sujeción a las transferencias de datos a un tercer país para la identificación de nacionales de terceros países que regula el art. 46 RGPD. Ahora bien, en este último supuesto, las decisiones de adecuación o acuerdos de readmisión con la mayoría de países de retorno posibilitan, excepcionalmente, la aplicación de un criterio de interés público que prevé el art. 50.1 d) del Reglamento 2018/1725, el cual se aparta de las disposiciones del RGPD. Un supuesto conflictivo que no resultaría ajeno a elevar el riesgo de intercambio de datos de potenciales sujetos perseguidos con terceros países y podría contrariar, indirectamente, el principio fundamental a la no devolución. 
3.3. La ampliación de datos biométricos.

Desde la plena operatividad de Eurodac, no se han proporcionado pautas concretas y específicas sobre el uso y procesamiento de los datos personales. Consecuentemente, ha sido discutible doctrinalmente si el almacenamiento de sus datos han constituido per se elementos suficientes para catalogarlo como un Sistema de Información con incidencia directa en la protección de los datos personales. La razón estribaba en que este incluía, esencialmente, huellas dactilares con fines de identificación de las distintas categorías de sujetos. $^{480}$

Esta tipología de datos biométricos ausente tanto en la anterior Directiva de protección de datos 95/46/CE como en el Convenio $\mathrm{n}^{\mathrm{o}} 108$ reflejaron el carácter subsidiario de la protección de datos en este SI. Es más, la especial sensibilidad de este tipo de información propició la iniciación de un ciclo de estudios por parte de De Hert o Kindt, que aludieron a que el mero procesamiento de este dato poseía entidad suficiente para que su tratamiento entrara dentro del alcance de la Directiva de protección de datos 95/46/CE y las leyes nacionales en transposición de la misma. ${ }^{481}$ En este sentido se pronunció la STJUE Michael Schwarz contra Stadt Bochum, de 17 de octubre de $2013,{ }^{482}$ la cual disponía que la recopilación y el procesamiento de este dato podía constituir una clara interferencia en el derecho a la vida privada y protección de datos. Efectivamente, su particularidad en el ámbito del SECA estriba en la revelación de características físicas o fisiológicas únicas de una persona, que permiten una rápida y $a$ priori inequívoca identificación de los sujetos. Un dato especialmente útil para verificar la identidad de aquellos sujetos que presentaban varias solicitudes en diferentes EEMM y que, desde 2018, lleva implementando el ACNUR. ${ }^{483}$

Esta STJUE reflejó que el simple procesamiento de huellas dactilares interfería en la

\footnotetext{
${ }^{480}$ GUILD, E., Chapter IV. Unreadable Papers?, The EU's first experiences with biometrics: Examining EURODAC and the EU's Borders, en: J. LODGE (ed.), Are you who you say you are? The EU and Biometric Borders, Nijmegen, Wolf Legal Publishers, 2007, pp. 31- 43.

${ }^{481}$ DE HERT, P., Biometrics: legal issues and implications: Brussels, European Commission, 2005; KINDT E.J., "Biometric Data, Data Protection and the Right to Privacy", en: Privacy and Data Protection Issues of Biometric Applications, Law, Governance and Technology Series, vol. 12. Springer, Dordrecht, 2013, p. 224.

${ }^{482}$ STJUE Michael Schwarz contra Stadt Bochum, de 17 de octubre de 2013. Asunto C-291/12.

${ }^{483}$ El ACNUR lleva aplicando esta ampliación biométrica desde el año 2018, aprovechando sus beneficios para perfeccionar la verificación de las identidades e incrementar la eficiencia de su sistema de recogida de datos. ACNUR, Biometric identity management system, 2018. Disponible en: http://www.unhcr.org/550c304c9.html
} 
protección de los datos personales. Una particulariad que incidió directamente en el actual Reglamento, que sigue el objetivo inicialmente marcado de operar exclusivamente con impresiones dactilares, sin conservar otro dato de carácter personal como el nombre o su nacionalidad -al margen del sexo de la persona-.

Ahora bien, en 2013, momento coincidente con la aplicación del actual Reglamento de Eurodac, el ACNUR comenzó a implementar un Sistema de Gestión de Identidad Biométrica (BIMS) que recogía las huellas dactilares y, de forma pionera, el escaneo del iris de los refugiados, así como una foto completa de su rostro. ${ }^{484}$ Una ampliación que, hasta el momento, se había relacionado estrictamente con el intento de alcanzar una mayor seguridad en la lucha contra el terrorismo pero que había resultado infructuosa. Ningún sistema biométrico pudo ofrecer garantías suficientes para erradicar o reducir cualquier acto delictivo o terrorista. ${ }^{485}$

Este novedoso identificador biométrico fue previsto en la Agenda Europea de Migración del año 2015 como solución a los problemas a los que se enfrentaron las autoridades nacionales en la toma de impresiones dactilares, donde se apreciaban, con cierta asiduidad, frecuentes daños en las yemas de los dedos. ${ }^{486}$ Una situación que propició su formal incorporación en la PRE del año 2016, la cual amplía la tipología de datos personales susceptible de tratamiento al reconocimiento facial, por medio de la recopilación de fotografías digitales.

Esta responde a la necesidad de solventar la manifiesta imposibilidad en la consecución de los fines de Eurodac, lo que provocó que ciertos EEMM aplicaran medidas restrictivas de derechos como la detención o el uso de la fuerza. ${ }^{487}$ Un

\footnotetext{
${ }^{484}$ ACNUR, Biometric Identity Management System (BIMS). Enhancing Registration and Data Management, octubre 2013. Accesible en: http://www.unhcr.org/550c304c9.pdf

${ }^{485}$ European Biometrics Portal, Biometrics in Europe. Trend Report, 2007, p. 6; BALDACCINI, A., "Counter-Terrorism and the EU Strategy for Border Security: Framing Suspects with Biometric Documents and Databases", European Journal of Migration and Law, vol. 10, n 1, 2008, pp. 31- 49.

${ }^{486}$ Comisión Europea, Comunicación de la Comisión al Parlamento Europeo, al Consejo, al Comité Económico y Social Europeo y al Comité de las Regiones «Una Agenda Europea de Migración», $\operatorname{COM}(2015) 240$ final de 13.5 .2015 , pp. 13 y 14.

${ }^{487}$ En julio de 2014, la Comisión llevó a cabo una encuesta a los EEMM para determinar la legislación aplicable y las prácticas nacionales en la toma de las huellas dactilares y su transmisión a la base de datos Eurodac. (Comisión Europea, "Ad-Hoc Query on EURODAC Fingerprinting", 22 de septiembre de 2014). Los resultados fueron dispares. Mientras que en la mayoría de los EEMM no permitían el uso de medidas coercitivas en la toma las huellas dactilares de los solicitantes de solicitudes de protección internacional, la mitad de ellos informaron que si la empleaban para el resto de categorías. Además, se reveló que en siete Estados se imponían sanciones a quienes se niegan a tomar las huellas dactilares, desde la detención (en cinco de ellos) hasta y multas (en otros dos), al margen de Italia, Grecia y
} 
escenario que recibió críticas por parte de Dernbach, precisamente, por la equiparación automática de grupos en situación de vulnerabilidad a otras categorías de personas, como posibles delincuentes o sospechosos de la comisión o participación de delitos grave. ${ }^{488}$ Ello, sin considerar otros factores eminentemente subjetivos de compleja evaluación como la frecuente reticencia o el miedo a proporcionar sus datos especialmente en los solicitantes de protección internacional, perseguidos por sus países de origen, tránsito o tras su interceptación por mafias organizadas dedicadas a la trata de seres humanos-. Una circunstancia que, a nuestro juicio, vulnera la presunción de inocencia y limita excesivamente sus derechos e intereses.

Además, a las huellas dañadas, destruidas o a la negativa de los sujetos a la toma de las mismas se sumaron otros elementos de carácter objetivo como la escasa calidad y las fallas en el registro y transmisión de las huellas dactilares. De hecho, el último informe de eu-LISA del año $2018^{489}$ constató que un total de 20.929 de estos datos habían sufrido persistentes errores y/o inexactitudes, lo que originó el rechazo por el Sistema Central de Eurodac y la imposibilidad de una comparación adecuada conforme al art. 25 del Reglamento Eurodac (art. 26 PRE).

Por consiguiente, la mencionada propuesta especifica en el art. 2 el deber de los EEMM de tomar y transmitir impresiones dactilares y una imagen facial de las tres categorías de personas, garantizando que los EEMM impongan igualmente dichas obligaciones a estos sujetos. Una disposición que fue concretada por la enmienda $\mathrm{n}^{\mathbf{o}} 39$, que añadió la necesidad de respetar la dignidad y la integridad física de la persona durante todo el proceso de toma de impresiones dactilares y la captación de la imagen facial. Una previsión que pretende adelantarse y prevenir los riesgos durante la toma y captación biométrica, la cual, indudablemente, interferirá en un mayor grado en los

\footnotetext{
Dinamarca, que no contestaron el mencionado cuestionario. (Comisión Europea, "Summary of EMN AdHoc Query n 588 - Eurodac Fingerprinting", septiembre de 2014). Esta situación llevó a que la Comisión publicara un documento no oficial en octubre de 2014 en el que facultó, por primera vez, el empleo de la detención y/o la fuerza para obtener las huellas dactilares en los supuestos en los que los sujetos se negasen a cooperar en la toma de las huellas dactilares. (Comisión Europea, "Commission non-paper for SCIFA on Best Practices for upholding the Obligation in the Eurodac Regulation to take fingerprints", 13 de octubre de 2014). Un supuesto que la FRA analizó e instó a que las autoridades nacionales incluyeran las razones por las que el sujeto en cuestión rechaza facilitar sus datos biométricos. FRA, "Fundamental rights implications of the obligation to provide fingerprints for Eurodac", 05/2015, octubre de 2015.

${ }^{488}$ DERNBACH, A., "Eurodac fingerprint database under fire by human rights activists", 2015, en https://www.euractiv.com/section/justice-home-affairs/news/eurodac-fingerprint-database-under-fire-byhuman-rights-activists/. Accedido el 1 de julio de 2019.

${ }^{489}$ Eu-LISA, Eurodac - 2018, ob. cit., p. 13.
} 
derechos de los solicitantes de protección internacional. Para tal fin, la PRE amplía los datos biométricos a las imágenes faciales, permitiendo disponer de todos los elementos necesarios para identificar a los solicitantes de asilo y, simultáneamente, dar respuesta a los problemas estructurales acaecidos desde los orígenes de Eurodac en el procesamiento de las huellas dactilares. Además, incluye novedosas disposiciones para efectuar una comparación de ambos datos biométricos tanto conjuntamente como por separado (arts. 15 y 16 PRE).

Resulta innegable que esta propuesta continúa apostando decididamente por la biometría para determinar la identidad más exacta de dichas personas, articulando la comparación de una imagen facial como último recurso, esto es, en caso de imposibilidad en la toma de las impresiones dactilares porque estas resulten dañadas o como consecuencia de amputaciones (Considerandos 5, 6 y 10 PRE). En similares términos, la enmienda $\mathrm{n}^{\circ} 5 \mathrm{PE}$, sin referirse en términos absolutos, alude a la necesidad de estos datos como un elemento que "garantiza una elevada precisión de la identificación". Esta extensión se justifica, principalmente, por la mayor certeza de que este tipo de datos que, en comparación con otros, presentan un margen de error menor y, por ende, son más seguros a la hora de identificar, sin ningún género de duda, a los distintos individuos susceptibles de procesamiento por este sistema. ${ }^{490} \mathrm{Sin}$ embargo, este afán por mejorar la calidad en la toma de las huellas digitales se ha enfrentado a una serie de desafíos, entre los que podemos destacar los siguientes:

1. Las serias preocupaciones sobre el respeto de los derechos individuales a la integridad física y la dignidad humana mientras se recopilan sus datos biométricos y;

2. los problemas relativos a la validez de los datos dactiloscópicos recopilados, los cuales siguen presentando un considerable margen de error asociado a las técnicas de huellas digitales.

Como ya se ha abordado anteriormente, la interoperabilidad de Eurodac al amparo del Reglamento 818/2019 buscará solventar estos conflictos, aunque ello también suponga extender -todavía más- la biometría por medio de su identificación en otros

\footnotetext{
${ }^{490}$ Sobre los márgenes de errores en la biometría, remitimos a: BALDACCINI, A., Counter-Terrorism and the EU Strategy for Border Security: ob. cit., p. 37; BEIRENS H., Cracked Foundation. Uncertain Future: Structural Weaknesses in the Common European Asylum System, Brussels, Migration Policy Institute Europe, 2018, p. 5; MAGHIROS, I. "Biometrics at the Frontiers: Assessing the Impact on Society, en: European Commission, Joint Research Centre RE et Institute for Prospective Technological Studies (eds.)", Technical Report Series, 1 de junio de 2005, p. 166.
} 
SSII. Un riesgo que vaticinó en 2018 la FRA en la Declaración anexa al informe del Grupo de expertos de alto nivel sobre sistemas de información e interoperabilidad cuando declaró que "la interoperabilidad no debía conducir al procesamiento de mayor tipología de datos que los necesarios para los fines existentes en virtud de los instrumentos jurídicos individuales". 491

Pese a ello, esta ampliación supondrá un trascendental avance que puede reportar cuantiosas ventajas tanto para los nacionales de terceros países como para los distintos EEMM, reduciendo considerablemente el número de detenciones y elevando la propia seguridad de los Estados. No obstante, llama poderosamente la atención que el objeto principal que refleja la exposición de motivos de la propuesta no haya sido aumentar la eficacia del sistema o corregir los frecuentes márgenes de errores, sino "reducir nuevas infraestructuras de comunicación entre los Estados miembros para compartir información sobre los migrantes irregulares que no hayan solicitado asilo". De este modo, la PRE encuadra la toma de imágenes faciales como un "modelo piloto", de forma que el futuro Reglamento sea capaz de fomentar la aplicación de programas de reconocimiento facial en toda su extensión. ${ }^{492}$

Ahora bien, a nuestro juicio, no resultará ajena a la concurrencia de riesgos imprevistos y de compleja solución, fundamentalmente, si las autoridades nacionales no invierten en formación adecuada y equipo técnico como así manifiesta el Considerando 28 PRE. $^{493}$ Las nuevas técnicas de identificación perfeccionadas y favorables a los intereses de los Estados que pretende implementarse por medio de este sistema puede conducir a una forma popular de "paranoia tecnológica" 494 que cuestione seriamente el pleno respeto a la protección de los datos personales. Por tanto, deberá acometerse un análisis acerca de las garantías de protección de datos que prevé la mencionada

\footnotetext{
${ }^{491}$ High-level expert group on information systems and interoperability, Final Report, Mayo 2017. Disponible https://ec.europa.eu/transparency/regexpert/index.cfm?do=groupDetail.groupDetailDoc\&id=32600\&no= 1

${ }^{492}$ Para la consecución de estos objetivos, encomienda a la Agencia eu-LISA un estudio sobre el software de reconocimiento facial para evaluar su exactitud y fiabilidad antes de que se incorpore al Sistema Central.

${ }^{493}$ Sin perjuicio de la apremiante labor de cooperación por parte de la GEFC y la futura AAUE, que también estarán capacitadas a tomar datos biométricos para el efectivo control de las fronteras exteriores (arts. 10.3 y 13.7 PRE).

${ }^{494}$ Este concepto fue acuñado por Alterman en: ALTERMAN, A., "A piece of yourself: Ethical issues in biometric identification", Ethics and Information Technology, vol. 5, 2003, p. 146.
} 
propuesta y que ya fue objeto de notable crítica por el SEPD, que recomendó llevar a cabo una evaluación de impacto acerca de la necesidad de recopilar y utilizar las imágenes faciales en las distintas categorías de personas de Eurodac. ${ }^{495}$ Máxime, en vista de la falta de estudios relevantes sobre el particular y su impacto en el derecho a la intimidad y vida privada de los solicitantes de asilo de los arts. 8 y 52.3 CDFUE y art. 8 CEDH.

El funcionamiento de este SI afecta a las distintas categorías de sujetos y, muy especialmente, a colectivos vulnerables, generando consecuencias adversas en los derechos de privacidad y protección de datos. En este caso, conviene establecer, en primer término, que los datos biométricos se encuentran definidos tanto en el art. $4.14^{\circ}$ RGPD como en el art. $3.13^{\circ}$ de la Directiva de protección de datos en el ámbito penal como aquellos "obtenidos a partir de un tratamiento técnico específico, relativos a las características físicas, fisiológicas o conductuales de una persona física que permitan o confirmen la identificación única de dicha persona, como imágenes faciales o datos dactiloscópicos". Una definición de biometría que, desde una perspectiva técnica, contempla la norma ISO/IEC 2382-37 reformada en el año $2017 .{ }^{496}$ Igualmente, desde un enfoque jurídico, los ars. 9 RGPD, 10 de la Directiva de protección de datos en el ámbito penal y 6 del Convenio 108+ los clasifican dentro de la categoría de sensibles, sobre los cuales, como regla general, queda prohibido su tratamiento.

El apartado 2 g) RGPD excluye directamente la prohibición ante una imperiosa razón de un interés público esencial -como se produce con cuestiones de control migratorio y en la gestión de las solicitudes de protección internacional-. Para ello, el mismo impone un límite que se concreta en la proporcionalidad del objetivo perseguido y el establecimiento de medidas adecuadas y específicas para proteger los intereses y derechos fundamentales de los interesados. ${ }^{497}$

\footnotetext{
${ }^{495}$ SEPD, Opinion on the First reform package on the Common European Asylum System..., ob. cit., p. 9 .

${ }^{496}$ Tecnologías de la información - Vocabulario - Parte 37: Biométricos: 2017. Un análisis sobre esta norma técnica, remitimos a: JASSERAND, C., "Legal Nature of Biometric Data: From 'Generic' Personal Data to Sensitive Data”, European Data Protection Law review, vol. 2. nº 3, 2016, p. 299.

${ }^{497}$ Sobre un estudio del principio de proporcionalidad en el procesamiento de datos biométricos, véase: KINDT E., The processing of Biometric Data. A Comparative Legal Analysis with a focus on the Proportionality Principle and recommendations for a Legal framework, Katholieke Univerisiteit Leuven 2012. https://lirias.kuleuven.be/bitstream/123456789/345184/1/PH_D_text_PartI\%2BPartII_17.04-Pservice.pdf
} 
No obstante, conviene igualmente abordar que esta mayor recopilación se encuentra condicionada por dos cuestiones esenciales:

En primer lugar, el deber de proporcionar información que contempla tanto el actual art. 29 de Eurodac como su propuesta de reforma en el art. 30 -esta última reforzada por la exigencia de que se suministre de forma concisa, transparente, inteligible y fácilmente accesible, utilizando un lenguaje claro y sencillo- ${ }^{498}$

Y, en segundo lugar, en virtud del principio de subsidiariedad. Pese a que el art. 15 menciona indistintamente la comparación de ambos datos biométricos, el art. 16 PRE prevé que la comparación de las imágenes faciales se realice como último recurso, articulándose exclusivamente para el caso de que se produzcan uno de los problemas anteriormente mencionados y que imposibilite a la consecución del objetivo de Eurodac. De este modo, el futuro Eurodac deberá instaurarse como un "sistema perfeccionado" en la dimensión de eficiencia y eficacia, salvaguardando la protección los datos e información personal.

Ahora bien, aunque dispone de mayores garantías para los usuarios, en el presente, no se conocen los beneficios del empleo extensivo de identificadores biométricos, lo cual puede conducir a una serie de retos en el derecho a la protección de datos personales y que merecen reflejar a continuación:

a) Como se ha desarrollado anteriormente, la recopilación y el almacenamiento y empleo de huellas dactilares no siempre puede efectuarse, fundamentalmente, si estas han resultado dañadas o destruidas o, incluso, ante la imposibilidad o negativa de registro. El problema radica en que no puede establecerse fehacientemente si se trata de causas imputables o no al sujeto, pese a que las autoridades fronterizas sospechen de que las ha destruido deliberadamente, vulnerando la presunción de inocencia.

En este punto, converge la necesidad y pertinencia en la ampliación de los datos biométricos que, a diferencia de otros SSII como VISA, seguirá siendo obligatoria en Eurodac (art. 2). Así, aunque los EEMM ostentan la capacidad de imponer sanciones o emplear la coacción de manera proporcional de conformidad con su Derecho nacional a

\footnotetext{
${ }^{498}$ Sobre el particular, compartimos con Rommetveit la idea por la que la eficacia del procesamiento debe acompasarse en todo momento de mecanismos de interacción con las distintas categorías de sujetos afectados. ROMMETVEIT K., "Introducing Biometrics in the European Union: Practice and Imagination", en DELGADO A. (eds.) Technoscience and Citizenship: Ethics and Governance in the Digital Society. The International Library of Ethics, Law and Technology, vol 17. Springer, Cham, 2016, p. 125.
} 
los sujetos que dificulten y se nieguen a facilitar sus datos biométricos de conformidad con el art. 2.3 PRE, ${ }^{499}$ lo cierto es que las imágenes faciales pueden solventar o, cuanto menos reducir, estas limitaciones generalizadas de derechos. Así, no debemos obviar que estas técnicas de procesamiento resultan, a priori, menos invasivas.

b) En coherencia con lo anterior, debe subrayarse que, en los últimos años, las conocidas "búsquedas especiales" en el marco de Eurodac provocaron inquietudes acerca del posible uso indebido de la finalidad de la recopilación de datos biométricos por parte de las autoridades nacionales. ${ }^{500}$ Efectivamente, las imágenes faciales constituyen una valiosa categoría de datos sensibles susceptible de utilización para multitud de fines que exceden de los anteriormente señalados en Eurodac. Esto evidencia su "potencial e inherente sesgo tecnológico" difícilmente conciliable con el principio de limitación de la finalidad, ${ }^{501}$ cuya inaplicación puede generar una manifiesta descoordinación, por cuanto la transmisión de estos datos biométricos al Sistema Central resulta vinculante.

$\mathrm{Y}$, a pesar de que pueden efectuarse excepciones bajo condiciones muy concretas, en fiel cumplimiento con los principios de necesidad y proporcionalidad, la dificultad radicará en una excepcionalidad que pugnará directamente con aquellas cuestiones que impactan en la seguridad de los EEMM. La utilización de estos datos para propósitos que exceden de los dispuestos en el Reglamento Eurodac en los contextos de migración y asilo hacia la prevención de situaciones que afectan o pueden afectar a la seguridad de los Estados constituye una desviación de uso o "function creep". Un riesgo que estriba no tanto en la ampliación de las características y funciones que han previsto cada uno de los reglamentos Eurodac desde su creación en el año 2003 sino, más bien, en una aplicación distinta a la legalmente dispuesta.

\footnotetext{
${ }^{499}$ Sobre el particular, deberá seguirse el documento de trabajo de los servicios de la Comisión sobre la aplicación de Eurodac relativo a las "mejores prácticas" para la obtención de los datos biométricos. Comisión Europea, Documento de Trabajo sobre la implementación del Reglamento Eurodac en lo relativo a la obligación de tomar las huellas dactilares, 27 de mayo de 2015 [SWD(2015) 150 final].

${ }^{500}$ Comisión Europea, Informe anual al Parlamento Europeo y al Consejo sobre las actividades de la Unidad Central EURODAC en 2011 (Informe de la Comisión al Parlamento Europeo y al Consejo), 21 de septiembre de 2012, $\operatorname{COM}(2012) 533$ final.

${ }^{501}$ Para un estudio sobre este principio, remitimos a: BROUWER, E., "Legality and Data Protection Law: The Forgotten Purpose of Purpose Limitation" en L. BESSELINK, F. PENNINGS y S. PRECHAL (eds.), The Eclipse of the Legality Principle in the European Union, Kluwer Law Internacional, 2011, pp. 273294.
} 
c) Finalmente, al margen de Eurodac, la inclusión de los datos biométricos junto con información adicional-como por ejemplo, aquella relativa a la salud-, puede conducir a una indirecta elaboración de perfiles mediante la incorporación de datos especialmente sensibles que fueron recopilados con una finalidad distinta. ${ }^{502}$ Incluso puede producir contradicciones de gran calado tendentes a la creación de perfiles inexactos o erróneos, principalmente, si los datos facilitados por el solicitante no fueron correctos. Una afirmación que ya puso de manifiesto el GT29 durante la pasada década. ${ }^{503}$

Por lo tanto, coexiste un conflicto entre el respeto a las garantías en materia de protección de datos y las acciones destinadas a garantizar la seguridad de los EEMM. Previamente a la entrada en vigor del nuevo Reglamento, Eu-LISA deberá implementar medidas de seguridad adaptadas a estas modificaciones que permitan garantizar el almacenamiento, acceso y utilización de estos datos de acuerdo con su finalidad, prohibiendo el uso de los datos biométricos para aquellos fines que excedan de los inicialmente dispuestos. Igualmente, resultará esencial el control de la legalidad sistémico de los EEMM (art. 24 PRE), que deberán llevarse a cabo por parte de las APDs, englobando desde la toma de los datos biométricos, su transmisión al Sistema Central, su exactitud y, si fuera necesaria, su actualización y/o posterior comparación.

3.4. La rebaja de la edad en la toma y transmisión de datos biométricos de los 14 a los 6 años de edad.

La PRE también incorpora otra de las novedades más destacadas, el drástico descenso de edad para la toma de datos biométricos desde los 14 años fijados actualmente hasta los 6 años de edad conforme a lo dispuesto en el Considerando $17 \mathrm{y}$ en los arts. 10.1 13.1, 14.1. Estos menores han permanecido invisibles en este sistema y se han enfrentado a un "doble riesgo"; tanto en su condición de solicitantes de asilo

\footnotetext{
${ }^{502}$ Un conflicto que fue analizado en la pasada década y que puede producirse tras la aplicación del nuevo Eurodac: KINDT, E., MULLER, L. (eds.), Deliverable 3.10. Biometrics in identity management, Proyecto Fidis Future of Identity in the Information Society, 2007.

${ }^{503}$ Este problema fue abordado hace más de una década el GT29 cuando destacó el potencial riesgo a una identidad asociada permanentemente con los datos biométricos que exige Eurodac Grupo de Trabajo del Artículo 29, "Dictamen $\mathrm{n}^{\circ}$ 7/2004 sobre la inclusión de elementos biométricos en los permisos de residencia y de los visados teniendo en cuenta el establecimiento del sistema europeo de información sobre visados (VIS)", 11 de agosto de 2004, p. 4.
} 
como por su prematura edad. ${ }^{504}$ De hecho, la nota explicativa de la Comisión ${ }^{505}$ destacó que la separación de los niños de sus familias así como la falta de control en la atención o servicios sociales infantiles por parte de las autoridades constituían razones suficientes que justificaban esta rebaja tan destacada de la edad para la toma de los datos biométricos.

Una reforma que pretende mejorar la escasa seguridad de este colectivo por medio de la identificación de sujetos menores de 14 años, lo que faculta a una identidad extendida a efectos de establecer vínculos familiares entre los distintitos EEMM. Este descenso de la edad persigue proteger eficazmente a los menores migrantes, hasta ahora invisibles para el sistema. Precisamente, la exposición de motivos PRE lo justifica en el hecho que las autoridades nacionales recurren comúnmente a la recogida de datos biométricos de menores de 14 años "para la expedición de visados, pasaportes o permisos de residencia biométricos y a efectos de control de la inmigración en general”. Y parte de esta idea para determinar la idoneidad de la edad mínima a 6 años radica en "el reconocimiento de las impresiones dactilares de los niños puede hacerse con un grado de exactitud satisfactorio". Una afirmación que recibió el reproche por parte del SEPD, que consideró que el mero hecho de que algunos EEMM hubieran adoptado estas prácticas no garantizaba per se que fueran proporcionadas. ${ }^{506}$

En consecuencia, esta realidad ha influido en la propia PRE, donde el Considerando 24 no deja margen de duda de que se tratará de un criterio vinculante, disponiendo que deberá exigirse a las autoridades nacionales que tomen los datos biométricos de estos menores a partir de los 6 años de edad. Esta justificación viene amparada por estudios precedentes que concluyeron que este registro no resultaba especialmente invasivo en sus derechos y libertades. ${ }^{507}$

\footnotetext{
${ }^{504}$ DRYWOOD, E., "'Child-proofing' EU law and policy: interrogating the law-making processes behind European asylum and immigration provision", The International Journal of Children's Rights, vol. 19, $\mathrm{n}^{\circ}$ 3, 2011, p. 427.

${ }^{505}$ Comisión Europea, Nota Explicativa del Documento de trabajo de los servicios de la Comisión sobre la implementación del Reglamento Eurodac en relación con la obligación de tomar las huellas dactilares, SWD (2015) 150 final.

${ }^{506}$ Véase párrafo 27. Supervisor Europeo de Protección de Datos (SEPD). Opinión 07/2016 sobre la reforma..., ob. cit, 21 de septiembre de 2016.

${ }^{507}$ Por un lado, el SCG de Eurodac declaró en el año 2009 que algunos EEMM empleaban medidas técnicas avanzadas, incluida la investigación con rayos X, para estimar la edad de un niño a efectos de aplicación de este sistema. (Eurodac Supervision Coordination Group, Second Inspection Report 2009, 24 de junio de 2009, pp. 17-19). Por otro lado, el Informe del Centro de Investigación Conjunta indicó en el año 2013 que la edad de 6 años resultaba apropiada para la toma de datos biométricos siempre y cuando
} 
Todos estos factores influyeron en la adopción final de la PRE, que introdujo ciertos límites a la actuación de los EEMM con miras a evitar toda una serie de potenciales inconvenientes que pueden suscitarse durante la toma de datos biométricos, destacando los siguientes:

1. Inicialmente, el Considerando 30 excluye que pueda aplicarse cualquier tipo de coacción sobre sujetos vulnerables, supuesto que fue objeto de especial pronunciamiento por parte de la Organización Internacional para las Migraciones (OIM) en el año $2018,{ }^{508}$ que apuntó que esta prohibición debía operar en términos absolutos, es decir, no podía contemplarse el uso de la fuerza bajo ninguna circunstancia.

2. Seguidamente, el art. 2.2 exige que se lleve a cabo "de manera adaptada a sus necesidades", respetando su dignidad e integridad física. Además, las autoridades nacionales deberán recibir formación específica al efecto, notificar al menor acerca del procedimiento de un modo coherente, adaptado a su edad y procurando que esté acompañado en todo momento por un adulto.

No olvidemos, como hemos puesto de manifiesto, que el refuerzo de este nuevo SI excede de las cuestiones intrínsecas del asilo. Es por ello por lo que, a nuestro juicio, se produce un riesgo - cuanto menos elevado- a que no se respeten las altas garantías exigibles durante la toma, procesamiento y comparación de los datos biométricos de este colectivo y que conviene analizar detalladamente:

a) Para el propósito de facilitar los objetivos del Reglamento de Dublín, el art. 10 PRE contempla la toma de los datos biométricos. Esta nueva disposición parece ser irrelevante por cuanto la STJUE MA y otros c. Reino Unido, de 6 de junio de 2013, ${ }^{509}$ ateniendo al interés superior del menor, declaraba que el EM en el que se encontraba presente el menor no acompañado resultaba directamente responsable de la solicitud de asilo, independiente de las reglas competencias del Reglamento de Dublín.

Y, pese a que nada dispone la PRD IV en este sentido, lo cierto es que siguiendo el razonamiento del TJUE, la toma y procesamiento de estos datos biométricos no se efectuará expresamente con los fines de determinación del EM responsable de tramitar

los operadores recibieran un nivel adecuado de capacitación para adquirir datos biométricos de alta calidad. (Joint Research Centre, Technical Report Fingerprint Recognition for Children, 2013).

${ }^{508}$ OIM, Joint Statement: Coercion of Children to Obtain Fingerprints and Facial Images is Never Acceptable, 13 de marzo de 2018. Accesible en: https://www.iom.int/news/joint-statement-coercionchildren-obtain-fingerprints-and-facial-images-never-acceptable

${ }^{509}$ STJUE, MA y Otros c. Reino Unido, de 6 de junio de 2013 (Asunto C-648/11). 
la solicitud. Por lo tanto, en estos casos, el menor no acompañado no deberá ser transferido al EM donde presentó inicialmente su primera solicitud de asilo. Una garantía que únicamente contempla la jurisprudencia del TJUE y que, consideramos que debería tipificarse en el futuro Reglamento. ${ }^{510}$

b) La PRE prevé la toma de los datos dactiloscópicos por parte de las autoridades nacionales en esta nueva franja de edad a las diferentes categorías de nacionales de terceros países que hemos concretado en anterior epígrafe. Una potestad que podrá efectuarse por parte de la GEFC siempre que las autoridades nacionales soliciten asistencia técnica y operativa en sus fronteras exteriores.

Asimismo, de conformidad con el art. 10.7 PRE, estos podrán asistir a los EEMM en circunstancias excepcionales que requieran soporte asistencial, implementando intervenciones fronterizas rápidas en las fronteras exteriores de los EEMM sometidos a una carga desproporcional de flujos migratorios. Unas actuaciones que, de acuerdo con el informe presentado por Guild, Costello y Moreno-Lax a la Comisión LIBE del PE, resultan transcendentales, puesto que determinan directamente el futuro de los sujetos que han sido objeto de registro y tramitación de su solicitud. ${ }^{511}$

Por lo que se refiere al Reglamento 2019/1896, de 13 de noviembre de 2019 regulador de la GEFC, se incluyen referencias específicas para los menores. El Considerando 78 requiere el desarrollo de planes de estudio básicos comunes y formación especializada en gestión de fronteras y retorno, en particular, en la protección de las personas vulnerables como los niños. De igual modo, su art. 62.2 exige emplear esta formación para hacer frente a las necesidades específicas de estos menores, en particular, los no acompañados. En este sentido, quizá hubiera sido más oportuno dotar a la GEFC con facultades meramente operativas, asistenciales o colaborativas y, únicamente, atribuir la ejecución formal de tales actos a las autoridades nacionales.

Ahora bien, esta reducción de edad a las dos categorías de migrantes irregulares no resulta necesaria para los fines de la Directiva de retorno. El art. 10.2 (art. 12.2 de la

\footnotetext{
${ }^{510}$ El Comité Meijers fue realmente crítico con esta disposición e instó a que este criterio fuera clarificado de una forma más contundente en la mencionada propuesta. Meijers Committee, standing committee of experts on international immigration, refugee and criminal law, the Eurodac recast proposal (COM (2016) 272 final)...ob. cit., p. 5.

${ }^{511}$ GUILD, E., COSTELlO, C., MORENO-LAX, V., Implementation of the 2015 Council Decisions establishing provisional measures in the area of international protection for the benefit of Italy and of Greece, Study for the LIBE Committee of the European Parliament, 2017, pp. 55 y ss. (PE 583 132).
} 
propuesta $)^{512}$ contempla exclusivamente la devolución en virtud del interés superior de un niño. Por lo tanto, las autoridades nacionales deberán tener la plena certeza de que el retorno se efectuará a un Estado donde se encuentre algún familiar y que disponga de instalaciones y medios de acogida adecuados a sus necesidades específicas.

Además, debe subrayarse que los niños suelen recibir autorización para permanecer por razones humanitarias en los EEMM, lo que ha inaplicado de forma generalizada las políticas de devolución para los niños no acompañados. ${ }^{513}$ En estos casos, la reducción de la edad únicamente deberá motivarse en aras de una mayor protección de los niños no acompañados, por ejemplo, aprovechando estos beneficios para proporcionar una asistencia social específica a sus necesidades o identificar a posibles víctimas de trata.

c) Finalmente, en relación con la finalidad de prevenir, detectar e investigar delitos graves a través del acceso policial que disponen tanto los arts. 20 y 21 del actual Reglamento Eurodac (arts. 21 y 22 PRE), en nuestra opinión, el procesamiento de datos biométricos de los niños tampoco resulta estrictamente necesario. En la mayor parte de los EEMM, la edad mínima de responsabilidad penal es de 14 años, ${ }^{514}$ incluso para los delitos más graves. Ello refleja no solo la irrelevancia en la toma de los datos biométricos, sino también un aumento en la posibilidad de que los niños migrantes sean estigmatizados y/o criminalizados.

Recuérdese que, en el plano jurisprudencial, tanto el TJUE como el TEDH otorgan altas garantías en la protección de los niños migrantes. La STEDH $S$ y Marper c. Reino Unido, de 4 de diciembre de $2008^{515}$ determinó que la conservación indiscriminada de datos biométricos de personas sin ningún tipo de vínculo penal $\mathrm{y}$, principalmente, los niños, constituía una interferencia desproporcionada con el derecho a la vida privada y la protección de datos. Además, la STJUE Tele2 -anteriormente mencionada- exigió que el acceso por parte de las autoridades policiales a la información de los niños migrantes únicamente debía otorgarse en supuestos muy tasados, esto es, si había

\footnotetext{
${ }^{512}$ Comisión Europea, Propuesta de Directiva relativa a normas y procedimientos comunes en los Estados miembros para el retorno de los nacionales de terceros países en situación irregular (refundición). Contribución de la Comisión Europea a la reunión de líderes celebrada en Salzburgo los días 19 y 20 de septiembre de 2018, COM(2018) 634 final 2018/0329 (COD), 12 de septiembre de 2018.

${ }^{513}$ Comisión Europea, DG Migration and Home Affairs, Comparative Study on Practices in the Field of Return of Minors, Final Report, (HOME/2009/RFXX/PR/1002), diciembre de 2011.

${ }^{514}$ Sobre un estudio comparativo en este extremo, véase: Comisión Europea, Summary of contextual overviews on children's involvement in criminal judicial proceedings in the 28 Member States of the European Union, 16 de abril de 2014, pp. 92 y ss.

${ }^{515}$ STEDH $S$ y Marper c. Reino Unido, de 4 de diciembre de 2008. Demandas 30562/04 y 30566/04.
} 
razones para considerar que un sujeto individualmente considerado resulta sospechoso o está relacionado con un delito de notoria entidad. Por lo tanto, con carácter general, consideramos que la toma y procesamiento de los datos biométricos al menor de 14 años no resulta proporcional para los múltiples fines que persigue Eurodac.

A nuestro juicio, supone una vulneración del derecho a la vida privada y la protección de datos personales de los arts. 7 y 8 CDFUE, al igual que el principio del interés superior del niño consagrado en el art. 24.2 CDFUE. Por su temprana edad, los niños deben ser objeto de un elevado nivel de protección, de manera que esta recopilación biométrica debería efectuarse únicamente en su propio beneficio con fines exclusivos de eficiencia y eficacia en su correcta identificación.

c) Finalmente, esta reducción drástica de la edad para la toma de datos biométricos también viene igualmente tipificada en el Reglamento 2019/818 de interoperabilidad, que permitirá consultar sus datos únicamente cuando sea en el interés superior del menor, prohibiendo su comprobación como regla general si estos son menores de 12 años (Considerando 28 y art. 20 del Reglamento). Esta disposición superará la situación desfavorable actual.

Como señala el informe de Identidad digital en el contexto de la migración y de los refugiados, en Italia, durante el proceso de registro de los menores se han visto comprometidos los derechos a la privacidad, protección de datos y consentimiento informado. ${ }^{516}$ Un hecho que fue contrastado por la FRA cuando descubrió que los derechos e intereses se veían afectados por motivos de distinta índole. Por ejemplo, las autoridades nacionales debían lidiar con el trato hostil de los niños, también existían serias dudas con respecto a la calidad de las huellas dactilares en plena transformación y acaecía un elevado riesgo de que los menores fueran traumatizados durante este registro. ${ }^{517}$ Por todo ello, la interoperabilidad, tal y como se regula en su Reglamento, constituirá una herramienta valiosa para rastrear a los niños desaparecidos, siempre que se integre el esfuerzo de las autoridades nacionales por cooperar activamente con el resto de EEMM o, como propone Brouwer, de informar a los niños desaparecidos en el

\footnotetext{
${ }^{516}$ LATONERO M., HIATT K., NAPOLITANO A., CLERICETTI G., PENAGOS M., Digital Identity in the Migration \& Refugee Context: Italy Case Study, Data and Society, vol. 4, 2019, p. 16. Disponible en: https://datasociety.net/wp-content/uploads/2019/04/DataSociety_DigitalIdentity.pdf

${ }^{517}$ FRA, Under watchful eyes - biometrics, EU IT-systems..., op.cit, p. 108.
} 
Sistema de Información Schengen (SIS II). ${ }^{518}$ Solo de esta manera, la interoperabilidad redundará en un claro beneficio para los menores.

\subsection{El periodo de conservación de los datos.}

La PRE introduce novedades sustanciales en el tiempo de conservación de los datos almacenados en Eurodac. Tanto el art. 12.1 del actual Reglamento Eurodac como el art. 17.1 PRE disponen de un periodo de conservación de los datos similar y fijado en 10 años. Un plazo que el PE, en su enmienda $\mathrm{n}^{\circ} 101$, consideró excesivo y propuso rebajar a un total de $5 .{ }^{519}$ Es más, como apunta Vavoula, este periodo de conservación implica una teórica equiparación entre las tres categorías de nacionales de terceros países antes referidos, con el conseguiente perjuicio para los solicitantes de protección internacional. $^{520}$

Sin embargo, este periodo de conservación persigue el objetivo de superar las limitaciones temporales del actual Reglamento Eurodac, desde la mera determinación del primer país de entrada con arreglo al Reglamento de Dublín -para el supuesto de que se haya presentado una solicitud de asilo en un segundo EEMM- hacia un verdadero sistema de control y contención de la migración irregular que compense la libertad de circulación y la falta de controles internos entre EEMM. De esta manera, promoverá que las autoridades nacionales sean capaces de expedir los documentos necesarios a efectos de acelerar los procedimientos de retorno y readmisión y reducir, igualmente, el tiempo de detención para los migrantes irregulares objeto de deportación (Considerando 12 PRE).

Esta extensión pretende justificarse en virtud del ámbito de aplicación de Eurodac a categorías de migrantes más amplias, pues requiere de un periodo mayor de conservación de los datos de forma que permita llevar a cabo un eficiente seguimiento de las distintas categorías de migrantes irregulares. En esta línea, la exposición de

\footnotetext{
${ }^{518}$ BROUWER E., "Interoperability and Interstate Trust: a Perilous Combination for Fundamental Rights", EU Immigration and Asylum Law and Policy, 11 de junio de 2019. Disponible en: https://eumigrationlawblog.eu/interoperability-and-interstate-trust-a-perilous-combination-forfundamental-rights/

${ }^{519}$ Parlamento Europeo, Informe sobre la propuesta de Reglamento del Parlamento Europeo y del Consejo relativo a la creación del sistema «Eurodac», ob. cit, enmienda n ${ }^{0} 101$.

${ }^{520}$ VAVOULA N., "The 'Puzzle' of EU Large-Scale Information Systems for Third-Country Nationals: Surveillance of Movement and Its Challenges for Privacy and Personal Data Protection”, European Law Review, octubre de 2019, p. 2 (pendiente de publicación).
} 
motivos de la PRE considera este plazo "adecuado" con base en dos cuestiones discutiblemente conexas:

1) alude a que otras bases de datos comunitarias en materia de justicia y asuntos de interior (JAI) contemplan un plazo similar de conservación de sus datos. ${ }^{521}$ Una justificación que resulta escasamente relevante para el SEPD pues, como resulta obvio, cada uno de estos instrumentos persigue una finalidad distinta. ${ }^{522}$

2) También hace mención de la duración de hasta 5 años de la prohibición de entrada que puede imponerse a un migrante irregular en virtud del art. 11 de la Directiva de retorno. Así, el Considerando 33 PRE dispone que un período de conservación de 5 años resultaría necesario para la conservación de los datos biométricos.

Al respecto, apunta a un "objetivo dual" consistente tanto en "prevenir y controlar eficazmente los movimientos no autorizados de nacionales de terceros países o apátridas que no tengan derecho a permanecer en la Unión" como en tomar las acciones oportunas "para ejecutar satisfactoriamente el retorno y la readmisión efectivos a terceros países", respetando el derecho a la protección de los datos personales. Precisamente, el mencionado Considerando alude a criterios generales de contención de movimientos secundarios y ejecución de órdenes de retorno; pero nada establece acerca de la pertinencia de ampliar este periodo de tiempo. Consecuentemente, el SEPD consideró que los 5 años no estaban suficientemente justificados en la PRE, recomendando proporcionar más detalles acerca de esta extensión para los fines de Eurodac. ${ }^{523}$

Resulta innegable que la conservación de esos datos durante más tiempo permite garantizar un mejor control de todas aquellas cuestiones que afectan directamente a la seguridad de los Estados. Una reforma que, a pesar de que fomentará una supervisión eficaz a nivel nacional de los movimientos secundarios dentro de la UE, en el supuesto de que la persona no esté autorizada a residir en otro EEMM, no resultará ajena a consecuencias sumamente desventajosas, en particular, a sanciones que puedan imponerse. Un hecho que evidencia su complejo y difícil encaje con el respeto de la

\footnotetext{
${ }^{521}$ Concretamente, el art. 23 del Sistema de Información Visa y el art. 31 del Sistema de Entradas y Salidas.

${ }^{522}$ Supervisor Europeo de Protección de Datos (SEPD). Opinión 07/2016 sobre la reforma..., ob. cit, párrafo 30 .

${ }^{523}$ Supervisor Europeo de Protección de Datos (SEPD). Opinión 07/2016 sobre la reforma..., ob. cit, párrafo 31.
} 
vida privada y protección de datos personales reconocidos en los arts. 7 y 8 CDFUE y el art. $8 \mathrm{CEDH}$ y que han sido objeto de aproximación jurisprudencial por ambos tribunales.

Por una parte, el TJUE analizó la extensión del principio de necesidad en la duración de los períodos máximos de conservación de los datos. Su Sentencia Digital Rights Ireland, de 8 de abril de 2014 estableció que la mera existencia de un período máximo de conservación no resultaba suficiente para cumplir con los objetivos de la CDFUE, pues este "debía basarse en criterios objetivos para garantizar su limitación a lo estrictamente necesario". ${ }^{524}$ Por su parte, la STJUE Tele2, de 21 de diciembre de $2016^{525}$ declaró que resultaban injustificadas las legislaciones nacionales que contemplasen un periodo de conservación de datos genérico e indiscriminado, pues excedía de los límites estrictamente necesarios. Con ello, estos pronunciamientos del TJUE no dejan atisbo de duda de la exigencia de justificar y concretar los motivos específicos por los cuales se decide ampliar el periodo de conservación de los datos contenidos en Eurodac, supuesto carente en la PRE.

Por otra parte, es posible que este periodo de conservación de datos en Eurodac se presente con mayor frecuencia en el futuro ante el TEDH como ya ha abordado -de forma más amplia- este Tribunal en sus sentencias Zakharov c. Rusia, de 4 de diciembre de 2015 y Szabo y Vissy c. Hungría, de 12 de enero de $2016 .^{526}$ En ellas, se ponía fin a la arbitrariedad de la vigilancia masiva al constituir una violación del art. 8 CEDH. Además, la STEDH Ayçaguer c. Francia, de 22 de junio de $2017^{527}$ vuelve a situar al derecho a la protección de datos personales en un lugar destacado tras su directa colisión con la seguridad de los Estados. En este asunto, el TEDH reiteró la prohibición a un registro generalizado e indiferenciado de personas, un recordatorio sumamente pertinente en un momento de especial tensión entre los intereses nacionales y el derecho a la protección de datos.

El objetivo de este periodo en Eurodac se aproxima al intercambio información entre distintas autoridades nacionales y europeas con un claro interés radicado en dar

\footnotetext{
${ }^{524}$ STJUE Digital Rights Ireland, de 8 de abril de 2014, ob. cit.

${ }^{525}$ STJUE Tele2, de 21 de diciembre de 2016, ob. cit.

${ }^{526}$ SSTEDH Zakharov c. Rusia, de 4 de diciembre de 2015. Demanda $n^{\circ}$ 47143/06; Szabo y Vissy c. Hungría, de 12 de enero de 2016. Demanda no 37138/14

${ }^{527}$ STEDH Ayçaguer c. Francia, de 22 de junio de 2017, ob. cit.
} 
respuesta a los problemas que inciden en una seguridad cada vez más europeizada. ${ }^{528}$ Una creciente dificultad que ya vaticinó el SEPD en 2011 cuando aludió a que el incremento de "las actividades policiales y judiciales a escala internacional en el ámbito de la lucha contra el terrorismo y otras formas de delincuencia organizada internacional, basadas en un gran intercambio de información con fines represivos (...) obligaba a plantearse seriamente cómo garantizar la protección de los datos personales en un mundo globalizado, sin incidir (...) en las operaciones de tratamiento de datos a escala internacional". 529

Además, aunque esta ampliación incide en la legislación de protección de datos de la UE, concretamente, la aplicación del principio de limitación del tratamiento al que ya hemos hecho referencia anteriormente, no es menos cierto que emergen dos cuestiones complejas desde un enfoque constitucional:

- En primer lugar, el periodo de conservación de los datos contenidos en Eurodac no coincide con el tiempo que dura la prohibición de entrada -hasta 5 años-. El SEPD apuesta por adaptar ambos periodos al individuo, de forma que una vez expirado el plazo de prohibición de entrada de un individuo, la información personal deberá borrarse de la base de datos Eurodac. ${ }^{530}$ En caso contrario, un sujeto sobre el que ya no pesa la mencionada prohibición podría ver limitados sus derechos por cuanto su información todavía consta en Eurodac hasta el plazo total de 5 años.

$\mathrm{Y}$ en este aspecto, el ECRE fue especialmente crítico con este plazo marcado de 5 años, alegando que este no resultaba necesario a efectos de retorno en vista de que esta Directiva fija un tiempo máximo de internamiento a efectos de expulsión de 18 meses (art. 15.5 y 15.6). ${ }^{531}$ Este plazo no solo resulta excesivo para los fines que se persiguen, sino que tampoco incluye un criterio de concreción alguno. Por ende, debería preverse

\footnotetext{
${ }^{528}$ TEDH, Reserch Division, Internet: case-law of the European Court of Human Rights, junio de 2015, p. 13.

${ }^{529}$ SEPD, Dictamen del Supervisor Europeo de Protección de Datos sobre la Comunicación de la Comisión al Parlamento Europeo, al Consejo, al Comité Económico y Social Europeo y al Comité de las Regiones — «Un enfoque global de la protección de los datos personales en la Unión Europea» (2011/C181/01), $\quad 14$ de enero de 2011, párrafo 15. http://www.edps.europa.eu/EDPSWEB/webdav/site/mySite/shared/Documents/Consultation/Opinions/20 11/11-01-14_Personal_Data_Protection_EN.pdf.

${ }^{530}$ Supervisor Europeo de Protección de Datos (SEPD). Opinión 07/2016 sobre la reforma..., ob. cit, párrafo 32.

${ }^{531}$ ECRE, Comments on the Commission Proposal... ob. cit., p. 10.
} 
un periodo de conservación "de hasta un máximo de 5 años", garantizando una regla proporcional adaptada a cada sujeto. ${ }^{532}$

- En segundo lugar, el art. 17 PRE, en cualquiera de sus modalidades, dispone que el período de conservación se inicia a partir de la fecha en la que "se hayan tomado sus impresiones dactilares". Ahora bien, el mencionado artículo no establece el plazo concreto por el que empieza a computarse, especialmente, en los supuestos en los que los datos biométricos se toman en sucesivas ocasiones -como consecuencia del cruce irregular de frontera o la presencia del migrante de forma ilegal en el territorio de un EEMM-. Esto podría conducir a que el plazo de los 5 años comenzara a computarse desde su inicio cada vez que una autoridad nacional recoge la información personal, generando un periodo ilimitado en el tiempo en la conservación de los datos. ${ }^{53}$

Esta fue la razón por la que el SEPD recomendó incluir en la mencionada disposición el momento exacto de la toma de los primeros datos biométricos, a fin de determinar el inicio exacto de este plazo. ${ }^{534}$ Consecuentemente, estas fueron finalmente previstas en las enmiendas $\mathrm{n}^{\mathrm{o}} 102$ y 103 que llevó a cabo la Comisión LIBE. ${ }^{535}$ Pese a ello, quizá hubiera resultado más apropiado incluir que este plazo de tiempo fuera computado con independencia de su procesamiento no solo por un EEMM, sino incluyendo también a la GEFC o la futura AAUE.

- Finalmente, y al margen del Sistema de Información Eurodac, el periodo de conservación de los datos en la legislación de protección de datos en ámbito nacional se encuentra actualmente pendiente de dos cuestiones prejudiciales ante el TJUE.

El 19 de Julio de 2018, el Tribunal Constitucional Belga elevó una cuestión prejudicial al $\mathrm{TJUE}^{536}$ sobre dos aspectos. En primer término, en relación con la "prohibición general de conservación de los datos" y sus limitaciones, solicitó si los

${ }^{532}$ Desafortunadamente, el Informe del PE nada contempla en las enmiendas acerca de este extremo.

${ }^{533}$ En este cómputo del plazo, de forma análoga en la Directiva de retorno, en la STJUE Ouhrami, de 26 de julio de 2017 (asunto C-225/16), el TJUE sostuvo que la duración de una prohibición de entrada, que en principio no debe exceder de 5 años, debía computarse a partir de la fecha de salida en que la persona interesada del territorio de los Estados miembros. La STJUE estableció que solo después de que la persona haya salido realmente, la prohibición de entrada produce sus efectos legales.

${ }^{534}$ Supervisor Europeo de Protección de Datos (SEPD). Opinión 07/2016 sobre la reforma..., ob. cit, párrafo 33.

${ }^{535}$ Parlamento Europeo, Informe sobre la propuesta de Reglamento ..., ob. cit, enmiendas no 102 y 103.

${ }^{536}$ TJUE, Petición de decisión prejudicial planteada por la Cour constitutionnelle (Bélgica) el 2 de agosto de 2018 - Ordre des barreaux francophones et germanophone, Académie Fiscale ASBL, UA, Liga voor Mensenrechten ASBL, Ligue des Droits de l'Homme ASBL, VZ, WY, XX / Conseil des ministers. (Asunto C-520/18). 
criterios fijados por la jurisprudencia anterior del TJUE debían considerarse o no acumulativos o, si por el contrario, la falta de un único requisito -en este caso, la naturaleza específica de la conservación de datos- constituía elemento suficiente para determinar la incompatibilidad de la legislación nacional con la CDFUE. La segunda cuestión planteada se centró en las consecuencias de una legislación nacional declarada ilegal ante la falta de los requisitos reconocidos de la STJUE Tele2. De esta forma, preguntó si resultaba lícito emplear los datos conservados en virtud de esa disposición ilegítima para evitar la elevada inseguridad jurídica en lo que concierne a los datos utilizados en investigaciones o procedimientos penales.

Sobre esta última, el Consejo de Estado Francés el 3 de agosto de 2018, ${ }^{537}$ en relación con el art. 15 de la Directiva 2002/58/CE sobre la privacidad y las comunicaciones electrónicas, ${ }^{538}$ llevó a que los jueces franceses preguntaran al TJUE si la adopción de legislaciones nacionales sobre la conservación de datos que interferían en el derecho a la privacidad podía justificarse si se encaminaba a proteger la seguridad nacional al amparo del art. 4 TUE.

Ciertamente, estos próximos pronunciamientos del TJUE sobre el alcance del periodo de conservación de datos arrojarán luz sobre un ámbito enormemente complejo y fragmentado a nivel nacional, solventando la elevada inseguridad jurídica en lo que respecta a la conservación de los datos personales. ${ }^{539}$ Recuérdese que, con independencia del funcionamiento técnico de Eurodac y del periodo de conservación de los datos en el Sistema Central, los EEMM disponen de sus propias legislaciones nacionales y pueden recopilar información personal sensible derivada directa $\mathrm{o}$ indirectamente de Eurodac por cuestiones que afectan a su propia seguridad nacional. Unas acciones que podrían contrariar las garantías de la PRE y de la legislación de protección de datos aplicable.

\footnotetext{
${ }^{537}$ TJUE, Petición de decisión prejudicial planteada por el Conseil d'État (Francia) el 3 de agosto de 2018- French Data Network, La Quadrature du Net, Fédération des fournisseurs d'accès à Internet associatifs / Premier ministre, Garde des Sceaux, ministre de la Justice. (Asunto C-512/18)

${ }^{538}$ Esta faculta a los EEMM a establecer medidas que limiten la confidencialidad de las comunicaciones y los datos de tráfico siempre que constituyan medidas proporcionadas y apropiadas para proteger "la seguridad nacional (es decir, la seguridad del Estado), la defensa, la seguridad pública, o la prevención, investigación, descubrimiento y persecución de delitos".

${ }^{539}$ Recuérdese que en 2014, la STJUE Digital Rights Ireland declaró inválida la Directiva sobre la conservación de datos en la STJUE. Los EEMM tuvieron que adaptar sus legislaciones nacionales en lo relativo a la conservación de los datos de las comunicaciones electrónicas relacionadas con las bases de datos con el fin de combatir delitos graves de acuerdo con la salvaguardias del TJUE.
} 
A falta de respuestas a las dos cuestiones prejudiciales que permitan concretar el futuro de las garantías en la conservación de los datos masivos en los distintos sistemas nacionales, lo cierto es que nos encontramos en un contexto marcado por la exigencia en el respeto de la legislación de protección de datos $\mathrm{y}$, al mismo tiempo, el mantenimiento de la seguridad nacional. Esta división de competencias nacionales y comunitarias exigirá una modulación de los principios de necesidad y proporcionalidad de los distintos plazos de conservación de datos y su excepcionalidad. Con ello, las legislaciones nacionales únicamente deberían conservar estos datos más allá del periodo establecido para combatir delitos graves, limitándose a lo estrictamente necesario con respecto a la categoría de los datos, los medios de comunicación afectados, las personas afectadas y el período de conservación.

Sin embargo, parecen reflejarse reticencias de hondo calado en los EEMM y en sus agencias de seguridad pública y nacional. Así consta en el informe de Privacy International del año 2017, que llegó a la conclusión de que la mayor parte de los EEMM disponen de leyes de conservación de datos que no cumplen con los requisitos de la jurisprudencia del TJUE. Además, alertó de que casi la mitad de ellos disponen de una legislación nacional de acuerdo con la transposición de la invalidada Directiva 2006/24 sobre la conservación de datos generados o tratados en relación con la prestación de servicios de comunicaciones electrónicas de acceso público o de redes públicas de comunicaciones. ${ }^{540}$

Asimismo, en marzo de 2017, el Consejo de la UE inició un proceso de reflexión sobre la conservación obligatoria de las comunicaciones electrónicas entre los representantes de los EEMM y las agencias de la UE como Frontex o Europol. ${ }^{541}$ Durante este periodo, Europol abogó por una aplicación distinta del periodo de conservación que permitiera integrar los requisitos jurisprudenciales del TJUE a los fines de carácter policial. ${ }^{542}$ También presentó un documento de trabajo en el que

\footnotetext{
${ }^{540}$ Véase Privacy International, National Data Retention Laws since the CJEU's Tele-2/Watson Judgment, septiembre de 2017. Accesible en: https://privacyinternational.org/sites/default/files/201712/Data\%20Retention_2017.pdf

${ }^{541}$ Statewatch, The "reflection process" on data retention: working documents discussed by Council published, 28 de febrero de 2018. Accesible en: http://www.statewatch.org/news/2018/feb/eu-drdreflection-docs.htm

${ }^{542}$ Europol, Proporcionate data retention for law enforcement purposes, Data retention function, 18 de septiembre de 2017 (WK 9957/2017 INIT). Disponible en: http://www.statewatch.org/news/2018/feb/eucouncil-data-retention-europol-presentation-targeted-data-ret-wk-9957-17.pdf
} 
determinó que las diferentes categorías de datos para los amplios fines policiales requerían la aplicación de diferentes niveles de protección. ${ }^{543}$

Estas sugerencias de Europol fueron respaldadas por la Presidencia Búlgara y Austriaca del Consejo en los documentos producidos durante el periodo de reflexión. El 6 de junio de 2019, se adoptaron las Conclusiones del Consejo de la UE sobre la conservación de datos con la finalidad de combatir la delincuencia. El Consejo solicitó a la Comisión la iniciativa legislativa sobre la conservación de los datos personales, estableciendo "un régimen de conservación de datos aplicable a toda la UE, en consonancia con los requisitos derivados de la jurisprudencia del Tribunal de Justicia, teniendo en cuenta, al mismo tiempo, las necesidades de las autoridades competentes y las particularidades de la lucha contra el terrorismo". ${ }^{544}$ Conclusiones que subrayan la importancia de la conservación de los datos como una herramienta esencial en la lucha contra la delincuencia y reafirman el interés de los EEMM de un nuevo marco armonizado. ${ }^{545}$ Sin embargo, paralelamente, no dejan de evidenciar el amplio margen de discrecionalidad que ostentan los EEMM a la hora de proceder a la conservación de los datos y el acceso de los distintos sujetos actores de seguridad. Será el TJUE el que deberá proporcionar respuestas más claras y contundentes que eviten las interpretaciones arbitrarias y excesivamente amplias en ámbito nacional.

\section{El acceso a Eurodac por parte de las fuerzas policiales nacionales y Europol.}

4.1. El acceso policial del actual Reglamento Eurodac hasta la propuesta de reforma de Eurodac: un conflicto entre seguridad y protección de datos.

\footnotetext{
${ }^{543}$ Europol, Data categories to be retained for law enforcement purposes DAPIX Friends of Presidency meeting, 15 de mayo de 2017 (WK 5380/2017). Accesible en: http://www.statewatch.org/news/2018/feb/eu-council-data-retention-europol-data-to-be-retained-wk5380-17-censored.pdf

${ }^{544}$ Consejo de la Unión Europea, Conclusiones del Consejo de la Unión Europea sobre la conservación de datos a efectos de lucha contra la delincuencia, 27 de mayo de 2019 (9663/19).

${ }^{545}$ Este texto incluye algunos puntos importantes, por ejemplo, se refieren a la lucha contra la delincuencia en general y solo una vez hacen mención del requisito de gravedad del delito que dispone el TJUE a fin de que los esquemas de conservación de datos sean legales. Además, se refieren a delitos graves como el terrorismo o el delito cibernético - y pese a que reconoce que la gravedad de los delitos está definida por la legislación nacional, la ciberdelincuencia resulta bastante arbitraria-. Finalmente, el Consejo invitó a la Comisión a "seguir evaluando, entre otros, los conceptos de conservación de datos generales, específicos y restringidos".
} 

datos.

Desde la entrada en vigor del Reglamento Eurodac el 20 de julio de 2015, las autoridades policiales y la Europol están habilitadas para acceder a este SI a efectos de prevenir, detectar e investigar la comisión de ataques terroristas y otros delitos considerados como graves. ${ }^{546}$ Un acceso que ha priorizado las cuestiones relativas a seguridad en detrimento de los derechos fundamentales, en especial, del derecho a la protección de datos y de la vida privada.

Resulta necesario destacar que este SI cuenta con escasos estudios doctrinales sobre su impacto en este derecho. Ello pesar de que, al margen de la ausencia del nombre de los sujetos, Eurodac haya recopilado desde sus orígenes distintos datos personales, comprendiendo tanto las huellas dactilares, sexo, fecha de toma de huellas dactilares y un número de referencia del Estado que proporciona la información. Este conjunto de datos permite una clara identificación de un sujeto y se encuentran regulados en los arts. 10 y siguientes del Reglamento Eurodac (arts. 11 y siguientes PRE). ${ }^{547}$

Sin embargo, desde que se barajara la primera de las propuestas del actual Reglamento Eurodac en el 2009, tanto el SEPD como el Comité Meijers abordaron de forma contundente los riesgos emergentes derivados de este acceso. ${ }^{548}$ Una advertencia que fue nuevamente destacada durante la reforma del 2013 cuando el SEPD sugirió

\footnotetext{
${ }^{546} \mathrm{La}$ regulación del acceso a Eurodac por parte de las distitnas autoridades se encuentra previsto en los arts. $1.2,5$ a 7 y 19 a 22 del Reglamento Eurodac.

${ }^{547}$ Entre los escasos estudios, cabe mencionar a van der PLOEG, que destacó que la Directiva 95/46/CE de protección de datos era aplicable en toda su extensión a Eurodac. van der PLOEG, I., "The Illegal Body: 'Eurodac' and the Politics of Biometric Identification" Ethics and Information Technology, vol. 1, $\mathrm{n}^{\circ} 4$, 1999, p. 299. Disponible en: http://dx.doi.org/10.1023/A:1010064613240

${ }^{548}$ Riesgos que emergían de la potencial contradicción con los principios de proporcionalidad, limitación de la finalidad y legitimidad en el tratamiento de los datos.Véase, en particular, los apartados 29 y 35. Supervisor Europeo de Protección de Datos (SEPD), Dictamen del Supervisor Europeo de Protección de Datos sobre la propuesta modificada de Reglamento del Parlamento Europeo y del Consejo relativo a la creación del sistema «Eurodac» para la comparación de las impresiones dactilares para la aplicación efectiva del Reglamento (CE) no [.../...] (por el que se establecen los criterios y mecanismos de determinación del Estado miembro responsable del examen de una solicitud de protección internacional presentada en uno de los EEMM por un nacional de un tercer país o un apátrida) y sobre la propuesta de Decisión del Consejo relativa a las solicitudes de comparación con datos Eurodac presentadas por los servicios de seguridad de los EEMM y Europol a efectos de la aplicación de la ley, OJ C 92/01, 10 de abril de 2010; Comité Meijers, Propuesta modificada del Reglamento Eurodac (COM (2009) 342) relativa a la decisión de comparación con los datos de Eurodac por parte de las autoridades policiales de los Estados miembros y Europol para fines policiales (COM (2009) 344), CM0910, Utrecht, 30 de septiembre de 2009 , p. 1.
} 
llevar a cabo una evaluación de impacto que determinara si los instrumentos existentes resultaban suficientes antes de la adopción de la mencionada propuesta de Reglamento. Asimismo, subrayó que debía tenerse en cuenta las condiciones de acceso a los datos de los solicitantes de asilo por parte de las autoridades policiales y Europol, un supuesto que no parecía contemplarse en la citada propuesta. ${ }^{549}$

También la doctrina comenzó a advertir que el acceso que contemplaban estas propuestas excedía de los fines concretos que contemplaba Eurodac hacia cuestiones relacionadas con la seguridad de los Estados. Consecuentemente, la información exclusivamente recopilada para fines de asilo -conforme al Reglamento de Dublín-, iba a ser empleada para fines de investigación y lucha contra el terrorismo y una amplia tipología de "delitos". ${ }^{550} \mathrm{Y}$, pese a que no se refirieron a las condiciones de acceso ni a la gravedad del delito, lo cierto es que evidenció serias dudas de cumplimiento con la protección de datos personales del art. 8 CDFUE.

Fruto de la emergencia de este conflicto, el Grupo de Trabajo del Artículo 29 (GT 29) destacó en 2013 las consecuencias sumamente desventajosas en los derechos e intereses de los solicitantes de protección internacional. Afirmó que el acceso de las autoridades policiales a las huellas dactilares podían determinar de forma automática si un sujeto había cometido cualquier tipo de delito, pese a que en un principio no se sospechase del mismo. Consideró que los solicitantes de asilo eran investigados de forma automática ante la posible comisión de delitos, ${ }^{551}$ de forma que aquellos que no habían cometido delito alguno podían enfrentarse a la incoación de un procedimiento e investigación penal que no se produciría con respecto a otro sujeto más allá de las dos categorías de migrantes irregulares. Una cuestión sumamente perjudicial para los intereses de este colectivo en situación de vulnerabilidad que, indudablemente, podía incrementar la tasa de denegación de la solicitudes de protección internacional por cuestiones radicadas en seguridad nacional.

\footnotetext{
${ }^{549}$ SEPD, Opinion of the European Data Protection Supervisor on the amended proposal for a Regulation of the European Parliament and of the Council on the establishment of "EURODAC" for the comparison of fingerprints, 2013, OJ 28/3.

${ }^{550}$ TZANOU, M., "The EU as an Emerging Surveillance Society: The Function Creep Case Study and Challenges to Privacy and Data Protection", Vienna Online Journal on International Constitutional Law, vol. 4, n' 3 2010, p. 425; BESTERS, M., BROM, F., "Greedy' Information Technology: The Digitalization of the European Migration Policy", European Journal of Migration and Law, vol. 12, 2010, p. 465.

${ }^{551}$ Un efecto que fue primeramente abordado por el Grupo de Trabajo del Art. 29, Opinión 03/2013 sobre la limitación de la finalidad, 4 de abril de 2013, p. 68. (00569/13/EN WP 203).
} 
Tal fue la gravedad de esta situación, que un amplio sector doctrinal encabezado por Brouwer, Vavoula, Bourbeau o Roots apuntaron que este acceso iba a ser empleado como potencial arma discriminatoria focalizada, precisamente, mediante el sometimiento de los solicitantes de protección internacional a controles e investigación adicionales a los que no se enfrentarían otras categorías de sujetos. ${ }^{552}$

Y sobre esta situación, fue abordado un caso análogo en la STJUE Huber Heinz c. Bundesrepublik Deutchland, de 16 de diciembre de 2008, ${ }^{553}$ cuyos hechos probados determinaron la manifiesta discriminación que sufrían los extranjeros que residían en territorio alemán cuando las autoridades de este país procedían a la recopilación y registro de sus datos personales. Esta información, exclusivamente procesada para ciudadanos no nacionales, se empleaba para diversos fines, lo que propició que el TJUE declarara que el procesamiento sistemático de los datos personales únicamente de las personas no nacionales y con fines de prevención de delitos graves constituía una medida desproporcional $\mathrm{y}$, a todas luces, discriminatoria por motivos basados en la nacionalidad de los sujetos.

Además, al margen de esta mayor probabilidad de que estos sujetos puedan identificarse ante la comisión de un delito, lo cierto es que también se ha visto seriamente comprometida su presunción de inocencia. De acuerdo con un estudio que llevó a cabo en el año 2013, este sistema disponía de una tasa de errores elevada. Así, con independencia del peligro que supone una "aplicación automática" de los solicitantes de asilo en las investigaciones penales, no fueron aislados los escenarios en los que las huellas dactilares de dos o más sujetos resultaban coincidentes. ${ }^{554}$

De esta manera, la notoria preeminencia de la seguridad nacional ha articulado un derecho de acceso policial a los datos personales en Eurodac que ha interferido

\footnotetext{
${ }^{552}$ VAVOULA, N., "The recast Eurodac Regulation: Are Asylum Seekers Treated as Suspected Criminals", en: BAUlOZ, C., INELI-CIGER, M., SINGER S., STOYANOVA, V., (eds.), Seeking Asylum in the European Union: Selected Protection Issues Raised by the Second Phase of the Common European Asylum System, 2015, p. 261; BROUWER E., The Use of Biometrics at the Borders: A European Policy and Law Perspective, en: VAN DER HOF, S., GROOTHUIS M. (eds.) Innovating Government. Information Technology and Law Series, vol 20. T. M. C. Asser Press, 2011, p. 248; BOURBEAU P., Handbook on Migration and Security, Elgar, 2017, p. 240; ROOTS, L., "The New EURODAC Regulation: Fingerprints as a Source of Informal Discrimination", Baltic Journal of European Studies Tallinn University of Technology, vol. 5, $\mathrm{n}^{\circ}$ 2, 2015, pp. 108-129.

${ }^{553}$ STJUE Huber Heinz c. Bundesrepublik... ob. cit.

${ }^{554}$ Sobre el estudio acerca de la tasa de error de EURODAC, remitimos a: KENK, V.S., KRIŽAJ, J., ŠTRUC, J., DOBRIŠEK S., "Smart Surveillance Technologies in Border Control”, European Journal of Law and Technology, vol. 4, $\mathrm{n}^{\circ}$ 2, 2013, pp. 1-12.
} 
negativamente no solo en el derecho de asilo del art. 18 CDFUE, sino también en el derecho a la protección de datos personales del art. 8 CDFUE y en el derecho fundamental a la vida privada del art. $8 \mathrm{CEDH}$.

Sobre el particular, cabe destacar que el TEDH lleva reconociendo en una vasta jurisprudencia la interferencia con el art. $8 \mathrm{CEDH}$ a un amplio catálogo de límites en la recogida, tratamiento y almacenamiento de información personal, inclusive, si son efectuados a través de los sistemas específicos que disponen los servicios de seguridad. ${ }^{555}$ La STEDH S. y Marper c. Reino Unido, de 4 de diciembre de $2008^{556}$ marcó un verdadero punto de inflexión en este ámbito, no únicamente por la atribución de carácter sensible a las huellas dactilares, sino por la exigencia social imperiosa de preservar las garantías adecuadas y la proporcionalidad de la finalidad legítima perseguida. Sin embargo, la especial injerencia no ha resultado arbitraria, más bien ha venido amparada por su tipicidad en Eurodac, constituyendo conforme a su apartado $2^{\circ}$ una medida "necesaria para la seguridad nacional, la seguridad pública (...) la defensa del orden y la prevención del delito, la protección de la salud (...)”, esencialmente en contextos convulsos como las pasadas crisis migratorias o el incremento de los ataques terroristas.

En clara vinculación con este régimen excepcional, la STJUE Rechnungshof $c$. Österreichischer Rundfunk y otros y Christa Neukomm y Joseph Lauermann c. Österreichischer Rundfunk, de 20 de mayo de $2003,{ }^{557}$ ha constituido una de las escasas sentencias que ha proporcionado cierta orientación sobre el alcance de la seguridad en el tratamiento de datos conforme a la Directiva 95/46/CE. La mencionada Sentencia interpretó el art. 13 de esta Directiva, que permitía a los EEMM la derogación de algunas de sus disposiciones por razón de seguridad del Estado, defensa, seguridad

\footnotetext{
${ }^{555}$ Véanse las SSTEDH Gillow c. Reino Unido, de 24 de noviembre de 1986 (demanda no 9063/80); Leander c. Suecia, de 26 de marzo de 1987 (demanda no 9248/81); Amann c. Suiza, de 16 de febrero de 2000 (demanda $\mathrm{n}^{\circ}$ 27798/95); Weber y Savaria c. Alemanía, de 26 de junio de 2006 (demanda $\mathrm{n}^{\circ}$ 54934/00); PG y JH c. Reino Unido, de 25 de septiembre de 2001 (demanda $\mathrm{n}^{\mathrm{o}}$ 44787/98); Rotaru c. Rumanía, de 4 de mayo de 2000 (demanda no 28341/95).

${ }^{556}$ STEDH S. y Marper c. Reino Unido... ob. cit. Sobre un análisis de esta Sentencia, remitimos a GONZÁLEZ FUSTER, G., "TEDH - Sentencia de 04.12.2008, S. y Marper c. Reino Unido, 30562/04 y 30566/04 - Artículo 8 CEDH - Vida privada- Injerencia en una sociedad democrática - Los límites del tratamiento de datos biométricos de personas no condenadas", Revista de Derecho Comunitario Europeo, $\mathrm{n}^{\mathrm{0}} 33$, mayo/agosto, 2009, pp. 619-633.

${ }^{557}$ STJUE Rechnungshof c. Österreichischer Rundfunk y otros y Christa Neukomm y Joseph Lauermann c. Österreichischer Rundfunk, de 20 de mayo de 2003. Asuntos acumulados C-465/00, C-138/01 y C$139 / 01$.
} 
pública o la prevención, investigación o detección de infracciones penales, entre otras. Su razonamiento estribó en que, mientras que la Directiva de protección de datos tenía como objetivo principal garantizar la libre circulación de datos personales, no permanecía ajena a la necesidad de que los EEMM protegieran eficazmente sus derechos e intereses particulares.

Para tal fin, y desde el prisma del art. $8 \mathrm{CEDH}$, verificó si la legislación pertinente preveía algún tipo de injerencia en la vida privada y, en caso afirmativo, si resultaba justificado. Sustentándose en la jurisprudencia del TEDH, el Tribunal de Luxemburgo destacó la necesidad de que las interferencias fueran proporcionales al objetivo perseguido, lo que llevó a una ponderación entre el interés público de garantizar el uso óptimo de los fondos públicos y la interferencia en el derecho a la vida privada.

4.1.2. El acceso policial en la propuesta de reforma de Eurodac y su impacto en la legislación de protección de datos.

Por lo que respecta al propio funcionamiento del acceso en el actual Reglamento Eurodac, el Considerando 13 pone de manifiesto el carácter intrusivo en la vida privada, incluso a los efectos de prevención, detección o investigación de los delitos de terrorismo o de otros delitos graves por el cambio de finalidad original del propio sistema. Su versión en el Considerando 20 PRE presenta leves mejoras en este sentido adicionando, por primera vez, el respeto al art. 52.1 CDFUE y aludiendo, de igual forma, a los principios de legalidad, necesidad y proporcionalidad como elementos ineludibles para la consecución del interés general. ${ }^{558}$

Sin embargo, lo realmente conflictivo estriba en las serias limitaciones en lo que atañe al cumplimiento de la legislación de protección de datos. Máxime cuando el propio Reglamento reconoce explícitamente que el cambio de la finalidad original de Eurodac "puede suponer" una injerencia en el derecho fundamental al respeto de la vida

\footnotetext{
${ }^{558}$ Un supuesto que la propuesta, remitiendo a la Comunicación de la Comisión al Consejo y al Parlamento Europeo, de 24 de noviembre de 2005, sobre una mayor eficacia, interoperabilidad y sinergia entre las bases de datos europeas, tipifica en el Considerando 10 (Considerando 17 PRE) cuando dispone lo siguiente: "el principio de proporcionalidad exige que Eurodac solo pueda ser consultado con esos fines cuando lo exija un interés superior de seguridad pública, es decir, cuando el acto cometido por el delincuente o el terrorista que deba ser identificado sea lo suficientemente reprensible como para justificar búsquedas en una base de datos en la que se registran personas sin antecedentes penales (...) que el umbral que deben respetar las autoridades responsables de la seguridad interior para poder consultar Eurodac debe ser siempre, por tanto, considerablemente más elevado que el umbral que debe respetarse para poder consultar bases de datos penales".
} 
privada, aunque lo supedita a la imperante necesidad de emplear los datos como mecanismo fundamental en el ámbito de la cooperación policial (Considerando 14 o 21 PRE). ${ }^{559}$

En este sentido, justifica este acceso en la importancia de que los servicios de seguridad puedan disponer y comparar la información de una forma más completa y actualizada $\mathrm{y}$, de esta manera, luchar de una forma más eficaz contra los delitos de terrorismo y otros delitos graves (Considerando 8 o 15 PRE). Además, subraya que las condiciones de acceso fueron diseñadas siguiendo el modelo del "Sistema de Información Visa", ${ }^{560}$ consistente en un acceso extraordinario, esto es, únicamente en los supuestos de prevención, detección e investigación de ataques terroristas o delitos graves (Considerando 31 o $41 \mathrm{PRE}$ ) y bajo unas condiciones especialmente rigurosas, en vista de que la falta presunción de la comisión o participación en delitos de terrorismo $\mathrm{u}$ otros delitos graves (Considerando 15 o 22 PRE). ${ }^{561}$

Por lo tanto, el propio Reglamento Eurodac ya establecía que el acceso podía contrariar seriamente la limitación de la finalidad, apostando encarecidamente por el exhaustivo cumplimiento de los criterios de proporcionalidad, necesidad y especial extraordinariedad. Ahora bien, estas "tímidas salvaguardas" previstas en el mencionado Reglamento han sido, a todas luces, insuficientes. Una vez que las autoridades policiales nacionales exigen el acceso a Eurodac por razones de seguridad nacional o con fines de prevención, detección o investigación de los delitos de terrorismo o de otros delitos graves, el mencionado régimen del acceso se reduce exponencialmente.

En este sistema radican dos obstáculos en la protección efectiva de los datos personales:

\footnotetext{
${ }^{559}$ Considerando 14 (Considerando 21 PRE): "La posibilidad de comparar una impresión dactilar (...) dotará a las autoridades designadas de los EEMM de un instrumento muy valioso a la hora de prevenir, detectar o investigar los delitos de terrorismo u otros delitos graves, cuando, por ejemplo, la única prueba disponible en la escena de un delito sean impresiones dactilares latentes".

${ }^{560}$ Sobre el acceso al mencionado Sistema, remitimos al estudio de: SERRA CRISTÓBAL, R., "E1 control de datos de circulación de personas... ob. cit., pp. 315 y ss.

${ }^{561}$ La Enmienda $n^{\circ} 19$ del parlamento Europeo se esforzaba en otorgar razones de peso en este acceso, sugiriendo incorporar la necesidad de este acceso en los siguientes términos: (...) estas autoridades no siempre pueden disponer datos del sospechoso, el autor del delito o la victima cuyo caso están investigando, lo que puede dificultar la capacidad para comprobar datos biométricos consultando bases de datos como Eurodac (...).
} 
a) la elevada frecuencia con la que el Reglamento de aparta de las garantías de protección de datos parece constituir "un contexto ordinario" en vez de propiciar que las excepciones resulten especialmente tasadas y especificadas y;

b) la conexión directa con el concepto de delito grave resulta muy dispar. $\mathrm{Su}$ definición corresponde a los EEMM bajo ciertos estándares mínimos que contempla el art. $2.1 \mathrm{k}$ ) del Reglamento Eurodac (o art. $3.1 \mathrm{~m}$ ) PRE. ${ }^{562}$

El amplio alcance de las autoridades nacionales en la determinación de un delito como grave fue objeto de interpretación por parte de la STJUE de 2 de octubre de $2018,{ }^{563}$ que analizó una cuestión prejudicial planteada por el Ministerio Fiscal de Tarragona en relación con la "gravedad de un delito" de los arts. 7 y 8 CDFUE, como una de las condiciones necesarias que facultan a las autoridades públicas al acceso a los datos conservados por los proveedores de servicios de comunicaciones electrónicas. ${ }^{564}$

La Audiencia Provincial de Tarragona solicitó al TJUE una aclaración del concepto de "delito grave" que dispone, en este caso, el art. 15.1 de la Directiva 2002/58 sobre la privacidad y las comunicaciones electrónicas, así como los criterios requeridos para calificarlo como tal a la luz de los arts. 7 y 8 CDFUE. Asimismo, preguntó si la gravedad debía catalogarse únicamente en atención a la pena que puede imponerse al delito o, si era necesario, igualmente, identificar la lesividad en los bienes jurídicos individuales y/o colectivos. Y, en relación con la pena imponible, preguntó cuál debía

\footnotetext{
${ }^{562}$ En lo relativo a los delitos graves, todavía se contemplan en el art. 2.2 de la Decisión 2002/584/JAI. Además, el art. $2.1 \mathrm{k}$ ) del reglamento Eurodac (o art. $3.1 \mathrm{~m}$ ) PRE) lo definen como "la forma de delincuencia que corresponda o sean equivalente a aquéllas a que se refiere el art. 2.2 de la Decisión Marco 2002/584/JAI y que estén penados en el Derecho nacional con una pena o una medida de seguridad privativas de libertad de una duración máxima no inferior a tres años".

Por su parte, para la consideración de los ataques terroristas, el art. 2.1 j) del reglamento [art. 3.1 1) PRE] remite al concepto de delitos de terrorismo que proporcionaba la anterior Decisión Marco 2002/475/JAI. Puesto que, en la actualidad, se encuentra derogada por la Directiva 2017/541 relativa a la lucha contra el terrorismo, los parámetros conceptuales se encuentran recogidos en la extensa definición de su art. 3. Este remite a aquellos que tipificados por el Derecho nacional, que, por su naturaleza o contexto, "pueden perjudicar gravemente a un país o a una organización internacional", y cuyos fines sean a) intimidar gravemente a una población; b) obligar indebidamente a los poderes públicos o a una organización internacional a realizar un acto o a abstenerse de hacerlo; c) desestabilizar gravemente o destruir las estructuras políticas, constitucionales, económicas o sociales fundamentales de un país o de una organización internacional.

${ }^{563}$ STJUE (Gran Sala), de 2 de octubre de 2018. Petición de decisión prejudicial planteada por la Audiencia Provincial de Tarragona Procedimiento prejudicial. Asunto C-207/16.

${ }^{564}$ En este caso, el Ministerio Fiscal exigía el acceso a los metadatos relacionados con una tarjeta SIM activada y que correspondía a un teléfono robado durante un período de tiempo específico, limitado y con el único propósito de identificar al supuesto sustractor, excluyendo el acceso a las comunicaciones efectuadas a través del terminal.
} 
ser el umbral mínimo y si era compatible con una previsión general de límite en 3 años de prisión.

En la mencionada sentencia, pese a que el TJUE no concretó una definición sobre delito grave, estableció que estas condiciones estrictas de acceso a los datos retenidos no podían representar per se una interferencia relevante en los derechos fundamentales de privacidad y protección de datos. Únicamente requirió la implementación de los principios establecidos por su jurisprudencia anterior (STJUE Digital Rights Ireland y otros) en los supuestos en los que el nivel de intrusión en la esfera privada resulte significativo, cuestión que no se produce en la presente cuestión prejudicial. Por lo tanto, de acuerdo con el Tribunal de Luxemburgo, la "gravedad" de un delito únicamente es necesaria para justificar una limitación de notoria entidad en los derechos fundamentales. Dicho de otro modo, el TJUE no requiere que el delito revista especial gravedad si no hay interferencia grave en el derecho a la privacidad y a la protección de datos.

El fallo de esta Sentencia posee una importancia crucial en la catalogación de delitos graves que prevé Eurodac. Así, cabe preguntarse si esta interferencia en el acceso a este SI constituye un supuesto de gran relevancia o, si por el contrario, puede rebajarse la consideración de delito grave a cualquier delito de menor gravedad. A nuestro juicio, la “virtualización" del acceso a Eurodac puede reflejar una "aparente incidencia menor" en la privacidad y protección de datos, pues el sujeto no se expone de forma física a una flagrante vulneración de sus derechos. Sin embargo, no debe obviarse que las condiciones de acceso que radican en cuestiones que comprometen la seguridad de los EEMM únicamente se contemplan para delitos de terrorismo o delitos graves, lo que exige una interpretación de estos términos de acuerdo con los parámetros que proporciona Eurodac.

Ciertamente, este debería ser el enfoque en el futuro Eurodac, que continuará permitiendo a las autoridades policiales el acceso a los datos de este Sistema con el fin de prevenir, detectar e investigar los delitos graves y el terrorismo. Ello, además de identificar a los nacionales de terceros países que cruzan las fronteras exteriores con el propósito de acceder a su información relativa a sus desplazamientos dentro de la UE y controlar eficazmente los movimientos secundarios y fortalecer la política de retorno de la UE. 
$\mathrm{Y}$ aunque, como veremos a continuación, la mencionada propuesta se centra en establecer condiciones estrictas de acceso para intentar compensar la discriminación a la que se enfrentan las distintas categorías de sujetos, vinculadas indirectamente con la comisión de delitos graves o incluso terroristas, ${ }^{565}$ lo cierto es que resulta incluso más intrusiva que el actual Reglamento por los siguientes argumentos:

- Por un lado, permitirá el acceso a todos los datos personales a un amplio conjunto de autoridades de los EEMM, Europol y servicios de seguridad;

- por otro, también adicionará mayores datos personales, ampliando la disponibilidad de la información a los efectos de "permitir el acceso a efectos de control de la inmigración ilegal a la UE y los movimientos secundarios de los migrantes irregulares dentro de su territorio y la prevención, investigación, detección de delitos de terrorismo o de especial gravedad". 566

Todo ello, considerando que este objetivo "no puede alcanzarse de manera suficiente por los Estados miembros actuando por sí solos", ${ }^{567}$ lo cual requiere un cambio de paradigma en el modelo de intercambio de información entre las distintas autoridades legitimadas para acceder a los datos contenidos en Eurodac.

Por consiguiente, la próxima versión de Eurodac, en aras de "compensar" el elevado número de autoridades policiales con potestad para acceder a los datos contenidos en Eurodac, y la asiduidad con la que estas se apartan de los principios de protección de datos antes mencionados dispondrá en su próxima versión de una de las más esperadas limitaciones en materia de acceso e intercambio de información, el principio de subsidiariedad. Este excluirá las comparaciones sistemáticas de datos personales contenidos en Eurodac, salvo en caso de necesidad para los fines de prevención, detección o investigación de los delitos de terrorismo o de otros delitos graves (Considerando 41). Igualmente, permitirá el acceso a condición de que se haya realizado con anterioridad una búsqueda previa en las bases de datos nacionales del EM y en los sistemas automatizados de todos los demás EEMM y no hayan resultado

\footnotetext{
${ }^{565}$ Véase la Exposición de motivos de la Propuesta.

${ }^{566}$ Sobre esta facultad, como hemos señalado anteriormente, la prohibición expresa del acceso a la base de datos Eurodac por parte de autoridades de terceros países que no son parte en el Reglamento de Dublín. Esta prohibición se amplía a la consulta de los datos por parte de un EEMM en nombre de un tercer país.

${ }^{567}$ Comisión Europea, Propuesta de Reglamento relativo a la creación del sistema Eurodac..., ob. cit., $\operatorname{COM}(2016) 272$ final 2016/0132 (COD), p. 8.
} 
fructíferas, esto es, no hayan permitido establecer la identidad efectiva del sujeto de los datos (Considerando 42). ${ }^{568}$

Ahora bien, estas sustanciales mejoras en el acceso no resultarán ajenas a una serie de críticas de enorme calado, especialmente, sobre el uso a posteriori de esta información y que exigirá abordarse desde dos perspectivas:

1. La PRE quizá debería haber contemplado referencias explícitas al principio de limitación de la finalidad sobre el uso de los datos con fines policiales. La mera remisión al cumplimiento de los principios de legalidad, proporcionalidad y necesidad no parece suficiente. Precisamente, se requiere de una orientación más concreta sobre las condiciones de acceso a los datos contenidos en este sistema.

Máxime, en vista de que algunos EEMM en virtud del acceso de sus autoridades policiales a Eurodac almacenan datos de solicitantes de asilo en sus sistemas automatizados de identificación de huellas dactilares (AFIS) ${ }^{569}$ y que, como apunta Vavoula, su uso adicional por parte de las distintas autoridades policiales constituye un peligro inherente al almacenamiento centralizado de datos personales. Una vez que la información se almacena para una finalidad específica, coexiste una alta posibilidad a que los datos vuelvan a emplearse para objetivos que no fueron concebidos inicialmente para tal fin. ${ }^{570}$

2. Además, pese a que los datos están accesibles durante 3 años para los solicitantes de asilo tal y como dispone el apartado $2^{\circ}$ del art. 19, la PRE no contempla un plazo para el resto de las categorías de sujetos (apartados $3^{\circ}$ y $4^{\circ}$ ), lo que induce a suponer que el plazo será mayor. El memorando explicativo justifica tal diferencia en que la probabilidad de renovación de la residencia de los solicitantes de asilo resulta mayor que para los que no lo solicitan. Un supuesto que recibió un duro reproche por parte del

\footnotetext{
${ }^{568}$ Véase, igualmente, la enmienda $\mathrm{n}^{\circ} 31$ del Parlamento Europeo.

${ }^{569}$ Desde el inicio de Eurodac, Gemalto (Compañía Thales) ha sido proveedor de Eurodac, considerado el sistema de identificación de huellas dactilares automatizado (AFIS) más grande del mundo, con 32 países afiliados. Sobre la operatividad de este sistema remitimos a: https://www.gemalto.com/govt/biometrics/afis-history

${ }^{570}$ VAVOULA N., "Towards the normalisation of surveillance of movement in an era of 'Privacy Spring'?”, en: VERMEULEN G., LIEVENS E., (eds.), Data protection and privacy under pressure: transatlantic tensions, EU surveillance, and big data, Maklu, 2017, p. 234.
} 
SEPD, que recomendó equiparar el bloqueo de los datos de ambas categorías de individuos al período genérico de 3 años. ${ }^{571}$

Indudablemente, esta diferencia reconoce implícitamente una mayor vinculación de criminalidad para aquellas categorías de sujetos que no obtienen estatuto de protección internacional. De ello, pueden realizarse dos lecturas: primero, un primer punto de partida en la desvinculación de la criminalidad hacia los solicitantes de protección internacional y segundo, una menor protección hacia las dos categorías de migrantes irregulares que incluye Eurodac.

\subsection{Las modalidades de acceso con fines policiales a Eurodac.}

La PRE diferencia entre dos sujetos que, desde el actual Reglamento, pueden acceder a la base de datos Eurodac y consultar los datos con fines de prevención, detención o investigación de ataques terroristas y otros delitos graves, esto es: las autoridades nacionales y la Europol.

Con respecto a la primera, este acceso únicamente procede por parte de los EEMM. Los cuatro países asociados al Sistema de Dublín (Islandia, Noruega, Liechtenstein y Suiza), no ostentan el acceso directo a esta base de datos, por lo que han celebrado y firmado acuerdos complementarios con aquellos Estados asociados que deseen participar. ${ }^{572}$ Y, por lo que respecta a Europol, este acceso cumple con el objetivo de su Reglamento 2016/794 relativo a Europol. Específicamente, regula en las fuentes de información (art. 17) que este organismo solo trate "la información que le haya sido facilitada por: a) los Estados miembros, de conformidad con su Derecho nacional y con el artículo 7; b) organismos de la Unión, países terceros y organizaciones internacionales, de conformidad con el capítulo $\mathrm{V}$; c) por entidades privadas $\mathrm{y}$

\footnotetext{
${ }^{571}$ Supervisor Europeo de Protección de Datos (SEPD). Opinión 07/2016 sobre la reforma..., ob. cit, parágrafos 34 y 35 .

${ }^{572}$ Acuerdo entre la Comunidad Europea, la República de Islandia y el Reino de Noruega relativo a los criterios y mecanismos para determinar el Estado responsable de examinar las peticiones de asilo presentadas en un Estado miembro o en Islandia o Noruega (DO L 93 de 3.4.2001, p. 40); Acuerdo entre la Comunidad Europea y la Confederación Suiza sobre los criterios y mecanismos para determinar el Estado responsable del examen de una solicitud de asilo presentada en un Estado miembro o en Suiza (DO L 53 de 27 de febrero de 2008, p. 5); Protocolo entre la Comunidad Europea, la Confederación Suiza y el Principado de Liechtenstein sobre la adhesión del Principado de Liechtenstein al Acuerdo entre la Comunidad Europea y la Confederación Suiza sobre los criterios y mecanismos para determinar el Estado responsable del examen de una solicitud de asilo presentada en un Estado miembro o en Suiza (DO L 160 de 18 de junio de 2011, p. 39).
} 
particulares de conformidad con el capítulo V.”

Hasta el momento, pese a que Dinamarca no participa en la adopción del acervo del título V del Protocolo n. ${ }^{\circ} 22$-por lo que no ha participado en este Reglamento-, la Decisión 2019/836 del Consejo, de 13 de mayo de 2019 establece que los servicios de seguridad designados de los demás Estados participantes y Europol puedan solicitar una comparación de los datos dactiloscópicos con los datos transmitidos al Sistema Central de Eurodac por Dinamarca y viceversa. ${ }^{573}$ Además, dado que el Reglamento Eurodac está intrínsecamente relacionado con el Reglamento Dublín III y, ambos conforman el conocido como “Sistema de Dublín”, el acceso de Reino Unido dependerá de un nuevo acuerdo entre la UE y este país. ${ }^{574}$

Por lo que respecta a este epígrafe, abordaremos las distintas autoridades que intervienen directa o indirectamente en el acceso a Eurodac, así como los desafíos que plantea la propuesta de la Comisión en lo que concierne al buen funcionamiento de este sistema, su coherencia y las garantías en la protección de los datos personales.

\subsubsection{El acceso a Eurodac efectuado por las autoridades nacionales.}

4.2.1.1. Acceso por parte de las autoridades designadas de los EEMM.

El art. 5 del Reglamento Eurodac (art. 6 PRE) ofrece un concepto de autoridades designadas por los EEMM a efectos de cumplimiento de la ley y dispone lo siguiente: ”los EEMM designarán a las autoridades que estarán autorizadas a solicitar comparaciones con los datos de Eurodac con arreglo al presente Reglamento". ${ }^{575}$ Estas autoridades tienen la función principal de prevenir, detectar o investigar delitos de terrorismo $\mathrm{u}$ otros delitos graves, excluyendo directamente a las agencias o unidades

\footnotetext{
${ }^{573}$ Decisión 2019/836 del Consejo de 13 de mayo de 2019 sobre la celebración del Protocolo del Acuerdo entre la Comunidad Europea y el Reino de Dinamarca relativo a los criterios y mecanismos de determinación del Estado miembro responsable del examen de una solicitud de asilo presentada en Dinamarca o cualquier otro Estado miembro de la Unión Europea y a «Eurodac» para la comparación de las impresiones dactilares para la aplicación efectiva del Convenio de Dublín, en lo que respecta al acceso a Eurodac a efectos de aplicación de la ley, 24 de mayo de 2019 (L 138/3).

${ }^{574}$ En este punto, debe vaticinarse que se dispondrá de un acuerdo tal y como así consta en las discusiones formalmente planteadas y que recoge el informe presentado en 2018 a la Comisión LIBE. Parlamento Europeo, The EU-UK relationship beyond Brexit: options for Police Cooperation and Judicial Cooperation in Criminal Matters, Policy Department for Citizens' Rights and Constitutional Affairs Directorate General for Internal Policies of the Union, julio de 2018, p. 53. (PE 604.975).

${ }^{575}$ Además, la Enmienda $n^{\circ} 63$ completa esta definición atribuyendo a eu-LISA la facultad de publicar y modificar en línea una lista consolidada de tales autoridades. Un supuesto más eficiente que la publicación formal en el DOUE que elevará las garantías de la publicidad de esta información.
} 
cuya única competencia sea la inteligencia en relación con la seguridad nacional.

Ciertamente, la definición de estas autoridades es la misma que la que dispone el VIS en el art. 2.1 e) de la Decisión Consejo 2008/633/JAI, ${ }^{576}$ lo que ha comportado un alto "grado de estandarización" sobre las autoridades responsables de tramitar y gestionar datos personales en los distintos SSII. Y como abordó Baldaccini en uno de los escasos estudios sobre el acceso de las autoridades a este sistema, esto ha comportado una teórica "materialización" de la finalidad policial de acceso a la información contenida en esta base de datos. ${ }^{577}$

Ahora bien, por lo que respecta a las autoridades designadas, se precisan dos formalidades específicas:

El apartado $2^{\circ}$ establece que los EEMM deben disponer de una lista de autoridades designadas, con la finalidad de determinar cuales son las autoridades responsables a efectos de dotar de publicidad al resto de EEMM para conocer, con exactitud, las autoridades encargadas del citado acceso. Para ello, el apartado $3^{\circ}$ prevé que cada EEMM deba otorgar publicidad de una lista de unidades operativas dependientes de las autoridades designadas que estén autorizadas a solicitar comparaciones con los datos de Eurodac a través del Punto de Acceso Nacional, definido como el sistema de cada EEMM designado que se comunica con el Sistema Central y donde las unidades operativas de las autoridades designadas presentan las solicitudes de comparación con los datos almacenados en el Sistema Central, y que como más adelante se aborda, deben ir motivadas por la autoridad verificadora. ${ }^{578}$

En una labor de concreción, los EEMM han comunicado a la Comisión la lista de las autoridades designadas para tal efecto. ${ }^{579}$ Este listado, anejo al Reglamento Eurodac, permite corroborar grandes disparidades entre el número de autoridades tanto designadas como dependientes para acceder a tales datos. Por ejemplo, en Bélgica,

\footnotetext{
${ }^{576}$ Decisión 2008/633/JAI del Consejo de 23 de junio de 2008 sobre el acceso para consultar el Sistema de Información de Visados (VIS) por las autoridades designadas de los EEMM y por Europol, con fines de prevención, detección e investigación de delitos de terrorismo y otros delitos graves.

${ }^{577}$ BALDACCINI, A., Counter-Terrorism and the EU Strategy for Border Security... ob.cit., p. 41.

${ }^{578}$ Véase el Considerando 29 reglamento Eurodac y 39 PRE, art. 2 e) o 3 g) PRE, art. 3.3 o 4.3 PRE o art. 5.3 o 6.3 PRE.

${ }^{579}$ Siguiendo así el objetivo establecido el Considerando 28 del Reglamento Eurodac o 38 PRE. Para más información, véase: Lista de autoridades designadas que tienen acceso a los datos registrados en el Sistema Central Eurodac, de conformidad con el artículo 27, apartado 2, del Reglamento (UE) no 603/2013, a los efectos establecidos en el artículo 1, apartado 1, del mismo Reglamento (2015/C 237/01), 25 de julio de 2015 .
} 
Dinamarca, Estonia, Irlanda, Francia, Alemania o Bulgaria únicamente disponen de una autoridad con potestad para acceder a los datos registrados en el Sistema Central Eurodac. En el otro extremo, se sitúa Finlandia con un total de 22, Italia con 18, Austria con 14 y Grecia con $12 .{ }^{580}$ Además, determinados países han incluido en el listado a agencias de inteligencia, lo cual contraría la mencionada disposición por cuanto reúne en un mismo departamento a distintas autoridades policiales así como agencias de inteligencia.

4.2.1.2. Autoridades verificadoras de los EEMM a los efectos de cumplimiento de la ley.

Amén de las unidades designadas, tanto el Reglamento Eurodac como su propuesta requieren el establecimiento de autoridades de verificación (arts. 6 y 7 respectivamente), las cuales tienen encomendada la facultad de comprobar el cumplimiento de la legalidad del acceso. Por tanto, se contempla una doble obligación para los EEMM consistente en designar tanto a las autoridades que tendrán derecho a solicitar el acceso como aquellas encargadas de verificar la legalidad de las solicitudes de comparación.

El vigente y el futuro Reglamento Eurodac establecen la obligación de que los EEMM designen a una autoridad nacional única o una unidad dependiente de dicha autoridad con funciones de verificación, lo que implícitamente viene a subrayar una mera función más allá de su funcionamiento ordinario hacia su responsabilidad en los casos relativos a "la prevención, detección o investigación de los delitos de terrorismo o de otros delitos graves". Esta autoridad se ha diseñado en Eurodac de forma muy precisa y oportuna, otorgando un carácter eminentemente restrictivo.

Ahora bien, resulta insólito que la función de esta autoridad se prevea exclusivamente en su Considerando 29 (Considerando 39 PRE), teniendo en consideración su función transcendental de verificar la petición de las unidades operativas y si la solicitud de comparación con los datos almacenados en el Sistema Central de Eurodac resulta motivada. De ser así, lo presentará formalmente salvo casos excepcionales y de urgencia, esto es, cuando sea necesario tener un acceso rápido para

\footnotetext{
${ }^{580}$ En el caso de España, cuentan con un total de 3: 1) Unidad Central de Identificación, Comisaría General de Policía Científica Cuerpo Nacional de Policía, Ministerio del Interior, 2) Subdirección General de Asilo (Oficina de Asilo y Refugio), Dirección General de Política Interior, Ministerio del Interior y 3) Unidad Central de Fronteras, Sección Asilo, Comisaría General de Extranjería y Fronteras Cuerpo Nacional de Policía, Ministerio del Interior.
} 
responder a una amenaza específica y real relacionada con delitos de terrorismo u otros delitos graves. En este caso, la autoridad verificadora deberá tramitar la solicitud con la mayor celeridad posible, cumpliendo inmediatamente después con la función de verificación.

De esta manera, la petición se efectúa mediante una "solicitud de información" entre los EEMM y Eurodac. ${ }^{581}$ En esta, la autoridad designada solicita las comparaciones de datos, la autoridad competente verifica la solicitud e inmediatamente después, la envía al punto de acceso nacional, pudiendo regresarla a la autoridad designada para su aclaración. Todo ello mediante el punto de acceso nacional, que actúa de intermediario entre la autoridad verificadora y el Sistema Central. Además, la enorme flexibilidad de esta autoridad parte del hecho de que tanto la autoridad designada como la autoridad verificadora pueden formar parte de la misma organización, de conformidad con el Derecho nacional (Considerando 30 o 40 PRE).

Esta situación puede acarrear un conflicto de intereses. Las autoridades encargadas de prevenir, detectar o investigar los delitos de terrorismo u otros delitos graves pueden mostrar cierta tendencia a anteponer la seguridad nacional en detrimento de las garantías requeridas para acceder eficazmente a los datos contenidos en Eurodac.

Igualmente, estas autoridades no están especializadas en la verificación y el control de la normativa de protección de datos que dispone tanto el presente Reglamento (lex specialis) como de la Directiva de protección de datos en el ámbito penal (lex generalis) conforme al Considerando 38 PRE. Esto, indudablemente, puede generar situaciones que contraríen la legislación de protección de datos y, en concreto, la seguridad de los datos, el principio de necesidad y proporcionalidad, la limitación de la finalidad en la comparación de datos y el riesgo a posteriori de deviación de uso o function creep. Por ello, la PRE debería haber instaurado una nueva autoridad ad hoc encargada de esta potestad y no únicamente reflejar a lo largo de su articulado simples criterios organizativos de la autoridad de verificación.

En lo relativo al párrafo $2^{\circ}$, se establece una definición muy laxa de independencia. Concretamente, dispone que esta autoridad "no recibirá instrucciones de ellas por lo que se refiere al resultado de la verificación". Sin embargo, no clarifica la propia

\footnotetext{
${ }^{581}$ PEERS, S., MORENO-LAX, V., GARLICK M., GUILD E., Eurodac, en: PEERS, S., MORENOLAX, V., GARLICK M., GUILD, E., (eds.), EU Immigration and Asylum Law (Text and Commentary): Second Revised Edition, vol. 3, Brill/Nijhoff, 2015, p. 439.
} 
estructura o naturaleza de este órgano de forma que permita esclarecer el alto más alto de independencia. Simplemente dispone que la autoridad verificadora será distinta de las unidades operativas del art. 6.3 del Reglamento, que deben presentar las solicitudes de comparación con los datos almacenados en el Sistema Central, motivadas a través de la autoridad verificadora. ${ }^{582}$

De la misma forma, parece contradictorio que el párrafo $3^{\circ}$ faculte a los EEMM a designar más de una autoridad verificadora pese a sus limitaciones funcionales, es decir, solo si se requiere para "reflejar" sus estructuras organizativas y administrativas. En todo caso, esta verificación por parte de esta autoridad deberá llevarse a cabo en todos los casos, garantizando el pleno cumplimiento de las condiciones "para solicitar comparaciones de datos dactiloscópicos con los datos de Eurodac" (apartado $2^{\circ}$ ). Por ende, exclusivamente el personal debidamente habilitado de la autoridad verificadora estará autorizado para recibir y transmitir solicitudes de acceso a Eurodac, debiendo formular la solicitud de comparación de datos dactiloscópicos al Punto de Acceso Nacional.

Y, para finalizar, conviene hacer mención de que el control de la legalidad en las condiciones de acceso a los datos de Eurodac que llevan a cabo las autoridades de verificación pugnará directamente con el régimen jurídico previsto para la interoperabilidad. En las SSTJUE Digital Rights Ireland y Tele2 que hemos examinado, el TJUE estableció que este acceso debía estar sujeto a condiciones estrictas y, en todo caso, sujetas a la verificación previa en el cumplimiento de tales condiciones por parte de una autoridad verificadora independiente.

En este sentido, la interoperabilidad puede comprometer seriamente este control, permitiendo un acceso "rutinario" a este sistema ${ }^{583}$ y propiciando una peligrosa flexibilidad de estas condiciones. Una interconexión que, a juicio del SEPD, resulta significativa y puede contrariar directamente el derecho a la vida privada. ${ }^{584}$ Sin embargo, en nuestra opinión, resulta poco probable que esta interconexión de datos

\footnotetext{
${ }^{582}$ De hecho, el mismo Considerando 39 señala que las unidades operativas de las autoridades designadas autorizadas para solicitar dichas comparaciones con los datos de Eurodac no deben actuar como autoridad verificadora, debiendo ser independientes frente a las autoridades designadas, siendo asimismo responsables de garantizar, de modo independiente, el estricto cumplimiento de las condiciones de acceso conforme al citado Reglamento.

${ }^{583}$ VAVOULA, N., The recast Eurodac Regulation... ob. cit., p. 270.

${ }^{584} \mathrm{SEPD}$, Resumen sobre las propuestas de dos Reglamentos por los que se establece un marco para la interoperabilidad..., ob. cit., conclusión $\mathrm{n}^{\circ} 148$.
} 
respete las condiciones de acceso de Eurodac pues va en contra de su propio objetivo de proporcionar rápidamente información sobre un sujeto para contextos muy determinados y que requieren de absoluta inmediatez. Por todo ello, no se sabe cuál será el papel de estas autoridades y las condiciones finales de acceso pero lo cierto es que, se cuestionará su aplicación práctica, independencia y objetividad, generando serias preocupaciones en el derecho a la protección de datos de este Sistema de Información.

\subsubsection{El acceso a Eurodac efectuado por la Oficina Europea de Policía (Europol).}

Tradicionalmente, la iniciativa de otorgar acceso policial a las bases de datos de la UE se ha vinculado a aquellos escenarios que poseen controles de inmigración y fronteras, ${ }^{585}$ una modalidad que ha emergido del principio de disponibilidad en el flujo e intercambio de la información y cuya función ha pretendido facilitar un acceso rápido y directo a la información que disponía cualquier otro $\mathrm{EM}^{586}$

Este acceso ha sido empleado en aras de obtener una mayor cantidad de datos, lo cual ha permitido aumentar la eficiencia en los procedimientos nacionales. Ahora bien, en el ámbito del SECA ha planteado serias dudas para Brouwer, precisamente, por la potencial incompatibilidad con el criterio de necesidad, específicamente, ante la confluencia de grandes bases de datos sobre datos concernientes a personas individualmente consideradas. ${ }^{587}$ Una situación que ha evidenciado la compleja tarea de determinar qué datos son necesarios y pertinentes para fines específicos y cuales exceden de estos límites.

Y, por lo que respecta a las condiciones de acceso a Eurodac por parte de Europol, cabe destacar que tanto el art. 7 del Reglamento Eurodac como el art. 8 PRE regulan esta tipología de acceso, la cual establece condiciones similares a las que deben cumplir las autoridades verificadoras -en este caso, disponer de una unidad especializada ${ }^{588}$ con

\footnotetext{
${ }^{585}$ MURPHY, C., EU Counter-Terrorism Law Pre-Emption and the Rule of Law, Hart Publishing, 2012, p. 147.

${ }^{586}$ Este principio se distinguió de la interoperabilidad pues mientras que el primero se centra en el intercambio de información disponible entre diferentes autoridades nacionales solo para fines de cumplimiento de la ley, el segundo se centra en la "interconexión" entre las diferentes bases de datos. BROUWER, E., 'Data Surveillance and Border Control in the EU: Balancing Efficiency and Legal Protection', en: BALZACQ T., CARRERA, S., (eds.), Security Versus Freedom? A Challenge for Europe's Future, Ashgate, 2013, p. 137; GOIZUETA VÉRTIZ, J., "La cooperación policial en el seno de Europol: el principio de disponibilidad y..., ob. cit., p. 96.

${ }^{587}$ BROUWER, E.: Eurodac: Its limitations and temptations, ob. cit., p. 232.

${ }^{588}$ En lugar de unidad especializada, la enmienda $\mathrm{n}^{\circ} 67$ del PE alude a una simple autoridad y elimina el criterio de independencia y el Punto de Acceso Nacional.
} 
agentes de Europol debidamente habilitados-, además de tener designada una unidad operativa autorizada para solicitar comparaciones con los datos de Eurodac a través del Punto de Acceso Nacional.

Por su parte, a diferencia de las autoridades de los EEMM, al acceso de Europol a este SI resulta acotado por un criterio de subsidiariedad, consistente en un acceso en última instancia bajo dos condiciones -tanto formal como material- que desarrollan los arts. 20 o 21 PRE:

1. Respecto a la primera, siempre y cuando se haya procedido a realizar comparaciones con otras bases de datos y, en todo caso, no hayan permitido establecer la identidad del sujeto de los datos. ${ }^{589}$

Específicamente, menciona tres bases de datos:

- Eurodac,

- las dactiloscópicas de ámbito nacional como de la totalidad de los EEMM ${ }^{590}$ siempre que la comparación sea posible desde un criterio técnico, a menos que existan razones fundadas para considerar que esta no permitirá establecer la identidad del sujeto de los datos- $\mathrm{y}$;

- el Sistema de Información Visa.

2. En relación con la segunda, exige el cumplimiento de las siguientes condiciones de carácter acumulativo:

a) la exigencia de la comparación a efectos de prevención, detección o investigación de delitos de terrorismo o de otros delitos graves. Con ello, Europol deberá cumplir con el principio de necesidad y proporcionalidad, es decir, le corresponderá apreciar un interés superior de seguridad pública para acceder a la consulta requerida;

b) de forma individualizada, esto es, en ningún caso, procediendo a realizar comparaciones sistemáticas;

c) y cuando se aprecien "motivos razonables" para considerar que la comparación con los datos de Eurodac "contribuirá sustancialmente a la prevención, detección o investigación de cualquiera de los delitos en cuestión". A tal efecto, debe entenderse

\footnotetext{
${ }^{589}$ Este requisito de falta de identificación se elimina en la enmienda $\mathrm{n}^{\circ} 113 \mathrm{PE}$.

${ }^{590}$ De conformidad con la Decisión 2008/615/JAI del Consejo, de 23 de junio de 2008, sobre la profundización de la cooperación transfronteriza, en particular en materia de lucha contra el terrorismo y la delincuencia transfronteriza. DO L 210, 6.8.2008, p. 1-11.
} 
como tal, una sospecha fundada de que la persona sospechosa, el autor o la víctima de un delito de terrorismo o de otro delito grave corresponden a una de las tres categorías de sujetos de Eurodac.

Efectivamente, Eurodac impone ciertos límites al tratamiento de la información de Europol en una clara necesidad de ponderación entre el intercambio eficiente y rápido de la misma para efectuar investigaciones y el respeto al contenido esencial de los derechos humanos, especialmente, en lo relativo a la protección de datos personales. Además, el apartado $2^{\circ}$ incluye el principio de limitación de la finalidad, facultando únicamente a la búsqueda de datos dactiloscópicos en Eurodac para su posterior comparación sobre una cuestión concreta. Ello, teniendo en consideración que su objeto no radica tanto en la asistencia y ayuda a los EEMM para fines de retorno, sino en una mejora y más eficiente identificación de sujetos que pueden comprometer la seguridad europea en su conjunto, determinando aquellos que han podido estar implicados en la comisión o participación de actos terroristas o delitos graves.

Esta disposición pretende reducir la desviación de uso de estos datos dactiloscópicos, puesto que Europol tiene acceso a una gran cantidad de información a través sus propios sistemas, de los EEMM o de otras bases de datos europeas (VISA, Schengen, PNR, etc.). Por lo tanto, un acceso sin la tipificación de estos límites previstos en la PRE podría contrariar seriamente los principios de protección de datos antes mencionados.

Asimismo, por lo que concierne a las condiciones de acceso a Eurodac por parte de Europol, los arts. 21 o 22 PRE establece que su autoridad designada podrá formular una solicitud en soporte electrónico, la cual exige que esté motivada para proceder a la comparación de los datos dactiloscópicos de Eurodac de acuerdo con los siguientes tres requisitos:

- dentro de sus límites competenciales,

- cumpliendo con el principio de necesidad en el cumplimiento del cometido de Europol y,

- respetando el principio de subsidiariedad, esto es, en defecto de la falta de identidad en las comparaciones que pueda efectuar con otros SSII. ${ }^{591}$

Para ello, torna a tipificar las mismas condiciones de procesamiento que las previstas

${ }^{591} \mathrm{La}$ enmienda $\mathrm{n}^{\circ} 117 \mathrm{PE}$ sugiere añadir un nuevo apartado que faculte a Europol solicitar información adicional al EM afectado de conformidad con su propio Reglamento 2016/794. 
para las autoridades designadas, es decir, que se proceda de forma individualizada (apartado $2^{\circ}$ ) y concluye estableciendo que el tratamiento a partir de estas comparaciones estará sujeto a la autorización del EM de origen (apartado $3^{\circ}$ ). Todo ello, sin perjuicio de que, al amparo del Considerando 12 del Reglamento Eurodac (Considerando 19 PRE), las solicitudes de Europol para la comparación de datos de Eurodac deban realizarse de forma extraordinaria, pues "solo deben admitirse en casos concretos", cumpliendo fielmente con las condiciones estrictas anteriormente señaladas.

Además de las disposiciones en Eurodac, también el Reglamento Europol 2016/794 de 11 de mayo de 2016 y que entró en vigor en 2017, adopta un enfoque preventivo o proactivo mediante la protección de datos desde el diseño y la transparencia respecto al DPO y el SEPD con objeto de aumentar los altos estándares necesarios en materia de seguridad y protección de datos. Para ello, aplica, al efecto, una serie de garantías procedimentales a toda modalidad de acceso a la información.

El art. 17.3 contempla el acceso a los SSII si resulta "necesario para el desempeño de sus tareas". A su vez, dispone que las condiciones de acceso deberán regirse por su Reglamento o por las disposiciones aplicables de dichos instrumentos jurídicos, siempre y cuando este último prevea normas de acceso más estrictas -también el principio de legalidad se extiende a la necesidad y proporcionalidad para el desempeño de sus tareas-. Estas condiciones de acceso suponen un cambio trascendental en el ámbito de la protección de datos de Europol que, además, supedita la recogida de los datos a fines específicos de tratamiento tal como tipifican los Considerandos 26 y $34 .{ }^{592}$ Por lo tanto, el Reglamento Eurodac delimita sus actuaciones de acceso bajo el criterio de individualización y extraordinariedad por cuanto prevé condiciones de acceso más estrictas que la que ofrece el Reglamento de funcionamiento de esta agencia de la UE.

Sobre esta cuestión, los Documentos de programación de Europol han mostrado una escasa evolución sobre los avances en materia de acceso. El Documento que abarca los años 2017-2019 estableció que los EEMM debían reforzar los canales de intercambio de información con Europol para el cumplimiento de ley y, más concretamente, en el contexto del acceso a Eurodac, cuyas ventajas para fines de prevención e identificación

\footnotetext{
${ }^{592}$ Para un análisis sobre la anterior Decisión 2009/371/JAI del Consejo, de 6 de abril de 2009, por la que se crea la Oficina Europea de Policía (Europol), remitimos a: GACITÚA ESPÓSITO, A. L., El derecho fundamental a la protección de datos personales en el ámbito de la prevención y represión penal europea (en busca del equilibrio entre la libertad y la seguridad). Barcelona: Universidad Autónoma de Barcelona, 2014, pp. 221 y ss.
} 
de delitos graves o terrorismo eran notables. ${ }^{593}$

Sin embargo, el último documento publicado reflejó que el acceso a las principales bases de datos centrales -SIS, VIS y Eurodac- aún no se había efectuado de forma completa y declaró que la Europol debía acelerar el trabajo en curso para establecer una eficaz conexión con Eurodac. ${ }^{594}$ Finalmente, el documento que fija las actuaciones de Europol para los años 2019-2021 pretende hacer uso de una mejor conectividad y apoyo del acceso de la Europol a una amplia variedad de información, en virtud de la propuesta de la Comisión sobre la interoperabilidad de los SSII europeos. ${ }^{595}$

4.3. El Reglamento 2019/818 de interoperabilidad y su impacto en el acceso a los datos de Eurodac

La interoperabilidad generará un nuevo modelo de acceso en el futuro Eurodac. El art. 1 del Reglamento 2019/818 pretende adaptar "los procedimientos y condiciones para el acceso de las autoridades designadas y de la Europol a (...) Eurodac con fines de prevención, detección o investigación de los delitos de terrorismo u otros delitos graves" por medio de la racionalización de "las condiciones de acceso de las autoridades designadas (...) a Eurodac, garantizando conjuntamente las condiciones necesarias y proporcionadas para dicho acceso" de conformidad con el art. 2 f). Y, pese a que alude de forma continuada a una labor de adaptación, lo cierto es que todo parece indicar que flexibilizará tales condiciones.

Desde un enfoque orgánico, Eurodac ha creado cuatro componentes centrales para la interoperabilidad que, en el presente, no han sido plenamente adoptados y que son los siguientes: el portal europeo de búsqueda (PEB), un servicio de correspondencia biométrica compartido (SCB compartido), un registro común de datos de identidad (RCDI) y un detector de identidades múltiples (DIM). ${ }^{596}$

El novedoso "pluriacceso" se llevará a cabo mediante el Portal europeo de búsqueda (PEB) que regula el art. 6 a fin de facilitar "el acceso rápido, ininterrumpido,

\footnotetext{
${ }^{593}$ Europol Programming Document 2017 - 2019, adoptado por la Consejo de Administración el 17 de enero de 2017, p. 4.

${ }^{594}$ Europol Programming Document 2018 - 2020, adoptado por la Consejo de Administración el 30 de noviembre de 2017, p. 6.

${ }^{595}$ Europol Programming Document 2019 - 2021, adoptado por la Consejo de Administración el 30 de noviembre de 2018 , p. 8.

${ }^{596}$ Considerando 9 y art. 1.2 Reglamento 818/2019.
} 
sistemático y controlado de las autoridades de los Estados miembros y de las agencias de la Unión a los sistemas de información de la UE, a los datos de Europol y las bases de datos de Interpol para el desempeño de sus tareas y de conformidad con sus derechos de acceso, así como con los objetivos y fines de (...) Eurodac”.

El PEB pretende adoptar un control sistemático e inmediato de acceso a la información de las múltiples bases de datos europeas, pero posee limitaciones en su funcionamiento, más allá de que especifiquen las autoridades facultadas para proceder a tal fin. ${ }^{597}$ Además, este portal debería emplease de manera que se garantice una búsqueda iniciada por las autoridades nacionales -designadas y verificadoras- como Europol, que gocen de la legitimación para acceder a tales datos. De lo contrario, se desvirtuaría el sistema de garantías de los SSII, menoscabando el principio de limitación de la finalidad. ${ }^{598}$

Sin embargo, las condiciones de consulta resultan excesivamente ambiguas. De conformidad con el art. 9.1 del Reglamento 2019/818, los usuarios de este Portal “iniciarán una consulta mediante la presentación de datos alfanuméricos y/o biométricos al PEB. Cuando se haya iniciado una consulta, el PEB consultará (...) Eurodac, (...) los datos de Europol y las bases de datos de Interpol al mismo tiempo que los datos presentados por el usuario y de conformidad con el perfil de este". Y, seguidamente, el apartado $4^{\mathrm{o}}$ dispone que “el PEB no facilitará información relativa a los datos almacenados en los SSII de la UE, los datos de Europol y las bases de datos de Interpol a los que el usuario no tenga acceso con arreglo al Derecho de la Unión y nacional aplicable".

Este procedimiento se estructura en dos fases:

1) el acceso a las autoridades policiales a Eurodac que solo tienen un objetivo "secundario" sobre este sistema - conectado con la prevención, investigación, detección o persecución de los delitos de terrorismo o de otros delitos graves- y;

\footnotetext{
${ }^{597} \mathrm{El}$ art. 7.1 de esta Reglamento estipula que este acceso "se reservará a las autoridades de los Estados miembros y a las agencias de la Unión que tengan acceso como mínimo a uno de los sistemas de información de la UE".

${ }^{598}$ En esta línea se pronuncia el SEPD al disponer que un acceso rutinario o excesivamente representaría una violación grave de este principio, una violación de las salvaguardas de los derechos fundamentales de los nacionales de terceros países. SEPD, Dictamen sobre las propuestas de dos reglamentos..., ob. cit., p. 3.
} 
2) las búsquedas basadas en el "éxito/no éxito", es decir, cuando a posteriori se genere una coincidencia, las autoridades policiales solicitarán el acceso a la información necesaria de acuerdo con las normas y salvaguardas respectivas de cada sistema.

El problema se inicia en la primera fase, pues la totalidad las autoridades designadas de los EEMM podrían consultar y conocer la existencia de información en una determinada base de datos. Precisamente, esta amplitud fue criticada por la FRA, que reconoció que esta disposición podría propiciar interpretaciones divergentes en aplicación de este Reglamento y de los específicos para cada SI. ${ }^{599}$ Además, el Comité Meijers exigió una evaluación del principio de proporcionalidad sobre las condiciones de este acceso teniendo presente que todas las autoridades designadas nacionales podrían, a través de este Portal, conocer que la información sobre un nacional de un tercer país se almacena en una de las bases de datos de la UE. ${ }^{600}$

Por todo ello, el futuro de la interoperabilidad con respecto a la PEB debería diseñarse de manera muy restrictiva, de forma que salvaguarde las altas garantías requeridas en el derecho de asilo. En este sentido, Eurodac no debería ceder información en el contexto de la interoperabilidad, al menos, en lo que se refiere a los nacionales de terceros países registrados en este sistema como solicitantes de protección internacional, sino del resto de categorías de migrantes.

En el servicio de correspondencia biométrica (SCB compartido) se almacenarán las plantillas biométricas obtenidas a partir de los datos a los que se refiere el art. $13 \mathrm{y}$ permitirá consultar datos biométricos a través de varios SSII de la UE. Asimismo, el art. 17 creará el Registro común de datos de identidad (RCDI) con objeto de facilitar la identificación correcta de las personas que han sido registradas en Eurodac -o en el resto de SSII- y proporcionar el acceso por parte de las autoridades designadas y de Europol a este sistema cuando sea necesario para fines de prevención, detección o investigación de delitos terroristas u otros delitos graves de conformidad con el art. 22. En este caso, solventa los perjuicios anteriormente señalados puesto que el apartado $3^{\circ}$ obliga a que el acceso de las autoridades se efectúe de conformidad con los derechos de acceso previstos en Eurodac o el cualquier SSII al efecto.

\footnotetext{
${ }^{599}$ FRA, Interoperability and fundamental rights implications. Opinion $1 / 2018$ of the European Union Agency for Fundamental Rights, 11 de abril de 2018, p. 19. Disponible en: https://fra.europa.eu/sites/default/files/fra_uploads/fra-2018-opinion-01-2018-interoperability_en.pdf ${ }^{600}$ Meijers Committee, Comments on the Proposal ..., ob. cit., p. 5.
} 
Además, este modo de consulta se lleva a cabo de forma extraordinaria para los casos del art. 20 del Reglamento 2019/818, esto es: “a) cuando una autoridad policial no sea capaz de identificar a una persona debido a la falta de un documento de viaje o de otro documento fiable que demuestre su identidad; b) cuando existan dudas sobre los datos de identidad facilitados por dicha persona; c) cuando existan dudas en cuanto a la autenticidad del documento de viaje u otro documento fiable facilitado por dicha persona; d) cuando existan dudas en cuanto a la identidad del titular del documento de viaje u otro documento fiable, o e) cuando la persona no pueda o se niegue a cooperar".

Finalmente, el detector de identidades múltiples (DIM) del art. 25 del Reglamento 2019/818 apoyará al funcionamiento del RCDI y la consecución de los objetivos de los SSII, incluido Eurodac. De tal manera que, en el caso de que se produzca alguna correspondencia, el art. 28.2 exige crear un vínculo entre todos estos datos coincidentes y el vínculo que ya existía sobre un SI en concreto, que se extenderá a datos semejantes o análogos y localizados en otro SSII.

4.4. La protección de datos personales en Eurodac: la seguridad de los datos en el acceso a la información

Para finalizar el presente Capítulo, conviene enfatizar que, pese a que Eurodac no constituye una base de datos de carácter policial en sentido estricto, el simple acceso y comparación de las huellas dactilares vinculadas con investigaciones penales por parte de las autoridades policiales nacionales y la Europol se erige como el corolario de la incidencia de la seguridad en el derecho a la privacidad y en la protección de datos. ${ }^{601}$

En esta línea, el Considerando 43 (Considerando 53 PRE) destaca la inexorable obligación de respetar la legislación de protección de datos como condición necesaria para asegurar el buen funcionamiento de Eurodac. Ello aparece concretado por parámetros de garantía de una correcta aplicabilidad del mismo y del Reglamento de Dublín como la seguridad de los datos, la elevada calidad técnica y la legalidad de las consultas. Además, permite constatar la firme apuesta de este sistema en la promoción de actuaciones que garanticen el buen funcionamiento en lo que atañe a la transmisión de los datos por medio de las distintas modalidades de acceso al mismo.

\footnotetext{
${ }^{601}$ DIMITROVA D., De HERT P., The Right of Access Under the Police Directive: Small Steps Forward, en: MEDINA M., MITRAKAS A., RANNENBERG K., SCHWEIGHOFER E., TSOUROULAS N. (eds.) Privacy Technologies and Policy, Springer, Cham, 2018, p. 33.
} 
Por su parte, el art. 35.4 PRE no establece mayores novedades en lo relativo a las condiciones de acceso que las que contempla el actual Reglamento Eurodac en el art. 33.4 al prever expresamente que las autoridades designadas, las autoridades verificadoras y Europol deben guardar únicamente los registros de las búsquedas a efectos de control por parte de las APDs nacionales y el SEPD sobre el tratamiento efectuado. Ahora bien, no es menos cierto que también introduce, de forma genérica, que este acceso "deberá respetar las normas de la UE", una referencia que, pese a no concretar ningún tipo de ámbito jurídico, exige una aproximación en la protección de datos personales. Ello, en vista de que Eurodac recopila información biométrica de carácter sensible y, en cuanto a la determinación de las condiciones de acceso a la luz de esta Directiva, estos datos deben tratarse respetando un "nivel adecuado de seguridad y confidencialidad", ${ }^{602}$ prohibiendo el acceso sin la autorización que exige este Reglamento y garantizando estrictas condiciones de acceso. Se trata de criterios ineludibles para mantener la seguridad del tratamiento de los datos.

Por lo tanto, las medidas de acceso a los mismos deberán ser elevadas, especialmente por parte de eu-LISA que, como gestora del Sistema Central de Eurodac y responsable de la gestión operativa de este sistema, deberá concretar su actividad de elaboración del Plan y del Sistema de Continuidad Operativa. Ello, teniendo en cuenta la seguridad de los datos (arts. 4.1 Reglamento Eurodac o 5.1 PRE) y el flujo de información que transmiten los EEMM tanto antes de su transmisión al Sistema Central y durante este procedimiento, así como la que reciben del Sistema Central (arts. 23.2 del Reglamento Eurodac o 24.2 PRE). De este modo, eu-LISA deberá desarrollar las acciones y los cambios pertinentes en su estructura interna que permitan un estricto sistema de acceso a dichos datos. Máxime, cuando esta Agencia ostenta la gestión operativa de muy diversos SSII a gran escala y debe tener en cuenta la naturaleza especialmente sensible de los datos que registra Eurodac.

No obstante, eu-LISA no tiene acceso directo al contenido de los registros de Eurodac. Razón por la que esta obligación resultará aplicable a los EEMM en toda su extensión. Las autoridades nacionales son las encargadas de gestionar la información de la que son responsables - de ahí la dualidad prevista entre las autoridades designadas

\footnotetext{
${ }^{602}$ Sobre el particular, véase el Considerando 28 de la Directiva de protección de datos en el ámbito penal.
} 
para solicitar el acceso a Eurodac y las verificadoras de las condiciones necesarias para su aprobación-.

Por ende, debe examinarse una de las cuestiones más relevantes en la protección de la información, esto es, la seguridad de los datos de Eurodac. Esta viene definida por la Directiva de protección de datos en el ámbito penal en el art. $3.11^{\circ}$ de forma negativa entendiendo como tal, una violación de la seguridad de los datos personales aquella ocasionada por el “(...) acceso no autorizado a datos personales transmitidos, conservados o tratados de otra forma" y se contempla en toda su extensión en el art. 34 del Reglamento Eurodac (art. 36 PRE), que especifica y concreta el contenido que dispone el art. 29 de la Directiva de protección de datos en el ámbito penal.

Y con respecto a esta Directiva, a pesar de que el art. 3.2 establece específicamente que esta no se aplica al tratamiento de datos personales tanto en el ejercicio de una actividad no comprendida en el ámbito de aplicación del Derecho de la Unión -como es el caso de la seguridad nacional- como por parte de las instituciones, órganos $\mathrm{u}$ organismos de la Unión -entre ellas, a eu-LISA o Europol-, ${ }^{603}$ en los restantes supuestos, las medidas de seguridad en Eurodac se regirán directamente por las dispuestas en esta Directiva. Es más, incluso la enmienda $n^{\circ} 140$ PE tipifica una novedad que aumenta de forma exponencial las garantías en la protección de los sujetos. Al efecto, dispone que eu-LISA informe a la mayor brevedad y siempre que sea posible acerca de un incidente de seguridad que suponga un riesgo para los derechos y libertades de los interesados.

En la actualidad, de acuerdo con el último informe presentado por eu-LISA en junio de $2019,{ }^{604}$ no se han producido incidentes relacionados con la operatividad de Eurodac

\footnotetext{
${ }^{603}$ Estas se encuentran vinculadas por sus regímenes de protección de datos de conformidad con sus propios reglamentos y de acuerdo con el Reglamento 2018/1725 de protección de datos de las instituciones, órganos y organismos de la UE.

${ }^{604}$ En 2018, Eurodac estuvo disponible el 99,98\% del tiempo. De hecho, este informe detalló que la indisponibilidad, incluido el tiempo por mantenimiento, fue de tan solo 1 hora y 47 minutos durante todo el año. Tanto es así, que refleja que, hasta el momento, no han sido registrados incidentes críticos. Información accesible en: Eu-LISA, Annual report 2018 .. ob. cit, p. 4.

Los últimos incidentes registrados acaecieron en 2015, cuando el Service Desk registró un total de 512 incidentes relacionados con el funcionamiento de Eurodac ( 9 críticos, 263 altos, 143 ordinarios y 97 de baja prioridad) si bien no vinculado estrictamente a cuestiones de seguridad. La mayoría de ellos fueron relacionados con presiones de capacidad, que originaron retrasos en los tiempos de respuesta a lo que euLISA respondió implementando una hoja de ruta para hacer frente adecuadamente a la nueva realidad. Consejo de la UE, Informe anual sobre las actividades de 2015 del sistema central de Eurodac, incluido
} 
por cuestiones relacionadas con la seguridad de los datos. No obstante, la Directiva de protección de datos en el ámbito penal exige adaptar la seguridad del tratamiento al "riesgo de probabilidad y gravedad variables" para los derechos y libertades de las personas. En este caso, el futuro Reglamento Eurodac deberá requirir un alto nivel elevado de seguridad, tanto por el riesgo de los datos objeto de acceso y ulterior tratamiento como por la consideración de la biometría como dato sensible de conformidad con lo dispuesto en el art. 10 de esta Directiva. ${ }^{605}$

Así, este sistema establece que se trata de una obligación que se inicia desde el EM de origen, encargado de garantizar en primera instancia la seguridad de los datos previamente a su transmisión al Sistema Central y durante la misma (apartado $1^{\circ}$ ). Igualmente, se extiende al resto de EEMM participantes, tal y como dispone el apartado $2^{\circ}$, que deben adoptar todas las medidas necesarias -incluido un plan de seguridad- que permita controlar la integridad del acceso por medio de dos canales:

1. El acceso a los equipos y a la entrada de la instalación, denegando el acceso de las personas no autorizadas a los equipos de tratamiento de datos y a las instalaciones nacionales en el EM que lleva a cabo operaciones de conformidad con el objetivo de Eurodac (letra b) -también se contempla en la letra a) del apartado 2 del art. 29 de la Directiva de protección de datos en el ámbito penal-.

2. El acceso a los datos, asegurando que el personal autorizado únicamente esté legitimado para acceder a aquellos sobre los que ostenta autorización, mediante identificaciones personales y de utilización única, así como claves de acceso confidenciales (letra f) Reglamento Eurodac o g) PRE -igualmente recogido en el art. 29.2 e) de la mencionada Directiva-.

Además, insta a los EEMM a que garanticen por un lado, que las autoridades con derecho de acceso a Eurodac establezcan perfiles que detallen las funciones y responsabilidades de las personas autorizadas para el acceso, registro, actualización, supresión e investigación de datos $-\mathrm{y}$ que pongan esos perfiles y cualquier otra información pertinente a disposición de las autoridades nacionales de control a efectos de supervisión de acuerdo con lo dispuesto en el Capítulo VI RGPD, el art. 41 Directiva de protección de datos en el ámbito penal [letra g Reglamento Eurodac o h) PRE]-. Por

su funcionamiento técnico y su seguridad de conformidad con el artículo 40, apartado 1, del Reglamento (UE) no 603/2013, 2 de marzo de 2017, 6754/17, p. 10.

${ }^{605}$ Sobre el particular, remitimos al epígrafe 3.3 en el que se aborda la ampliación de datos biométricos. 
otro lado, el control de los datos consistente en la posibilidad de verificar y determinar a qué autoridades pueden transmitirse datos personales mediante equipos de transmisión de datos [letra h Reglamento Eurodac o i) PRE]. ${ }^{606}$

Finalmente, los EEMM deberán informar a eu-LISA de los incidentes de seguridad detectados en sus sistemas. Asimismo, esta agencia deberá comunicar a los EEMM, a Europol y al SEPD sobre los incidentes de seguridad que se produzcan y, todos ellos, deberán cooperar durante un incidente de seguridad (párrafo $3^{\circ}$ ). ${ }^{607}$ Obligación que se extiende a la Agencia, que deberá adoptar todas las medidas apropiadas para alcanzar los objetivos de seguridad anteriormente analizados para garantizar el buen funcionamiento de Eurodac (apartado $4^{\circ}$ ).

\section{Consideraciones finales sobre el impacto de la propuesta de Reglamento de}

\section{Eurodac en la seguridad y en el derecho a la protección de datos.}

El actual Reglamento Eurodac ha priorizado las cuestiones relativas a la seguridad de los EEMM en detrimento de la protección efectiva de los derechos humanos. Un conflicto entre dos dimensiones que ha situado los derechos de las distintas categorías de sujetos en un plano secundario, propiciando que este SI no reúna las altas garantías necesarias que exige el derecho a la vida privada (arts. 7 CDFUE y 8 CEDH) y la protección de datos de carácter personal (art. 8 CDFUE).

De tal forma, el mencionado Reglamento no contempla un régimen jurídico claro y uniforme en materia de protección de datos, lo que ha generado un marco de fuerte inseguridad jurídica. A tal efecto, remite tanto a la Directiva 95/46/CE como a la Decisión marco 2008/977/JAI y al Reglamento 2001/45 para las actividades desarrolladas por las instituciones, organismos, oficinas y agencias de la UE. Todas

\footnotetext{
${ }^{606}$ Véase igualmente el art. 29.2 f) de la Directiva de protección de datos en el ámbito penal. Además, al margen del acceso a Eurodac, introduce un amplio conjunto de medidas para garantizar la seguridad de los datos más allá del acceso a los mismos como la protección los datos de forma física, por ejemplo, mediante la elaboración de planes de emergencia para la protección de infraestructuras críticas (letra a), el control de los soportes de datos (letra c), control de la conservación (letra d), el control del usuario (letra e nueva en la PRE), control de la entrada de datos (letra f), control del registro de datos (letra j), control del transporte (letra k), recuperación (letra 1), fiabilidad e integridad (letra m) o el control interno (letra n). Estos principios en materia de seguridad de datos se encuentran alineados con los principios del apartado 2 del art. 29 de la Directiva de protección de datos en el ámbito penal.

${ }^{607}$ La PRE añade sin perjuicio de la notificación y comunicación de una violación de un dato personal de conformidad con los arts. 31 y 32 RGPD o arts. 28 y 29 de la Directiva de protección de datos en el ámbito penal.
} 
ellas, actualmente superadas por la efectiva aplicación del RGPD y de la Directiva de protección de datos en el ámbito penal, por un lado, y el Reglamento 2018/1725 relativo a la protección de las personas físicas en lo que respecta al tratamiento de datos personales por las instituciones, órganos y organismos de la Unión, y a la libre circulación de esos datos, por otro. Este desfase temporal en lo que a la protección de la información se refiere permite constatar la apremiante necesidad de aprobar la PRE, la cual lleva más de 3 años pendiente de aprobación y sobre la que actualmente, carece de consenso entre el PE y el Consejo. Y, en relación con esta propuesta, no resulta baladí destacar que prevé la aplicación de la nueva normativa comunitaria de protección de datos de una forma excesivamente amplia por cuanto dispone de referencias tanto al RGPD como a la Directiva de protección de datos en el ámbito penal para la regulación de múltiples aspectos sobre los que nos hemos detenido.

En un intento por determinar de forma exhaustiva el derecho supletorio en esta materia, esta última Directiva resultará de aplicación al tratamiento general de datos personales en relación con Eurodac, esencialmente, en los supuestos que este sea efectuado por las autoridades nacionales encargadas del examen de las solicitudes de protección internacional presentadas por un nacional de un tercer país o un apátrida. Es más, únicamente deberá excluirse en el tratamiento que lleven a cabo las autoridades designadas o verificadoras competentes de los EEMM para fines de "prevención, investigación, detección o persecución de los delitos de terrorismo o de otros delitos graves, en particular la protección frente a las amenazas contra la seguridad pública y la prevención de las mismas".

Efectivamente, la PRE incorpora un conjunto de novedades de hondo calado, algunas de las cuales plantean jurídicamente serias dudas sobre su coherencia con la legislación de protección de datos y sobre las que nos hemos detenido individualmente con objeto de aportar las siguientes conclusiones:

1. El primero de ellos está relacionado con el mayor alcance del objeto de este SI, que ya no únicamente determina el EM responsable para la tramitación de una solicitud de protección internacional, sino que también incluye la identificación de migrantes en situación irregular. Aunque esta justificación estriba en la exigencia de un control más eficiente de aquellos individuos que pretenden ingresar o permanecer en forma irregular en la UE, así como de los movimientos secundarios -potenciando su posterior readmisión y retorno a países de origen-, no es menos cierto que esta extensión se 
contempla meramente sobre la dimensión de seguridad y eficiencia, careciendo de las garantías suficientes en la protección de los datos personales -teniendo en cuenta los grandes y conflictivos intereses en juego entre seguridad y protección-.

2. En relación con la transferencia de datos a terceros países con fines de retorno, se trata de una de las novedades más destacadas que prevé el art. 38 PRE. Esta transferencia únicamente permite a las autoridades nacionales transferir la información de sujetos que no cumplan con las condiciones exigibles para la obtención del estatuto de protección internacional. Sin embargo, aumentará la posibilidad de que la información concerniente a este colectivo en situación de vulnerabilidad pueda cederse a terceros estados. Ello, principalmente, tras destacarse por parte del FRA los frecuentes márgenes de errores en la determinación de la tipología de sujetos.

Esta excepcional transferencia de datos deberá "compensarse" tanto por la exigencia de que se realice exclusivamente para fines de retorno como por la directa sujeción a las reglas que regula el art. 46 RGPD. Nuevamente, el problema radicará en que esta disposición no resultará fácilmente aplicable puesto que la mayor parte de los países de origen no reúnen las altas condiciones que exige el RGPD.

De igual modo, esta transferencia de datos puede llevarse a cabo por organismos asistenciales en frontera como la GEFC o la futura AAUE. En este caso, sí existen o existirán garantías adecuadas a través de acuerdos vinculantes jurídicamente entre las autoridades públicas como dispone el art. 48 del Reglamento 2018/1725. Ahora bien, se contempla una excepción en el art. $50.1 \mathrm{~d}$ ), que facultará a transferir estos datos por "razones importantes de interés público", un precepto que podría emplearse con el propósito de eludir las altas garantías que contempla el RGPD. Por ello, estas causas deberán resultar tasadas, concretas e individualmente adoptadas, de manera que el interés público perseguido sea superior al particular del organismo en cuestión.

3. En cuanto a la adición de las imágenes fáciles como nueva categoría de datos biométricos, esta ampliación viene a responder a la necesidad de solventar los grandes perjuicios que provocaron las fallas en la recopilación y registro de las huellas dactilares -factores que, recordemos, comprometieron seriamente la seguridad de algunos EEMM-. En este aspecto, la finalidad de tratamiento en Eurodac no resulta 1o suficientemente clara, máxime en vista de que se trata de una categoría especial de datos que regulan los arts. $4.14^{\circ}$ RGPD y $3.13^{\circ}$ de la Directiva de protección de datos en el ámbito penal. 
El art. 16 PRE contempla expresamente que la comparación de la imagen facial se lleve a cabo como último recurso, esto es, en caso de que las huellas dactilares presenten errores que impidan la consecución de los objetivos de Eurodac. Si bien, constituye la única y tímida mención del principio de subsidiariedad, el cual resulta insuficiente, principalmente, si son contabilizadas las frecuentes y reiteradas alusiones de la propuesta a la necesidad de recopilar ambos datos biométricos sin diferencia ni orden de prelación alguno.

Así, la PRE no debería apostar por obtener y registrar cada vez más datos en Eurodac con el único objetivo de superar la frecuente indeterminación de los sujetos que se encuentran bajo el Sistema de Dublín, sino en establecer procedimientos más eficientes que analicen y procesen esos datos de un modo coherente y garante con los derechos fundamentales. En este caso, deberá controlarse estrictamente la legalidad del tratamiento biométrico por parte de las APDs, tal y como regula el art. 26 PRE, teniendo en consideración que esta ampliación aumenta el riesgo de vulneración del principio de limitación de la finalidad e, incluso, tiende a desviarse de su objeto principal. Ello podría generar una pérdida del control de esta información con efectos sumamente críticos en el ámbito del SECA.

4. Además, esta recopilación de datos, cada vez más amplia, no únicamente se prevé desde el enfoque objetivo anteriormente analizado, sino también subjetivo, es decir, incluyendo las tres categorías de sujetos. Sobre esta cuestión, debe destacarse que la reducción de la edad para la toma de datos biométricos a los menores comprendidos entre 6 y 14 años no tiene un objetivo claro. Independientemente de que, en vista de crisis migratoria y los problemas que han afectado a la seguridad de los EEMM, resulta comprensible el compromiso de la UE por aumentar las técnicas de control de movimientos migratorios así como de la prevención, detección e investigación de delitos graves.

5. Además, con la ampliación del período de conservación de datos las dos categorías de migrantes irregulares en la PRE, pretenden potenciarse los procedimientos de retorno y readmisión. Esta ampliación se justificó tras los escenarios críticos que se han producido en los últimos tiempos y sobre los cuales el actual Reglamento Eurodac no ha proporcionado respuestas concluyentes en aspectos como la carencia de una eficaz identificación de la migración irregular o la ausencia de control efectivo de los movimientos secundarios. 
6. El acceso de las autoridades policiales y de la Europol a los datos que ya recoge el actual Reglamento Eurodac constituye otro de los aspectos que ha comprometido seriamente el derecho a la protección de datos del art. 8 CDFUE. Este acceso se encuentra supeditado a la necesidad de disponer y comparar esta información en el objetivo de la lucha contra el terrorismo y otros delitos graves. Ahora bien, como recuerdan los Considerandos 13 o 20 PRE, este acceso supone un cambio trascendental, lo cual planteará serias dudas sobre su compatibilidad con el principio de limitación de la finalidad.

Así, este marco jurídico impacta directamente en el derecho a la protección de los datos personales, una situación que se agrava por dos cuestiones inherentes al propio funcionamiento de Eurodac:

a) por la disparidad de la conceptualización de delito grave la cual corresponde, en última instancia, a los EEMM y;

b) porque dispondrá de un periodo de conservación de los datos de 3 años, únicamente para la categoría de los solicitantes de protección internacional (art. 19.3 PRE). Un silencio que fue criticado por el SEPD, que recomendaba equipararlo al resto de categorías de sujetos.

Finalmente, las medidas de acceso están íntimamente relacionadas con la seguridad de los datos, pero nada regula en relación con la normativa de protección de datos. Al efecto, las autoridades nacionales -tanto las designadas para solicitar el acceso a Eurodac como las verificadoras de las condiciones necesarias para su aprobación- y Europol deberán aplicar altas medidas de seguridad de acuerdo con lo dispuesto en el art. 34 del Reglamento Eurodac (art. 36 PRE). Estas causas se contemplan de forma análoga en el art. 29 de la Directiva de protección de datos en el ámbito penal, por lo que esta Directiva deberá aplicarse de forma supletoria. 


\section{CAPÍTULO 4.}

\section{EL SISTEMA EUROPEO COMÚN DE ASILO Y SUS RETOS MÁS INMEDIATOS EN EL ORDENAMIENTO JURÍDICO ESPAÑOL: ESPECIAL REFERENCIA A CEUTA Y MELILLA.}

\section{Introducción.}

Al contrario de lo ocurrido durante la crisis de refugiados que tuvo lugar entre los años 2014 y 2016, el número de llegadas de solicitantes de protección internacional en España ha sufrido un crecimiento exponencial desde 2017, duplicándose en comparación con los datos del año anterior con más de 30.000 solicitudes y casi triplicándose si tenemos en cuenta las más de 55.000 en el año $2018 .{ }^{608}$ Esta información fue recientemente actualizada por la Comisión Española de Ayuda al Refugiado (CEAR) destacando que, solamente en el primer trimestre de 2019, se presentaron 26.629 solicitudes, ${ }^{609}$ llegando a más de 100.000 durante todo este último año.

Todos estos datos sitúan a España como el $5^{\circ}$ país de Europa por número de solicitudes, tras Alemania, Francia, Grecia e Italia, lo que lleva a preguntarnos si realmente este país está inmerso en una grave crisis migratoria y de asilo o, si por el contrario, se trata simplemente de un alto número de llegadas a nuestras fronteras. Como punto de partida, debemos destacar que el informe anual del Consejo de Seguridad Nacional español no cataloga este incremento como una crisis migratoria. ${ }^{610}$ Precisamente, este repunte no sigue los mismos patrones de comportamiento que aquellos que tuvieron que soportar los estados de primera línea o entrada de nacionales de terceros países que huían de conflictos bélicos en terceros estados -principalmente, Siria, Afganistán o Irak- durante la crisis de 2015 y 2016 y que azotó en buena medida a Grecia e Italia. Recordemos que esta supuso una amenaza directa a su seguridad nacional, no únicamente por el volumen de nacionales de terceros países con intención de entrar a través de sus fronteras terrestres y marítimas, sino también por la

\footnotetext{
${ }^{608}$ Ministerio de Interior, Oficina de Asilo y Refugio, Asilo en cifras 2018, septiembre de 2019, pp. 19 y 24.

${ }^{609}$ CEAR, Informe 2019: Las personas refugiadas en España y Europa. Disponible en: https://www.cear.es/wp-content/uploads/2019/07/INFORME_CEAR_2019.pdf

${ }^{610}$ Consejo de Seguridad Nacional, Informe Anual de Seguridad Nacional de 2018, marzo 2019, p. 126.
} 
procedencia de estos migrantes. Además, como examinamos en el primer Capítulo, las mafias organizadas y las organizaciones dedicadas a la trata de personas también aprovecharon los déficits fronterizos de estos estados para favorecer la entrada de nacionales de terceros países con un perfil delincuente o, incluso, terrorista.

Lo que es indiscutible es que nuestro país se ha convertido en la ruta principal para la entrada de migrantes y refugiados en Europa durante los últimos dos años (2017-2019). Esto ha provocado serias carencias de recursos humanos y administrativos necesarios para gestionar el volumen de solicitudes de protección internacional. Ello, pese a beneficiarse de un total de 779 millones de euros provenientes tanto del Fondo de Asilo, Migración e Integración (FAMI) como del Fondo de Seguridad Interior (FSI), en este caso, con 325.9 millones desde 2015 hasta octubre de $2019 .{ }^{611}$

El repunte en estos dos últimos años no solo representa el mayor número de migrantes de las últimas décadas en España, sino que en clara vinculación con ello, también evidencia una de las tasas de reconocimiento del derecho de asilo y protección subsidiaria más bajas de toda Europa, de tan solo un $9 \%$-solamente superado por Hungría con tan solo un 6\%- ${ }^{612}$ Ahora bien, centrándonos en la procedencia de las llegadas, debemos destacar que, de los 16.200 nacionales sirios que solicitaron asilo en la UE en el segundo trimestre de 2019, el 57\% lo hizo en Alemania, mientras que el 90\% de los venezolanos solicitó asilo en España (un total de 9.700). Por lo tanto, a pesar de que Siria y Afganistán continúan siendo las principales nacionalidades de entrada en la UE en países como Alemania, Grecia, Chipre y Francia, en lo que atañe a España, la mayoría proceden de Venezuela. ${ }^{613}$

Particularmente, la mayor parte de los nacionales venezolanos no entran dentro de la definición estricta de refugiado ni protección subsidiaria. Sus solicitudes de asilo han sido, mayormente, rechazadas -un 93.9\% en 2018-; la mayoría de ellos huyen de una profunda crisis política y económica, razón por la que España ha previsto alternativas para garantizar su residencia legal, a través de la concesión de permisos de residencia

\footnotetext{
${ }^{611}$ Comisión Europea, Managing Migration EU Financial Support to Spain, octubre de 2019. Accesible en: https://ec.europa.eu/home-affairs/sites/homeaffairs/files/what-we-do/policies/european-agendamigration/201910_managing-migration-eu-financial-support-to-spain_en.pdf

${ }^{612}$ En Alemania un 38\%, Grecia o Luxemburgo un 52\%. Incluso Italia dobla a las cifras de España (18\%). Eurostat, Asylum quarterly report, septiembre de 2019, p. 10. Disponible en: https://ec.europa.eu/eurostat/statistics-explained/pdfscache/13562.pdf

613 Eurosat, five main citizenships of (non-eu) asylum applicants 2019. Disponible en: https://ec.europa.eu/eurostat/statistics-explained/index.php/Asylum_quarterly_report
} 
temporales por razones humanitarias tras la denegación de sus solicitudes de protección internacional. $^{614}$

Sin embargo, lo verdaderamente alarmante estriba en las dificultades que experimenta el sistema nacional de asilo para afrontar esta gran magnitud de peticiones de protección internacional. Como destacó el Defensor del Pueblo (DP) en su último Informe, más de 78.000 solicitudes de protección internacional se encontraban todavía pendientes de resolución por parte de la OAR. Una realidad que se agrava por los más de 64.000 migrantes interceptados intentando acceder de manera irregular a España ${ }^{615} \mathrm{y}$ el correspondiente estrés excesivo en puntos fronterizos concretos específicos, como los aeropuertos de Madrid-Bajaras y Barcelona-El Prat - para aquellos que llegan por vía aérea- y Ceuta y Melilla -por vía terrestre o marítima desde el continente africano- y que han provocado una manifiesta desprotección de colectivos vulnerables, como los menores no acompañados. ${ }^{616}$

Además, en su cómputo total, estos datos no han podido resultar más desfavorables. En junio de 2019, la CEAR alertó de que alrededor de 100.000 solicitudes de asilo todavía no habían sido resueltas. ${ }^{617}$ Una circunstancia que tiene su razón de ser en los escasos medios materiales y humanos, a todas luces insuficientes, para garantizar un procedimiento de asilo o protección subsidiaria con todas las garantías.

Efectivamente, con miras a prevenir la incapacidad en la tramitación de las solicitudes de protección internacional y garantizar el acceso efectivo a este procedimiento, una de las primeras medidas nacionales fue adoptada durante el inicio de

\footnotetext{
${ }^{614}$ Así consta en el informe de AIDA de 5 de marzo de 2019, que recoge la concesión por parte de las autoridades españolas de permisos de residencia renovables anuales "por razones humanitarias de protección internacional" a nacionales venezolanos cuyas solicitudes de asilo fueron rechazadas de plano entre enero de 2014 y febrero de 2019. Asylum Information Database (AIDA). Asylum Country Report: Spain, 2018, p. 12. Disponible en: http://www.asylumineurope.org/sites/default/files/reportdownload/aida_es_2018update.pdf

${ }^{615}$ DP, Informe anual 2018. Volumen I Informe de gestión, Madrid, 2019, pp. 199 y 200.

${ }^{616}$ El DP, en su Recomendación de 29 de mayo de 2017, formulada ante la Dirección General de Política Interior apuntó a que no existe protocolo para actuar en los casos de menores no acompañados donde la entidad de protección no le tutela ni tampoco tienen representante legal en España, recomendando la adopción de las medidas necesarias para garantizar la formalización de solicitudes de protección internacional a los menores solos en estos casos. Defensor del Pueblo, Informe anual 2017 y debates en las Cortes Generales. Volumen I.1 Informe de gestión, Madrid, 2018, p. 241.

${ }^{617}$ Como señala el Informe del 2019, el acceso al sistema de asilo se enfrenta una grave situación, con largas esperas para formalizar las solicitudes y cerca de ochenta mil expedientes pendientes de resolución a fines de 2018, una cifra que ya ascendía a 93.140 en febrero de 2019. Véase CEAR, Informe 2019, ob. cit., p. 152.
} 
la crisis migratoria europea. Pese a que su incidencia en España fue residual, el 4 de septiembre de 2015, el Gobierno presidido por Mariano Rajoy creó la Comisión Interministerial para la Crisis de los Refugiados para afrontar unas afluencias a gran escala que se producían, esencialmente, en las rutas de llegada hacia Grecia e Italia. Tras esta creación, comenzó a vislumbrarse la necesidad de acometer profundas reformas en el sistema nacional de asilo con miras a prever posibles futuras llegadas a gran escala de migrantes a nuestras fronteras, sentando las bases para promover un futuro sistema de acogida más eficaz y eficiente a corto y largo plazo. El principal problema estribó en que las actuaciones de esta Comisión resultaban muy descoordinadas, motivo por el que el DP instó a su revisión orgánica y funcional con miras a incrementar su eficacia en la gestión de las solicitudes. ${ }^{618}$

Además, la inauguración de esta Oficina se complementó con la ejecución de un programa de refuerzo temporal que contó con 77 trabajadores. Una dotación que fue posible gracias al Fondo de Asilo, Migración e Integración de la UE que proporcionó soluciones al gran aumento de solicitudes de protección internacional en la UE en este periodo de tiempo. De hecho, de acuerdo con el informe de evaluación intermedio del año 2017, esta dotación “permitió examinar un número mayor de expedientes así como adoptar un número significativamente mayor de resoluciones -pasando de 3.315 en 2015 a 7.655 en 2016-, manteniendo estables los plazos de resolución de expedientes entre los 9-11 meses de media, sin alcanzar los 6 meses establecidos en la ley y fijado como objetivo en el momento de elaborar el PN". ${ }^{619}$ Este programa concluyó a finales de diciembre del 2018 en un momento en el que el número de solicitudes continuaba aumentando a un ritmo imparable, por lo que esta reducción del personal de la Oficina volvió a situar a la OAR en una situación muy precaria en la gestión eficaz de las solicitudes.

En consecuencia, la incapacidad manifiesta de la OAR para tramitar y resolver, en un tiempo prudencial -esto es, en torno a tres meses o, como regula el art. 24.3 LAPS, hasta un máximo de seis- ${ }^{620}$ un elevado número solicitudes de protección internacional

\footnotetext{
${ }^{618}$ DP, Informe anual 2016 y debates en las Cortes Generales I. Informe, Madrid, 2017, p. 55.

${ }^{619}$ Programa Nacional FAMI España, Informe de evaluación intermedia del FAMI (01/01/2014 30/06/2017), $\quad$ p. $9 . \quad$ Disponible en: http://extranjeros.mitramiss.gob.es/es/Fondos_comunitarios/fami/documentos/informe_intermedio_pn_fa mi_2014_2020_es.pdf

${ }^{620} \mathrm{El}$ art. 24.3 LAPS dispone que "Transcurridos seis meses desde la presentación de la solicitud sin que se haya notificado la correspondiente resolución, la misma podrá entenderse desestimada (...)". Sin
} 
requiere de efectivas reformas que reviertan este contexto. Con independencia de esta Oficina de carácter temporal, estas reformas fueron iniciadas en 2016, cuando el Ministerio del Interior reforzó la OAR mediante la incorporación de un total de 94 nuevos efectivos temporales para la realización de labores de apoyo a la instrucción y tramitación de expedientes de protección internacional. Una medida nacional acaecida en un momento sumamente pertinente, habida cuenta de que el incremento exponencial de solicitudes de protección internacional no se debía a un colapso funcional, sino a una plantilla que no respondía al volumen de migrantes que se encontraban en las fronteras exteriores españolas.

Mención aparte merecen los medios materiales desactualizados y anticuados que comúnmente ha dispuesto esta Oficina, ${ }^{621}$ uno de los principales motivos de esa falta generalizada de eficiencia en la tramitación de los expedientes de protección internacional. Asimismo, el DP se pronunció en el estudio El asilo en España. La Protección internacional y los recursos del sistema de acogida, recomendando el empleo de SSII que permitieran publicitar estadísticas y datos de interés no confidenciales sobre protección internacional -como los tiempos medios de resolución de los expedientes- y la mejora de la gestión en la tramitación de estos procedimientos. ${ }^{622}$ Estas Recomendaciones fueron finalmente tomadas en consideración por parte del ejecutivo socialista, que aprobó, mediante el Decreto Ley 6/2018, una oferta extraordinaria de empleo público de esta Oficina compuesta por un total de 231 plazas permanentes, ${ }^{623}$ actualizando igualmente la web ministerial sobre la difusión de datos e información estadística relevante de la OAR.

En el presente, mientras estas plazas están siendo cubiertas, se han contratado 176

perjuicio de que la Administración resuelva expresamente aún fuera de plazo de conformidad con el art. 19.7 LAPS informando debidamente a la persona interesada del motivo de la demora.

${ }^{621}$ En este sentido, el Ministerio del Interior subrayó que los sistemas informáticos llevaban sin renovarse desde 2006, agravándose por la razón de que la OAR ha contado con un total de 60 plazas desde su creación en 1992. Gobierno de España, Ministerio del Interior (Sala de Prensa). Las responsables de la Oficina de Asilo y Refugio presentan al Defensor del Pueblo las medidas puestas en marcha para acelerar la resolución de solicitudes, 30 de noviembre de 2018. Disponible en: http://www.interior.gob.es/ca/prensa/noticias/-/asset_publisher/GHU8Ap6ztgsg/content/id/9639817

${ }^{622}$ Recomendación $\mathrm{n}^{\circ}$ 11. DP, Estudio sobre El asilo en España. La Protección internacional y los recursos del sistema de acogida, junio de 2016. Accesible en: https://www.defensordelpueblo.es/wpcontent/uploads/2016/07/Asilo_en_Espa\%C3\%B1a_2016.pdf

${ }^{623}$ Véase Real Decreto-ley 6/2018, de 27 de julio, por el que se aprueba una oferta de empleo público extraordinaria y adicional para el refuerzo de medios en la atención a asilados y refugiados. BOE núm. 184, de 31 de julio de 2018, pp. 76876 a 76878. 
interinos para la realización de tareas de refuerzo, lo que constituye un considerable esfuerzo hacia una inminente mayor estabilidad, algo verdaderamente necesario en la lucha contra todos aquellos escenarios que requieren una actuación continuada, eficiente y eficaz de la OAR. Ello, teniendo en consideración que, en estos últimos años, la demanda de solicitudes es casi 20 veces mayor a la experimentada en el 2012. Sin embargo, los medios humanos y materiales de esta Oficina están fuertemente descompasados con esta nueva realidad.

Una mayor dotación de personal especializado en la gestión de solicitudes de asilo que no proporcionará soluciones eficientes a este aumento del número de solicitudes, sino que deberán preverse juntamente con actuaciones concretas. A la modernización de estos sistemas informáticos capaces de impulsar la prevención temprana de todos aquellos escenarios que requieran el despliegue y la intervención operativa específica de autoridades administrativas o policiales, se le adiciona la reciente creación de un sistema propio de guardias para el procedimiento de frontera en los aeropuertos de Madrid y Barcelona. En este caso, pretende incrementarse el despliegue policial especializado en estos puntos. Un claro intento de adaptación a las llegadas que sufre este país y compensar los graves retrasos acaecidos en el año 2018 en las fronteras exteriores aéreas. ${ }^{624}$

Lejos de quedarse aquí, el Protocolo marco de protección de las víctimas de trata de seres humanos ${ }^{625}$ establece parámetros contundentes sobre la manera más apropiada de proceder en caso de identificar indicios razonables de que una persona puede ser víctima de trata de seres humanos. El apartado V.D. 3. ${ }^{\circ}$ exige que, cuando en "la instrucción de un expediente de solicitud de protección internacional se aprecien indicios de que la persona solicitante pudiera ser víctima de trata de seres humanos, la OAR lo pondrá en conocimiento de la Sección de Asilo de la Comisaría General de

\footnotetext{
${ }^{624}$ Si bien, desde febrero de 2019, a todos los solicitantes de protección internacional de origen palestino se les exige un visado de tránsito, lo cual obstaculiza seriamente las vías de llegada legales y seguras a territorio nacional por parte de una de las nacionalidades más numerosas que llega por vía aérea. Sobre esta cuestión, remitimos a: Comisión Europea, Lista de terceros países cuyos nacionales deben poseer una visa de tránsito aeroportuario al pasar por el área de tránsito internacional de aeropuertos ubicados en el territorio de uno o varios Estados miembros, 1 de febrero de 2019. Disponible en: https://www.cear.es/wp-content/uploads/2019/01/visados_transito_esp.pdf

${ }^{625}$ Protocolo marco de protección de las víctimas de trata de seres humanos, adoptado mediante Acuerdo de 28 de octubre de 2011 por los Ministerios de Justicia, del Interior, de Empleo y Seguridad Social y de Sanidad, Servicios Sociales e Igualdad, la Fiscalía General del Estado y el Consejo General del Poder Judicial.
} 
Extranjería y Fronteras a fin de que esta lo comunique a la unidad policial competente para su identificación”, por si pudiera resultar de aplicación el art. 59 bis de la Ley de Extranjería. En caso afirmativo, el apartado VI.B. prevé medidas como entrevistas confidenciales en un idioma comprensible y con intérprete si fuera necesario, el traslado a entornos adecuados en función del sexo, edad y otras circunstancias personales, etc.

Ahora bien, como recoge el Informe del Proyecto "Identification of TRafficked Asylum seeKers' Special needs" (Tracks), en el que participa la CEAR ${ }^{626}$ como único participante por parte de España, la aplicación de este Protocolo en España no incluye medidas de necesaria adopción contra este colectivo muy vulnerable, como la obligación de informar a la víctima de trata de que puede presentar una solicitud de protección internacional conforme al art.11.6 de la Directiva 36/2011, de prevención y lucha contra la trata de seres humanos o, en el caso de su presentación en aeropuertos, que las ONGs de referencia y especializadas puedan estar presentes en los aeropuertos principales españoles.

Las conclusiones del mencionado estudio resultaron muy reveladoras, exigiendo la correspondiente mejora de los sistemas de recopilación de estos datos y de los mecanismos de detección temprana, en especial, en las costas de Ceuta y Melilla, la evaluación sistemática de las necesidades de las víctimas de trata de seres humanos como solicitantes de protección internacional e, incluso, la adopción de un "Mecanismo Nacional de Derivación" para contar con criterios armonizados y coherentes en ambos procedimientos. $^{627}$

Todos estos acontecimientos nos llevan a acometer un análisis sobre las presiones concretas que sufre el sistema de asilo español en dos puntos fronterizos concretos: los que afectan a la entrada de migrantes por las ciudades autónomas de Ceuta y Melilla. Dichos emplazamientos que están experimentando un alto número de solicitudes de protección internacional en los últimos tiempos. Una situación que no solo parece

\footnotetext{
${ }^{626}$ Ahora bien, como recoge el Informe del Proyecto 'Identification of TRafficked Asylum seeKers' Special needs" (Tracks) en el que participa la CEAR -único participante por parte de España-, el Protocolo en su vertiente española no incluye medidas de necesaria adopción contra este colectivo muy vulnerable, como la obligación de informar a la víctima de trata de que puede presentar una solicitud de protección internacional conforme al art.11.6 de la Directiva 36/2011, de prevención y lucha contra la trata de seres humanos o, en el caso de su presentación en aeropuertos, que las ONGs de referencia y especializadas puedan estar presentes en los aeropuertos principales españoles. TRACKS, Identificación de las necesidades especiales de solicitantes de asilo víctimas de trata y respuesta a las mismas. Informe resumido. Panorama Nacional España, 2018, p. 16 (HOME/2014/AMIF/AG/ASYL/7849).

${ }^{627}$ TRACKS, Identificación de las necesidades especiales de solicitantes de asilo... ob. cit., pp. 27 y 28.
} 
responder al contexto político que experimentan distintos países subsaharianos, sino también a las actuaciones que están efectuando las autoridades marroquíes. En este sentido, no conviene obviar que estas procedieron al desmantelamiento de los campamentos de estos migrantes subsaharianos, provocando un efecto rebote en las fronteras de Ceuta y Melilla. ${ }^{628}$ Además, la cooperación de España con Marruecos se ha visto fuertemente resentida en los últimos años. En particular, la mayor laxitud en la vigilancia de las costas del norte de Marruecos parece producirse a raíz de la decisión del TJUE, de 27 de febrero de 2018 que declaró la separación de Marruecos de sus próximas aguas del Sáhara Occidental. ${ }^{629}$

Indudablemente, estas acciones propiciaron que muchos de los migrantes continuaran su viaje a través del mar o intentaran saltar las vallas de Ceuta y Melilla, lo que ha supuesto un considerable repunte de solicitudes de protección internacional que se encuentra fuertemente descompasado con el volumen escaso que tradicionalmente ha tenido Melilla -o, nulo en el caso de Ceuta- Al efecto, acometeremos las pertinentes modificaciones que deberían incorporarse en el ordenamiento jurídico español a la luz de la propuesta de reforma SECA para estar en condiciones de enfrentarse a los desafíos emergentes que han menoscabado gravemente un derecho constitucionalmente reconocido en su art. 13.4 CE y en los Tratados internacionales ratificados por España y que han puesto en serio riesgo los valores sobre los que se sustenta la UE como la lucha contra la exclusión social, la discriminación y la solidaridad (art. 2 TUE).

Seguidamente, examinaremos el derecho a la protección internacional en el procedimiento fronterizo de Ceuta y Melilla, las conocidas "devoluciones en caliente", las restricciones a la libertad de circulación de los solicitantes de protección internacional y la situación actual de los Centros de Estancia Temporal de Inmigrantes y de los Centros de Internamiento de Extranjeros, finalizando con una serie de conclusiones al respecto.

\footnotetext{
${ }^{628}$ Los asentamientos de estos migrantes en los campamentos de Fez o Casablanca resultaban claves para su supervivencia pero el cierre o la destrucción de estos ha motivado que la única alternativa posible fuera continuar hacia el norte del país e intentar entrar masivamente en Ceuta y Melilla. Para un estudio sobre el particular, remitimos a: PORGES M., "Western Sahara and Morocco: Complexities of Resistance and Analysis" en: DE VRIES L., ENGLEBERT P., SCHOMERUS M. (eds.), Secessionism in African Politics. Palgrave Series in African Borderlands Studies. Palgrave Macmillan, Cham, 2019, pp. 127-149.

${ }^{629}$ La STJUE, de 27 de febrero de 2018 (Asunto C-266/16) determinó que el acuerdo de pesca entre la UE y Rabat no podía contemplar las aguas saharauis, área donde se captura la mayor parte del pescado de la flota europea. Consecuentemente, para que Marruecos pueda aplicar la reducción de aranceles con la UE, debe señalar en el etiquetado los productos del Sáhara Occidental.
} 
2. La Ley de Asilo y de la Protección Subsidiaria: un balance crítico 2009-2019.

\subsection{Antecedentes}

El derecho de asilo reconocido el art. 13.4 de la Constitución Española (CE) de $1978^{630}$ fue inicialmente desarrollado mediante la Ley 5/1984 de 26 de marzo reguladora del derecho de asilo y de la condición de refugiado, la cual derogó la antigua Ley de Asilo preconstitucional del año 1855 e incorporó formalmente las disposiciones previstas en la Convención de Ginebra. ${ }^{631}$

En un principio, el constituyente de 1978 fue especialmente precavido a la hora de incluir la dimensión de seguridad en la CE, así lo constató Alzaga Villaamil con la siguiente matización: "subyace la tesis de que el Estado español se reserva, en última instancia, el graduar la concesión o denegación de este derecho, en función de consideraciones humanitarias, pero también de sus intereses o, si se quiere, de la llamada razón de Estado". ${ }^{632}$ Ahora bien, la trascendencia de la Ley 5/1984 radicó tanto en la distinción entre el derecho de asilo y la condición de refugiado, ${ }^{633}$ como en la inclusión del asilo por razones humanitarias - precedente del actual derecho a la protección subsidiaria-. Además, la discrecionalidad del Estado respecto a la concesión o denegación del derecho de asilo se restringió en virtud de los instrumentos internacionales. Particularidad que fue abordada por Pérez Sola, destacando que el principio de no devolución actuaba como límite frente a esta discrecionalidad, de tal

\footnotetext{
${ }^{630}$ Constitución Española. Boletín Oficial del Estado, 29 de diciembre de 1978, núm. 311, pp. 29313 a 29424

${ }^{631}$ La adhesión del Reino de España había tenido lugar el 22 de julio de 1978.

${ }^{632}$ ALZAGA VILlAAMIL, O., La Constitución Española de 1978 (Comentario sistemático), Madrid: Ediciones del Foro, 1978, p. 180. Consecuentemente, esta se previó, por un lado, en la prohibición de la devolución en el art. 5, supeditada a la adopción de todas aquellas medidas cautelares adoptadas por "la Autoridad gubernativa por motivos de salud o seguridad pública". Por otro, el art. 14 dispuso que la concesión del asilo por razones humanitarias otorgaba "un permiso de residencia temporal por un plazo de seis meses". De esta forma, una vez transcurrido este plazo, se procedía a la revisión del estatuto, pudiendo aplicar la revocación del mismo, siempre que se diera justa causa que afectase al "orden público interior, seguridad exterior del Estado o intereses internacionales del mismo" y fuera debidamente motivado.

${ }^{633} \mathrm{El}$ derecho de asilo fue concebido de manera independiente como la "protección graciable dispensada por el Estado en el ejercicio de su soberanía" (art. 3) y, en consecuencia, como un acto discrecional y no controlable judicialmente (art. 21), mientras que la condición de refugiado fue conceptualizada como un derecho fundamental susceptible de control judicial (art. 1) en virtud de la Ley 62/1978 de Protección Jurisdiccional de los Derechos Fundamentales de la Persona.
} 
modo que la Administración no estaba vinculada a conceder asilo pero el individuo ostentaba el derecho a solicitarlo y a obtenerlo. ${ }^{634}$

Tras diez años, el Preámbulo de la Ley 9/1994, de 19 de mayo modificó la Ley 5/1984 reguladora del asilo y de la condición de refugiado. Una reforma requerida en el ordenamiento jurídico nacional para "impedir la utilización fraudulenta con fines de inmigración del sistema de protección de los refugiados", ${ }^{635}$ otorgar respuestas contundentes frente a temores al uso fraudulento del asilo por parte de los migrantes económicos y garantizar la celeridad en el examen individualizado de las solicitudes.

Siguiendo las exigencias de armonización con el ordenamiento jurídico comunitario, resulta necesario recordar a grandes rasgos las siguientes cuestiones:

- Se procedió a unificar el estatuto del asilo y la condición de refugiado y se forjó una noción cada vez más coherente de "protección internacional”;

- Asimismo, desde la fase de inadmisión a trámite que dispuso el art. 5, se persiguió solventar la exigencia de un examen individualizado con todas las garantías de las solicitudes de asilo cuando fueran apreciadas, entre otras, distintas causas de exclusión internacionalmente reconocidas en los arts. 1F y 33.2 de la Convención.

Esta novedosa fase procedimental sentó las bases de un derecho de asilo que requería progresivamente de parámetros más eficientes, identificando aquellas solicitudes en las que a priori no concurrían los elementos sustanciales o procesales y que facultaban a proporcionar una mayor celeridad a este procedimiento. Una disposición excepcional que ha sido aplicada con frecuencia en el seno del procedimiento de protección internacional para eludir los compromisos internacionales, como en el caso de la exclusión, el sometimiento al procedimiento fronterizo o la inadmisión a trámite por cuestiones que penden de la seguridad nacional.

Sobre este hecho se pronunció Santolaya Machetti en el año 2001, aludiendo a los efectos tan desventajosos que causaba la gran apertura de esta disposición para multitud de contextos como la falta de coherencia y efectividad del sistema nacional de asilo. ${ }^{636}$

\footnotetext{
${ }^{634}$ PEREZ SOLA, N. "El derecho de asilo y la condición de refugiado", Revista Derechos y Libertades, $\mathrm{n}^{\mathrm{o}} 25$, Época II, junio 2011, p. 275.

${ }^{635}$ GALPARSORO, J. "Una nueva ley de asilo en tiempos de crisis" en: Régimen jurídico del derecho de asilo en la Ley 12/2009. Centro de Estudios Políticos y Constitucionales. Madrid, 2010, p. 37.

${ }^{636}$ SANTOLAYA MACHETTI, P. El derecho de asilo en la Constitución Española, Lex Nova, 2001, p. 35.
} 
Además de esta inadmisión a trámite, otra de las reformas más destacadas y conflictivas de la reforma de 1994 estribó en la posibilidad de presentar la solicitud de asilo en los puestos fronterizos. De tal forma, los apartados 1 y 5 del art. 5 prohibieron el rechazo en frontera o la expulsión de un solicitante mientras que no se hubiera inadmitido a trámite su petición o se hubiera resuelto sobre la misma, sin perjuicio de la adopción de todas aquellas cautelas necesarias por razón de salud o seguridad públicas o la atención a las necesidades de humanas necesarias e inmediatas. No cabe obviar que, fruto de esta disposición, el art. 5.7 garantizó la detención de los solicitantes en las instalaciones en frontera hasta que se tomara una decisión final.

Esta disposición fue igualmente contemplada en la actual LAPS, lo que constituye uno de los extremos más problemáticos por su incompatibilidad con el art. 17.2 CE, que prohíbe que la entrada ilegal en territorio nacional pueda ser sancionada "cuando haya sido realizada por una persona que reúna los requisitos para ser beneficiaria de la protección internacional prevista en esta Ley". Es más, la Directriz 4.1 relativa a los criterios y estándares aplicables a la detención de los solicitantes de asilo del ACNUR ha dispuesto que la detención debe ser una medida excepcional y únicamente puede justificarse mediante un fin legítimo, esto es, para proteger el orden público, la salud pública y la seguridad nacional. ${ }^{637}$

En definitiva, la regulación de las condiciones de permanencia en frontera de aquellos solicitantes de protección internacional planteó contradicciones entre la protección del derecho de asilo y los derechos reconocidos y el control de la migración, especialmente, en una pluralidad de escenarios como la incapacidad para hacer frente a un elevado número de sujetos y la limitación de los medios personales y materiales. Así, este conflicto fue abordado en el ámbito de la gestión y control de las fronteras y del aumento de la eficiencia del procedimiento de asilo en virtud de la inadmisión a trámite de las solicitudes. Este escaso avance entre los intereses nacionales y su prevalencia o no sobre la protección del derecho de asilo, así como las herramientas que podían

\footnotetext{
${ }^{637}$ Tal y como recuerda el ACNUR, esta debe articularse exclusivamente con miras a evitar las fugas o en casos en que exista probabilidad de que no haya cooperación, para las solicitudes manifiestamente infundadas o claramente abusivas -mediante los procedimientos acelerados-, para la identificación inicial y la verificación de seguridad o con objeto de registrar, en el contexto de una entrevista preliminar, los elementos en los cuales se basa una solicitud de protección internacional, que no se pudo obtener sin recurrir a la detención. Es más, recuerda que la detención no puede emplearse bajo ningún modo como sanción por la entrada ilegal y/o una disuasión para los solicitantes de asilo y, ni que decir tiene, con fines de expulsión hacia solicitantes de asilo. ACNUR, Directrices sobre los criterios y estándares aplicables a la detención de solicitantes de asilo y las alternativas a la detención, 2012, pp. 16-19.
} 
solventar este compromiso fueron mitigados en el plano comunitario a través del conocido "Sistema de Dublín". 638

2.2. La Ley de Asilo y de la Protección Subsidiaria a la luz del futuro SECA.

A finales de 2009 entró en vigor la Ley 12/2009, de 30 de octubre, reguladora del derecho de asilo y de la protección subsidiaria con el propósito de satisfacer las necesidades emanantes de la normativa comunitaria - de la primera fase- y reflejando, al mismo tiempo, las interpretaciones y los criterios del TJUE y TEDH, que suponían rotundas mejoras en las garantías de las personas solicitantes y beneficiarias de protección internacional. ${ }^{639}$

Las causas esenciales que motivaron la aprobación de la nueva Ley se centraban en una labor de adaptación del ordenamiento jurídico nacional al SECA, a la CDFUE y al CEDH tal y como dispone el Preámbulo de la ley cuando alude a esta internalización de la regulación del derecho de asilo impuesta por nuestro texto constitucional: "no solo en virtud del artículo 93 en lo atinente a la Unión Europea, sino de forma más amplia en los mandatos interpretativo y aplicativo establecidos, respectivamente, en el (...) artículo 10 y el mismo apartado del 96". De este modo, como apuntara García Mahamut, esta ley supuso un grandísimo avance, teniendo en cuenta que la anterior ya no daba "cabida a situaciones que revisten tal gravedad que no pueden quedar sin respuesta en un Estado Democrático de Derecho en el siglo XXI". ${ }^{640}$

Como resultado, la ley española fue catalogada en el inicio de la pasada década como una de las legislaciones más garantistas con el derecho de asilo y protección subsidiaria.

\footnotetext{
${ }^{638}$ Inicialmente por el Reglamento Eurodac, mediante el Reglamento 2000/2725 del Consejo, de 11 de diciembre de 2000 y, posteriormente, el de Dublín -Reglamento 2003/343, de 18 de febrero de 2003-.

${ }^{639}$ Para un comentario a la mencionada Ley, remitimos a: GARCÍA MAHAMUT, R., en: "Artículo 13.4”, Comentario a la Consitución Española 40 Aniversario 1978-2018, PÉREZ TREMS, P., SAIZ ARNAIZ, A. (Dir.), Valencia, Tirant lo Blanch, 2018, pp. 329-340; Ídem., "El nuevo régimen jurídico del derecho de asilo..., ob. cit., pp. 15-91; SANTOLAYA MACHETTI, P., La reforma del derecho de asilo por la Ley 12/2009, en: Coloquios Jurídicos sobre América Latina. Seminario: Las reformas legales en los ámbitos de extranjería y asilo, Universidad de Alcalá, 19 de febrero de 2010; BUISÁN GARCÍA, N., Derecho de Asilo y protección de los refugiados, en: Casas Baamonde M. E., Rodríguez M., (Dir.), Comentarios a la Constitución Española. Madrid: Wolters Kluwer, 2009; ORTEGA GIMÉNEZ, A., ALARCÓN MORENO, J. "Luces y sombreas de la nueva Ley de Asilo", Iuris, enero de 2010; SARDINA CÁMARA, P., "Comentarios a la Ley 12/2009, de 30 de octubre, reguladora del derecho de asilo y de la protección subsidiaria”, Diario La Ley, n 7370, 2010; KAHALE CARRILLO, D.T., El nuevo sistema de derecho de asilo y de la protección subsidiaria, Andavira editora, 2017, pp. 67 y ss.

${ }^{640}$ GARCÍA MAHAMUT R., "El nuevo régimen jurídico del derecho de asilo...ob. cit., p. 53.
} 
Prueba de ello es que, diez años más tarde de su entrada en vigor y, ante la falta de transposición formal de las actuales Directivas de acogida, reconocimiento, procedimiento - del año 2011 la primera y 2013 las otras dos- que contemplaba la segunda fase del SECA, sigue otorgando verdaderos derechos subjetivos a sus titulares. Si bien, cabe destacar que Galparsoro ya vaticinó el "retroceso por la pérdida de garantías y aumento de la arbitrariedad en la Administración, como consecuencia de las políticas migratorias en las que se prima el control de fronteras, la gestión de flujos y la seguridad como es entendida por los gobiernos". ${ }^{641}$ Dificultades que, fuera de toda duda, se extienden hasta nuestro días.

No obstante, la mencionada Ley tomó como referencia las propuestas del 2008 correspondientes a las que conformarían la segunda fase del SECA. ${ }^{642}$ Indudablemente, esto no es suficiente hoy día, debiendo criticarse con firmeza la inacción del legislador por integrar a nuestro ordenamiento jurídico a esta segunda fase mediante la incorporación de las sustanciales modificaciones que fueron contenidas en los textos finales de las directivas. Mayormente, cuando estas introducían estándares mínimos que la LAPS debía mantener, sin perjuicio de incorporar aquellas otras disposiciones más favorables.

En el presente, esta ley debe mirar a la inminente reforma del SECA, que persigue la creación de un "nuevo" sistema capaz de ofrecer soluciones a las graves e imprevistas presiones migratorias y a la falta generalizada de información y control de los flujos mixtos de migrantes. La reforma holística del SECA dotará a los ordenamientos jurídicos nacionales de un alto nivel de uniformidad y coherencia. Una apuesta decidida por transformar dos directivas claves -la de Reconocimiento y Procedimiento comúnen reglamentos comunitarios además de mejorar tanto los reglamentos del "Sistema de Dublín”, como la Directiva de Acogida, capaz de potenciar la armonización de sus

\footnotetext{
${ }^{641}$ GALPARSORO J., "Una ley para el asilo en tiempos de crisis" en GARCÍA MAHAMUT, R., ob. cit., p. 138.

${ }^{642}$ En este caso, fueron transpuestas las Directivas adoptadas durante la I fase del SECA, concretamente: la Directiva 2003/86/CE, del Consejo, de 22 de septiembre, sobre el derecho de reagrupación familiar relativo a los refugiados; la Directiva 2004/83/CE, del Consejo, de 29 de abril, por la que se establecen normas mínimas relativas a los requisitos para el reconocimiento y el estatuto de nacionales de terceros países o apátridas como refugiados o personas que necesitan otro tipo de protección internacional y al contenido de la protección concedida; la Directiva 2005/85/CE, del Consejo, de 1 de diciembre, sobre normas mínimas para los procedimientos que deben aplicar los Estados miembros para conceder o retirar la condición de refugiado.
} 
condiciones en los distintos EEMM y mejorar las perspectivas de integración de los solicitantes de protección internacional.

Dicho esto, la reforma integral del SECA introduce sustanciales novedades que giran en torno a la dimensión de seguridad, eficacia, eficiencia con miras ya no solo a reducir, sino a "eliminar" de manera categórica los movimientos secundarios, los abusos y, en mayor medida, la prestación de un mayor apoyo a los EEMM más afectados por las grandes afluencias de migrantes, entre los que indudablemente se encuentra España. En este punto, previamente a abordar todos aquellos escenarios que han comprometido la plena efectividad del sistema nacional de asilo y, con independencia del Sistema de Dublín que se abordan en los Capítulos II y III, se concretarán las disposiciones reguladas en las propuestas de Reglamento de Procedimiento, Reconocimiento y Directiva de Acogida, las cuales requerirán modificaciones de hondo calado en la LAPS y su futura concreción en el reglamento de desarrollo de esta Ley.

1. Por lo que respecta a la propuesta de Reglamento de Procedimiento común, esta supondrá una "reconceptualización" de los procedimientos de protección internacional con miras a dotar a estos de una mayor sencillez, claridad y brevedad; incrementar las garantías procesales de salvaguarda de los derechos de los solicitantes; disponer de normas más estrictas para prevenir el abuso del sistema -sancionando las solicitudes manifiestamente abusivas y eliminando los incentivos a los movimientos secundarios-; y armonizar las normas sobre los países seguros.

La inclusión de plazos especialmente breves para el procedimiento administrativo agilizará los procedimientos. Conforme a la propuesta, son "razonables para que los solicitantes accedan al procedimiento y para concluir el estudio de las solicitudes en las fases administrativa y de recurso".

En efecto, la solicitud se considerará realizada desde el momento en el que el individuo manifieste su deseo de solicitar la protección internacional (art. 25.1), lo cual implicará que el registro deberá efectuarse con celeridad, esto es, en un plazo de tres días hábiles desde la realización (art. 27.1) -siguiendo el plazo marcado por la actual Directiva sobre procedimientos de asilo-. Posteriormente, el solicitante podrá presentar su solicitud en un plazo de diez días hábiles desde su registro, plazo que comenzará a computar siempre y cuando haya tenido la oportunidad efectiva de hacerlo dentro de dicho plazo. (art. 28.1), con excepción de los menores no acompañados, cuyo plazo comenzará cuando sea nombrado un tutor y lo haya entrevistado personalmente 
(artículo 32.2). Se trata de una novedad respecto al plazo previsto en la actual Directiva de procedimiento, que dispone que el registro se realice en el plazo máximo de 6 días hábiles siguientes a la formulación de la solicitud (párrafo $2^{\circ}$ del art. 6.1).

Además, por lo que respecta a la normativa española, la LAPS regula la presentación de las solicitudes en el Capítulo I del Título II (arts. 16 y ss.) y como tal, no recoge que la solicitud deba entenderse realizada desde el momento en el que tiene intención de solicitar protección internacional. En su defecto, el art. 17.1 simplemente regula que el procedimiento comenzará "con la presentación de la solicitud, que deberá efectuarse mediante comparecencia personal de los interesados que soliciten protección (...)". Asimismo, tampoco el apartado $2^{\circ}$ regula la fase de registro en el plazo tan breve y, en lo relativo a la formalización/presentación de la solicitud, contempla que "La comparecencia deberá realizarse sin demora y, en todo caso, en el plazo máximo de un mes desde la entrada en el territorio español", frente a los diez días hábiles de la propuesta de Reglamento.

Por lo tanto, la futura LAPS no solo deberá incluir garantías sobre la forma de presentación de la solicitud, sino que también exigirá unos plazos más reducidos tanto de registro (3 días hábiles desde la recepción) y de presentación de solicitud (10 días hábiles desde su registro). Estas modificaciones incrementarán las garantías de los derechos de los solicitantes de protección internacional y exigirán un replanteamiento integral de la infraestructura nacional para proceder al registro y presentación, habida cuenta de la falta de recursos materiales y personales para hacer frente a este nuevo procedimiento trifásico.

No menos relevante del efecto directo del este Reglamento serán los derechos y las obligaciones de los solicitantes y que requerirá una reformulación del art. 18 LAPS sobre los siguientes términos:

a) Por lo que respecta a los derechos de los solicitantes de protección internacional, el art. 13 de la mencionada propuesta contempla el derecho de acceso de estos y de sus asesores jurídicos a las grabaciones o transcripciones de las entrevistas o informes, previamente a dictarse una resolución. También, la entrevista personal de los apartados 4 a 8 del art. 17 LAPS exigirá la documentación escrita de todas las manifestaciones que sustancien en la solicitud, salvo que se haya documentado claramente que no tiene perspectivas tangibles de éxito o no da lugar a nuevos elementos o resultados relevantes (art. 42.3 de la propuesta). 
Asimismo, las causas de denegación del art. 9 LAPS deberán tipificar la renuncia a la solicitud por retirada explícita de la misma -ya sea por iniciativa propia o por no cumplir con las obligaciones derivadas de este Reglamento de procedimiento, Dublín o la Directiva de Acogida- (Considerado 25 y 43 de la propuesta). Por su parte, la LAPS también deberá incluir la adopción de garantías más contundentes para menores y, en especial, de aquellos no acompañados (arts. 20 a 22). Concretamente, la identificación de sus necesidades tan pronto como sea posible (art. 20.1) o la exclusión de la aplicación del procedimiento acelerado o de urgencia para los menores no acompañados que actualmente regula el art. 25 LAPS, salvo en dos supuestos: que procedan de un país de origen seguro o que constituyan un peligro para la seguridad nacional o el orden público (art. 40.5 a) y b) de la propuesta). Es más, con carácter general, el art. 19.3 de esta propuesta limitará la aplicación de los procedimientos fronterizos para los menores no acompañados que contempla el art. 21 LAPS.

b) La propuesta también impone varias de obligaciones atribuibles a los solicitantes, esto es, su deber de cooperar con las autoridades a lo largo de todo el procedimiento. Aunque este deber se encuentra recogido en el art. 18.2 LAPS, las actuaciones del solicitante adquirirán una importancia clave en el futuro Reglamento de procedimiento, hasta el punto de que estas determinarán su responsabilidad en el seno del procedimiento (art. 7 de la propuesta), mediante la imposición de nuevas sanciones en caso de incumplimiento que podrán conllevar hasta el rechazo de plano de la solicitud formalizada.

2. En relación con la propuesta de Reglamento de Reconocimiento, su aprobación exigirá la modificación de gran parte del articulado de la LAPS, que regula las condiciones para el reconocimiento del derecho de asilo en el Capítulo I Título I y que podemos distinguir entre dos categorías:

a) El refuerzo de algunas garantías tendentes a la unificación de criterios en todos los estados de la UE:

El art. 4 de la propuesta exige al solicitante que coopere exhaustivamente durante todo el procedimiento de determinación de su estatuto, debiendo también presentar todos los elementos disponibles, así como la obligación de permanecer en el territorio nacional durante todo el procedimiento, tal y como regulan los arts. 18.2 y 22 LAPS. En este caso, la normativa española deberá incluir dos nuevas cuestiones: por un lado, la obligación de residir tras ser beneficiario del estatuto de protección internacional (art. 
29). Por otro, la adopción de desincentivos si el sujeto se encontrara en otro EM en el que no tenga permiso para permanecer o residir (art. 44). Estos desincentivos, en todo caso, deberán ser proporcionales y no serán razón suficiente para revocar el estatuto previamente otorgado - más bien, el cese de determinados derechos de acogida como el alojamiento, comida o determinadas prestaciones económicas-.

Otra de las novedades de la propuesta radica en la posibilidad de que los EEMM no concedan protección ante "necesidades surgidas in situ" (art. 5.3), esto es, cuando se presente una solicitud posterior sobre la base de unas circunstancias que el solicitante ha creado tras tomar una decisión propia posteriormente a haber dejado su país de origen. En consecuencia, el art. 15 LAPS aunque ya contempla esta cuestión basándose en fundados temores de ser perseguido o el riesgo real de sufrir daños grave, deberá adicionar un nuevo apartando que establezca la posibilidad que contempla la mencionada propuesta.

Igualmente, la propuesta pretende asegurar que los EEMM no ofrezcan protección a los conocidos como desplazados internos, es decir, si los solicitantes pueden desplazarse internamente a otra parte del estado de origen del que proceden (art. 8.1). Un supuesto que acota la propia definición de refugiado y protección subsidiaria de los arts. 3 y 4 LAPS y que deberá hacerse mención en la normativa española. Consecuentemente, la LAPS deberá excluir de protección internacional a aquellos que pueden tener protección en otra parte del territorio, evaluando necesariamente si el solicitante puede viajar legalmente a otra parte del país perseguido con total seguridad y establecerse en este territorio.

El art. 25 PRR también mejorará la protección de las familias que se han formado en los países de tránsito, reconociendo expresamente el derecho a la unidad familiar. Clarifica la lex specialis de esta disposición en relación con las normas de la Directiva sobre reagrupación familiar, lo cual se traduce en que podrá solicitarse un permiso de residencia con arreglo a los procedimientos nacionales cuando no se cumplan las condiciones para acogerse a la protección internacional. Ello, siempre que sea compatible con la situación jurídica del miembro de la familia que se trate.

En cambio, la LAPS únicamente dispone en el art. 31.2 la adopción de medidas necesarias para mantener la unidad de la familia pero no prevé la posibilidad de expedirse un permiso de residencia si no tuviera derecho a protección internacional. De hecho, el art. 36.2 LAPS autoriza la residencia en España únicamente con carácter 
provisional a expensas de la resolución de la solicitud de protección internacional y en los términos que reglamentariamente se determinen. Por tanto, la ley deberá fijar claramente la residencia por mantenimiento de la unidad familiar, con independencia de que reúna o no las condiciones del estatuto de protección internacional, limitándose a la situación legal del miembro de la familia de que se trate y desarrollando por vía reglamentaria tales condiciones.

Por último, el art. 36 de la propuesta otorgará una mayor consideración al interés superior del menor. En este sentido, requerirá a las autoridades nacionales que, en un plazo máximo de 5 días hábiles, adopten las medidas necesarias para que el menor no acompañado posea un tutor $\mathrm{u}$ organización encargada de su cuidado y bienestar o cualquier otro tipo de representación adecuada. En este caso, la LAPS resulta muy garantista, disponiendo en los arts. 47 y 48 LAPS de condiciones análogas o semejantes. Ahora bien, también es cierto que en el futuro reglamento de desarrollo deberán concretarse todos los extremos desarrollados en la citada propuesta. ${ }^{643}$

b) El endurecimiento de las condiciones en los procedimientos de revisión de la protección.

El procedimiento de revisión constituye una de las cuestiones más relevantes de la propuesta, que requerirá la cooperación de las autoridades nacionales con las agencias especializadas en el procesamiento de información en fronteras. Una medida que pretende contribuir a aumentar eficiencia sin precedentes en este sistema y detectar posibles abusos o cambios de circunstancias en las condiciones por las que se concedió estatuto de refugiado o protección subsidiaria.

En este aspecto, a pesar de que el art. 33 LAPS regula la reducción o retirada de las condiciones de acogida, no contempla la revisión de las condiciones previamente analizadas y que dieron lugar a la efectiva concesión del estatuto de protección internacional. En este sentido, conforme a los arts. 15 y 21 PRR, se propone tipificar la obligación de las autoridades decisorias nacionales a efectuar revisiones exhaustivas en

\footnotetext{
${ }^{643}$ Concretamente, las funciones del tutor, el alojamiento adecuado de estos menores no acompañados en este caso, con parientes adultos, con una familia de acogida y en centros especializados en el alojamiento de estos menores $\mathrm{u}$ otros adecuados- (apartado $2^{\circ}$ ), no separando a los hermanos, teniendo en cuenta en todo momento el grado de madurez (apartado $3^{\circ}$ ), limitando al mínimo necesario los cambios de residencia (apartado $4^{\circ}$ ), prácticas necesarias como la búsqueda de familiares tras la concesión de la protección internacional (apartado $5^{\circ}$ ) así como la especificación de una formación continuada para las autoridades y operadores que trabajan con este colectivo vulnerable (apartado $6^{\circ}$ ).
} 
los casos en los que se produzcan modificaciones significativas relevantes en el país de origen que aparezcan reflejadas en documentos a nivel de la UE. Disposiciones que deben conjugarse con la incorporación de información constante del país de origen a través del análisis común de la información que regulan los arts. 8 y 10 del Reglamento AAUE.

De esta forma, esta información podrá emplearse durante la revisión del estatuto concedido con objeto de potenciar la retirada de los estatutos que ya no sean necesarios y llevándose a cabo en dos supuestos:

- cuando este arroje un cambio significativo en el país de origen pertinente [apartado a)] y;

- durante las renovaciones, por primera vez, de los permisos de residencia [apartado b)].

3. Finalmente, como ya hemos puesto de manifiesto, la propuesta de Directiva de Acogida supondrá la única excepción por la que se regula mediante directiva todas aquellas condiciones que deberán transponer los ordenamientos jurídicos nacionales en el ámbito del SECA. Y, en una labor de concreción en el ordenamiento jurídico español, la LAPS, sin perjuicio de la labor de concreción que requerirá el futuro Reglamento de desarrollo, deberá transponer las siguientes disposiciones:

El derecho a la información deberá modificarse en sintonía con las novedades del art. 5 de la citada propuesta, que vinculará a España a informar a los solicitantes mediante una "plantilla común, tan pronto como sea posible, y a más tardar en el momento de la presentación de su solicitud, de los beneficios de que pueden gozar y las obligaciones que deben cumplir en relación con las condiciones de acogida, incluidas las circunstancias en las que se puede restringir la concesión de condiciones materiales de acogida". Un nuevo y eficiente "mecanismo estandarizado" que no solo pretende asegurar que los solicitantes conozcan la información más relevante sobre las condiciones de acogida que le son propias, sino también que estas sean semejantes en todos los EEMM.

Además, el art. 36.1 f) LAPS únicamente prevé el acceso a la educación tras la concesión del derecho de asilo o de la protección subsidiaria, con independencia de la asistencia sanitaria y asistencia jurídica gratuita para los solicitantes, en cuyo caso, se extiende a la formalización de la solicitud y a toda la tramitación del procedimiento (art. 
16.2 LAPS). En este supuesto, la mencionada propuesta supone un avance trascendental, exigirá que se garantice el acceso a la educación de los menores a los 2 meses como máximo de haber presentado su solicitud de protección internacional. En efecto, el art. 36 LAPS deberá incluir como beneficiarios de este derecho a los solicitantes de protección internacional. Una disposición que garantizará que los derechos básicos no sean provistos en un lapso excesivamente amplio de tiempo máxime, en vista de la dilación en la resolución de las solicitudes-. Por ende, esta mejora evitará que los menores puedan encontrarse generalizadamente desescolarizados.

Asimismo, la LAPS ya otorgaba un alto nivel de protección para los menores de acompañados, disponiendo específicamente un Título $\mathrm{V}$ para individuos vulnerables y necesitados de protección internacional. ${ }^{644}$ En esta línea, el art. 25.1 b) LAPS prevé la tramitación de urgencia de las solicitudes formuladas por menores no acompañados y que, de acuerdo con el apartado $4^{\mathrm{o}}$, reduce los plazos a la mitad.

Sin embargo, esta reducción no ha supuesto una garantía eficaz de protección efectiva, en vista de los retrasos generalizados de las solicitudes de protección internacional. Por ello, el art. 23 de la propuesta deberá transponerse en la LAPS mediante la necesaria inclusión de la obligación de que estos reciban asistencia de inmediato -en un plazo menor a 5 días a partir del momento en que el menor no acompañado presente una solicitud de protección internacional-, teniendo también derecho a un tutor/representante que vele por el disfrute de sus derechos y el cumplimiento de sus obligaciones.

En relación con los permisos de trabajo, el art. 32 LAPS prevé la autorización "para trabajar en España en los términos que reglamentariamente se establezcan". Sin embargo, la falta de reglamento que desarrolle las condiciones y los plazos para esta concesión exige acometer qué aspectos de la normativa comunitaria deberán transponerse en el futuro reglamento de desarrollo.

La propuesta contempla un acceso más rápido al mercado laboral en el art. 15, disponiendo de un plazo de máximo 6 meses para conseguir un permiso de trabajo que

\footnotetext{
${ }^{644}$ De acuerdo con el Preámbulo de la LAPS "se profundiza en la mencionada línea garantista derivada del interés superior del menor y de la voluntad de evitar discriminaciones por razón de género o que afecten a personas con discapacidad, personas mayores y otras en situación de precariedad, pues alcanza a todos los ámbitos del sistema de asilo".
} 
deberá concretar la LAPS. Se excluyen los supuestos en los que el solicitante abuse del sistema de asilo, esto es, que la demora pueda atribuirse a este o se sigan los trámites del procedimiento acelerado -ya sea ante la consideración de la solicitud infundada o contradictoria o por ocultación o falsedad en la información o documentación presentada-.

Finalmente, una de las novedades más importantes que deberá preverse en la futura LAPS estriba en la elaboración de "planes de contingencia" que regula el art. 28 de la propuesta. Precisamente, esta obligación pretende garantizar que España esté en condiciones de proporcionar una capacidad de acogida adecuada en todo momento. Por ello, su adopción resultará crucial en aquellos momentos en los que se enfrente a un alto número de solicitantes de protección internacional, tal y como lleva acaeciendo en estos últimos años.

En consecuencia, este extremo deberá desarrollarse reglamentariamente de acuerdo con lo dispuesto en el apartado $2^{\circ}$ y $3^{\circ}$ de la propuesta, que señalan que estos planes se lleven a cabo empleando una plantilla previamente elaborada por la AAUE, debiendo no únicamente notificarse a la misma en el plazo de 6 meses desde el momento que entre en vigor de la presente propuesta, sino también actualizarse cada dos años. También, su remisión a la Agencia tras su cumplimentación, informando cuando sea activado al resto de EEMM, a la Comisión Europea y a la AAUE y evaluándose por parte de esta última. ${ }^{645}$

2.3. La falta de reglamento de la LAPS: abordando su necesidad y pertinencia.

Uno de los principales déficits que sufre la regulación del derecho de asilo en España es la falta de desarrollo reglamentario de la LAPS. Una previsión que, de conformidad con la Disposición Final Tercera, autorizaba al ejecutivo a desarrollar reglamentariamente "cuantas disposiciones de carácter reglamentario exija el desarrollo de la presente Ley" en el plazo de 6 meses desde la entrada en vigor de la LAPS a finales del año 2009. Sin embargo, este retraso llega hasta el día de hoy, lo cual ha implicado la todavía vigencia del Real Decreto 203/1995, de 10 de febrero, correspondiente a la anterior reforma legislativa del sistema de asilo. Un hecho insólito

${ }^{645}$ De conformidad con el Capítulo 5 de la propuesta Reglamento de la Agencia. 
que, a juicio de García Vitoria, "ha roto esa sincronización" 2009-2019, exceptuando la adopción de un reglamento de desarrollo para cada Ley de asilo y prestándose a interpretaciones restrictivas de la Administración contrarias al espíritu de la LAPS y a la normativa reguladora del SECA.

Una carencia normativa que ha creado una elevada inseguridad jurídica y una generalizada discrecionalidad en la Administración, que ha tomado, con relativa asiduidad, decisiones arbitrarias y restrictivas de derechos, en concreto, en el seno del procedimiento fronterizo, de urgencia, la tramitación de visados por razones humanitarias tanto en embajadas y consulados como en territorio nacional. Es más, también han afectado gravemente a las condiciones de acogida, en esencia, en la tramitación de solicitudes de una forma diferenciada en caso de sujetos vulnerables, reagrupación familiar, asistencia jurídica.

El 8 de noviembre de 2013 se hizo público un Proyecto de Real Decreto por el que se aprueba el Reglamento de la Ley 12/2009, de 30 de octubre, reguladora del Derecho de Asilo y de la protección subsidiaria. ${ }^{647}$ Este fue presentado al Consejo General del Poder Judicial (CGPJ), que emitió su Informe el 31 de enero de $2014 .{ }^{648}$ Una primera iniciativa con miras a solventar esta ausencia de reglamento y sus carencias formales y materiales. Por un lado, el mencionado Proyecto únicamente transponía la Directiva de Reconocimiento, no incluía las relativas al procedimiento y acogida ${ }^{649} \mathrm{y}$, por otro, la concreción del concepto de "daños graves" a los efectos de concesión de protección subsidiaria o el de “agentes de persecución” preveía conceptos jurídicos indeterminados, fomentando una interpretación excesivamente restrictiva del alcance de la protección conferida por la LAPS y el SECA. ${ }^{650}$

Lejos de quedaste ahí, el CGPJ también fue muy crítico con la adopción de la previsión del carácter vinculante de la "personalización" de la persecución (art. 6.3 del

\footnotetext{
${ }^{646}$ GARCÍA VITORIA I., "Una década sin Reglamento de Asilo en España. Obstáculos e interpretaciones divergentes", Anuario CIDOB de la Inmigración 2018, p. 118.

${ }^{647}$ Disponible en el siguiente enlace: http://www.intermigra.info/archivos/impresos/RGtoASILObrr1.pdf

${ }^{648}$ Consejo General del Poder Judicial, Informe al Proyecto de Real Decreto por el que se aprueba el Reglamento de la Ley 12/2009, de 30 de octubre, reguladora del Derecho de Asilo y de la protección subsidiaria, de 31 de enero de 2014.

${ }^{649} \mathrm{Sin}$ perjuicio de que desarrollara aspectos concretos del procedimiento de asilo y protección subsidiaria de la LAPS, esto es, la presentación de la solicitud; la admisión a trámite; determinación del Estado miembro responsable del examen de la solicitud conforme al sistema Dublín; la instrucción; finalización; y los efectos de la resolución adoptada.

${ }^{650}$ Ídem, pp. 15-17.
} 
Proyecto) y con la propia definición de delitos graves de las causas de exclusión del estatuto de refugiado o protección subsidiaria de los arts. 8.2.b) y 11.b) LAPS. En este caso, la gravedad fue sustituida por la consideración de "especialmente reprobables" (art. 9.3 del Proyecto). Una extensión que, lejos de desarrollar la LAPS, restringiría las garantías de los solicitantes y aumentaría la tasa de exclusión, razón por la que el CGPJ sugirió retirar estas especificaciones por considerar que no tenían cabida alguna en el mandato del reglamento. ${ }^{651}$

Efectivamente, a pesar de que el objetivo de este proyecto era "dar seguridad jurídica al procedimiento administrativo de tramitación y, en su caso, concesión de protección internacional con una regulación detallada, tanto del procedimiento aplicable como del estatuto de protección", ${ }^{652}$ este se quedó a medio camino. Únicamente transponía la Directiva de Reconocimiento, sin abordar aspectos esenciales que afectaban al propio procedimiento de protección internacional y, principalmente, a las condiciones de acogida. Su finalidad de pormenorizar las disposiciones de la LAPS implicaron una restricción excesiva del ámbito material y personal excediendo de su cometido ante la falta de concreción de la LAPS y en virtud de la aplicación de disposiciones contrarias a esta y a la normativa europea e internacional.

En octubre de 2016, a pesar de que el Ministerio del Interior puso de manifesto su notorio avance, puesto que únicamente faltaba el dictamen del Consejo de Estado. Sin embargo, este todavía no ha sido aprobado. En consecuencia, el intento de Proyecto de Reglamento puede considerarse un intento fracasado por dotar al ordenamiento jurídico español de contundentes respuestas necesarias a una Ley incapaz de prever, con un alto nivel de detalle, todas aquellas cuestiones que regula una extensísima normativa comunitaria. Así, no solo ha superado el mandato constitucional de desarrollar la LAPS, adoptando conceptos que restringen las garantías de este derecho, sino que la carencia de reglamento durante el periodo 2009-2019 ha supuesto que las directivas de Reconocimiento, Procedimiento y de Acogida de esta segunda fase del SECA no hayan

\footnotetext{
${ }^{651}$ Ídem, pp. 17-21.

${ }^{652}$ MORGADES GIL S., "La política de asilo en España en el contexto europeo: cambios recientes y perspectivas de desarrollo normativo", Anuario de la Inmigración en España 2014, edición 2015, pp. 241-242.
} 
sido transpuestas en el plazo establecido. ${ }^{653}$

En esta línea, debe recordarse que el 25 de julio de 2019, la Comisión Europea decidió enviar dictamenes motivados a España y Bulgaria, así como una carta de notificación formal a Portugal ante la falta de transposición de la práctica totalidad de la Directiva 2013/32/CE sobre los procedimientos de asilo. ${ }^{654}$ Instó a la urgencia de la reforma con miras a detener la creciente disparidad con respecto a las legislaciones de otros EEMM que si cumplieron con los plazos previstos para la transposición de las mencionadas directivas. Estos efectos desventajosos han generado que la jurisprudencia remita al contenido de estas directivas comunitarias para colmar los frecuentes vacíos en la LAPS a los que hemos hecho referencia con anterioridad.

Cabe aducir a que esta falta de aprobación ha sido, en parte, la causante de la incapacidad para otorgar respuestas a los múltiples y muy variados escenarios a los que se lleva enfrentando este derecho en los últimos tiempos. Compartimos el criterio de Montilla Martos y García Vitoria, que ahondaron en la idea de la continuidad de un régimen en el que sigue "sin estructurarse de una forma adecuada el derecho de asilo en España". 655

Buena prueba de esta situación desfavorable parece reflejarse en los últimos tres informes del DP ${ }^{656}$ así como en el último informe de la CEAR. Este último señalando la gran dificultad para proceder a la reagrupación familiar a la par que ahondó en los perjuicios que suponen los siguientes aspectos:

- la formulación de solicitudes en misiones diplomáticas,

- la aplicación de los plazos en el procedimiento en frontera y en los CIE,

\footnotetext{
${ }^{653}$ La Directiva de Reconocimiento debió trasponerse 21 de diciembre 2013, la de procedimiento el 20 de julio 2015 -con excepción del art. 31.3 a 5 que debía trasponerse el 20 de julio de 2018 - y la de acogida el 20 de julio de 2015.

${ }^{654}$ Comisión Europea, "July infringements package: key decisions", 25 de Julio de 2019. Disponible en: https://europa.eu/rapid/press-release_INF-19-4251_en.htm

${ }^{655}$ MONTILLA MARTOS, J.A., GARCÍA VITORIA, I, RODRÍGUEZ CANDELA, J. L., "Política y normativa española sobre inmigración y asilo". ¿Bajo perfil o inacción?", Anuario de la Inmigración en España 2017, 2018, p. 110.

${ }^{656}$ El correspondiente al año 2016 destacó que la falta de desarrollo reglamentario dificultaba "gravemente la gestión de las obligaciones de protección internacional suscritas por España" (DDP, Informe anual 2016...,ob. cit.,p. 54). En cambio, los dos últimos informes reflejan que la ausencia de desarrollo reglamentario afecta a los solicitantes de protección internacional y, de manera muy pronunciada, a la reagrupación familiar, impidiendo la tramitación de procedimientos de reagrupación familiar en los supuestos de los cónyuges de los refugiados con sus respectivas parejas (DDP, Informe anual $2017 \ldots$ ob. cit., p. 244; DDP, Informe anual 2018... ob. cit., p. 282).
} 
- los criterios en relación con las razones humanitarias o;

- la falta de desarrollo del art. 46 LAPS relativo a las personas en situación de especial vulnerabilidad, que requieren de un tratamiento diferenciado inexistente en la actualidad.

Ahora bien, revelador fue que esta ya no instara urgentemente al desarrollo reglamentario, sino a la necesidad de actualización de la LAPS mediante la transposición de las directivas de esta segunda fase del SECA.

En el presente, consideramos que este Proyecto de Reglamento no solo debería retrasarse hasta la plena aprobación del "paquete de reforma del SECA", sino que convendría que la LAPS fuera reformulada en su totalidad, en vista de los cambios muy trascendentales que prevé la normativa comunitaria en su tercera fase y que, en resumidas palabras, transformarán jurídicamente estos instrumentos en reglamentos comunitarios -a excepción de la acogida-.

Este efecto directo en el ordenamiento jurídico nacional solventará la falta de adaptación de la legislación nacional a la normativa reguladora del SECA, razón por la cual este proyecto de Reglamento resulta papel mojado en estos momentos. Por ende, aunque compartimos la opinión de García Vitoria sobre la necesidad de aprobar un nuevo Reglamento de Asilo que contemple en toda su extensión condiciones de acogida y reduzca así la discrecionalidad administrativa, ${ }^{657}$ a nuestro juicio, este debería reformularse en su totalidad tras la entrada en vigor de la tercera fase del SECA. Máxime cuando impondrá una innovadora "arquitectura jurídica" con miras a solventar los problemas estructurales que se ha venido enfrentando el ordenamiento jurídico español en la última década.

En definitiva, será necesario dotar de un nuevo enfoque al futuro Reglamento que desarrolle la LAPS, teniendo presente que ya no requiere armonizar y dotar de coherencia a las disposiciones de la Ley. Este deberá superar las contradicciones y lagunas jurídicas de una legislación nacional desfasada, criterios sobre los que se asentó el proyecto -y que fueron durante la pasada década tan demandados-, sino de una labor de concreción y desarrollo de las disposiciones de la LAPS.

Por todo ello, la aprobación de este Proyecto de Reglamento debería condicionarse a la entrada en vigor del nuevo SECA y tras ella, a la reforma de la LAPS. De esta forma,

${ }^{657}$ GARCÍA VITORIA I., Una década sin Reglamento de Asilo en España... ob.cit., p. 127. 
el futuro Reglamento deberá especificar las disposiciones de la propuesta de reforma del SECA y, en mayor medida, las condiciones de acogida, aprovechando el mayor margen nacional de esta última. Solo de este modo se dotará al ordenamiento jurídico español de una elevada seguridad jurídica en el ámbito del derecho a la protección internacional.

\section{Luces y sombras del procedimiento fronterizo de Ceuta y Melilla y su}

\section{impacto en el derecho a la protección internacional.}

\subsection{Estado actual de la cuestión.}

La gestión de los flujos migratorios en las fronteras de Ceuta y Melilla lleva desde el año 2015 obstaculizando la entrada de nacionales de terceros países, entre los que se incluyen aquellos en clara necesidad de protección. A ello le antece la creación en el año 2014 de dos oficinas de asilo en estos emplazamientos, momento coincidente con la primera solicitud de asilo en un puesto fronterizo terrestre en la historia de España, lo cual motivó que el ACNUR reconociera su considerable avance en términos políticos. Ello, a pesar de que, a efectos prácticos, esta creación no comportara más que una infraestructura mínima para cumplir "lo ya dispuesto en la ley hace 20 años, medios que ya debieran haber existido y cuya ausencia podría haber afectado a la confianza en el sistema de asilo". 658

Ahora bien, mientras que la Oficina adscrita a Melilla estuvo plenamente operativa tras su inauguración en marzo de 2015 -en uno de los momentos más críticos por su coincidencia con la crisis migratoria que azotaba a Europa-, este no fue el caso de la Oficina de Protección Internacional (OPI) de la frontera del Tarajal en Ceuta, la cual se dilató más de 4 años en abrir sus puertas, en concreto, el pasado 1 de septiembre de 2019 . $^{659}$

\footnotetext{
${ }^{658}$ ACNUR, ACNUR da la bienvenida a la creación de oficinas de asilo en puestos fronterizos de Ceuta y Melilla, 6 de noviembre de 2014 (https:/www.acnur.org/noticias/press/2014/11/5b0c1a5669/acnur-dala-bienvenida-a-la-creacion-de-oficinas-de-asilo-en-puestos-fronterizos-de-ceuta-y-melilla.html). Para un análisis sobre esta cuestión, remitimos al estudio de Vallés Ferrero. VALLÉS FERRERO M., “¿Vallas al asilo? Apuntes sobre el sistema de protección internacional en España", Anuario CIDOB de la Inmigración 2015-2016, 2016, p. 239.

${ }^{659}$ Hasta el momento, operaba el CETI de Ceuta, un dispositivo de "primera acogida provisional" destinado a ofrecer servicios y prestaciones sociales básicas a inmigrantes y solicitantes de asilo que llegaban a esta ciudad. En el plano doctrinal, ha sido el CETI de Melilla el que ha sido ampliamente abordado, precisamente, por el volumen de inmigrantes que acogió hasta 2014, que prácticamente cuadriplicó su capacidad. Sobre el particular, remitimos a los siguientes estudios: BONDANINI, F. B., La
} 
En 2015, España todavía no experimentaba esta crisis con la suficiente intensidad. En el puesto fronterizo de Beni-Enzar (Melilla), alrededor de 1.000 refugiados sirios solicitaron protección internacional - principal nacionalidad que estaba llegando a Europa huyendo del conflicto en ese país, una cifra muy baja si tenemos en cuenta las altísimas solicitudes que estaban manejando otros EEMM-. La importancia no radicaba tanto en el número total de entradas, sino en el cambio de tendencia de las mismas y que originó que los solicitantes comenzaran a demandar asilo de manera regular en este punto fronterizo. ${ }^{660}$ De hecho, el $80 \%$ de estos nacionales sirios que solicitaron protección internacional en España lo hicieron en Melilla, datos que contrastan con el último informe anual de la CEAR, que refleja como hasta el 30 de agosto de 2019, en el puesto fronterizo Ceutí de El Tarajal no había sido registrada ninguna solicitud de asilo, pese a su apertura hacía más de 4 años. ${ }^{661}$

Todo ello denota que, a pesar de que estas dos ciudades autónomas constituyen la vía de entrada principal de los nacionales de terceros países a España, han registrado un número muy bajo $-\mathrm{o}$ prácticamente nulo en el caso de Ceuta- de solicitudes de protección internacional.

Precisamente, las vías de entrada en estos puestos fronterizos han sido diseñadas como "diques de contención" en detrimento de articular una vía segura y efectiva para solicitar protección internacional. Un hecho que se produce tras los rechazos generalizados de ciudadanos marroquíes -a quienes denegaron la entrada en España por estas fronteras a un total de 223.500, un 97.0\% del total de los rechazos en España-, ${ }^{662}$

construcción identitaria de los migrantes en las fronteras de Europa. El caso del Centro de Estancia Temporal de Inmigrantes de Melilla, Tesis doctoral. Universidad de Granada, 2014; CALVO MARISCAL L., Situación actual del asilo y refugio en la frontera sur de España: la práctica en las ciudades de Ceuta y Melilla, en: SÁNCHEZ FRÍAS, A., DE ASÍS PEÑA DÍAZ F., SALINAS DE FRÍAS A., MARTÍNEZ PÉREZ E.J., La Unión Europea y la protección de los derechos fundamentales, 2018, pp. 233-246; LÓPEZ-SALA, A., "La inmigración irregular en Ceuta y Melilla en 2014: prácticas de control y debate público", Anuario CIDOB de la Inmigración, 2015, pp. 169-192.

660 ACNUR, Country update, Spain, octubre-noviembre de 2015. Accesible en: https://data2.unhcr.org/en/situations/mediterranean/location/5226.

${ }^{661}$ Al día siguiente, un grupo de migrantes saltó la valla con la finalidad de solicitar protección internacional en Ceuta, momento en el cual comenzó a tramitarrse el procedimiento a través de la vía de urgencia. Por su parte, cabe recordar que tampoco habían sido frecuentes las peticiones de asilo en Melilla, aunque considerablemente mayor, donde un total de 1.742 personas habían solicitaron asilo en este puesto fronterizo hasta octubre de 2019, una cifra que ascendía a 2.800 durante todo 2018. CEAR, La odisea de solicitar asilo en fronteras españolas, 15 de octubre de 2019. Disponible en: https://www.cear.es/solicitar-asilo-en-fronteras/

${ }^{662}$ Durante todo el año de 2018, la tasa de denegaciones de entrada en los puestos fronterizos legales de entrada a nuestro país a través de Beni Enzar (Melilla) y El Tarajal (Ceuta) se situó en un 97,5\% y supuso 
al igual que por toda una serie de actuaciones como las "devoluciones en caliente", la militarización de estas fronteras o las grandes vallas a las que comenzaron a colocarse concertinas en el año 2005. Contextos que, indudablemente, fomentaron que los nacionales de terceros países, en su mayoría ciudadanos subsaharianos, en su intento por llegar legalmente a Ceuta y Melilla, apostaran por entrar de forma irregular por vía marítima o terrestre como solución más viable o factible para llegar a territorio nacional. Una situación que exige la adopción de contundentes respuestas que afronten esta crítica falta de acceso a las fronteras españolas.

Una de las más recientes respuestas por parte del Ministerio del Interior fue la retirada de las concertinas de la valla de Ceuta en diciembre de $2019 .{ }^{663}$ Un proceso que, sin embargo, necesitará de la intervención de otros organismos y agencias para avanzar en estas reformas con miras a dotar al sistema español de la asistencia necesaria para prevenir estos conflictos y otorgar mayores garantías en la protección de los derechos humanos.

La próxima e inminente tercera fase del SECA arrojará ciertas luces a esta obstaculización. Además, la asistencia de agencias especializadas en control fronterizo como la GEFC o la futura AAUE facilitarán la adopción de políticas más garantes con la protección de los derechos humanos, supliendo la prioridad de los EEMM por reducir, externalizar los costes y mantener las "amenazas" fuera de las fronteras de la UE, priorizándose incluso a la protección de los solicitantes de asilo. ${ }^{664}$

Sin embargo, estas aún dependen del control que se efectúa desde el otro lado de la frontera. Los controles de la policía marroquí no siempre han sido los esperados. A

un flujo de entrada residual en nuestro país, representando el 5\% del total de entradas por vía aérea, marítima y terrestre de las cifras totales de entrada.

DP, Mecanismo Nacional de Prevención. Informe Anual 2018, Supervisión de lugares de privación de libertad en España, de acuerdo con el Protocolo facultativo a la Convención de las Naciones Unidas contra la tortura y otros tratos o penas crueles, inhumanos o degradantes (OPCAT), Madrid 2019, p. 29; Eurostat, Aplicación de las estadísticas de la legislación de inmigración, junio de 2019, p. 11. Accesible en: https://ec.europa.eu/eurostat/statistics-explained/pdfscache/37449.pdf

${ }^{663}$ Estas están siendo sustituidas por elementos menos lesivos como el refuerzo de la vigilancia para evitar la entrada irregular de inmigrantes. Recordemos que el 14 de octubre de 2019, la Secretaría de Estado de Seguridad firmaba la resolución para coronar las vallas con estos sistemas inhumanos. A finales de enero de 2020, el Ministerio del Interior inició los trámites para la retirada de la tercera de las vayas fronterizas situada en Melilla. Véase La Razón, "Interior retira la tercera valla forteriza de Melilla que instaló el Gobierno de Zapatero", 21 de enero de 2020.

${ }^{664}$ Una postura que fue abordada en el siguiente estudio: TRIANDAFYLLIDOU, A., "Nuevos retos para Europa: migración, seguridad y derechos de ciudadanía", Revista CIDOB d'Afers Internacionals, n 69, Fundació CIDOB, mayo 2005, p. 47. 
modo de ejemplo, en julio de 2018, un grupo de aproximadamente ochocientos migrantes saltaron las vallas fronterizas de Ceuta, de los cuales casi 600 ingresaron finalmente en la ciudad que fueron rechazados por "teóricamente" en suelo español.

En este caso, el Ministerio del Interior catalogó estos puntos como "conceptos operativos de frontera" con la finalidad de excluir la aplicación de la normativa del SECA y respaldar la legalidad de las devoluciones en caliente. ${ }^{665}$ Esta medida fue igualmente complementada con la reactivación del acuerdo de readmisión firmado en 1992 con Marruecos. ${ }^{666}$ Un acuerdo que únicamente había sido empleado en casos excepcionales y para un número muy limitado de migrantes y que facilitó "devoluciones express" - o en menos de 24 horas- de 116 migrantes subsaharianos desde Ceuta a Marruecos, lo cual provocó que ONG como un "Partido Por un Mundo Más Justo" iniciara una denuncia por infracción del derecho de la UE ante la CE. ${ }^{667}$ Igualmente, el Colegio de Abogados de Melilla presentó una queja ante el DP -si bien este ya había comenzado a investigar de oficio la devolución de estos migrantes a Marruecos con anterioridad-. ${ }^{668}$ Lejos de quedarse aquí, estas prácticas fueron reprobadas por el

\footnotetext{
${ }^{665}$ Con la reforma de la Ley Orgánica de Extranjería (LOEx) en 2015 pasaron a denominarse "elementos de contención fronterizos". Sobre esta cuestión, remitimos a: MARTÍNEZ ESCAMILLA, M., SÁNCHEZ TOMÁS, J. M., "Devoluciones ilegales en la Frontera Sur. Análisis jurídico de las denominadas devoluciones en caliente", febrero de 2015, p. 24 y ss. Disponible en: https://eprints.ucm.es/28256/.

Véase igualmente el informe jurídico "rechazos en frontera": ¿frontera sin derechos?. Análisis de la disposición adicional décima de la Ley Orgánica 4/2000, de 11 de enero, sobre derechos y libertades de los extranjeros en España y su integración social, introducida por la Ley Orgánica 4/2015, de 30 de marzo, de protección de la seguridad ciudadana 13 de abril de 2015. Disponible en: https://eprints.ucm.es/29379/1/Informe\%20rechazo\%20en\%20frontera.pdf

${ }^{666}$ Acuerdo entre el Reino de España y Marruecos, firmado en Madrid el 13 de febrero de 1992. Publicado en el BOE núm. 100, de 25 de abril de 1992, y su entrada en vigor definitiva se produjo el 21 de octubre de 2012 (BOE núm. 299, de 13 de diciembre de 2012).

${ }^{667}$ Para un análisis sobre este Acuerdo, véase: BURGOS GOYE M. C., La errática política migratoria española de la inmigración africana en las ciudades autónomas de Ceuta y Melilla, Revista de derecho migratorio y extranjería, $\mathrm{n}^{\circ} .37,2014$, p. 311 y ss. Además, como denunció Partido Por un Mundo Más Justo, el 23 de agosto de 2018, fueron devueltas 114 personas desde Ceuta a Marruecos el día y el 21 de octubre de ese mismo año, 55 desde Melilla. El País, "El Gobierno desempolva un convenio de hace 26 años para expulsar a 116 migrantes", 24 de agosto de 2018. Partido Por un Mundo Más Justo, Denuncia a la Comisión Europea. Disponible en: https://www.porunmundomasjusto.es/wpcontent/uploads/2018/05/Denuncia-Comisi\%C3\%B3n-Europea-Devoluciones-en-Caliente.pdf.

${ }^{668}$ Cuarto Poder, "El Defensor del Pueblo investiga la devolución en caliente a Marruecos de 114 personas en Agosto", 22 de octubre de 2018; Consejo General de la Abogacía Española, El Colegio de Abogados de Melilla presenta una queja al Defensor del Pueblo por la devolución de migrantes a Marruecos, 5 noviembre 2018.
} 
Representante Especial del Consejo de Europa sobre Migración y Refugiados ${ }^{669}$ y por la FRA $^{670}$-en ámbito europeo- así como por el ACNUR $^{671}$ y el Subcomité para la Prevención de la Tortura de Naciones Unidas ${ }^{672}$-en ámbito internacional-. Todos ellos mostraron su profunda preocupación por los retrocesos que llevaron a cabo diferentes Estados, incluido España en el trato dispensado a los migrantes.

Estas acciones justifican no solo que el número de entradas de migrantes por estas fronteras hayan sido residuales, sino también, las solicitudes de protección internacional presentadas. Hasta finales de 2018, en Melilla tan solo fueron presentadas un total de 3.475 solicitudes de protección internacional, situándose como el $4^{\circ}$ lugar por número de solicitudes, por detrás de Madrid, Barcelona y Valencia. ${ }^{673}$

Dicho esto, a continuación abordaremos un estudio sobre el derecho a la protección internacional en Ceuta y Melilla. En particular, analizaremos cómo las "devoluciones en caliente" en estos puestos fronterizos han obstaculizado el acceso efectivo al procedimiento de protección internacional. Seguidamente, acometeremos uno de los debates más actuales sobre el derecho o no que tienen los solicitantes de trasladarse a la península, finalizando profundizando sobre los principales problemas a los que se enfrenta este colectivo en los Centros de Estancia Temporal de Inmigrantes (CETI) y CIE.

${ }^{669}$ Consejo de Europa, Informe de la misión de investigación del Embajador Tomáš Boček, Representante Especial del Secretario General sobre migración y refugiados a España, 18-24 de marzo de 2018, $\quad(\mathrm{SG} / \operatorname{Inf}(2018) 25), \quad 3$ de septiembre de 2018. Disponible en: https://search.coe.int/cm/Pages/result_details.aspx?ObjectId=09000016808d2c31\#_ftn6

${ }^{670}$ FRA, "Los retrocesos de los migrantes son una preocupación creciente en algunos Estados miembros", 26 de marzo de 2018. Disponible en: https://fra.europa.eu/en/news/2018/migrant-pushbacks-growingconcern-some-member-states

${ }^{671}$ ACNUR, "Viajes desesperados. Refugiados y migrantes que llegan a Europa y a las fronteras de Europa", enero-agosto 2018, p. 7. Accesible (en versión inglesa) en: https://bit.ly/2Cyt9LU

${ }^{672}$ Por su parte, en octubre de 2017, el Subcomité para la Prevención de la Tortura de Naciones Unidas también instó a que el Gobierno de España no efectuara devoluciones sumarias sin un examen previo e individualizado que determinase el potencial riesgo de tortura al retornar a su país de origen. Una conclusión a la que llegaron tras una visita a España los días 15 y el 16 de octubre para la supervisión del Protocolo Facultativo de la Convención contra la Tortura y Otros Tratos o Penas Crueles, Inhumanos o Degradantes. Nota de prensa de la Oficina del Alto Comisionado de las Naciones Unidas de 31 de octubre de 2017.

Disponible

en: https://www.ohchr.org/sp/NewsEvents/Pages/DisplayNews.aspx?NewsID=22329\&LangID=S

${ }^{673}$ Ministerio de Interior, Dirección General de Política Interior, Avance de datos de protección internacional, aplicación del Reglamento de Dublín y reconocimiento del estatuto de apátrida Datos provisionales acumulados entre el 1 de enero y el 31 de diciembre de 2018. Disponible en: http://www.interior.gob.es/documents/642012/9639326/Avance_datos_proteccion_internacional_2018_1 2_31.pdf/e5eb6d13-6552-4269-b4b0-33f87a0ccf1c 
3.2. Régimen jurídico de las "devoluciones en caliente" y su conflicto con el derecho a la protección internacional.

Desde 1999, las autoridades policiales han llevado a cabo rechazos y devoluciones sumarias de distintas categorías de nacionales de terceros países que llegan a la frontera de España con Marruecos. Acciones que han sido efectuadas sin ningún tipo de identificación ni valoración individualizada sobre las circunstancias personales específicas, imposibilitando a aquellos sujetos que se encuentran en territorio español acceder al procedimiento de protección internacional en España.

Además, no se han publicitado cifras concretas sobre el número de nacionales de terceros países que han sido devueltos "en caliente", salvo el cambio de tendencia en los últimos años. En 2018, el Gobierno de Pedro Sánchez publicó que, durante ese año se produjeron un total de 658 devoluciones en caliente en Ceuta y Melilla, 51 más que el año anterior. ${ }^{674}$

Aún con todo, estas prácticas llevan siendo reprobadas por parte del DP desde el año 2005, como así consta en su Informe del año 2006 cuando mencionó lo siguiente: “La práctica de devolver de manera expeditiva a todas las personas cuando ya se encuentran en territorio español, sin cumplir con las formalidades de la ley, deja sin posibilidad alguna de solicitar protección a las personas que puedan desear acogerse a ese derecho". 675

Con la entrada en vigor de la LOPSC el 1 de abril de 2015, estas devoluciones fueron legalizadas. Ello, con independencia de que se produjeran con anterioridad al margen de la ley, cuando la Guardia Civil empleaba estas prácticas como parte de sus funciones de vigilancia y salvaguarda de la integridad de las fronteras españolas, adoptando enfoques distintos dependiendo si los migrantes entraban por puntos fronterizos autorizados o, si por el contrario, eran detectados entrando de forma irregular. ${ }^{676}$ De esta forma, se

\footnotetext{
${ }^{674}$ El País, Los Gobiernos de PP y PSOE ocultaron las devoluciones en caliente desde 1999, 1 de noviembre de 2019. (https://elpais.com/politica/2019/10/31/actualidad/1572547222_256861.html); El Diario, El Gobierno central cifra por primera vez las devoluciones en caliente: 658 en 2018 en las fronteras de Ceuta y Melilla, 13 de enero de 2019. (https://www.eldiario.es/andalucia/devolucionescaliente_0_854964586.html)

${ }^{675}$ Defensor del Pueblo, Informe anual 2005 y debates en las Cortes Generales, 2006, p. 294. Acceso al documento: https://www.defensordelpueblo.es/wp-content/uploads/2015/05/INFORME2005informe.pdf

${ }^{676}$ Mientras que en el año 2014, un total de 17.281 migrantes fueron devueltos, hasta mayo de 2015, la cifra era de 3.446. Sobre el particular, véanse los siguientes informes: Informe conjunto, Ceuta y Melilla centros de selección a cielo abierto a las puertas de África, diciembre de 2015, p. 58
} 
instauró un modelo de coordinación y cooperación entre autoridades policiales sin precedentes, en el que la Guardia Civil ha colaborado eficazmente con otros cuerpos policiales, en concreto, la policía nacional, incluso con la gendarmería marroquí, con fructuosos resultados para el control migratorio de España en estas fronteras vulnerables, pero en serio detrimento en la protección de los derechos humanos y, en concreto, en el acceso efectivo para solicitar protección internacional.

El punto de inflexión se produjo en marzo de 2015, cuando el Gobierno adoptó una enmienda a la LOEx en la que introdujo la posibilidad de "rechazar en frontera" a los nacionales de terceros países que cruzaban la frontera ilegalmente. Una enmienda adoptada por la Ley Orgánica de Protección de la Seguridad Ciudadana (LOPSC), que previó un régimen especial para Ceuta y Melilla ${ }^{677}$ consistente en que, cuando un nacional de un tercer país se encuentre dentro del territorio fronterizo español, esto es, en la "línea fronteriza de la demarcación territorial" entre Marruecos y España, se podrá proceder a su rechazo dentro del territorio español mediante vías ad hoc controladas por autoridades policiales fronterizas "a fin de impedir su entrada ilegal en España".

Debe apuntarse que el procedimiento parlamentario de debate de los proyectos y proposiciones de ley resultó fradulento con base en el criterio jurisprudencial del TC, que reconoce no dar lugar a la aprobación de enmiendas que pretendan introducir contenidos materialmente desconectados del objeto de la iniciativa legislativa. ${ }^{678} \mathrm{De}$ hecho, este precepto motivó, que el 21 de mayo de 2015, los Grupos Parlamentarios Socialista, IU, ICV-EUiA, CHA: La Izquierda Plural, Unión Progreso y Democracia y

(http://www.migreurop.org/article2721.html?lang=fr). Datos que permiten constatar que durante 2014 y, al margen de la legalidad, las devoluciones en caliente eran más frecuentes que tras la entrada en vigor de la LOPSC. Sobre esta cuestión, veáse: Sacar del Laberinto, Informe Frontera Sur 2018, Servicio Jesuita al $\begin{array}{llllll}\text { Migrante, noviembre } & \text { de } & 2018, & \text { p. } & 18 . & \text { (https://sjme.org/wp- }\end{array}$ content/uploads/2018/11/Sacar_del_laberinto_SJM.pdf)

${ }^{677}$ A estos efectos, tanto la Disposición final primera de la LOPSC modifica la Disposición Adicional Décima de la LOEx en los siguientes términos:

1. Los extranjeros que sean detectados en la línea fronteriza de la demarcación territorial de Ceuta o Melilla mientras intentan superar los elementos de contención fronterizos para cruzar irregularmente la frontera podrán ser rechazados a fin de impedir su entrada ilegal en España.

2. En todo caso, el rechazo se realizará respetando la normativa internacional de derechos humanos y de protección internacional de la que España es parte.

3. Las solicitudes de protección internacional se formalizarán en los lugares habilitados al efecto en los pasos fronterizos y se tramitarán conforme a lo establecido en la normativa en materia de protección internacional.

${ }^{678}$ SSTC 119/2011, de 5 de julio de 2011; 136/2011, de 13 de septiembre de 2011. 
el Grupo Parlamentario Mixto interpusieran recurso de inconstitucionalidad, en el presente pendiente de resolución por el TC. ${ }^{679}$

Así, como recuerda Bilbao Ubillos, se acudió al expediente de presentación de una enmienda "en el último minuto -el día en que concluía el plazo de presentación de enmiendas- para introducir, de tapadillo, por la puerta de atrás, un régimen excepcional y eludir así los informes de los órganos con funciones consultivas". ${ }^{680}$ Por lo tanto, esta enmienda creó un procedimiento de devolución ad hoc que no sigue procedimiento alguno y no reúne las garantías de la LOEx. Además, supone una clara violación del principio de arbitrariedad (art. 9.3 CE), tutela judicial efectiva (art. 24.1 CE) -no se garantiza el acceso efectivo a los tribunales para ejercer los derechos de defensa-, así como el derecho a la revisión judicial (art. $106 \mathrm{CE}$ ).

En consecuencia, debemos reflejar que esta modalidad de devolución infringe tanto la legislación de extranjería como la de asilo por los siguientes argumentos:

- Por lo que respecta a la primera, por no constituir acto administrativo alguno ni adoptar un procedimiento administrativo que reúna todas las garantías que regula la legislación general sobre procedimiento administrativo de conformidad con el art. 20.2 LOEx.

- En relación con la segunda, porque esta "forma de devolución" imposibilita el acceso efectivo a solicitar asilo o protección subsidiaria, de forma que el Estado español es manifiestamente incapaz de adoptar medidas contundentes para impedir que aquellos sujetos que han sido perseguidos o han padecido daños graves puedan recibir protección, quebrantando así los arts. 13.4 CE y 14.2 LAPS.

En este sentido, recuérdese que no pasaron ni siquiera dos años de su aplicación cuando España fue condenada por el TEDH en la Sentencia N.D y N.T. c. España, de 2

\footnotetext{
${ }^{679}$ El mencionado recurso se centró en la desconexión existente entre las disposiciones de la LOPSC con la LOEx, tras la modificación de esta última a través de la enmienda introducida al articulado del Proyecto de Ley de la LOPSC. Dos leyes orgánicas que parten de diferentes preceptos constitucionales de manera que, como señala el recurso, la norma introducida no regula la actuación de las Fuerzas y cuerpos de seguridad del Estado (FCSE) en las fronteras españolas, sino que introduce un nuevo procedimiento administrativo por la vía de hecho, consistente en la expulsión de extranjeros desde las fronteras de Ceuta y Melilla. Recurso de inconstitucionalidad $\mathrm{n}^{\mathrm{o}}$ 3848-2015, contra los artículos 20, 35.1; 36.1, 2, 8, 22 y 23; 37.7 y la disposición final primera de la Ley Orgánica 4/2015, de 30 de marzo, de protección de la seguridad ciudadana y admitida a trámite el 21 de julio de 2015.

${ }^{680}$ BILBAO UBILLOS J.M., "La llamada Ley Mordaza: la Ley Orgánica 4/2015 de protección de la seguridad ciudadana, Teoría y Realidad Constitucional, $\mathrm{n}^{\circ}$ 36, 2015, p. 256.
} 
de octubre de $2017^{681}$ por estas devoluciones sumarias de Melilla a Marruecos, siguiendo toda una jurisprudencia muy asentada y que afectaba, en especial, a países como Italia y Grecia. ${ }^{682}$ Una primera condena a nuestro país que, pese a suponer "una batalla ganada en el Derecho internacional de los Derechos Humanos" como refleja Soler García ${ }^{683} \mathrm{y}$, al margen de la falta de transposición de las Directivas de Reconocimiento, procedimiento y acogida de la segunda fase del SECA, ha generado un marco jurídico incapaz de proporcionar respuestas contundentes y garantes con la protección internacional. El Gobierno - entonces presidido por Mariano Rajoy- solicitó con éxito la remisión a la Gran Sala de esta decisión condenatoria, negándose a enmendar el régimen jurídico fronterizo de Ceuta y Melilla de la LOPSC, cuya audiencia tuvo lugar el 26 de septiembre de 2018 y la decisión final está pendiente a fecha de redacción. Un acuciante fallo sobre la legalidad o no de estas medidas que será sumamente revelador, especialmente, si tenemos en cuenta que estas prácticas continuan acaeciendo en la actualidad. ${ }^{684}$

No menos trascendentales han sido las consecuencias de este primer pronunciamiento del TEDH. Ese mismo año, fueron formuladas otras dos demandas

\footnotetext{
${ }^{681}$ Sentencia N.D y N.T. c. España, de 2 de octubre de 2017 (Asuntos $n^{\text {o }} 8675 / 15$ y 8697/15). La mencionada Sentencia se refería a dos hombres subsaharianos, de Malí y Costa de Marfil, respectivamente, que alegaron haber sido expulsados de forma colectiva y sumaria del territorio español el 13 de agosto de 2014 como parte de un grupo de más de 75 personas. individuos. El 3 de octubre de 2017, el TEDH sostuvo por unanimidad que se había violado la prohibición a la expulsión colectiva del derecho a un recurso efectivo junto con dicha prohibición en virtud del art. 4 del Protocolo 4 y el art. 13 CEDH. El TEDH determinó que los recurrentes, $N D$ y $N T$, habían sido expulsados y enviados de regreso a Marruecos en contra de sus voluntades y que las medidas de expulsión se tomaron en ausencia de una decisión administrativa o judicial previa, ya que los recurrentes no fueron identificados por las autoridades españolas, concluyendo que estas medidas eran de naturaleza colectiva. Por último, señaló la existencia de un vínculo claro entre la expulsión colectiva a la que N.D. y N.T. fueron sometidos en la frontera de Melilla y el hecho de que, efectivamente, se les impidió tener acceso a presentar un recurso ante una autoridad competente con objeto de obtener una evaluación exhaustiva y rigurosa de sus solicitudes previamente a su expulsión.

${ }^{682}$ Véase sobre el particular las SSTEDH Sharifi y otros c. Italia y Grecia, de 21 de octubre de 2014; "Hirsi Jamaa y otros c. Italia"... ob. cit.

${ }^{683}$ SOLER GARCÍA C., La prohibición de las expulsiones colectivas de extranjeros en la jurisprudencia del Tribunal Europeo de Derechos Humanos: especial referencia al caso de España, Revista General de Derecho Europeo, no 45, 2018, p. 160.

${ }^{684}$ Debe recordarse que, a pesar de que el Gobierno de Pedro Sánchez se mostró abierto a examinar estas medidas, tal y como se hizo eco el diario El País, Interior advirtió de que "no habrá ningún cambio legislativo fuera de los acuerdos europeos sobre inmigración". Así, justificó tales devoluciones sobre la base de que estos inmigrantes no habían pisado suelo español y por ende, no podía hablarse de devoluciones en caliente. El País, "Interior justifica las 'devoluciones en caliente", 27 de julio de 2018. Disponible en: https://elpais.com/politica/2018/07/26/actualidad/1532631050_515643.html
} 
individuales contra España en los asuntos Doumbe Nnabuchi c. España ${ }^{685}$ y Balde y Abel c. España ${ }^{686}$-ambos pendientes de resolución y que afectan a las devoluciones de los dos puestos fronterizos de Melilla y Ceuta-. En similares líneas, invocan la violación de la prohibición de tortura del art. $3 \mathrm{CEDH}$ que reconoce una amplia jurisprudencia de este Tribunal. ${ }^{687}$

En el último asunto, se refiere a hechos producidos con posterioridad a la entrada en vigor de la Disposición adicional décima de la LOEx. Incuestionablemente, como reconoce Sánchez Tomás, despejará cualquier duda sobre la pretendida legalización de esas conductas que se han seguido defendiendo o tolerando, incluso tras el cambio de Gobierno. ${ }^{688}$ A su vez, estamos de acuerdo con Cuadrón Ambite cuando alude a que, pese a su necesidad para garantizar un control eficaz de las presiones migratorias, "no puede ser óbice para legalizar actuaciones o vías de hecho que per se, son ilegítimas". ${ }^{69}$

Cabe destacar que en febrero de 2019, el Comité de los Derechos del Niño (CDN) de la ONU concluyó que las devoluciones en caliente vulneran los derechos contenidos en los arts. 3, 20 y 37 de la Convención de los Derechos del Niño. Aludiendo a la situación en España, el Dictamen de este Comité apuntó que las autoridades españolas no

\footnotetext{
${ }^{685}$ En el caso Doumbe Nnabuchi c. España (asunto $n^{\circ}$. 19420/15) se aduce a la vulneración del art. 3 CEDH ante el empleo de una violencia desproporcionada por parte de los agentes de la Guardia Civil durante la inmovilización de estos sujetos durante las tareas de detención y posterior entrega a las autoridades marroquís. Como consta en el escrito de demanda, en un intento de acceder a Melilla superando el dispositivo fronterizo de control el 15 de octubre de 2015, el demandante pudo saltar dos de las tres vallas que separaban Marruecos con Melilla. En la última de ellas se mantuvo durante horas. Los agentes de la Guardia Civil proporcionaron una escalera para que este descendiera, aunque propinaron una serie de golpes con sus porras. Como consecuencia, este cayó al suelo desde una altura de dos metros quedando inconsciente y siendo inmediatamente entregado a los miembros del cuerpo auxiliar de fronteras marroquíes sin recibir asistencia sanitaria.

${ }^{686}$ Por su parte, en el asunto Balde y Abel c. España (asunto $n^{\circ}$. 20351/17) igualmente se hace mención del carácter colectivo de la expulsión, el riesgo de sufrir malos tratos al ser devueltos a Marruecos, la imposibilidad de solicitar protección internacional o protección por razones humanitarias así como el examen individual de los demandantes por parte de las autoridades españolas. A diferencia del anterior, este asunto es más complejo, precisamente, por haber sufrido malos tratos con carácter previo por parte de fuerzas auxiliares marroquíes y la dificultad de identificar si estos fueron o no continuados tras su detención en la frontera de Ceuta.

${ }^{687}$ Sobre el particular, remitimos a las SSTEDH: Hirsi Jamaa y otros c. Italia... op.. cit., Saadi c. Italia... ob. cit., Othman (Abu Qatada) c. Reino Unido, ob. cit., Salah Sheekh c. Países Bajos, de 11 de enero de 2007 (Asunto 1948/04); N.K. c. Francia, de 19 de diciembre de 2013 (Asunto n 7974/1).

${ }^{688}$ SANCHEZ TOMÁS J.M., "Las devoluciones calientes en el TEDH en el Tribunal Europeo de Derechos Humanos (STEDH, AS. N.D. y N.T. vs España), Revista Española de Derecho Europeo, $\mathrm{n}^{\circ}$ 65, Enero-Marzo 2018, pp. 101-135.

${ }^{689}$ CUADRÓN AMBITE S., Extranjeros en frontera. un estudio jurídico-práctico del reconocimiento, protección y límites del derecho de entrada en España, Dykinson, 2019, p. 189.
} 
identifican a los menores, no tienen en cuenta el interés superior del menor, no se proporcionan asistencia especial como menor de edad y se incumple manifiestamente la prohibición de tortura u otros tratos crueles, inhumanas o degradantes. Así, instó al Estado español a revisar la legislación que autoriza a procede con este tipo de devoluciones de los menores de edad. ${ }^{690}$

Por ende, las garantías previstas en la normativa reguladora del SECA han resultado papel mojado en la política española, procediendo a la devolución quasi automática de los individuos sin una comunicación previa con las autoridades nacionales encargadas de facilitar el acceso al procedimiento y garantizar las condiciones de acogida adecuadas.

Por lo que respecta al ordenamiento jurídico nacional, este está conformado por dos bloques normativos -el de extranjería y el asilo- que, como ha reflejado González García, no están lo suficientemente integrados. ${ }^{691}$ Esto no implica que el legislador deba optar por uno u otro, sino que debe respetar los compromisos internacionales asumidos. Así lo señalan Fernández Pérez o Sagarra Rias cuando se refieren a que el estándar mínimo exigible a los Estados conlleva una obligación de diligencia consistente en la prevención de los daños que han podido sufrir los migrantes ${ }^{692} \mathrm{y}$ que, en última instancia, podría dar lugar a que estos debieran recibir estatuto de protección internacional. No debemos obviar que los extranjeros son titulares de una serie de derechos y libertades en territorio español. Estos se traducen en que deben poder acceder a un procedimiento con todas las garantías antes señaladas, vinculando al legislador a respetar en núcleo esencial de cualquier derecho fundamental o libertad pública (art. 53.1 CE).

Estos rechazos en frontera o "devoluciones en caliente" que introdujo la LOPSC a través de una enmienda parlamentaria, a pesar de ser materia que incorporó la LOEx,

\footnotetext{
${ }^{690}$ Naciones Unidas, Convención sobre los Derechos del Niño, Dictamen aprobado por el Comité en relación con el Protocolo Facultativo de la Convención sobre los Derechos del Niño relativo a un procedimiento de comunicaciones respecto de la Comunicación $n^{\circ} 4 / 2016,1$ de febrero de 2019

${ }^{691}$ GONZÁLEZ GARCÍA J., "Expulsiones «en caliente», devoluciones y petición de asilo en Ceuta y Melilla”, Revista de Administración Pública, nº 196, Madrid, enero-abril, 2015, p. 312.

${ }^{692}$ FERNÁNDEZ PÉREZ, A., "La regulación de las devoluciones y expulsiones de extranjeros: la ilegalidad de las devoluciones de extranjeros efectuadas sin las debidas garantías", Diario La Ley, $\mathrm{n}^{\circ}$ 8382, 2014; SAGARRA TRIAS, E. "Devoluciones en caliente y la "Ley Orgánica de Protección de la Seguridad Ciudadana": ¿Medida sancionadora inconstitucional en España?", Revista vLex, nº130, 2015.
} 
estableció una devolución al margen de un procedimiento con todas las garantías. ${ }^{693} \mathrm{El}$ art. 58 de la mencionada Ley contempla la expulsión aparejada a la prohibición de entrada de hasta 5 años (apartado $1^{\circ}$ ), extendiéndose hasta un máximo de 10 años si el sujeto en cuestión supone "una amenaza grave para el orden público, la seguridad pública, la seguridad nacional o para la salud pública" (apartado $2^{\circ}$ ). Ahora bien, lo verdaderamente relevante a estos efectos es la regulación de la devolución "sin expediente" que prevé el apartado $3^{\circ}$, que no exige la tramitación de un expediente de expulsión, tanto si los expulsados incumplen la prohibición de entrada en territorio español (letra a) como "Los que pretendan entrar ilegalmente en el país" (letra b). Apartado que viene complementado por el apartado $1^{\circ}$ de la Disposición Adicional Décima de la LOEx, que faculta a rechazar a aquellos que crucen de forma irregular la frontera de Ceuta o Melilla.

Este "procedimiento especial" para los nacionales de terceros países que pretenden entrar a través de las fronteras de Ceuta y Melilla en territorio nacional, limita directamente con el pleno respeto de la normativa internacional de derechos humanos y de protección internacional que prevé el apartado $2^{\circ}$ de la Disposición Adicional Décima y el art. 58.4 LOEx. En concreto, concurre una alta probabilidad de contravenir el principio de no devolución en aquellos contextos en los que los nacionales de terceros países podrían obtener la condición de asilo o protección subsidiaria y, sin embargo, se les imposibilita su acceso al procedimiento. Así se refería Ruiz Sutil cuando reconocía que, "el mecanismo establecido por la LOEx no es capaz por sí mismo de discriminar cuando nos encontramos ante una persona susceptible de esta protección". 694

La cuestión relevante estriba en determinar en qué preciso momento puede considerarse que el sujeto ha formalizado una solicitud de protección internacional, pues marcará la prohibición de la devolución hasta que se adopte una decisión sobre su inadmisión. Una labor realmente compleja en virtud de las expresiones que adopta la mencionada Disposición como las siguientes: "que sean detectados en la línea

\footnotetext{
${ }^{693}$ La LOEx abarca tanto aquellas que regula tanto el procedimiento sancionador -aplicable a aquellos migrantes en situación irregular que se encuentran en territorio español y sobre los que se ha dictado una orden de expulsión- como un procedimiento de devolución rápido y eficiente -para aquellos interceptados en el momento que entren en territorio nacional-.

${ }^{694}$ RUIZ SUTIL C., El rechazo en frontera o la denominada "devolución en caliente" y su regulación en la LOEX, Revista española de derecho internacional, vol.. 68, nº 2, 2016, p. 334.
} 
fronteriza" o que "pretendan entrar ilegalmente en el país". Conceptos que no delimitan claramente este periodo de tiempo concreto.

Tampoco el Reglamento de Extranjería (REx), aprobado por el Real Decreto $557 / 2011,{ }^{695}$ proporciona una definición en este ámbito. Su art. 23.1 únicamente alude a extranjeros que "pretendan entrar irregularmente en el país" o "que sean interceptados en la frontera o en sus inmediaciones". Ahora bien, tal y como dispone el art. 23.2 REx, tras la interceptación de los migrantes en estos dos escenarios, serán las Fuerzas y cuerpos de seguridad del Estado (FCSE) las encargadas de conducirlos "con la mayor brevedad posible a la correspondiente Comisaría del Cuerpo Nacional de Policía, para que pueda procederse a su identificación y, en su caso, a su devolución”. El art. 23.3 REx recuerda los conocidos criterios principales de acogida como el "derecho a la asistencia jurídica, así como a la asistencia de intérprete, si no comprende o habla las lenguas oficiales que se utilicen", que deberán suministrarse de forma gratuita. ${ }^{696}$

Al margen del ordenamiento jurídico español, debemos traer a colación las condiciones que preverá el futuro SECA y que exigirán una labor más aquilatada en la determinación de la categoría del migrante en cuestión. Por ejemplo, la futura Directiva de Acogida dispondrá de contundentes mejoras de estos derechos, incluyendo la atención médica, el asesoramiento y asistencia psicosocial adecuados en caso de trauma, alojamiento, la alimentación, vestido, artículos sanitarios o la identificación de los solicitantes que precisen garantías procedimentales específicas conforme a sus Considerandos 31 y 41 y art. 21.

También la profunda reforma del futuro Reglamento Eurodac, en especial, en lo relativo a las transferencias de datos a terceros países a efectos de retorno y su interoperabilidad con el resto de SSII europeos ayudarán a la consecución de estos objetivos, creando herramientas más perfeccionadas que aseguren la rápida identificación de aquellas personas en clara necesitad de protección internacional y su

\footnotetext{
${ }^{695}$ Real Decreto 557/2011, de 20 de abril, por el que se aprueba el Reglamento de la Ley Orgánica 4/2000, sobre derechos y libertades de los extranjeros en España y su integración social, tras su reforma por Ley Orgánica 2/2009. «BOE» núm. 103, de 30/04/2011.

${ }^{696}$ De conformidad con los parámetros fijados por la jurisprudencia del TEDH, que impone que se realice por personal especializado en la gestión y tramitación de entrevistas de posibles solicitantes de protección internacional, asistencia jurídica gratuita e intérprete si no conocieran la lengua del Estado en el que se encuentre. También exige una evaluación individual sobre la situación personal y la posibilidad de que estos soliciten asilo si así lo requieren. Las SSTEDH M.S.S. c. Bélgica y Grecia, ob. cit., M. A. c. Chipre, de 23 de julio de 2013 (Asunto ${ }^{\circ}$ 41872), Gebremedhin c. Francia, de 16 de abril de 2007 (Asunto ${ }^{\circ}$ 25389/05).
} 
diferenciación con aquellas que no la requieren.

En definitiva, aun cuando el migrante haya sido detectado en la línea fronteriza o pretenda su entrada ilegal en nuestro país, deberá procederse a su identificación conforme al REx y, en su caso, a la posterior devolución. Durante esta fase necesariamente debería tipificarse la obligación de una identificación inequívoca que faculte o no a la iniciación de un procedimiento de protección internacional o retorno, así como a la provisión de los medios de acogida generales y específicos. Unas garantías que, en virtud del avance de las nuevas tecnologías, no comprometerán, en exceso, la tan "demandada" eficiencia necesaria para proceder a las devoluciones sumarias de migrantes irregulares. Ello, teniendo en consideración que, como regula la letra b) del art. 23.6, no podrá ejecutarse la resolución de devolución, quedando en suspenso hasta su inadmisión a trámite o la resolución final, en sintonía con el art. 19 LAPS. Es más, la mera admisión a trámite de esta solicitud "llevará aparejada la autorización de entrada y la permanencia provisional del solicitante”.

3.3. La libertad de circulación de los solicitantes de protección internacional desde Ceuta y Melilla.

A principios de la pasada década, la Secretaría de Estado de Seguridad del Ministerio del Interior adoptó un criterio restrictivo que tenía como objeto limitar los derechos tras la admisión a trámite de una solicitud de protección internacional. Consideró que la normativa le dejaba espacio para limitarla, a pesar de que estos habían formalizado su solicitud y contaban con el permiso de estancia regular, por lo que circunscribió el acceso a la península de los solicitantes de protección internacional en Ceuta y Melilla. De esta forma, se adoptó una restricción especial -que no era aplicable a personas que formalizaban su solicitud en otras partes de España- y que partió de la base de las condiciones particulares de estas ciudades autónomas en el Acuerdo Schengen, según el cual "España se reserva el derecho a mantener los controles documentales en las conexiones entre las ciudades autónomas y la península”.

En consecuencia, la justificación de esta medida radicó en la complejidad del procedimiento de protección internacional, el cual requería una exhaustiva identificación del nacional del tercer país. El art. 19.1 LAPS y el art. 11 del Reglamento de Asilo 203/1995 disponen que esta solicitud supone la autorización de permanencia provisional en España, pero no implica que los solicitantes tengan plena libertad de 
circulación y puedan trasladarse libremente a la península. Ello, pese a que cuando la solicitud de protección internacional ha sido admitida, estos se encuentran en una situación administrativa de regularidad y como tal deberían ostentar el derecho a circular libremente por todo el territotio nacional, como así reconoce el art. 5 LOEx. ${ }^{697}$ De la misma forma parece confirmarlo el art. 18.2 d) LAPS, que establece la obligación de comunicar los cambios de domicilio. Una afirmación que tácitamente reconoce esta libertad aunque igualmente la condiciona a la efectiva concesión del derecho de asilo o de protección subsidiaria [art. 36.1. h)].

Por lo pronto, esta limitación a la libertad de circulación del art. 19 CE vulnera el mandato constitucional del art. 13.1 por imperativo del 10.2 de nuestra Carta Magna, que dispone que “(...) las Leyes y tratados que regulan la circulación de extranjeros en España deben respetar el grado de libertad que reconocen los arts. 12 y 13 del Pacto internacional a todas las personas que se hallan legalmente en el territorio del Estado y las medidas que repercuten sobre la libre circulación de las personas deben fundarse en una Ley, y aplicarla en forma razonada y razonable ${ }^{698}$ Es más, el DP recomendó en 2013 que se permitiera el acceso a la península tanto a los solicitantes de protección internacional si la solicitud estaba admitida a trámite como a los residentes en los CETI de Ceuta y Melilla, ${ }^{699}$ reiterándose en su Informe de 2016. Esta vez, instó a una aclaración necesaria sobre la limitación de la libertad de circulación que pretendía adoptarse en el nuevo reglamento de asilo. ${ }^{700}$ Un supuesto que, al restringir a un

\footnotetext{
697 “1. Los extranjeros que se hallen en España (...) tendrán derecho a circular libremente por el territorio español y a elegir su residencia sin más limitaciones que las establecidas con carácter general por los tratados y las Leyes, o las acordadas por la autoridad judicial, con carácter cautelar o en un proceso penal o de extradición en el que el extranjero tenga la condición de imputado, víctima o testigo, o como consecuencia de sentencia firme.

2. No obstante, podrán establecerse medidas limitativas especificas (...) excepcionalmente por razones de seguridad pública, de forma individualizada, motivada y en proporción a las circunstancias que concurran en cada caso, por resolución del Ministro del Interior, adoptada de acuerdo con las garantías jurídicas del procedimiento sancionador previsto en la Ley. Las medidas limitativas, cuya duración no excederá del tiempo imprescindible y proporcional a la persistencia de las circunstancias que justificaron la adopción de las mismas, podrán consistir en la presentación periódica ante las autoridades competentes y en el alejamiento de fronteras o núcleos de población concretados singularmente."

${ }^{698}$ SSTC 94/1993, de 22 de febrero, FJ 4 ; 116/1993, de 29 de marzo, FJ 2; 24/2000, de 31 de enero, FJ $4^{\circ}$.

${ }^{699}$ Recomendación del DP que fue rechazada. Recomendación 13/2013, de 1 de marzo, formulada a la Comisaría General de Extranjería y Fronteras del Ministerio del Interior, para que se permita el acceso a la península a los solicitantes de protección internacional con solicitud admitida a trámite, residentes en los CETI de Ceuta y Melilla (12218762).

${ }^{700}$ DP, Informe anual 2016..., ob. cit.,p. 248.
} 
derecho fundamental debería contemplarse en la reforma de la LOEx bajo supuestos muy tasados, proporcionados y limitados en el tiempo con objeto de subsanar la elevada inseguridad jurídica que sufren los solicitantes de protección internacional que se encuentran en estos emplazamientos.

Además, estas restricciones se han agravado tras los discordantes fallos -aun en sentencias estimatorias- que han pronunciado los Tribunales Superiores de Justicia (TSJ) de Andalucía y Madrid en los últimos años. Por ejemplo, el TSJ de Andalucía reconoció en uno de sus primeros pronunciamientos que este derecho se encontraba condicionado por la notificación del domicilio en los casos en los que ha sido admitida a trámite la solicitud de asilo de manera -por ende, solo se trata de un derecho definitivo una vez se obtiene la condición de asilado-. ${ }^{701}$ Asimismo, declaró nulas las medidas de retención en Ceuta de las personas solicitantes de asilo admitidas a trámite. ${ }^{702}$

En este mismo sentido ha fallado el TSJ de Madrid. Sus últimos pronunciamientos han ido anulando las reiteradas resoluciones del Comisario General de Fronteras, reconociendo que no existía impedimento para que un solicitante de asilo con documentación en vigor pudiera trasladarse a la Península. Asimismo, diferencia entre la mera aplicación de controles de identidad a los que podían verse sometidos desde Ceuta o Melilla a la península de cualquier otra limitación de mayor calado, como el derecho a circular libremente por todo el territorio español. ${ }^{703}$ En particular, es la STJM $n^{o}$ 9/2018, de 17 de enero de 2019 la que recoge el criterio que ha venido manifestado este Tribunal. Concretamente, su FJ $4^{\circ}$ especifica las dos consecuencias o efectos de la admisión a trámite; la primera de ellas “ (...) es que dicha persona no podrá ser objeto de retorno, devolución o expulsión hasta que se resuelva su solicitud (art.19.1), quedando el interesado obligado a comunicar su cambio de domicilio [18.2.d)], lo que implica que está facultado para realizar dicho cambio" y la segunda; que "(...) tal situación de regularidad en territorio español permitía su traslado (...) desde Ceuta a la Península (...)".

Por lo tanto, se produce un criterio manifiestamente discordante entre las resoluciones Comisaría General de Fronteras de Ceuta y Melilla-que prevé el art. 4.2

\footnotetext{
${ }^{701}$ STSJA n $^{\mathrm{o}} 1177 / 2010$, de 25 octubre de 2010, FJ $4^{\mathrm{o}}$.

${ }^{702}$ STSJA, no 437/2010, de 28 de octubre del 2010; STSJA n ${ }^{\circ}$ 525/2010, de 10 de febrero del 2011; STJA $\mathrm{n}^{\circ} 527 / 2010$, de 13 de enero de 2011.

${ }^{703}$ SSTSJM n 490/2015, de 11 de mayo de 2015; n 667/2017, de 29 septiembre de 2017; STSJ de Madrid, 817/2018, de 20 de octubre de 2018; STSJ de Madrid, 841/2018, de 5 de noviembre de 2018
} 
del Reglamento de la LOEx y la Orden INT/558/2019, de 16 de mayo de 2019- ${ }^{704}$ y los TSJ de Andalucía y Madrid; estos últimos reiterando que no existe impedimento alguno para que los mencionados solicitantes puedan trasladarse al territorio español peninsular.

La CEAR, defensora a ultranza de la supresión de las restricciones a la libertad de circulación de las personas solicitantes de protección internacional subrayó en su Informe de 2018 los criterios discrecionales y discriminatorios para los traslados a la Península. ${ }^{705}$ Advirtió del nulo impacto que han tenido las sentencias y las recomendaciones del DP, haciendo mención de que "la Comisaría General de Extranjería y Fronteras mantiene su criterio por el que las personas solicitantes de asilo que se encuentran en las ciudades autónomas no tienen derecho a viajar a la Península aunque sus solicitudes hayan sido admitidas a trámite". ${ }^{706}$

Este incumplimiento revela las limitaciones del control judicial cuando este se plantea en términos muy concretos en relación con los actos administrativos en cuestión. Las declaraciones por parte de los tribunales constatan que estas decisiones administrativas resultan contrarias a la libre circulación de los solicitantes de protección internacional.

Por fortuna, el TS fijará jurisprudencia sobre si los solicitantes de protección internacional en situación regular tienen o no derecho a cambiar su domicilio en España $\mathrm{y}$, en definitiva, si restringirá o no la libertad de circulación. El último asunto fue objeto de recurso de casación por parte de la Abogacía del Estado, en el que fue invocado interés casacional, teniendo en consideración el amplísimo número de solicitantes de protección internacional que pueden verse afectados por una decisión de este tipo. ${ }^{707}$

Este reconocimiento sobre el derecho a trasladarse libremente por el territorio nacional peninsular de los solicitantes de protección internacional debidamente

\footnotetext{
${ }^{704}$ Esta describe en su Anexo IV la estructura orgánica y funciones actualizadas de los Servicios Centrales y Periféricos de la Dirección General de la Policía, en el que se relacionan los puestos fronterizos y sus correspondientes puertos en Ceuta y Melilla, todos ellos gestionados por la policía nacional y adscritos a las Comisarías sitas en estas ciudades. La Orden INT/558/2019, de 16 de mayo, por la que se modifica la Orden INT/28/2013, de 18 de enero, por la que se desarrolla la estructura orgánica y funciones de los servicios centrales y periféricos de la Dirección General de la Policía. Publicado en el BOE de 23 de mayo de 2019, $\mathrm{n}^{\circ} 123$.

${ }^{705}$ CEAR, Informe 2018: Las personas refugiadas en España y Europa, p. 82 y 136.

706 Ídem, p. 84.

${ }^{707}$ Auto TS, de 1 de octubre de 2019.
} 
documentados por parte del TS garantizará la necesaria libertad de circulación de estos solicitantes. En efecto, merece una doble lectura:

- A favor de esta limitación, esta decisión administrativa parece responder a razones de eficacia procesal. Aunque estos deban comunicar cualquier cambio de domicilio, resultaría especialmente complejo la interposición de un recurso contra la desestimación de la solicitud de un organismo que se encuentra en Ceuta y Melilla -en este caso, requeriría la tramitación mediante procedimiento abreviado ante los Juzgados de lo Contencioso-Administrativo o los Juzgados Centrales de lo ContenciosoAdministrativo, de acuerdo con el art. 78.1 de la Ley 29/1998, de 13 de julio, reguladora de la jurisdicción contencioso-administrativa-. Ello, teniendo en cuenta las frecuentes limitaciones económicas que comúnmente disponen.

- Por el contrario, dos razones justificarían, a nuestro juicio, la supresión de esta medida:

a) Por un lado, la excesiva dilación en el tiempo de los procedimientos de protección internacional, cuestión especialmente compleja ante la sobrecarga que ha sufrido España en los últimos años o las dificultades probatorias, que han alejado el objetivo de proporcionar una respuesta en un plazo breve de tiempo. ${ }^{708}$ Por lo tanto, aún previéndose esta restricción en un futuro, sería manifiestamente desproporcionado mantener a un solicitante fuera de la península durante un periodo considerable e incluso indeterminado de tiempo.

b) Por otro lado, la permanencia de la totalidad de los solicitantes en estos puestos fronterizos no está acompasada con los medios de acogida apropiados, en especial, en Melilla, donde se han presentado la práctica totalidad de las solicitudes en estos puntos estos últimos años. El CETI de este emplazamiento cuadriplicaba su capacidad y sus condiciones tampoco han sido realmente aptas para albergar refugiados y realizar una gestión adecuada de esta audiencia al interesado. Así lo constató Francesca Friz-Prguda, representante en España del ACNUR en España. ${ }^{709}$

\footnotetext{
${ }^{708}$ No olvidemos que este fue uno de los reproches que subrayó la STEDH A. C. y otros contra España antes mencionada.

${ }^{709}$ Prácticamente la totalidad de los diarios nacionales se hicieron eco en el año 2016 de las afirmaciones de Francesca Friz-Prguda, cuando aludió a que estos Centros estaban diseñados para albergar hombres jóvenes trabajadores, no mujeres y niños traumatizados, instando a transformar estas instalaciones en "centros de identificación y derivación rápida" que permitiera servir de "canal" de asilo, ya sea mediante la protección de los más vulnerables o del retorno.
} 
Además, no cabe duda de los graves perjuicios que supone para aquellos más vulnerables la permanencia en estos CETI. Asociaciones como LGTBI Kifkif o Amlega han denunciado los que afectan a aquellos que pretentan solicitudes por motivos de orientación sexual o identidad de género en estos centros. Específicamente, apuntaban a que una mayoría de estos individuos "sufren agresiones lgtbifóbicas mayores incluso de las vividas en sus países de procedencia y que han motivado su huida". 710

Tampoco han sido espacios apropiados para albergar a menores no acompañados, a pesar de las ayudas que fueron otorgadas durante los últimos años tanto mediante el Real Decreto 1340/2018 $8^{711}$-en el que la Administración General del Estado otorgó 40 millones de euros a Ceuta y Melilla para atender las necesidades de estos sujetos especialmente vulnerables o la concesión directa de subvenciones a las Ciudades de Ceuta y Melilla para labores de mantenimiento-, como por la mejora de la atención prestada en los centros de acogida de menores extranjeros -recordemos que el Consejo de Ministros aprobó el 30 de octubre de 2019 una partida de 6 millones y medio para este fin-. ${ }^{712}$

En resumen, la solución debería radicar en un fiel equilibrio entre ambas cuestiones, debiendo concretarse supuestos tasados y específicos en los que impera la obligación de un solicitante de permanecer en Ceuta y Melilla durante la determinación del estatuto de protección internacional y que excede, efectivamente, de las razones de seguridad pública que prevé el art. 5 LOEx.

Consiguientemente, deberían incluirse, sin exhaustividad alguna, los siguientes supuestos: cuando la identificación de un sujeto resulte especialmente compleja, este tenga varias identidades, se negase manifiestamente a colaborar con las autoridades

\footnotetext{
${ }^{710}$ KIFKIF y AMLEGA consideran favorable que el Supremo sienta jurisprudencia sobre la salida de personas solicitantes de asilo en Ceuta y Melilla, 1 de octubre de 2019. Disponible en: https://kifkif.info/kifkif-y-amlega-consideran-favorable-que-el-tribunal-supremo-acepte-sentarjurisprudencia-sobre-la-salida-de-personas-solicitantes-de-proteccion-internacional-en-ceuta-y-melilla/

${ }^{711}$ Real Decreto 1340/2018, de 29 de octubre, por el que se aprueban las normas especiales reguladoras de las subvenciones que se otorgarán en régimen de concesión directa a las comunidades autónomas y Ciudades de Ceuta y Melilla para la atención a los menores extranjeros no acompañados acogidos en el año 2018. «BOE» núm. 262, de 30 de octubre de 2018, pp. 104923 a 104928.

${ }^{712} \mathrm{La}$ cuantía de estas subvenciones fue destinada al mantenimiento y mejora de los servicios de atención inmediata y acogida, financiando asimismo los servicios de información, asistencia social y formación de los menores extranjeros no acompañados durante el periodo comprendido entre el periodo del 1 de enero de 2019 hasta el 31 de diciembre de 2019. Consejo de Ministros, Subvenciones a Ceuta y Melilla para atender a menores extranjeros no acompañados, 31 de octubre de 2019. Disponible en: https://www.lamoncloa.gob.es/consejodeministros/Paginas/enlaces/311019enlace-menores.aspx
} 
españolas o en virtud del interés superior de un menor no acompañado y que requiera su permanencia en dependencias especiales.

De forma simultánea, deberían trasladarse sin mayores dilaciones a personas pertenecientes a grupos vulnerables, en concreto, a aquellos que solicitan asilo por orientación sexual o identidad de género o menores no acompañados con la mayor brevedad. Precisamente, se reducirían las grandes diferencias en los derechos de acogida que origina el punto geográfico nacional en el que se presenta la solicitud de protección internacional y que tuvo como efecto, como bien señaló Vallés Ferrero, "la drástica disminución de solicitudes de asilo en las ciudades autónomas que solo se ha revertido tras la apertura de las oficinas de asilo". ${ }^{713}$

3.4. La situación de los Centros de Estancia Temporal de Inmigrantes y de los Centros de Internamiento de Extranjeros en Ceuta y Melilla.

La última de las cuestiones sobre las que profundizaremos son las condiciones que afectan a los solicitantes de protección internacional en su permanencia en los CETI y CIE sitos en Ceuta y Melilla. Una infraestructura permanente que, desde 2018, el Gobierno español presidido por Pedro Sánchez ha "ampliado" mediante el establecimiento de nuevos centros capaces de gestionar eficazmente los flujos en frontera nacional y llevar a cabo la identificación de las vulnerabilidades de las personas en los primeros días de llegada, agilizando los trámites de identificación de migrantes. Para tal fin, se han creado instalaciones específicas para emergencias y derivaciones tras el repunte que ha sufrido España en los últimos 3 años. Estos se denominan Centros de Recepción o Acogida Temporal de Extranjeros (Centros de Acogida Temporal de Extranjeros, CATE) y Centros de Recepción y Referencia de Emergencia (Centros de Acogida de Emergencia y Derivación, CAED).

Al margen de estos centros temporales, los CETI comenzaron a operar en Melilla 1999 y, un año más tarde el de Ceuta. Estos han contado con diferencias operativas importantes. Mientras que el primero cuenta con aproximadamente 900 personas, el segundo apenas ha albergado más de 512. Aun así, en ambos confluye su adecuación como medida de control y supervisión de los flujos migratorios, que permite albergar a diferentes categorías de nacionales de terceros países. Además, junto a los Centros de

${ }^{713}$ VALLÉS FERRERO M., “¿Vallas al asilo? ... ob. cit., p. 242 
Acogida de Refugiados (CAR), han integrado la "red pública de centros de migraciones", conforme dispone el art. 294.2 REx.

En estos CETI se ha vinculado de forma evidente el fenómeno migratorio hacia una dinámica excluyente, que "ayuda a la transformación del migrante en una persona no bienvenida y en exceso. ${ }^{714} \mathrm{Se}$ ha catalogado a amplios grupos de migrantes -incluyendo a los solicitantes de protección internacional- bajo el estigma de la migración irregular, asociado a efectos sumamente nocivos como la expulsión o la devolución. Es más, aquellos que permanecen en estos centros son generalmente considerados como "no deseados" y su privación de libertad durante la espera de una decisión no está exenta de profundos menoscabos en sus derechos y libertades.

En este sentido, los migrantes que permanecen en los CETI de Ceuta y Melilla a la espera de su traslado a la península tienen acceso a servicios básicos y, a diferencia de los CIE, no están privados de libertad. Ahora bien, las condiciones de acogida no han respetado un estándar mínimo, tal y como constató el Representante especial del Secretario General del Consejo de Europa para la Migración y los Refugiados en su visita a España. ${ }^{715}$

Una de las principales razones por las que debería garantizarse la libre circulación de los solicitantes de protección internacional desde los CETI de Ceuta y Melilla estriba en esta cuestión. La desproporcional carga que sufren estos centros justifica la tesis que hemos sostenido consistente en una prelación de traslado hacia la península, donde estas infraestructuras y las condiciones de acogida resultan más apropiadas. Por esta razón, debería priorizarse el traslado de aquellos cuyas condiciones de acogida mejorarían considerablemente, como los solicitantes por motivos de orientación sexual o identidad de género o sujetos especialmente vulnerables como los menores no acompañados. Progresivamente, esta traslado debería emplearse para aquellos otros solicitantes de protección internacional. De nuevo, el problema radicará en identificar y discernir a los solicitantes de protección internacional entre las distintas categorías de migrantes para proceder a tal fin, complejidad que, como ya hemos abordado, tratará de solventar el futuro Reglamento de Eurodac y su interoperabilidad con los distintos SSII europeos.

\footnotetext{
${ }^{714}$ BONDANINI, F. B., La construcción identitaria de los migrantes ..., ob. cit., p. 195.

${ }^{715}$ Pese a confirmar las fuertes mejorías que disponen los solicitantes de protección internacional en la España peninsular, no es menos cierto que sugirió profundas mejoras en las condiciones de vida, educación, asistencia sanitaria, idiomas y cursos de formación. Consejo de Europa, Informe de la misión de investigación del Embajador Tomáš Boček..., ob. cit. Párrafos 3.1 y 3.2.
} 
Ahora bien, España no solamente cuenta con CETI para gestionar los flujos migratorios y de asilo en Ceuta y Melilla, los CIE se rigen por el RD 162/2014, de 14 de marzo, el cual el TS anuló parcialmente en la Sentencia 807/2015, de 10 de febrero de 2015 por contrariar la Directiva de retorno y la LOEx. ${ }^{716}$

Estos se definen en el art. 62 bis LOEx como "establecimientos públicos de carácter no penitenciario el ingreso y estancia en los mismos tendrá únicamente finalidad preventiva y cautelar, salvaguardando los derechos y libertades reconocidos en el ordenamiento jurídico, sin más limitaciones que las establecidas a su libertad ambulatoria, conforme al contenido y finalidad de la medida judicial de ingreso acordada (...)".

Estos centros han servido para garantizar la efectividad de una orden de expulsión, en especial, de los migrantes rescatados en el mar. Tanto es así, que si esta no puede ejecutarse dentro del plazo de 72 horas, los CIE han servido como infraestructura frecuente para su detención y garantizar la ulterior expulsión. Una práctica que no ha tenido los resultados esperados puesto que solo una mínima parte de los migrantes han sido devueltos a sus países de origen en virtud de la falta de acuerdos bilaterales de España con la mayor parte de estos terceros estados. De tal forma que, cuando expira la duración máxima de detención de 60 días en el CIE (art. 21.2 del mencionado Reglamento), la persona queda en libertad con una orden de expulsión pendiente. ${ }^{717}$

Además, la permanencia en un CIE también ha facultado a solicitar protección internacional conforme regula el art. 25.2 LAPS. Dada la naturaleza del internamiento recordemos que estos se encuentran privados de libertad de circulación-, se exige su tramitación urgente, siguiendo los trámites de las solicitudes presentadas en puestos

\footnotetext{
${ }^{716}$ Sentencia 807/2015, de 10 de febrero de 2015 (nº recurso 373/2014). El TS anuló los arts. 4.3 párrafo 2; 16.2 párrafo K; el 21.3 y el 55.2 párrafo 1 del reglamento, aprobado por el Gobierno en marzo de 2014. Los dos primeros por contrariar el art. 17.2 de la Directiva europea 2008/115, que reconocía el derecho de las familias internadas en espera de expulsión a que se les facilite su alojamiento por separado que garantice un grado adecuado de intimidad. El tercero por ser contrario a la LOEx, que no permite un nuevo internamiento por cualquiera de las causas previstas en un mismo expediente de expulsión y el cuarto, que facultaba a proceder a registros personales incluso con desnudo integral ante dos supuestos diferenciados que deberían ser concurrentes, por razones de seguridad o ante la apreciación existencia de motivos fundados para considerar que el interno esconde objetos o sustancias prohibidas. Para un análisis sobre la mencionada sentencia, remitimos a: SÁNCHEZ VARELA J.L., la realidad de los centros de internamiento de extranjeros: situación de las personas internadas, XIV edición del Máster Universitario en Protección Internacional de los Derechos Humanos (Universidad de Alcalá), 2018, p. 40 y ss.

${ }^{717}$ Regulado por el Real Decreto 162/2014, de 14 de marzo, por el que se aprueba el reglamento de funcionamiento y régimen interior de los centros de internamiento de extranjeros.
} 
fronterizos (art. 21 LAPS). En todo caso, requiere la notificación de la resolución a la persona interesada en el plazo máximo de tan solo cuatro días desde su presentación.

No obstante, este breve periodo de tiempo ha sido en los últimos años generalmente transgredido, lo que ha provocado que transcurrido el mismo sin que fuese dictada resolución administrativa, fuera concedida una autorización provisional de entrada hasta que fuera dictada la correspondiente resolución, suspendiendo la devolución y permitiendo la libertad de circulación del extranjero. Esto ha generado el generalizado incumplimiento de la notificación del art. 21 LAPS como sucedió en el caso de un nacional argelino, que por resolución de la Delegación del Gobierno en Melilla de 30 de marzo de 2017, fue objeto de una orden de expulsión del territorio nacional con prohibición de entrada en España durante un período de 3 años. Este solicitó y recurrió ante la Audiencia Nacional (AN), exigiendo su salida del CIE y su derecho a la libre circulación por transgredir el plazo marcado por la LAPS. La AN reconoció el derecho del recurrente a que su petición fuera tramitada por el procedimiento ordinario una vez transcurrido el plazo de los cuatro días y, aparejado a ello, la autorización de entrada y obtención del permiso de la residencia provisional en España.

Sin embargo, esta sentencia fue recurrida en casación por parte de la Abogacía del Estado y nos proporciona uno de los primeros pronunciamientos del TS sobre esta cuestión. La STS 3410/2019, de 29 de octubre de $2019^{718}$ anuló la sentencia recurrida al considerar que la solicitud de asilo incurría en un fraude de ley por dos motivos:

1. porque la protección internacional no se solicitó en la frontera, al haber entrado ilegalmente en España y;

2. por cuanto no tenía ni una sola de las circunstancias para considerarse refugiado. Su único propósito era sobrepasar el plazo que legalmente tiene la Administración para responder a esta, eludiendo la expulsión del territorio nacional, su salida del CIE y gozar de la concesión automática de residencia provisional.

Esta acción fue considerada como un ejercicio antisocial del derecho. En efecto, este uso fraudulento de la ley, al que alude el TS, exige detener este tipo de conductas que perjudican gravemente la tramitación urgente. Esto requiere el procedimiento de protección internacional en aquellos casos en los que los sujetos se encuentran privados de libertad.

${ }^{718}$ STS 3410/2019, de 29 de octubre de 2019 (n $\mathrm{n}^{\circ}$ recurso 1059/2018). 
En el presente, muy variados y de diversa índole son los obstáculos que han experimentado los CIE y que evidencian su inadecuación para los solicitantes de protección internacional, entre los que conviene abordar los siguientes:

1. La CEAR denunció públicamente la falta de acceso a la asistencia jurídica para aquellas personas que llegan por mar, destacando los casos frecuentes en los que la policía se ha puesto en contacto con los abogados de extranjería para notificar la orden de expulsión. Esta notificación debería producirse en el momento en que estos llegan a España. Igualmente, los abogados suelen llevar a cabo las reuniones en entornos poco adecuados en los CIE, por ejemplo, de forma colectiva o en presencia de agentes de policía. $^{719}$

2. Seguidamente, no menos importante ha sido el duro reproche del DP sobre estos centros, ${ }^{720}$ los cuales no se han adecuado al sistema de registro de las solicitudes de asilo a la Ley de Procedimiento Administrativo Común de las Administraciones Públicas, aplicable en defecto de la LAPS -máxime cuando nada regula esta última sobre esta cuestión y que debió incorporarse, en toda su extensión, en su reglamento de desarrollo-. Se trata de un aspecto que, fuera de toda duda, condicionó el acceso efectivo al procedimiento de solicitud de protección internacional, vulnerando la normativa de asilo antes referida y poniendo en serio riesgo la vida e integridad de estas personas.

3. Finalmente, como recoge el Informe de la Comisión de Observación de Derechos Humanos (CODH) de julio de 2014, en las instalaciones de los CIE se producen "violaciones sistemáticas de los derechos humanos". ${ }^{721}$ Así lo constata un estudio elaborado por cuatro universidades españolas, que detalla cómo las condiciones de vida de los internos varían considerablemente dependiendo del CIE en el que se encuentren. Sus conclusiones resultaron reveladoras pues la práctica totalidad de ellos incumple

\footnotetext{
${ }^{719}$ Durante 2017, los ciudadanos marroquíes que anteriormente fueron devueltos a Marruecos dentro de las 72 horas también fueron detenidos en la CIE. CEAR, Refugiados y migrantes en España: Los muros invisibles tras la frontera sur, diciembre de 2017, p. 16.

${ }^{720}$ Sobre el análisis individualizado de estos CIE, remimitos a: DP, Informe anual 2018..., ob. cit., p. 225 y ss.

${ }^{721}$ Informe de la Comisión de Observación de Derechos Humanos (CODH). Vulneraciones de derechos humanos en la frontera sur - Melilla Julio de 2014. Disponible en: http://www.cvongd.org/ficheros/documentos/informe_melilladdhh_difusion.pdf
} 
alguno de los requisitos que establece la normativa vigente. ${ }^{722}$

Con vistas a detener esta intolerable situación, la Comisaría General de Extranjería y Fronteras impartió instrucciones a todos los CIE para solventar estos déficits y así ajustarse a lo dispuesto en la mencionada ley y preservar la protección requerida en estos casos. En opinión del Defensor, mientras no exista una regulación específica para registrar las solicitudes de protección internacional, la Comisaría General de Extranjería y Fronteras debe dictar instrucciones para que dichas solicitudes sean tramitadas de forma inmediata, registrando la solicitud y entregando copia de la misma al interno para que tengan garantizados los derechos que conlleva la condición de solicitante, entre otros, la suspensión de los procedimientos de expulsión y devolución. ${ }^{723}$

Ahora bien, en el seno del procedimiento internacional, el art. 29 LAPS dispone de las vías de recurso contra las decisiones que han sido adoptadas y, solamente contempla la tramitación de urgencia para la solicitud de suspensión del acto recurrido en vía contencioso-administrativa. De acuerdo con el art. 22 de dicha Ley, "en todo caso, durante la tramitación de la petición de reexamen y del recurso de reposición (...) así como en los supuestos en los que se solicite la adopción de las medidas a las que se refiere el apartado segundo de su artículo 29, la persona solicitante de asilo permanecerá en las dependencias habilitadas a tal efecto".

La excesiva dilación del procedimiento no es, como regla general, una causa imputable al solicitante. Sin embargo, este no solo debe permanecer en estas dependencias durante más tiempo del que debería, sino que tampoco dispone de una fecha cierta de resolución, aumentando su desconfianza en el procedimiento e incentivando el riesgo de fuga.

Igualmente, estos efectos se agravan en los supuestos en los que el solicitante decida interponer un recurso contra una decisión. El tiempo de internamiento se alargará

\footnotetext{
${ }^{722}$ Situación actual de los centros de internamiento de extranjeros en España y su adecuación al marco legal vigente. Informe elaborado por las Clínicas Jurídicas de ICADE (Universidad Pontificia Comillas), Per la Justícia Social (Universidad de Valencia), Dret al Dret (Universidad de Barcelona) y el Observatorio de Derechos Humanos (Universidad de Valladolid) para la Organización No Gubernamental "Pueblos Unidos-Servicio Jesuita a Migrantes", junio de 2015. Disponible en: https://www.icade.comillas.edu/images/Clinica_Juridica_ICADE/Informe_situacion_actual_CIE_junio_1 5.pdf

${ }^{723}$ Véase Comunicado de prensa del DP "Interior acepta la Recomendación del Defensor para adecuar el sistema de registro de las solicitudes de asilo en los cie a la normativa vigente", 17 de julio de 2018. Disponible en: https://www.defensordelpueblo.es/noticias/proteccion-internacional-cie-2/
} 
todavía más y este recurso carecerá de efecto suspensivo. Así, el art. 41.1 b) de la Directiva de procedimiento (o art. 43 b) de su propuesta de Reglamento) únicamente exceptúa el derecho a permanecer en caso de solicitudes posteriores "tras una resolución definitiva por la que se desestime esa solicitud por infundada", excepcionando en el art. 46.2 (art. 52.2 de la mencionada propuesta) la suspensión automática en aquellos supuestos en los que las solicitudes sean manifiestamente infundadas, inadmisibles, tras el rechazo de reapertura de la solicitud o en aquellos casos en los que los solicitantes procedan de un tercer país seguro europeo.

En definitiva, salvo estos casos excepcionales, la suspensión no será automática, deberá decidirse por parte del órgano jurisdiccional competente. El solicitante debe poder permanecer en territorio nacional hasta que se decida sobre dicha suspensión (art. 46.8 de la Directiva). Como novedad, la propuesta en el art. 54.4 exigirá mediante su efecto directo que el tribunal competente "examine la resolución denegatoria de la concesión de protección internacional en cuanto a hecho y a derecho".

Por lo tanto, debería establecerse un filtro previo a la suspensión de la devolución, siempre y cuando pueda determinarse si la pretensión puede ser sostenible, si está fundada, si las alegaciones son coherentes, verosímiles o suficientes o no contradice toda la información sobre la que se dispone del solicitante. Esta paralización de la devolución debería adoptarse si, razonablemente, se apreciase una de estas características, aunque no pueda constatarse su certeza. Y, al margen de la Directiva de Acogida, se otorgarán incentivos para garantizar que los solicitantes permanezcan a disposición de las autoridades a lo largo del procedimiento, permitiendo una evaluación efectiva de sus alegaciones, contribuyendo a la aplicación eficaz los procedimientos y requisitos de protección internacional y asegurando que estos no se den a la fuga y respeten las obligaciones que se les impone. ${ }^{724}$

Como novedad en este sentido, prevé un nuevo motivo de internamiento en el art. 8.3 c), por el que si al solicitante se le ha asignado un lugar de residencia concreto, pero este no haya cumplido esta obligación y persista el riesgo de fuga, podrá ser internado a los

\footnotetext{
${ }^{724}$ Por ejemplo, el art. 7.3 obliga a los EEMM a imponer, si es necesario, la obligación al solicitante de contactar con asiduidad con las autoridades cuando existan razones para considerar que existe riesgo de fuga. Este término se encuentra definido en el art. 2.10 de la mencionada propuesta como "la combinación de una acción deliberada para evitar los procedimientos de asilo aplicables y el hecho de no seguir estando disponible para las autoridades competentes, en particular por haber abandonado el solicitante el territorio en que tenga la obligación de estar presente".
} 
efectos de asegurar el cumplimiento de la obligación de residir en un determinado lugar. Por ello, supedita la libertad de circulación a la previa asignación de un lugar de residencia.

Por último, como señala el último Informe del DP, debería apostarse por la adopción de un "protocolo de intervención" que contemple todo un conjunto de medidas materiales y humanos, incluyendo las siguientes:

a) las infraestructuras idóneas, los medios humanos especializados necesarios y los criterios de colaboración y coordinación entre administraciones, organizaciones internacionales y ONG. ${ }^{725}$ Específicamente, un "catálogo de infraestructuras próximas a las localidades de llegada" para que puedan ser empleadas para este fin, toda vez que la diversidad de los puntos de acceso irregulares costeros y la imprevista intensidad de los flujos dificulta la creación de infraestructuras fijas. Un modelo provisional que, fuera de toda duda, reduciría la incidencia de los flujos en la seguridad del Estado español con objeto de dar una respuesta eficiente a los flujos migratorios y de asilo.

b) Los equipos multidisciplinares móviles bien formados que vayan más allá de los medios estrictamente policiales y sean capaces de tramitar solicitudes de protección internacional e identificar contextos de especial vulnerabilidad, como la detección de víctimas de trata o los procedimientos de determinación de la edad, para el caso de los menores no acompañados.

Apoyándonos en el criterio del DP, estos sistemas de organización y gestión deberían rediseñarse holísticamente, adoptando un nuevo "modelo de integración y coordinación de los distintos organismos involucrados" tanto de la Administración General del Estado como de las diversas comunidades autónomas y de los ayuntamientos. Asimismo, este modelo debería incluir la creación de un fondo presupuestario de dotación mixta (Estado-comunidades autónomas) con el que atender adecuadamente sus competencias en la materia, especialmente reforzado en las comunidades donde se registra una mayor presencia de personas extranjeras, tal y como defiende ESN Spain $2018 .^{726}$ En la actualidad, ya se contabilizan más de 1000 Centros de Emergencia de Acogida que asisten en aquellos contingentes a gran escala de migrantes irregulares en fronteras costeras. Este alto grado de cooperación y coordinación entre el Estado

\footnotetext{
${ }^{725}$ DP, Informe anual $2018 \ldots$ ob. cit., p. 12 y ss.

${ }^{726}$ Comisión Europea, Spain EMN Country Factsheet, 2018. Disponible en: https://ec.europa.eu/homeaffairs/sites/homeaffairs/files/2018_emn_country_factsheet_es_final_en.pdf
} 
español y las CCAA será elemento esencial para lograr una equilibrada distribución de solicitantes de protección internacional con condiciones adecuadas de acogida a lo largo de todo el territorio nacional.

\section{Recapitulaciones finales.}

España, a diferencia de las crisis de refugiados que tuvieron lugar entre los años 2014 a 2015, ha sufrido una crisis migratoria tardía, donde el número de llegadas de solicitantes de protección internacional en España lleva creciendo de forma exponencial desde el año 2017 hasta la actualidad. Esto prueba que nuestro país se ha convertido entre 2017 a 2019 en una de las rutas por antonomasia en la entrada de migrantes y refugiados en Europa. Una realidad que ha evidenciado manifiestas carencias de recursos humanos y administrativos necesarios para gestionar este volumen desproporcionado de solicitudes.

Ahora bien, como se ha señalado, estos altos flujos migratorios han sacado a la luz carencias estructurales en el sistema de acogida Español, aproximando las cuestiones de migración ampliamente considerada a la seguridad nacional y orden público. Al margen de la seguridad nacional, que actúa como excepción a la aplicación de la normativa comunitaria de asilo, tanto la CE y la LAPS desarrollan estos dos conceptos de seguridad, que afectan directa o indirectamente en la protección de este derecho constitucionalmente reconocido en el art. 13.4 CE.

Estos deben aplicarse a aquellos sujetos que no solo hagan peligrar la seguridad de España, sino que también desarrollen actuaciones incompatibles con el estatuto de protección internacional. Pues bien, mientras que el orden público en este ámbito exige su aplicación ante un peligro manifiesto, reiterado y concreto de un bien jurídico superior y que aporte razones convincentes que aseguren que esta restricción no comprometa en exceso la efectividad del sistema nacional de asilo y protección subsidiaria; la seguridad pública resulta más amplia y limita el alcance del derecho de asilo tras la emergencia de situaciones que incrementan el riesgo a la protección efectiva, tanto de los ciudadanos, los distintos bienes jurídicos en España, así como el mantenimiento del orden social.

Ambas vertientes de seguridad en el ámbito de la protección internacional requieren la apremiante apertura de España hacia nuevos y cada vez más perfeccionados 
organismos europeos especializados como la GEFC, cuya actividad centralizada en el control de las fronteras exteriores exigirá atribuir por parte de España la capacidad de actuación dentro de sus fronteras. Un hecho que no supone una cesión de soberanía a organismos especializados capaces de asumir competencias nacionales en la gestión de la migración y asilo. Estos tratan de instaurar un nuevo modelo de cooperación necesario para afrontar los distintos escenarios convulsos a los que se enfrenta España y que requiere el desarrollo de técnicas de coordinación fronteriza. Máxime teniendo en cuenta que las autoridades españolas no disponen de medios individuales suficientes para abordarlas eficazmente, de tal modo que, si así se produjera, propiciaría una excesiva flexibilización de sus compromisos internacionales.

Los nacionales de terceros países, en su mayoría ciudadanos subsaharianos, en su intento por llegar legalmente a puestos fronterizos de Ceuta y Melilla, han priorizado su entrada de forma irregular como solución más factible para llegar a territorio español. Ello teniendo presente que, las devoluciones en caliente generalizadas, la acción de la Guardia Civil o las detenciones en centros no penitenciarios han justificado no únicamente un reducido número de solicitudes de protección internacional en Melilla, sino su inexistencia en el caso de Ceuta hasta el 30 de agosto de 2019, con independencia de que estos puntos limitan directamente con la frontera marroquí y, en definitiva, con el continente africano.

Adentrándonos en las devoluciones en caliente, estas prácticas no son nuevas, llevan adoptándose desde 1999, a pesar de no proporcionarse cifras concretas sobre el número de nacionales de terceros países que han sido objeto de esta modalidad de devolución. Tras su legalización con la entrada en vigor de la LOPSC el 1 de abril de 2015 que, a su vez, enmendó la Disposición final primera de la LOEx, regulando el régimen especial para Ceuta y Melilla, introdujo un contenido materialmente desconectado del objeto de la iniciativa legislativa $-\mathrm{y}$ que el TC en una extensa jurisprudencia cataloga como fraude del procedimiento parlamentario-. Se prevé un procedimiento de devolución ad hoc que no solo no reúne las garantías de la LOEx, sino que trasgrede el principio de arbitrariedad (art. 9.3 CE), la tutela judicial efectiva (art. 24.1 CE) y el derecho a la revisión judicial (art. $106 \mathrm{CE}$ ).

Tras dos años en vigor, cabe recordar que, de una forma absolutamente previsible, el TEDH condenó a España por estas devoluciones, equiparables a expulsiones colectivas que impidieron el acceso efectivo a un recurso ante una autoridad competente que 
evaluara con exhaustividad y rigurosidad de sus solicitudes previamente a la expulsión. Pese a todo, la sentencia se encuentra recurrida ante la Gran Sala.

No obstante, debe criticarse la excesiva amplitud de la mencionada Disposición, que no concreta el preciso momento en que debe considerarse que un sujeto ha formalizado una solicitud de protección internacional, aludiendo a términos ambiguos como "que sean detectados en la línea fronteriza" o que "pretendan entrar ilegalmente en el país" y que marcará la prohibición de la devolución hasta que se adopte una decisión sobre su inadmisión.

- Por lo que respecta a la restricción a la libertad de circulación de los solicitantes de protección internacional desde Ceuta y Melilla, esta medida -a todas luces, discriminatoria- parece justificarse tanto por la previsión del Acuerdo Schengen, que reserva a España el derecho a mantener los controles documentales como por la especial complejidad del procedimiento de protección internacional. Sin embargo, reveladores han sido los fallos que han ido pronunciando -en repetidas ocasiones- los TSJ, reiterando que no existe impedimento alguno para que los mencionados solicitantes puedan trasladarse al territorio español peninsular.

- Finalmente, refiriéndonos a la situación que experimentan los solicitantes de protección internacional en los CETI y CIE en Ceuta y Melilla, estos centros han sido complementados con la creación otros nuevos capaces de gestionar eficazmente los altos flujos a los que lleva enfrentándose estas dos ciudades autónomas en los últimos dos años.

Por lo que respecta a los CETI, aun con sustanciales diferencias entre cada uno de ellos, consideramos que los solicitantes de protección internacional no deberían permanecer en ellos por las siguientes razones:

1. Estos deben convivir con distintas categorías de migrantes, están expuestos a ataques y agresiones y lo que es peor, puede aumentar el riesgo a su devolución, en concreto, si no se disponen de parámetros claros de identificación entre las diferentes categorías de extranjeros.

2. Estos no reciben las condiciones óptimas de vida, educación o asistencia sanitaria -incluida psicológica- que demanda este grupo vulnerable y que, por el contrario, si disponen generalmente los solicitantes de protección internacional en la España peninsular. 
En cambio, en referencia a los CIE, la Administración debe ser capaz de notificar la resolución al solicitante de protección internacional en el plazo máximo de tan solo cuatro días desde su presentación (art. 21), en especial, ante el riesgo que supone la permanencia para el solicitante en estos centros. Recordemos que este no solo se encuentra privado de libertad, sino que propicia que los extranjeros que deban ser expulsados soliciten protección internacional para aprovecharse de los efectos de este procedimiento, prácticamente opuestos. Un fraude de ley reconocido por la STS 3410/2019, de 29 de octubre de 2019 y que se justifica por las siguientes diferencias: como regla general, estos pueden estar detenidos en estos centros hasta un máximo de 60 días, mientras que si solicitan asilo, tan solo 4. Además, en el supuesto de que haya transcurrido este plazo - como así ha resultado con asiduidad-, sin que haya sido dictada resolución administrativa, tendrían derecho a una autorización provisional de entrada hasta que se dicte la correspondiente resolución, la suspensión de la devolución y su libertad de circulación. 


\section{CONCLUSIONES FINALES}

En el presente estudio hemos acometido un exhaustivo análisis sobre los distintos escenarios recientes que han comprometido la seguridad nacional y europea. Concretamente, partimos de las crisis migratorias y de refugiados que se iniciaron en 2014 y afectaron al régimen de garantías del derecho a la protección internacional que regula el marco jurídico del SECA y las legislaciones nacionales. Así, abordamos dos de los retos más destacados a los que se enfrentará este sistema europeo a corto y medio plazo: sus excepciones por razones de seguridad nacional y, en directa conexión con esta, su impacto en el derecho a la protección de datos.

Por todo ello, debemos concluir con las siguientes consideraciones finales:

1. A pesar de una interesante dimensión de seguridad cada vez más europeizada que pretende incorporar la futura reforma integral del SECA, no conviene obviar que todas estas medidas encaminadas a mantener y garantizar la seguridad nacional y el orden público deberán ponerse en práctica, en última instancia, por parte de las autoridades nacionales. Así, deberá respetarse un fiel equilibrio entre la protección de los intereses nacionales y europeos y la efectividad del derecho a la protección internacional, especialmente, ante parámetros imprevistos y de difícil ponderación como la radicalización o el reclutamiento de los solicitantes de protección internacional y de los refugiados. Los Estados de acogida son los que, en definitiva, deben implementar políticas preventivas desde una fase inicial, es decir, tanto si el sujeto se encuentra sometido al procedimiento de determinación del oportuno estatuto -estableciendo medidas proporcionadas a la entrada de nacionales de terceros países que pudieran comprometer la seguridad- como si ya ostenta el estatuto de refugiado o protección subsidiaria -adoptando políticas concretas y adaptadas al propio perfil del solicitante, considerando el lugar de procedencia, sexo, motivo de persecución, edad, género, etc.-.

2. Por lo que respecta a las cláusulas de exclusión del estatuto de protección internacional, la definición de grave delito común previsto en la letra b) de los arts. 12 y 17 de la Directiva de Reconocimiento ha producido una enorme asimetría en las legislaciones nacionales. Ello ha ido en detrimento de la función homogeneizadora del SECA, el principio de seguridad jurídica y la protección efectiva de este derecho, a pesar de la lógica interpretación restrictiva de las cláusulas limitadoras que reconoce la jurisprudencia del TJUE y que, por lo demás, se inscribe en una línea coherente con el principio favor libertatis que se desprende de los arts. 52.3 y 53 CDFUE. 
Ahora bien, la propuesta de Reglamento de Reconocimiento dispone, por primera vez, de una definición de delito común grave. Esto implicará modificaciones de gran calado en las legislaciones nacionales como, sin duda, este será el caso del ordenamiento español. Así, el art. 8.2 $2^{\circ}$ LAPS abarca dentro de delito grave a efectos de exclusión no solo los relativos a la vida, la libertad, la indemnidad, la libertad sexual o la delincuencia organizada, sino también "la integridad de las personas o el patrimonio, siempre que fuesen realizados con fuerza en las cosas, o violencia o intimidación en las personas". Y qué duda cabe de que el delito de robo, pese a tener la consideración de delito grave en el $\mathrm{CP}$, no será coherente con la definición que tipificará el futuro Reglamento de Reconocimiento. Por lo tanto, este concepto en la LAPS deberá restringirse en exclusiva a aquellos delitos graves que sean manifiestamente incompatibles con la seguridad de España.

3. En relación con lo anterior, las causas de exclusión del derecho a la protección subsidiaria llevan aparejadas menores garantías, puesto que facultan para excluir a un sujeto ante conductas que pongan en peligro a la comunidad o seguridad del EM en el que se encuentra el solicitante. Indudablemente, este estatuto otorga una flexibilidad sin precedentes en la determinación de la exclusión correspondiente.

En este sentido, el presente estudio, tras evaluar la valiosa información que ha proporcionado Eurostat o Frontex en los últimos años, confirma y parte del hecho contrastado de que algunos EEMM o no han proporcionado datos sobre las subcategorías de protección internacional o, simplemente, han tendido a conceder de forma generalizada el estatuto de protección subsidiaria a solicitantes procedentes de Siria -principalmente-, en contra del criterio empleado por el ACNUR o la EASO. Con ello, advertimos la escasa exhaustividad en la clasificación de ambas categorías tras escenarios sumamente complejos como las crisis migratorias y de asilo de los últimos tiempos, agravadas por la patente falta generalizada de información relacionada con los solicitantes de protección internacional.

A nuestro juicio, estas causas han motivado la concesión generalizada del estatuto de protección subsidiaria. Una categorización que, aunque a priori resulta análoga o semejante, flexibiliza considerablemente la aplicación de las cláusulas de exclusión y menoscaba gravemente la institución del asilo.

Es más, ciertos Estados concedieron aleatoriamente un estatuto u otro de acuerdo con unas necesidades -nacionales en todo caso- que excedieron del marco conceptual 
contemplado en la Convención de Ginebra y en la normativa reguladora del SECA. Una situación que refleja la inseguridad jurídica a la que se han enfrentado los solicitantes de protección internacional en su llegada al territorio de un EM, acrecentando los muy perjudiciales efectos de la lotería de asilo, consistente en la divergente calificación entre asilo o protección subsidiaria en función del país de acogida que se encargara de tramitar la solicitud.

Este conflicto, que se inicia a causa de la escasa información de la que generalmente han dispuesto las autoridades nacionales de los solicitantes, deberá revertirse tras la implementación del régimen de interoperabilidad entre los distintos SSII europeos, entre los que se incluye Eurodac. Esta operatividad funcional será capaz de solventar $-\mathrm{o}$ al menos, reducir- las lagunas estructurales a las que hemos hecho referencia. No obstante, podría propiciar situaciones susceptibles de menoscabar el ejercicio efectivo de un derecho, como consecuencia de una aplicación indiscriminada y generalizada de las cláusulas de exclusión que limite o vede el acceso efectivo al procedimiento de protección internacional. Efectos contrarios tanto a la propia Directiva de Reconocimiento como al criterio jurisprudencial del TJUE. De este modo, la mayor disponibilidad de la información requerirá elevar los estándares de protección de las cláusulas de exclusión, debiendo contrastar la información y, en la medida de lo posible, otorgar al afectado el derecho a conocer tal información y alegar lo que estime pertinente en el seno de este procedimiento.

4. En relación con el régimen jurídico relativo a la revocación, la vigente Directiva de Reconocimiento de 2013 expresa varios déficits que reconoce una extensa jurisprudencia tanto del TJUE -en aplicación de esta Directiva y del art. 4 CDFUE-, como del TEDH -por su directa incidencia en el art. 3 CEDH-. Semejantes déficits se reconducen a la exigencia de proceder a la evaluación individualizada de todas las circunstancias personales con carácter previo a la adopción de una decisión final de revocación y la inequívoca distinción entre la revocación y las acciones posteriores restrictivas de derechos como la expulsión. Esta última, necesariamente, deberá llevarse a cabo tras una decisión firme que constate de forma fehaciente que la devolución a su país de origen o residencia -en el caso de los apátridas- no vulnerará la prohibición a la tortura, los tratos y penas inhumanos y degradantes, para evitar la conculcación del principio de non-refoulement. 
Por ende, estas deberían preverse en el futuro Reglamento de Reconocimiento. Ello sin perjuicio de que esta propuesta de Reglamento introduzca un nuevo "modelo de revisiones sistemáticas y periódicas" que afectará a la identificación de posibles causas de revocabilidad, tal y como ya desarrolla el modelo alemán y cuyas consecuencias son, actualmente, desconocidas. Si bien, en nuestra opinión, estas revisiones propiciarán una peligrosa noción de "temporalidad" del derecho a la protección internacional por medio de un constante flujo de intercambio de información entre la AAUE y los EEMM y del vigente régimen de la interoperabilidad de los SSII comunitarios. Una combinación que, pese a llevar aparejada una mejora exponencial de las dimensiones de seguridad y eficiencia de los procedimientos nacionales, podría ir en detrimento del derecho a la protección internacional. Es más, el mayor alcance del principio de disponibilidad de la información -identificando que el sujeto ha vuelto a su país de origen o de anterior residencia, que estos países pueden ya garantizar su protección o, simplemente, previendo cualquier anomalía que determine su incompatibilidad con la seguridad del Estado de acogida- aumentará, correlativamente, las tasas de revocación.

Por todo ello, aunque el futuro SECA apueste decididamente por un reglamento comunitario en lugar de la reforma de la vigente Directiva con miras a promover una mayor coherencia y uniformidad en los procedimientos nacionales de revocación, las modificaciones previstas generarán, implícitamente, un marco jurídico de revocación "ordinario" con respecto a lo que debería ser más bien marginal o subsidiario, acrecentando la sensación de incertidumbre que sufren los individuos afectados sobre el uso que se hace de sus datos personales por cuestiones que dependen de la seguridad de los Estados.

5. Adentrándonos en la determinación del complejo régimen jurídico aplicable al derecho a la protección de datos personales en el ámbito del actual y futuro SECA, la propuesta de reforma del SECA prevé la aplicación del RGPD y de la Directiva 2016/680 de protección de datos en el ámbito penal.

Ahora bien, es indiscutible que los siguientes obstáculos comprometerán la plena aplicación del RGPD:

a) Teóricamente, este excluye directamente de aplicación el asilo, el control de fronteras y la inmigración -y, ni que decir tiene, la seguridad nacional-, así como la intervención de un amplio conjunto de agencias u organismos europeos encargados de gestionar la información. 
b) Al intercambio de información a gran escala entre autoridades nacionales y organismos europeos se le adiciona el gran despliegue policial o la escasa formación de las autoridades nacionales sobre la legislación de protección de datos. Factores que lastran considerablemente la aplicación eficaz del RGPD.

A nuestro juicio, la plena extensión a los derechos de los solicitantes comportaría una excesiva limitación para los EEMM en la consecución de los objetivos encaminados a gestionar eficaz y eficientemente las solicitudes de protección internacional y preservar sus intereses nacionales. En el otro extremo, tampoco las autoridades nacionales deben limitar de forma indiscriminada los derechos de los solicitantes. Estos límites deberán responder a imperantes razones concretas de seguridad nacional que permitan aumentar la seguridad jurídica en un ámbito tan sensible y fragmentado como este y evitar la criminalización de este colectivo. Por lo tanto, consideramos que deberá procurarse un equilibrio continuo entre dos factores que a priori parecen opuestos o contradictorios entre sí, pero que de facto no dejan de complementarse para la consecución de diversos objetivos: la protección efectiva de los solicitantes de protección internacional y la respuesta eficaz que deben proporcionar los EEMM a la gestión del asilo y la prevención de la delincuencia, crimen organizado o incluso terrorismo. En suma, el difícil equilibrio derivado de la clásica tensión dialéctica entre libertad y seguridad.

6. La amplia flexibilidad en la toma de decisiones a la hora de intercambiar información entre autoridades nacionales se encuentra supeditada a diversas formalidades vinculantes como el principio de confidencialidad, el deber de designar un punto de contacto nacional y la potenciación de comunicación entre los EEMM y la Comisión. La reforma de Reglamento de Dublín promoverá una cooperación sin precedentes para evitar la recogida de datos similares e investigaciones paralelas, prestando atención al respeto de la información obtenida antes de la ejecución de los traslados, a los datos sanitarios, necesarios para proporcionar la asistencia debida e inmediata o el régimen de cooperación administrativa.

Más relevante será el derecho a la información de los solicitantes, supeditado al deber de colaboración y cooperación con las autoridades nacionales, una transformación radical que generará un genuino "intercambio de información" entre autoridades e interesados y que no resultará ajeno a riesgos estructurales que derivan de la propia relación entre las partes al establecer, al efecto, una mayor rigidez del sistema. Los solicitantes deberán adaptarse a las exigencias del procedimiento y proporcionar toda la 
información a su alcance en tiempo y forma como requisito previo a la facilitación del derecho a la información.

Sin embargo, este enfoque manifiestamente restrictivo podría agravar la generalizada desconfianza de los solicitantes en el procedimiento, por lo que deberían ser las autoridades las que cumplieran desde un inicio con el deber de proporcionar asistencia a los solicitantes para promover una buena relación entre las partes y superar la generalizada falta de trasparencia en el procedimiento de protección internacional.

7. Por añadidura, debemos advertir que el procesamiento de información en el ámbito del SECA también pretende trasladar progresivamente su gestión desde el seno de los EEMM hacia el ámbito comunitario. Si bien, la necesidad de una acción rápida y de urgencia sobre flujos migratorios y la intervención eminentemente en fronteras de las agencias y organismos europeos podría propiciar constantes interferencias en el derecho fundamental a la protección de datos personales, en vista de que ostentarán amplias y perfeccionadas facultades en relación con la gestión e intercambio de datos personales. A nuestro juicio, existe un conflicto de intereses entre el fomento de un exhaustivo tratamiento de la información personal y la potenciación de eficientes mecanismos de cooperación entre estos con las autoridades nacionales. $\mathrm{Y}$ pese a que deberían proporcionarse "marcos jurídicos proactivos" en este ámbito, se derivan los siguientes desafíos que pueden comprometer el respeto de la protección de los datos personales que procesan estas dos agencias:

A. La AAUE asumirá una facultad básica en el procesamiento e intercambio de información sobre solicitantes de protección internacional para fines concretos de asistencia o cooperación con las autoridades nacionales. Sin embargo, esta agencia procesará información personal de amplias categorías de sujetos, lo que exige una labor de concreción sobre las distintas funciones de intercambio con el resto de organismos europeos y autoridades nacionales -sobre todo, porque exceden de la mera gestión de la información relativa a la protección internacional derivando hacia cuestiones migratorias más amplias-. Un alcance que puede poner en riesgo los principios de necesidad, proporcionalidad y limitación de la finalidad del art. 4 del Reglamento $2018 / 1725$.

B. Por otro lado, consideramos que la recientemente modificada GEFC carece de una notable falta de concreción. Su ámbito de actuación resulta excesivamente amplio abarcando la gestión de la migración y de las fronteras, la protección internacional o, 
incluso, las relacionadas con la delincuencia transfronteriza y terrorismo-. Esto incidirá negativamente en las garantías de la protección de datos, dificultando la clasificación de cada tipología de datos procesados y cuyo régimen jurídico variará sustancialmente en función de si se trata de datos operativos, que disponen de una escasa relevancia a estos efectos, de aquellos realmente personales. Además, esta agencia dispone de la posibilidad de transferir datos a una autoridad de un tercer país o a una organización internacional en el caso de que sea necesario para proceder al retorno. Y a pesar de que estas deben ejecutarse de forma individualizada, lo cierto es que ello puede aumentar el riesgo de que se produzca un intercambio de información sobre posibles solicitantes de protección internacional. Por lo tanto, esta Agencia debería abordar el procesamiento de amplias categorías de sujetos, diferenciándolos exhaustivamente con objeto de aplicar garantías jurídicas distintas y que divergen desde la prohibición absoluta de intercambio de información personal de asilo con terceros países hasta su legitimación en el caso de ejecución de una orden de retorno.

8. Eurodac, adscrito al funcionamiento del Reglamento de Dublín y, ambos conformando el Sistema de Dublín, también contempla en su propuesta de reforma tanto la aplicación del RGPD como de la Directiva de protección de datos en el ámbito penal.

Ahora bien, en esta propuesta convergen dos circunstancias que merecen subrayarse:

a) la excesiva frecuencia con la que prevé aspectos relacionados con la seguridad nacional podría desvirtuar este sistema de protección, dado que no se especifica ningún criterio excepcional o subsidiario. Por ello, serán las APDs quienes deberán efectuar el control nacional de la legalidad del tratamiento de los datos personales, incluida su transmisión desde y hacia Eurodac de acuerdo con el art. 35.1 PRE, de modo que permita su adecuación y adaptación a supuestos concretos y específicos;

b) ni que decir tiene que el nuevo régimen jurídico de la interoperabilidad entre los SSII de la UE que regula el Reglamento Europeo 2019/818 en el ámbito de la cooperación policial y judicial, el asilo y la migración va a marcar un precedente de dimensiones considerables y desconocidas. Esta nueva interconectividad se erigirá como una de las acciones claves en el funcionamiento en la PRE cuya incidencia en el derecho a la protección de datos resulta clara, por cuanto afectará a cada una de las modificaciones que prevé la mencionada propuesta.

Ahora bien, a pesar de que generará un cambio de paradigma en la manera en la que 
se comunican las autoridades nacionales, garantizando una disponibilidad de la información sin precedentes, nada viene regulado en su propuesta de reforma. Por ello, la interoperabilidad no debe convertirse en una "interconexión automática de información", sino en una nueva técnica eficiente que favorezca la sinergia de esfuerzos para dar solución a escenarios realmente complejos y sobre los que un solo EM no puede actuar por sí mismo. Este requiere de una mayor disponibilidad de la información en la toma de decisiones, sin perder de vista el riesgo que supondrá su aproximación entre las cuestiones relacionadas con la migración y asilo a las que dependen de la propia seguridad europea y nacional. Ello propiciará una progresiva desaparición de los límites legales entre el cumplimiento de la ley, el control de inmigración y el asilo y la intensificación radical de la vigilancia de todos los individuos no pertenecientes a la UE. De esta manera, podrían quedar desvirtuados los esfuerzos de la PRE por garantizar, en la medida de lo posible, la efectiva ponderación entre el aumento de la eficiencia y el pleno respeto de la privacidad y la protección de datos de los nacionales de terceros países.

9. Asimismo, resulta obvio que no son ciertamente escasas las disposiciones de la PRE que inciden en el derecho a la protección de datos personales. Consecuentemente, en un intento por clarificar cada una de ellas, haremos las siguientes observaciones:

9.1. Este sistema dispone de un alcance muy amplio, determinando el EM responsable para la tramitación de una solicitud de protección internacional o identificando migrantes en situación irregular. A nuestro juicio, esto no supone un cambio de la finalidad en sentido estricto, sino más bien una adición a multitud de propósitos o finalidades que exceden de las cuestiones intrínsecas de asilo para desplazarse hacia otras relacionadas con la seguridad nacional. Ahora bien, el riesgo de que la información relativa a los solicitantes de asilo exceda de su objeto principal resulta particularmente elevado. Por tal razón, debería incluirse una referencia expresa al respeto de la limitación de la finalidad que regula el art. 3.3) de la Directiva de protección de datos en el ámbito penal, mediante la adopción de medios técnicos que permitan reflejar que el tratamiento de los datos personales está limitado a fines muy determinados y excluyentes entre sí entre la protección internacional, la prevención y control de movimientos secundarios y el retorno a terceros países. Igualmente, las APDs deberán verificar la licitud del tratamiento, poniendo a disposición del interesado -en concreto, los solicitantes de protección internacional- la información necesaria relativa 
a esta limitación de tratamiento [art. 13.1 e) de la Directiva]. Esto reduciría considerablemente el margen de discrecionalidad de las autoridades nacionales en la consecución de los fines determinados, garantizando no solo la protección de los datos recopilados, sino aumentando exponencialmente la transparencia y la confianza de los interesados sobre el uso de los mismos.

9.2. La transferencia de datos a terceros países con fines de retorno (art. 38) supone otra de las novedades más destacadas de la PRE por la que se pretende mejorar la política de retorno de la UE y la gestión de la migración irregular. Y aunque se aplica exclusivamente a esta categoría de sujetos, quizá debería contemplarse en un instrumento jurídico distinto de esta propuesta que no permitiera relacionar -ni siquiera mínimamente- el alcance de la misma a sujetos que realmente se encuentran en una clara necesidad de protección internacional.

9.3. Otro de los puntos críticos de la propuesta de Eurodac está relacionado con una nueva categoría de datos biométricos: las imágenes fáciales. Una ampliación que responde a la necesidad de solventar los grandes perjuicios que provocaron las fallas en la recopilación y registro de las huellas dactilares. En este punto, creemos que la PRE debería establecer procedimientos más eficientes que analicen y procesen esos datos de un modo coherente y garante con los derechos fundamentales, previendo un control eficaz y continuo de la legalidad por parte de las APDs. Ello teniendo en consideración que esta ampliación aumenta el riesgo de vulneración del principio de limitación de la finalidad e, incluso, tiende a desviarse de su objeto principal, pudiendo generar una pérdida del control de esta información con efectos sumamente críticos en el ámbito del SECA.

9.4. Asimismo, la reducción de la edad en la PRE para la toma de datos biométricos a los menores comprendidos entre 6 y 14 años no tiene un objetivo claro. En este sentido, a pesar de que su Exposición de Motivos justifica su inclusión en el sistema con fines de identificación -y con ello, la garantía de su protección eficaz-, el procesamiento de estos datos parece radicar más bien en la imperante necesidad de identificar a la totalidad de los migrantes irregulares, incluidos los niños, para fines que exceden de las cuestiones intrínsecas de asilo derivando hacia un instrumento de lucha contra el crimen y delincuencia, control de la migración ilegal y la prevención de los movimientos secundarios cuyos efectos pueden ser contraproducentes, contraviniendo el derecho a la vida privada y la protección de datos personales (arts. 7 y 8 CDFUE), así 
como el respeto al principio del interés superior del niño (art. 24.2 CDFUE). Consiguientemente, la PRE debería recopilar datos biométricos de los niños a partir de 6 años exclusivamente para todos los efectos que le sean favorables, evitando que el empleo de estos datos sensibles pueda menoscabar sus derechos y libertades.

9.5 De igual modo, la ampliación del período de conservación de las dos categorías de migrantes irregulares a las que hemos hecho referencia es otra de las novedades previstas por la PRE, la cual muestra la imperante necesidad de obtener, durante un mayor periodo de tiempo, información que proporcione respuestas a los problemas de seguridad de los EEMM. Desde nuestro punto de vista, esta reforma puede implicar una "peligrosa vigilancia masiva" por parte de los EEMM o de la Europol. Esto iría en serio detrimento de las garantías en el derecho a la protección de los datos personales, aumentando el riesgo de vulneración del principio de limitación de la finalidad así como una posible desviación de uso o function creep. Por ello, su interferencia no resulta justificada a la luz de la necesidad y proporcionalidad de los arts. 7 y 8 CDFUE, por lo que debería incluirse una "modulación" de este periodo con base en criterios eminentemente objetivos y que no excedan de los fines específicos de Eurodac, en sintonía con la CDFUE y la jurisprudencia del TJUE.

9.6 Finalmente, en lo que respecta al acceso de las autoridades policiales y de la Europol, la mera posibilidad de que las autoridades policiales puedan acceder a la práctica totalidad de los datos que recoge este sistema ante la única sospecha de que hayan podido cometer un delito implica una criminalización de facto de los solicitantes de asilo. Una acción que, con mucha probabilidad, se agravará tras la aplicación del Reglamento 818/2019 de interoperabilidad, puesto que las autoridades nacionales y Europol tendrán acceso instantáneo a la información no solo de Eurodac sino del resto de SSII europeos.

Fruto de ello, puede apreciarse cierto grado de equiparación entre las tres categorías de sujetos de Eurodac, lo cual supone indirectamente una base de datos con una potencial tendencia a la discriminación de los solicitantes de protección internacional. Aun cuando la "virtualización" del acceso a Eurodac refleja una aparente o escasa incidencia en la privacidad y protección de datos, supone una de las reformas más conflictivas de este sistema. Sus condiciones de acceso deberían interpretarse de forma restrictiva, bajo el paraguas no solo del principio de subsidiariedad que contempla la PRE, esto es, estableciendo condiciones más estrictas de acceso y excluyendo las 
comparaciones sistemáticas, sino también salvaguardando el principio de limitación de la finalidad y otorgando verdaderas medidas preventivas de protección que respeten los principios de proporcionalidad y necesidad.

10. En relación con las políticas de seguridad y el impacto en el derecho a la protección internacional en España, debemos primeramente destacar que no solo la LAPS no transpone formalmente las Directivas que conforman el actual SECA, sino que carece de desarrollo reglamentario. Una inacción del legislador durante la década pasada (2009-2019) que ha generado una generalizada inseguridad jurídica. Sin embargo, a nuestro juicio, debería retrasarse hasta la aprobación del nuevo e inminente SECA, un sistema totalmente reformado que, como hemos analizado, requerirá de profundas reformas en nuestro ordenamiento jurídico que sean capaces de proporcionar soluciones a los graves escenarios que han comprometido la seguridad de nuestro país como las graves e imprevistas presiones migratorias o la falta generalizada de información y control de los flujos mixtos de migrantes, entre otros--.

En este punto, lo que sí debemos poner de manifiesto es que, a diferencia de otros Estados europeos que aplicaron una política de "frontera cerrada" tras los flujos migratorios a gran escala, este no ha sido el caso de España, aun disponiendo de una de las tasas más bajas de Reconocimiento en Europa.

11. En particular, adentrándonos en los puestos fronterizos de Ceuta y Melilla, estos llevan sufriendo en los últimos tiempos una falta de medios de acogida suficientes para garantizar la tramitación de las solicitudes de protección internacional y cuyas consecuencias no han podido resultar más adversas. Las devoluciones sumarias legalizadas fueron objeto de condena por el TEDH y, aunque este fallo se encuentra recurrido ante la Gran Sala, lo cierto es que puede suponer una flagrante violación implícita del principio de no devolución, en esencia, si no se evalúa de forma exhaustiva el perfil del nacional del tercer país. El próximo pronunciamiento no debería dilatarse durante más tiempo, tanto por la patente necesidad de sentar doctrina jurisprudencial sobre esta cuestión como para paralizar las actuaciones que todavía siguen ejecutándose en la actualidad.

12. Las entradas irregulares en territorio español no deben lastrar el acceso efectivo al procedimiento de protección internacional. Muchos de estos nacionales de terceros países en clara necesidad de recibir protección internacional han rehusado la entrada legal a nuestro país por Ceuta y Melilla ante el temor de ser devueltos, por el fuerte 
despliegue policial o, simplemente, porque no disfrutan de los mismos derechos de acogida que aquellos solicitantes en la península. En cambio, migrantes con gran conocimiento sobre el terreno o que disponen de recursos económicos han sido capaces de llegar a la España peninsular y presentar la correspondiente solicitud de protección internacional.

Dicho lo cual, no podrá procederse a la devolución de un migrante aun cuando haya entrado de forma irregular, debiendo identificarse exhaustivamente al mismo y la categoría a la que pertenece. Una medida que, ineludiblemente, requerirá de la asistencia de organismos y agencias a nivel europeo como la recientemente creada GEFC o la futura AAUE y de un intercambio de información sin precedentes que proporcionará la interoperabilidad del futuro Reglamento de Eurodac con los distintos SSII europeos.

13. En coherencia con lo expuesto anteriormente, debemos destacar dos de los efectos de la presentación de la solicitud de protección internacional que han socavado gravemente los derechos de este colectivo en situación de vulnerabilidad y las soluciones que, correlativamente, proponemos:

a) Por un lado, el criterio manifiestamente opuesto entre las resoluciones de la Comisaría General de Fronteras de Ceuta y Melilla -que han prohibido el derecho a circular libremente por territorio español- y varios TSJ, que han ido paralelamente anulando estos actos administrativos. En un intento por reducir esta colosal inseguridad jurídica que compromete seriamente la protección de los derechos fundamentales de este colectivo en situación de vulnerabilidad y, a la espera de que el TS se pronuncie sobre esta cuestión, debería garantizarse esta libre circulación por la totalidad del territorio nacional por dos factores: en primer lugar, ante la excesiva dilación no imputable al solicitante del periodo de tiempo en los que se sustancia el procedimiento de protección internacional y, en segundo lugar, por la falta estructural de medios de acogida en estos puestos fronterizos, lo cual hace inevitable una acción de la Administración que apueste por infraestructuras más aptas y mejor condicionadas. Una medida que estará sujeta a las correspondientes limitaciones a esta libre circulación, esto es, si el solicitante puede poner en riesgo la seguridad nacional o el orden público; si se negara a cooperar con las autoridades; o ante solicitudes manifiestamente infundadas o excesivas -respetando en todo caso, los principios de necesidad, proporcionalidad y excepcionalidad-. 
b) Por otro lado, los CETI no resultan apropiados para albergar a determinados solicitantes -como es el caso de los solicitantes por motivos de orientación sexual o identidad de género o los menores no acompañados-. Habría de adoptarse un "orden de prelación de traslados" hacia la península, debiendo priorizarse a estos solicitantes, donde las condiciones de acogida son más ventajosas. De este modo, estos CETI únicamente deberían servir como lugar estrictamente temporal mientras se lleva a cabo la exhaustiva identificación de los migrantes. Su estancia deberá reducirse hasta el mínimo necesario, aprovechando los beneficios que dispondrá el futuro intercambio de información y la interoperabilidad entre los SSII europeos, que reducirá sustancialmente esta labor de identificación y registro.

c) Finalmente, la convivencia de estos solicitantes con otras categorías de sujetos irregulares en los CIE no solo dificulta su exhaustiva identificación, sino que propicia actuaciones fraudulentas por parte de nacionales de terceros países que deben ser expulsados y que, sin embargo, solicitan protección internacional para aprovecharse de los beneficios que implica la tramitación mediante este procedimiento. El Ministerio del Interior debería desplegar más medios materiales y humanos que garanticen el cumplimiento del plazo de 4 días para la tramitación urgente (art. 21 LAPS) en la notificación al solicitante. Ello, sin perjuicio de que la futura reforma de la LOEx regule este tipo de actuaciones fraudulentas como infracciones muy graves (art. 54). 


\section{FINAL CONCLUSIONS}

In the present study we have undertaken an exhaustive analysis on the different recent scenarios that have compromised the national and European security. Specifically speaking, we stem from the migration and refugee crises that began in 2014, which affected the system of guarantees in the right to international protection, which regulates the legal framework of the CEAS and national legislations. Thus, we address two of the most prominent challenges this European system will face in a short and medium-term: its exceptions for reasons of national security and, with a direct connection to it, its impact on the right to data protection.

Therefore, we must conclude our overview with the following final considerations:

1. Despite an interesting and increasingly Europeanised security dimension that intends to incorporate the future comprehensive reform of the CEAS, it should not be forgotten that all these measures aimed at maintaining and guaranteeing national security and public order must ultimately be carried out by national authorities of the MS. Thus, the right balance between the protection of national and European interests and the effectiveness of the right to international protection must be respected, especially in unforeseen contexts, particularly, in unforeseen and complex weighting parameters such as the radicalisation or recruitment of international protection applicants and refugees.

Host countries should implement preventive policies from the early stage, that is to say, whether the person is subjected to the procedure for determining the appropriate international protection status -establishing measures provided for the entry of thirdcountry nationals who might compromise national security- or with refugee status or subsidiary protection -in this particular case, implementing specific policies adapted to the applicant's own profile, such as place of origin, sex, reason for persecution, age, gender, and so on.

2. With regard to the exclusion clauses concerning the international protection status, the common definition of serious crime referred to in point b) of articles 12 and 17 of the Qualification Directive constitutes a legal precept that has produced a huge disparity as far as national legislations are concerned. This has been detrimental to the homogenising function of the CEAS, undermining the principle of legal certainty and the effective protection of this right in spite of the logical restrictive interpretation of the 
limiting clauses that the jurisprudence of the CJEU recognize. Moreover, these clauses fall within the scope of a coherent approach linked to the principle of favor libertatis that arises from articles 52.3 and 53 CFREU.

However, the proposal for a Qualification Regulation has, has included for the first time, a definition of a serious non-political crime. This will imply major changes in national legislation, such as, undoubtedly, will be the case of the Spanish legislation.

It will require major changes in national laws, especially in the Spanish legal system. Article $8.2^{\circ}$ of the Spanish Asylum Law (LAPS) includes within the serious crime for the purpose of exclusion not only those related to life, liberty, indemnity, sexual freedom or organised crime, but also "the integrity of persons or property, provided that they were carried out with force in things, or violence or intimidation in people". There is no doubt that the crime of theft, despite being considered a serious crime in the Spanish Penal Code (CP), will not be consistent with the definition of the forthcoming Qualification Regulation. Therefore, this concept in the LAPS should be applicable exclusively to those serious crimes that are manifestly incompatible with the security of Spain.

3. In relation to the foregoing assertion, after evaluating the valuable information that Eurostat or Frontex have provided in the last few years, the exclusion causes relating to the right to subsidiary protection requires lower guarantees compared to the refugee status. It entitles the exclusion of a subject from a behaviour that endangers the community or security of the MS in which the applicant is simply located. Without a shadow of doubt, this legal status gives unprecedented flexibility in determining the corresponding exclusion.

In this regard, after evaluating the valuable information that Eurostat has provided in recent years, the present study underlines the hypothesis that some MS have not provided sufficient data on subcategories of international protection or, basically, have adopted a trend to grant subsidiary protection status for applicants coming from Syria, against the criteria adopted by the UNHCR or the EASO. Consequently, it needs to be considered that the lack of competition in the classification of both categories of international protection after following extremely complex scenarios such as the last migratory and asylum crisis have been aggravated by the general lack of information related to applicants for international protection. Although conclusive evidence on the matter cannot be provided, these causes have provoked the widespread granting of the 
subsidiary protection status. A categorisation that rebates considerably the application of the exclusion clauses, undermining the high guarantees in the institution of asylum.

Some evidences have been provided proving that one statute or another was granted according to national needs that exceeded the conceptual framework contemplated in the Geneva Convention and in the legal instruments governing the CEAS. A situation that reflects the legal insecurity faced by applicants for international protection upon arrival in the territory of an MS, enhancing the damaging effects of the asylum lottery, consisting of the divergent qualification between asylum or subsidiary protection depending on the host country that is competent to examine the application.

This conflict, which occurs due to the limited information available to national authorities, must be reversed after the implementation of the interoperability regime between the different European Information Systems, including Eurodac. This functional operability will be able to solve, or at least to reduce, the structural gaps previously referred. However, it could lead to situations that would undermine the effective exercise of a right as a result of an indiscriminate and widespread application of exclusion clauses that limit effective access to the international protection procedure.

These effects are contrary to both the Qualification Directive itself and the jurisprudential criterion of the CJEU. Therefore, the greater availability of the information will require not only raising the standards of protection of the exclusion clauses, but also comparing the information and, as far as possible, granting the individual concerned the right to know such information and to take whatever measure that they consider to be adequate.

4. In relation to the revocation legal system, the current Qualification Directive (2013) contains several deficits that recognise the extensive jurisprudence of both the CJEU -in application of this Directive and article 4 CFRUE-, and the ECHR -due to its direct impact on article 3-. In this sense, the future Regulation should provide the requirement to proceed to an individualised evaluation of all personal circumstances prior to the adoption of a final decision of revocation. Also, the unequivocal distinction between revocation and the subsequent rights-restrictive actions such as expulsion should be incorporated. This must be carried out after a firm decision that confirms, in a reliable way, that the return to their country of origin -or residence for stateless persons- will not violate the prohibition of torture, inhuman or degrading treatment or punishment. 
Therefore, these particularities should be foreseen in the future Qualification Regulation, taking into account that this proposal for a Regulation will introduce a new "systematic and periodic review model" that will affect the identification of possible causes of revocability, as the German model is currently implementing. As we explained earlier, although those consequences are at present unknown, it should be noted that it would lead to a dangerous notion of "temporality" in the right to international protection. The steady and massive flow of information exchange between the future European Agency for Asylum and MS will be exacerbated by virtue of the current interoperability regime. A combination that, while increasing the security and efficiency dimensions, it might be detrimental to the right to international protection. Moreover, the greater scope of the principle of availability of information needs to be outlined, for example, by identifying that the individual has returned to their country of origin or previous residence, these countries can already guarantee their protection or, simply, by providing for any anomaly that determines its incompatibility with the security of the host State. An advantage that, however, could increase the revocation rates.

For all these reasons, even if the future CEAS is firmly committed to implement different regulations, instead of the reform of the current Directive, with a view to promoting greater coherence and uniformity in national revocation procedures, the planned modifications will implicitly generate a legal framework of "ordinary" revocation. This structure should be marginal or subsidiary in order to increase the feeling of uncertainty suffered by individuals facing the use of their personal data for issues linked to the security of MS.

5. In an attempt to determine the legal right regime applicable to the protection of personal data, the proposed CEAS reform aims at providing for the application of the GDPR and Directive 2016/680 of personal data in the fields of judicial cooperation in criminal matters. However, the following obstacles could compromise the full application of the GDPR:

a) Theoretically speaking, the scope directly excludes asylum, border control, and immigration fields but also national security, as well as the intervention of a broad set of European agencies or bodies responsible for managing information.

b) In addition to the large-scale police deployment and the low level of training concerning to national authorities on data protection legislation, it is important to 
highlight the large-scale information exchange and sharing between national authorities and European bodies. Factors that significantly undermine the effective application of the GDPR.

In our view, the full length of the applicants' rights would evidence an excessive limitation of MS in the achievement of managing international protection applications in a timely manner as well as preserving their national interests. In addition, national authorities should not generally limit the rights of applicants. These must respond to prevailing concrete national security reasons that allow increasing legal security in this sensitive and fragmented area of law, avoiding the criminalisation of this group in situation of vulnerability. Therefore, we are of the opinion that a continuous balance must be carried out between two factors that a priori seem opposite or contradictory, but de facto do not cease to complement to each other in order to achieve a set of objectives, specifically: the effective protection of applicants for international protection and the effective response that MS should provide to asylum management, on the one side, and the prevention of crime, organised crime or even terrorism, on the other.

6. The broad flexibility during decision-making when it comes to exchanging information between national authorities is subjected to binding formalities. This includes the principle of confidentiality, the duty to designate a national contact point and a more fluent communication between MS and the Commission. The reform of the Dublin Regulation will promote unprecedented cooperation with a view to avoiding the collection of similar data and parallel investigations, paying special attention to the respect of the information obtained, prior to the execution of the transfers, to the health data, necessary to provide due and immediate assistance or the administrative cooperation regime. Hence, the right to information of the applicants will be more relevant. This is subject to the duty of collaboration and cooperation with the national authorities. A radical transformation that will imply a genuine "exchange of information" between authorities and stakeholders but will not avoid structural risks that derive from the relationship between the parties involved. Applicant's conducts must be adapted to the requirements of the procedure and provide all the information available to them in a timely manner and as a pre-requisite to the facilitation of the right to information.

However, this manifestly restrictive approach could exacerbate the widespread distrust of the applicants in the asylum procedure. The authorities should comply with 
the duty to provide effective assistance to the applicants to promote relationship of trust between the parties and overcome the widespread lack of transparency in the international protection procedure. In short, the difficulty of striking a balance from the classical dialectical tension between freedom and security.

7. Subsequently, we can observe that the reporting process of information within the SECA scope also aims to progressively move its management from the MS to the community level. Although, the need for quick and urgent action on migration flows and eminently intervention at the borders of European agencies could lead to constant interference with the fundamental right to personal data protection, given that they will have wide powers in relation to the management and exchange of personal data. In our opinion, a conflict of interests coexists between the promotion of an exhaustive treatment of personal information and the strengthening of efficient cooperation mechanisms between applicants and national authorities. Although a "proactive legal frameworks" should be provided in this area, the following challenges may compromise the respect of the protection of personal data processed which have been:

A. The European Agency for Asylum will assume a basic assignment in the processing and exchange information on applicants for international protection for specific purposes related to assistance or cooperation with national authorities. However, this agency will process personal information from wide-ranging categories of subjects, which will require the development of specific action on the different exchange functions with other European organizations and national authorities especially since they exceed the mere management of relative information to international protection towards broader migration issues-. A scope that might jeopardize the principles of necessity, proportionality, and purpose limitation according to article 4 of Regulation 2018/1725.

B. On the other hand, we consider that the recently modified European Border and Coast Guard Agency suffers from a lack of specificity. Its scope of action is exceedingly wide-ranging from the management of migration and international protection applications to those related to cross-border crime and terrorism. This will adversely affect the data protection guarantees, making it difficult to classify each type of data processed. Furthermore, the legal regime will vary substantially depending on the category of personal data processed. In addition to it, this agency provides the possibility of transferring data to a third country authority or international organisation 
if it is necessary to proceed with the return. And although these transfers must be executed individually, the truth is that it can increase the risk of an exchange of information on potential applicants for international protection. Therefore, this Agency should address the processing of broad categories of persons, differentiating all of them exhaustively in order to apply different legal guarantees. These will range from the absolute prohibition of exchange of personal asylum information with third countries to their legitimacy in the case of enforcement of a return order.

8. The Eurodac Information System, attached to the operation of the Dublin Regulation -both forming the Dublin System-, also includes in its proposed reform the application of the GDPR and the Data Protection Directive in criminal matters.

However, two circumstances converge in this proposal:

a) Needless to say, the excessive frequency in which it foresees aspects related to national security could distort this protection system, since no exceptional or subsidiary criteria are itemised. Therefore, Data Protection Authorities shall carry out national control of the legality of the processing of personal data, including its transmission to and from Eurodac in accordance with art. 35.1 of the Eurodac proposal so that this system will allow its adaptation to specific assumptions.

b) It goes without saying that the new legal regime of interoperability between the EU information systems that European Regulation 2019/818 provides that in the field of police and judicial cooperation, asylum and migration will set a precedent of considerable and unknown dimensions. This new interconnectivity will be established as one of the key actions in the operation of the Eurodac proposal. However, its impact on the right to data protection seems to be clear. It will affect each of the modifications provided for in the aforementioned proposal.

In this sense, although it will generate a paradigm shift in the way in which national authorities communicate and guarantee unprecedented availability of information, there is a lack of regulation in their reform proposal. Therefore, interoperability should not become an "automatic interconnection of information", but a new efficient technique that favours the synergy of efforts to solve really complex scenarios in which a single MS cannot act on its own. It requires greater availability of information during the decision-making, without a view of the risk that its approach will entail between issues related to migration and asylum to those that depend on European and national security. 
This will lead to a progressive disappearance of the legal boundaries between law enforcement, immigration control and asylum and the radical intensification of surveillance of all non-EU individuals. In this way, efforts in the Eurodac proposal to guarantee, as far as possible, the effective weighting between increased efficiency and full respect for the privacy and data protection of third-country nationals could be distorted.

9. Likewise, the provisions of the Eurodac proposal that affect the right to the protection of personal data are substantial. Consequently, in an attempt to clarify every clause, we will make the following observations:

9.1. This system has a very wide scope, determining the MS responsible for the examination of an application for international protection and also identifying migrants in an irregular situation. In our opinion, this does not imply a change of purpose in a strict sense of the word but an addition to multiple commitments that exceed the intrinsic asylum issues towards others related to national security. However, the risk of infringing the principle of purpose limitation is particularly high. For this reason, a reference of this principle regulated in art. 3.3 of the above-mentioned Directive should be included. This would be conducted through the adoption of technical means that reflect that the processing of personal data is limited to very specific and mutually exclusive purposes between international protection, prevention, and control of secondary movements and return to third countries.

Likewise, the Data Protection Authorities must verify the lawfulness of the treatment and the person concerned should know for what reasons the treatment can be limited (art. 13.1 e) of the Directive). This would considerably reduce the margin of discretion of the national authorities to the pursuit of the determined commitments, guaranteeing not only the protection of the data collected but exponentially increasing the transparency and confidence of the interested parties as well.

9.2. The transfer of data to third countries for return purposes (art. 38 Eurodac proposal) is another of the most outstanding developments in the Eurodac proposal. It is intended to improve the EU's return policy and the management of irregular migration. Although it applies exclusively to this category of subjects, it should be contemplated in another legal instrument that would not allow relating -even minimally- this scope for those who are applicants to international protection. 
9.3. Another of the critical points of the above proposal is that related to a new category of biometric data: facial images. An extension that responds to the need to solve the damages caused by failures in the collection and registration of fingerprints. At this point, we believe that the Eurodac proposal should establish more efficient procedures so as to analyse and process that data in a manner that guarantees consistency of fundamental rights, providing for effective and continuous control of legality by the DPAs. We should take into consideration that this extension increases the risk of violation of the principle of purpose limitation and, even, it tends to deviate from its main purpose, which may lead to a loss of control of this information with extremely critical effects in the CEAS.

9.4. Likewise, the reduction of the age according to Eurodac proposal for the collection of biometric data for children between 6 and 14 years of age does not have a clear objective. In this sense, although its Explanatory Memorandum justifies its inclusion in the system for identification purposes -guaranteeing its effective protection-, the processing of these personal data seems to lie rather in the prevailing need for identifying all irregular migrants, including children, for reasons that exceed intrinsic asylum issues towards an instrument to reduce crime, control of illegal migration and the prevention of secondary movements. The effects may be counterproductive, contravening the right to privacy and the protection of personal data (articles 7 and 8 CFREU), as well as respecting the principle of the best interests of the child (article 24.2 CFREU). Consequently, the proposal should envisage a collection of biometric data of children from 6 years old exclusively for favourable effects, avoiding the use of this sensitive data that can weakens their rights and freedoms.

9.5. Likewise, the extension of the period of conservation for the different categories of irregular migrants in the Eurodac proposal is another novelty foreseen in Eurodac proposal, which shows the imperative need to obtain, for a longer period of time, information that provides further answers to tackle national security problems. From our point of view, this reform may involve "dangerous mass surveillance", which would seriously undermine the guarantees in the right to the protection of personal data, increasing the risk of violation of the principle of purpose limitation as well as function creep. This interference is not justified in the light of the principle of necessity and proportionality of articles 7 and 8 CFREU. Therefore, a "modulation" of this period of 
time should be implemented based on objective criteria that do not exceed the specific purposes of Eurodac, in line with the CFREU and the CJEU jurisprudence.

9.6. Finally, with regard to the access of the law enforcement authorities and Europol, the mere possibility that they can reach to almost the whole personal data collected by Eurodac under the mere suspicion that they have been able to commit a crime implies a criminalization de facto of asylum seekers. An action that, with a high degree of probability, will be aggravated after the application of the Interoperability Regulation 818/2019, since the national authorities and Europol will have instant access to information not only contained in Eurodac but also from other sources of European information systems.

As a result of it, some degree of "harmonisation" can be identified between the different categories of Eurodac subjects. This indirectly creates a database prone to the discrimination of asylum seekers. Even though the "virtualisation" of access to Eurodac reflects an apparent or low impact on privacy and data protection, it is considered as one of the most conflicting reforms. Their access conditions should be interpreted restrictively, under the umbrella which have been made not only of the principle of subsidiarity contemplated in the proposal, that is to say, establishing a more restrictive access conditions and excluding systematic comparisons, but also safeguarding the principle of purpose limitation and granting preventive protection measures in the light of the principles of proportionality and necessity.

10. Concerning security policies and the impact on the right to international protection in Spain, we must first emphasize that not only the Spanish Asylum Act (LAPS) does not formally transpose the Directives in the CEAS package that are actually in force in the current SECA, but that it lacks regulatory development. In fact, the inaction by the Spanish legislator during the last decade (2009-2019) has generated widespread legal uncertainty. However, from our point of view, we consider that it should be delayed until the approval of the new SECA, a completely new and reformed system that, as it is analysed before, will require profound reforms in our legal system, so that it will be able to provide solutions to the different scenarios that have compromised the security of Spain -such as the serious and unforeseen migratory pressures or the general lack of information and control of mixed migrant flows, among others-. 
At this point, what we should assume about it is the fact, unlike other European states that have applied a "closed border" policy after a large migratory flow, this has not been the case in Spain, despite having one of the lowest recognition rates in Europe.

11. Focusing on the border posts of Ceuta and Melilla, in recent times they have suffered a lack of sufficient reception facilities to guarantee the processing of applications for international protection, the consequences of which have been adverse. The "legalised" summary returns were condemned by the ECHR and, although the judgment is appealed to the Grand Chamber, in our opinion these could imply a flagrant indirect violation of the principle of non-refoulement, essentially, if the profile of the third country national is not thoroughly evaluated. So the forthcoming pronouncement should not be extended for a longer time. The need to establish a jurisprudential doctrine on this issue is crucial to paralyse the actions that are still being carried out today.

12. Irregular entries into Spanish territory must not impede effective access to the international protection procedure. Many of these third-country nationals who are in clear need of international protection have been refused legal entry in our country by Ceuta and Melilla hotspots, given the fear of being returned due to the strong police deployment. Also due to the fact that they do not enjoy the same reception rights to those applicants allocated in the peninsula. On the other hand, migrants who bring extensive knowledge on the ground or with sufficient economic resources have been able to reach peninsular Spain and submit the corresponding application for international protection.

All things consider, we are of the opinion that a migrant shall not be returned, even if he has entered irregularly. He must be thoroughly identified categorised. A measure that, inevitably, will require the efficient assistance of European organizations and agencies such as the European Border and Coast Guard Agency or the future EU Agency for Asylum. An unprecedented exchange of information that will be combined with the interoperability between EU information systems that include Eurodac.

13. In line with what we have stated above, two of the effects of the lodging of international protection applications that have seriously undermined the rights of this group in a situation of vulnerability as well as the proposed solutions must be highlighted: 
On the one hand, the manifestly opposite criterion between the resolutions of the General Border Commission of Ceuta and Melilla, which have prohibited the right to move freely through Spanish territory, and several judgments of the Spanish Supreme Courts (TSJ), which, have been annulling in parallel these administrative acts. In an attempt to reduce this colossal legal uncertainty which seriously compromises the protection of the fundamental rights of this group awaiting a final appellate decision from the Supreme Court of Spain, the right to freedom of movement should be guaranteed throughout the entire national territory for two main factors:

a) First of all, due to the excessive delay not attributable to the applicant for international protection and, secondly, due to the structural lack of means of reception at these border posts. The Spanish Administration should create more suitable infrastructures by gradually transferring asylum seekers to the peninsula. A measure that will be subject to the corresponding limitations to free movement, that is, if the applicant could compromise national security or public order; would refuse to cooperate with national authorities; or if the applications would be considered to be manifestly unfounded or excessive -respecting in any case, the principles of necessity, proportionality and exceptionality as well-.

b) On the other hand, the Migrant Temporary Stay Centres (CETI) are not suitable to accommodate certain categories of applicants, especially those particularly disadvantaged or vulnerable subjects such as seekers for sexual orientation or gender identity reasons or involving unaccompanied minors too. An "order of precedence for transfers" to the peninsula should be made, and these applicants should be prioritised, where reception conditions are more advantageous and appropriate for this vulnerable group. In this way, these CETI should only serve as a temporary place, while the exhaustive identification of migrants is carried out. The prolonged stay in these infrastructures should be reduced to a minimum, taking advantage of the benefits for reducing identification and registration tasks that will be provided by the future exchange of information and interoperability between European information systems.

c) Finally, the coexistence of these applicants for international protection with other categories of migrants in the Migration Detention Centres (CIEs) hinders the exhaustive identification and also encourages fraudulent actions taken by third-country nationals that must be returned. As it is pointed out, they often request international protection to take advantage of the benefits of this procedure. To avoid these potential conflicts, the 
Ministry of Interior should deploy further material and human resources to ensure compliance with the 4-day deadline for urgent processing (art. 21 LAPS) in the notification to the applicant. Notwithstanding that the future reform of the Spanish Immigration Act (LOEx) should include this type of fraudulent action as one of the most serious infringements (art. 54). 


\section{ANEXO BIBLIOGRÁFICO}

\section{DOCUMENTOS DOCTRINALES}

\subsection{OBRAS GENERALES, MONOGRAFÍAS Y LIBROS COLECTIVOS}

- ALLOTEY, P., The health of refugees: public health perspectives from crisis to settlement, Oxford: Oxford University Press, 2003.

- $\quad$ AlZAGA VILlaAMIL, O., La Constitución Española de 1978 (Comentario sistemático), Madrid: Ediciones del Foro, 1978.

- BAHTIYAR, Z., Exclusion clauses of the Refugee Convention in relation to national immigration legislations, European policy and human rights instruments: Article $1 F$ versus the non-refoulement principle, Oisterwijk: Wolf Legal Publishers (WLP), 2016.

- BECKER, U., HAGN, J, Reform of the European AsylumSystem: Why Common Social Standards are Imperative, CESifo DICE Report, fo Institut - Leibniz-Institut für Wirtschaftsforschung an der Universität München, vol. 14, nº 4, 2016.

- BEIRENS, H., Cracked Foundation. Uncertain Future: Structural Weaknesses in the Common European Asylum System, Brussels, Migration Policy Institute Europe, 2018.

- BOHLIN, A., Protection at the cost of Privacy. A study of the biometric registration of refugees, Master's Thesis, University of Lund, 2008.

- BONDANINI, F. B., La construcción identitaria de los migrantes en las fronteras de Europa. El caso del Centro de Estancia Temporal de Inmigrantes de Melilla. Tesis doctoral. Universidad de Granada, 2014.

- $\quad$ BOURBEAU, P., Handbook on Migration and Security, Elgar, 2017.

- BÜRLI, N., The Principle of Non-Refoulement under the ECHR and the UN Convention against Torture and Other Cruel, Inhuman or Degrading Treatment or Punishment Eman, Hamdan Brill/Nijhoff, 2016.

- CLAYTON, G., Textbook on Immigration and Asylum Law, Oxford University Press, 2016, 7th edition.

- COLLETT, E., Future EU policy development on immigration and asylum: Understanding the challenge, MPI policy brief series, $\mathrm{n}^{\circ} 4,2014$.

- COSTELlO, C., The Human Rights of Migrants and Refugees in European Law, Oxford, Oxford University Press, 2016.

- $\quad$ CRAIG, P., EU Administrative Law, Oxford: Oxford University Press, 2012.

- CUADRÓN AMBITE, S., Extranjeros en frontera. un estudio jurídico-práctico del reconocimiento, protección y límites del derecho de entrada en España, Dykinson, 2019.

- DE HERT, P., Biometrics: legal issues and implications: Brussels, European Commission, 2005.

- DÍAZ LAFUENTE, J., Asilo y refugio por motivos de orientación sexual e identidad de género, Madrid, Congreso de los Diputados, 2016, pp. 1-336.

- GACITÚA ESPÓSITO, A. L., El derecho fundamental a la protección de datos personales en el ámbito de la prevención y represión penal europea (en busca del equilibrio entre la libertad y la seguridad). Barcelona: Universidad Autónoma de Barcelona, 2014

- GRABENWARTER, C., European Convention on Human Rights. Commentary, Munich, CH Beck, Hart, Nomos, 2014. 
- GUILD, E., COSTEllO, C., GARLICK, M., MORENO-LAX, V., MOUZOURAKIS, M., "New approaches, alternative avenues and means of access to asylum procedures for persons seeking international protection". Study for the LIBE Committee. European Parliament, ${ }^{\circ}$ 20, 2014.

- GUILD, E., COSTELLO, C., MORENO-LAX, V., Implementation of the 2015 Council Decisions establishing provisional measures in the area of international protection for the benefit of Italy and of Greece, Study for the LIBE Committee of the European Parliament, 2017.

- JANS J., Profiling of asylum seekers, The Office of the Commissioner-general for Refugees and Stateless persons, 2010.

- $\quad$ KAHAlE CARRILlO, D.T., El nuevo sistema de derecho de asilo y de la protección subsidiaria, Andavira editora, 2017.

- $\quad$ KAUNERT, C., European internal security - towards supranational governance in the area of freedom, security and justice?, Europe in Change, Manchester University Press, Manchester, 2011.

- $\quad$ KINDT E., The processing of Biometric Data. A Comparative Legal Analysis with a focus on the Proportionality Principle and recommendations for a Legal framework, Katholieke Univerisiteit Leuven 2012.

- KINDT, E., MULLER, L. (eds.), Deliverable 3.10. Biometrics in identity management, Proyecto Fidis Future of Identity in the Information Society, 2007.

- $\quad$ LÓPEZ AGUILAR, J.F., Europa: Parlamento y Derechos. Paisaje tras la Gran Recesión, Tirant lo Blanch, 2017.

- MAGHIROS, I. Biometrics at the Frontiers: Assessing the Impact on Society, en: European Commission, Joint Research Centre RE et Institute for Prospective. For the European Parliament Committee on Citizens' Freedoms and Rights, Justice and Home Affairs (LIBE), Technological Studies (eds.), Technical Report Series, 1 de junio de 2005.

- MARTÍNEZ ALARCÓN, M.L., La política Europea de Protección Internacional. Sistema Europeo Común de Asilo, Thomson Reuters Aranzadi, $1^{\mathrm{a}}$ edición, 2018.

- MORENO LAX, V., Assessing Asylum in Europe - Extraterritorial Border Controls and Refugee Rights under EU Law, Oxford, Oxford University Press, 2017.

- MURPHY, C., EU Counter-Terrorism Law Pre-Emption and the Rule of Law, Hart Publishing, 2012.

- PARUSEL, B., SCHNEIDER, J., Reforming the Common European Asylum System: Responsibility-sharing and the harmonisation of asylum outcomes, Report 2017:9, Delmi, 2017.

- $\quad$ PEERS, S., MORENO-LAX, V., GARLICK M., GUILD E., Eurodac, en: EU Immigration and Asylum Law (Text and Commentary): Second Revised Edition, vol. 3, Brill/Nijhoff, 2015.

- $\quad$ PEERS S., HERVEY, T., KENNER, J., WARD A. (eds.), The EU Charter of Fundamental Rights - A Commentary, Oxford (Hart), 2014.

- RIJPMA, J., The proposal for a European Border and Coast Guard: evolution or revolution in external border management?, Study for the LIBE Committee of the European Parliament, 2016.

- SANTOLAYA MACHETTI, P. El derecho de asilo en la Constitución Española, Lex Nova, 2001. 
- SCHNEIDER, G., RIEDEL, L., The Asylum Lottery: Recognition Rates Vary Strongly within Germany, EU Immigration and Asylum Law and Policy: Droit et Politique de l'Immigration et de l'Asile de l'UE, 2017.

- TAZREITER, C., Asylum Seekers and the State. The Politics of Protection in a Security-Conscious World, London Routledge, 2017.

- TORPEY, J., The Invention of the Passport. Surveillance, Citizenship, and the State, Cambridge: Cambridge University Press, 2018.

- VALDEZ ARROYO, F., Ampliación del concepto de refugiado en el derecho internacional contemporáneo, Fondo Editorial PUCP, 2004.

- Van BALLEGOOIJ W., BAKOWSKI P., The cost of non-Europe in the fight against terrorism, EPRS, European Parliament, 2018.

- VIDINO, L et. BRANDON J., Countering Radicalization in Europe, The International Centre for the Study of Radicalisation and Political Violence (ICSR), London, 2012.

- $\quad$ ZAUN N., EU Asylum Policies: The Power of Strong Regulating States. Basingstoke, Palgrave Macmillan, 2017.

- ZIOTTI R., Cultures of Border Control: Schengen and the Evolution of Europe's Frontiers, Chicago II, University of Chicago Press, 2008.

\subsection{ARTÍCULOS DE REVISTAS}

\section{- Extranjeras}

- ALTERMAN, A., "A piece of yourself: Ethical issues in biometric identification", Ethics and Information Technology, vol. 5, 2003, pP. 139-150-

- ANDERSSON, R., "Hardwiring the Frontier? The Politics of Security Technology in Europe's 'Fight against Illegal Migration'”, Security Dialogue, vol. 47, $\mathrm{n}^{\mathrm{o}} 1,2016$, pp. 22-39.

- $\quad$ ANDRE V., F. MANSOURI, LOBO M., "A Fragmented Discourse of Religious Leadership in France: Muslim Youth between Citizenship and Radicalization," Journal of Muslim Minority Affairs, vol. 35, $\mathrm{n}^{\circ} .2,2015$, pp. 89-117.

- ANGELONI, S., SPANO, F.M., "Asylum Seekers in Europe: Issues and Solutions", Journal of International Migration and Integration, vol. 19, $\mathrm{n}^{\circ}$ 2, mayo de 2018, pp. 473-495.

- ARCHICK, K., "US-EU Cooperation against Terrorism", Congressional Research Service, diciembre 2014, pp. 1-30.

- BAIRD, T., "Functional Actorness? Border Security in the EU and Turkey", International Journal of Public Administration, vol. 38, n 12, 2015, pp. 849-859.

- BALDACCINI, A., "Counter-Terrorism and the EU Strategy for Border Security: Framing Suspects with Biometric Documents and Databases", European Journal of Migration and Law, vol. 10, n 1, 2008, pp. 31-49.

- BALDWIN-EDWARDS M., K. BLITZ B. et. CRAWLEY H., "The politics of evidence-based policy in Europe's 'migration crisis", Journal of Ethnic and Migration Studies", vol. 45, no 12, 2019, pp. 2139-2155.

- BEDUSCHI, A., "Digital identity: Contemporary challenges for data protection, privacy and non-discrimination rights", Big Data \& Society, 2019, pp. 1-6.

- BESSELINK, L.F.M., "National and constitutional identity before and after Lisbon", Utrecht Law Review, vol. 6, n 3, 2010, pp. 36-49. 
- BESTERS, M., BROM, F., “Greedy' Information Technology: The Digitalization of the European Migration Policy", European Journal of Migration and Law, vol. 12, 2010, pp. 455-470.

- BIGO, D., "The (in)securitization practices of the three universes of EU border control: Military/Navy-borderguards/police-database analysts", Security Dialogue, vol. 45, no 3, 2014, pp. 209-225.

- BREMBERG, N., "The European Union as Security Community-Building Institution: Venues, Networks and Co-operative Security Practices", Journal of Common Market Studies, vol. 53, no 3, 2015, pp. 674-692.

- BROUWER E., "Interoperability and Interstate Trust: a Perilous Combination for Fundamental Rights", EU Immigration and Asylum Law and Policy, 11 de junio de 2019.

- BROUWER, E., Eurodac: "Its limitations and temptations", European Journal of Migration and Law, vol. 4, $\mathrm{n}^{\mathrm{o}}$ 2, 2002, pp. 231-247.

- BUNYAN, T., The "point of no return" Interoperability morphs into the creation of a Big Brother centralised EU state database including all existing and future Justice and Home Affairs databases, Statewatch, mayo de 2018.

- CHENG, I.H., DRILLICH, A., SCHATTNER, P., "Refugee experiences of general practice in countries of resettlement: a literature review", British Journal of General Practice, $\mathrm{n}^{\mathrm{o}}$ 65, 2015, pp. 171-176.

- CORNELISSE, G., "What's wrong with Schengen? Border Disputes and the Nature of Integration in the Area without Internal Borders", Common Market Law Review, $\mathrm{n}^{\circ}$ 51, 2014, pp. 741-770.

- COMTE, F., "A New Agency Is Born in the European Union: The European Asylum Support Office", European Journal of Migration and Law, vol. 12, n 4, 2010, pp. 373-405.

- CRAGE, S., "The More Things Change ... Developments in German Practices towards Asylum Seekers and Recognised Refugees", Journal German Politics, vol. 25, $n^{\circ} 3,2016$, pp. 344-365.

- De BIE, J. L., De POOT, C. J., VAN DER LEUN, J. P., "Jihadi networks and the involvement of vulnerable immigrants: reconsidering the ideological and pragmatic value", Global Crime, vol. 15, no 3-4, 2014, pp. 275-298.

- De HERT, P., PAPAKONSTANTINOU, V., "The New Police and Criminal Justice Data Protection Directive: A First Analysis", New Journal of European Criminal Law, vol. 7, nº1, 2016, pp. 7-19.

- De BRUYCKER, P., "The European Border and Coast Guard: A new Model Built in an old logic", European Papers, A Journal on Law and Integration, n ${ }^{\circ}$ 1, 2016, pp. 559-569.

- De VRIES, G., “The European Union's Role in the Fight against Terrorism”, Irish Studies in International Affairs, vol. 16, 2005, pp. 3-9.

- DEN HEIJER, M., RIJPMA, J., SPIJKERBOER, T., "Coercion, Prohibition, and Great Expectations: The Continuing Failure of the Common European Asylum System", Common Market Law Review, no 53, 2016, pp. 607-642.

- DERNBACH, A., "Eurodac fingerprint database under fire by human rights activists", 2015.

- DINGOTT ALKOPHER, T., BLANC, E., "Schengen Area shaken: the impact of immigration-related threat perceptions on the European security community", Journal of International Relations and Development, vol. 20, $\mathrm{n}^{\circ}$ 3, 2017, pp. 511-542. 
- DRYWOOD, E., "Child-proofing' EU law and policy: interrogating the lawmaking processes behind European asylum and immigration provision", The International Journal of Children's Rights, vol. 19, n 3, 2011, pp. 405-428.

- DOBBS, M., "The Shifting Battleground of Article 4(2) TEU: Evolving National Identities and the corresponding need for EU management?", European Journal of Current Legal Issues, vol. 21, n 2, 2015.

- DOBBS, M., "Sovereignty, Article 4(2) TEU and the Respect of National Identities: Swinging the Balance of Power in Favour of the Member States?", Yearbook of European Law, vol. 33, n 1, 2014, pp. 298-334.

- ELEFTHERIADOU, M., "Refugee Radicalization/militarization in the age of the European refugee crisis: A Composite model", Terrorism and Political Violence Journal, 2018, pp. 1-22.

- FARRAJ, A., "Refugees and the Biometric Future: The Impact of Biometrics on Refugees and Asylum Seekers", Columbia Human Rights Law Review, n 42, 2010, pp. 891-941.

- $\quad$ FERRARIS V., "Economic Migrants and Asylum Seekers in Ten Fingers: Some Reflections on Eurodac and Border Control", Centre Border-Criminologies Blog, 2017.

- FIJNAUT, C., "The Refugee Crisis - The End of Schengen”, European Journal of Crime, Criminal Law and Criminal Justice, vol. 23, no 4, 2015, pp. 313-332.

- FRANTZIOU, E., "Constitutional Reasoning in the European Union and the Charter of Fundamental Rights: In Search of Public Justification", European Public Law, vol. 25, no 2, 2019, pp. 183-203.

- GRILlER, S., ORATOR, A.,"Everything Under Control? The "Way Forward" for European Agencies in the Footsteps of the Meroni Doctrine", European Law Review, 2010, pp. 3-35.

- GUILD, E. et. GARLICK, M., "Refugee protection, counter-terrorism and exclusion in the European Union", Refugee Studies Quarterly, vol. 29, n 4, 2010, pp. 63-82.

- GUILD, E., "Seguridad, Terrorismo y Asilo en el Schengen Area", Anuario CIDOB de la Inmigración, 2015-2016, pp. 58-78.

- HALL J., "Are Migrants More Extreme than Locals after War? Evidence from a Simultaneous Survey of Migrants in Sweden and Locals in Bosnia", Journal of Conflict Resolution, vol. 60, $\mathrm{n}^{\mathrm{o}}$ 1, 2016, pp. 89-117.

- HATHAWAY, J. C., "The Global Cop-Out on Refugees”, International Journal of Refugee Law, 2019, pp. 591-604.

- HOLLINS, K. "Comparative international approaches to establishing identity in undocumented asylum seekers," Lowy Institute's Migration and Border Policy Project, $\mathrm{n}^{\mathrm{o}} 8,11$ de abril de 2018.

- HUYSMANS, J., BUONFINO, A., "Politics of exception and unease: immigration, asylum and terrorism in parliamentary debates in the UK", Political Studies, vol. 56, n 4, 2008, pp. 766-788.

- JACOBSEN, K. L., "Experimentation in Humanitarian Locations: UNHCR and Biometric Registration of Afghan Refugees", Security Dialogue, vol. 46, n 2, 2015, pp. 144-164.

- JONES, W., TEYTELBOYM, A., “The International Refugee Match: A System that Respects Refugees' Preferences and the Priorities of States", Refugee Survey Quarterly, vol. 36, nº 2, 2017, pp. 84-109.

- KALKMANN, M., "Das Gesetz zur Einführung der Mitwirkungspflicht in Widerrufsverfahren”, Asylmagazin 1-2/2019. 
- KAUNERT, C., LÉONARD, S., "The development of the EU asylum policy: venue-shopping in perspective", Journal of European Public Policy, vol. 19, n 9, 2012, pp. 1396-1413.

- KAPFERER, S., "Exclusion Clauses in Europe - A Comparative Overview of State Practice in France, Belgium and the United Kingdom", International Journal of Refugee Law, vol. 12, 2000, pp. 195-221.

- KEPHART, J. L., "Immigration and Terrorism: Moving Beyond the 9/11 Staff Report on Terrorist Travel”, Connections, vol. 5, no 2, 2006, pp. 55-97.

- KERWIN, D., "How Robust Refugee Protection Policies Can Strengthen Human and National Security", Journal on Migration and Human Security, vol. 4, n $\mathrm{n}^{\mathrm{o}}$ 3, 2016, pp. 83-140.

- JACOBSEN, K. L., "On Humanitarian Refugee Biometrics and New Forms of Intervention", Journal of Intervention and Statebuilding, 2017, pp. 529-551.

- JASSERAND, C., "Legal Nature of Biometric Data: From 'Generic' Personal Data to Sensitive Data", European Data Protection Law review, vol. 2. n 3, 2016, pp. 297-311.

- KENK, V.S., KRIŽAJ, J., ŠTRUC, J., DOBRIŠEK S., "Smart Surveillance Technologies in Border Control", European Journal of Law and Technology, vol. 4, $\mathrm{n}^{\mathrm{o}}$ 2, 2013.

- KOSIŃSKA, A.M., "The Problem of Exclusion from Refugee Status on the Grounds of Being Guilty of Terrorist Acts in the CJEU Case-law: Commentary on the Lounani Case", European Journal of Migration and Law, vol. 19, n 4, 2017, pp. 425446.

- KOURACHANIS, N., "Asylum Seekers, Hotspot Approach and Anti-Social Policy Responses in Greece (2015-2017)", Journal of International Migration and Integration, vol. 19, $\mathrm{n}^{\mathrm{o}}$ 4, 2018, pp. 1153-1167.

- KUNER, C., "International Organizations and the EU General Data Protection Regulation Exploring the Interaction between EU Law and International Law", International Organizations Law Review, vol. 16, $\mathrm{n}^{\mathrm{o}}$ 1, 2019, pp. 1158-191.

- KUNER, C., DAN JERKER B., SVANTESSON, C., LYNSKEY, O., MILLARD, C., "Data protection and humanitarian emergencies", International Data Privacy Law, vol. 7, $\mathrm{n}^{\circ}$ 3, 1 de agosto de 2017, pp. 147-148.

- $\quad$ LARSAEUS, N., "The Relationship between Safeguarding Internal Security and Complying with International Obligations of Protection. The Unresolved Issue of Excluded Asylum Seekers", no 73, Nordic Journal of International Law, 2004, pp. 6997.

- $\quad$ LATONERO, M., HIATT, K., NAPOLITANO, A., ClERICETTI, G., PENAGOS, M., Digital Identity in the Migration \& Refugee Context: Italy Case Study, Data and Society, vol 4, 2019, pp. 1-42.

- LENAERTS, K., "Exploring the Limits of the EU Charter of Fundamental Rights", European Constitutional Law Review, vol. 8, nº. 3, 2012, pp. 375-403.

- LENAERTS, K., "Limits on Limitations: The Essence of Fundamental Rights in the EU", German Law Journal, vol. 20, nº 6, 2019, pp. 779-793.

- MITSILEGAS V., "Solidarity and Trust in the Common European Asylum System”, Comparative Migration Studies, vol. 2, n² 2, 2014, pp. 181-202.

- LOESCHER, G., MILNER, J., "Protracted Refugee Situations and State and Regional Insecurity", Conflict, Security, and Development, vol. 4, no. 1, 2014, pp. 3-20.

- NADIG, A., "Human Smuggling, National Security, and Refugee Protection", Journal of Refugee Studies, vol. 15, 1, 1 de marzo de 2002, pp. 1-25. 
- NESSER, P., "Jihadism in Europe after the Invasion of Iraq: Tracing Motivational Influences from the Iraq War on Jihadism in Western Europe", Studies in Conflict and Terrorism, vol. 29, no 4, 2006, pp. 323-342.

- NEUMANN, P. R., "Radicalized: New Jihadists and the Threat to the West", Democracy and Security, vol. 13, n 4, London: IB Tauris, 2016, pp. 395-396.

- NEYLON, A., "Producing Precariousness: 'Safety Elsewhere' and the Removal of International Protection Status under EU Law", European Journal of Migration and Law, vol. 21, no 1, 2019, pp. 1-25.

- NORREDAM, M., MYGIND, A., KRASNIK, A., "Access to health care for asylum seekers in the European Union-a comparative study of country policies", European Journal of Public Health, vol. 16, n 3, June 2006, pp. 286-90.

- OOSTEROM-STAPLES, H., "Using National Security and Public Policy to Combat Terrorism: The Case of the Netherlands", European Journal of Migration and Law, vol.10, $\mathrm{n}^{\mathrm{o}} 1,2008$, pp. 51-75.

- ORSINI, G., ROOS, C., "EU hotspots, relocation and absconded migrants in Italy. How to save Schengen within a failing Dublin system?", EL-CSID Policy Brief, Issue 2017/03, octubre de 2017, pp. 1-8.

- OWEN, D., "Refugees, EU Citizenship and the Common European Asylum System A Normative Dilemma for EU Integration", Ethical Theory and Moral Practice, Springer, 2019, pp. 347-369.

- PARKER, B., "Security lapses at aid agency leave beneficiary data at risk", The New Humanitarian, noviembre de 2017.

- PEERS S., "Foreign fighters' helpers excluded from refugee status: the ECJ clarifies the law", Blogspot EU Law Analysis, 31 de enero de 2017.

- PEERS, S., "Data protection rights and administrative proceedings", Blogspot EU Law Analysis, de 17 de julio de 2014.

- PRESHOVA, D., "Battleground or meeting point? Respect for national identities in the European union - Article 4(2) of the treaty on European Union", Croatian Yearbook of European Law and Policy, nº 8, 2012, pp. 267-298.

- QUIRINE, E., "Digital Security Governance and Accountability in Europe: Ethical Dilemmas in Terrorism Risk Management", Journal of Politics and Law, vol. 6, $n^{\text {o }} 4$, 2013, pp. 35-45.

- RACHOVITSA, A., "Engineering and lawyering privacy by design: Understanding online privacy both as a technical and an international human rights issue", International Journal of Law and Information Technology, $\mathrm{n}^{\mathrm{o}} 24,2016, \mathrm{pp}$. 374399.

- RAHMAN, Z., "Biometrics in the Humanitarian Sector", The Engine Room and Oxfam, marzo de 2018, pp. 1-22.

- REIDY, E. "How a fingerprint can change an asylum seeker's life", The New Humanitarian, 21 de noviembre de 2017.

- SCARNECCHIA D.P., RAYMOND N.A., GREENWOOD F., HOWARTH C, POOLE D.N., "A Rights-based Approach to Information in Humanitarian Assistance", PLOS Currents Disasters, ed. 1, 20 de septiembre de 2017.

- SCHARTUM DW, "Making privacy by design operative", International Journal of Law and Information Technology, vol. 24, $\mathrm{n}^{\circ}$ 2, 2016, pp. 151-175.

- SCHMID, A., P., "Radicalisation, De-Radicalisation, Counter-Radicalisation: A Conceptual Discussion and Literature Review", The International Centre for CounterTerrorism - The Hague 4, n 2, 2013, pp. 1-97. 
- SINGER, S., "Exclusion Clauses of the Refugee Convention in Relation to National Immigration Legislations, European Policy and Human Rights Instruments: Article $1 F$ versus the Non-Refoulement Principle", International Journal of Refugee Law, vol. 29, $\mathrm{n}^{\mathrm{o}}$ 1, marzo de 2017, pp. 198-200.

- SPIKERBOER, T., "The human costs of burden control”, European Journal of Migration and Law, 9 (1), 2007, pp. 147-161

- $\quad$ STRONG, J, VARADY, C, CHAHDA, N., "Health status and health needs of older refugees from Syria in Lebanon”, Conflict and Health, 2015, vol. 9, n 1, 2015.

- $\quad$ PEERS, S., "Legislative Update, EU Inmigration and Asylum Competence and Decision Marking in the Treaty of Lisbon", European Journal of Migration and Law, vol. 10, n 2, 2008, pp. 219-247.

- PLOEG, I., "The Illegal Body: 'Eurodac' and the Politics of Biometric Identification" Ethics and Information Technology, vol. 1, no 4, 1999, pp. 295-302.

- ROOTS, L., "The New EURODAC Regulation: Fingerprints as a Source of Informal Discrimination", Baltic Journal of European Studies Tallinn University of Technology, vol. 5, $\mathrm{n}^{\mathrm{o}}$ 2, 2015, pp. 108-129.

- TANGERMANN, J., "Documenting and Establishing Identity in the Migration Process Challenges and Practices in the German Context Focussed", Study by the German National Contact Point for the European Migration Network (EMN), European Union Working Paper, $\mathrm{n}^{\mathrm{o}}$ 76, 27 de septiembre de 2017, pp. 1-62.

- TRAUNER, F., "Asylum policy: the EU's 'crises' and the looming policy regime failure", Journal of European Integration, vol. 38, n 3, 2016, pp. 311-325.

- TZANOU, M., "The EU as an Emerging Surveillance Society: The Function Creep Case Study and Challenges to Privacy and Data Protection", Vienna Online Journal on International Constitutional Law, vol. 4, no 3 2010, pp. 407-427.

- VAVOULA N., "The 'Puzzle' of EU Large-Scale Information Systems for Third-Country Nationals: Surveillance of Movement and Its Challenges for Privacy and Personal Data Protection", European Law Review, octubre de 2019 (pendiente de publicación), pp. 1-32.

- VON BOGDANDY, A., SCHILL, S., "Overcoming Absolute Primacy: Respect for National Identity under the Lisbon Treaty", Common market law review, vol, $48, \mathrm{n}^{\circ}$ 5, 2011, pp. 1417-1453.

- TAMBOU, O., "The New French Antiterrorism Law: Towards a Balance between Security and Liberty after the State of Emergency?", European Data Protection Law Review, vol. 3, n 4, 2017, pp. 518-523.

- TSOURDI, L., "Bottom-up Salvation? From Practical Cooperation Towards Joint Implementation Through the European Asylum Support Office", European Papers: a Journal on Law and Integration, vol. 1, no 3 2016, pp. 997-1031 .

- ZAUN, N., "States as Gatekeepers in EU Asylum Politics: Explaining the Nonadoption of a Refugee Quota System", Journal of Common Market Studies, vol. 56, $\mathrm{n}^{\circ} 1$, 2018, pp. 44-62.

- Nacionales

- ARRUFAT CÁRDAVA, A., "Revocación de la condición de refugiado por riesgo para la seguridad nacional", Revista Española de Derecho Internacional, Madrid, enero-junio, 2014, pp. 226-229.

- ALlUÉ BUIZA, A., "Los derechos fundamentales en Turquía, un claro retroceso", Teoría y Realidad Constitucional, no 38, 2016, pp. 471-485. 
- $\quad$ ALMQVIST, J.M., "El derecho de asilo y los límites a su aplicación por delito de lesa humanidad", Revista Española de Derecho Internacional, Madrid, enero-junio, 2014, pp. 181- 237.

- $\quad$ BILBAO UBILlOS, J.M., "La llamada Ley Mordaza: la Ley Orgánica 4/2015 de protección de la seguridad ciudadana, Teoría y Realidad Constitucional, $\mathrm{n}^{\mathbf{0}} 36,2015$, pp. 217-260.

- BONFIGLIO, S.,"The Right not to be criminalised", Democrazia e Sicurezza, Democracy Security Review, anno III, n 3, 2013, pp. 1-7.

- BURGOS GOYE, M. C., "La errática política migratoria española de la inmigración africana en las ciudades autónomas de Ceuta y Melilla", Revista de derecho migratorio y extranjería, $\mathrm{n}^{\circ}$ 37, 2014, pp. 301-328.

- CARRERA HERNÁNDEZ, F.J., "Jurisprudencia española en materia de Derecho internacional público - Comentarios de sentencias - Revocación del estatuto de refugiado por motivos de seguridad nacional", Revista Española de Derecho Internacional, Madrid, enero-junio, 2014, pp. 201-205.

- DEL VALlE GÁlVEZ, A., "Unión Europea, crisis de refugiados y limes imperii", Revista General de Derecho Europeo, n. 38, 2016, pp. 1-13.

- De VERGOTTINI, G., "La difícil convivencia entre libertad y seguridad. Respuestas de las democracias al terrorismo", Revista de Derecho Político, n 61, 2004.

- De VERGOTTINI, "El diálogo entre tribunales", Teoría y Realidad Constitucional, $\mathrm{n}^{\circ} 28,2011$, pp. 335-352.

- $\quad$ FERNÁNDEZ PÉREZ, A., "La regulación de las devoluciones y expulsiones de extranjeros: la ilegalidad de las devoluciones de extranjeros efectuadas sin las debidas garantías", Diario La Ley, no 8382, 2014, pp. 309-329.

- FERNÁNDEZ ROJO, D., "Los hotspots: expansión de las tareas operativas y cooperación multilateral de las agencias europeas Frontex, Easo y Europol", Revista de Derecho Comunitario Europeo, $\mathrm{n}^{\circ}$ 61, 2018, pp. 1038-1043.

- FERNÁNDEZ ROJO, D., "Reglamento 2016/1624: de Frontex a la Guardia Europea de Fronteras y Costas", Revista General de Derecho Europeo, no 41, 2017, pp. 223-251.

- GARCÍA MAHAMUT, R., "La ductilidad del derecho a la protección internacional (refugio y protección subsidiaria) ante las crisis humanitarias: un desafío para Europa y para el Sistema Común de Asilo", Teoría y Realidad Constitucional, $\mathrm{n}^{\mathrm{o}}$ 38, 2016, pp. 211-238.

- GARCÍA MAHAMUT, R., VIGURI CORDERO, J., "La protección de los datos personales de los solicitantes de protección internacional en el (nuevo) Sistema Europeo Común de Asilo: grandes desafíos y graves deficiencias", Teoría y Realidad Constitucional, $\mathrm{n}^{\mathrm{o}}$ 44, 2019, pp. 237-270.

- GARCÍA ROCA, J., "El diálogo entre el Tribunal Europeo de Derechos Humanos y los Tribunales Constitucionales en la construcción de un orden público europeo", Teoría y Realidad Constitucional, n 30, 2012, pp. 183-224.

GARCÍA VITORIA, I., "Una década sin Reglamento de Asilo en España. Obstáculos e interpretaciones divergentes", Anuario CIDOB de la Inmigración 2018.

- GIL BAZO, M., "Refugee Status, Subsidiary Protection, and the Right to Be Granted Asylum Under EC Law", UNHCR, New Issues in Refugee, Research Paper, $\mathrm{n}^{\mathrm{o}}$ 136, 5 de enero de 2007, pp. 1-33.

- GOIG MARTÍNEZ, J.M., "Inmigración, asilo y refugio ante los retos actuales de la política exterior europea", Revista de Derecho UNED, $\mathrm{n}^{\circ} 18,2016$, pp. 55-84. 
- GOIZUETA VÉRTIZ, J., "La cooperación policial en el seno de Europol: el principio de disponibilidad y la confidencialidad de la información", Revista Española de Derecho Constitucional, $\mathrm{n}^{\circ}$ 110, 2017, pp. 75-103.

- GONZÁLEZ FUSTER G., "TEDH - Sentencia de 04.12.2008, S. y Marper c. Reino Unido, 30562/04 y 30566/04 - Artículo $8 \mathrm{CEDH} \mathrm{-} \mathrm{Vida} \mathrm{privada-} \mathrm{Injerencia} \mathrm{en}$ una sociedad democrática - Los límites del tratamiento de datos biométricos de personas no condenadas", Revista de Derecho Comunitario Europeo, $\mathrm{n}^{\mathbf{0}} 33$, mayo/agosto, 2009, pp. 619-633.

- GONZÁLEZ GARCÍA, J., "Expulsiones «en caliente», devoluciones y petición de asilo en Ceuta y Melilla", Revista de Administración Pública, no 196, Madrid, eneroabril, 2015, pp. 309-329.

- GONZÁleZ VEGA, J., "Mitos y mistificaciones: la Unión Europea y la protección internacional (a propósito de la crisis de los refugiados)", Revista de Derecho Comunitario Europeo, ${ }^{0}$ 56, 2017, pp. 27-75.

- JIMENA QUESADA, L., "La consagración de los derechos fundamentales: de principios generales a texto fundacional de la Unión Europea", Cuadernos europeos de Deusto, $\mathrm{n}^{\circ}$ 50, 2014, pp. 173-197.

- JIMENA QUESADA, L., "The Protection of Forcibly Displaced Persons under the European Social Charter", en Joint UNHCR/Council of Europe Colloquium on the Role of the Regional Human Rights Courts in Interpreteing and Enforcing Legal Standards for the Protection of Forcibly Displaced Persons. Conference Report, Strasbourg, Council of Europe, 2011, pp. 109 -119.

- LOPEZ GUERRA, L., "La evolución del Sistema Europeo de Protección de Derechos Humanos, Teoría y Realidad Constitucional, n 42, 2018, pp. 111-130.

- $\quad$ LOPEZ GUERRA, L., "El Tribunal Europeo de Derechos Humanos, el Tribunal de Justicia de la UE y «le mouvement nécessaire des choses»", Teoría y Realidad Constitucional, $\mathrm{n}^{\mathrm{o}}$ 39, 2017, pp. 163-188.

- LOPEZ GUERRA, L., "El diálogo entre el Tribunal Europeo de Derechos Humanos y los tribunales españoles. Coincidencias y divergencias", Teoría y Realidad Constitucional, $\mathrm{n}^{\mathrm{o}} 32,2013$, pp. 139-158.

- $\quad$ LOPEZ AGUILAR, J. F., "De nuevo (y todavia) Polonia: Rule of Law y art.7 TUE en el Parlamento Europeo y el Tribunal de Justicia", Teoría y Realidad Constitucional, $\mathrm{n}^{\mathrm{o}}$ 44, 2019, pp. 137-176.

- LOPEZ AGUILAR, J. F., "El caso de Polonia en la UE: retrocesos democráticos y del estado de derecho y "dilema de Copenague»", Teoría y Realidad Constitucional, $\mathrm{n}^{\mathrm{o}} 38,2016$, pp. 101-142.

- LOPEZ AGUILAR, J.F., "El legislador europeo en materia de seguridad y justicia tras el Tratado de Lisboa: avances hacia la cooperación judicial penal en la UE", Teoría y Realidad Constitucional, $\mathrm{n}^{\mathrm{o}}$. 32, 2013, pp. 179-204.

- LÓPEZ-SALA, A., "La inmigración irregular en Ceuta y Melilla en 2014: prácticas de control y debate público", Anuario CIDOB de la Inmigración, 2015, pp. 169-192.

- MARIA PORTILlA, F. J., "Examen de las Sentencias del Tribunal de Estrasburgo que afectan al Reino de España", Teoría y Realidad Constitucional, $\mathrm{n}^{\circ}$ 42, 2018, pp. 273-310.

- MARTÍNEZ ESCAMILLA, M., SÁNCHEZ TOMÁS, J. M., "Devoluciones ilegales en la Frontera Sur. Análisis jurídico de las denominadas devoluciones en caliente", febrero de 2015, pp. 1081-1103. 
- MARTÍNEZ LOPEZ-SAEZ, M., “A la búsqueda de la identidad constitucional: una aproximación al caso español y europeo en clave de pluralismo constitucional y diálogo judicial", Revista de Derecho Político, n 105, 2019, pp. 315-358.

- MORGADES GIL, S., "La política de asilo en España en el contexto europeo: cambios recientes y perspectivas de desarrollo normativo", Anuario de la Inmigración en España 2014, edición 2015, pp. 225-248.

- MORGADES GIL, S., "La protección de los demandantes de asilo por razón de su vulnerabilidad especial en la jurisprudencia del Tribunal Europeo de Derechos Humanos", Revista de Derecho Comunitario Europeo, no 37, 2010, pp. 801-842.

- MONTILLA MARTOS, J.A., GARCÍA VITORIA, I, RODRÍGUEZ CANDELA, J. L., "Política y normativa española sobre inmigración y asilo". ¿Bajo perfil o inacción?", Anuario de la Inmigración en España 2017, 2018, pp. 106-122.

- PORRAS RAMÍREZ, J. M., "El sistema europeo común de asilo y la crisis de los refugiados. Un nuevo desafío de la globalización", Revista de Estudios Políticos, $\mathrm{n}^{\mathrm{o}}$ 175, 2017, pp. 207-234

- OLESTI RAYO, A., "Las políticas de la Unión Europea relativas al control de las fronteras, asilo e inmigración", Revista de Derecho Constitucional Europeo, $\mathrm{n}^{\circ}$ 10, 2008, pp. 13-48.

- ORTEGA GIMÉNEZ, A., ALARCÓN MORENO, J. "Luces y sombreas de la nueva Ley de Asilo", Iuris, enero de 2010, pp. 42-49.

- PEREZ SOLA, N. "El derecho de asilo y la condición de refugiado", Revista Derechos y Libertades, n 25, Época II, junio 2011, pp. 269-308.

- PUIG DE LA BELLACASA, R., "Europa ante sí misma", Claves de Razón Práctica, no 244, 2016, pp. 9-19.

- $\quad$ ROCA TRÍAS, E., GARCÍA COUSO S., “¿Es real el diálogo entre tribunales? Cuestión prejudicial y control de constitucionalidad por vulneración de derechos y libertades fundamentales", Teoría y Realidad Constitucional, n 39, 2017, pp. 529-548.

- RUIZ SUTIL C., "El rechazo en frontera o la denominada "devolución en caliente" y su regulación en la LOEX", Revista española de derecho internacional, vol.. 68, $\mathrm{n}^{\mathrm{o}} 2$ 2, 2016, pp. 329-336.

- SAGARRA TRIAS, E. "Devoluciones en caliente y la "Ley Orgánica de Protección de la Seguridad Ciudadana": ¿Medida sancionadora inconstitucional en España?", Revista vLex, nº130, 2015, pp. 22-32.

- SANCHEZ TOMÁS, J.M., "Las devoluciones calientes en el TEDH en el Tribunal Europeo de Derechos Humanos (STEDH, AS. N.D. y N.T. vs España), Revista Española de Derecho Europeo, no 65, Enero-Marzo 2018, pp. 101-135.

- SÁNCHEZ VARELA, J.L., "La realidad de los centros de internamiento de extranjeros: situación de las personas internadas", XIV edición del Máster Universitario en Protección Internacional de los Derechos Humanos (Universidad de Alcalá), 2018, pp. 1-75.

- SANTOS VARA, J., "La transformación de Frontex en la Agencia Europea de la Guardia de Fronteras y Costas: ¿hacia una centralización en la gestión de las fronteras?", Revista de Derecho Comunitario Europeo, n 59, 2018, pp. 143-186.

- SARDINA CÁMARA, P., "Comentarios a la Ley 12/2009, de 30 de octubre, reguladora del derecho de asilo y de la protección subsidiaria", Diario La Ley, $\mathrm{n}^{\circ} 7370$, 2010.

- $\quad$ SERRA CRISTÓBAL, R., "El control de datos de circulación de personas en la UE como mecanismo de salvaguarda de la seguridad nacional", Revista de derecho político, $\mathrm{n}^{\mathrm{o}} 102,2018$, pp. 305-332. 
- SERRA CRISTÓBAL, R., "Los derechos fundamentales en la encrucijada de la lucha contra el terrorismo yihadista. Lo que el constitucionalismo y el derecho de la Unión Europea pueden ofrecer en común", Teoría y Realidad Constitucional, $\mathrm{n}^{\circ} 38$, 2016, pp. 487-503.

- SOLER GARCÍA, C., La prohibición de las expulsiones colectivas de extranjeros en la jurisprudencia del Tribunal Europeo de Derechos Humanos: especial referencia al caso de España, Revista General de Derecho Europeo, no 45, 2018, pp. 107-160.

- $\quad$ TRIANDAFYLLIDOU, A., "Nuevos retos para Europa: migración, seguridad y derechos de ciudadanía", Revista CIDOB d'Afers Internacionals, $\mathrm{n}^{\mathrm{0}}$ 69, Fundació CIDOB, mayo 2005, pp. 39-59.

- VALLÉS FERRERO, M., ¿Vallas al asilo? Apuntes sobre el sistema de protección internacional en España, Anuario CIDOB de la Inmigración 2015-2016, 2016, pp. 226-245.

\subsection{CAPÍTULOS DE LIBRO}

- ADLER, E. BARNETT, M., "Security Communities in Theoretical Perspective" en: Security Communities, Cambridge University Press, 1998, pp. 29-65.

- ARENAS HIDALGO, N., "Derecho Internacional y Europeo de las Personas Refugiadas" en: MARIÑO MENÉNDEZ F.M., PÉREZ GONZÁLEZ C., CEBADA ROMERO A., (Coords.). Instrumentos y Regímenes de Cooperación Internacional, TROTTA, 2017, pp. 177-202.

- BAYLIS, E. A., "National Security and Political Asylum" en: D'APPOLLONIA, A. C., REICH S., (Eds.), Immigration, Integration, and Security: America and Europe in Comparative Perspective, University of Pittsburgh Press, 2010, pp. 164-180.

- BOEHM, F., "Data Protection Standard in the AFSJ", en: Information sharing and data protection in the Area of Freedom, Security and Justice - Towards harmonised data protection principles for information exchange at EU-level, Springer, 2011, pp. 19-173.

- BOGGIA COSADIA, F., "Protection subsidiare et menace à l'ordre public: l'application de la clause d'exclusion de l'article 17(1)(d) de la directive 2004/83/CE du Conseil de l'Union européenne en France" en: CHETAIL V., LALY-CHEVALIER C., (eds.), Asile et extradition: Théorie et pratique de l'exclusion du statut de réfugié, Bruylant, 2014, pp. 56-78.

- BOROWSKY, M, “Artikel 52” en: MEYER J., (ed.), Charta der Grundrechte der Europäischen Union, Baden-Baden $4^{\text {a }}$ edición Nomos, 2014, pp. 771-811.

- BROUWER, E., "Data Surveillance and Border Control in the EU: Balancing Efficiency and Legal Protection" en: BALZACQ T., CARRERA S., (eds.), Security Versus Freedom? A Challenge for Europe's Future, Ashgate, 2013, pp. 137-155.

- BROUWER, E., "Legality and Data Protection Law: The Forgotten Purpose of Purpose Limitation" en: L. BESSELINK, F. PENNINGS, S. PRECHAL (eds.), The Eclipse of the Legality Principle in the European Union, Kluwer Law Internacional, 2011, pp. 273-294.

- BROUWER, E., "Effective Remedies in Immigration Procedures: ECHR" en: Digital Borders and Real Rights, Effective Remedies for Third-Country Nationals in the Schengen Information System, 2008, Brill | Nijhoff, pp. 177-243.

- BUISÁN GARCÍA, N., "Derecho de Asilo y protección de los refugiados" en: CASAS BAAMONDE M. E., RODRÍGUEZ M., (Dir.), Comentarios a la Constitución 
Española. Madrid: Wolters Kluwer, 2009.

- BURGORGUE-LARSEN, L., "A Huron at the Kirchberg Plateau or a Few Naïve Thoughts on Constitutional Identity in the Case-Law of the Judge of the European Union" en: ARNAIZ A., LLIVINA C., (eds.), National Constitutional Identity and European Integration, Cambridge, Intersentia, 2013, pp. 275-304.

- BUZAN, B., "Security Analysis: Conceptual Apparatus" en: BUZAN B., WAEVER O., WILDE de JAAP (eds), Security. A New Framework for Analysis, Boulder, CO, London, Lynne Rienner, 1998, pp. 21-48.

- CALVO MARISCAL, L., "Situación actual del asilo y refugio en la frontera sur de España: la práctica en las ciudades de Ceuta y Melilla" en: SÁNCHEZ FRÍAS, A., DE ASÍS PEÑA DÍAZ F., SALINAS DE FRÍAS A., MARTÍNEZ PÉREZ E.J., La Unión Europea y la protección de los derechos fundamentales, 2018, pp. 233-246.

- CLAES, M., "Negociating Constitutional Identity or Whose Identity is it Anyway? en: Constitutional Conversations in Europe: Actors, Topics and Procedures, Intersentia, 2012, pp. 205-233.

- KLAMBERT, M., "Article 4" en: Commentary on the EU: Treaties and the Charter of Fundamental Rights, KLAMERT, M., KELLERBAUER, M., TOMKIN J. (eds.), Oxford, 2019.

- DE BRUYCKER P., "Towards a new European consensus on migration and asylum" en: DE BRUYCKER P., DE SOMER, M., DE BROUWER, J. (eds.), From Tampere 20 to Tampere 2.0: Towards a new European consensus on migration, European Policy Centre, diciembre de 2019, pp. 145-159.

- DE WITTE, B., "Exclusive Member State Competences - Is There Such a Thing?" en: GARBEN, S. et. GOVAERE, I., (eds.), The Division of Competences Between the EU and the Member States: Reflections on the Past, the Present, and the Future, Portland, OR: Hart Publishing, 2017, pp. 71-72.

- DIAZ LAFUENTE, J., "Los desafíos de la sociedad global digitalizada y la protección de datos personales. Análisis de la elaboración de perfiles en el Reglamento General de Protección de Datos de la Unión Europea" en: GARCÍA MAHAMUT R., TOMÁS MALlÉN, B. (eds.), El Reglamento General de Protección de Datos. Un enfoque nacional y comparado. Especial referencia a la LO 3/2018 de protección de datos y garantía de los derechos digitales, Ed. Tirant lo Blanch. Valencia, 2019, pp. 287-309.

- DIMITROVA D., De HERT P., "The Right of Access Under the Police Directive: Small Steps Forward" en: MEDINA M., MITRAKAS A., RANNENBERG K., SCHWEIGHOFER E., TSOUROULAS N. (eds.), Privacy Technologies and Policy, Springer, Cham, 2018, pp. 11-130.

- DONAIRE VILLA, F. J. “¿De qué hablamos cuando hablamos de coordinación en el ámbito de la Unión Europea y, por tanto, del ELSJ?" en F. J. DONAIRE VILLA et. A. OLESTI RAYO (dirs.). Técnicas y ámbitos de coordinación en el Espacio de Libertad, Seguridad y Justicia, Marcial Pons, Madrid, 2015, pp. 13-46.

- $\quad$ EL-ENANY, N., THIELEMANN, E., "The Impact of EU Asylum Policy on National Asylum Regimen” en: WOLFF S., GOUDAPPEL F., et. De ZWAAN J. (eds.), Freedom Security and Justice after Lisbon and Stockholm, The Hague, TMC Asser, 2011, pp. 97-116.

- $\quad$ EULE T.G., BORRELLI L.M., LINDBERG A., WYSS A., "Decision-Making and the Role of Law” en: Migrants Before the Law, Palgrave Macmillan, Cham, 2019, pp. 81-110. 
- GARCÍA MAHAMUT, R., en: “Artículo 13.4”, Comentario a la Consitución Española 40 Aniversario 1978-2018, PÉREZ TREMS, P., SAIZ ARNAIZ, A. (Dir.), Valencia, Tirant lo Blanch, 2018, pp. 329-340.

- GARCÍA MAHAMUT, R., "El nuevo régimen jurídico del derecho de asilo y de la protección subsidiaria en España a la luz de la Ley 12/2009, de 30 de octubre: principales novedades y desafíos" en: GARCÍA MAHAMUT, R., GALPARSORO, J., VIDAL FUEYO, M., Régimen Jurídico del derecho de asilo en la Ley 12/2009, $1^{\mathrm{a}}$ edición, Centro de Estudios Políticos y Constitucionales, Madrid, 2010, pp. 15-91.

- GALPARSORO, J. "Una nueva ley de asilo en tiempos de crisis" en: GARCÍA MAHAMUT, R., GALPARSORO, J., VIDAL FUEYO, M., Régimen Jurídico del derecho de asilo en la Ley 12/2009, $1^{\mathrm{a}}$ edición, Centro de Estudios Políticos y Constitucionales, Madrid, 2010, pp. 95-138.

- GILBERT, S., "Exclusion under Article 1F since 2001: Two steps backwards, one step forward" en: CHETAIL V., BAULOZ C. (eds.), Research Handbook on International Law and Migration. Research Handbooks in International Law (Cheltenham: Edward Elgar Publishing), 2014, pp. 519-540.

- GONZALEZ FUSTER, G., GUTWIRTH, S., "When 'digital borders' meet 'surveilled geographical borders'. Why the future of EU border management is a problema" en: BURGESS E., GUTWIRTH S., (eds.), A Threat Against Europe?: Security, Migration and Integration, Vubpress, 2011, pp. 509-528.

- GROUSSOT, X., "Constitutional Dialogues, Pluralism and Conflicting Identities" en: AVBELJ M., KOMÀREK J., (eds.), Constitutional Pluralism in the European Union and Beyond, Oxford: Hart Publishing, 2012, pp. 319-341.

- $\quad$ GROENENDIJK, K., "New Borders Behind Old Ones: Post-Schengen Controls Behind internals Borders and Inside The Netherlands and Germany" en: GROENENDIJK K., GUILD E., MINDERHOUD P., (eds.), In Search of Europe's Borders, Kluwer Law International, La Haya, 2003.

- GUILD, E., "Chapter IV. Unreadable Papers?, The EU's first experiences with biometrics: Examining EURODAC and the EU's Borders" en: J. LODGE (ed.), Are you who you say you are? The EU and Biometric Borders, Nijmegen, Wolf Legal Publishers, 2007, pp. 31-43.

- HATHAWAY, J., FOSTER, M., "Serious harm" en: The Law of Refugee Status. Cambridge: Cambridge University Press, 2014, pp. 182-287.

- HUYSMANS, J., "Migrants as a security problem: Dangers of 'securitizing' societal issues" en: MILES R., THRANHARDT D, (eds.). Migration and European integration: The dynamics of inclusion and exclusion. London: Pinter Publishers, 1995, pp. 53-61.

- JAKULEVIČIENĖ, L., "The Common European Asylum System" en: DE BRUYCKER P., DE SOMER, M., DE BROUWER, J. (eds.), From Tampere 20 to Tampere 2.0: Towards a new European consensus on migration, European Policy Centre, diciembre de 2019, pp. 87-103.

- JIMENA QUESADA, L., "El asilo en los instrumentos europeos de derechos humanos: sinergias y optimización protectora ante la crisis humanitaria", en la obra colectiva Europa, ¿Tierra de asilo? Desafios y respuestas, Ararteko, Colección "Jornadas sobre derechos humanos", Vitoria-Gasteiz, 2016, pp. 1-36.

- KOSER, K., CUNNINGHAM, A., "Migration, Violent Extremism and Terrorism: Myths and Realities" en: Global Terrorism Index 2015: Measuring and Understanding the Impact of Terrorism Institute for Economics and Peace, 2015, pp. 83-85. 
- KINDT, E., "Biometric Data, Data Protection and the Right to Privacy" en: Privacy and Data Protection Issues of Biometric Applications, Law, Governance and Technology Series, vol. 12. Springer, Dordrecht, 2013, pp. 87-272.

- LAUTERPACHT, E., BETHLEHEM, D., "The scope and content of the principle of non-refoulement: Opinion" en: FELLER, E., TÜRK V., NICHOLSON F., (eds.), Refugee Protection in International Law Cambridge, CUP, 2003, pp. 87-177.

- LÉONARD, S., KAUNERT, C., "The development of the Common European Asylum System (CEAS). The absence of securituzation in the EU asylum policy venue" en: Refugees, Security and the European Union, Roudledge, UACES Contemporary European Studies, 2019, pp. 108-121.

- $\quad$ LOPEZ AGUILAR, J.F., "La protección de datos en la UE: el punto de vista del Parlamento Europeo" en: GARCÍA MAHAMUT R., TOMÁS MALLÉN, B. (eds.), El Reglamento General de Protección de Datos. Un enfoque nacional y comparado. Especial referencia a la LO 3/2018 de protección de datos y garantía de los derechos digitales, Editorial Tirant lo Blanch. Valencia, 2019, pp. 31-48.

- MAIANI, F., "The Dublin III Regulation: A New Legal Framework for More Humane System?" CHETAIL, V., DE BRUYCKER P., MAIANI F. (eds.), Reforming the Common European Asylum System, Immigration and Asylum Law and Policy in Europe, vol. 39, Brill | Nijhoff, pp. 99-142.

- PORGES, M., "Western Sahara and Morocco: Complexities of Resistance and Analysis" en: DE VRIES L., ENGLEBERT P., SCHOMERUS M. (eds.), Secessionism in African Politics. Palgrave Series in African Borderlands Studies. Palgrave Macmillan, Cham, 2019, pp. 127-149.

- RIJPMA, J., "Frontex and the European System of Border Guards: The Future of European Border Management", en FLETCHER, M., HERLIN-KARNELL E., MATTERA C., (eds.). The European Union as an Area of Freedom, Security and Justice. 2016, London: Routlegde, pp. 217-246.

- ROMMETVEIT, K., "Introducing Biometrics in the European Union: Practice and Imagination", en DELGADO A. (ed.) Technoscience and Citizenship: Ethics and Governance in the Digital Society. The International Library of Ethics, Law and Technology, vol 17. Springer, Cham, 2016, pp. 113-126.

- SANTOLAYA MACHETTI, P., "La reforma del derecho de asilo por la Ley 12/2009, en: Coloquios Jurídicos sobre América Latina", Seminario: Las reformas legales en los ámbitos de extranjería y asilo, Universidad de Alcalá, 19 de febrero de 2010.

- VAVOULA, N., "Towards the normalisation of surveillance of movement in an era of 'Privacy Spring'?”, en: VERMEULEN G., LIEVENS E., (eds.), Data protection and privacy under pressure: transatlantic tensions, EU surveillance, and big data, Maklu, 2017, pp. 215-248.

- VAVOULA, N., "The recast Eurodac Regulation: Are Asylum Seekers Treated as Suspected Criminals", en: BAULOZ, C., INELI-CIGER, M., SINGER S., STOYANOVA V., (eds.), Seeking Asylum in the European Union: Selected Protection Issues Raised by the Second Phase of the Common European Asylum System, 2015, pp. 247-273.

- VEDSTED-HANSEN, J., "Reception conditions as human rights: pan-European standard or systemic deficiencies?" en CHETAIL, V., DE BRUYCKER P., MAIANI F. (eds.), Reforming the Common European Asylum System, Immigration and Asylum Law and Policy in Europe, vol. 39, Brill | Nijhoff, pp. 319-324. 
- VIGURI CORDERO, J., "Los mecanismos de certificación (códigos de conducta, sellos y marcas)", en RALLO LOMBARTE, A., y GARCÍA MAHAMUT, R. (eds.), Hacia un nuevo derecho europeo de protección de datos, Editorial Tirant lo Blanch. Valencia, 2015, pp. 901-959.

- VIGURI CORDERO, J., "Los mecanismos de certificación en la Ley Orgánica de Protección de Datos y Garantía de los Derechos Digitales: un nuevo paradigma a la luz del RGPD" en GARCÍA MAHAMUT R., TOMÁS MALLÉN, B. (eds.), El Reglamento General de Protección de Datos. Un enfoque nacional y comparado. Especial referencia a la LO 3/2018 de protección de datos y garantía de los derechos digitales, Editorial Tirant lo Blanch. Valencia, 2019, pp. 369-389.

- VON DANWICH, T., "The Rule of Law in the Recent Jurisprudence of the ECJ", en: SCHROEDER W. (ed.), Strengthening the Rule of Law in Europe. From a Common Concept to Mechanisms of Implementation, Hart Publishing, Modern Studies in European Law, 2016.

- VÖLKEL J., "When Interior Ministers play diplomats. Fatal ambiguities in Europe's securitised migration policy", en: JÜNEMANN A, FROMM N., SCHERER N, (eds.), Fortress Europe? Challenges and Failures of Migration and Asylum Policies, Wiesbaden: Springer VS. 2017, pp. 83-103.

- SCOTT, M., "Refugee from Climate Change-Related Harm. Evaluating the Scope of International Protection within the Common European Asylum System", en: BAULOZ C., INELI-CYGER M., SINGER S., STOYANOVA V. (eds.), Seeking Asylum in the European Union. Selected Protection Issues Raised by the Second Phase of the Common European Asylum System, Leiden: Brill/Nijhoff, 2015.

\section{DOCUMENTOS INTERNACIONALES}

\subsection{NORMATIVA INTERNACIONAL}

- Convención sobre el Estatuto de los Refugiados, adoptada en Ginebra, Suiza, el 28 de julio de 1951 por la Conferencia de Plenipotenciarios sobre el Estatuto de los Refugiados y de los Apátridas (Naciones Unidas), convocada por la Asamblea General en su resolución 429 (V), del 14 de diciembre de 1950. Entrada en vigor: 22 de abril de 1954, de conformidad con el artículo 43 Serie Tratados de Naciones Unidas, No 2545, Vol. 189.

- Protocolo sobre el Estatuto de los Refugiados. Firmado en Nueva York el 31 de enero de 1967. Entrada en vigor: 4 de octubre de 1967.

- Declaración Universal de Derechos Humanos (DUDH). Adoptada y proclamada por la Asamblea General en su resolución 217 A (III), de 10 de diciembre de 1948.

- ONU, Convención sobre los Derechos del Niño, Dictamen aprobado por el Comité en relación con el Protocolo Facultativo de la Convención sobre los Derechos del Niño relativo a un procedimiento de comunicaciones respecto de la Comunicación $n^{\text {o }}$ 4/2016, 1 de febrero de 2019.

\subsection{DOCUMENTOS INTERNACIONALES}

- Alto Comisionado de las Naciones Unidas para los Refugiados (ACNUR)

- ACNUR, Comentarios sobre la Propuesta de la Comisión Europea para un Reglamento de Procedimientos de Asilo, abril de 2019, COM (2016) 467.

- $\quad$ ACNUR, Biometric identity management system, 2018.

- ACNUR, Guidance on the Protection of Personal Data of Persons of Concern to UNHCR, 23 de agosto de 2018. 
- $\quad$ ACNUR, "Viajes desesperados. Refugiados y migrantes que llegan a Europa y a las fronteras de Europa", enero-agosto 2018.

- ACNUR, Modelo de acuerdo sobre el intercambio de datos personales con los gobiernos en el contexto de la entrega del proceso de determinación de la condición de refugiado, Ginebra: ACNUR.

- ACNUR, Directrices sobre protección internacional no. 5: La aplicación de las cláusulas de exclusión: El artículo $1 F$ de la Convención de 1951 sobre el Estatuto de los Refugiados, 4 de septiembre 2003, HCR/GIP/03/05, apartado 14.

- Human Rights Press Unit, Factsheet - derogation in time of emergency, noviembre de 2017.

- ACNUR, Left in limbo, Study on the implementation of the Dublin III Regulation, agosto de 2017.

- ACNUR, Comentarios sobre la propuesta de la Comisión Europea del Reglamento del Parlamento Europeo y del Consejo sobre el establecimiento de "Eurodac" para la comparación de las impresiones dactilares para la aplicación efectiva del [Reglamento (UE) n. ${ }^{\circ}$ 604/2013, por el que se establecen los criterios y mecanismos de determinación del Estado miembro responsable del examen de una solicitud de protección internacional presentada en uno de los Estados miembros por un nacional de un tercer país o un apátrida y de la identificación de un nacional de un tercer país o un apátrida en situación ilegal, y a las solicitudes de comparación con los datos de Eurodac presentadas por los servicios de seguridad de los Estados miembros y Europol a efectos de aplicación de la ley, mayo de 2017.

- $\quad$ ACNUR, Country update, Spain, octubre-noviembre de 2015.

- ACNUR, Política sobre la Protección de Datos Personales de las Personas del Interés del ACNUR, mayo 2015.

- ACNUR, Privacy Impact Assessment of UNHCR Cash Based Interventions, diciembre de 2015.

- ACNUR, ACNUR da la bienvenida a la creación de oficinas de asilo en puestos fronterizos de Ceuta y Melilla, 6 de noviembre de 2014.

- ACNUR, Note on the Mandate of the High Commissioner for Refugees and his Office, octubre de 2013.

- ACNUR, Biometric Identity Management System (BIMS). Enhancing Registration and Data Management, octubre 2013.

- ACNUR, Recomendaciones de aspectos importantes de la protección de los refugiados en Italia, julio de 2013.

- ACNUR, Directrices sobre los criterios y estándares aplicables a la detención de solicitantes de asilo y las alternativas a la detención, 2012.

- ACNUR, Comentarios sobre la propuesta modificada de la Comisión Europea de Directiva del Parlamento Europeo y del Consejo sobre procedimientos comunes para otorgar y retirar el estado de protección internacional (refundición) COM (2011) 319 final, enero de 2012.

- ACNUR, Comentarios del ACNUR sobre la Propuesta de la Comisión Europea para la reforma del Reglamento del Parlamento Europeo y del Consejo por el que se establecen los criterios y mecanismos para la determinación del EM responsable del examen de una solicitud de protección internacional presentada en uno de los EEMM por un nacional de un tercer país o por un apátrida (“Dublín II") $\operatorname{COM(2008)~820,~de~} 3$ de diciembre de 2008. 
- ACNUR, Public statement in relation to Salahadin Abdulla and Others $v$. Bundesrepublik Deutschland pending before the Court of Justice of the European Union, C-175/08. C-176/08. C-178/08 \& C-179/08 (Geneva: UNHCR, August 2008).

- ACNUR, Documento del ACNUR sobre la aplicación de las cláusulas de exclusión: el artículo 1F de la Convención de 1951 sobre el Estatuto de los Refugiados, septiembre de 2003.

- ACNUR, Cancelación del Estatuto de Refugiado, NU Doc. PPLA/2003/02, marzo de 2003. (Ginebra: ACNUR, 2003).

- ACNUR, Handbook for registration. Procedures and Standards for Registration, Population Data Manegement and Documentation, 2003.

- ACNUR, La aplicación de las cláusulas de exclusión: El artículo $1 \mathrm{~F}$ de la Convención de 1951 sobre el Estatuto de los Refugiados, 4 de septiembre de 2003 (HCR/GIP/03/05).

- ACNUR, La situación de los refugiados en el mundo. 50 años de acción humanitaria, Icaria Editorial, 2000.

- ACNUR, CCPR General Comment No. 16: Article 17 (Right to Privacy), The Right to Respect of Privacy, Family, Home and Correspondence, and Protection of Honour and Reputation, 8 de abril de 1988.

- Centre for Humanitarian Data. OCHA. Data Responsibility Guidelines: Working Draft. March. The Hague, The Netherlands, 2019.

- Global Terrorism Index 2018, Measuring the impact of terrorism, Institute For Economics and Peace, 12 de agosto de 2019.

- Organización Internacional para las Migraciones (OIM), Joint Statement: Coercion of Children to Obtain Fingerprints and Facial Images is Never Acceptable, 13 de marzo de 2018.

- Comité Internacional de la Cruz Roja, Handbook on Data Protection in Humanitarian Action, KUNER C., MARELLICA M. (eds.), 2017.

- Resolución Naciones Unidas, Resolución 2396 (2017) Aprobada por el Consejo de Seguridad en su 8148 a sesión, celebrada el 21 de diciembre de 2017.

- Naciones Unidas, Programa de Alimentos Mundial, Internal Audit of Beneficiary Management Office of the Inspector General Internal Audit Report, noviembre de 2017 (AR/17/17).

- Federación Internacional de Derechos Humanos (FIDH), The United Nations Counter-Terrorism Complex, Bureaucracy, Political Influence and Civil Liberties, $\mathrm{n}^{\mathrm{o}}$ 700, septiembre de 2017.

- Information and Cooperation Forum (ICF), Evaluation of the implementation of the Dublin III Regulation, marzo de 2016.

- Consejo de seguridad de Naciones Unidas, Resolución Naciones Unidas 2322 (2016). Aprobada por el Consejo de Seguridad en su 7831 ${ }^{\mathrm{a}}$ sesión, celebrada el 12 de diciembre de 2016 (S/RES/2322).

- Naciones Unidas, Informe del Relator Especial de las Naciones Unidas sobre la promoción y la protección de los derechos humanos y las libertades fundamentales en la lucha contra el terrorismo, de 23 de septiembre de 2014 (A/69/397).

- Comité Internacional de la Cruz Roja, "normativa profesional relativa a la labor de protección llevada a cabo por los agentes humanitarios y los defensores de los derechos humanos en los conflictos armados y otras situaciones de violencia”, 2013.

- Organización Internacional para las Migraciones (OIM), Manual de Protección de Datos, 2010. 
- Amnistía Internacional, Acción Urgente, Ucrania obligada a paralizar extradición, 22 de enero de 2010 (UA 07/10).

- Resolución Naciones Unidas 1624 (2005). Aprobada por el Consejo de Seguridad en su 5261a sesión, celebrada el 14 de septiembre de 2005 S/RES/1624 (2005).

- Resolución Naciones Unidas 1373 (2001). Aprobada por el Consejo de Seguridad en su $4385^{\mathrm{a}}$ sesión, celebrada el 28 de septiembre de 2001 (S/RES/1373 (2001).

\section{DOCUMENTOS EUROPEOS}

\subsection{NORMATIVA DE LA UE}

- Reglamento (UE) 2019/817 del Parlamento Europeo y del Consejo de 20 de mayo relativo al establecimiento de un marco para la interoperabilidad de los sistemas de información de la UE en el ámbito de las fronteras y los visados y por el que se modifican los Reglamentos (CE) no 767/2008, (UE) 2016/399, (UE) 2017/2226, (UE) 2018/1240, (UE) 2018/1726 y (UE) 2018/1861 del Parlamento Europeo y del Consejo, y las Decisiones 2004/512/CE y 2008/633/JAI del Consejo.

- Reglamento (UE) 2019/818 del Parlamento Europeo y del Consejo de 20 de mayo relativo al establecimiento de un marco para la interoperabilidad entre los sistemas de información de la UE en el ámbito de la cooperación policial y judicial, el asilo y la migración y por el que se modifican los Reglamentos (UE) 2018/1726, (UE) 2018/1862 y (UE) 2019/816.

- Reglamento (UE) 2019/1896 del Parlamento Europeo y del Consejo de 13 de noviembre de 2019 sobre la Guardia Europea de Fronteras y Costas y por el que se derogan los Reglamentos (UE) n. ${ }^{\circ}$ 1052/2013 y (UE) 2016/1624 (DOUE de 14 de noviembre de 2019).

- Decisión 2019/836 del Consejo de 13 de mayo de 2019 sobre la celebración del Protocolo del Acuerdo entre la Comunidad Europea y el Reino de Dinamarca relativo a los criterios y mecanismos de determinación del Estado miembro responsable del examen de una solicitud de asilo presentada en Dinamarca o cualquier otro Estado miembro de la Unión Europea y a «Eurodac» para la comparación de las impresiones dactilares para la aplicación efectiva del Convenio de Dublín, en lo que respecta al acceso a Eurodac a efectos de aplicación de la ley, 24 de mayo de 2019 (L 138/3).

- Consejo de la Unión Europea, Propuesta de Reglamento del Parlamento Europeo y del Consejo sobre la prevención de la difusión de contenidos terroristas en línea (15336/18), de 6 de diciembre de 2018.

- Reglamento (UE) 2018/1725 del Parlamento Europeo y del Consejo de 23 de octubre de 2018 relativo a la protección de las personas físicas en lo que respecta al tratamiento de datos personales por las instituciones, órganos y organismos de la Unión, y a la libre circulación de esos datos, y por el que se derogan el Reglamento (CE) n. ${ }^{\circ}$ 45/2001 y la Decisión n. ${ }^{\circ}$ 1247/2002/CE (DOUE de 21 de noviembre de 2018).

- Reglamento (UE) 2018/1726 del Parlamento Europeo y del Consejo, de 14 de noviembre de 2018, relativo a la Agencia de la Unión Europea para la Gestión Operativa de Sistemas Informáticos de Gran Magnitud en el Espacio de Libertad, Seguridad y Justicia (eu-LISA), y por el que se modifican el Reglamento (CE) n. ${ }^{\circ}$ 1987/2006 y la Decisión 2007/533/JAI del Consejo y se deroga el Reglamento (UE) n. ${ }^{\circ}$ 1077/2011. PE/29/2018/REV/1. OJ L 295, de 21 de noviembre de 2018, pp. 99-137. 
- Consejo Europeo de Protección de Datos, Directrices 3/2018 sobre el alcance territorial del RGPD GDPR (Artículo 3) - Versión para consulta pública. Adoptado el 16 de noviembre de 2018.

- Propuesta de Reglamento relativo a la Agencia de Asilo de la Unión Europea y por el que se deroga el Reglamento (UE) n. ${ }^{\circ}$ 439/2010. Contribución de la Comisión Europea a la reunión de dirigentes celebrada en Salzburgo los días 19 y 20 de septiembre de 2018. COM(2018) 633 final 2016/0131 (COD).

- Comisión Europea, Propuesta de Directiva relativa a normas y procedimientos comunes en los Estados miembros para el retorno de los nacionales de terceros países en situación irregular (refundición). Contribución de la Comisión Europea a la reunión de líderes celebrada en Salzburgo los días 19 y 20 de septiembre de 2018, COM(2018) 634 final 2018/0329 (COD), 12 de septiembre de 2018.

- Consejo de Europa, Convenio para la protección de las personas con respecto al tratamiento automatizado de datos de carácter Personal, Comité de Ministros, Elsinore, 18 de mayo de 2018.

- Recomendación del Consejo de 22 de mayo de 2018 relativa a la promoción de los valores comunes, la educación inclusiva y la dimensión europea de la enseñanza.

- Declaración conjunta sobre las prioridades legislativas de la UE para 2018-2019. OJ C 446, 29 de diciembre de 2017, pp. 1-3.

- Directiva (UE) 2017/541 del Parlamento Europeo y del Consejo de 15 de marzo de 2017 relativa a la lucha contra el terrorismo y por la que se sustituye la Decisión marco 2002/475/JAI del Consejo y se modifica la Decisión 2005/671/JAI del Consejo.

- Decisión de Ejecución 2017/818 del Consejo de 11 de mayo de 2017 por la que se establece una Recomendación para prorrogar la realización de controles temporales en las fronteras interiores en circunstancias excepcionales que pongan en peligro el funcionamiento global del espacio Schengen.

- Propuesta de Reglamento sobre el respeto de la vida privada y la protección de los datos personales en el sector de las comunicaciones electrónicas y por el que se deroga la Directiva 2002/58/CE (Reglamento sobre la privacidad y las comunicaciones electrónicas). COM/2017/010 final - 2017/03 (COD).

- Propuesta de Reglamento sobre el respeto de la vida privada y la protección de los datos personales en el sector de las comunicaciones electrónicas y por el que se deroga la Directiva 2002/58/CE (Reglamento sobre la privacidad y las comunicaciones electrónicas). COM/2017/010 final - 2017/03 (COD).

- Reglamentos 2016/399 del Parlamento Europeo y del Consejo, de 9 de marzo de 2016, por el que se establece un Código de normas de la Unión para el cruce de personas por las fronteras y 2017/458 del Parlamento Europeo y del Consejo, de 15 de marzo de 2017, por el que se modifica el Reglamento (UE) 2016/399 en lo relativo al refuerzo de los controles mediante la comprobación en las bases de datos pertinentes en las fronteras exteriores.

- Directiva (UE) 2017/541 del Parlamento y del Consejo de 15 de marzo de 2017 relativa a la lucha contra el terrorismo y por la que se sustituye la Decisión marco 2002/475/JAI del Consejo y se modifica la Decisión 2005/671/JAI del Consejo, OJ L $88,31 / 03 / 2017$.

- Recomendaciones 2016/1989 del Consejo, de 11 de noviembre de 2016, y (UE) 2017/246 del Consejo, de 7 de febrero de 2017, para prorrogar la realización de controles temporales en las fronteras interiores en circunstancias excepcionales que pongan en peligro el funcionamiento global del espacio Schengen. 
- Recomendación de la Comisión, de 12 de mayo de 2017, sobre los controles policiales proporcionados y la cooperación policial en el espacio Schengen, C(2017) 3349 final.

- Reglamento (UE) 2016/794 del Parlamento Europeo y del Consejo, de 11 de mayo de 2016, relativo a la Agencia de la Unión Europea para la Cooperación Policial (Europol) y por el que se sustituyen y derogan las Decisiones 2009/371/JAI, 2009/934/JAI, 2009/935/JAI, 2009/936/JAI y 2009/968/JAI del Consejo. OJ L 135, 24 de mayo de 2016, pp. 53-114.

- Corrección de errores del Reglamento (UE) 2016/679 del Parlamento Europeo y del Consejo, de 27 de abril de 2016, relativo a la protección de las personas físicas en lo que respecta al tratamiento de datos personales y a la libre circulación de estos datos y por el que se deroga la Directiva 95/46/CE (Reglamento general de protección de datos). L 127/3, 23 de mayo de 2018.

- Comisión Europea, Propuesta modificada de Reglamento del Parlamento Europeo y del Consejo relativo a la Agencia de Asilo de la Unión Europea y por el que se deroga el Reglamento (UE) n. ${ }^{\circ}$ 439/2010, 12 de septiembre de 2018 COM(2018) 633 final 2016/0131 (COD).

- Reglamento (UE) 2016/679 del Parlamento Europeo y del Consejo, de 27 de abril de 2016, relativo a la protección de las personas físicas en lo que respecta al tratamiento de datos personales y a la libre circulación de estos datos y por el que se deroga la Directiva 95/46/CE (Reglamento general de protección de datos) (DO L 119 de 4.5.2016, pp. 1-88).

- Directiva (UE) 2016/680 del Parlamento Europeo y del Consejo, de 27 de abril de 2016, relativa a la protección de las personas físicas en lo que respecta al tratamiento de datos personales por parte de las autoridades competentes para fines de prevención, investigación, detección o enjuiciamiento de infracciones penales o de ejecución de sanciones penales, y a la libre circulación de dichos datos y por la que se deroga la Decisión Marco 2008/977/JAI del Consejo (DO L 119 de 4.5.2016, pp. 89-131).

- Comisión Europea, Propuesta de Reglamento del Parlamento Europeo y del Consejo por el que se establecen los criterios y mecanismos de determinación del EM responsable del examen de una solicitud de protección internacional presentada en uno de los EEMM por un nacional de un tercer país o un apátrida (texto refundido) $\operatorname{COM}(2016) 270$ final

- Comisión Europea, Propuesta de Reglamento del Parlamento Europeo y del Consejo por el que se establece un procedimiento común en materia de protección internacional en la Unión y se deroga la Directiva 2013/32/UE, COM(2016) 467 final 2016/0224 (COD)

- Comisión Europea, Propuesta de Directiva del Parlamento Europeo y del Consejo por la que se aprueban normas para la acogida de los solicitantes de protección internacional (texto refundido), $\operatorname{COM(2016)~} 465$ final

- Comisión Europea, Propuesta de Reglamento (...) por el que se establecen normas relativas a los requisitos para el reconocimiento de nacionales de terceros países o apátridas como beneficiarios de protección internacional, a un estatuto uniforme para los refugiados o para las personas con derecho a protección subsidiaria y al contenido de la protección concedida y por el que se modifica la Directiva 2003/109/CE del Consejo, de 25 de noviembre de 2003, relativa al estatuto de los nacionales de terceros países residentes de larga duración, $\operatorname{COM(2016)~} 466$ final

- Comisión Europea, Propuesta de Reglamento del Parlamento Europeo y del Consejo por el que se establecen los criterios y mecanismos de determinación del Estado miembro responsable del examen de una solicitud de protección internacional 
presentada en uno de los Estados miembros por un nacional de un tercer país o un apátrida (texto refundido), $\operatorname{COM(2016)~} 270$ final.

- Comisión Europea, Propuesta de Reglamento del Parlamento Europeo y del Consejo relativo a la creación del sistema «Eurodac» para la comparación de las impresiones dactilares para la aplicación efectiva del [Reglamento (UE) n. ${ }^{\circ}$ 604/2013, por el que se establecen los criterios y mecanismos de determinación del Estado miembro responsable del examen de una solicitud de protección internacional presentada en uno de los Estados miembros por un nacional de un tercer país o un apátrida] y de la identificación de un nacional de un tercer país o un apátrida en situación ilegal, y a las solicitudes de comparación con los datos de Eurodac presentadas por los servicios de seguridad de los Estados miembros y Europol a efectos de aplicación de la ley (refundición), $\operatorname{COM(2016)~} 272$ final.

- Comisión Europea, Propuesta de Reglamento relativo a la Agencia de Asilo de la Unión Europea y por el que se deroga el Reglamento (UE) n. ${ }^{\circ}$ 439/2010 $\mathrm{COM} / 2016 / 0271$ final.

- Comisión Europea, Propuesta de Reglamento por el que se crea un Sistema Europeo de Información y Autorización de Viajes (SEIAV) y por el que se modifican los Reglamentos (UE) n. ${ }^{\circ}$ 515/2014, (UE) 2016/399, (UE) 2016/794 y (UE) 2016/1624 (COM(2016) 731 final)).

- Servicio Europeo de Acción Exterior, Una visión común, una actuación conjunta: una Europa más fuerte, Estrategia global para la política exterior y de seguridad de la Unión Europea 28 y 29 de junio de 2016.

- Decisión (UE) 2015/1601 del Consejo de 22 de septiembre de 2015 por la que se establecen medidas provisionales en el ámbito de la protección internacional en beneficio de Italia y Grecia, 24 de septiembre de 2015 (L 248/80).

- Directiva 2013/33/UE del Parlamento Europeo y del Consejo, de 26 de junio de 2013 , por la que se aprueban normas para la acogida de los solicitantes de protección internacional. DO L 180 de 29.6.2013, pp. 96-116.

- Directiva 2013/32/UE del Parlamento Europeo y del Consejo, de 26 de junio de 2013, sobre procedimientos comunes para la concesión o la retirada de la protección internacional, OJ L 180, 29.6.2013, pp. 60-95.

- Reglamento (UE) n 604/2013 del Parlamento Europeo y del Consejo, de 26 de junio de 2013, por el que se establecen los criterios y mecanismos de determinación del Estado miembro responsable del examen de una solicitud de protección internacional presentada en uno de los Estados miembros por un nacional de un tercer país o un apátrida, OJ L 180, 29.6.2013, pp. 31-59.

- Reglamento (UE) n 603/2013 del Parlamento Europeo y del Consejo, de 26 de junio de 2013, relativo a la creación del sistema «Eurodac» para la comparación de las impresiones dactilares para la aplicación efectiva del Reglamento (UE) n ${ }^{\circ}$ 604/2013, por el que se establecen los criterios y mecanismos de determinación del Estado miembro responsable del examen de una solicitud de protección internacional presentada en uno de los Estados miembros por un nacional de un tercer país o un apátrida, y a las solicitudes de comparación con los datos de Eurodac presentadas por los servicios de seguridad de los Estados miembros y Europol a efectos de aplicación de la ley, y por el que se modifica el Reglamento (UE) $n{ }^{\circ} 1077 / 2011$, por el que se crea una Agencia europea para la gestión operativa de sistemas informáticos de gran magnitud en el espacio de libertad, seguridad y justicia, OJ L 180, 29.6.2013, p. 1-30.

- Directiva 2011/95/UE del Parlamento Europeo y del Consejo, de 13 de diciembre de 2011, por la que se establecen normas relativas a los requisitos para el reconocimiento de nacionales de terceros países o apátridas como beneficiarios de 
protección internacional, a un estatuto uniforme para los refugiados o para las personas con derecho a protección subsidiaria y al contenido de la protección concedida. OJ L 337, 20.12.2011, pp. 9-26.

- Acuerdo entre la Comunidad Europea y la Confederación Suiza sobre los criterios y mecanismos para determinar el Estado responsable del examen de una solicitud de asilo presentada en un Estado miembro o en Suiza (DO L 53 de 27 de febrero de 2008); Protocolo entre la Comunidad Europea, la Confederación Suiza y el Principado de Liechtenstein sobre la adhesión del Principado de Liechtenstein al Acuerdo entre la Comunidad Europea y la Confederación Suiza sobre los criterios y mecanismos para determinar el Estado responsable del examen de una solicitud de asilo presentada en un Estado miembro o en Suiza (DO L 160 de 18 de junio de 2011).

- Consejo de la UE, Programa de Estocolmo: Una Europa abierta y segura que sirva y proteja al ciudadano [Diario Oficial $n^{\circ}$ C 115 de 4/5/2010]. Comunicación de la Comisión al Parlamento Europeo, al Consejo, al Comité Económico y Social Europeo y al Comité de las Regiones, de 20 de abril de 2010 - Garantizar el espacio de libertad, seguridad y justicia para los ciudadanos europeos - Plan de acción por el que se aplica el Programa de Estocolmo [COM(2010) 171 final - no publicada en el Diario Oficial].

- Reglamento (UE) n ${ }^{\circ}$ 439/2010 del Parlamento Europeo y del Consejo, de 19 de mayo de 2010, por el que se crea una Oficina Europea de Apoyo al Asilo. OJ L 132, 29.5.2010, pp. 11-28.

- Directiva 2002/58/CE del Parlamento Europeo y del Consejo, de 12 de julio de 2002 , relativa al tratamiento de los datos personales y a la protección de la intimidad en el sector de las comunicaciones electrónicas (Directiva sobre la privacidad y las comunicaciones electrónicas), «DOCE» $\mathrm{n}^{\mathrm{o}} 201$, de 31 de julio de 2002. OJ L 201, 31.7.2002, pp. 37-47.

- Acuerdo entre la Comunidad Europea, la República de Islandia y el Reino de Noruega relativo a los criterios y mecanismos para determinar el Estado responsable de examinar las peticiones de asilo presentadas en un Estado miembro o en Islandia o Noruega (DO L 93 de 3 de abril de 2001);

- Reglamento (CE) n ${ }^{\circ} 45 / 2001$ de 18 de diciembre de 2000 relativo a la protección de las personas físicas en lo que respecta al tratamiento de datos personales por las instituciones y los organismos comunitarios y a la libre circulación de estos datos. OJ L 8, 12.1.2001, pp. 1-22.

- Consejo de Europa, Convenio para la protección de las personas con respecto al tratamiento automatizado de datos de carácter personal, hecho en Estrasburgo el 28 de enero de 1981.

- Comisión Europea, Propuesta de Reglamento (...) por el que se establece un procedimiento común en materia de protección internacional en la Unión y se deroga la Directiva 2013/32/UE.

- Tratado de Funcionamiento de la Unión Europea (30 de marzo de 2010 (C 83/47).

- Reglamento (UE) n 439/2010 del Parlamento Europeo y del Consejo, de 19 de mayo de 2010, por el que se crea una Oficina Europea de Apoyo al Asilo. DO L 132 de 29 de mayo de 2010, pp. 11/28.

- Programa de Estocolmo - Una Europa abierta y segura que sirva y proteja al ciudadano [Diario Oficial $\mathrm{n}^{\circ} \mathrm{C} 115$ de 4 de mayo de 2010].

- Decisión 2008/615/JAI del Consejo, de 23 de junio de 2008, sobre la profundización de la cooperación transfronteriza, en particular en materia de lucha contra el terrorismo y la delincuencia transfronteriza. OJ L 210, 6 de agosto de 2008, pp. 1-11. 
- Decisión 2008/633/JAI del Consejo, de 23 de junio de 2008 , sobre el acceso para consultar el Sistema de Información de Visados (VIS) por las autoridades designadas de los Estados miembros y por Europol, con fines de prevención, detección e investigación de delitos de terrorismo y otros delitos graves. OJ L 218, 13 de agosto de 2008, pp. 129-136.

- Tratado de Lisboa por el que se modifican el Tratado de la Unión Europea y el Tratado constitutivo de la Comunidad Europea (DO C 306 de 17.12.2007)

- Directiva 2004/83/CE del Consejo de 29 de abril de 2004 por la que se establecen normas mínimas relativas a los requisitos para el reconocimiento y el estatuto de nacionales de terceros países o apátridas como refugiados o personas que necesitan otro tipo de protección internacional y al contenido de la protección concedida.

- Directiva 2001/55/CE del Consejo, de 20 de julio de 2001, relativa a las normas mínimas para la concesión de protección temporal en caso de afluencia masiva de personas desplazadas y a medidas de fomento de un esfuerzo equitativo entre los Estados miembros para acoger a dichas personas y asumir las consecuencias de su acogida. DO L 212 de 7 de agosto de 2001, pp. 12/23.

- Carta de los Derechos Fundamentales de la Unión Europea, 30 de marzo de 2010 (C-83/391).

- Convenio de aplicación del Acuerdo de Schengen de 14 de junio de 1985 entre los Gobiernos de los Estados de la Unión Económica Benelux, de la República Federal de Alemania y de la República Francesa relativo a la supresión gradual de los controles en las fronteras comunes. DO L 239 de 22 se septiembre de 2000, pp. 19/62.

- Consejo Europeo de Tampere. Conclusiones de la Presidencia, 15 y 16 de octubre de 1999.

- Convenio relativo a la determinación del Estado responsable del examen de las solicitudes de asilo presentadas en los Estados miembros de las Comunidades Europeas - Convenio de Dublín. DO C 254 de 19.8.1997, pp. 1-12

- Tratado de Ámsterdam por el que se modifican el Tratado de la Unión Europea, los Tratados constitutivos de las Comunidades Europeas y determinados actos conexos Declaraciones relativas al artículo K.7 del Tratado de la Unión Europea modificado por el Tratado de Ámsterdam. DO C 340 de 10 de noviembre de 1997, pp. 308.

- $\quad$ Tratado de la Unión Europea (DO C 191 de 29.7.1992, pp. 1-112).

\subsection{DOCUMENTOS DE LA UE}

- Comité Económico y Social Europeo, Dictamen sobre la Propuesta de Reglamento del Parlamento Europeo y del Consejo por el que se establecen los criterios y mecanismos de determinación del EM responsable del examen de una solicitud de protección internacional presentada en uno de los EEMM por un nacional de un tercer país o un apátrida (texto refundido) [COM(2016) 270 final - 2016/0133(COD)], SOC/543, 19 de octubre de 2016.

- Consejo de la Unión Europea

- Consejo de la Unión Europea, Reunión informal de ministros de Justicia y Asuntos de Interior, 18 y 19 de julio de 2019.

- Consejo de la Unión Europea, Conclusiones del Consejo de la Unión Europea sobre la conservación de datos a efectos de lucha contra la delincuencia, 27 de mayo de $2019(9663 / 19)$. 
- Consejo de la Unión Europea, Interoperabilidad de los sistemas de información de la UE: el Consejo adopta dos Reglamentos, 14 de mayo de 2019.

- Consejo de la Unión Europea, Informe de progreso de la Presidencia, 26 de febrero de 2019.

- Consejo de la Unión Europea, Reforma del Sistema Europeo Común de Asilo y Reasentamiento. Informe de progreso 6600/19, 26 de febrero 2019.

- Secretaría General del Consejo de la Unión Europea, "Frontex Annual Activity Report 2017”, 27 de junio de 2018, FRONT 199, COMIX 352.

- Consejo de la Unión Europea, Revisión intermedia de las directrices estratégicas de JAI - Información de la Presidencia, 1 de diciembre de 2017, (15224/1/17 REV 1).

- Consejo de la Unión Europea, Conclusiones del Consejo en las que se recomienda realizar controles de seguridad en caso de migración irregular, 8 de junio de $2017(10152 / 17)$.

- Consejo de la Unión Europea, Conclusiones del Consejo relativas a la Estrategia Global sobre Política Exterior y de Seguridad de la Unión Europea-Conclusiones del Consejo (13202/16), 17 de octubre de 2016.

- Consejo de la Unión Europea, Conclusiones del Consejo sobre la convergencia en las prácticas de asilo, 21 de abril de 2016, 8210/16 (ASIM 58).

- Consejo de la UE, Declaración UE-Turquía, Comunicado de prensa, 144/16, 18 de marzo de 2016.

- Consejo de la Unión Europea, "Nota de la Delegación de Noruega al Grupo de Trabajo en Fronteras", 25 de noviembre de 2015.

- Consejo de la Unión Europea, "Nota de la Delegación de Suecia al Grupo de Trabajo en Fronteras", 12 de noviembre de 2015.

- Consejo de la Unión Europea, "Nota de la Delegación de Eslovenia al Grupo de Trabajo en Fronteras", 20 de octubre de 2015

- Consejo de la Unión Europea, "Nota de la Delegación Permanente de Dinamarca al Secretario General del Consejo de la Unión Europea", 19 de octubre de 2015.

- Consejo de la Unión Europea, "Nota de la Delegación Austríaca al Grupo de Trabajo en Fronteras, 17 de septiembre de 2015.

- Consejo de la Unión Europea, "Nota de la Delegación Alemana al Grupo de Trabajo en Fronteras", 14 de septiembre de 2015.

- Consejo de la Unión Europea, "Nota de la Delegación de Francia al Grupo de Trabajo en Fronteras", 11 de febrero de 2016.

- Consejo de la Unión Europea, Estrategia de Seguridad Interior de la Unión Europea. Hacia un modelo europeo de seguridad, Doc. 5842/2/2010, marzo de 2010.

- Consejo de la Unión Europea, Pacto europeo sobre inmigración y asilo, 24 de septiembre de 2008.

- Consejo de la Unión Europea, Additional measures to combat terrorism proposals by the German delegation, 13176/01, Bruselas, 24 de octubre de 2001.

- Consejo Europeo de Tampere, Conclusiones de la Presidencia, 15 y 16 de octubre de 1999.

- Comisión Europea

- Comisión Europea, Guidance note - Research on refugees, asylum seekers \& migrants.

- Comisión Europea, Migración y Asuntos de Interior, Identificación de solicitantes (EURODAC). 
- Comisión Europea, Managing Migration EU Financial Support to Spain, octubre de 2019.

- Comisión Europea, July infringements package: key decisions, 25 de julio de 2019.

- Comisión Europea, Lista de terceros países cuyos nacionales deben poseer una visa de tránsito aeroportuario al pasar por el área de tránsito internacional de aeropuertos ubicados en el territorio de uno o varios Estados miembros, 1 de febrero de 2019.

- Comisión Europea, Security Union, A Europe that protects: 15 out of 22 Security Union legislative initiatives agreed so far, 20 de marzo de 2019.

- Comisión Europea, A Europe that protects: EU cities against radicalisation, 26 de febrero de 2019.

- Comisión Europea, Una Europa que protege: la Comisión pide un mayor esfuerzo para garantizar la adopción de las propuestas sobre seguridad, 11 de diciembre de 2018.

- Comisión Europea, Reforma del Sistema Europeo Común de Asilo: qué cambiará con las reformas y por qué las necesitamos ahora, diciembre de 2018.

- Comisión Europea, Security Union, A Europe that protects: Fighting Terrorism Online: Public-private sector cooperation as important as ever at the fourth EU Internet Forum, 5 de diciembre 2018.

- Comisión Europea, Spain EMN Country Factsheet, 2018.

- Comisión Europea, Factsheets Compilation, 2017-2018.

- Comisión Europea, A Europe that protects: Countering terrorist content online. 12 de septiembre de 2018.

- Comisión Europea, Contribución de la Comisión Europea a la reunión de dirigentes celebrada en Salzburgo los días 19 y 20 de septiembre de 2018. COM(2018) 633 final 2016/0131 (COD).

- Comisión Europea, State of the Union 2018. A fully equipped European Border and Coast Guard - Questions and Answers. Strasbourg, 12 de septiembre de 2018.

- Comisión Europea, EU Budget for the Future, 13 de junio de 2018

- Comisión Europea, A Europe that protects: EU Mayors' Conference: “'Building Urban Defences Against Terrorism", 8 de marzo de 2018.

- Comisión Europea, Comunicación de la Comisión al Parlamento Europeo, al Consejo, al Comité Económico y Social europeo y al Comité de las Regiones «relativa al cumplimiento de la Agenda Europea de Migración», de 27 de septiembre de 2017 $\operatorname{COM}(2017) 558$ final.

- Comisión Europea, Comunicación de la Comisión al Parlamento Europeo, al Consejo Europeo y al Consejo «sobre la protección y refuerzo Schengen», de 27 de septiembre de $2017 \mathrm{COM}(2017) 570$ final.

- Comisión Europea, 8..$^{\circ}$ Informe de avance hacia una Unión de la Seguridad genuina y efectiva. $\operatorname{COM}(2017) 354$ final, junio de 2017.

- Comisión Europea, High-level expert group on information systems and interoperability, Final report, 11 de mayo de 2017. (2017)2412067.

- Comisión Europea, Primer informe anual sobre el mecanismo de la UE para los refugiados en Turquía, marzo de 2017, $\operatorname{COM}(2017) 130$ final.

- Comisión Europea, Comunicación de la Comisión al Parlamento Europeo y al Consejo. Sistemas de información más sólidos e inteligentes para la gestión de las fronteras y la seguridad, de 6 de abril de 2016. COM(2016) 205 final 
- Comisión Europea, Comunicación de la Comisión al Parlamento Europeo y al Consejo «Hacia una reforma del Sistema Europeo Común de Asilo y una mejora de las vías legales a Europa», 6 de abril de 2016. COM(2016) 197 final.

- Comisión Europea, Comunicación de la Comisión al Parlamento Europeo, al Consejo Europeo y al Consejo «Restablecer Schengen - Hoja de ruta», 4 de marzo de 2016, $\operatorname{COM}(2016) 120$ final.

- Comisión Europea, Comunicación de la Comisión al Parlamento Europeo y al Consejo, Plan de acción para intensificar la lucha contra la financiación del terrorismo, COM/2016/050 final, 2 de febrero de 2016.

- Comisión Europea, Comunicación de la Comisión al Parlamento Europeo y al Consejo, Octavo informe bianual sobre el funcionamiento del espacio Schengen. Del 1 de mayo al 10 de diciembre de 2015, de 15 de diciembre de 2015, COM(2015) 675 final).

- Comisión Europea, Opinión sobre la necesidad y proporcionalidad de los controles y las fronteras interiores reintroducidas por Alemania y Austria, Bruselas, 23 de octubre de 2015, 7100 final.

- Comisión Europea, Comunicación de la Comisión al Parlamento Europeo, al Consejo, al Comité Económico y Social Europeo y al Comité de las Regiones «Una Agenda Europea de Migración», de 13 de mayo de 2015. COM(2015) 240 final.

- Comisión Europea, Documento de Trabajo sobre la implementación del Reglamento Eurodac en lo relativo a la obligación de tomar las huellas dactilares, 27 de mayo de 2015 (SWD(2015) 150 final).

- Comisión Europea, Comunicación de la Comisión al Parlamento Europeo, al Consejo, al Comité Económico y Social Europeo y al Comité de las Regiones una Agenda Europea de Migración, COM(2015) 240 final, 13 de mayo de 2015.

- Comisión Europea, Comunicación al Parlamento Europeo, al Consejo, al Comité Económico y Social Europeo y al Comité de las Regiones, Agenda Europea de Seguridad. 28 de abril de 2015. COM(2015) 185 final.

- Comisión Europea, Commission non-paper for SCIFA on Best Practices for upholding the Obligation in the Eurodac Regulation to take fingerprints, 13 de octubre de 2014.

- Comisión Europea, Summary of EMN Ad-Hoc Query $\mathrm{n}^{\mathrm{o}} 588$ - Eurodac Fingerprinting, septiembre de 2014.

- Comisión Europea, Summary of contextual overviews on children's involvement in criminal judicial proceedings in the 28 Member States of the European Union, 16 de abril de 2014.

- Comisión Europea, Comunicación de la Comisión al Parlamento Europeo, al Consejo, al Comité Económico y Social Europeo y al Comité de las Regiones, «prevenir la radicalización hacia el terrorismo y el extremismo violento: una respuesta más firme de la UE», COM (2013) 941 final, Bruselas, de 15 de enero de 2014.

- Comisión Europea, EU Internet Forum: Bringing together governments, Europol and technology companies to counter terrorist content and hate speech online, Press release, 3 de diciembre de 2015 .

- Comisión Europea, Informe anual al Parlamento Europeo y al Consejo sobre las actividades de la Unidad Central EURODAC en 2011 (Informe de la Comisión al Parlamento Europeo y al Consejo), 21 de septiembre de 2012, COM(2012) 533 final.

- Comisión Europea, DG Migration and Home Affairs, Comparative Study on Practices in the Field of Return of Minors, Final Report, (HOME/2009/RFXX/PR/1002), diciembre de 2011. 
- Comisión Europea, Panorama general de la gestión de la información en el espacio de libertad, seguridad y justicia, $\operatorname{COM(2010)~} 385$ final, 20 de julio de 2010.

- Comisión Europea, Comunicación de la Comisión al Parlamento Europeo, al Consejo, al Comité Económico y Social Europeo y al Comité de las Regiones plan de política de asilo un planteamiento integrado de la protección en toda la UE, 17 de junio de 2008, $\operatorname{COM}(2008) 360$ final.

- Comisión Europea, Libro Verde sobre el futuro sistema europeo común de asilo, de 6 junio 2007, $\operatorname{COM(2007)~} 301$ final.

- Comisión Europea, Comunicación de la Comisión al Consejo y al Parlamento Europeo, de 10 de mayo de 2005, «Programa de La Haya: Diez prioridades para los próximos 5 años. Una asociación para la renovación europea en el ámbito de la libertad, la seguridad y la justicia» [COM (2005) 184 final - Diario Oficial C 236 de 24.9.2005].

- Comisión Europea, Comunicación de la Comisión al Consejo y al Parlamento Europeo sobre una mayor eficacia, interoperabilidad y sinergia entre las bases de datos europeas en el ámbito de la Justicia y los Asuntos de Interior, Bruselas, 24 de noviembre de 2005, $\operatorname{COM}(2005) 597$ final.

- European Migration Network (EMN), Ad-Hoc Query on Impact of false/forged documents in the immigration and asylum procedures, 16 de junio de 2017.

\section{- Parlamento Europeo}

- Parlamento Europeo, Detecting and protecting victims of trafficking in hotspots. Ex-post evaluation, julio de 2019 (PE 631.757).

- Parlamento Europeo, Interoperabilidad entre los Sistemas de información fronteriza y de seguridad de la UE, junio de 2019 (PE 628.267).

- Parlamento Europeo, Comisión de Libertades Civiles, Justicia y Asuntos de Interior, Informe sobre la propuesta de Reglamento del Parlamento Europeo y del Consejo sobre la Guardia Europea de Fronteras y Costas y por el que se derogan la Acción Común n. ${ }^{\circ}$ 98/700/JAI del Consejo, el Reglamento (UE) n. ${ }^{\circ}$ 1052/2013 del Parlamento Europeo y del Consejo y el Reglamento (UE) 2016/1624 del Parlamento Europeo y del Consejo, (COM(2018)0631 - C8-0406/2018 - 2018/0330(COD)), 12 de febrero de 2019.

- Parlamento Europeo, The migration issue, Briefing. EU policies - Delivering for citizens, 2019.

- Parlamento Europeo, Humanitarias Visas, European Added Value. Assessment accompanying the European Parliament's legislative own-initiative report (Rapporteur: Juan Fernando López Aguilar), Study European Parliamentary Research Service, octubre de 2018.

- Parlamento Europeo, The EU-UK relationship beyond Brexit: options for Police Cooperation and Judicial Cooperation in Criminal Matters, Policy Department for Citizens' Rights and Constitutional Affairs Directorate General for Internal Policies of the Union, julio de 2018.

- Parlamento Europeo, EU asylum, borders and external cooperation on migration Recent developments, mayo de 2018.

- Parlamento Europeo, Preparación del Programa de trabajo de la Comisión para 2017. Resolución del Parlamento Europeo, de 6 de julio de 2016, sobre las prioridades estratégicas para el programa de trabajo de la Comisión para 2017 (2016/2773(RSP)). DO C 101, de 16 de marzo de 2018.

- Parlamento Europeo, Informe sobre la propuesta de Reglamento del Parlamento Europeo y del Consejo relativo a la creación del sistema «Eurodac» para la comparación 
de las impresiones dactilares para la aplicación efectiva del [Reglamento (UE) n. $^{\circ}$ $604 / 2013$, por el que se establecen los criterios y mecanismos de determinación del Estado miembro responsable del examen de una solicitud de protección internacional presentada en uno de los Estados miembros por un nacional de un tercer país o un apátrida y de la identificación de un nacional de un tercer país o un apátrida en situación ilegal, y a las solicitudes de comparación con los datos de Eurodac presentadas por los servicios de seguridad de los Estados miembros y Europol a efectos de aplicación de la ley (versión refundida) (COM(2016)0272 - C8-0179/2016 - 2016/0132(COD)), 8 de junio de 2017.

- Parlamento Europeo. Servicio de Estudios del Parlamento Europeo (EPRS), Recast Eurodac Regulation, 10 de marzo, 2017.

- Parlamento Europeo, The Cost of Non-Schengen: Civil Liberties, Justice and Home Affairs aspects Cost of Non-Europe Report, Septiembre de 2016.

- Parlamento Europeo, Comisión de Libertades Civiles, Justicia y Asuntos de Interior, Informe sobre la propuesta de Reglamento del Parlamento Europeo y del Consejo por el que se establecen los criterios y mecanismos de determinación del Estado miembro responsable del examen de una solicitud de protección internacional presentada en uno de los Estados miembros por un nacional de un tercer país o un apátrida (texto refundido), de 6 de noviembre de 2017. (COM(2016)0270 - C80173/2016 - 2016/0133(COD)).

- Parlamento Europeo, Proyecto de resolución legislativa del Parlamento Europeo sobre el establecimiento de "Eurodac" para la comparación de huellas dactilares, 9 de junio de 2017.

\section{- Oficina Europea de Policía (Europol)}

- $\quad$ Europol, European Union Terrorism Situation and Trend Report (TE-SAT), La Haya, 2019.

- $\quad$ Europol, European Union Terrorism Situation and Trend Report (TE-SAT), La Haya, 2018.

- Europol Programming Document 2019 - 2021, adoptado por la Consejo de Administración el 30 de noviembre de 2018.

- Europol Programming Document 2018 - 2020, adoptado por la Consejo de Administración el 30 de noviembre de 2017.

- Europol, Proporcionate data retention for law enforcement purposes, Data retention function, 18 de septiembre de 2017 (WK 9957/2017 INIT).

- Europol, Data categories to be retained for law enforcement purposes DAPIX Friends of Presidency meeting, 15 de mayo de 2017 (WK 5380/2017).

- Europol Programming Document 2017 - 2019, adoptado por la Consejo de Administración el 17 de enero de 2017.

- $\quad$ Europol, Changes in modus operandi of Islamic State (IS) revisited, 2016.

- Europol, European Union Terrorism Situation and Trend Report (TE-SAT), La Haya, 2016.

- Europol, EU Internet Referral Unit, Year One Report Highlights, European Police Office, 2016.

- Europol and technology companies to counter terrorist content and hate speech online, Press release, 3 de diciembre de 2015.

- Agencia de Derechos Fundamentales de la Unión Europea (FRA). 
- FRA, Interoperability and fundamental rights implications. Opinion 1/2018 of the European Union Agency for Fundamental Rights, 11 de abril de 2018.

- FRA, "Los retrocesos de los migrantes son una preocupación creciente en algunos Estados miembros", 26 de marzo de 2018.

- FRA, Under watchful eyes - biometrics, EU IT-systems and fundamental rights, marzo de 2018.

- FRA, Fundamental rights and the interoperability of EU information systems: borders and security, 2017.

- $\quad$ FRA y Consejo de Europa, Handbook on European data protection law, 2018.

- FRA, "Fundamental rights implications of the obligation to provide fingerprints for Eurodac", 05/2015, octubre de 2015.

- FRA, The duty to inform applicants about asylum procedures: the asylum-seeker perspective, 2010.

- Agencia de la Unión Europea para la Gestión Operativa de Sistemas de TI a gran escala en el Área de Libertad, Seguridad y Justicia (Eu-LISA)

Eu-LISA, EURODAC - 2018, Annual Statistics, Factsheet, febrero de 2019.

Eu-LISA, EURODAC-2018 Annual Report, junio de 2019

Eu-LISA, EURODAC-2017. Annual Report, junio de 2018

Eu-LISA, DPO Annual Work Report 2017. Data Protection Officer Ares(2018) 1040021.

- Agencia Europea de la Guardia de Fronteras y Costas (Frontex)

- FRONTEX, Risk Analysis for 2019.

- FRONTEX, A year in review. First 12 months of the European Border and Coast Guard Agency, Varsovia, 2017.

- $\quad$ FRONTEX, Risk analysis for 2016.

- Asylum Information Database (AIDA)

- $\quad$ AIDA., Asylum Country Report: Spain, 2018.

- AIDA, The Dublin system in 2017. Overview of developments from selected European countries, marzo de 2018.

- $\quad$ AIDA, Country Report France: Fourth Update, December 2015.

- Consejo Europeo de Refugiados y Exiliados (ECRE)

- ECRE, Comentarios sobre la Propuesta de refundición del Reglamento Eurodac, $\operatorname{COM}(2016)$ 272, Julio de 2016.

- ECRE, Comentarios sobre la propuesta de la Comisión sobre el Reglamento Dublín IV COM(2016) 270, octubre de 2016.

- ECRE, Comentarios sobre el documento de trabajo de los servicios de la Comisión Europea "sobre la aplicación del Reglamento Eurodac en lo que respecta a la obligación de toma de huellas digitales", junio de 2015.

- ECRE, Comentarios sobre la propuesta de la Comisión sobre el Reglamento de Eurodac COM(2016) 272, julio de 2016.

- ECRE, Lotería de asilo en la UE en 2010 (basado en los datos de las tendencias globales del ACNUR), 2011.

- Grupo de Trabajo del Artículo 29 (GT29) 
- GT29, "Dictamen sobre las propuestas de la Comisión sobre el establecimiento de un marco para la interoperabilidad entre los sistemas de información de la UE en el ámbito de las fronteras y los visados, así como la cooperación policial y judicial, el asilo y la migración", 11 de abril de 2018, WP266.

- GT29, "Opinion 04/2014 on surveillance of electronic communications for intelligence and national security purposes", 819/14/EN, WP 215, 10 de abril de 2014.

- GT 29, Opinión 03/2013 sobre la limitación de la finalidad, 4 de abril de 2013. (00569/13/EN WP 203).

- GT29, "Dictamen n 7/2004 sobre la inclusión de elementos biométricos en los permisos de residencia y de los visados teniendo en cuenta el establecimiento del sistema europeo de información sobre visados (VIS)", 11 de agosto de 2004.

- GT29, Dictamen 10/2001 del Artículo 29 sobre la necesidad de un enfoque equilibrado en la lucha contra el terrorismo, 14 de diciembre de 2001.

- Oficina Europea de Apoyo al Asilo (EASO)

- $\quad$ EASO, Annual Report 2018, 24 de junio de 2019

- EASO, Privacy Statement Concerning the Processing of Personal Data Related to the Distribution of EASO, 1 de febrero de 2019 (EASO/CSU/2019/013).

- Oficina Europea de Apoyo al Asilo (EASO), Briefing Paper. Access to Information in the Context of Asylum: Exploring Existing Resources, Good Practices and Ways Forward, 2018.

- EASO, Guía Práctica de la EASO. Exclusión, enero de 2017,

- EASO y FRONTEX, Access to the Asylum. Procedure. What you need to know. Publications Office of the European Union, 2016.

- EASO, Exclusión: Artículos 12 y 17 de la Directiva de Reconocimiento (2011/95/UE). Análisis Judicial, enero de 2016.

- $\quad$ EASO, Annual Report, julio de 2015.

- Supervisor Europeo de Protección de Datos (SEPD)

- $\quad$ SEPD, Dictamen 4/2018 sobre las propuestas de dos reglamentos que establecen un marco para la interoperabilidad entre los sistemas de información a gran escala de la UE, 16 de abril de 2018.

- SEPD, Protección de Datos y Privacidad en 2018: Más allá del RGPD, 20 Marzo 2018.

- SEPD, Resumen ejecutivo del dictamen del Supervisor Europeo de Protección de Datos sobre el primer paquete de reformas del Sistema Europeo Común de Asilo (Reglamentos Eurodac, EASO y Dublín), enero de 2017 (2017/C 9/04).

- SEPD, Dictamen del Supervisor Europeo de Protección de Datos sobre el segundo paquete de fronteras inteligentes de la UE, 13 diciembre de 2016 (C 463/11).

- SEPD, Migration, security and fundamental rights: A critical challenge for the EU, 22 de septiembre de 2016.

- SEPD, Opinión 07/2016 sobre la reforma del primer paquete Sistema Europeo Común de Asilo de 21 de septiembre de 2016.

- SEPD, Opinion 02/2016, Recomendaciones del Supervisor Europeo de Protección de Datos relativas a la propuesta de Reglamento Europeo sobre la Guardia Europea de Fronteras y Costas, 18 de marzo de 2016.

- SEPD, Opinion of the European Data Protection Supervisor on the amended proposal for a Regulation of the European Parliament and of the Council on the establishment of "EURODAC" for the comparison of fingerprints, 2013, OJ 28/3. 
- SEPD, Dictamen del Supervisor Europeo de Protección de Datos sobre la Comunicación de la Comisión al Parlamento Europeo, al Consejo, al Comité Económico y Social Europeo y al Comité de las Regiones - «Un enfoque global de la protección de los datos personales en la Unión Europea» (2011/C-181/01), 14 de enero de 2011

- SEPD, Dictamen del Supervisor Europeo de Protección de Datos sobre la propuesta modificada de Reglamento del Parlamento Europeo y del Consejo relativo a la creación del sistema «Eurodac» para la comparación de las impresiones dactilares para la aplicación efectiva del Reglamento (CE) no [.......] (por el que se establecen los criterios y mecanismos de determinación del Estado miembro responsable del examen de una solicitud de protección internacional presentada en uno de los EEMM por un nacional de un tercer país o un apátrida) y sobre la propuesta de Decisión del Consejo relativa a las solicitudes de comparación con datos Eurodac presentadas por los servicios de seguridad de los EEMM y Europol a efectos de la aplicación de la ley, OJ C 92/01, 10 de abril de 2010.

\subsection{DOCUMENTOS DE ESTADOS EUROPEOS}

- Rapport intérimaire de la Commission chargée de l'évaluation de la politique du retour volontaire et de l'éloignement forcé d'étrangers présenté au Ministre de l'Asile et de Migration le 22 février 2019.

- Consejo de Estado Francés, de 11 de abril de 2018 (n 402242). Esta decisión se encuentra actualmente recurrida $\left(\mathrm{n}^{\circ} 402242\right)$.

- Plan de acción anglo-francés publicado en 2017 incluía varias propuestas de acceso a contenido cifrado de información, así como la eliminación de material extremista entre ambos países. French-British Action Plan, 13 de junio de 2017.

- Decisión de la Junta de Apelaciones de Refugiados de Dinamarca, de 6 de febrero de 2017.

- Budapest Centre For Mass Atrocities Prevention, Capabilities of the Visegrad Group in preventing extremism, 2017.

- Bundesamt für Migration und Flüchtlinge (BAMF), Estadística de asilo entre 2015 y agosto de 2016.

- Reino Unido. Home Office, Asylum policy instruction Revocation of refugee status Version 4.0, 16 de enero de 2016.

- Ministerio de Defensa, La vision stratégique pour la Défense, 26 de junio de 2016, Bélgica.

- Ministerio de Alemania, Libro Blanco sobre la política de seguridad alemana y el futuro de la Bundeswehr, 19 de septiembre de 2016.

- Ministerio de Defensa de Italia, Libro Blanco para la Seguridad Internacional y la Defensa, 30 de abril de 2015.

- Parlamento de Ucrania, Resolución N 462-VIII, 21 de mayo de 2015.

- Danish Institute for International Studies, An Introduction to the Danish approach to countering and preventing extremism and radicalization, 2015.

- Country Report Hungary: Fourth Update, noviembre de 2015.

- Country Report UK: Fourth Update, noviembre de 2015.

- Ministerio de Defensa Nacional de Grecia. Libro Blanco sobre Defensa, 2014.

\subsection{JURISPRUDENCIA DE PAÍSES EUROPEOS}

- Bulgaria: Judgment on threat to national security of Syrian asylum applicant, 4 de septiembre de 2018. 
- Tribunal Administrativo Federal Suizo, de 8 de febrero de 2018 (Solicitud n ${ }^{\circ}$ D635/2018).

- Corte de Apelaciones de Irlanda, Sentencia BS \& RS c. The Refugee Appeals Tribunal \& ors (IECA 179), 14 de junio de 2017.

- Corte de Apelación de Reino Unido, Sentencia AH (Argelia) c. Secretario de Estado del Ministerio de Interior, de 14 de octubre de 2015 (C1/2013/712).

- Sala de Inmigración y Asilo del Tribunal Superior (Reino Unido), Sentencia de 25 de julio de 2013, AH (Article 1F b)).

- Sentencia del Tribunal Constitucional (Austria), de 13 de diciembre de 2011, U 1907/10, 15 .

\subsection{JURISPRUDENCIA DEL TJUE}

- STJUE Mohammed Bilali y Bundesamt für Fremdenwesen und Asyl, de 23 de mayo de 2019 (asunto C-720/17).

- STJUE $M$ y otros contra Ministerstvo vnitra y X. y X. C. Commissaire général aux réfugiés et aux apatrides, de 14 de mayo de 2019 (Asuntos acumulados C-391/16, C-77/17 y C-78/17).

- STJUE (Gran Sala), de 2 de octubre de 2018. Petición de decisión prejudicial planteada por la Audiencia Provincial de Tarragona Procedimiento prejudicial. Asunto C-207/16).

- STJUE Shajin Ahmed contra Bevándorlási és Menekültügyi Hivatal de 13 de septiembre de 2018. Asunto C-369/17.

- TJUE, Petición de decisión prejudicial planteada por el Conseil d'État (Francia) el 3 de agosto de 2018 - French Data Network, La Quadrature du Net, Fédération des fournisseurs d'accès à Internet associatifs / Premier ministre, Garde des Sceaux, ministre de la Justice. (Asunto C-512/18)

- TJUE, Petición de decisión prejudicial planteada por la Cour constitutionnelle (Bélgica) el 2 de agosto de 2018 - Ordre des barreaux francophones et germanophone, Académie Fiscale ASBL, UA, Liga voor Mensenrechten ASBL, Ligue des Droits de l'Homme ASBL, VZ, WY, XX / Conseil des ministers. (Asunto C-520/18).

- $\quad$ STJUE (Gran Sala), H.F, de 2 de mayo de 2018. Asuntos acumulados C-331/16 K y C-366/16.

- STJUE (Gran Sala) A y otros/Minister van Buitenlandse Zaken de 14 de marzo 2017. Asunto C-158/14.

- STJUE, The Queen a instancias de Western Sahara Campaign UK contra Commissioners for Her Majesty's Revenue and Customs, Secretary of State for Environment, Food and Rural Affairs, de 27 de febrero de 2018. Asunto C-266/16.

- STJUE Soufiane El Hassani y Minister Spraw Zagranicznych, de 13 de diciembre de 2017. Asunto C-403/16.

- STJUE Hungría y Eslovaquia c. Consejo de la UE, de 6 de septiembre de 2017. Asuntos acumulados C-643/15 y C-647/15.

- $\quad$ STJUE Ouhrami, de 26 de julio de 2017 (asunto C-225/16)

- TJUE (Gran Sala), Dictamen 1/15, de 26 de julio de 2017.

- $\quad$ STJUE Staatsanwaltschaft Offenburg, de 21 de junio de 2017 (Asunto C-9/16)

- $\quad$ STJUE Lounani, de 31 de enero de 2017. Asunto C-573/16

- STJUE Tele2 Sverige AB c. Post- och telestyrelsen y Secretary of State for the Home Department c. Tom Watson y otros, de 21 de diciembre de 2016. Asunto C203/15.

- $\quad$ STJUE Remondis, de 21 de diciembre de 2016. Asunto C-51/15. 
- STJUE Nabiel Peter Bogendorff von Wolffersdorff c. Standesamt der Stadt Karlsruhe y Zentraler Juristischer Dienst der Stadt Karlsruhe, de 2 de junio de 2016. Asunto C-438/14.

- STJUE Izsák and Dabis, de 10 de mayo de 2016. Asunto T-529/13.

- STJUE J. N. y Staatssecretaris van Veiligheid en Justitie, de 15 de febrero de 2016. Asunto C-601/15.

- STJUE Andre Lawrence Shepherd contra Bundesrepublik Deutschland, de 26 de febrero de 2015. Asunto c-472/13.

- STJUE, A, B y C de 2 diciembre de 2014. Asuntos acumulados C-148/13, C-149/13 y C-150/13.

- STJUE Y.S c. Minister voor Immigratie, Integratie en Asiel Minister voor Immigratie, Integratie en Asiel c. M.S., de 17 de julio de 2014. Asuntos acumulados C141/12 y C-372/12.

- STJUE Torresi, de 17 de julio de 2014. Asunto C-58/13.

- $\quad$ STJUE Digibet and Albers, de 12 de junio de 2014. Asunto C-156/13.

- STJUE, Digital Rights Ireland y Seitlinger y otros, de 8 de abril de 2014 (Asuntos acumulados C-293/12 y C-594/12).

- $\quad$ STJUE, MA y Otros c. Reino Unido, de 6 de junio de 2013 (Asunto C-648/11).

- STJUE ZZ/Secretary of State for the Home Department, de 4 de junio de 2013. Asunto C-300/11.

- $\quad$ STJUE Anton Las c. PSA Antwerp NV, de 16 de abril de 2013. Asunto C-202/11.

- $\quad$ STJUE Karem El Kott, de 19 de diciembre 2012. Asunto c-364/11.

- STJUE Atiqullah Adil y Minister voor Immigratie, Integratie en Asiel, de 19 de julio de 2012. Asunto C-278/12

- $\quad$ STJUE Minh Khoa Vo, de 10 de abril de 2012. Asunto C-83/12.

- STJUE Alexandre Achughbabian y Préfet du Val-de-Marne, de 6 de diciembre de 2011. Asunto C-329/11.

- STJUE Comisión c. Gran Ducado de Luxemburgo, de 24 de mayo de 2011. Asunto C-51/08.

- STJUE Runevič-Vardyn and Wardyn, de 12 de mayo de 2011. Asunto C-391/09.

- STJUE Sayn-Wittgenstein, de 22 de diciembre de 2010. Asunto C-208/09

- $\quad$ STJUE Bundesrepublik Deutschland c. B and D, de 9 de noviembre de 2010. Asuntos acumulados C-57/09 and C-101/09).

- STJUE Melki y Abdeli, de 22 de junio de 2010. Asuntos acumulados C-188/10 y C189/10.

- $\quad$ STJUE Comisión c. Portugal, de 4 de marzo de 2010. Asunto C-38/06.

- $\quad$ STJUE Abdulla y Otros c. Bundesrepublik Deutschland, de 2 de marzo de 2010. Asuntos acumulados C-175/08, C-176/08, C-178/08 y C-179/08

- STJUE (Gran Sala) Comisión Europea c. República Italiana, de 15 de diciembre de 2009. Asunto C-387/05.

- STJUE Heinz Huber c. Bundesrepublik Deutchland, de 16 de diciembre de 2008. Asunto $\mathrm{n}^{\circ} \mathrm{C}-524 / 06$.

- STJUE Rechnungshof c. Österreichischer Rundfunk y otros y Christa Neukomm y Joseph Lauermann c. Österreichischer Rundfunk, de 20 de mayo de 2003. Asuntos acumulados C-465/00, C-138/01 y C-139/01.

- STJUE Alexander Dory c. Bundesrepublik Deutschland, de 11 de marzo de 2003. Asunto C186-01.

- STJUE Alfredo Albore, de 13 de julio de 2000. Asunto C-423/98. 
- $\quad$ STJUE Tanja Kreil y Bundesrepublik Deutschland, de 11 de enero de 2000. Asunto C-285/98.

- STJUE Angela Maria Sirdar c. The Army Board y Secretary of State for Defence, de 26 de octubre de 1999. Asunto C-273/97.

- STJUE Comisión c. República Francesa, de 9 de diciembre de 1997. Asunto C265/95.

- STJUE Campus Oil Limited y otros c. Minister for Industry and Energy y otros, de 10 de julio de 1984. Asunto 72/83.

- STJUE Comisión c. Gran Ducado de Luxemburgo, de 2 de Julio de 1996. Asunto C-473/93.

\section{DOCUMENTOS DEL CONSEJO DE EUROPA}

- Consejo de Europa, Asamblea Parlamentaria sobre Asuntos Jurídicos y Derechos Humanos, Presuntas detenciones secretas y traslados ilegales entre Estados que implican a Estados miembros del Consejo de Europa, Documento $\mathrm{n}^{\mathrm{o}} 10957$, pp. 12 y 15-24, 2 de junio de 2006.

- Consejo de Europa, Informe de la misión de investigación del Embajador Tomáš Boček, Representante Especial del Secretario General sobre migración y refugiados a España, 18-24 de marzo de 2018, (SG/Inf(2018)25), 3 de septiembre de 2018.

\subsection{NORMATIVA DEL CONSEJO DE EUROPA}

- Convenio Europeo de Derechos Humanos, Convenio para la Protección de los Derechos Humanos y de las Libertades Fundamentales. Roma, 4 de noviembre de 1950.

- Carta Social Europea. (Revisada). Firmada en Estrasburgo el 3 de mayo de 1996.

- Consejo de Europa, Convenio para la protección de las personas con respecto al tratamiento automatizado de datos de carácter Personal, Comité de Ministros, Elsinore, 18 de mayo de 2018 .

\subsection{JURISPRUDENCIA DEL TEDH}

- STEDH Catt c. Reino Unido, de 24 de enero de 2019 (Demanda no. 43514/15).

- STEDH Alparslan Altan c. Turquía, de 16 de abril de 2019 (Demanda $n^{\circ}$ 12778/17).

- $\quad$ STEDH M.A. c. Estonia, de 2 de octubre de 2018 (Demanda no 46173/18).

- $\quad$ STEDH Xc. Países Bajos, de 10 de julio de 2018 (Demanda n. 14319/17).

- $\quad$ STEDH M.A. c. Francia, de 1 de febrero de 2018 (Demanda ${ }^{\circ}$ 9373/15).

- $\quad$ STEDH X c. Suecia, de 9 de enero de 2018 (Demanda no 36417/16).

- STEDH Ayçaguer c. Francia, de 22 de junio de 2017 (Demanda no 8806/12).

- STEDH Balde y Abel c. España, de 12 de junio de 2017 (Demanda no 20351/17).

- TEDH, Guía sobre el art. 15 del Convenio Europeo de los Derechos Humanos, abril de 2017.

- STEDH Ilias y Ahmed c. Hungría, de 14 de marzo de 2017 (Demanda no 47287/15).

- $\quad$ STEDH Otros c. Suecia, de 23 de agosto de 2016 (Demanda n n $^{\circ}$ 59166/12).

- $\quad$ STEDH, F.G. c. Suecia, de 23 de marzo de 2016 (Demanda no 43611/11).

- $\quad$ STEDH Nasr et Ghali c. Italia, de 23 de febrero de 2016 (Demanda no 6528/11). 
- STEDH Szabo y Vissy c. Hungría, de 12 de enero de 2016. (Demanda $\mathrm{n}^{\circ}$ 37138/14).

- SSTEDH Zakharov c. Rusia, de 4 de diciembre de 2015. (Demanda $\mathrm{n}^{\circ}$ 47143/06)

- STEDH Doumbe Nnabuchi c. España, 14 de diciembre de 2015 (Demanda no 19420/15).

- $\quad$ STEDH A.S. c. Suiza, de 30 de junio de 2015 (Demanda n ${ }^{\circ}$ 39350/13).

- STEDH Khlaifia y otros c. Italia, de 1 de septiembre de 2015 (Demanda $\mathrm{n}^{\circ}$ 16483/12).

- $\quad$ STEDH Tarakhel c. Suiza, de 4 de noviembre de 2014 (Demanda no 29217/12)

- STEDH Husayn (Abu Zubaydah) c. Polonia, de 24 de julio de 2014 (Demanda $\left.\mathrm{n}^{\mathrm{o}} 7511 / 13\right)$.

- STEDH A.C. c. España, de 24 de abril de 2014 (Demanda no 6528/11).

- TEDH, División de Investigación. Seguridad nacional y jurisprudencia europea, 2013.

- $\quad$ STEDH M. A. c. Chipre, de 23 de julio de 2013 (Demanda $\mathrm{n}^{\circ}$ 41872).

- STEDH El-Masri c. Macedonia, de 13 de diciembre de 2012 (Demanda $\mathrm{n}^{\mathrm{o}}$ 39630/09).

- STEDH Labsi c. Eslovaquia, de 24 de septiembre de 2012 (Demanda ${ }^{\circ}$ 33809/08).

- STEDH Hirsi Jamaa y otros c. Italia, de 23 de febrero 2012 (Demanda $\mathrm{n}^{\circ}$ 27765/09).

- STEDH Othman (Abu Qatada) c. Reino Unido, de 17 de enero de 2012 (Demanda ${ }^{\circ}$ 8139/09).

- $\quad$ STEDH H.R. c. Francia, de 22 septiembre de 2011 (Demanda no 64780/09).

- STEDH Abd Al Rahim Hussayn Muhammad Al Nashiri c. Polonia, de 6 de mayo de 2011 (Demanda n ${ }^{\circ}$ 28761/11).

- STEDH M.S.S. c. Bélgica y Grecia, de 21 de enero de 2011 (Demanda ${ }^{\circ}$ 30696/09).

- STEDH Daoudi c. Francia, de 3 de diciembre de 2009 (Demanda n ${ }^{\circ}$ 19576/08)

- STEDH $S$ y Marper c. Reino Unido, de 4 de diciembre de 2008 (Demandas 30562/04 y 30566/04).

- STEDH Gebremedhin c. Francia, de 16 de abril de 2007 (Demanda no 25389/05).

- STEDH Weber y Savaria c. Alemanía, de 26 de junio de 2006 (Demanda no $54934 / 00)$.

- STEDH PG y JH c. Reino Unido, de 25 de septiembre de 2001 (Demanda $\mathrm{n}^{\circ}$ 44787/98).

- $\quad$ STEDH Hilal c. el Reino Unido, de 6 de marzo de 2001 (Demanda $n^{\circ}$ 45276/99).

- $\quad$ STEDH Rotaru c. Rumanía, de 4 de mayo de 2000 (Demanda no 28341/95).

- STEDH Amann c. Suiza, de 16 de febrero de 2000 (Demanda n 27798/95).

- STEDH Ahmed c. Austria, de 17 de diciembre de 1996 (Demanda no 25964/94).

- STEDH Chahal c. Reino Unido, de 15 de noviembre de 1996 (Demanda no 22414/93).

- STEDH Brannigan and Mcbride c. Reino Unido, de 26 de mayo de 1993 (Demanda $\mathrm{n}^{\mathrm{o}} 14553 / 89$ )

- STEDH Soering c. Reino Unido, de 7 de julio de 1989 (Demanda n ${ }^{\circ}$ 14038/88).

- STEDH Leander c. Suecia, de 26 de marzo de 1987 (Demanda nº 9248/81). 
9063/80).

- STEDH Gillow c. Reino Unido, de 24 de noviembre de 1986 (Demanda n $^{\circ}$

- $\quad$ STEDH Lawless c. Irlanda, de 1 de julio de 1961 (Demanda no 332/57).

\section{DOCUMENTOS DEL ORDENAMIENTO JURÍDICO ESPAÑOL}

\subsection{NORMATIVA ESPAÑOLA}

- Consejo de Ministros, Subvenciones a Ceuta y Melilla para atender a menores extranjeros no acompañados, 31 de octubre de 2019.

- Orden INT/558/2019, de 16 de mayo, por la que se modifica la Orden INT/28/2013, de 18 de enero, por la que se desarrolla la estructura orgánica y funciones de los servicios centrales y periféricos de la Dirección General de la Policía. Publicado en el BOE de 23 de mayo de 2019, $\mathrm{n}^{\mathrm{o}} 123$.

- Real Decreto 1340/2018, de 29 de octubre, por el que se aprueban las normas especiales reguladoras de las subvenciones que se otorgarán en régimen de concesión directa a las comunidades autónomas y Ciudades de Ceuta y Melilla para la atención a los menores extranjeros no acompañados acogidos en el año 2018. «BOE» núm. 262, de 30 de octubre de 2018, pp. 104923 a 104928.

- Real Decreto-ley 6/2018, de 27 de julio, por el que se aprueba una oferta de empleo público extraordinaria y adicional para el refuerzo de medios en la atención a asilados y refugiados. «BOE» núm. 184, de 31 de julio de 2018, pp. 76876 a 76878.

- Real Decreto 162/2014, de 14 de marzo, por el que se aprueba el reglamento de funcionamiento y régimen interior de los centros de internamiento de extranjeros.

- Real Decreto 557/2011, de 20 de abril, por el que se aprueba el Reglamento de la Ley Orgánica 4/2000, sobre derechos y libertades de los extranjeros en España y su integración social, tras su reforma por Ley Orgánica 2/2009. «BOE» núm. 103, de 30/04/2011.

- Ley 12/2009, de 30 de octubre, reguladora del derecho de asilo y de la protección subsidiaria. «BOE» núm. 263, de 31/10/2009.

- Consejo General del Poder Judicial, Informe al Proyecto de Real Decreto por el que se aprueba el Reglamento de la Ley 12/2009, de 30 de octubre, reguladora del Derecho de Asilo y de la protección subsidiaria, de 31 de enero de 2014.

- Acuerdo entre el Reino de España y Marruecos, firmado en Madrid el 13 de febrero de 1992. Publicado en el BOE núm. 100, de 25 de abril de 1992, y su entrada en vigor definitiva se produjo el 21 de octubre de 2012 (BOE núm. 299, de 13 de diciembre de 2012).

- Constitución Española. Boletín Oficial del Estado, 29 de diciembre de 1978, núm. 311, pp. 29313 a 29424.

\subsection{JURISPRUDENCIA ESPAÑOLA}

- $\quad$ STS 3410/2019, de 29 de octubre de 2019 (recurso no 1059/2018)

- $\quad$ STS 1884/2019, de 10 de junio de 2019 (recurso $n^{0}$ 5805/2017)

- $\quad$ STS 212/2019, de 29 de enero de 2019 (recurso $n^{\circ}$ 4835/2017)

- $\quad$ STS 2021/2014, de 30 de mayo de 2014 (recurso $n^{0} 3511 / 2013$ )

- $\quad$ STS 818/2009, de 17 de diciembre de 2009 (recurso $n^{\circ} 4858 / 2006$ )

- $\quad$ STS, de 2 de octubre de 2008 (recurso no 66/2006)

- $\quad$ STS 583/2008, de 27 de marzo de 2008 (recurso n ${ }^{\circ}$ 192/2006)

- $\quad$ SAN de 30 de enero de 2017 (recurso n ${ }^{\circ} 253 / 2015$ )

- $\quad$ SAN de 21 de diciembre de 2015 (recurso no 281/2014) 
- $\quad$ SAN de 25 de enero de 2013 (recurso $\mathrm{n}^{\circ}$ 937/2011)

- SAN, de 26 de diciembre de 2013 (recurso ${ }^{\circ} 5689 / 2013$ )

- SAN, de 3 de octubre de 2013 (recurso ${ }^{\circ} 4001 / 2013$ )

- $\quad$ STSJM, 841/2018, de 5 de noviembre de 2018

- $\quad$ STSJM, 817/2018, de 20 de octubre de 2018

- STSJM n $^{\circ} 667 / 2017$, de 29 septiembre de 2017

- $\quad$ SSTSJM no 490/2015, de 11 de mayo de 2015

- STSJA n $525 / 2010$, de 10 de febrero del 2011

- $\quad$ STJA n ${ }^{\circ} 527 / 2010$, de 13 de enero de 2011

- STSJA, no 437/2010, de 28 de octubre del 2010

\subsection{DOCUMENTOS NACIONALES}

- Presidencia de Gobierno, La Oficina de Asilo y Refugio resuelve en 2019 cinco veces más solicitudes de protección internacional que el año pasado, 19 de diciembre de 2019.

- Consejo de Seguridad Nacional, Informe Anual de Seguridad Nacional de 2018.

- Programa Nacional FAMI España, Informe de evaluación intermedia del FAMI (01/01/2014 - 30/06/2017).

- Sacar del Laberinto, Informe Frontera Sur 2018, Servicio Jesuita al Migrante, noviembre de 2018.

- TRACKS, Identificación de las necesidades especiales de solicitantes de asilo víctimas de trata y respuesta a las mismas. Informe resumido. Panorama Nacional España, 2018. (HOME/2014/AMIF/AG/ASYL/7849).

- Plataforma de solidaridad con los inmigrantes de Málaga, Informe sobre el encarcelamiento de 572 personas migrantes en la prisión de Archidona durante 52 días: otro agujero negro para los derechos humanos, 2018.

- Presidencia de Gobierno, Estrategia de Seguridad Nacional, 2017.

- Informe conjunto, Ceuta y Melilla centros de selección a cielo abierto a las puertas de África, diciembre de 2015

- Informe de la Comisión de Observación de Derechos Humanos (CODH). Vulneraciones de derechos humanos en la frontera sur - Melilla Julio de 2014.

- Informe elaborado por las Clínicas Jurídicas de ICADE (Universidad Pontificia Comillas), Per la Justícia Social (Universidad de Valencia), Dret al Dret (Universidad de Barcelona) y el Observatorio de Derechos Humanos (Universidad de Valladolid) para la Organización No Gubernamental "Pueblos Unidos-Servicio Jesuita a Migrantes", junio de 2015.

- Informe jurídico "rechazos en frontera": ¿frontera sin derechos?. Análisis de la disposición adicional décima de la Ley Orgánica 4/2000, de 11 de enero, sobre derechos y libertades de los extranjeros en España y su integración social, introducida por la Ley Orgánica 4/2015, de 30 de marzo, de protección de la seguridad ciudadana 13 de abril de 2015. Proyecto I+D+i IUSMIGRANTE (DER 2011-26449)

- Ministerio de Defensa de España, Estrategia de Seguridad Nacional, 31 de mayo de 2013.

- Defensor del Pueblo (DP)

- DP, Mecanismo Nacional de Prevención. Informe Anual 2018, Supervisión de lugares de privación de libertad en España, de acuerdo con el Protocolo facultativo a la Convención de las Naciones Unidas contra la tortura y otros tratos o penas crueles, inhumanos o degradantes (OPCAT), Madrid 2019. 
- DP, Informe anual 2018. Volumen I Informe de gestión, Madrid, 2019.

- Comunicado de prensa del DP “Interior acepta la Recomendación del Defensor para adecuar el sistema de registro de las solicitudes de asilo en los cie a la normativa vigente", 17 de julio de 2018.

- DP, Informe anual 2017 y debates en las Cortes Generales. Volumen I.1 Informe de gestión, Madrid, 2018.

2017

- DP, Informe anual 2016 y debates en las Cortes Generales I. Informe, Madrid,

- DP, Estudio sobre El asilo en España. La Protección internacional y los recursos del sistema de acogida, junio de 2016.

- DP, Informe anual 2005 y debates en las Cortes Generales, 2006.

\section{- Ministerio del interior}

- Ministerio de Interior, Oficina de Asilo y Refugio, Asilo en cifras 2018, septiembre de 2019

- Ministerio de Interior, Oficina de Asilo y Refugio, Asilo en cifras 2017, julio de 2019

- Ministerio de Interior, Dirección General de Política Interior, Avance de datos de protección internacional, aplicación del Reglamento de Dublín y reconocimiento del estatuto de apátrida Datos provisionales acumulados entre el 1 de enero y el 31 de diciembre de 2018.

- Gobierno de España, Ministerio del Interior (Sala de Prensa). Las responsables de la Oficina de Asilo y Refugio presentan al Defensor del Pueblo las medidas puestas en marcha para acelerar la resolución de solicitudes, 30 de noviembre de 2018.

- Comisión Española de Ayuda al Refugiado (CEAR)

- CEAR, Refugiados y migrantes en España: Los muros invisibles tras la frontera sur, diciembre de 2017,

- CEAR, Informe 2018: Las personas refugiadas en España y Europa,

- CEAR, Informe 2019: Las personas refugiadas en España y Europa. 2019.

- CEAR, La odisea de solicitar asilo en fronteras españolas, 15 de octubre de

\section{OTROS DOCUMENTOS}

- Standing committee of experts on international inmigraiton, refugee and criminal law (Meijers Committee).

- Meijers Committee, Standing Committee of Experts on International Immigration, Refugee and Criminal Law, Comments on the proposal for a Regulation on preventing the dissemination of terrorist content online, CM1904. (COM (2018) 640 final).

- Meijers Committee Standing Committee of Experts on International Immigration, Refugee and Criminal law, CM1817 Comments on the draft for a new Regulation on a European Border and Coast Guard, (COM (2018) 631 final) and the amended proposal for a Regulation on a European Union Asylum Agency (COM(2018) 633 final), 27 de noviembre de 2018.

- Meijers Committee, Comments on the Proposal for a Regulation of the European Parliament and of the Council on establishing a framework for interoperability between EU information systems (police and judicial cooperation, asylum and migration) 12 de diciembre de 2017, COM (2017) 794, 19 de febrero de 2018 (CM1802). 
- Meijers Committee, standing committee of experts on international immigration, refugee and criminal law, Note on the proposed reforms of the Dublin Regulation (COM (2016) 197), the Eurodac recast proposal (COM (2016) 272 final), and the proposal for an EU Asylum Agency (COM(2016)271 final), CM1609.

- Comité Meijers, Propuesta modificada del Reglamento Eurodac (COM (2009) 342) relativa a la decisión de comparación con los datos de Eurodac por parte de las autoridades policiales de los Estados miembros y Europol para fines policiales (COM (2009) 344), CM0910, Utrecht, 30 de septiembre de 2009.

- Identification of TRafficked Asylum seeKers' Special Needs (TRACKS), Identification and response to the needs of Trafficked Asylum Seekers. A Comparative Report for the Republic of Cyprus, France, Ireland, Italy, Spain, The Uk and Switzerland, enero de 2018 (HOME/2014/AMIF/AG/ASYL/7849).

- Oficina Europea de Estadística (Eurostat)

- $\quad$ Eurostat, Asylum quarterly report, septiembre de 2019

- Eurosat, five main citizenships of (non-eu) asylum applicants 2019

- Eurostat, Aplicación de las estadísticas de la legislación de inmigración, junio de 2019

- Eurostat, "First instance decisions on applications by citizenship, age and sex. Annual aggregated data", marzo de 2018.

- Eurostat, Resoluciones en primera instancia sobre solicitudes de protección internacional, 2015.

- Otros documentos

- RAN Policy Paper, Developing a local prevent framework and guiding principles - Part 2, noviembre 2018.

- Federación Europea de Sindicatos de Servicios Públicos (EPSU), European Court of Auditors finds irregularities in EASO and FRONTEX spending, 16 de octubre de 2018.

- The People for Change Foundation, Legal and Procedural Information for Asylum Seekers in Europe: Comparative Report, abril de 2018.

- Radicalisation Awareness Network (RAN) Collection, Preventing Radicalisation to Terrorism and Violent Extremism. Approaches and Practices, 2018.

- Statewatch, The "reflection process" on data retention: working documents discussed by Council published, 28 de febrero de 2018.

- $\quad$ EUObserver, "El contrabando de migrantes encabeza las prioridades delictivas de la UE", 10 de octubre de 2017.

- Privacy International, National Data Retention Laws since the CJEU's Tele2/Watson Judgment, septiembre de 2017.

- Euractiv, Commission readies sanctions against the Visegrad Four, 7 de junio de 2017.

- High-level expert group on information systems and interoperability, Final Report, mayo 2017.

- Secretariado del Grupo de Coordinación y Supervisión de Eurodac, Informe de actividad 2016-2017.

- HM Government, Review of the Balance of Competences between the United Kingdom and the European Union: Asylum \& non-EU Migration, febrero de 2014. 
- Radicalisation Awareness Network (RAN), Centro de Excelencia, Ex Post Paper, The refugee and migrant crisis: new pressing challenges for CVE policies, 8 de mayo de 2016.

- Consejo de la Abogacía Europea (CCBE), Comentarios sobre la propuesta de la Comisión de Reglamento por el que se establecen los criterios y mecanismos para determinar el Estado miembro responsable del examen de una solicitud de protección internacional presentada en uno de los Estados miembros por un nacional de un tercer país o un apátrida (versión refundida) - COM (2016) 270.

- Joint Research Centre, Technical Report Fingerprint Recognition for Children, 2013.

- Eurodac Supervision Coordination Group, Second Inspection Report, 2009, 24 de junio de 2009.

- $\quad$ European Biometrics Portal, Biometrics in Europe. Trend Report, 2007. 
